UNIVERSIDADE DE SÃO PAULO

FACULDADE DE ZOOTECNIA E ENGENHARIA DE ALIMENTOS

PÂMELA ALMEIDA ALEXANDRE

Abordagem de biologia de sistemas para a determinação de mecanismos moleculares associados à eficiência alimentar de bovinos Nelore 


\title{
Abordagem de biologia de sistemas para a determinação de mecanismos moleculares associados à eficiência alimentar de bovinos Nelore
}

\author{
Versão corrigida
}

Tese apresentada à Faculdade de Zootecnia e Engenharia de Alimentos da Universidade de São Paulo, como parte dos requisitos para obtenção do Título de Doutora em Ciências do programa de pós-graduação em Biociência Animal.

Área de concentração: Genética, Biologia Molecular e Celular.

Orientador: Prof. Dr. Heidge Fukumasu 
Ficha catalográfica elaborada pelo

Serviço de Biblioteca e Informação, FZEA/USP, com os dados fornecidos pelo(a) autor(a)

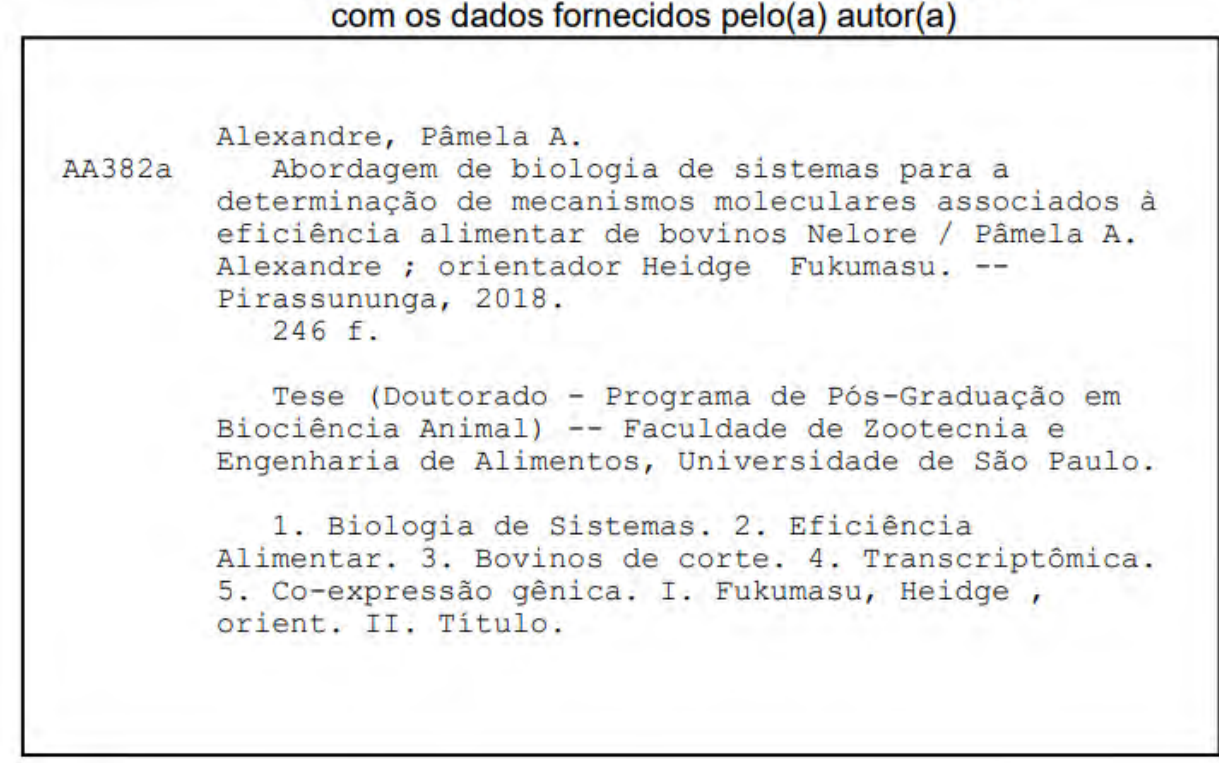

Permitida a cópia total ou parcial deste documento, desde que citada a fonte - o autor 


\begin{abstract}
Abordagem de biologia de sistemas para a determinação de mecanismos moleculares associados à eficiência alimentar de bovinos Nelore
\end{abstract}

Tese apresentada à Faculdade de Zootecnia e Engenharia de Alimentos da Universidade de São Paulo, como parte dos requisitos para obtenção do Título de Doutora em Ciências do programa de pós-graduação em Biociência Animal.

\title{
Data de aprovação: 25/01/2019
}

Banca Examinadora:

Prof. Dr. Heidge Fukumasu

Faculdade de Zootecnia e Engenharia de Alimentos - Universidade de São Paulo Presidente da Banca Examinadora

Prof. Dr. Fernando Sebastián Baldi Rey

Universidade Estadual Paulista “Júlio de Mesquita Filho" - Campus Jaboticabal

Prof. Dr. José Bento Sterman Ferraz

Faculdade de Zootecnia e Engenharia de Alimentos - Universidade de São Paulo

Dra. Aline Silva Mello César

Escola Superior de Agricultura "Luiz de Queiroz" - Universidade de São Paulo

Dr. Miguel Henrique de Almeida Santana

Faculdade de Zootecnia e Engenharia de Alimentos - Universidade de São Paulo

Dra. Polyana Cristine Tizioto

NGS Soluções Genômicas 
Aos meus amados pais, Heleni e Wanderlei, pelos valores ensinados e apoio incondicional em cada passo da minha jornada.

Dedico 


\section{AGRADECIMENTOS}

À minha família pelo apoio e pela segurança que sempre me proporcionaram. Agradeço especialmente aos meus pais. Minhas conquistas sempre serão de vocês.

Ao professor Heidge, meu orientador há 9 anos. Tudo que eu sou academicamente devo a você e, como dizem que não existe ex-orientador, acho que vou continuar devendo. Obrigada pela oportunidade.

Ao professor Bento pelo apoio e amizade. Feliz o dia em que entrei em sua sala em busca de conselho. De lá para cá tudo de bom que já aconteceu na minha carreira tem a sua mão e por isso, pelos cafés e boas conversas, vou ser sempre grata.

À minha "marida" Yonara pela paciência e companheirismo ao longo de tantos anos. Por dividir a casa, a vida, os cachorros, os sonhos e as frustrações.

À Tássia (Mulan), minha gêmea de coração, por dividir os mesmos planos e sonhos e assim, não deixar eu me sentir sozinha. Obrigada pela companhia mesmo à distância.

Ao querido amigo Kazu por estar sempre por perto, pela paciência em ouvir sobre pesquisa por horas, pelos "rolês" mais inesperados e oportunidades de irritar seus alunos (rs).

A todos os amigos do LOCT. Que o grupo siga crescendo unido e com cada vez mais sucesso. Obrigada aos amigos: Pedros pelas conversas e caronas, Pedrinho Ratto pela ajuda em vários momentos, Gabi Ribeiro por revisar a tese, e à Arina pela ajuda indispensável no laboratório sempre que precisei.

A todos os amigos do GMAB pela companhia. Ao Gerson, companheiro de conversas e aventuras científicas. Obrigada especialmente à Elisângela pela disposição em ajudar todas as milhares de vezes que precisei. Sem você essa tese não existiria.

To professor Haja Kadarmideen for the opportunity to spend 6 weeks at the University of Copenhagen and to Gianluca for the friendship and all the help during this period. During my time in Denmark, I was lucky enough to spend time and learn from incredible people I will never forget: Suraya, Marcella, Viktor, and Lisette.

To Laercio (Juca) Porto-Neto for the support and for making possible my sixmonths internship at CSIRO, Australia; to Toni Reverter for accepting to teach and supervise me; and to Marina Naval-Sanchez for the analysis performed and the help with the manuscript. These amazing people are co-authors of the first experiment in this 
thesis and responsible for my personal and professional growth during my time in Australia.

À Faculdade de Zootecnia e Engenharia de Alimentos da Universidade de São Paulo, onde estou a 12 anos, pela oportunidade de me formar Zootecnista, Mestre em Ciências e agora Doutora em Ciências. Obrigada aos professores que contribuíram para minha formação, tanto compartilhando conhecimento quanto me inspirando com seu exemplo.

À FAPESP pelas bolsas de doutorado (Proc. 2015/22276-3) e estágio de pesquisa no exterior (BEPE Proc. 2017/14707-0) e pelo auxílio financeiro (Temático Proc. 2014/07566-2).

À CAPES pela bolsa de doutorado.

Ao Banco Santander pela bolsa de mobilidade internacional. 
"May your choices reflect your hopes, not your fears."

Nelson Mandela 


\section{RESUMO}

ALEXANDRE, P. A. Abordagem de biologia de sistemas para a determinação de mecanismos moleculares associados à eficiência alimentar de bovinos Nelore. XXX f. Tese (Doutorado) - Faculdade de Zootecnia e Engenharia de Alimentos, Universidade de São Paulo, Pirassununga, 2018.

A eficiência alimentar (EA) é um fenótipo complexo, controlado por diversos processos biológicos. Determinar e entender esses processos é fundamental para selecionar animais superiores ou mesmo orientar decisões de manejo com o objetivo de aumentar a produtividade e diminuir o impacto ambiental da pecuária. Neste trabalho, propusemos analisar a EA através de uma abordagem de biologia de sistemas, baseada em transcriptômica multitecidual, a fim de gerar um entendimento sistêmico dessa característica. Para isso, 18 animais extremos para consumo alimentar residual foram selecionados a partir de um grupo de 98 bovinos Nelore machos inteiros e tiveram seu transcriptoma de hipotálamo, pituitária, adrenal, músculo e fígado sequenciado (RNAseq). Os reads gerados foram alinhados com o genoma de referência bovino (UMD3.1), filtrados e a expressão de cada gene foi estimada. A partir desses dados três abordagens de análises de dados foram desenvolvidas. Na primeira, cinco critérios de inclusão foram definidos para selecionar genes e construir uma rede de co-expressão para os cinco tecidos, de forma que além de indicarmos diversos genes e processos associados à EA, também fomos capazes de determinar dois genes reguladores, o NR2F6 e o TGFB1. $\mathrm{Na}$ segunda abordagem focamos no eixo hipotálamo-pituitária-adrenal, também utilizando análises de co-expressão, mas dessa vez sem partir de prévia seleção de genes e concluímos que o sistema de recompensa do cérebro pode estar envolvido no estímulo para maior consumo de alimentos observado no grupo de baixa EA. Finalmente, com a terceira abordagem, identificamos RNAs longos não codificadores (lncRNAs) expressos nos cinco tecidos e encontramos 30 transcritos expressos diferencialmente entre a alta e baixa EA na pituitária, músculo e adrenal, sendo que alguns deles se mostraram relacionados a processos já previamente demostrados como sendo associados a essa característica. Concluímos que, apesar de não conseguirmos determinar nesse momento o papel da maior susceptibilidade ao estresse, reportado na literatura para animais de baixa EA, no estímulo para maior ingestão de alimentos desse grupo, o sistema de recompensa hipotalâmico parece estar envolvido nesse processo. A maior ingestão pode ser a causa da resposta inflamatória observada no fígado, sendo ela de origem bacteriana, indicada pela maior concentração de endotoxina sérica nos animais menos eficientes. $\mathrm{O}$ maior turnover de proteínas no músculo de animais de baixa EA já havia sido indicado como um dos fatores que levam ao maior gasto energético nesses indivíduos e foi confirmado nesse trabalho. Além de alguns fatores de transcrição serem indicados como reguladores centrais desse fenótipo, lncRNAs também parecem ter função regulatória importante na EA.

Palavras-chave: consumo alimentar residual, conversão alimentar, eixo hipotálamopituitária-adrenal, fígado, inflamação, músculo, RNAseq, co-expressão gênica, RNA longo não codificador 


\section{ABSTRACT}

ALEXANDRE, P. A. Systems biology approach for determination of molecular mechanisms associated with feed efficiency in Nellore cattle. $143 \mathrm{f}$. PhD Thesis Faculdade de Zootecnia e Engenharia de Alimentos, Universidade de São Paulo, Pirassununga, 2018.

Feed efficiency (FE) is a complex phenotype, controlled by several biological processes. Determining and understanding these processes is fundamental to select superior animals or even guide management decisions, aiming to increase productivity and reduce the environmental impact of livestock. In this work, we propose to analyze FE through a systems biology approach, based on multi-tissue transcriptomics, in order to generate a systemic understanding of this trait. For this purpose, 18 extreme animals for residual feed intake were selected from a group of 98 male Nellore cattle and had their hypothalamus, pituitary, adrenal gland, muscle and liver transcriptome sequenced (RNAseq). Reads generated were aligned with the bovine reference genome (UMD3.1), filtered and the expression of each gene was estimated. From these data three experiments were developed. In the first one, five inclusion criteria were defined to select genes and to construct a network of coexpression for the five tissues, so that besides indicating several genes and processes associated with EA, we were also able to determine two regulatory genes, NR2F6 and TGFB1. In the second experiment, we focused on the hypothalamic-pituitary-adrenal axis, also using co-expression analysis, but this time without starting from previous selected genes. We conclude that the reward system of the brain might be involved in the stimulus for higher feed intake observed in the low EA group. Finally, in the third experiment, we identified long noncoding RNAs (lncRNAs) expressed in the five tissues and found 30 transcripts differentially expressed between the high and low FE in the pituitary, muscle and adrenal, and some of them were related to previously demonstrated processes associated to this trait. We conclude that although we cannot determine at this time the role of higher susceptibility to stress, reported in the literature for animals of low FE, in the stimulus for higher feed intake of this group, the hypothalamic reward system seems to be involved in this process. The higher ingestion might be the cause of the inflammatory response observed in the liver of, being of bacterial origin, indicated by the higher concentration of serum endotoxin in less efficient animals. The higher turnover of proteins in the muscle of low FE animals had already been indicated as one of the factors that lead to higher energy expenditure in these individuals and it was confirmed in this study. In addition to some transcription factors being indicated as central regulators of this phenotype, lncRNAs also appear to play an important regulatory role in FE.

Keywords: feed conversion, gene co-expression, hypothalamic-pituitary-adrenal axis, inflammation, liver, long non-coding RNA, muscle, Residual feed intake, RNAseq 


\section{LISTA DE FIGURAS}

Figura 1 - Representação do fenômeno descrito como causação descendente (downward causation)

Figura 2 - Exemplo de rede co-expressão baseada em power law

Figura 3 - Seis passos nos quais a expressão gênica eucariótica pode ser controlada. .. 35

Figura 4 - Localização genômica relativa a genes codificadores de proteínas e mecanismos regulatórios de RNAs longos não codificantes (lncRNAs) no núcleo, citoplasma e compartimentos extracelulares.

Figura 5 - Gráficos de dispersão mostrando genes diferencialmente expressos entre alta e baixa eficiência alimentar (EA) da glândula adrenal, hipotálamo, fígado, músculo e pituitária (pituitária).

Figura 6 - Genes selecionados para construção de redes de co-expressão.

Figura 7 - Rede de co-expressão de genes construída utilizando 1317 genes.

Figura 8 - Cinco principais genes reguladores da rede de co-expressão gênica (EPC1, NR2F6, MED21, ENSBTAG00000031687 e CTBP1) e seus primeiros vizinhos.

Figura 9 - Gene TGFB1 e seus primeiros vizinhos na rede. 66

Figura 10 - Gene FGF21 e seus primeiros vizinhos na rede.

Figura 11 - Mapeamento de alvos diretos do gene NR2F6.

Figura 12 - Mapeamento da via de sinalização do TGFB1 através da ligação do SMAD3/MYOD ao DNA.

Figura 13 - Quantificação de endotoxinas no soro de animais de alta e baixa eficiência alimentar

Figura 14 - Genes diferencialmente expressos, na abordagem 1, entre alta e baixa eficiência alimentar no hipotálamo, pituitária e adrenal.

Figura 15 - Clusterização dos módulos baseado em module eigengene (ME - primeira componente principal).

Figura 16 - Correlações entre módulo eigengene (ME) e medidas de conversão alimentar (CA) e consumo alimentar residual (CAR) - hipotálamo-pituitária-adrenal.. 78

Figura 17 - Representação das vias do KEEG (azul escuro) e principais termos do gene ontology (vermelho) enriquecidos (Paj<0,05) nos módulos associados à eficiência alimentar. 
Figura 18 - Genes centrais do módulo Grey60 determinados através de correlação significativa $(\mathrm{P}<0,05)$ com consumo e ganho residual e alta filiação ao módulo $(\mathrm{FM}>0,8)$.

Figura 19 - Genes centrais do módulo Skyblue3 determinados através de correlação significativa $(\mathrm{P}<0,05)$ com conversão alimentar e alta filiação ao módulo $(\mathrm{FM}>0,8) \ldots 83$

Figura 20 - Genes centrais do módulo Maroon determinados através de correlação significativa $(\mathrm{P}<0,05)$ com conversão alimentar e alta filiação ao módulo $(\mathrm{FM}>0,8) \ldots 83$

Figura 21 - Clusterização dos módulos do hipotálamo baseado em modulo eigengene (ME - primeira componente principal).

Figura 22 - Correlações entre módulo eigengene (ME) e medidas de conversão alimentar (CA) e consumo alimentar residual (CAR) - hipotálamo.

Figura 23 - Rede de interação de proteínas considerando hub genes no módulo Tan do hipotálamo.

Figura 24 - Clusterização dos módulos da pituitária baseada em module eigengene (ME - primeira componente principal).

Figura 25 - Correlações entre módulo eigengene (ME) e medidas de conversão alimentar (CA) e consumo alimentar residual (CAR) - pituitária.

Figura 26 - Rede de interação de proteínas considerando hub genes no módulo Darkturquoise da pituitária.

Figura 27 - Clusterização dos módulos da adrenal baseada em module eigengene (ME primeira componente principal).

Figura 28 - Correlações entre módulo eigengene (ME) e medidas de conversão alimentar (CA) e consumo alimentar residual (CAR) - adrenal.

Figura 29 - Distribuição dos lncRNA identificados de acordo com sua classificação... 96

Figura 30 - Gráfico de Venn do número de lncRNA expressos por tecido. Os valores entre parênteses indicam o número total de lncRNAs expressos no tecido.

Figura 31 - Relação entre miRNAs e lncRNA diferencialmente expressos (DE) entre alta e baixa eficiência alimentar

Figura 32 - Relação de complementariedade entre lncRNA diferencialmente expressos (DE) entre alta e baixa eficiência alimentar (EA) e mRNAs.

Figura 33 - Relação entre lncRNA diferencialmente expressos (DE) entre alta e baixa eficiência alimentar (EA) e mRNA DE entre alta e baixa EA na abordagem 1, por tecido.

Figura 34 - Previsão de estrutura secundária plana dos lncRNAs TCONS_00000153P (A), TCONS_00002325M (B), TCONS_00004881P (C) e TCONS_00005426 (D). . 107 
Figura 35 - Resumo das características associadas à baixa eficiência alimentar em nosso estudo anterior (Alexandre et al., 2015) e no atual.....

Figura Suplementar 1 - Principais termos enriquecidos no módulo Grey60.

Figura Suplementar 2 - Principais termos enriquecidos no módulo Skyblue3. 150

Figura Suplementar 3 - Termos enriquecidos no módulo Maroon 


\section{LISTA DE TABELAS}

Tabela 1 - Caracterização fenotípica dos animais de alta e baixa eficiência alimentar utilizados no experimento.

Tabela 2 - Dados relativos ao mapeamento de reads com o genoma de referência bovino (UMD3.1) por amostra.

Tabela 3 - Genes diferencialmente conectados e diferencialmente expressos entre alta e baixa eficiência alimentar.

Tabela 4 - Enriquecimento funcional de vias metabólicas (KEEG-WebGesalt) dos genes nos três módulos associados à eficiência alimentar.

Tabela 5 - Enriquecimento funcional de vias metabólicas (KEEG-STRING) dos genes nos três módulos associados à eficiência alimentar.

Tabela 6 - Enriquecimento funcional de vias metabólicas (KEEG-WebGestalt) dos módulos associados à conversão alimentar no hipotálamo usando todos os genes.

Tabela 7 - Enriquecimento funcional de vias metabólicas (KEEG-WebGestalt) dos genes centrais nos módulos associados à conversão alimentar no hipotálamo.

Tabela 8 - Enriquecimento funcional (STRING) dos módulos associados à conversão alimentar no hipotálamo usando todos os genes.

Tabela 9 - Enriquecimento funcional (STRING) dos módulos associados ao consumo e ganho residual na pituitária usando todos os genes*.

Tabela 10 - Número de transcritos considerados potenciais lncRNA após aplicação de cada critério de exclusão.

Tabela 11 - lncRNA diferencialmente expressos.

Tabela 12 - Descrição dos lncRNA diferencialmente expressos e mRNAs com expressão gênica correlacionada à deles.

Tabela 13 - Blast dos 1ncRNA diferencialmente expressos na base de dados NONCODE (FANG et al., 2018).

Tabela suplementar 1 - Genes diferencialmente expressos entre alta e baixa eficiência alimentar.

Tabela suplementar 2 - Genes selecionados para construção da rede de co-expressão.161

Tabela suplementar 3 - Genes diferencialmente conectados entre alta e baixa eficiência alimentar. 
Tabela suplementar 4 - Enriquecimento funcional usando a plataforma STRING dos genes diferencialmente expressos na abordagem 1 no hipotálamo, pituitária e adrenal de animais de alta e baixa eficiência alimentar. 185

Tabela suplementar 5 - Genes contidos no módulo Grey60...................................... 188

Tabela suplementar 6 - Genes contidos no módulo Skyblue3 .................................... 201

Tabela suplementar 7 - Genes contidos no módulo Maroon....................................... 204

Tabela suplementar 8 - Genes contidos no módulo Tan do hipotálamo. ..................... 208

Tabela suplementar 9 - Genes contidos no módulo Pink do hipotálamo. .................... 212

Tabela suplementar 10 - Genes contidos no módulo Darkturquoise da pituitária......... 218

Tabela suplementar 11 - Genes contidos no módulo Lightsteelblue1 da pituitária...... 229

Tabela suplementar 12 - Genes contidos no módulo Plum1 da pituitária.................... 231

Tabela suplementar 13 - Enriquecimento funcional (STRING) dos genes contidos no módulo Darkturquoise associado ao consumo alimentar residual na pituitária. .......... 233

Tabela suplementar 14 - Genes contidos no módulo Grey da adrenal. ........................ 236

Tabela suplementar 15 - Sítios de ligação de miRNA previstos em lncRNA diferencialmente expressos entre alta e baixa eficiência alimentar.

Tabela suplementar 16 - Enriquecimento funcional (STRING) dos genes com homologia com a fita complementar dos RNAs longos não codificadores diferencialmente expressos entre alta e baixa eficiência alimentar. 


\section{LISTA DE SIGLAS}

$\begin{array}{ll}\text { CA } & \text { Conversão alimentar } \\ \text { CAR } & \text { Consumo alimentar residual } \\ \text { CMS } & \text { Consumo de matéria seca } \\ \text { DE } & \text { Diferencialmente expresso } \\ \text { EA } & \text { Eficiência alimentar } \\ \text { FM } & \text { Filiação ao módulo } \\ \text { FT } & \text { Fator de transcrição } \\ \text { GMD } & \text { Ganho médio diário } \\ \text { ID } & \text { Identidade } \\ \text { lncRNA } & \text { RNA longo não codificador } \\ \text { ME } & \text { Módulo eigengene - primeira componente principal do módulo } \\ \text { miRNA } & \text { Micro RNA } \\ \text { NCBI } & \text { US National Center for Biotechnology Information } \\ \text { ncRNA } & \text { RNA não codificador } \\ \text { ORF } & \text { Região aberta de leitura - Open reading frame } \\ \text { Paj } & \text { Valor de P ajustado por correção para múltiplos testes } \\ \text { PVN } & \text { Núcleo paraventricular - hipotálamo } \\ \text { SG } & \text { Significância gênica } \\ \text { TS } & \text { Tecido específico } \\ \text { UTR } & \text { Untranslated - regiões não traduzidas em proteína }\end{array}$


1. INTRODUÇÃ

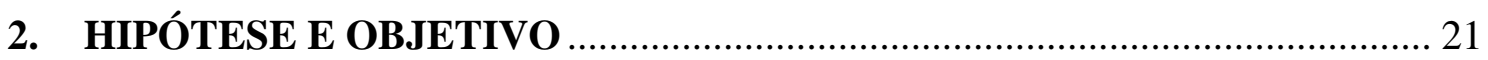

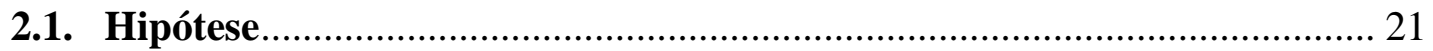

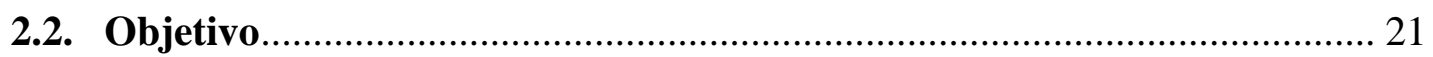

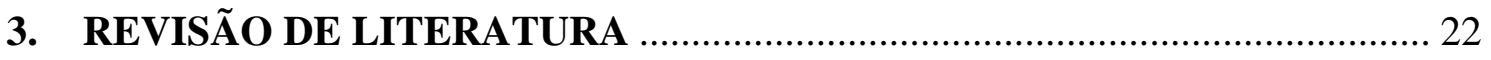

3.1. Visão holística da eficiência alimentar ................................................... 22

3.2. Biologia de sistemas e redes de co-expressão ................................................ 30

3.3. Mecanismos de regulação da expressão gênica ......................................... 35

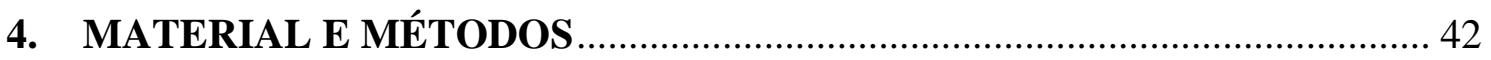

4.1. Obtenção de dados fenotípicos e amostras biológicas .............................. 42

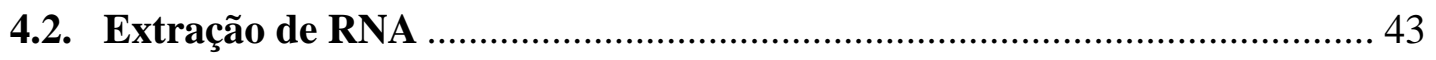

4.3. Preparo e sequenciamento de bibliotecas de RNA ................................... 43

4.4. Controles de qualidade e alinhamento com referência ............................ 44

4.5. Abordagem 1 - Expressão gênica multitecidual associada à eficiência

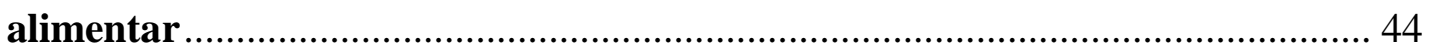

4.5.1. ESTIMATIVA DE EXPRESSÃO GÊNICA E NORMALIZAÇÃO ...... 44

4.5.2. SELEÇÃO DE GENES PARA CONSTRUÇÃO DE REDES ................. 45

4.5.3. ANÁLISE DE REDE DE CO-EXPRESSÃO ........................................ 46

4.5.4. VALIDAÇÃO DE REGULADORES ATRAVÉS DE ANÁLISE DE ENRIQUECIMENTO DE SÍTIOS DE LIGAÇÃO ............................................. 47

4.5.5. CONECTIVIDADE DIFERENCIAL .................................................. 47

4.5.6. ENRIQUECIMENTO FUNCIONAL .................................................... 48

4.5.7. DOSAGEM DE ENDOTOXINA SÉRICA …....................................... 48

4.6. Abordagem 2 - $O$ papel do eixo hipotálamo-pituitária-adrenal sobre a eficiência alimentar em bovinos de corte ............................................................ 49

4.6.1. DETERMINAÇÃO DE MÓDULOS DE CO-EXPRESSÃO .................. 49

4.6.2. ENRIQUECIMENTO FUNCIONAL ............................................ 50

4.7. Abordagem 3 - Identificação de RNAs longos não codificadores em múltiplos tecidos de bovinos Nelore e sua associação com a eficiência alimentar 51

4.7.1. IDENTIFICAÇÃO DE IncRNA EM DADOS DE RNAseq 51 
4.7.2. EXPRESSÃO DIFERENCIAL E CARACTERIZAÇÃO DE lncRNAs. 52

4.7.3. INVESTIGAÇÃO DA RELAÇÃO ENTRE lncRNA E miRNAs ............ 53

4.7.4. INVESTIGAÇÃO DO PAPEL REGULATÓRIOS DOS IncRNAs NA EXPRESSÃO DE mRNAs EM CIS E TRANS ……............................................. 53

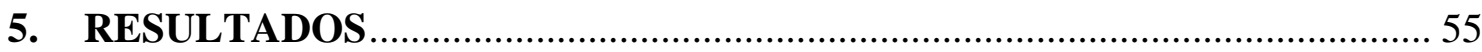

5.1. Abordagem 1 - Expressão gênica multitecidual associada à eficiência alimentar

5.1.1. .CARACTERIZAÇÃO FENOTÍPICA DOS ANIMAIS 55

5.1.2. EXPRESSÃO DIFERENCIAL 56

5.1.3. PRINCIPAIS GENES RELACIONADOS À EFICIÊNCIA ALIMENTAR 60

5.1.4. REDE DE CO-EXPRESSÃO E PROCESSOS BIOLÓGICOS RELACIONADOS À EFICIÊNCIA ALIMENTAR

5.1.5. NR2F6 COMO REGULADOR CHAVE DAS MUDANÇAS

TRANSCRICIONAIS NO FÍGADO

5.1.6. REGULAÇÃO DO TGFB NO MÚSCULO ATRAVÉS DA INTERAÇÃO COM SMAD3/MYOD1 ............................................................ 71

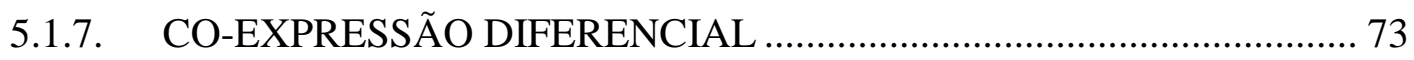

5.1.8. Validação das vias associadas à inflamação e resposta humoral antimicrobiana.....

5.2. Abordagem 2 - O papel do eixo hipotálamo-pituitária-adrenal sobre a eficiência alimentar em bovinos de corte

5.2.1. SÍNTESE DOS DADOS DE EXPRESSÃO DIFERENCIAL DOS TRÊS ORGÃOS

5.2.2. CO-EXPRESSÃO INTEGRADA DE GENES NO HIPOTÁLAMO,

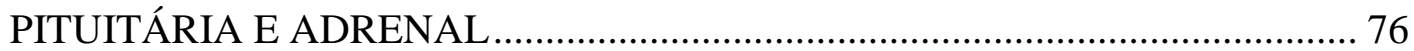

5.2.3 CO-EXPRESSÃO DE GENES NOS ORGÃOS DE FORMA INDIVIDUALIZADA 84

5.3. Abordagem 3 - Identificação de RNAs longos não codificadores em múltiplos tecidos de bovinos Nelore e sua associação com a eficiência alimentar 95

5.3.1. IDENTIFICAÇÃO DOS lncRNAs EM 5 TECIDOS DE BOVINOS NELORE

5.3.2. IncRNA EXPRESSOS DIFERENCIALMENTE ENTRE ALTA E BAIXA EFICIÊNCIA ALIMENTAR 
5.3.3. FUNÇÃO DOS IncRNA DIFERENCIALMENTE EXPRESSOS COMO

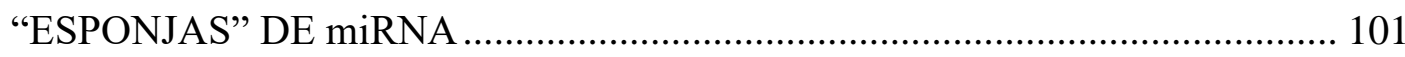

5.3.4. FUNÇÃO DOS IncRNA DIFERENCIALMENTE EXPRESSOS COMO

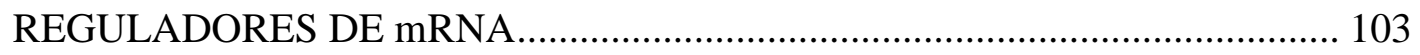

6. DISCUSSÃ

6.1. Abordagem 1 - Expressão gênica multitecidual associada à eficiência alimentar

6.2. Abordagem 2 - O papel do eixo hipotálamo-pituitária-adrenal sobre eficiência alimentar em bovinos de corte

6.3. Abordagem 3 - Identificação de RNAs longos não codificadores em múltiplos tecidos de bovinos Nelore e sua associação com a eficiência alimentar 122

6.4. Discussão final 128

7. CONCLUSÃO 132

REFERÊNCIAS 133

APÊNDICE A - Figuras Suplementares

APÊNDICE B - Tabelas Suplementares 


\section{INTRODUÇÃO}

Desde a domesticação das primeiras espécies, a seleção animal é realizada com objetivo de atender as necessidades humanas e essas, vêm se modificando ao longo do tempo. Hoje, entre os principais objetivos de seleção está o aumento da produtividade para acompanhar o crescimento da população mundial (UNITED NATIONS, 2011) e o consequente aumento na demanda por proteína animal, principalmente a carne, que deve chegar a 470 milhões de toneladas ao ano até 2050 (FAO, 2009). Além disso, também podemos citar: (1) a identificação de animais superiores para características de mensuração difícil ou onerosa; (2) a necessidade de utilização eficiente dos recursos naturais visando a redução da produção de poluentes, como o gás metano, outros gases do "efeito estufa" e dejetos, diminuindo assim o impacto ambiental da pecuária e; (3) a menor competição de alimentos usados nos sistemas produtivos com a alimentação humana (HAYES; LEWIN; GODDARD, 2013). Uma maneira de atender esses objetivos é através da seleção de animais para melhor eficiência alimentar (EA), uma vez que animais mais eficientes consomem menos alimento para produzir a mesma quantidade de carne (KOCH et al., 1963) e dessa forma, produzem proporcionalmente menos poluentes (CANTALAPIEDRA-HIJAR et al., 2018; NKRUMAH et al., 2006), tendo como consequência o aumento da produtividade do sistema e lucratividade do produtor.

A dificuldade em incorporar medidas de EA em programas de melhoramento animal reside no fato de que, para calculá-las, é necessário medir diariamente o consumo de alimento e o ganho de peso para cada animal, por um período de pelo menos 70 dias (ARCHER et al., 1997) o que demanda tempo, dinheiro, infraestrutura e mão de obra especializada. Por isso, foram realizados diversos trabalhos visando identificar marcadores moleculares associados à EA que facilitassem a identificação de animais superiores (DE OLIVEIRA et al., 2014; ROLF et al., 2011; SANTANA et al., 2014b; SHERMAN; NKRUMAH; MOORE, 2010). Porém, é possível perceber que para cada população analisada, diferentes processos biológicos parecem ser mais importantes. Isso porque entre diferentes populações e diferentes raças existem variações no padrão de desequilíbrio de ligação e os efeitos estimados dos marcadores em uma raça podem não ser aplicados a outra raça. Soma-se o fato que a EA é uma característica de moderada herdabilidade ( 0,3, ARCHER et al., 1999; POLIZEL et al., 2018) em bovinos de corte, refletindo a grande importância do ambiente (dieta e manejo, por exemplo) e da interação 
deste com as células, tecidos e órgãos dos animais para essa característica. Assim, o conhecimento das complexas interações entre genes expressos é importante para indicar quais genes e elementos regulatórios poderiam afetar o fenótipo, permitindo que as avaliações genômicas foquem em alterações causais, que teriam maior probabilidade de afetarem mecanismos em comum entre raças e mesmo entre espécies diferentes (SNELLING et al., 2013)

Com o objetivo de encontrar genes e vias metabólicas importantes para a EA, diversos trabalhos estudaram expressão diferencial associada a EA, principalmente no fígado, um órgão importante no metabolismo de bilirrubina, ácidos biliares, carboidratos, lipídeos, xenobióticos, proteínas e também na imunidade. Foram encontrados mecanismos relacionados à organização, proliferação e sinalização celular, metabolismo de xenobióticos, síntese proteica e metabolismo de lipídeos e carboidratos, cascatas de coagulação e do complemento, estresse oxidativo mediado por NRF2, degradação de melatonina, metabolismo de glutationa e imunidade inata (CHEN et al., 2011; PARADIS et al., 2015; TIZIOTO et al., 2015, ALEXANDRE et al., 2015). Apesar de gerar importantes informações sobre os potenciais mecanismos envolvidos na regulação da EA, a análise da expressão diferencial por si só não fornece informações sobre as interações entre os genes ou sobre o comportamento de genes reguladores num sistema complexo. Isso porque quando se compara a expressão de um gene em duas condições, como alta e baixa EA, o contexto da regulação dessa expressão é perdido (HUDSON; DALRYMPLE; REVERTER, 2012b).

Para compreender fenótipos complexos como a eficiência alimentar é essencial uma visão como a do filósofo grego Aristóteles, de que "o todo é maior que a simples soma de suas partes". Nesse sentido, a abordagem de biologia de sistemas pode trazer informações importantes e mais completas para a compreensão dos mecanismos que regulam a EA, possibilitando a identificação de marcadores genéticos responsáveis pelos efeitos em questão ou mesmo a modulação desses efeitos pela dieta ou ambiente. Essa abordagem baseia-se no fato de que os genes interagem uns com os outros numa rede de interações que revela uma regulação mais complexa da transcrição, recuperando informações funcionais do tecido (FULLER et al., 2007; HUDSON; DALRYMPLE; REVERTER, 2012b). Essa metodologia foi utilizada durante o trabalho de mestrado desta autora, onde além das análises de redes de expressão gênica em amostras de biópsia hepática, diversas outras medidas foram coletadas e relacionadas com a EA 
(ALEXANDRE et al., 2015). Foi observado que os grupos de alta e baixa EA de bovinos Nelore apresentaram desempenho similar quanto ao peso inicial e final, ganho de peso, rendimento de carcaça, rendimento dos principais cortes e área de olho de lombo, mostrando que a taxa de crescimento e de deposição de músculo não apresentaram diferença entre os grupos. Por outro lado, desde o início do confinamento os animais de baixa EA tiveram maior ingestão de alimentos, maior conversão alimentar (menor eficiência em converter alimento em carne), maior espessura de gordura subcutânea desde o primeiro dia de avaliação e maior peso de gordura visceral medida no momento do abate. Por fim, os animais de baixa EA apresentaram níveis elevados tanto de colesterol quanto de gamma glutamil transpeptidase (GGT) o que indicou potenciais alterações hepáticas nestes animais ao fim do confinamento. A partir das análises de expressão gênica diferencial, co-expressão e co-expressão diferencial de amostras de biópsia hepática, foi possível determinar vias associadas ao metabolismo de lipídeos mas também à resposta imunológica e maior presença de inflamação hepática nos animais de baixa EA (ALEXANDRE et al., 2015). Foi proposto então que lesões hepáticas em animais de baixa EA ocorreriam em decorrência do estresse gerado por sobrecarga no metabolismo lipídico e/ou devido a maior infecção bacteriana causada pela maior ingestão de alimentos nesse grupo, sendo que naquele momento não foi possível determinar se esses processos estão associados entre si ou se só um é responsável pelo maior número de lesões e resposta inflamatória.

Tendo em vista os resultados encontrados analisando o fígado, um órgão central do metabolismo, e sabendo que a EA é um fenótipo complexo e outros mecanismos além do metabolismo são apontados como responsáveis por sua regulação, como o padrão de ingestão, a digestão, a atividade física, o estresse e a termorregulação (HERD; ARTHUR, 2009; HERD; ODDY; RICHARDSON, 2004), o objetivo desse trabalho foi somar aos resultados encontrados anteriormente, informações sobre o perfil transcriptômico de pituitária, hipotálamo, adrenal e músculo. Esses órgãos são responsáveis por controlar funções cruciais para o desenvolvimento e adaptação dos animais como controle do apetite, balanço hídrico, resposta ao estresse, regulação da temperatura corporal, crescimento, digestão, atividade sexual, entre outros. Dessa forma, uma teoria mais completa poderia ser formulada sobre como a EA é regulada em um contexto sistêmico. 


\section{HIPÓTESE E OBJETIVO}

\subsection{Hipótese}

A abordagem de biologia de sistemas, baseada em avaliação transcriptômica multitecidual, possibilita a construção de uma teoria para compreensão sistêmica da eficiência alimentar em bovinos de corte.

\subsection{Objetivo}

Propor uma teoria para compreensão sistêmica da eficiência alimentar em bovinos Nelore utilizando abordagem de biologia de sistemas baseada na análise do transcriptoma multitecidual de animais divergentes para esse fenótipo. 


\section{REVISÃO DE LITERATURA}

\subsection{Visão holística da eficiência alimentar}

Embora a base biológica para a variação individual na eficiência alimentar não tenha sido totalmente elucidada, é de senso comum que muitos processos fisiológicos estão envolvidos na regulação dessa característica, tais como a ingestão de alimentos, a digestão, a composição corporal, o metabolismo, a atividade física e a termorregulação (BASARAB et al., 2003; HERD; ARTHUR, 2009; HERD; ODDY; RICHARDSON, 2004). Recentemente outros processos adaptativos ou mesmo patológicos como a importância do sistema imune e a ocorrência de inflamação (ALEXANDRE et al., 2015; DE OLIVEIRA et al., 2014; JÉGOU et al., 2016; KARISA; MOORE; PLASTOW, 2014; KERN et al., 2016; PARADIS et al., 2015; SALLEH et al., 2017), assim como a importância da relação do microbioma e o animal (CANTALAPIEDRA-HIJAR et al., 2018; ELOLIMY et al., 2018; LI; GUAN, 2017; PAZ et al., 2018) têm sido associados à eficiência alimentar. A compreensão desses processos é de grande interesse, pois pode ajudar a direcionar estratégias de manejo para melhorar a performance dos animais, principalmente com relação a requerimentos nutricionais específicos; pode resultar em estratégias inovadoras para identificar animais superiores (biomarcadores), que reduzam o custo da avaliação dessa característica, e pode ainda nos indicar efeitos indesejados da seleção para EA com relação ao impacto em outras características de importância econômica (RICHARDSON et al., 2004). Por isso, durante muitos anos os estudos focaram na análise de vários aspectos específicos desta característica e hoje acredita-se que os animais com fenótipos divergentes para a eficiência alimentar também diferem no temperamento, comportamento alimentar, resposta ao estresse, apetite, deposição de gordura, consumo de oxigênio, gasto de energia, perda de calor, função mitocondrial e outros. Estes e outros aspectos relacionados à eficiência alimentar em bovinos serão discutidos a seguir.

Considerando que os animais eficientes consomem menos para ganhar o mesmo peso que os animais ineficientes, é razoável esperar que os primeiros gastem menos tempo nas atividades de alimentação, já que a ingestão é uma função do tamanho da refeição e sua frequência. De fato, a literatura relata uma variabilidade considerável nos comportamentos alimentares, sendo que os animais de baixa eficiência alimentar 
apresentam maior tempo em frente ao cocho e maior tempo de cabeça baixa, enquanto que os animais de alta eficiência alimentar passam mais tempo sendo sedentários e se alimentam mais lentamente (KELLY et al., 2010a, 2010b; KENNY et al., 2018; MCGEE et al., 2014). Além disso, existe um aparente aumento na digestibilidade dos alimentos nos animais de alta EA, mas não se sabe se essa maior habilidade digestiva é inerente desses animais ou se deve a menor taxa de passagem de alimentos devido à menor ingestão de matéria seca (KENNY et al., 2018). Mas por que alguns animais comem menos? Que mecanismos controlam as diferenças na saciedade? O apetite é um processo biológico complexo regulado por diferentes sinais provenientes de nutrientes, hormônios e células neurais que atuam sobre o hipotálamo (SARTIN; WHITLOCK; DANIEL, 2011). Muitos estudos têm focado em entender a influência do hormônio leptina sobre a eficiência alimentar por causa de seu papel na regulação do peso corporal, ingestão de ração, gasto de energia e até mesmo reprodução, inflamação e imunocompetência (KELLY et al., 2010a; RICHARDSON et al., 2004).

Embora algumas discordâncias possam ser encontradas na literatura, a maioria dos estudos mostra associação de níveis mais altos de leptina com menor EA, maior ingestão alimentar e maior deposição de gordura (FOOTE et al., 2016b; HOQUE; KATOH; SUZUKI, 2009; KELLY et al., 2010a; NKRUMAH et al., 2007; RICHARDSON et al., 2004). Esse fenótipo se assemelha ao de resistência à leptina observado em humanos obesos, no qual a maior porcentagem de gordura corporal aumenta os níveis de leptina que falham em modular a ingestão de alimentos devido a insensibilização de receptores do hipotálamo (MYERS et al., 2010). Deve-se considerar que na maior parte dos experimentos citados acima, utiliza-se animais em fase de terminação em confinamento caracterizados por já se encontrarem em uma fase avançada de deposição de gordura para finalização da carcaça, o que corrobora com a visão de animais "obesos". Por outro lado, os poucos estudos que tentam entender a complexa regulação da EA no hipotálamo não mostraram diferença no nível circulante de leptina entre as condições de alta e baixa EA (PERKINS et al., 2014b) ou mostraram maior expressão no tecido adiposo de animais com alta eficiência alimentar (PERKINS et al., 2014a).

A maior expressão de leptina no tecido muscular de animais de alta eficiência alimentar da raça Nelore, bem como o maior nível de leptina circulante, menor nível de colesterol plasmático e menor deposição de gordura também foi observado em nosso 
estudo (MOTA et al., 2017). Este resultado está de acordo com o papel fisiológico da leptina descrito em humanos, porém diferente da maioria da literatura em bovinos. Isto provavelmente se deu por causa de diferenças na deposição de gordura entre fêmeas, machos inteiros e machos castrados e também entre raças taurinas e zebuínas, sendo machos inteiros e raças zebuínas sabidamente mais tardios. Os animais utilizados em nosso experimento, assim como a maioria dos animais abatidos no Brasil, por serem inteiros e zebuínos são diferentes da maioria de literatura que usou fêmeas ou machos castrados de raças taurinas (HOQUE; KATOH; SUZUKI, 2009; KELLY et al., 2010a; NKRUMAH et al., 2007; RICHARDSON et al., 2004) e não estariam ainda no estado de "obesidade" que leva a falha na regulação do apetite exercida pela leptina.

Os resultados conflitantes, principalmente quando se compara bovinos taurinos com zebuínos, indicam que são necessários mais estudos para compreender a função endócrina na modulação do apetite em animais de EA divergente. No entanto, alguns genes importantes foram apontados como reguladores do apetite até o momento, tais como Neuropeptídio-Y (NPY), relaxina-3 (RLN3) e pro-opiomelanocortina (POMC) (PERKINS et al., 2014b). Também foi relatada associação de polimorfismos em genes relacionados à modulação do apetite, como o NPY e a enzima PDE3B, com a EA (SANTANA et al., 2014a, 2014c; SHERMAN et al., 2008). Em um estudo que avaliou as diferenças no perfil de expressão hormonal de vacas leiteiras com alta e baixa EA, os genes que regulam as vias de sinalização da adipocitocina e a via de sinalização da insulina foram expressos diferencialmente nos dois grupos (XI et al., 2015). Curiosamente, essa via de sinalização tem a leptina como fator chave e desempenha um papel importante no metabolismo lipídico (ZHAO; LI; QU, 2013).

Trabalhos avaliando variação no tamanho de órgãos com diferenças na EA apresentam resultados divergentes (KENNY et al., 2018), porém maior densidade da mucosa intestinal foi observada em animais de alta EA (MEYER et al., 2014), assim como maior número de células epiteliais no duodeno e íleo (MONTANHOLI et al., 2013). Além disso, menor turnover de proteína do músculo esquelético foi associada com animais eficientes, demonstrando a menor necessidade de energia para manutenção ou, em outras palavras, uma economia de energia em indivíduos eficientes (CASTRO BULLE et al., 2007).

Existem também consequências metabólicas da maior ingestão de alimentos o que, por sua vez, afeta medidas fenotípicas como a maior deposição de gordura 
subcutânea e visceral, relatada nos animais menos eficientes (BASARAB et al., 2003; GOMES et al., 2012; MADER et al., 2009). A maior ingestão de alimentos está associada à maior proporção de energia necessária para a manutenção, devido à maior energia despendida nas atividades de alimentação, digestão e metabolismo tecidual (HERD; ARTHUR, 2009; HERD; ODDY; RICHARDSON, 2004).

Utilizando evidências de estudos com bovinos, frangos, suínos e camundongos, alguns autores discutiram que o aumento da atividade física, comportamento de ingestão e estresse estão associados à menor eficiência alimentar e que levam a maior taxa metabólica e consumo de energia (HERD; ARTHUR, 2009; HERD; ODDY; RICHARDSON, 2004). Estudos em bovinos corroboram essas evidências ao reportar diferenças na eficiência alimentar entre os animais classificados como "temperamento adequado" e "temperamento reativo" (FRANCISCO et al., 2015). Animais mais reativos apresentam maior resposta ao estresse, ao manejo inicial e menor eficiência alimentar, o que sugere um envolvimento da ativação do eixo simpático-adrenal-medular e hipotálamo-pituitária-adrenal no controle desta característica. Resultado similar foi observado ao desafiar bovinos de corte utilizando hormônio adrenocorticotrófico exógeno e observar associação negativa entre níveis de cortisol e EA, além de uma interação tempo dependente, com os animais menos eficientes tendo uma resposta de cortisol mais prolongada (KELLY et al., 2017).

Os tecidos do leito esplâncnico (trato gastrointestinal, fígado, baço, pâncreas e depósitos de gordura mesentérica), juntamente com o tecido conjuntivo e os vasos sanguíneos associados, podem ser responsáveis por 35 a $60 \%$ do consumo total de oxigênio do corpo (SEAL; REYNOLDS, 1993) e essa variação parece estar associada à variação na ingestão de ração (HUNTINGTON et al., 1988), já que os animais de alta eficiência alimentar (baixa ingestão de ração) consomem menos oxigênio (CHAVES et al., 2015). Em conformidade, concentrações plasmáticas mais baixas de $\mathrm{CO}_{2}$ têm sido relatadas em animais com alta EA, o que sugere um processo de oxidação diminuído (GONANO et al., 2014). Com relação a isso, podem ser encontrados na literatura muitos estudos investigando diferenças na função mitocondrial em relação à EA que sugerem que existe maior controle da fosforilação oxidativa no fígado de animais com alta EA (LANCASTER et al., 2014) e que o aumento da função mitocondrial nesses animais pode contribuir para melhorar a eficiência alimentar (CONNOR et al., 2010). Também foram relatadas diferenças na proteína mitocondrial do complexo I de linfócitos de animais com 
fenótipos divergentes de EA (RAMOS; KERLEY, 2013). Nos suínos, diferenças na função mitocondrial foram relatadas ao analisar músculo (VINCENT et al., 2015) e transcriptoma sanguíneo (LIU et al., 2016), de modo que o menor metabolismo oxidativo foi associado com alta EA.

Em um cenário onde animais com baixa EA têm temperamento mais reativo, maiores requerimentos de energia de mantença, maior consumo de oxigênio e maior concentração de $\mathrm{CO}_{2}$ no sangue, é razoável hipotetizar que o aumento no metabolismo oxidativo poderia estar associado com maior desperdício de energia em forma de calor (GONANO et al., 2014). De fato, a literatura relata termógrafos mais quentes para indivíduos com baixa EA em ambientes termo-neutros, o que representa maior quantidade de calor dissipado pela radiação (ARCHER et al., 1999; MONTANHOLI et al., 2010). Por outro lado, em ambientes de temperaturas mais quentes, os animais ativam funções termorreguladoras e neste caso, os animais de baixa EA apresentaram termografias mais frias, o que poderia indicar um controle menos eficiente da homeostase corporal (MARTELLO et al., 2016).

Como discutido acima, muitos aspectos da eficiência alimentar devem ser considerados para compreender as diferenças fisiológicas relacionadas com esta característica. Nesse sentido, abordagens de alto rendimento, como tecnologias de sequenciamento de ácidos nucleicos e estudos de associação genômica ampla (GWAS), juntamente com integração de dados e metodologias de redes de co-expressão nos deram ideias mais profundas sobre a regulação deste fenótipo e hipóteses foram geradas. Essas análises apontaram regiões genômicas e genes candidatos associados à eficiência alimentar de bovinos de corte (DE OLIVEIRA et al., 2014; LU et al., 2013; ROLF et al., 2011; SANTANA et al., 2014b; SHERMAN; NKRUMAH; MOORE, 2010).

Karisa, Moore e Plastow (2014) propuseram que as variações na EA começam com diferenças na captação de glicose nas células pela influência dos genes GHR, insulina, creatina-AMPK e leptina sobre a eficiência de seu transporte em toda a membrana citoplasmática. Também foram identificadas diferenças no metabolismo energético e lipídico, de esteroides e colesterol, que poderiam influenciar a taxa de formação de acetil CoA (KARISA; MOORE; PLASTOW, 2014). De fato, diferenças na deposição de gordura e no metabolismo lipídico, com animais de baixa EA mostrando níveis mais elevados de colesterol, foram corroboradas por outros estudos, inclusive o desta autora (ALEXANDRE et al., 2015; MONTANHOLI et al., 2017). Nesse estudo, 
encontramos evidências de diferenças no primeiro passo na metabolização de lipídeos no fígado que é o transporte de ácidos graxos para a mitocôndria para sofrer $\beta$-oxidação. Esse resultado foi corroborado recentemente por BALDASSINI et al. (2018) que encontraram, em fígado de bovinos divergentes pra EA, diferença na presença das proteínas 3-cetoacil-CoA tiolase e glutamato desidrogenase 1 relacionadas à $\beta$-oxidação e à capacidade oxidativa dos animais. Nos ruminantes, a lipogênese ocorre com capacidade limitada no fígado, sendo principalmente realizada no tecido adiposo (HANNUN; OBEID, 2002). No entanto, na presença de níveis elevados de ácidos graxos, a oxidação desacoplada de NADPH torna-se mais provável, gerando aumento de radicais derivados de oxigênio e peróxido de hidrogênio no fígado (KNOCKAERT; FROMENTY; ROBIN, 2011). Maior estresse oxidativo e expressão de enzimas antioxidantes no fígado de bovinos de baixa EA já foram relatados em alguns estudos (AL-HUSSEINI et al., 2014; CHEN et al., 2011; TIZIOTO et al., 2015).

Em nosso trabalho, a análise de redes de genes expressos no fígado de animais de baixa EA também indicou inflamação hepática, confirmada por lesões hepáticas observadas na análise histopatológica e maior nível de GGT no soro (ALEXANDRE et al., 2015). Sugerimos, na época, que a maior expressão do fenótipo de inflamação em animais de baixa EA foi gerada pela maior quantidade de lesões hepáticas, potencialmente induzidas pelo estresse metabólico gerado pelo metabolismo energético/lipídico alterado e/ou devido ao aumento da infecção bacteriana provinda do sangue portal. Corroborando nossos achados, PARADIS et al. (2015) encontraram aumento na expressão de genes envolvidos com imunidade inata no fígado de animais de baixa EA. Esses autores levantaram a hipótese de que os animais de alta EA gastam menos energia para combater a inflamação sistêmica porque têm melhor resposta imune hepática inata contra endotoxinas e produtos bacterianos. Em vacas de leite, vias metabólicas relacionadas à imunodeficiência e metabolismo de lipídeos também foram identificadas em animais divergentes para EA (SALLEH et al., 2017). Além disso, em estudo recente realizado por nosso grupo e em vias de publicação, a análise do proteoma hepático dos mesmos animais avaliados por transcriptômica (ALEXANDRE et al., 2015) confirmou diferenças em vias relacionadas ao metabolismo energético (biossíntese de ácidos graxos e aminoácidos), estresse oxidativo e resposta imune (metabolismo microbiano e processamento e apresentação de antígeno), além de metabolismo de vitaminas e hormônios (FONSECA et al., 2018). 
O estresse oxidativo encontrado em animais de baixa EA também pode ser resultado da resposta imune e este é o ponto onde as duas possibilidades apresentadas anteriormente se conectam. Em suínos, maior inflamação intestinal e marcadores de infiltração de neutrófilos, juntamente com o aumento de endotoxina sérica, foram reportados em animais de baixa EA (MANI et al., 2013). Os mesmos autores levantaram a hipótese de que os animais eficientes têm melhor capacidade para neutralizar as endotoxinas e que as diferenças na população bacteriana poderiam explicar parcialmente a diminuição das endotoxinas circulantes. Em bovinos, já foram relatadas diferenças na população bacteriana intestinal entre animais de alta e baixa EA (MYER et al., 2016, 2017). Além disso, em humanos, a muito se questiona a provável relação entre lesão hepática decorrente de endotoxinas e susceptibilidade à xenobióticos (ROTH et al., 1997), sendo que em bovinos já foram demonstradas diferenças na expressão de genes responsáveis pelo metabolismo xenobiótico em fenótipos divergentes para EA (ALEXANDRE et al., 2015; CHEN et al., 2011; TIZIOTO et al., 2015). No entanto, não se pode ignorar que os animais de baixa EA têm maior ingestão de alimento em sistemas de confinamento e que este fato pode ser a causa de mais lesões hepáticas e consequente inflamação. A dieta de alto concentrado (milho e soja) fornecida em sistemas de confinamento é um desafio estressante para ruminantes, o que pode levar à acidose e até à ruminite, causando lesões nas paredes do rúmen que poderiam ser a porta de entrada para bactérias (LECHTENBERG et al., 1988; OWENS et al., 1998). Já foi observado que animais com maior ingestão de ração também têm maior prevalência de abscessos hepáticos causados por bactérias do rúmen (NAGARAJA; LECHTENBERG, 2007).

É importante mencionar que, apesar da literatura reportar poucas e inconsistentes diferenças com relação a variáveis associadas ao processo de fermentação primária no rúmen (KENNY et al., 2018), diferenças na população microbiana ruminal vêm sendo bastante estudadas e foram apontadas como fator contribuinte para a capacidade de aproveitamento do alimento ingerido e eficiência alimentar, com os animais de baixa EA apresentando microbioma com maior diversidade de vias metabólicas expressas (LI; GUAN, 2017; MCGOVERN et al., 2018; MYER et al., 2015, 2016; PAZ et al., 2018). Foram também encontradas diferenças na expressão de alguns genes no tecido ruminal como o NQO1, indicando menor estresse oxidativo nos animais de alta EA, e o ACAT1, indicando que esse grupo de animais pode estar aproveitando corpos cetônicos para produzir energia, já que consomem menos alimento e tem menos carboidratos disponíveis 
(KERN et al., 2017). Por fim, foi observado que animais de alta EA apresentam mais bactérias no rúmen porém menos bactérias metanogênicas, maior espessura de epitélio ruminal e melhor capacidade de manter o $\mathrm{pH}$ ruminal baixo ao longo do dia (LAM et al., 2018). Apesar de ainda não sabermos se a resposta inflamatória observada no fígado é uma resposta a bactérias oriundas do rúmen, parece claro que diferenças no metabolismo ruminal contribuem para diferenças na eficiência alimentar de bovinos, sendo que uma microbiota menos diversa parece estar ligada à menor necessidade de substrato e energia para proliferação microbiana, de forma que mais nutrientes são direcionados para o hospedeiro (CANTALAPIEDRA-HIJAR et al., 2018).

É prudente considerar que a seleção para maior eficiência alimentar pode influenciar outras características econômicas importantes. As diferenças na composição corporal e no metabolismo discutidas anteriormente podem ter impacto nas características reprodutivas. As novilhas de alta EA apresentam menor deposição de gordura e maturidade sexual mais tardia, o que por sua vez resulta em partos mais tarde na época de parição quando comparadas a novilhas de baixa EA (FERREIRA JÚNIOR et al., 2018; RANDEL; WELSH, 2013; SHAFFER et al., 2011). Além disso, há relato de que os touros com melhor EA também apresentam características de maturidade sexual tardia, por exemplo, diminuição da motilidade progressiva e maior abundância de anomalias na cauda dos espermatozoides (FONTOURA et al., 2016). Atualmente, no Brasil, a seleção para precocidade sexual de novilhas Nelore é considerada como um critério de seleção muito importante. Mas, se isso entrar em conflito com a seleção para eficiência alimentar, uma abordagem mais ampla deve ser fortemente recomendada. Novilhas de gestação precoce significam mais bezerros/vacas, menos vacas para produzir a mesma quantidade de carne e menos emissões de gases. Mas se o gado mais eficiente não for tão precoce, como será este equilíbrio? Definitivamente, mais estudos são necessários para entender a biologia da EA, a fim de selecionar animais eficientes sem comprometer outras características importantes de produção. 


\subsection{Biologia de sistemas e redes de co-expressão}

O projeto Genoma Humano, iniciado na década de 90 e com previsão de conclusão em 15 anos gerou tamanha revolução nas metodologias de sequenciamento (high throughput technologies) que acabou sendo concluído dois anos antes (OLSON, 1993). Depois dele, diversos outros organismos tiveram seu genoma concluído, incluindo bactérias, arqueas, eucariotos, vírus e organelas, totalizando mais de 1000 genomas presentes na base de dados do NCBI (https://www.ncbi.nlm.nih.gov/guide/genomesmaps/). Diversas aplicações usando sequenciamento, bem como outras tecnologias high throughput como a espectrometria de massas, geraram uma mudança de paradigma na pesquisa biológica na qual as estratégias de processamento de informação e ordenação do conhecimento passaram da abordagem botton-up, representada por uma "colcha de retalhos" na qual se estuda as partes para tentar entender o todo, para uma abordagem top-down cujo objetivo é avaliar de forma mais abrangente os fenótipos moleculares para então determinar em quais aspectos seriam importantes para focar. Dentro desse contexto surgiu a biologia de sistemas.

A biologia de sistemas, por ser uma área de pesquisa bastante abrangente e com diversas aplicações, é difícil de definir. $\mathrm{O}$ que as fontes de pesquisa concordam é que é uma abordagem holística e interdisciplinar, que usa modelagem matemática e computacional para estudar as complexas relações entre sistemas biológicos, que compreendem diversos tipos moleculares (BREITLING, 2010; INSTITUTE FOR SYSTEMS BIOLOGY, 2018a). Ao contrário do reducionismo, em que se acredita que sistemas complexos podem ser reduzidos às suas partes mais simples para serem decifrados ou explicados, a biologia de sistemas é baseada em holismo, onde se entende que redes de interação que formam organismos vivos como um todo são mais do que a soma de suas partes. Nesse sentido, a biologia de sistemas em seu aspecto mais amplo é referida como "a rede das redes" (INSTITUTE FOR SYSTEMS BIOLOGY, 2018b). Isso porque organelas formam redes de interações que tornam células funcionais e conjunto de células interagem para formar tecidos, assim como tecidos constituem redes que dão origem a órgãos, que por sua vez interagem para formar sistemas com funções específicas como o digestivo ou o reprodutor. A junção de todos esses sistemas dá origem a um organismo vivo que é, portanto, o resultado de diferentes níveis de interações. Desse ponto de vista, a biologia de sistemas é mais do que a aplicação de uma técnica em um 
conjunto específico de dados, mas uma forma de pensar questões biológicas entendendo que o fenótipo é o resultado da propagação de sinais em vários níveis.

É também cada vez mais evidente que a visão centro-gênica induzida pelo dogma central da biologia molecular é demasiadamente reducionista, sempre buscando uma relação causal direta em um único sentido. Desta forma, é fundamental reconhecer que níveis mais altos (tecidos, órgãos, organismo) regulam a expressão dos genes numa intrincada rede compartilhada de informações entre os diferentes níveis de organização biológica, um fenômeno descrito como causação descendente (Figura 1, NOBLE, 2006). Ou seja, é necessária uma visão mais holística, menos reducionista que culmina na definição de biologia de sistemas de Dennis Noble "Biologia de sistemas...é sobre colocar as coisas juntas ao invés de separadas, integração em oposto à redução”. Como área da ciência, a biologia de sistemas é particularmente o estudo das interações entre os componentes dos sistemas biológicos, e como estas interações dão origem à função e comportamento de um sistema. Do ponto de vista prático, a biologia de sistemas pode ser vista como uma série de protocolos usados para fazer pesquisa baseando-se em um ciclo contendo teoria, modelação analítica ou computacional para testar hipóteses específicas sobre um sistema biológico gerando novas informações que serão utilizadas para alimentar e refinar o modelo computacional ou teoria (KHOLODENKO; BRUGGEMAN; SAURO, 2005). 
Figura 1 - Representação do fenômeno descrito como causação descendente (downward causation)

\section{Downward causation}

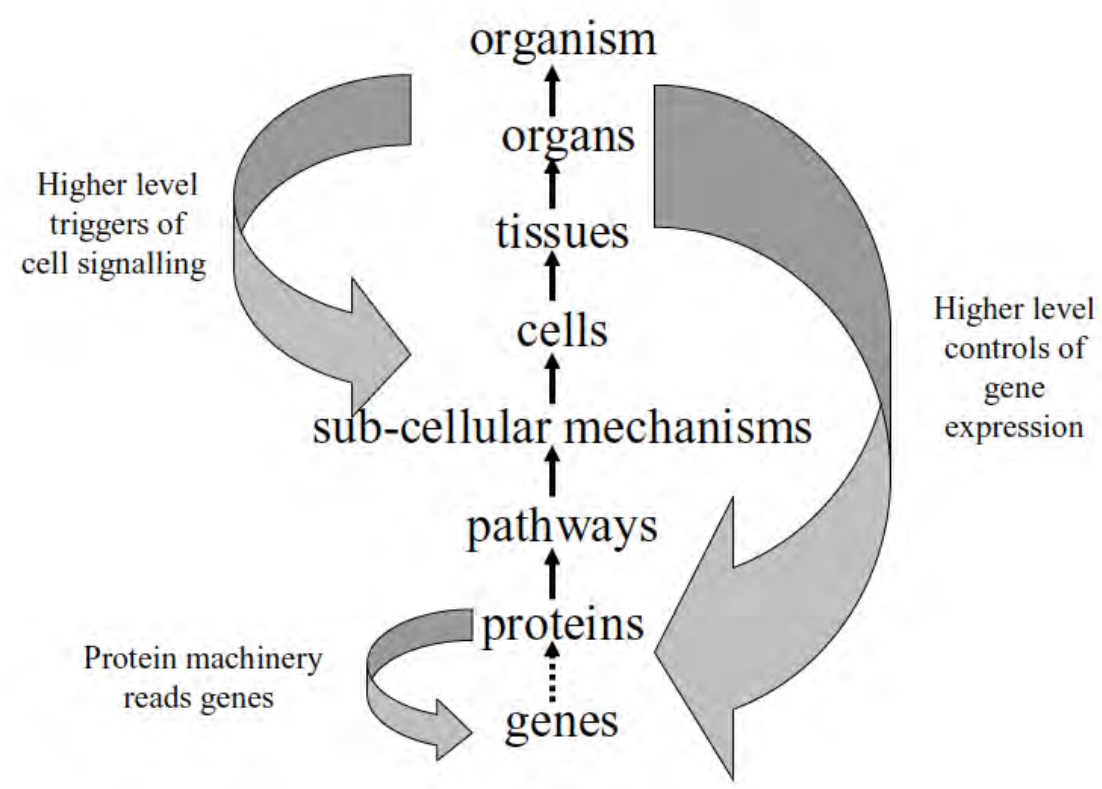

Em adição ao esquema representando o fluxo de informações baseado no dogma central da biologia molecular, a figura representa também a relação causal no sentido oposto exercida por níveis mais altos (organismo, órgãos, tecidos) na sinalização celular e expressão de genes e proteínas. Além disso, está representando o papel da maquinaria proteica em ler e interpretar genes, gerando um loop de causa e efeito que pode ser construído entre diversos níveis da organização biológica. Fonte: Noble (2006).

A arquitetura genética por trás de características complexas envolve uma variedade enorme de genes sensíveis a mudanças ambientais e, portanto, determinar os mecanismos responsáveis por elas representa um grande desafio (SWAMI, 2009). Sistemas biológicos complexos são regulados por milhares de moléculas de diferentes naturezas químicas. Nesse contexto, surge o termo "genética de sistemas". A genética de sistemas é uma versão especializada da biologia de sistemas, focada em populações, que visa elucidar complexas interações entre genes, proteínas, metabólitos, células e tecidos que se manifestam como variações fenotípicas, a fim de identificar as variantes genéticas relacionadas à característica de interesse (VOY, 2011). Estas abordagens baseiam-se no fato de que os genes e produtos de genes podem interagir uns com os outros numa rede complexa e por isso, o efeito da mudança no comportamento de um gene pode ser propagado através das interações e afetar outros genes (CHO; KIM; PRZYTYCKA, 2012). Esse comportamento é chamado em inglês de "power law" e em estatística é definido como uma relação funcional entre duas quantidades, sendo que a mudança 
relativa em uma, causa uma mudança proporcional na outra, independentemente do tamanho inicial das duas (BAR-YAM, 2011). Redes baseadas em power law tem como característica muitos nódulos com poucas conexões e poucos nódulos centrais com muitas conexões, que são chamados “hubs” (Figura 2, DE LA FUENTE, 2010).

Figura 2 - Exemplo de rede co-expressão baseada em power law.

Nódulos representam genes, com destaque para os genes centrais (hubs) em cinza escuro. Vértices representam a correlação entre a expressão dos genes. Fonte: própria autoria.

Os estudos de redes, quando aplicados a dados de transcriptoma, podem revelar uma regulação mais complexa da transcrição, detectando conjuntos de genes altamente co-expressos (FULLER et al., 2007). O resultado são conjuntos ou "módulos" de genes relacionados entre si, que tentam recuperar a informação estrutural e funcional do tecido (HUDSON; DALRYMPLE; REVERTER, 2012a). Esta estratégia pode ser particularmente útil para revelar a função biológica de novos genes, uma vez que se espera que genes co-expressos trabalhem coordenadamente para uma função biológica específica, representando uma via metabólica ou até mesmo um tipo celular. Como prova da importância da abordagem de co-expressão diferencial, HUDSON, REVERTER e DALRYMPLE (2009) estudando bovinos com e sem uma mutação no gene da miostatina que leva à dupla musculatura, não encontraram o gene como sendo diferencialmente expresso, mas puderam identificá-lo como importante baseando-se na análise de coexpressão diferencial, o que demonstra que a importância de um gene, ou conjunto de genes, para o fenótipo não está apenas ligado à diferença em sua abundância relativa.

Redes de genes fornecem uma representação eficiente das interações nas células e base para modelos matemáticos/estatísticos para estudar esses sistemas (SHOJAIE, 
2018). Uma rede é formada por diversos nódulos e vértices. Uma forma conveniente de representar os vértices de uma rede é através de uma matriz de adjacência, que é uma matriz quadrada com valores 1 se existir um vértice entre um nódulo na linha e um na coluna e 0 caso contrário. Para vértices que não se tem claro a direção da interação, o valor 1 é adicionado em ambas as direções. A presença de um vértice entre os nódulos i e $\mathrm{j}$ significa que conforme a expressão de $\mathrm{i}$ muda, espera-se que a expressão de $\mathrm{j}$ aumente/diminua. Na prática, observa-se $\mathrm{N}$ medidas de cada variável (que pode ser genes, proteínas, metabólitos, etc.) para diferentes indivíduos e tenta-se determinar quais variáveis são conectadas entre si. Porém, definir quais variáveis são relevantes não é uma tarefa clara e algumas estratégias como identificar genes centrais (hub genes) ou usar informações da literatura podem orientar essa seleção (SHOJAIE, 2018).

Existem duas classes gerais de métodos para inferência de redes: (1) os baseados em medidas marginais de associação, englobando associações lineares (redes de coexpressão) e não-lineares e (2) os baseados em medidas de associação condicional como redes Bayesianas ou redes dinâmicas Bayesianas (SHOJAIE, 2018). Os métodos baseados em redes de co-expressão/correlação são os mais simples e mais amplamente utilizados e assumem que os vértices correspondem à correlações de alta magnitude (SHOJAIE, 2018). Como a correlação é simétrica, a rede é não-direcionada, já que não é possível definir qual gene regula qual, a não ser utilizando conhecimento adicional da literatura. Um exemplo da aplicação dessa metodologia é a abordagem utilizada pelo pacote WGCNA - Weighted Gene Co-Expression Network Analysis (LANGFELDER; HORVATH, 2008) no ambiente R que define módulos de genes co-expressos baseados em correlação sem prévia utilização de dados da literatura para a seleção de genes. Posteriormente, os diversos módulos identificados são testados quando a sua correlação com fenótipos de interesse para identificar módulos relevantes para o tema investigado.

Uma limitação dessa análise é que correlações altas nem sempre significam interação direta. Além disso, várias relações biológicas não são lineares e essas são perdidas com esse tipo de metodologia. Uma maneira de contornar a primeira questão é utilizando metodologias baseadas em correlação parcial, como o PCIT - Partial Correlation And Information Theory (WATSON-HAIGH; KADARMIDEEN; REVERTER, 2010). Com ela obtém-se a correlação entre i e j depois de remover o efeito de outras variáveis, considerando-se que por vezes a "informação" passa por um vizinho mútuo de i e j e não diretamente entre eles. Em outras palavras, se A é correlacionado 
com B e com C, observaremos também uma correlação entre B e C, não pelo fato de ser uma relação real, mas por B e C compartilharem correlação com um vizinho em comum. Essa metodologia identifica e exclui essas correlações que não são verdadeiras.

Por fim, mais do que determinar a relação entre genes, vem se tornando cada vez mais importante entender a dinâmica celular que leva a mudanças no comportamento das redes. Por esse motivo, um número crescente de trabalhos vem analisando essa dinâmica através do mapeamento de redes em condições, espécies e tempos diferentes (IDEKER; KROGAN, 2012). Nessa abordagem, é feita a comparação da estrutura de duas sub-redes de co-expressão em condições fenotípicas diferentes. Essa comparação pode mostrar alterações em sistemas regulatórios através da diferença na conectividade de um gene nas duas condições, já que podemos admitir que genes com grande alteração de conectividade têm um papel importante para o fenótipo (DE LA FUENTE, 2010). O grau de conectividade $(\mathrm{K})$ de um nódulo é calculado pela soma dos vértices ligados a ele. Dessa maneira, interações diferenciais fortes não são as que necessariamente são fortes em uma das sub-redes, mas aquelas que mudam seu comportamento mais claramente (IDEKER; KROGAN, 2012). Assim, as interações diferenciais, também referidas como coexpressão diferencial, são um reflexo de quais processos celulares são diferencialmente importantes nas condições estudadas (IDEKER; KROGAN, 2012). Os métodos para análise de co-expressão diferencial, baseados na subtração de scores de interação (conectividade) em diferentes situações, são importantes para distinguir interações que desencadeiam processos celulares dinâmicos, daquelas que suportam funções de manutenção da célula (housekeeping).

\subsection{Mecanismos de regulação da expressão gênica}

A passagem de informação do DNA até a síntese da proteína compreende diversos passos nos quais a expressão gênica pode ser controlada: (1) controle pré-transcricional, (2) controle de processamento de mRNA, (3) transporte de mRNA e controle da localização na célula, (4) controle traducional, (5) controle da degradação do mRNA e (6) controle da atividade proteica (Figura 3) (ALBERTS, B.; JOHNSON, A.; LEWIS, J.; RAFF, M.; ROBERTS, K.; WALTER, 2008).

Figura 3 - Seis passos nos quais a expressão gênica eucariótica pode ser controlada. 


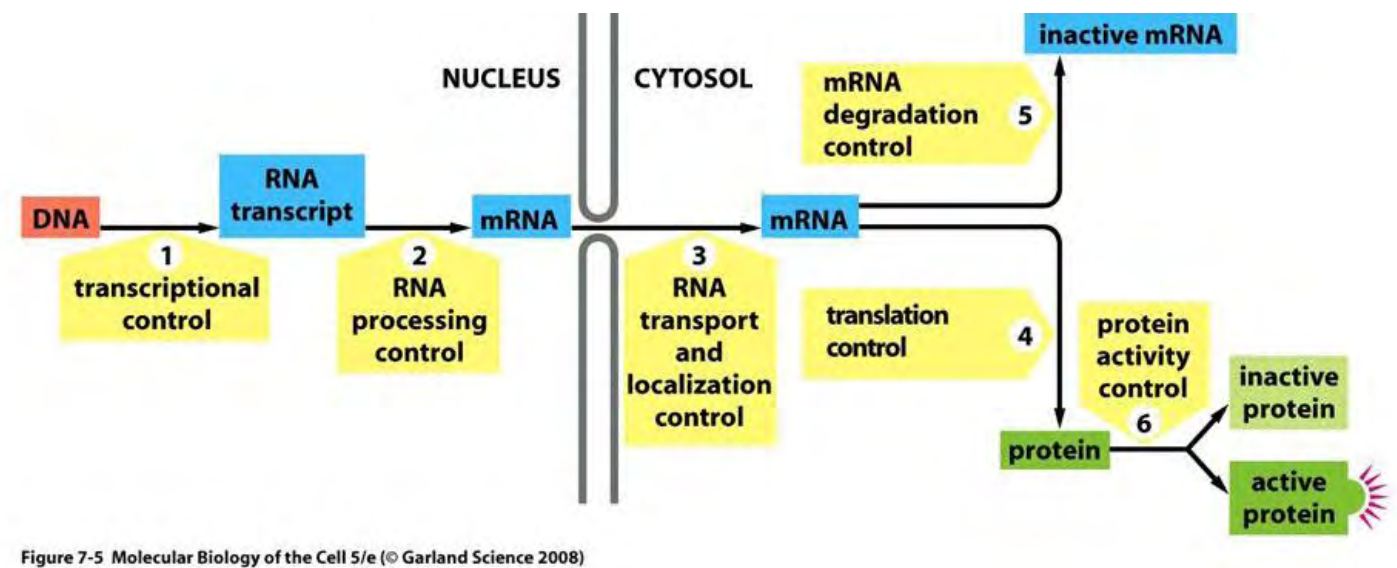

Fonte: Alberts, B.; Johnson, A.; Lewis, J.; Raff, M.; Roberts, K.; Walter (2008).

Para a maioria dos genes, os controles pré-transcricionais são os mais importantes (ALBERTS, B.; JOHNSON, A.; LEWIS, J.; RAFF, M.; ROBERTS, K.; WALTER, 2008). Esse controle pode ocorrer por diferentes mecanismos a saber: atividade de proteínas regulatórias e fatores de transcrição, modulação da cromatina e metilação de ilhas CpG. O primeiro mecanismo envolve dois elementos principalmente: pequenos trechos de DNA de uma sequência definida (ditas regiões regulatórias) e proteínas de regulação gênica que reconhecem e se ligam a esses trechos. As proteínas de regulação gênica são extensivamente complementares às características da dupla hélice de DNA em regiões regulatórias específicas, que envolvem tipicamente menos de 20 nucleotídeos. Essas proteínas podem ligar-se ao DNA como homodímeros ou como heterodímeros, compostos por duas subunidades diferentes, sendo que os últimos aumentam as possibilidades de ligação ao DNA que essas proteínas podem apresentar. No geral, a regulação gênica em eucariotos envolve muitas proteínas, regiões grandes de DNA e é bastante complexa (ALBERTS, B.; JOHNSON, A.; LEWIS, J.; RAFF, M.; ROBERTS, K.; WALTER, 2008). Inicialmente deve-se saber que todos os genes codificadores de proteínas são transcritos pela RNA polimerase II, que necessita de cinco fatores de transcrição (FT) gerais para exercer sua função. O acoplamento desses FT gerais acontece em etapas o que fornece a célula a capacidade de acelerar ou diminuir a taxa de início da transcrição em resposta a proteínas de regulação gênica. Além disso, muitas outras proteínas de regulação gênica podem atuar de grandes distâncias ao longo do DNA, permitindo com que um único gene seja regulado por várias delas (conhecidos como enhancers). Por fim, eucariotos apresentam um componente central da regulação gênica 
chamado de "mediador". Ele é formado por um complexo de 24 subunidades e serve como intermediário entre as proteínas de regulação gênica e a RNA polimerase.

Os trechos de DNA que promovem a regulação gênica são compostos pela região promotora, onde FT gerais e a polimerase se ligam, e todas as regiões reguladoras nas quais as proteínas de regulação gênica se ligam para estimular ou reprimir a expressão dos genes. Os FT gerais são poucos e abundantes na célula, se associando a todos os genes transcritos pela RNA polimerase II. Já as demais proteínas de regulação gênica variam muito e estima-se que $8 \%$ do genoma humano ( 2.000 genes) codifique essas proteínas (ALBERTS, B.; JOHNSON, A.; LEWIS, J.; RAFF, M.; ROBERTS, K.; WALTER, 2008). As proteínas de ativação gênica apresentam dois domínios, um com motivos estruturais que reconhecem as sequências de DNA reguladora e o outro responsável por acelerar a taxa de início da transcrição. Os ativadores têm como função atrair, posicionar e modificar os FT gerais, mediador e RNA polimerase II no promotor, de modo a promover a transcrição. Para isso eles podem inclusive alterar a estrutura da cromatina ao redor do promotor. Os ativadores podem agir em conjunto aumentando ainda mais a taxa de transcrição. Da mesma maneira agem as proteínas de repressão gênica. Uma mesma proteína pode atuar como parte de um complexo que ativa a transcrição ou como parte de um complexo que reprime a transcrição, de forma que proteínas eucarióticas de regulação gênica não são exclusivamente ativadoras ou repressoras, mas dependem da montagem final de todos os componentes do complexo. Essa montagem final depende do arranjo da sequência de DNA da região controladora e de quais proteínas de regulação estão presentes na forma ativa na célula. Assim, o tempo, o local e a taxa de transcrição dos genes em uma determinada condição são determinados pelo tipo de proteínas de regulação gênica que se ligam as regiões regulatórias do DNA.

Com relação ao controle traducional, observa-se um papel importante dos RNAs não codificadores (ncRNAs) na regulação dos RNAs que serão traduzidos em proteína. A definição de ncRNAs é bastante abrangente e engloba todos os tipos de RNA que não apresentam evidência de tradução em proteína. Na bioinformática, ncRNAs são identificados pela falta de quadros abertos de leitura (open reading frame - ORFs), seleção por tamanho e baixa homologia com proteínas conhecidas (MILLIGAN; LIPOVICH, 2015). Além disso, um valor arbitrário de 200 pares de bases é usado para separar os RNAs longos não codificantes (lncRNAs) de RNAs pequenos não codificantes, como os miRNA (MILLIGAN; LIPOVICH, 2015). Os pseudogenes, cópias de genes 
codificadores de mRNA que perderam sua capacidade de codificação de proteínas devido a mutações, também são considerados lncRNAs e devido à alta similaridade, podem regular seus genes parentais (WEIKARD; DEMASIUS; KUEHN, 2016).

Estruturalmente, os lncRNAs tem baixo ou nenhum potencial para codificar proteínas e baixa conservação entre espécies, além de não apresentarem um padrão em sua sequência, o que dificulta sua categorização e predição funcional (WEIKARD; DEMASIUS; KUEHN, 2016). São, portanto, considerados evolucionariamente menos conservados do que genes codificadores de proteínas, principalmente nos éxons, o que nesse caso não indica falta de função, já que podem dobrar-se em estruturas complexas, mediando o reconhecimento do alvo não só por pareamento de bases, mas também pela interação com sua estrutura terciária (DENIZ; ERMAN, 2017). Outra possibilidade é que essa aparente falta de conservação seja devido ao fato de que as ferramentas de bioinformática disponíveis não são capazes de reconhecer pequenas sequências conservadas, separadas por um longo loop que não é conservado, ideia que se torna plausível devido ao fato das regiões promotoras dos lncRNAs serem tão conservadas quanto as dos mRNAs (DENIZ; ERMAN, 2017). Essa flexibilidade estrutural, sem perder função, pode permitir com que essas sequências evoluam mais rapidamente.

Comparado com genes codificadores de proteínas, os lncRNAs são mais tecidoespecíficos e apresentam menor nível de expressão, porém, apresentam algumas características em comum como presença de múltiplos éxons, cauda poliA, cap 5' e podem conter ilhas $\mathrm{CpG}$ em suas regiões promotoras (DENIZ; ERMAN, 2017; WEIKARD; DEMASIUS; KUEHN, 2016). Uma forma de classificar os lncRNAs é através da sua localização no genoma, já que eles podem estar localizados (1) em regiões intergênicas, e nesse caso são chamados lincRNA (long intergenic non coding RNA); (2) em introns de genes codificadores de proteínas; (3) na fita oposta de genes codificadores de proteínas; (4) associados a regiões UTR ou promotoras de genes codificadores de proteínas; (5) regiões regulatórias (enhancers); ou ainda (6) ser uma isoforma sem capacidade de codificação de um gene codificador de proteínas (WEIKARD; DEMASIUS; KUEHN, 2016).

Os lncRNA estão envolvidos em vários processos biológicos como a modulação da expressão alelo específica e a regulação transcricional e pós-transcricional da expressão gênica, seja por meio de recrutamento de complexos modificadores de cromatina ou através da regulação dos níveis de metilação do DNA, podendo funcionar 
como guias e sinalizadores ou ainda precursores ou sequestradores de miRNAs (QUINN; CHANG, 2016). Também podem atuar como sequestradores de fatores de transcrição de seus alvos ou como scaffolds permitindo a formação de complexos multiproteicos (BATISTA; CHANG, 2013). Atuam no splicing alternativo, na formação do corpúsculo de Barr, na atividade de enzimas e podem também ser exportados em vesículas extracelulares e agirem em outras células (SALVIANO-SILVA et al., 2018). Em redes de genes, agem como componente funcional da regulação da expressão gênica, sendo expressos em padrão coordenado com outros genes (WEIKARD; DEMASIUS; KUEHN, 2016). São encontrados em maior concentração no núcleo das células onde podem atuar sobre genes próximos de seu sítio de transcrição (cis) ou controlar a expressão de um loci independente em outro cromossomo (trans) (DERRIEN et al., 2012). Enfim, são diversas as formas de atuação desses RNAs, sumarizadas na Figura 4 publicada por Salviano-silva et al. (2018). 
Figura 4 - Localização genômica relativa a genes codificadores de proteínas e mecanismos regulatórios de RNAs longos não codificantes (lncRNAs) no núcleo, citoplasma e compartimentos extracelulares.

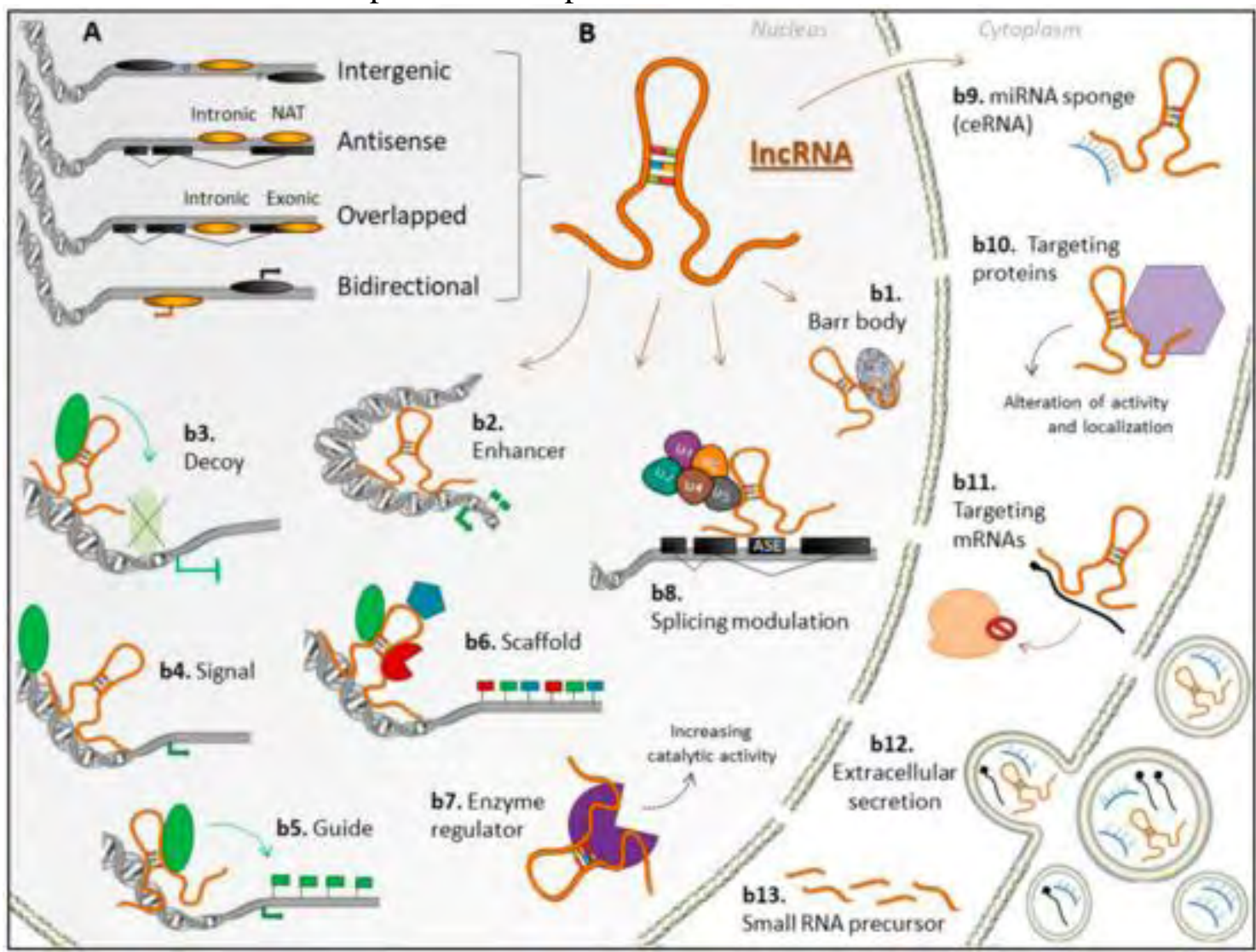

(A) Nomenclatura dos genes lncRNA (elipses douradas), de acordo com sua localização genômica em relação ao gene mais próximo (elipses pretas) e/ou exons de genes codificadores (retângulos pretos). (B) mecanismos reguladores dos lncRNAs: (b1) lncRNA Xist, componente do corpúsculo de Barr em fêmeas; (b2) agindo como enhancers, induzindo transcrição em cis ou em trans; (b3) como captador de proteínas reguladoras, como fatores de transcrição e modificadores da cromatina, bloqueando sua ligação ao DNA; (b4) como sinalizadores moleculares, ativando ou silenciando a expressão gênica através da sinalização para vias de regulação; (b5) guiando proteínas (em geral, modificadores de cromatina) para sítios alvo; (b6) como scaffolds, ligando diferentes proteínas e formando complexos de ribonucleoproteínas, que também afetam a expressão gênica; (b7) interagindo com enzimas, tais como quinases, regulando/intensificando a sua atividade catalítica e alterando a sua sinalização; (b8) modulação de splicing alternativo de transcritos primários; (b9) como RNA endógeno competidor (ceRNA), servindo como uma esponja para microRNAs (miRNAs), bloqueando seu efeito; (b10) visando proteínas, formando complexos moleculares que podem bloquear ou induzir efeitos funcionais, ou mesmo alterar a sua localização na célula; (b11) visando mRNAs, inibindo sua tradução em ribossomos. Além disso, os lncRNAs podem ser (b12) transferidos para outras células por vesículas extracelulares, onde eles podem produzir efeitos; (b13) precursores de miRNAs e outros pequenos RNA reguladores. Um lncRNA pode atuar por múltiplos mecanismos reguladores, tanto no núcleo quanto no citoplasma. O próprio b12 não é exatamente uma característica regulatória, no entanto, a liberação desses lncRNAs funcionais através de vesículas extracelulares é uma maneira de regular genes, RNAs ou proteínas em outros tecidos.

Fonte: SALVIANO-SILVA et al. (2018)

A forma mais comum de inferir o significado dos lncRNAs é através da expressão diferencial, porém, nesse caso, a exata função biológica não é identificada. Assim, metodologias chamas em inglês de guilt-by-association como a clusterização ou 
correlação com genes codificadores de proteínas com função conhecida são mais eficazes em tentar prever o papel de lncRNA importantes para determinado fenótipo (SIGNAL; GLOSS; DINGER, 2016). Além disso, a integração com outros conjuntos de dados funcionais, como assinaturas de cromatina e perfis de modificação de histonas, bem como a identificação dos fatores de transcrição responsáveis pela expressão dos lncRNAs também são úteis para anotar funcionalmente lncRNAs.

Em bovinos, um catálogo de lncRNAs em múltiplos tecidos foi publicado (KOUFARIOTIS et al., 2015). Apesar disso, existe pouca sobreposição entre esses e lncRNA encontrados por outros trabalhos (WEIKARD; DEMASIUS; KUEHN, 2016). Isso, torna mais uma vez evidente o caráter tecido/célula-específico, tempo-específico e condição-específico dos lncRNAs (WEIKARD; DEMASIUS; KUEHN, 2016). 


\section{MATERIAL E MÉTODOS}

\subsection{Obtenção de dados fenotípicos e amostras biológicas}

As amostras e dados apresentados neste tópico foram obtidos durante $\mathrm{o}$ desenvolvimento do trabalho de mestrado desta autora (Proc. FAPESP 2012/14792-3, Alexandre, 2015) em experimento realizado em 2013. Foram utilizados 98 bovinos machos inteiros da raça Nelore com aproximadamente 18 meses de idade e média de $401 \pm 31 \mathrm{~kg}$ de peso vivo, provenientes do rebanho da prefeitura do Campus da USP de Pirassununga e instalados no Confinamento Experimental do Departamento de Zootecnia, equipado para avaliar a ingestão individual de alimentos e ganho de peso. Todos os protocolos envolvendo esses animais foram aprovados pelo Comitê de Ética da Faculdade de Zootecnia e Engenharia de Alimentos da Universidade de São Paulo (FZEA/USPprotocolo 14.1.636.74.1). A dieta foi fornecida na forma de ração total misturada, duas vezes ao dia, sempre as 8 e 16 horas e as sobras de alimentação foram retiradas e pesadas diariamente para cálculo da ingestão de matéria seca diário. Pesagens foram realizadas ao início, ao fim e a cada 14 dias do período experimental que teve duração de 70 dias precedidos de 21 dias de adaptação à dieta e às instalações. A eficiência alimentar (EA) foi estimada através da medida de consumo alimentar residual (CAR - KOCH et al., 1963) e utilizada para ranquear os animais. A medida de conversão alimentar (CA) foi calculada pela razão do consumo de matéria seca médio diário (CMS) pelo ganho de peso médio diário. Os animais foram testados quanto à influência do touro (pai) e da instalação (Calan gates ou baias individuais) na estimativa do CAR e esses efeitos não foram significativos. Mais informações sobre o manejo e obtenção de dados fenotípicas dos animais utilizados neste estudo, bem como sua caracterização fenotípica, podem ser encontradas na dissertação de Alexandre (2015).

Os 40 animais selecionados como extremos de EA foram abatidos no abatedouro escola da Prefeitura do Campus de Pirassununga (PUSP-P) em dois dias, com seis dias de intervalo. Nesses dias, foram coletadas amostras de fígado, pituitária, hipotálamo, adrenal e músculo esquelético (Longissimus dorsi) de cada animal. Essas amostras foram rapidamente congeladas em nitrogênio líquido e armazenadas a $-80^{\circ} \mathrm{C}$. 


\subsection{Extração de RNA}

Para análise de RNAseq foram selecionadas amostras de 9 animais de cada extremo de eficiência alimentar (alta e baixa) através da medida de CAR. Para o hipotálamo e a pituitária, o tecido congelado em nitrogênio foi macerado com cadinho e pistilo e conservado em alíquotas a $-80^{\circ} \mathrm{C}$. Em seguida, RNA foi extraído desses tecidos utilizando um kit específico para esse fim (AllPrep DNA/RNA/PRotein Mini kit, QIAGEN, Crawley, UK). Para o fígado, músculo e glândula adrenal foi feito um corte no tecido congelado e o RNA foi extraído com o mesmo kit. A qualidade e concentração das amostras de RNA foram avaliadas pela determinação da razão A260/280 em espectrofotômetro (NanoDrop 2000, ThermoScientific, EUA) e pelo valor de integridade de RNA (RNA integrity number - RIN) através de eletroforese capilar em gel no equipamento Bioanalyzer 2100 com Labchips RNA 6000 Nano de acordo com as orientações do fabricante (Agilent Technologies Ireland, Dublin, Ireland). Foram mantidas apenas amostras que apresentaram RIN acima de 8 e razão 260/280 próxima a 2.

\subsection{Preparo e sequenciamento de bibliotecas de RNA}

As bibliotecas de RNA foram construídas utilizando-se o kit TruSeq ${ }^{\mathrm{TM}}$ RNA Sample Prep de acordo com o guia TruSeq ${ }^{\circledR}$ RNA Sample Preparation v2 (Illumina, USA, 2012, Part \# 15026495 Rev. D). Brevemente, os RNAs com cauda poliA foram isolados do total de $1 \mu \mathrm{g}$ de RNA total com beads de oligo-dT usando-se duas rodadas de purificação seguida de fragmentação. A síntese da primeira fita de cDNA foi realizada utilizando-se primers hexameros randômicos e transcriptase reversa. A segunda fita de cDNA foi então sintetizada em substituição à fita de RNA. O reparo das extremidades foi realizado pela ação de 3'-5'exonucleases que removem nucleotídeos sobressalentes na extremidade $3^{\prime}$ e a atividade da polimerase que preenche a extremidade 5', seguido da poliadenilação da extremidade 3' para prevenir que os fragmentos se liguem uns aos outros durante a ligação dos adaptadores. Adaptadores paired-end foram ligados à extremidade poliadenilada dos fragmentos. As bibliotecas foram amplificadas por PCR e então sequenciadas no equipamento Illumina HiSeq 2500 utilizando-se o kit TruSeq PE Cluster e TruSeq SBS Kit (2x100pb). Fígado, pituitária e hipotálamo foram sequenciados 
na mesma corrida, cada um em uma lane diferente. Músculo e adrenal foram sequenciados em uma segunda corrida, em diferentes lanes.

\subsection{Controles de qualidade e alinhamento com referência}

A qualidade do sequenciamento foi avaliada através do software FastQC (http://www.bioinformatics.babraham.ac.uk/projects/fastqc/) e nenhum filtro adicional foi realizado. O alinhamento de cada amostra com o genoma de referência bovino UMD3.1 foi realizado utilizando-se o software STAR (DOBIN et al., 2013), de acordo com os parâmetros padrão e incluindo o arquivo de anotação. A qualidade do alinhamento e comparação entre as diferentes amostras de cada tecido foi feita no software Qualimap2 (OKONECHNIKOV; CONESA; GARCÍA-ALCALDE, 2015). Em seguida, os reads alinhados foram filtrados usando o software Samtools (LI et al., 2009) para remover alinhamentos secundários, duplicatas de PCR e alinhamentos com baixa qualidade (-F 1792). Para realizar a contagem de reads por gene foi utilizado o programa HTseq (ANDERS; PYL; HUBER, 2014). A expressão gênica foi estimada em FPKM (Fragments Per Kilobase Per Million Fragments Mapped).

\subsection{Abordagem 1 - Expressão gênica multitecidual associada à eficiência alimentar}

\subsubsection{ESTIMATIVA DE EXPRESSÃO GÊNICA E NORMALIZAÇÃO}

Para essa abordagem, foram considerados todas as amostras de todos os tecidos e genes com valor médio de expressão inferior a 0,2 FPKM foram descartados. A normalização da expressão gênica foi realizada usando o seguinte modelo misto (REVERTER et al., 2005):

$$
Y_{i j k l}=\mu+L_{i}+G_{j}+G T_{j k}+G P_{j l}+e_{i j k l}
$$

Onde o valor de $\log 2$ FPKM para a i-ésima biblioteca (86 níveis), j-ésimo gene (17, 354 níveis), k- ésimo tecido (5 níveis), 1- ésimo fenótipo (2 níveis), representado por $Y_{\mathrm{ijkl}}$, foi modelado como uma função do efeito fixo da biblioteca $\left(L_{i}\right)$ e os efeitos aleatórios 
de gene $\left(G_{j}\right)$, gene por tecido $\left(G T_{j k}\right)$ e gene pelo fenótipo CAR $\left(G P_{j l}\right)$. O resíduo $\left(e_{i j k l}\right)$ foi considerado independente e identicamente distribuído. As estimativas e soluções do componente de variância para o modelo foram obtidas usando o programa VCE6 (ftp://ftp.tzv.fal.de/pub/vce6/doc/vce6-manual-3.1-A4.pdf). Valores de expressão média normalizada para cada gene foram definidos como a combinação linear das soluções para os efeitos aleatórios.

O modelo misto usado para normalizar os dados de expressão explicou $96 \%$ da variação na expressão gênica, dos quais a maior proporção (30\%) foi devido à especificidade do tecido. Por outro lado, as diferenças entre alta e baixa EA não explicaram uma porção importante da variação na expressão gênica $\left(2,7 \times 10^{-12} \%\right)$. Por esse motivo, a expressão média normalizada foi utilizada apenas para identificar genes tecido-específicos e os valores brutos de FPKM foram utilizados para a expressão diferencial e análise de co-expressão.

\subsubsection{SELEÇÃO DE GENES PARA CONSTRUÇÃO DE REDES}

Para selecionar um conjunto de genes relevantes para a análise de redes, definimos cinco categorias com base nos seguintes critérios de inclusão:

1. Diferencialmente expressos (DE) - O valor médio da expressão de cada gene, para cada grupo (alta e baixa EA) e cada tecido foi calculado e, em seguida, a expressão do grupo de baixa EA foi subtraída da expressão no grupo de alta EA. Em seguida, os genes foram classificados de acordo com sua expressão média em todas as amostras de cada tecido e divididos em cinco porções (bins). Os genes foram considerados diferencialmente expressos quando a diferença entre a expressão nos grupos de alta e baixa EA foi maior que 3,1 ou menor que $-3,1$ desvios padrão da média em cada bin, correspondendo a $\mathrm{P}<0,001$ no teste $\mathrm{t}$.

2. Genes contendo SNPs associados a EA - Genes que abrigam SNPs associados à eficiência alimentar, indicados principalmente por estudos de associação ampla (GWAS), foram identificados usando o banco de dados PubMed (www.ncbi.nlm.nih.gov/pubmed/) e o banco de dados Animal QTL (www.animalgenome.org/cgi-bin/QTLdb/index). Apenas dados de bovinos foram considerados, independentemente da raça. 
3. Tecido-específicos (TS) - Um gene foi considerado como tecido específico quando sua média normalizada em um determinado tecido foi maior que um desvio padrão da média de todos os genes naquele tecido E sua expressão média normalizada em todos os outros tecidos foi menor ou igual a zero.

4. Secretados - O banco de dados de secretoma humano (www.proteinatlas.org/humanproteome/secretome) foi usado para selecionar genes que codificam proteínas secretadas no plasma por qualquer um dos tecidos analisados (glândula adrenal, hipotálamo, fígado, músculo e pituitária).

5. Reguladores chave - Para identificar os principais genes reguladores a serem incluídos na rede de co-expressão, uma lista de genes foi obtida no Banco de Dados do Fator de Transcrição Animal (http://www.bioguo.org/AnimalTFDB/) e foi comparada a um conjunto de potenciais genes alvo em cada tecido, composto pelas categorias: TS, DE, genes contendo SNPs associados a EA e secretados. A análise foi baseada no método chamado regulatory impact factor (RIF, REVERTER et al., 2010), que compreende um conjunto de duas medidas projetadas para atribuir pontuações a genes reguladores consistentemente diferencialmente co-expressos com genes alvo e àqueles com a habilidade mais alterada de prever a abundância de genes alvo. A cada gene é atribuído um score e os que desviaram $\pm 1,96$ desvio padrão da média (correspondendo a $\mathrm{P}<0,05$ no teste $\mathrm{T}$ ) foram considerados significativos. Genes apresentando valor médio de expressão menor que a média de todos os genes expressos não foram considerados nesta análise.

Alguns dos genes selecionados pelas categorias acima foram representados por mais de um ensemble ID. Essas duplicações foram removidas para as próximas análises. Adicionalmente, os genes com expressão média entre as amostras igual a zero também foram removidos das análises futuras.

\subsubsection{ANÁLISE DE REDE DE CO-EXPRESSÃO}

Para a inferência da rede de genes, os genes selecionados pelas cinco categorias descritas anteriormente foram utilizados como nódulos e conexões significativas (arestas) foram identificadas entre eles usando o algoritmo de correlação parcial e teoria da informação (PCIT) (WATSON-HAIGH; KADARMIDEEN; REVERTER, 2010), considerando todos os animais e todos os tecidos. O PCIT determina a significância da 
correlação entre dois nódulos após contabilizar todos os outros nódulos na rede. $\mathrm{O}$ resultado do PCIT para correlações acima de 0.9 foi visualizado no Cytoscape (SHANNON et al., 2003).

\subsubsection{VALIDAÇÃO DE REGULADORES ATRAVÉS DE ANÁLISE DE ENRIQUECIMENTO DE SÍTIOS DE LIGAÇÃO}

$\mathrm{Na}$ rede de co-expressão criada, foram identificados os principais genes reguladores e seus genes alvo. Com o objetivo de investigar se esses genes alvos estavam enriquecidos para sítios de ligação dos reguladores mais conectados da rede, realizou-se uma análise chamada em inglês de motif discovery. Nessa análise, os primeiros vizinhos de cada gene regulador (genes com correlação direta) foram avaliados quando a presença de sítios de ligação usando duas ferramentas, o i-cistarget (HERRMANN et al., 2012) e o iRegulon, um plug-in do Cytoscape (JANKY et al., 2014). Essas ferramentas usam o genoma humano (hg19) como espécie de referência e, portanto, apenas genes ortólogos são considerados. Em seguida, com o intuito de validar a relação entre os sítios de ligação encontrados e os genes reguladores, foi realizada uma análise de enriquecimento utilizando dados de imunoprecipitação de cromatina (ChIP-seq) de fatores de transcrição específicos em linhagens de células do consórcio ENCODE, disponíveis publicamente. Finalmente, as regiões identificadas foram convertidas para coordenadas correspondentes no genoma do bovino e foi realizada a busca por regiões abertas de cromatina usando dados públicos de tecidos bovinos.

\subsubsection{CONECTIVIDADE DIFERENCIAL}

Para explorar genes diferencialmente conectados entre alta e baixa EA, duas redes foram criadas, uma para cada condição, usando a mesma metodologia descrita anteriormente. Em seguida, o número de conexões de cada gene em cada condição foi calculado e escalonado para que a conectividade variasse de 0 a 1 , possibilitando comparar o mesmo gene nas duas redes. A conectividade no grupo de baixa EA foi subtraída da conectividade do grupo de alta EA e resultados que se desviaram $\pm 1,96$ desvio padrão da média foram consideradas significativos (equivalente a $\mathrm{P}<0,05$ no teste $\mathrm{T}$ ). 


\subsubsection{ENRIQUECIMENTO FUNCIONAL}

A análise de enriquecimento funcional foi realizada na plataforma online GOrilla (Gene Ontology enRIchment anaLysis and visuaLizAtion tool, http://cblgorilla.cs.technion.ac.il/), utilizando todos os genes que passaram no filtro de FPKM como background, teste hipergeométrico e correção para múltiplos testes (FDR). O banco de dados humano foi utilizado para tirar proveito do conhecimento mais abrangente sobre as funções dos genes. Os termos do GO foram considerados significativos quando Paj <0,05. Para os genes nas redes de co-expressão, visualizados usando o Cytoscape, o enriquecimento funcional foi realizado com o plug-in BiNGO (MAERE; HEYMANS; KUIPER, 2005) usando os mesmos genes de background e teste estatístico.

\subsubsection{DOSAGEM DE ENDOTOXINA SÉRICA}

No último dia de confinamento (dia 70), sangue foi colhido da veia jugular de todos os animais em tubos a vácuo contendo ativador de coágulo. Os tubos foram centrifugados a $4^{\circ} \mathrm{C}$ a $3.500 \mathrm{rpm}$ durante 15 minutos para separação do soro. Alíquotas de soro foram armazenadas em freezer $-80^{\circ} \mathrm{C}$ até o momento da análise. A dosagem de endotoxinas no soro de 10 animais extremos de cada grupo de EA (alta e baixa), avaliados pelo CAR, foi realizada através de serviço terceirizado por ensaio de LAL (Lisado de Amebócitos do Limulus) com Kit Kinetic-QCL cromogênico cinético (Lonza, 50-650U). Para tanto as amostras foram aquecidas previamente a $70^{\circ} \mathrm{C}$ por 15 minutos e usadas puras ou diluídas 1:1 ou 1:4 de forma a diluir as endotoxinas para atingir a faixa de detecção do kit para quantificação absoluta. Uma amostra não apresentou quantificação, sendo indicada como $<0,01 \mathrm{EU} / \mathrm{ml}$ e o valor de $0,01 \mathrm{EU} / \mathrm{ml}$ foi atribuído a ela para o teste estatístico. Além disso, duas amostras apresentaram valores $\geq 2,5 \mathrm{DP}$ em relação à média de todas as amostras e foram retiradas da análise. Os grupos de alta e baixa EA foram testados por teste t de Student. 


\subsection{Abordagem 2 - O papel do eixo hipotálamo-pituitária-adrenal sobre a eficiência alimentar em bovinos de corte}

\subsubsection{DETERMINAÇÃO DE MÓDULOS DE CO-EXPRESSÃO}

Afim de avaliar o papel específico do eixo hipotálamo-pituitária-adrenal no controle da EA, foi realizada análise de co-expressão gênica utilizando apenas dados desses tecidos. Uma abordagem diferente da anterior foi empregada, utilizando o pacote WGCNA (Weighted Correlation Network Analysis) do R (LANGFELDER; HORVATH, 2008), em que nenhum critério de seleção baseado em conhecimento prévio foi utilizado para inclusão de genes na análise e a determinação de conjunto (módulos) de genes relevantes baseou-se posteriormente na correlação entre a expressão do módulo e medidas de EA.

Nessa abordagem, foram utilizados os genes expressos nos três tecidos, excluindo genes que apresentaram mais da metade das amostras com FPKM igual a zero. Além disso, foram excluídos genes que apresentam média < 1 FPKM e DP < 0,5 FPKM entre as amostras, já que genes que apresentam baixas contagens são menos confiáveis e genes que variam pouco fornecem informações limitadas numa análise de co-expressão (ŁABAJ et al., 2011). Por fim, por razões computacionais e assumindo que genes altamente conectados apresentam função biológica relevante (ZHANG; HORVATH, 2005), foram selecionados os 20.000 genes mais conectados para análise de co-expressão. A medida de conectividade foi calculada pela soma das correlações entre um gene e todos os outros genes na rede, utilizando a função softConnectivity e um expoente de 6 , escolhido utilizando-se um critério de topologia de escala livre $\left(\mathrm{R}^{2}>0,8\right)$.

Para os 20.000 genes selecionados, uma matriz de adjacência foi gerada por meio de correlação de Pearson entre todos os genes, elevada a um expoente $\beta$ (limiar suave) de 8 , também escolhido utilizando-se um critério de topologia de escala livre $\left(R^{2}>0,8\right)$. Em seguida, para definir conjuntos de genes com base no grau de sobreposição de genes partilhados entre vizinhos, uma medida sobreposição topológica (topological overlap measure - TOM) foi calculada e um valor entre 1 e 0 foi atribuído a cada par de genes. $\mathrm{O}$ valor 1 significa que dois genes compartilham os mesmos vizinhos e enquanto que o valor 0 significa que eles não compartilham vizinho algum. A matriz TOM foi então usada como entrada para uma clusterização hierárquica, que resulta em um dendrograma, cujos 
ramos são identificados para corte em função da sua forma usando um algoritmo de corte dinâmico de árvore (LANGFELDER; ZHANG; HORVATH, 2008). Foram definidos módulos apresentando pelo menos 30 genes e, módulos com correlação entre si maior que 0,9 foram agrupados. A esses módulos foi atribuído o nome de uma cor.

Para identificar módulos biologicamente relevantes para a EA a correlação de Pearson entre o módulo eigengene (primeira componente principal) e as medidas de EA (CA e CAR) foi calculada. Um módulo foi escolhido para análise posterior se apresentou correlação entre módulo e característica fenotípica $>0,4$ para $\mathrm{CA}$ ou $\mathrm{CAR}(\mathrm{P}<0,1)$. Além disso, os genes nos módulos selecionados foram utilizados para análise de enriquecimento funcional apenas se sua conectividade intra-modular no módulo foi $>0,6$ e a conectividade intra-modular em todos os outros módulos foi $<0,6$. A medida conectividade intra-modular ou filiação ao módulo (FM) mede o quão co-expresso um dado gene é com os outros genes dentro do módulo e pode ser usada como forma de destacar genes relevantes para o módulo. Também pode ser usada para identificar genes centrais da rede, com potencial papel regulatório sobre os demais. Esses genes também podem ser avaliados quanto à significância gênica (SG) que é calculada por teste de correlação (Pearson) entre o valor de expressão dos genes e a característica fenotípica e é uma indicação da importância biológica do gene para a eficiência alimentar.

A mesma análise também foi realizada para cada tecido individualmente. Igualmente, foram excluídos genes que apresentaram mais da metade das amostras com FPKM igual a zero e genes que apresentaram média $<1$ FPKM e DP $<0,5$ FPKM entre as amostras. Todos os demais genes foram utilizados, não havendo seleção por conectividade. Todos os genes em módulos significativamente correlacionados com as medidas de eficiência alimentar foram utilizados para a análise de enriquecimento funcional.

\subsubsection{ENRIQUECIMENTO FUNCIONAL}

A análise enriquecimento funcional foi realizada na plataforma online WebGestalt (ZHANG; KIROV; SNODDY, 2005) usando como background todos os genes que passaram o filtro de qualidade baseado em média e desvio padrão; teste hipergeométrico e correção para múltiplos testes (FDR). Foram considerados significativos termos e vias metabólicas com Paj<0,05. Para as análises individuais por tecido, os genes dos módulos 
significativos foram analisados usando a plataforma online STRINGv10 que identifica relações funcionais e interações entre proteínas ajudando a dar contexto para as análises moleculares de biologia de sistemas (SZKLARCZYK et al., 2015).

\subsection{Abordagem 3 - Identificação de RNAs longos não codificadores em múltiplos tecidos de bovinos Nelore e sua associação com a eficiência alimentar}

\subsubsection{IDENTIFICAÇÃO DE lncRNA EM DADOS DE RNAseq}

Para a identificação de lncRNA a partir de dados de RNAseq de hipotálamo, pituitária, fígado, músculo e adrenal, os reads de cada amostra, alinhados com o genoma de referência bovino (UMD3.1) e filtrados conforme descrito no item 4.4, foram utilizados como input no software Cufflinks (GHOSH; CHAN, 2016) que gerou um arquivo de anotação para cada amostra, usando como base a anotação de referência (Ensembl Release 92). Em seguida o Cuffmerge foi utilizado para combinar as anotações de todas as amostras de todos os tecidos e a referência em uma única anotação que representa o transcriptoma dos cinco tecidos. Nessa anotação, os transcritos são classificados de acordo com sua posição genômica em relação aos genes conhecidos, de forma que foi possível extrair apenas os das classes i (transcritos de introns), $\mathrm{j}$ (nova isoforma), o (sobreposição genérica com éxon de gene conhecido), u (transcrito intergênico) e x (sobreposição com gene conhecido na fita oposta).

Uma vez selecionados os novos transcritos com potencial para serem lncRNA, esse arquivo de anotação juntamente com o genoma de referência bovino (UMD3.1) foi utilizado para gerar um arquivo fasta contendo a sequência dos transcritos. Essas sequências passaram por quatro filtros: 1) tamanho; 2) presença de ORF; 3) homologia com sequência conhecida; e 4) potencial de codificação. No primeiro filtro, transcritos menores de 200pb foram excluídos, já que por definição esse tamanho separa ncRNA pequenos de longos. Em seguida, a ferramenta getorf do EMBOSS (RICE; LONGDEN; BLEASBY, 2000) foi utilizada para excluir transcritos que apresentaram ORFs maiores que 300pb entre um START e um STOP códon. Esse valor foi definido baseado no fato de que a maioria das proteínas anotadas em eucariotos apresentam mais do que 100 aminoácidos (NIAZI; VALADKHAN, 2012). Em seguida, os transcritos foram testados 
quando a sua similaridade com a base de dados UniProt/SwissProt (ftp://ftp.uniprot.org/pub/databases/uniprot/current_release/knowledgebase/complete/un iprot_sprot.fasta.gz) utilizando a ferramenta Blastx do BLAST+ (CAMACHO et al., 2009). Transcritos com homologia significativa com a base de dados (E valor $<10^{-6}$ ) foram excluídos. Os transcritos foram por fim testados quando ao seu potencial de codificação utilizando a ferramenta online CPC2 (KANG et al., 2017), sendo que transcritos que passaram pelos quatro filtros foram considerados novos lncRNAs.

Por fim, um arquivo de anotação contendo apenas os novos lncRNAs foi gerado e comparado através do Cuffcompare (TRAPNELL et al., 2013) com um arquivo de anotação do NCBI contendo não só os genes conhecidos, mas também os preditos (predicted) utilizando um método de predição de genes chamado GNOMON (http://www.ncbi.nlm.nih.gov/genome/guide/gnomon.shtml), que se baseia em sequencias completas ou parciais de proteínas de organismos modelo. Os lncRNAs identificados foram comparados com lncRNA previamente descritos em bovinos que estão presentes na base de dados NONCODE (FAFANG, S., ZHANG, L., GUO, J., NIU, Y., WU, Y., LI, H., ET AL. (2018). NONCODEV5: A COMPREHENSIVE ANNOTATION DATABASE FOR LONG NON-CODING RNAS. NUCLEIC ACIDS RES. 46, D308-D314. DOI:10.1093/NAR/GKX1107.NG et al., 2018) utilizando a ferramenta Blastn do BLAST+ (CAMACHO et al., 2009) e foram consideradas significativas homologias com E-valor $>10^{-6}$.

\subsubsection{EXPRESSÃO DIFERENCIAL E CARACTERIZAÇÃO DE lncRNAs}

O software Cuffdiff (TRAPNELL et al., 2013) foi utilizado juntamente com um arquivo de anotação contendo apenas os novos lncRNAs para testar a expressão diferencial entre alta e baixa EA em cada tecido, considerando sua capacidade de quantificação e avaliação a nível de transcrito. Transcritos com um valor absoluto de $\mathrm{Q}$ $<0,05$ foram considerados diferencialmente expressos (DE).

A fim de caracterizar os lncRNAs DE, foi realizada uma busca por homologia (Blastn) na base de dados de ncRNA NONCODE (FAFANG, S., ZHANG, L., GUO, J., NIU, Y., WU, Y., LI, H., ET AL. (2018). NONCODEV5: A COMPREHENSIVE ANNOTATION DATABASE FOR LONG NON-CODING RNAS. NUCLEIC ACIDS RES. 46, D308-D314. DOI:10.1093/NAR/GKX1107.NG et al., 2018) considerando 
todas as espécies. A homologia foi considerada significativa se o transcrito apresentou mais de 100pb de identidade com um lncRNA na base e E-valor > $10^{-6}$. Além disso, posição genômica dos lncRNAs foi utilizada para avaliar se eles se encontram em regiões de QTLs descritas no banco de dados Animal QTLdb (HU et al., 2013). A estrutura secundária de alguns lncRNA foram determinadas usando minimum free-energy and partition function e evitando pares de bases isolados utilizando o pacote Vienna RNA na plataforma online RNAfold WebServer (HOFACKER et al., 1989).

\subsubsection{INVESTIGAÇÃO DA RELAÇÃO ENTRE lncRNA E miRNAs}

Dentre as várias funções que os lncRNAs podem exercer, duas estão relacionadas com miRNA: os lncRNAs podem tanto ser precursores de miRNA quando atuarem como "esponjas" se ligando aos miRNA e evitando que eles realizem seu papel inibitório da expressão de mRNAs. Para testar a primeira função, utilizamos todos os miRNAs descritos para bovinos na base de dados miRBase (www.mirbase.org) e comparamos com a sequência dos lncRNA preditos utilizando a ferramenta Blastn do BLAST+ (CAMACHO et al., 2009) utilizando um E-valor mínimo de $10^{-6}$. Já para testar se os lncRNA identificados poderiam ser alvos de miRNAs, foi utilizado o programa miRanda (ENRIGHT et al., 2003) que identifica sítios de ligação de miRNA em duas etapas. Primeiramente é feito um alinhamento local entre cada miRNA e cada lncRNA que gera um score baseado em complementariedade. Em seguida, alinhamentos com alto score (>160) tem sua estabilidade termodinâmica calculada utilizando rotinas de dobragem da biblioteca RNAlib, que fazem parte do pacote ViennaRNA (HOFACKER et al., 1989). Finalmente, os alvos identificados com energia menor que o limiar de $-20 \mathrm{kcal} / \mathrm{mol}$ são reportados. Os miRNAs com sítios de ligação nos lncRNA DE foram convertidos para identificação de humanos e testados para enriquecimento funcional utilizando a plataforma online MiEEA (BACKES et al., 2016) usando teste exato de Fisher e correção para múltiplos testes.

\subsubsection{INVESTIGAÇÃO DO PAPEL REGULATÓRIOS DOS IncRNAs NA EXPRESSÃO DE mRNAs EM CIS E TRANS}


Para investigar o papel regulatórios dos lncRNAs DE em cis, os dados de expressão de mRNA em FPKM obtidos no item 4.4 e filtrado para excluir genes com valor médio de expressão inferior a 0,2 FPKM, foram utilizados para cálculo de correlação de Spearman entre os lncRNAs e mRNAs em uma janela de 100 kb upstream e downstream. Foram consideradas relevantes correlações superiores a $|0,7|$. Adicionalmente, os genes contidos nas mesmas janelas foram utilizados para análise de enriquecimento funcional usando a plataforma online STRINGv10 (SZKLARCZYK et al., 2015).

Já para investigar o papel regulatórios dos lncRNAs DE em trans os lncRNA foram transformados na sua fita complementar no sentido reverso e foram comparados com a base de transcritos de bovinos disponível no banco de dados do NCBI (https://ftp.ncbi.nlm.nih.gov/genomes/all/GCF/000/003/055/GCF_000003055.6_Bos_ta urus_UMD_3.1.1/GCF_000003055.6_Bos_taurus_UMD_3.1.1_rna.fna.gz) usando a ferramenta Blastn do BLAST+ (CAMACHO et al., 2009), a fim de identificar mRNAs alvos (E-valor $\left.>10^{-6}\right)$. 


\section{RESULTADOS}

\subsection{Abordagem 1 - Expressão gênica multitecidual associada à eficiência alimentar}

\subsubsection{CARACTERIZAÇÃO FENOTÍPICA DOS ANIMAIS}

Os grupos de alta e baixa EA, definidos após o confinamento dos 98 bovinos Nelore e avaliação do CAR, foram comparados com relação a diversas características em publicações anteriores (ALEXANDRE et al., 2015; MOTA et al., 2017): Os grupos não diferem quanto ao peso inicial, peso final, ganho de peso, área de olho de lombo e rendimento de carcaça, porém, os animais de baixa EA apresentam maior CMS e maior CA, maior deposição de gordura subcutânea e maior peso de gordura visceral, níveis séricos mais elevados de colesterol, GGT e leptina, maior expressão de leptina no músculo esquelético e perfil transcriptômico hepático associado à resposta inflamatória e metabolismo de gordura, além de maior proporção de espaços-porta com infiltrado inflamatório.

Para o presente trabalho, foram utilizados 9 animais de cada extremo de eficiência alimentar, que apresentam pequenas alterações de indivíduos extremos com relação as análises anteriores - diferença relacionada à disponibilidade de amostra biológica. Dessa forma, a Tabela 1 confirma a caracterização fenotípica dos grupos.

Tabela 1 - Caracterização fenotípica dos animais de alta e baixa eficiência alimentar utilizados no experimento.

\begin{tabular}{lccccc}
\hline & \multicolumn{2}{c}{ Alta EA $(\mathrm{n}=9)$} & \multicolumn{2}{c}{ Baixa EA $(\mathrm{n}=9)$} & \multirow{2}{*}{ P valor } \\
\cline { 2 - 5 } & Média & DP & Média & DP & 0,20 \\
Idade & 582,10 & 11,77 & 561,70 & 9,95 & 0,68 \\
PVI $(\mathrm{Kg})$ & 413,33 & 45,61 & 406,44 & 17,66 & 0,61 \\
PVF $(\mathrm{Kg})$ & 542,44 & 63,16 & 530,67 & 23,37 & $8,00 \times 10^{-04 *}$ \\
CMS $(\mathrm{Kg} / \mathrm{d})$ & 9,60 & 1,59 & 12,23 & 0,90 & 0,57 \\
GMD $(\mathrm{Kg} / \mathrm{d})$ & 1,88 & 0,55 & 1,76 & 0,27 & $1,70 \times 10^{-03 *}$ \\
CA & 5,35 & 1,00 & 7,06 & 0,94 & $2,09 \times 10^{-10 *}$ \\
CAR $(\mathrm{Kg} / \mathrm{d})$ & $-1,44$ & 0,29 & 1,57 & 0,46 & $1,07 \times 10^{-02 *}$ \\
GV $(\mathrm{kg})$ & 8,44 & 0,61 & 11,52 & 0,87 & \\
\hline
\end{tabular}

EA - eficiência alimentar; PVI - peso vivo inicial; PVF - peso vivo final; CMS - consumo médio diário de matéria seca; GMD - ganho de peso médio diário; CA - conversão alimentar; CAR - consumo alimentar residual; GV - gordura visceral (pélvica + renal).

$* \mathrm{P}<0,05$ - teste $\mathrm{T}$ de Student 


\subsubsection{EXPRESSÃO DIFERENCIAL}

Para essa abordagem, foram analisadas 86 amostras no total, sendo 18 amostras de fígado, hipotálamo e pituitária; 17 de músculo e 15 de adrenal, produzindo 13 milhões de reads por amostra em média (Tabela 2). A expressão gênica foi estimada para 24.616 genes presentes no genoma de referência (UMD 3.1) e após o controle de qualidade, 17.354 genes foram identificados como sendo expressos em pelo menos um dos cinco tecidos analisados.

A análise de expressão diferencial entre animais de alta e baixa EA resultou em 471 genes $\mathrm{DE}$ entre os tecidos $(\mathrm{P}<0,001$, Figura 5), sendo 111 na adrenal, 125 no hipotálamo, 91 no fígado, 104 no músculo e 98 na pituitária (Tabela Suplementar 1). Embora nenhum enriquecimento funcional significativo tenha sido encontrado para os 281 genes mais expressos na alta EA, os 248 genes mais expressos na baixa EA apresentaram enriquecimento significativo para termos como resposta a hormônios (Paj $\left.=5,43 \times 10^{-6}\right)$, regulação dos níveis hormonais $\left(\right.$ Paj $\left.=3,48 \times 10^{-6}\right)$, comunicação celular $\left(P a j=3,18 \times 10^{-4}\right)$, regulação da atividade de receptor celular $\left(\operatorname{Padj}=3,20 \times 10^{-4}\right)$, processo metabólico hormonal $\left(\mathrm{Paj}=5,86 \times 10^{-4}\right)$, resposta a corticosteróide $\left(\mathrm{Paj}=6,28 \times 10^{-4}\right)$, regulação de secreção $\left(\mathrm{Paj}=7,2 \times 10^{-4}\right)$, resposta a lipopolissacarídeo $\left(\mathrm{Paj}=7,9 \times 10^{-4}\right) \mathrm{e}$ regulação de proliferação celular $\left(\right.$ Paj $\left.=1,86 \times 10^{-3}\right)$. 
Tabela 2 - Dados relativos ao mapeamento de reads com o genoma de referência bovino (UMD3.1) por amostra.

\begin{tabular}{|c|c|c|c|c|c|c|}
\hline & $\begin{array}{l}\text { Reads } \\
\text { iniciais }\end{array}$ & $\begin{array}{c}\text { Reads } \\
\text { mapeados } \\
\text { unicamente } \\
\end{array}$ & $\begin{array}{c}\% \text { Reads } \\
\text { mapeados } \\
\text { unicamente }\end{array}$ & $\begin{array}{c}\text { Reads } \\
\text { mapeados a } \\
\text { múltiplos loci }\end{array}$ & $\begin{array}{c}\% \text { Reads } \\
\text { mapeados a } \\
\text { múltiplos loci }\end{array}$ & $\begin{array}{c}\text { \% Reads não } \\
\text { mapeados }\end{array}$ \\
\hline R08ADR & 17311712 & 15586139 & $90,03 \%$ & 776935 & $4,49 \%$ & $4,57 \%$ \\
\hline R19ADR & 15484176 & 14117844 & $91,18 \%$ & 726790 & $4,69 \%$ & $2,98 \%$ \\
\hline R20ADR & 14657646 & 13179304 & $89,91 \%$ & 575199 & $3,92 \%$ & $5,52 \%$ \\
\hline R31ADR & 15679237 & 13991555 & $89,24 \%$ & 730397 & $4,66 \%$ & $5,17 \%$ \\
\hline R33ADR & 14053710 & 12710211 & $90,44 \%$ & 560450 & $3,99 \%$ & $4,70 \%$ \\
\hline R34ADR & 14312597 & 13030561 & $91,04 \%$ & 526484 & $3,68 \%$ & $4,60 \%$ \\
\hline R36ADR & 14389095 & 12614771 & $87,67 \%$ & 649766 & $4,52 \%$ & $6,62 \%$ \\
\hline R52ADR & 15054920 & 13489178 & $89,60 \%$ & 646437 & $4,29 \%$ & $5,20 \%$ \\
\hline R54ADR & 13150194 & 11684224 & $88,85 \%$ & 591301 & $4,50 \%$ & $5,54 \%$ \\
\hline R57ADR & 13437974 & 11909581 & $88,63 \%$ & 655886 & $4,88 \%$ & $5,23 \%$ \\
\hline R77ADR & 14748191 & 13057917 & $88,54 \%$ & 808816 & $5,48 \%$ & $4,62 \%$ \\
\hline R78ADR & 11984837 & 10838506 & $90,44 \%$ & 505453 & $4,22 \%$ & $4,48 \%$ \\
\hline R84ADR & 13157352 & 11776054 & $89,50 \%$ & 595484 & $4,53 \%$ & $5,06 \%$ \\
\hline R95ADR & 12319556 & 10911616 & $88,57 \%$ & 553729 & $4,49 \%$ & $5,80 \%$ \\
\hline R99ADR & 12256301 & 11059466 & $90,23 \%$ & 429379 & $3,50 \%$ & $5,54 \%$ \\
\hline R08LIV & 16644352 & 12758767 & $76,66 \%$ & 1586882 & $9,53 \%$ & $8,23 \%$ \\
\hline R19LIV & 13464177 & 6528762 & $48,49 \%$ & 2137101 & $15,87 \%$ & $26,42 \%$ \\
\hline R20LIV & 15003365 & 4770874 & $31,80 \%$ & 4202572 & $28,01 \%$ & $20,82 \%$ \\
\hline R21LIV & 13264623 & 11929943 & $89,94 \%$ & 561538 & $4,23 \%$ & $4,96 \%$ \\
\hline R31LIV & 13979304 & 9218803 & $65,95 \%$ & 1822344 & $13,04 \%$ & $14,16 \%$ \\
\hline R33LIV & 12295848 & 4754769 & $38,67 \%$ & 2566076 & $20,87 \%$ & $27,95 \%$ \\
\hline R34LIV & 12793306 & 6579281 & $51,43 \%$ & 2227446 & $17,41 \%$ & $21,11 \%$ \\
\hline R36LIV & 12975925 & 11399184 & $87,85 \%$ & 675473 & $5,21 \%$ & $5,31 \%$ \\
\hline R50LIV & 12130923 & 10735178 & $88,49 \%$ & 614660 & $5,07 \%$ & $4,69 \%$ \\
\hline R52LIV & 14879963 & 3800256 & $25,54 \%$ & 2828636 & $19,01 \%$ & $42,99 \%$ \\
\hline R54LIV & 13473232 & 11384100 & $84,49 \%$ & 919420 & $6,82 \%$ & $5,62 \%$ \\
\hline R57LIV & 12510081 & 10887400 & $87,03 \%$ & 664990 & $5,32 \%$ & $5,76 \%$ \\
\hline R58LIV & 13161184 & 5562898 & $42,27 \%$ & 2210931 & $16,80 \%$ & $31,00 \%$ \\
\hline R77LIV & 12556002 & 10951016 & $87,22 \%$ & 642664 & $5,12 \%$ & $6,04 \%$ \\
\hline R78LIV & 12813151 & 7009237 & $54,70 \%$ & 1831523 & $14,29 \%$ & $23,03 \%$ \\
\hline R84LIV & 12892306 & 5875167 & $45,57 \%$ & 2242869 & $17,40 \%$ & $26,33 \%$ \\
\hline R95LIV & 12543809 & 7339635 & $58,51 \%$ & 2097051 & $16,72 \%$ & $15,13 \%$ \\
\hline R99LIV & 12609866 & 5962274 & $47,28 \%$ & 1448706 & $11,49 \%$ & $34,21 \%$ \\
\hline R08MUS & 15019248 & 14116482 & $93,99 \%$ & 332740 & $2,22 \%$ & $3,54 \%$ \\
\hline R19MUS & 12288101 & 11430883 & $93,02 \%$ & 265753 & $2,16 \%$ & $4,55 \%$ \\
\hline R20MUS & 12756385 & 11829913 & $92,74 \%$ & 243059 & $1,91 \%$ & $5,25 \%$ \\
\hline R21MUS & 14357638 & 13276713 & $92,47 \%$ & 286087 & $1,99 \%$ & $5,44 \%$ \\
\hline R33MUS & 12963449 & 11942468 & $92,12 \%$ & 269508 & $2,08 \%$ & $5,59 \%$ \\
\hline R34MUS & 12445124 & 11678594 & $93,84 \%$ & 238116 & $1,91 \%$ & $4,10 \%$ \\
\hline R36MUS & 11400396 & 10485333 & $91,97 \%$ & 216732 & $1,90 \%$ & $5,98 \%$ \\
\hline R50MUS & 13555912 & 12561142 & $92,66 \%$ & 256211 & $1,89 \%$ & $5,30 \%$ \\
\hline R52MUS & 13072121 & 12082510 & $92,43 \%$ & 294044 & $2,25 \%$ & $5,13 \%$ \\
\hline R54MUS & 12574759 & 11659308 & $92,72 \%$ & 250371 & $1,99 \%$ & $5,12 \%$ \\
\hline R57MUS & 11801962 & 10924216 & $92,56 \%$ & 225982 & $1,91 \%$ & $5,32 \%$ \\
\hline R58MUS & 12562287 & 11687683 & $93,04 \%$ & 240592 & $1,92 \%$ & $4,88 \%$ \\
\hline R77MUS & 14921977 & 13893210 & $93,11 \%$ & 289918 & $1,94 \%$ & $4,80 \%$ \\
\hline R78MUS & 14189133 & 13136846 & $92,58 \%$ & 312377 & $2,20 \%$ & $5,06 \%$ \\
\hline R84MUS & 13940639 & 12877578 & $92,37 \%$ & 286043 & $2,05 \%$ & $5,40 \%$ \\
\hline R95MUS & 13831924 & 12844993 & $92,86 \%$ & 244046 & $1,76 \%$ & $5,22 \%$ \\
\hline R99MUS & 12808965 & 12043672 & $94,03 \%$ & 269089 & $2,10 \%$ & $3,76 \%$ \\
\hline
\end{tabular}


Tabela 2 - Dados relativos ao mapeamento de reads com o genoma de referência bovino (UMD3.1) por amostra (continuação).

\begin{tabular}{|c|c|c|c|c|c|c|}
\hline & $\begin{array}{l}\text { Reads } \\
\text { iniciais }\end{array}$ & $\begin{array}{c}\text { Reads } \\
\text { mapeados } \\
\text { unicamente } \\
\end{array}$ & $\begin{array}{c}\text { \% Reads } \\
\text { mapeados } \\
\text { unicamente }\end{array}$ & $\begin{array}{c}\text { Reads } \\
\text { mapeados a } \\
\text { múltiplos loci }\end{array}$ & $\begin{array}{c}\% \text { Reads } \\
\text { mapeados a } \\
\text { múltiplos loci }\end{array}$ & $\begin{array}{l}\text { \% Reads não } \\
\text { mapeados }\end{array}$ \\
\hline R08HYP & 13120331 & 11914705 & $90,81 \%$ & 425570 & $3,24 \%$ & $5,09 \%$ \\
\hline R19HYP & 12065796 & 10993080 & $91,11 \%$ & 359479 & $2,98 \%$ & $5,22 \%$ \\
\hline R20HYP & 12229646 & 11140727 & $91,10 \%$ & 363576 & $2,97 \%$ & $5,16 \%$ \\
\hline R21HYP & 11893346 & 10777742 & $90,62 \%$ & 351426 & $2,95 \%$ & $5,71 \%$ \\
\hline R31HYP & 11960881 & 10933178 & $91,41 \%$ & 365918 & $3,06 \%$ & $4,68 \%$ \\
\hline R33HYP & 12636092 & 11608147 & $91,87 \%$ & 361462 & $2,86 \%$ & $4,62 \%$ \\
\hline R34HYP & 12003708 & 10956079 & $91,27 \%$ & 347913 & $2,90 \%$ & $5,04 \%$ \\
\hline R36HYP & 12254537 & 11223111 & $91,58 \%$ & 390742 & $3,19 \%$ & $4,32 \%$ \\
\hline R50HYP & 12250215 & 11219563 & $91,59 \%$ & 394271 & $3,22 \%$ & $4,31 \%$ \\
\hline R52HYP & 20032830 & 18232647 & $91,01 \%$ & 716024 & $3,57 \%$ & $4,43 \%$ \\
\hline R54HYP & 14109017 & 12986421 & $92,04 \%$ & 393962 & $2,79 \%$ & $4,52 \%$ \\
\hline R57HYP & 14436331 & 13303170 & $92,15 \%$ & 386658 & $2,68 \%$ & $4,52 \%$ \\
\hline R58HYP & 12955343 & 11899233 & $91,85 \%$ & 386847 & $2,99 \%$ & $4,43 \%$ \\
\hline R77HYP & 12324325 & 11069507 & $89,82 \%$ & 426089 & $3,46 \%$ & $5,73 \%$ \\
\hline R78HYP & 13706040 & 12595121 & $91,89 \%$ & 346096 & $2,53 \%$ & $5,12 \%$ \\
\hline R84HYP & 14842284 & 13721771 & $92,45 \%$ & 415513 & $2,80 \%$ & $4,14 \%$ \\
\hline R95HYP & 13471502 & 12503963 & $92,82 \%$ & 366132 & $2,72 \%$ & $3,85 \%$ \\
\hline R99HYP & 13274686 & 12062463 & $90,87 \%$ & 528359 & $3,98 \%$ & $3,84 \%$ \\
\hline R08PIT & 12935228 & 11666185 & $90,19 \%$ & 472050 & $3,65 \%$ & $4,99 \%$ \\
\hline R19PIT & 9811220 & 8825479 & $89,95 \%$ & 361946 & $3,69 \%$ & $5,12 \%$ \\
\hline R20PIT & 12715681 & 11458545 & $90,11 \%$ & 460337 & $3,62 \%$ & $4,89 \%$ \\
\hline R21PIT & 12309706 & 11226415 & $91,20 \%$ & 418667 & $3,40 \%$ & $4,49 \%$ \\
\hline R31PIT & 13418457 & 12142470 & $90,49 \%$ & 452634 & $3,37 \%$ & $5,02 \%$ \\
\hline R33PIT & 12883165 & 11521320 & $89,43 \%$ & 493580 & $3,83 \%$ & $5,21 \%$ \\
\hline R34PIT & 12940954 & 11679032 & $90,25 \%$ & 463072 & $3,58 \%$ & $4,81 \%$ \\
\hline R36PIT & 12622175 & 11379352 & $90,15 \%$ & 430086 & $3,41 \%$ & $5,29 \%$ \\
\hline R50PIT & 12935237 & 11771429 & $91,00 \%$ & 402353 & $3,11 \%$ & $4,98 \%$ \\
\hline R52PIT & 17199240 & 15699417 & $91,28 \%$ & 539539 & $3,14 \%$ & $4,77 \%$ \\
\hline R54PIT & 12518961 & 11279074 & $90,10 \%$ & 424703 & $3,39 \%$ & $5,52 \%$ \\
\hline R57PIT & 12497754 & 11183636 & $89,49 \%$ & 485927 & $3,89 \%$ & $5,21 \%$ \\
\hline R58PIT & 12375062 & 11169674 & $90,26 \%$ & 427837 & $3,46 \%$ & $5,07 \%$ \\
\hline R77PIT & 11507839 & 10343363 & $89,88 \%$ & 378295 & $3,29 \%$ & $5,76 \%$ \\
\hline R78PIT & 11937283 & 10875448 & $91,10 \%$ & 353817 & $2,96 \%$ & $5,16 \%$ \\
\hline R84PIT & 11166126 & 10092669 & $90,39 \%$ & 373385 & $3,34 \%$ & $5,20 \%$ \\
\hline R95PIT & 11637843 & 10615593 & $91,22 \%$ & 347245 & $2,98 \%$ & $5,06 \%$ \\
\hline R99PIT & 11815715 & 10803927 & $91,44 \%$ & 367121 & $3,11 \%$ & $4,55 \%$ \\
\hline
\end{tabular}


Figura 5 - Gráficos de dispersão mostrando genes diferencialmente expressos entre alta e baixa eficiência alimentar (EA) da glândula adrenal, hipotálamo, fígado, músculo e pituitária (pituitária).
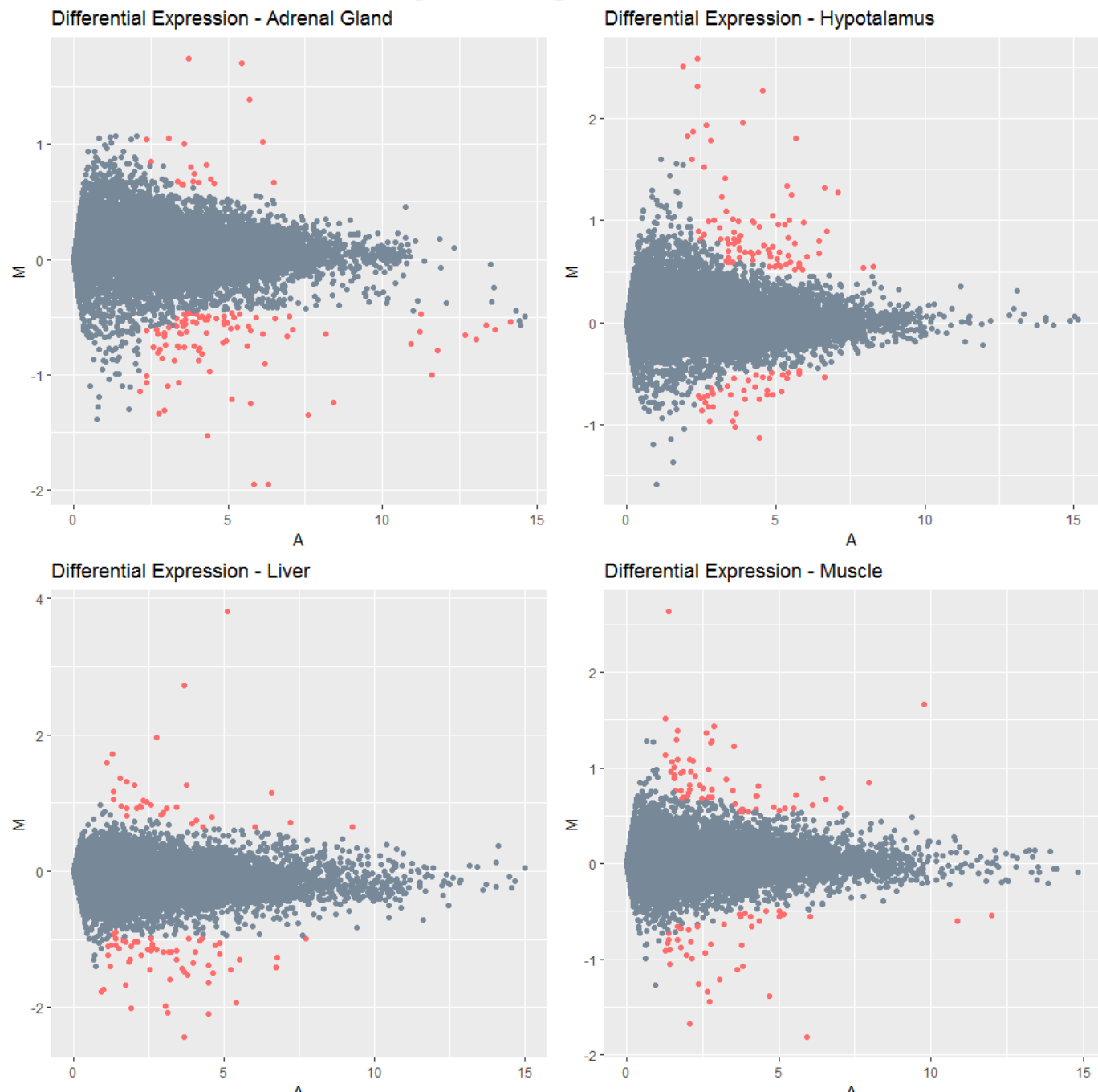

Differential Expression - Muscle

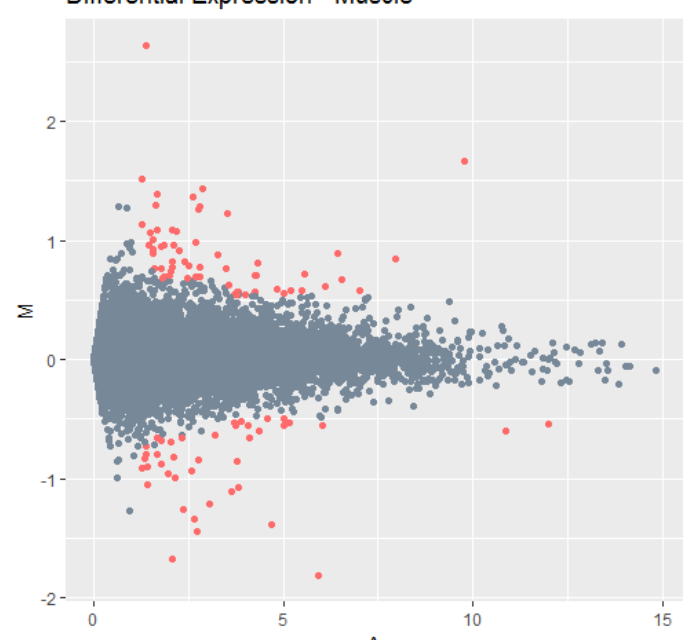

Differential Expression - Pituitary

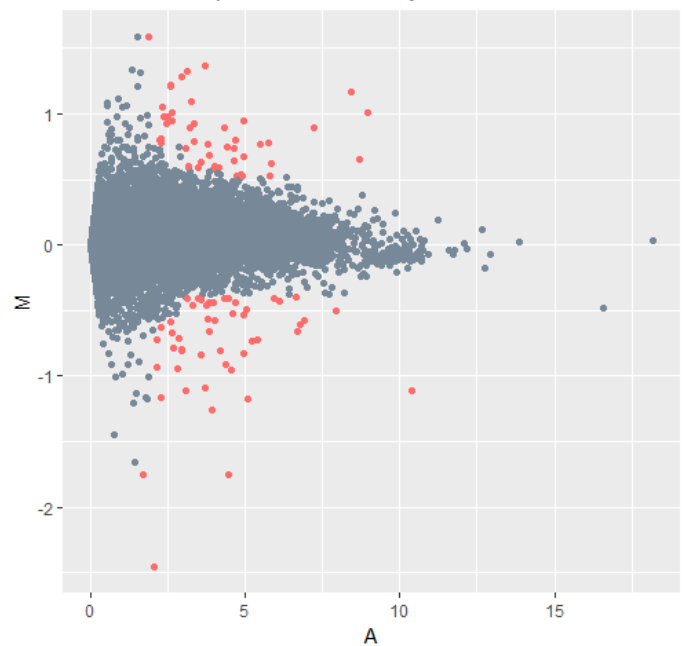

Os pontos representam a expressão média para um gene no grupo de alta EA subtraído da expressão média do mesmo gene no grupo de baixa EA (M) pelo valor médio de expressão em ambos os grupos (A). Pontos rosa representam genes significativos $(\mathrm{P}<0,001)$. Fonte: própria autoria. 


\subsubsection{PRINCIPAIS GENES RELACIONADOS À EFICIÊNCIA}

\section{ALIMENTAR}

A arquitetura genética por trás de características complexas envolve uma grande variedade de genes com padrão de expressão coordenada, o que pode ser representado por redes de co-expressão como um modelo para estudar suas relações e identificar genes reguladores centrais (SWAMI, 2009). Portanto, é importante selecionar genes relevantes de acordo com o fenótipo de interesse. Nesse estudo, definimos cinco categorias de genes para inclusão na análise de co-expressão: 1 - genes diferencialmente expressos (DE), 2 genes contendo SNPs previamente associados a EA, 3 - genes tecido-específicos (TS) considerando nossos cinco tecidos (ver métodos), 4 - genes que codificam proteínas secretadas no plasma por qualquer um dos cinco tecidos analisados (secretados) e 5 reguladores centrais.

Como relatado anteriormente, identificamos 471 genes DE entre animais com alta e baixa EA (Figura 6A). Adicionalmente, 267 genes foram selecionados por conter SNPs previamente associados com a EA, já que não somente diferenças nos níveis de expressão podem influenciar o fenótipo, mas também polimorfismo na sequência do DNA, que podem alterar o comportamento da proteína traduzida. Além disso, 396 genes foram selecionados por serem tecido-específicos; 22 na adrenal, 32 no hipotálamo, 215 no fígado, 218 no músculo e 9 na pituitária. Um total de 244 genes codificadores de proteínas secretadas no plasma foram selecionados devido ao seu potencial como potenciais biomarcadores de EA. Destes 244 genes, 135 tiveram maior expressão no fígado e foram enriquecidos para termos do GO tais como ativação da cascata do complemento (Paj = $\left.1,82 \times 10^{-19}\right)$, regulação da resposta inflamatória aguda $\left(\right.$ Paj $\left.=1,89 \times 10^{-14}\right)$, resposta imune inata $\left(\right.$ Paj $\left.=9,71 \times 10^{-12}\right)$, regulação negativa da atividade de endopeptidase (Paj $=2,35 \mathrm{x}$ $\left.10^{-10}\right)$, degranulação de plaquetas $\left(\right.$ Paj $\left.=1.08 \times 10^{-10}\right)$, regulação da coagulação $($ Paj = $3,39 \times 10^{-9}$ ), homeostase dos triglicerídeos $\left(\mathrm{Paj}=1,23 \times 10^{-6}\right)$, efluxo de colesterol (Paj $\left.=1,03 \times 10^{-5}\right)$. Finalmente, dos 1570 potenciais reguladores disponíveis na base de dados de fatores de transcrição, 78 foram identificados como principais reguladores dos genes selecionados por todas as outras categorias, ou seja, 78 genes apresentaram nível de expressão coordenada com muitos dos genes na rede, refletindo seu papel regulatório central nos tecidos. 
Considerando todos os critérios de inclusão, 1.317 genes foram selecionados para inclusão na análise de redes de co-expressão (Figura 6B, Tabela Suplementar 2), alguns deles selecionados por mais de uma categoria (Figura 6C). Com relação aos genes DE, seis deles também foram relatados anteriormente como abrigando SNPs associados com o fenótipo (LUZP2, MAOB, SFRS5, SLC24A2, SOCS3 e WIF1) e 13 deles foram os principais reguladores (HOPX, PITX1, CRYM, PLCD1, ND6, cytb, ND1, MT-ND4L, ND5, ATP8, ND4, ENSBTAG00000046711 e ENSBTAG00000048135). Vários dos genes que são ambos DE e reguladores estão envolvidos na cadeia respiratória (ND6, CytB, ND1, MT-ND4L, ND5, ATP8 e ND4) e foram mais expressos no grupo de alta EA.

Considerando genes que são tanto DE quanto secretados, 18 foram identificados (NOV, SPP1, CTGF, OXT, PTX3, VGF, CCL21, COL1A2, PGF, SOD3, SERPINA1, PRL, PON1, SST, JCHAINA, PCOLCE, IGFBP6 e SCG2). Além disso, quatro genes foram DE, secretados e tecido-específicos, dois no fígado (CXCL3 e IGFBP1) e dois na pituitária (NPY e CYP17A1). Os genes RARRES2 e PENK foram DE, secretados e reportados pela literatura como contendo SNP associado com EA (BOLORMAA et al., 2011, AnimalQTLdb). Outros genes dignos de destaque, devido ao seu conhecido papel em processos metabólicos, são AMH (hormônio anti-mulleriano), TSHB (hormônio estimulante da tiroide, subunidade beta), FGF21 (fator de crescimento de fibroblastos 21) e folistatina, mais expressos significativamente no grupo de alta EA; e PMCH (hormônio concentrador de pró-melanina), ADM (adrenomedulina) e FSHB (hormônio folículo estimulante, subunidade beta), mais expressos significativamente no grupo de baixa EA. 
Figura 6 - Genes selecionados para construção de redes de co-expressão.

A

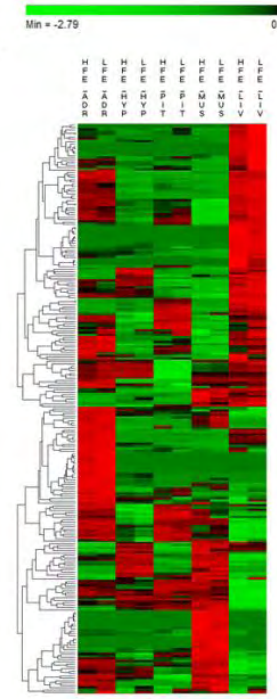

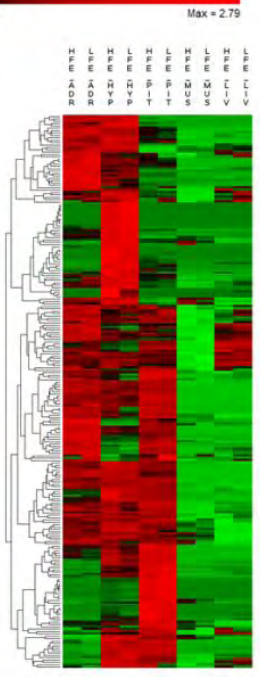

C

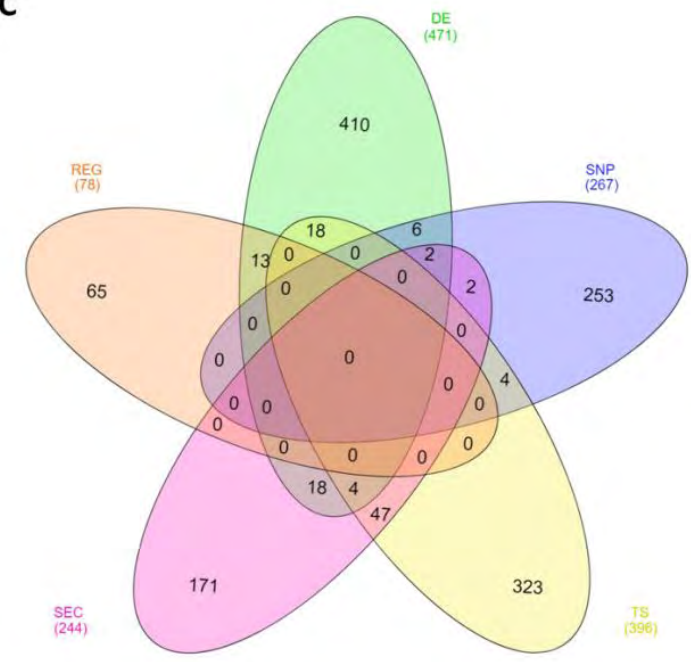

B

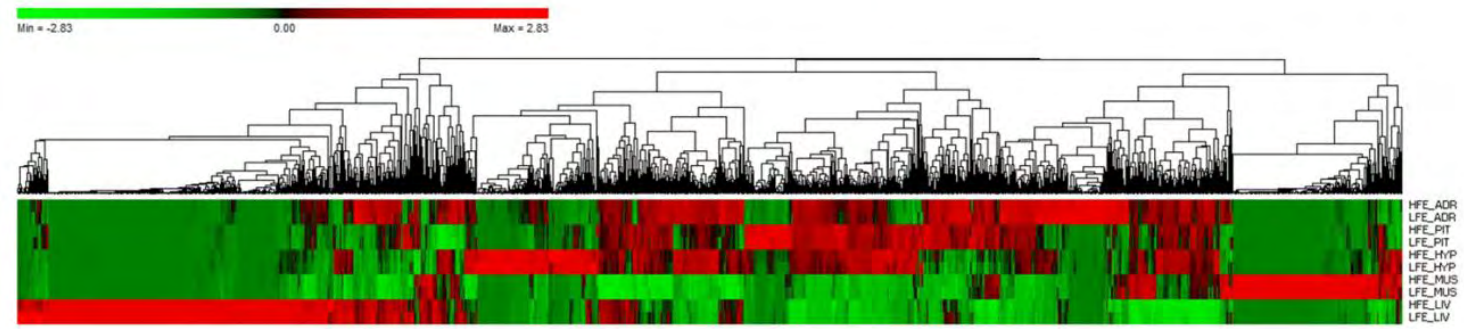

A) Heatmap da expressão média normalizada dos 471 genes diferencialmente expressos entre animais de alta eficiência alimentar (HFE) e animais de baixa eficiência alimentar (LFE) na glândula adrenal (ADR), hipotálamo (HYP), fígado (LIV), músculo (MUS) e pituitária (PIT). Genes (linhas) e amostras (colunas) foram agrupados por clusterização hierárquica baseada em distâncias euclidianas. B) Heatmap da expressão média normalizada de todos os 1.317 genes selecionados para a construção da rede. Genes (colunas) e amostras (linhas) foram agrupados por clusterização hierárquica baseada em distâncias euclidianas. C) Diagrama de Venn de 1.317 genes selecionados para construção da rede. Os critérios de inclusão para seleção de genes foram divididos em cinco categorias: genes diferencialmente expressos (DE), genes tecido-específicos (TS), genes que contém SNPs relatados pela literatura como associados à eficiência alimentar em bovinos de corte (SNP), genes codificadores de proteínas secretadas no plasma por pelo menos um dos tecidos (SEC) e reguladores chave (REG). Os números entre parênteses indicam o número total de genes em cada categoria. Fonte: própria autoria.

\subsubsection{REDE DE CO-EXPRESSÃO E PROCESSOS BIOLÓGICOS RELACIONADOS À EFICIÊNCIA ALIMENTAR}

A rede de co-expressão (Figura 7) foi composta por 1.317 genes e 91.932 conexões, com uma média de 70 conexões por gene. A maior parte das ligações (51\%) envolveram um gene DE e $23 \%$ delas foram dois genes DE. Conexões envolvendo genes TS representaram 49\% das conexões, com 119 conexões por gene em média, o que significa mais do que a média geral da rede e reflete a estreita relação entre os genes envolvidos nas funções específicas dos tecidos. Os reguladores chave foram a categoria 
menos representada na rede (apenas 78 genes) mas estiveram envolvidos em $11 \%$ das ligações na rede, com o valor mais elevado de ligações médias por gene, 131, o que está de acordo com a sua função regulatória. No que diz respeito as ligações dentro dos tecidos, quando todos os genes foram classificados na rede pelo número de ligações e observou-se os top 50 genes, 29 foram mais expressos no fígado, 15 no músculo e 3, 2 e 1 na pituitária, adrenal e hipotálamo, respectivamente. Este resultado indica um padrão de expressão muito bem coordenado no fígado e no músculo, que pode ser um reflexo do maior número de genes TS nesses tecidos e da maior presença de genes reguladores centrais que coordenam a expressão de muitos outros genes.

Figura 7 - Rede de co-expressão de genes construída utilizando 1317 genes.

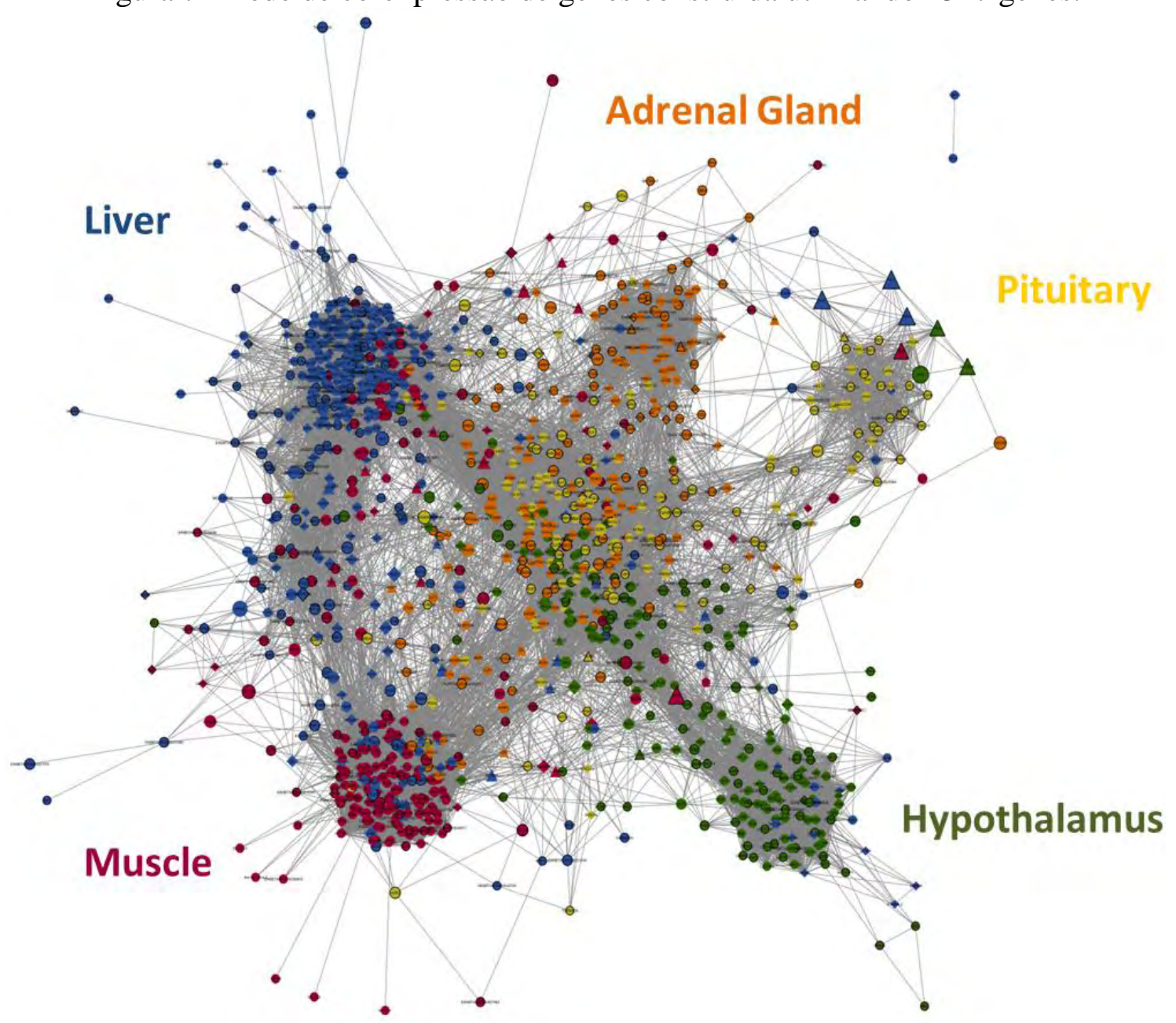

Nódulos com formato de diamante correspondem a genes codificadores de proteínas secretadas no plasma e triângulos correspondem a reguladores chave; todos os outros genes são representados por elipses. Nódulos com bordas pretas são diferencialmente expressos entre alta e baixa eficiência alimentar. As cores são relativas ao tecido de máxima expressão: azul representa fígado, vermelho representa músculo, amarelo representa pituitária, verde representa hipotálamo e laranja representa adrenal. O tamanho dos nódulos é relativo aos valores de expressão média normalizados em todas as amostras. Apenas correlações maiores que $|0,9|$ e seus respectivos genes estão mostradas na figura. Fonte: própria autoria. 
Na rede (Figura 7), os genes agrupam-se por tecido, o que se deve principalmente aos genes TS. Como mencionado anteriormente, a maioria dos genes codificadores de proteínas secretadas no plasma foram localizados no fígado. A maioria dos reguladores chave foram localizados perifericamente em relação aos agrupamentos de genes, o que poderia estar refletindo a natureza regulatória desses genes independente do tecido. Apesar disso, alguns reguladores chamam a atenção por causa de seu alto número de conexões.

Os cinco reguladores mais conectados foram EPC1, NR2F6, MED21, ENSBTAG00000031687 e CTBP1, variando de 317 a 284 conexões (Figura 8). Eles eram todos primeiros vizinhos uns dos outros e estavam ligados principalmente a genes com maior expressão no fígado, essencialmente enriquecido para resposta inflamatória aguda $\left(\right.$ Paj $\left.=4,5 \times 10^{-13}\right)$. 
Figura 8 - Cinco principais genes reguladores da rede de co-expressão gênica (EPC1, NR2F6, MED21, ENSBTAG00000031687 e CTBP1) e seus primeiros vizinhos.

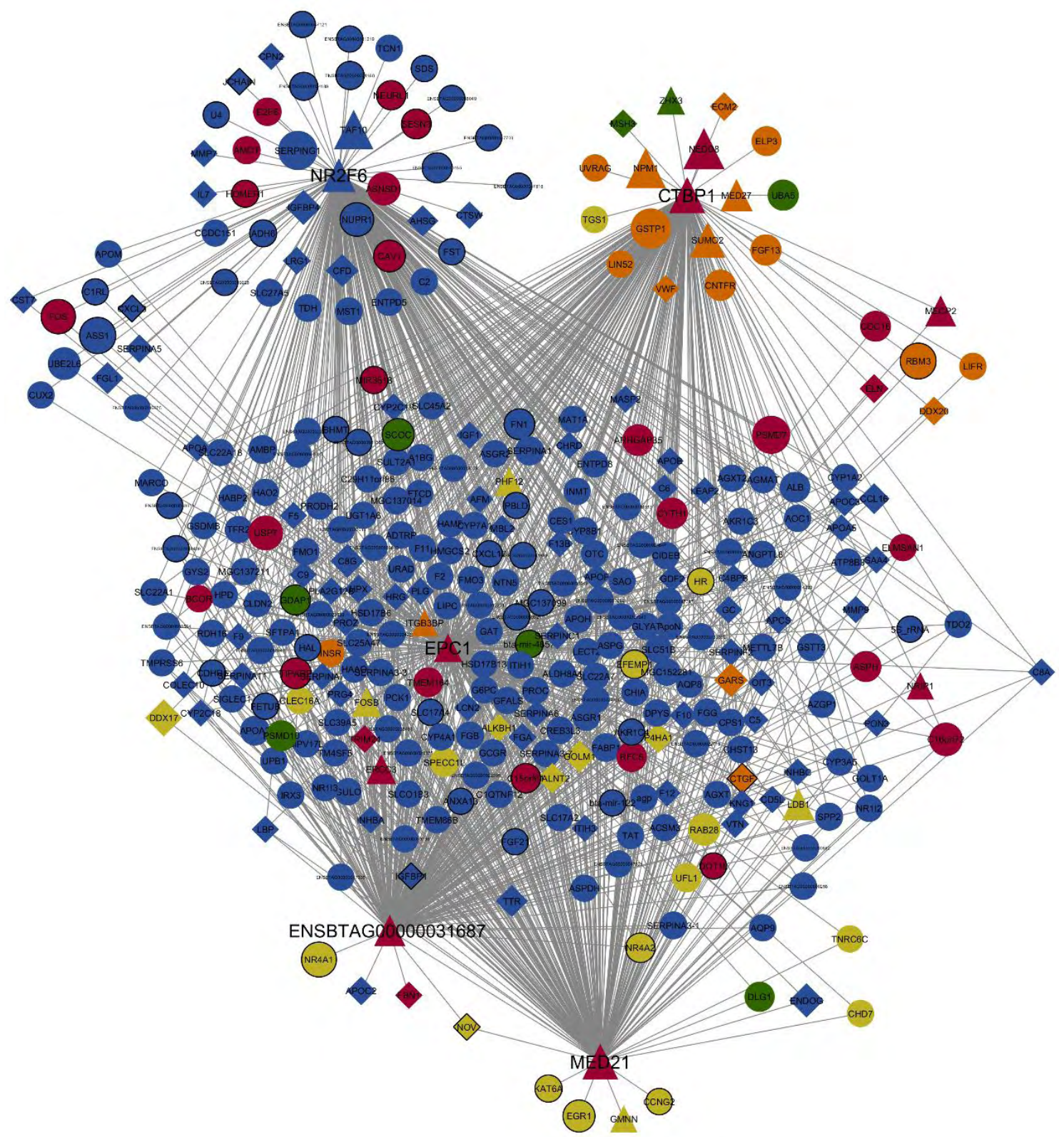

Nódulos com formato de diamante correspondem a genes codificadores de proteínas secretadas no plasma e triângulos correspondem a reguladores chave; todos os outros genes são representados por elipses. Nódulos com bordas pretas são diferencialmente expressos entre alta e baixa eficiência alimentar. As cores são relativas ao tecido de máxima expressão: azul representa fígado, vermelho representa músculo, amarelo representa pituitária, verde representa hipotálamo e laranja representa adrenal. O tamanho dos nódulos é relativo aos valores de expressão média normalizados em todas as amostras. Apenas correlações maiores que $|0,9|$ e seus respectivos genes estão mostradas na figura. Fonte: própria autoria.

O próximo regulador mais conectado foi o TGFB1 com 217 conexões (Figura 9).

Ele estava ligado, principalmente, a genes mais expressos no músculo que enriqueceram principalmente para o desenvolvimento de tecido muscular $\left(\mathrm{Paj}=6,87\right.$ x $\left.10^{-5}\right)$ e contração de músculo estriado $\left(\right.$ Paj $\left.=1,39 \times 10^{-5}\right)$. 
Figura 9 - Gene TGFB1 e seus primeiros vizinhos na rede.

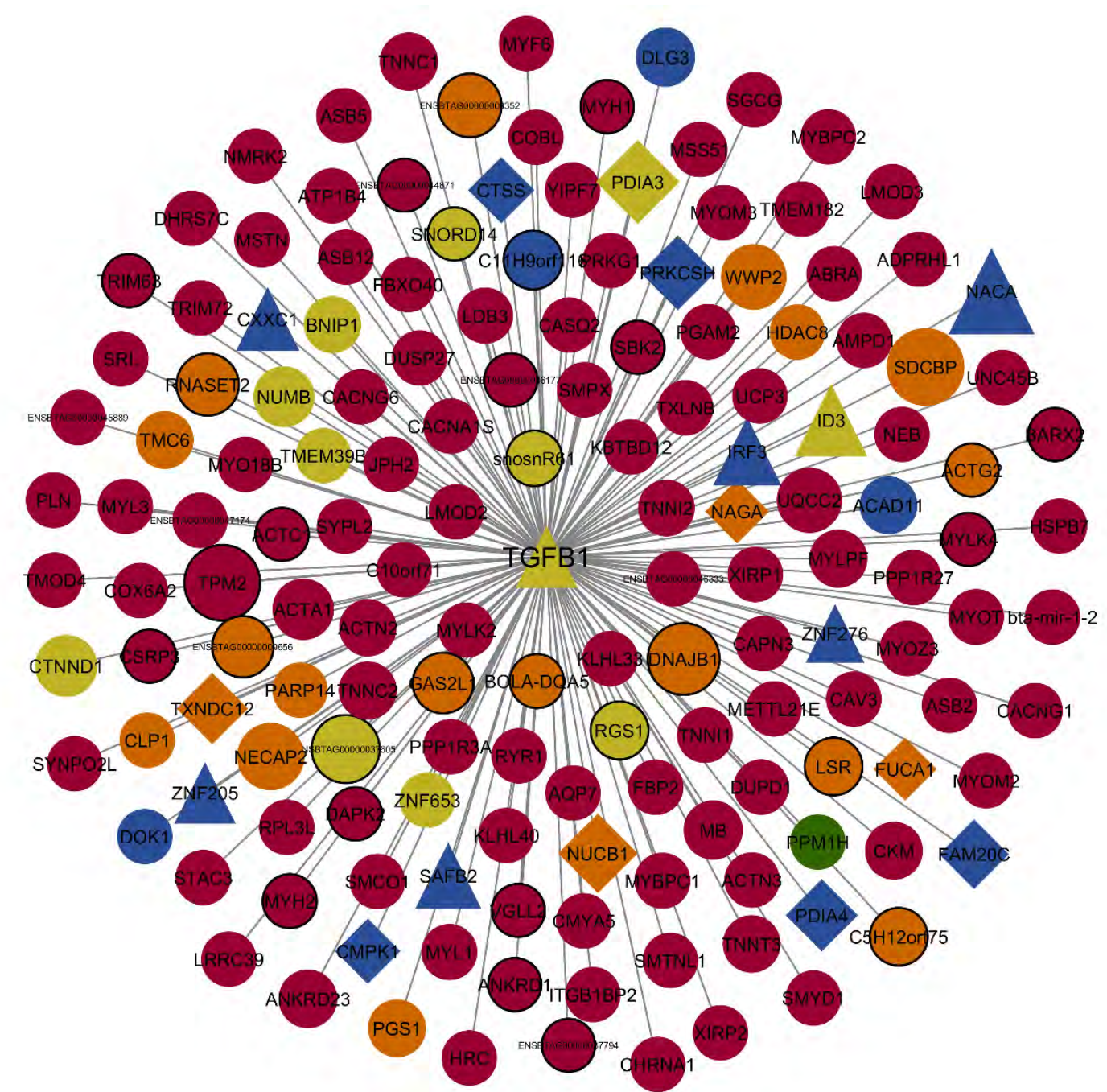

Nódulos com formato de diamante correspondem a genes codificadores de proteínas secretadas no plasma e triângulos correspondem a reguladores chave; todos os outros genes são representados por elipses. Nódulos com bordas pretas são diferencialmente expressos entre alta e baixa eficiência alimentar. As cores são relativas ao tecido de máxima expressão: azul representa fígado, vermelho representa músculo, amarelo representa pituitária, verde representa hipotálamo e laranja representa adrenal. O tamanho dos nódulos é relativo aos valores de expressão média normalizados em todas as amostras. Apenas correlações maiores que $|0,9|$ e seus respectivos genes estão mostradas na figura. Fonte: própria autoria.

Além de indicar os principais genes reguladores, a abordagem de rede pode ser útil para acessar o papel de genes específicos. Por exemplo, o gene FGF21, um hormônio menos expresso no fígado de animais de baixa EA, está diretamente ligado a genes enriquecidos para remodelação de partículas de lipoproteínas plasmáticas, regulação da oxidação de lipoproteínas e fluxo de colesterol (Paj $=5.64 \mathrm{E}^{-3}$, Figura 10). De fato, de acordo com a literatura, esse gene está associado à diminuição do peso corporal, dos triglicérides sanguíneos e do colesterol LDL (CHEUNG; DENG, 2014). 
Figura 10 - Gene FGF21 e seus primeiros vizinhos na rede.

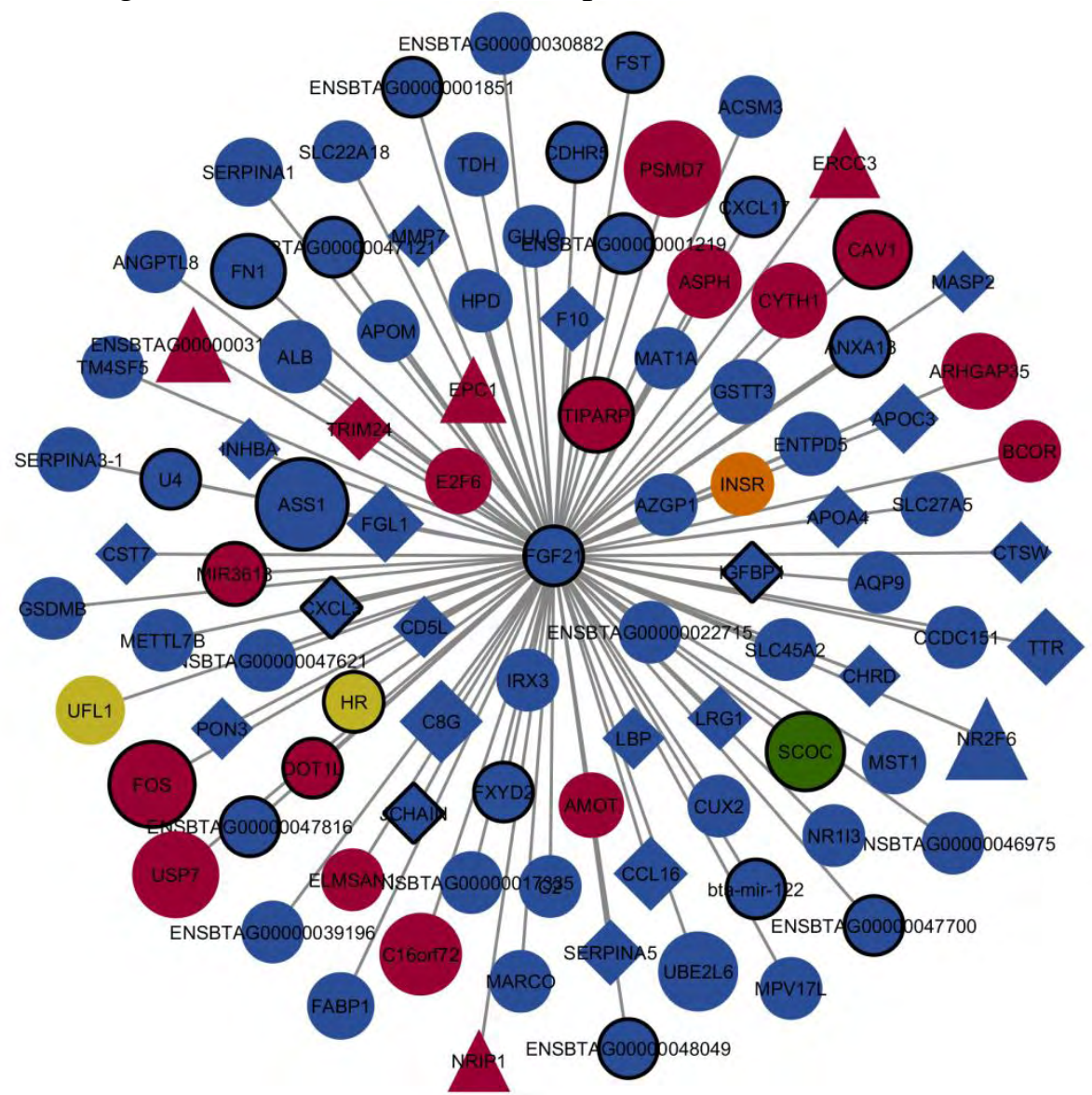

Nódulos com formato de diamante correspondem a genes codificadores de proteínas secretadas no plasma e triângulos correspondem a reguladores chave; todos os outros genes são representados por elipses. Nódulos com bordas pretas são diferencialmente expressos entre alta e baixa eficiência alimentar. As cores são relativas ao tecido de máxima expressão: azul representa fígado, vermelho representa músculo, amarelo representa pituitária, verde representa hipotálamo e laranja representa adrenal. O tamanho dos nódulos é relativo aos valores de expressão média normalizados em todas as amostras. Apenas correlações maiores que $|0,9|$ e seus respectivos genes estão mostradas na figura. Fonte: própria autoria.

\subsubsection{NR2F6 COMO REGULADOR CHAVE DAS MUDANÇAS TRANSCRICIONAIS NO FÍGADO}

Por meio da teoria da lei do poder (power-law theory), as redes de co-expressão apresentam muitos nódulos com poucas conexões e poucos nódulos centrais com muitas conexões (DE LA FUENTE, 2010), sendo os últimos indicados como genes reguladores centrais responsáveis pelas alterações transcricionais entre os fenótipos divergentes analisados (alta e baixa EA). Nesse estudo, indicamos reguladores centrais bem como seus genes alvos, isto é, seus primeiros vizinhos na rede. Esses genes são uma mistura de alvos diretos e indiretos. A fim de validar o papel regulador dos genes mais conectados da rede e identificar seus alvos diretos, realizamos uma busca por sítios de ligação 
(chamada em inglês de motif discovery) nos genes alvo. É válido ressaltar que a busca por sítios de ligação deve confirmar a presença de sítios de ligação dos fatores de transcrição (FT) em questão nas regiões reguladoras dos genes co-expressos. Dos cinco principais reguladores mais conectados na análise de co-expressão, apenas o NR2F6 tem a capacidade de se ligar ao DNA. Em contraste, os outros quatro reguladores atuam principalmente como co-fatores através de interações proteína-proteína. O CTBP1 é um corepressor com função durante a proliferação celular; o MED21 é um coativador que faz parte do complexo mediador e regula quase todos os genes dependentes de RNA polimerase II; e o EPC1 atua como modificador de histonas estando associado a apoptose, reparo de DNA e silenciamento gênico (STELZER et al., 2016).

A análise de 313 genes co-expressos com NR2F6 indicou sítios de ligação de HNF4-NR2F (transfac_pro-M01031) como o segundo motivo mais enriquecido de 9732 PWMs (position weight matrix) com uma pontuação normalizada de enriquecimento (NES) de 7,99 (Figura 11B). Mais do que isso, um total de 19 sítios de ligação associados a HNF4-NR2F2 foram enriquecidos no conjunto de dados, associando HNF4-NR2F2 a 168 genes-alvo diretos (Figura 11C). Devido à redundância do sítio de ligação ou à alta similaridade entre diversos FT, esses sítios podem ser associados a múltiplos FT desde o HNF4 até vários fatores nucleares, como o NR2F6 (score de similaridade FDR 1.41x10${ }^{5}$ ). Nossa análise de co-expressão indica que o NR2F6 é um FT central, uma vez que foi o FT com o maior número de ligações na rede de co-expressão (Figura 11C) e nem o HNF4 ou o NR2F2 foram priorizados por qualquer categoria de seleção para inclusão na rede, apesar de estarem presentes na matriz de expressão. 
Figura 11 - Mapeamento de alvos diretos do gene NR2F6.

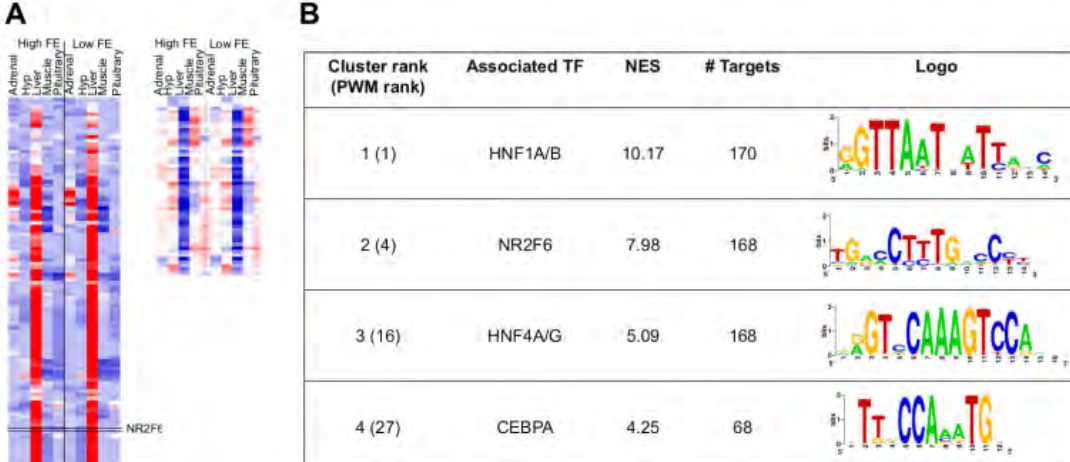

C

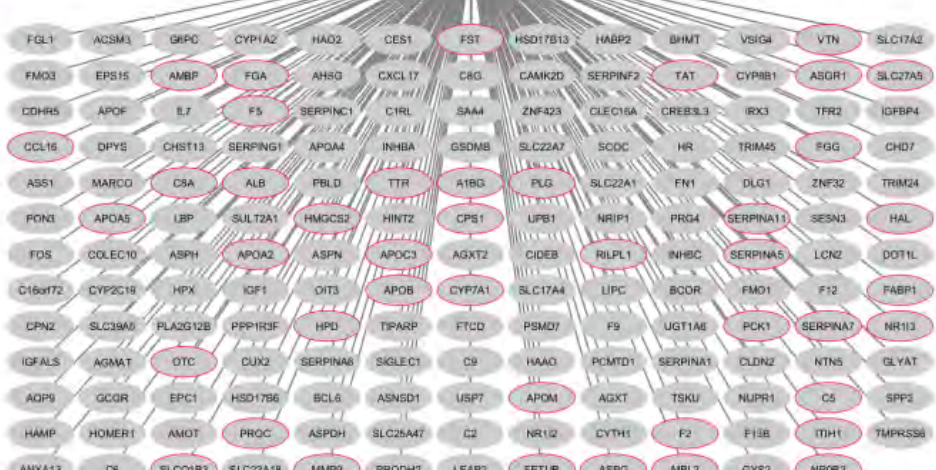

D
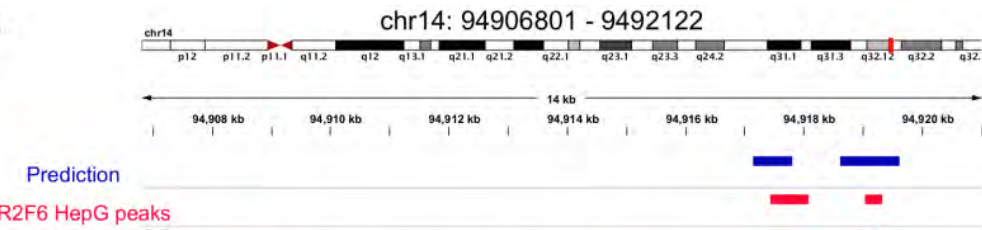

NR2F6 HepG peaks

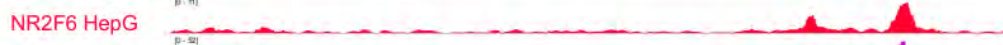

NR2F2 HepG HepG rep1

NR2F2 HepG HepG rep2 $\ldots$

NR2F2 Liver 1

NR2F2 Liver 2

H3K4me3 Liver

H3к27ac Liver

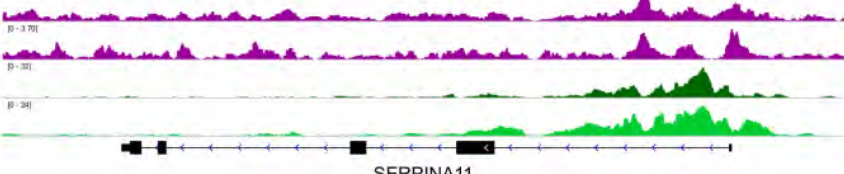

E

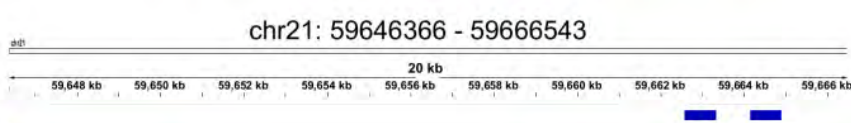
Predictio

H3K4me3 peaks

H3K27ac peaks

H3K4me3 Liver ${ }^{\text {m. }}$

HЗК 4 me3 Liver 2

H3K4me3 Liver 3

年

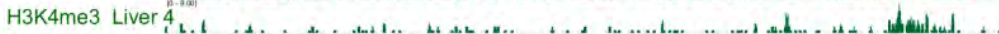

H3k27ac Liver

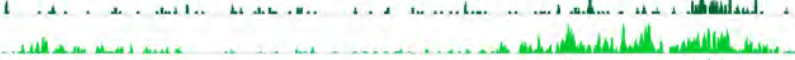

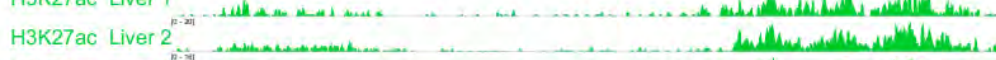

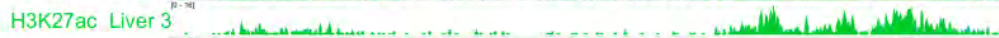

H3K27ac Liver 4 .

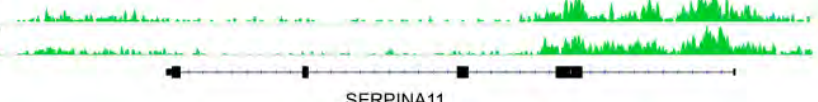

A) Heatmap dos 313 genes co-expressos com o NR2F6 em todos os tecidos; B) Resultados da busca por sítios de ligação enriquecidos nos genes mostrados em (A); C) Predição do genes alvos do NR2F6. Nódulos com contorno vermelho indicam genes conhecidos por serem alvo do NR2F6 em hepatócitos humanos; D) Exemplo de sítio de ligação do NR2F6 previsto para o gene SERPINA1. O sítio de ligação previsto se sobrepõe a dados de ChIPseq para sítios de ligação de NR2F2/RN2F6 em cultivos de células HepG2 e tecido hepático da base de dados do ENCODE, assim como a região de cromatina com marcas de histonas relacionadas a regiões regulatórias ativas (H3K27ac e H3K4me3) em tecido primário de humanos do RoadMap Epigenetics; E) Previsão de sítio de ligação do NR2F6 em coordenadas de bovinos (bosTau6) e sua sobreposição com região de cromatina com marcas de histonas relacionadas a regiões regulatórias ativas (H3K4me3) no fígado de bovinos (VILLAR et al., 2015). Fonte: própria autoria. 
Cada um dos possíveis alvos diretos do NR2F6 contém um ou mais sítios de ligação com alta afinidade para NR2F6 ou FT com motivos altamente similares. Para validar a ligação dessas regiões genômicas com o NR2F6, realizamos uma análise de enriquecimento dessas regiões utilizando dados públicos de análise de precipitação de cromatina (ChiP-seq) para FT específicos em linhagens de células hepáticas humanas do consórcio ENCODE (1394 sítios de ligação de fatores de transcrição). Esta análise, confirmou a ligação de TF com sítios de ligação semelhante ao NR2F6 em células HepG2, sendo HNF4A (NES = 8,57), HNF4G (NES = 7,83), RXRA (NES = 6,85) e NR2F2 (NES $=4,45)$ como o mais enriquecido. Dados de ChIPseq para NR2F6 em células HepG2 (SAVIC et al., 2015) também confirmam enriquecimento para os sítios de ligação de NR2F6 preditos em nosso experimento (Figura 11D).

Em seguida, para validar que os sítios de ligação previstos para o NR2F6 são funcionais no fígado, realizamos uma análise de enriquecimento funcional de regiões abertas de cromatina (655 registros) e modificações de histonas (2450 registros) usando registros de humanos. Esta análise resultou em FAIREseq (Formaldehyde-Assisted Isolation of Regulatory Elements Sequencing) em linhagens de células HepG2 e ChIPseq de H3K9ac e H3K4me3 em fígado adulto (E066 Roadmap Epigenomics Track) como registros mais enriquecidos, indicando que não apenas os genes alvo apresentam sítio de ligação para o gene NR2F6 mas também que essas regiões regulatórias são funcionais em hepatócitos humano (Figura 11D).

Em relação ao genoma bovino, um recente estudo de regiões abertas de cromatina (VILLAR et al., 2015) mapeou as regiões de promotores e enhancers em fígado utilizando H3K4me3 e H3K27ac ChIP-seq resultando em 13.796 promotores e 45.786 enhancers. Utilizando esses dados, foi realizada uma análise de enriquecimento funcional dos sítios de ligação do NR2F6 previstos convertidos em coordenadas do genoma bovino $(\mathrm{n}=779)$ resultando em 446 regiões identificadas como funcionais. Este número é significativamente maior em comparação a 43 regiões encontradas utilizando sítios de ligação aleatórios (teste de permutações 1000x) (Figura 11E).

Finalmente, além de sítios de ligação para NR2F6, os sítios mais enriquecidos foram para o gene HNF1A, em particular o motif swissregulon-HNF1A.p2 com um NES $=10.17$ e 20 motivos enriquecidos. Um total de 170 genes alvos foram associados ao HNF1A (Figura 11B). O HNF1 é sabidamente um regulador importante da expressão gênica do fígado (TRONCHE; YANIV, 1992), o que justifica seu achado. 


\subsubsection{REGULAÇÃO DO TGFB NO MÚSCULO ATRAVÉS DA INTERAÇÃO COM SMAD3/MYOD1}

A análise dos 217 genes co-expressos com TGFB1 (Figura 12A) mostrou que a maioria dos genes alvos foram enriquecidos para os principais reguladores da diferenciação muscular, como MEF2 (NES = 10,42) um fator de transcrição com 148 genes alvos diretos, e MYOD1 (NES = 8,12), um fator de transcrição com 135 genes alvo diretos (Figura 12B). Para avaliar a precisão dos nossos genes alvo previstos para o MYOD1 avaliou-se quantas dessas relações já tinham sido experimentalmente relatadas. Baseado em dados de ChIPseq para MYOD1 em miotubos de camundongos, 86 genes já tinham sido previamente associados com o MYOD1 resultando em uma taxa de sucesso de $63 \%$ (teste hipergeométrico $\mathrm{P}=1.72 \times 10^{-22}$ ).

O SMAD3, molécula efetora da sinalização do TGFB1 é conhecido por recrutar o MYOD1 para promover mudanças na transcrição durante a diferenciação muscular (MULLEN et al., 2011). Assim, avaliamos se os genes alvos preditos para o MYOD1 foram enriquecidos para genes alvo conhecidos do SMAD3 resultando em 21 dos 135 alvos do MYOD1, também sendo alvos do SMAD3 em dados de ChIPseq de miotubos (MULLEN et al., 2011). Verificou-se, portanto, uma associação estatisticamente significativa entre genes alvo do MYOD1 e os do SMAD3 em miotubos (teste hipergeométrico, $\mathrm{P}=1,98 \times 10^{-6}$ ) (Figura 12C). Em contraste, não houve associação significativa entre os genes previstos como alvos diretos do MYOD1 e genes alvo do SMAD3 em outras linhagens celulares, tais como pro-B e células tronco embrionárias (teste hipergeométrico, $\mathrm{P}=0,056$ e $\mathrm{P}=0,076$, respectivamente) (MULLEN et al., 2011). Isso está de acordo com o efeito da sinalização do TGFB impulsionada pela ligação tecido-específica do SMAD3 (LIU; BLACK; DERYNCK, 2001). Nossa análise previu 621 potenciais sítios de ligação do MYOD1, dos quais 114 (18\%) e 153 (24,5\%) estavam presentes em dados de ChIPseq para MYOD1 em miotubos C2C12 (MULLEN et al., 2011) e em miotubos primários (CAO et al., 2009), respectivamente. 
Figura 12 - Mapeamento da via de sinalização do TGFB1 através da ligação do SMAD3/MYOD ao DNA.

A High FE Low FE High FE Low FE B

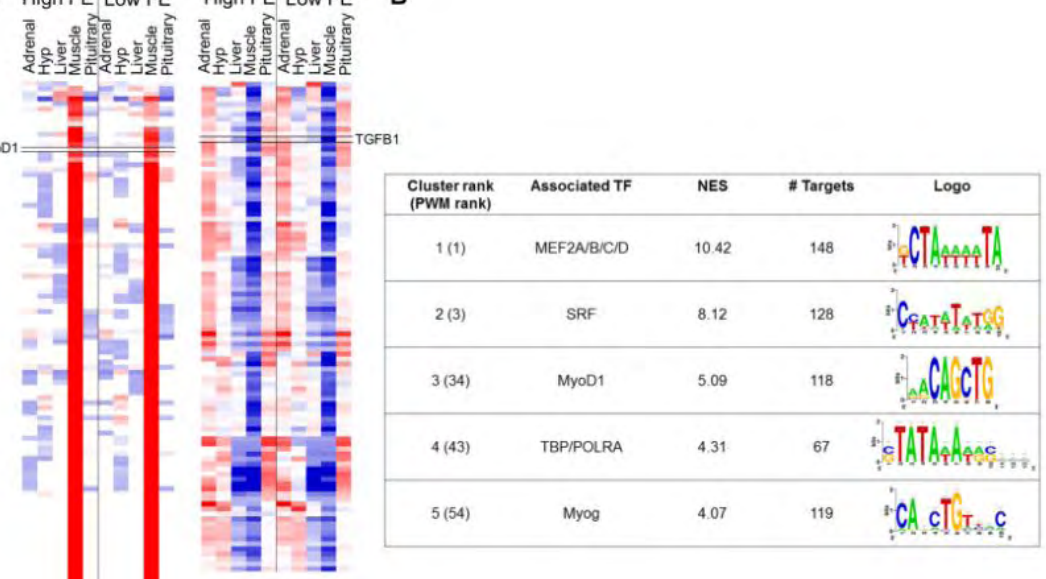

C

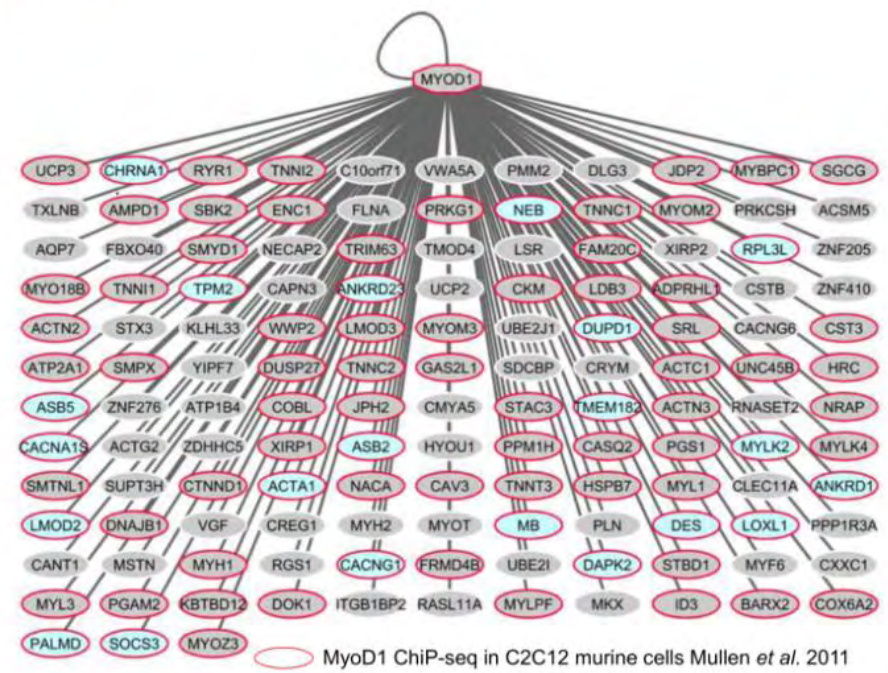

Smad3 ChiP-seq in C2C12 murine cells Mullen et al. 2011

D

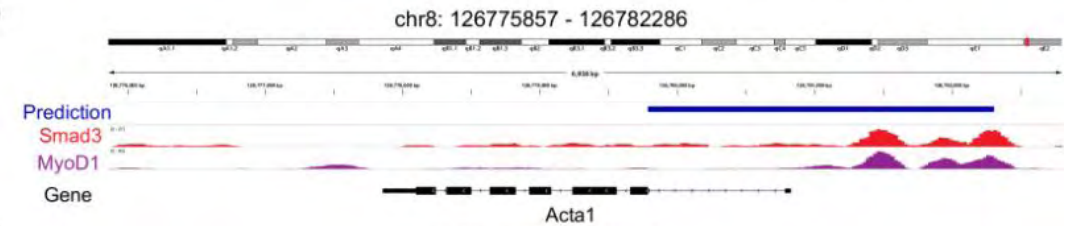

$\mathrm{E}$

chr28: $425010-431766$

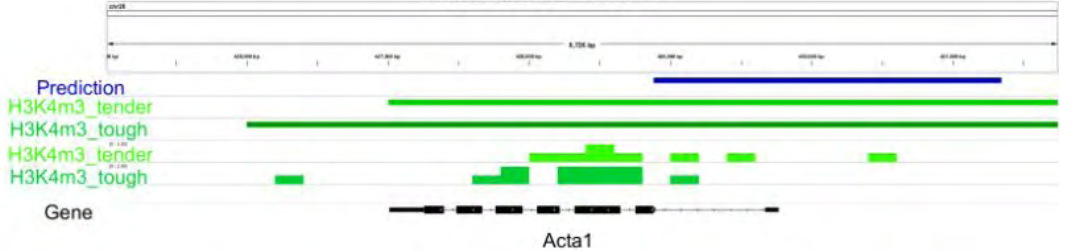

A) Heatmap dos 217 genes co-expressos com TGFB1; B) Resultados da busca por sítios de ligação enriquecidos nos genes mostrados em (A); C) Genes previstos como alvo do MYOD. Nódulos com contorno vermelho indicam alvos do MYOD em miotubos murinos (MULLEN et al., 2011) e nódulos com preenchimento azul indicam genes alvo do SMAD3, molécula efetora da sinalização do TGFB1, em miotubos murinos (MULLEN et al., 2011); E) Sítio de ligação previsto em coordenadas de bovinos (bosTau6) e sua sobreposição com região de cromatina com marcas de histonas relacionadas a regiões regulatórias ativas (H3K4me3) em tecido muscular de bovinos (CAO et al., 2009). Fonte: própria autoria. 
Finalmente, avaliamos se as regiões de ligação do MYOD1 previstas eram regiões reguladoras ativas em células musculares de diferentes espécies, sendo elas humana, murina e bovina. Para tanto, realizamos uma análise de enriquecimento em 2113 registros de regiões abertas de cromatina do ENCODE, o que resultou no enriquecimento de nossas regiões preditas de ligação do MYOD1 em regiões de H3K27ac (NES = 15,98) e H3K9ac $(\mathrm{NES})=8,78$ no músculo esquelético (Figura 12D). Ambas as marcas na cromatina estão associadas à transcrição ativa, H3K27ac relacionadas com sítios de enhancers ativos e H3K9ac relacionada com sítios de transcrição ativa (SHIN et al., 2012), validando assim que a maioria dos nossos sítios de ligação previstos estão ativos no músculo esquelético. Em bovinos, avaliamos a sobreposição de sítios de ligação previstos para o MYOD1 com regiões de H3K4me3 (CAO et al., 2009). Isso resultou na sobreposição de 275 das 653 regiões (42\%) enquanto que apenas 11 regiões se sobrepõem aleatoriamente (teste de 1000 permutações) (Figura 12E).

\subsubsection{CO-EXPRESSÃO DIFERENCIAL}

Embora a rede geral de co-expressão nos dê importantes informações sobre genes regulatórios e seu comportamento, ao criar redes específicas para alta e baixa EA e comparar a conectividade dos genes em cada uma delas, podemos identificar genes que mudam seu comportamento dependendo da situação, passando de altamente conectado para pouco conectado e vice-versa. Foram identificados 87 genes diferencialmente conectados entre alta e baixa $\mathrm{EA}(\mathrm{P}<0,05)$ : 63 expressos principalmente no fígado, 19 no músculo e 3, 1 e 1 no hipotálamo, adrenal e pituitária, respectivamente. Esses genes foram enriquecidos para termos como regulação da coagulação sanguínea (Paj = 3,14 x $\left.10^{-10}\right)$, fibrinólise (Paj = 7,71 x 10 $0^{-7}$ ), degranulação de plaquetas $\left(\right.$ Paj $\left.=7,49 \times 10^{-6}\right)$, resposta inflamatória aguda $\left(\mathrm{Paj}=2,18 \times 10^{-4}\right.$ ), regulação da atividade de peptidase (Paj $=6,16 \mathrm{x}$ $\left.10^{-4}\right)$, resposta humoral antimicrobiana $\left(\mathrm{Paj}=2,49 \times 10^{-3}\right)$ e indução de aglutinação bacteriana (Paj $=3,58 \times 10^{-2}$ ). É importante destacar que 20 dos genes diferencialmente conectados também foram diferencialmente expressos (Tabela 3), e três deles, SST, JCHAIN e IGFBP1, foram secretados no plasma, o que faz deles potenciais biomarcadores para a EA. 
Tabela 3 - Genes diferencialmente conectados e diferencialmente expressos entre alta e baixa eficiência alimentar.

\begin{tabular}{|c|c|c|c|c|c|}
\hline \multirow[b]{2}{*}{ Nome do gene } & \multicolumn{2}{|c|}{ Número de conexões } & \multirow[b]{2}{*}{ Categoria* } & \multirow[b]{2}{*}{$\begin{array}{l}\text { Tecido de } \\
\text { máxima } \\
\text { expressão }\end{array}$} & \multirow[b]{2}{*}{$\begin{array}{c}\text { Tecido de } \\
\text { expressão } \\
\text { diferencial }\end{array}$} \\
\hline & $\begin{array}{c}\text { Baixa } \\
\text { eficiência } \\
\text { alimentar }\end{array}$ & $\begin{array}{c}\text { Alta } \\
\text { eficiência } \\
\text { alimentar }\end{array}$ & & & \\
\hline SST & 0 & 45 & DE,SEC & Hipotálamo & Hipotálamo \\
\hline SNORA73 & 41 & 108 & $\mathrm{DE}$ & Fígado & Fígado \\
\hline ENSBTAG00000047700 & 56 & 111 & $\mathrm{DE}$ & Fígado & Fígado \\
\hline ENSBTAG00000047121 & 62 & 111 & DE & Fígado & Fígado \\
\hline ENSBTAG00000047816 & 53 & 96 & $\mathrm{DE}$ & Fígado & Fígado \\
\hline ENSBTAG00000039928 & 50 & 89 & $\mathrm{DE}$ & Fígado & Fígado \\
\hline ANXA13 & 115 & 63 & $\mathrm{DE}$ & Fígado & Fígado \\
\hline FST & 113 & 56 & $\mathrm{DE}$ & Fígado & Fígado \\
\hline PBLD & 115 & 55 & $\mathrm{DE}$ & Fígado & Fígado \\
\hline ENSBTAG00000021368 & 95 & 0 & $\mathrm{DE}$ & Fígado & Fígado \\
\hline JCHAIN & 52 & 113 & DE,SEC & Fígado & Fígado \\
\hline IGFBP1 & 55 & 0 & DE,TS,SEC & Fígado & Fígado \\
\hline SBK2 & 0 & 70 & DE & Músculo & Músculo \\
\hline ACTC1 & 54 & 0 & $\mathrm{DE}$ & Músculo & Músculo \\
\hline MYH1 & 0 & 47 & DE, TS & Músculo & Músculo \\
\hline $\mathrm{RH}$ & 119 & 50 & $\mathrm{DE}$ & Pituitária & Músculo \\
\hline TAGLN & 83 & 31 & $\mathrm{DE}$ & Adrenal & $\begin{array}{l}\text { Músculo, } \\
\text { Pituitária }\end{array}$ \\
\hline SFRP2 & 41 & 91 & $\mathrm{DE}$ & Hipotálamo & Pituitária \\
\hline FN1 & 119 & 69 & $\mathrm{DE}$ & Fígado & Pituitária \\
\hline CAV1 & 98 & 50 & DE & Músculo & Pituitária \\
\hline
\end{tabular}

*Genes diferencialmente expressos entre alta e baixa eficiência alimentar (DE), genes tecido-específicos (TS) e genes que codificam proteínas secretadas no plasma (SEC).

5.1.8. Validação das vias associadas à inflamação e resposta humoral antimicrobiana

Para validar a teoria proposta anteriormente (ALEXANDRE et al., 2015) e que foi confirmada por parte dos resultados destes experimentos onde a inflamação hepática associada à baixa EA é devida a lesões na tríade portal causadas por maior infecção bacteriana, analisamos a presença de endotoxinas no soro dos animais divergentes para EA. Foi possível detectar maior quantidade $(\mathrm{P}=0,05)$ no grupo de baixa $\mathrm{EA}(36,46 \pm 7,90$ EU/mL, N=10) em comparação ao de alta EA $(15,48 \pm 4,93 \mathrm{EU} / \mathrm{mL}, \mathrm{N}=8)$, o que atesta nossa hipótese e parte dos resultados deste trabalho (Figura 13). 
Figura 13 - Quantificação de endotoxinas no soro de animais de alta e baixa eficiência alimentar

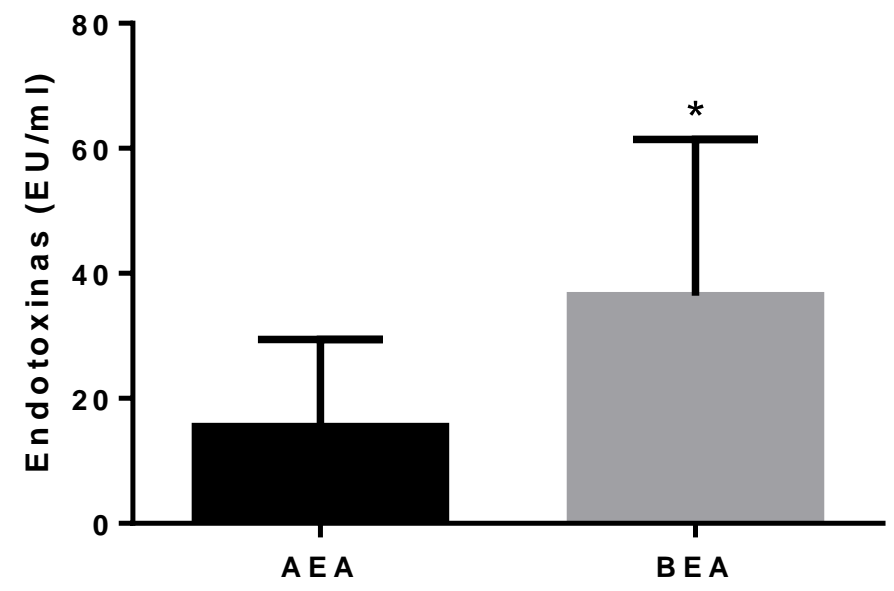

AEA - alta eficiência alimentar; BEA - baixa eficiência alimentar; * $\mathrm{P}=0,05$. Fonte: própria autoria.

\subsection{Abordagem 2 - O papel do eixo hipotálamo-pituitária-adrenal sobre a eficiência alimentar em bovinos de corte}

\subsubsection{SÍNTESE DOS DADOS DE EXPRESSÃO DIFERENCIAL DOS TRÊS ORGÃOS}

Na abordagem 1 foram identificados 125, 98 e 111 genes DE entre os animais de alta e baixa EA no hipotálamo, pituitária e adrenal, respectivamente (Figura 14). Os genes DE no hipotálamo foram enriquecidos principalmente para sinapse dopaminérgica $(\mathrm{Paj}=$ $\left.2,27 \times 10^{-3}\right)$, vício em anfetamina $\left(\mathrm{Paj}=4,10 \times 10^{-3}\right)$, resposta a íons de metal $(\mathrm{Paj}=6,11$ x $\left.10^{-3}\right)$, resposta ao estresse $(\mathrm{Paj}=0,02)$ e sinapse colinérgica $(\mathrm{Paj}=0,04)$. Já os genes DE na pituitária foram enriquecidos principalmente para subunidade beta de hormônio glicoproteico $\left(\mathrm{Paj}=2.68 \times 10^{-6}\right)$, proteína de ligação ao fator de crescimento semelhante à insulina $\left(P a j=5,10 \times 10^{-4}\right)$ e processamento e apresentação de antígeno (Paj $=1,18 \mathrm{x}$ $10^{-3}$ ). Já os genes DE na adrenal foram principalmente enriquecidos para fosforilação oxidativa $\left(\mathrm{Paj}=9,20 \times 10^{-06}\right)$, metabolismo de xenobióticos por citocromo P450 (Paj = $3,04 \times 10^{-4}$ ) e processamento e apresentação de antígeno (Pajj $=6,61 \times 10^{-3}$ ). A lista completa de termos enriquecidos para os três tecidos pode ser encontrada na Tabela Suplementar 4 . 
Figura 14 - Genes diferencialmente expressos, na abordagem 1, entre alta e baixa eficiência alimentar no hipotálamo, pituitária e adrenal.

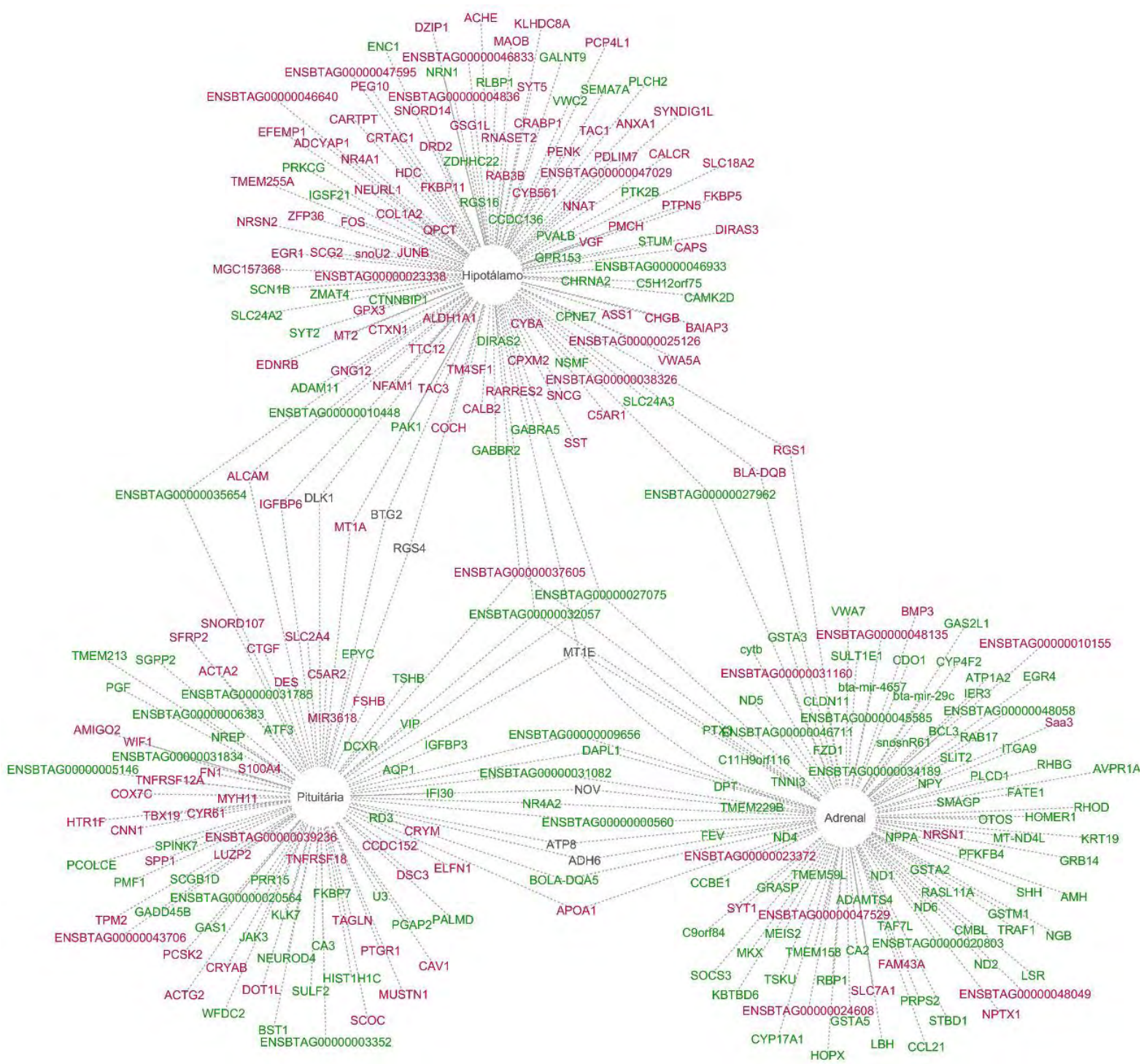

Genes representados em vermelho e verde foram mais e menos expressos na baixa eficiência alimentar, respectivamente. Genes em preto apresentaram discordância entre os tecidos (Tabela suplementar 1). Fonte: própria autoria.

\subsubsection{CO-EXPRESSÃO INTEGRADA DE GENES NO HIPOTÁLAMO, PITUITÁRIA E ADRENAL}

Com o intuito de caracterizar especificamente o papel do eixo hipotálamopituitária-adrenal sobre a eficiência alimentar de bovinos de corte, construímos uma rede de co-expressão utilizando os 20,000 genes mais conectados nos três tecidos, isto é: 8234 genes expressos no hipotálamo, 3909 genes expressos na pituitária e 7857 genes expressos na adrenal. Estes genes foram agrupados inicialmente em 58 módulos e em 
seguida foram combinados baseado em correlação superior a 0,9 entre os eigengenes (primeira componente principal), resultando em 27 módulos de genes co-expressos (Figura 15).

Figura 15 - Clusterização dos módulos baseado em module eigengene (ME - primeira componente principal).

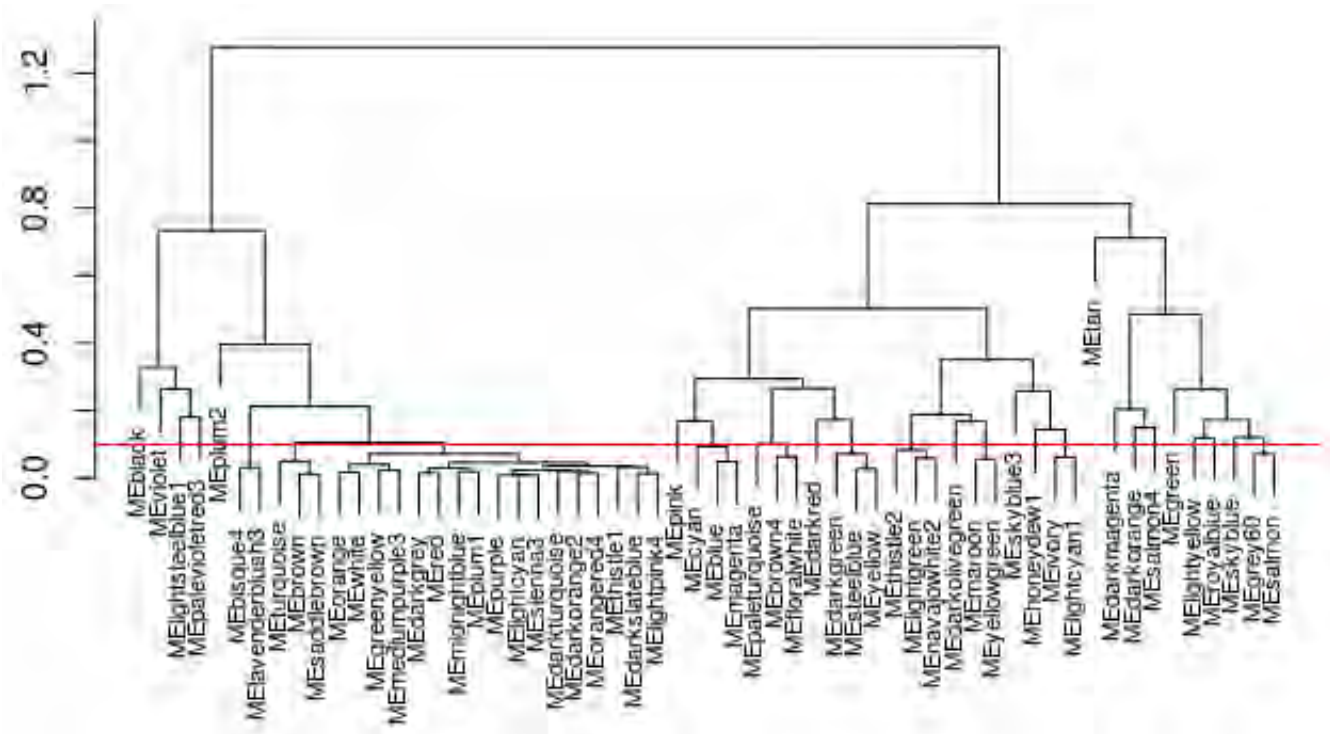

A linha contínua horizontal indica correlação de 0,9 . Fonte: própria autoria.

Espera-se que genes membros do mesmo módulo trabalhem cooperativamente em vias metabólicas relacionadas e que módulos correlacionados com a eficiência alimentar (CAR e CA) indiquem processos biológicos importantes para a regulação desse fenótipo. Utilizamos duas medidas de eficiência alimentar porque enquanto o CAR indica um desvio da ingestão de alimentos com relação à média predita para aquela população independente do ganho de peso, sendo mais interessante para a seleção de animais, a CA é uma medida mais direta da relação entre alimento ingerido e ganho de peso, podendo apontar resultados mais interessantes em uma análise de correlação. Dos 27 módulos, um apresentou correlação positiva com CAR e dois com CA (r $>0,4$ e $\mathrm{P}<0,1$, Figura 16). O módulo Grey60, mais expresso em animais com alto CAR (baixa EA), apresentou 808 genes e a proporção da variância de seus genes explicadas pelo eigengene foi de $65 \%$. Já os módulos Skyblue3 e Maroon, mais expressos em animais com maior CA (baixa EA) apresentaram 153 e 208 genes, respectivamente, e proporção da variância explicada pelo eigengene de $85 \%$ e $84 \%$, respectivamente. 
Figura 16 - Correlações entre módulo eigengene (ME) e medidas de conversão alimentar (CA) e consumo alimentar residual (CAR) - hipotálamo-pituitária-adrenal.

\begin{tabular}{|c|c|c|c|}
\hline MEblack & $-0.18(0.5)$ & $-0.004(1)$ & \\
\hline MEviolet & $-0.21(0.4)$ & $0.23(0.4)$ & $\Gamma 1$ \\
\hline MElightsteelblue1 & $-0.22(0.4)$ & $0.0095(1)$ & \\
\hline MEpalevioletred3 & $-0.13(0.6)$ & $0.21(0.4)$ & \\
\hline MEplum2 & $-0.024(0.9)$ & $0.093(0.7)$ & \\
\hline MEbisque4 & $0.18(0.5)$ & $0.3(0.2)$ & \\
\hline MEorange & $0.07(0.8)$ & $0.31(0.2)$ & \\
\hline MEskyblue3 & $0.54(0.02) *$ & $0.26(0.3)$ & -0.5 \\
\hline MEdarkolivegreen & $0.15(0.5)$ & $-0.17(0.5)$ & \\
\hline MEmaroon & $0.42(0.08) *$ & $0.035(0.9)$ & \\
\hline MEivory & $0.38(0.1)$ & $0.027(0.9)$ & \\
\hline MEthistle2 & $0.3(0.2)$ & $0.0089(1)$ & \\
\hline MEbrown4 & $0.18(0.5)$ & $0.078(0.8)$ & \\
\hline MEdarkred & $0.15(0.5)$ & $0.16(0.5)$ & -0 \\
\hline MEhoneydew1 & $0.28(0.3)$ & $0.063(0.8)$ & \\
\hline MEdarkgreen & $0.11(0.7)$ & $-0.02(0.9)$ & \\
\hline MEcyan & $0.15(0.6)$ & $-0.077(0.8)$ & \\
\hline MEpink & $-0.043(0.9)$ & $-0.17(0.5)$ & \\
\hline MEtan & $0.067(0.8)$ & $0.21(0.4)$ & \\
\hline MEdarkmagenta & $-0.089(0.7)$ & $0.016(0.9)$ & -0.5 \\
\hline MEdarkorange & $0.14(0.6)$ & $0.32(0.2)$ & \\
\hline MEsalmon4 & $-0.056(0.8)$ & $-0.012(1)$ & \\
\hline MEgreen & $0.14(0.6)$ & $0.23(0.4)$ & \\
\hline MEgrey 60 & $0.25(0.3)$ & $0.45(0.06) *$ & \\
\hline MEskyblue & $0.24(0.3)$ & $0.31(0.2)$ & \\
\hline MElightyellow & $0.1(0.7)$ & $0.28(0.3)$ & -1 \\
\hline MEroyalblue & $0.15(0.6)$ & $0.32(0.2)$ & \\
\hline
\end{tabular}

$* \mathrm{P}<0,1$. Fonte: própria autoria.

Após o filtro de qualidade (ver métodos), restaram 784 genes no módulo Grey60 sendo 774 expressos na pituitária e 10 no hipotálamo, sendo que esse módulo foi considerando como sendo de pituitária (Tabela suplementar 5). Esses genes foram enriquecidos para proteólise mediada por ubiquitina, biogênese de ribossomos e proteassomo (Tabela 4). Também apresentou enriquecimento para termos do GO relacionados a processo catabólico de proteínas dependente de ubiquitina (Figura 15, Figura Suplementar 1). Na análise de interação de proteína na plataforma STRING, foram encontradas 3912 interações quando 2224 eram esperadas ao acaso $\left(P=1,0 \times 10^{-16}\right)$ e as vias metabólicas enriquecidas foram semelhantes (Tabela 5).

Com relação ao módulo Skyblue3, 145 genes passaram pelo controle de qualidade, sendo 140 expressos no hipotálamo, 4 na pituitária e 1 na adrenal, sendo assim considerado um módulo de hipotálamo (Tabela suplementar 6). Este módulo foi o que apresentou a maior quantidade de vias enriquecidas, entre elas ritmo circadiano, secreção salivar e de ácido gástrico, transdução olfativa, sinapse dopaminérgica e via de sinalização de ocitocina (Tabela 4). Termos do GO enriquecidos para esse modulo 
incluem via de sinalização do receptor de dopamina, cognição e regulação da biossíntese de AMPc (Figura 17, Figura Suplementar 2). Com relação à análise de interação de proteínas, foram encontradas 108 interações quando apenas 49 eram esperadas ao acaso $\left(\mathrm{P}=3,47 \times 10^{-13}\right)$ e vias similares foram enriquecidas (tabela 5).

O módulo Maroon apresentou 205 genes após o controle de qualidade, 203 expressos no hipotálamo, 1 na pituitária e 1 na adrenal, sendo também considerado um módulo de hipotálamo (Tabela suplementar 7). Esse módulo, assim como o Skyblue3, apresentou enriquecimento da via de sinalização da ocitocina e também do MAPK. Quanto aos termos do GO, apresentou enriquecimento para modulação da transmissão sináptica (Figura 17, Figura Suplementar 3). Na análise de interação de proteínas, foram encontradas 166 interações quando 61 eram esperadas ao acaso $\left(\mathrm{P}=1,0 \times 10^{-16}\right)$ e também houve enriquecimento de vias similares (Tabela 5).

Tabela 4 - Enriquecimento funcional de vias metabólicas (KEEG-WebGesalt) dos genes nos três módulos associados à eficiência alimentar.

\begin{tabular}{|c|c|c|c|c|}
\hline Módulo & KEEG ID & Nome & Genes & FDR \\
\hline Grey60 & bta04120 & Proteólise mediada pela ubiquitina & 19 & $1,39 \times 10^{-02}$ \\
\hline Grey60 & bta03008 & Biogênese do ribossomo em eucariotos & 13 & $2,93 \times 10^{-02}$ \\
\hline Grey60 & bta03050 & Proteassomo & 9 & $3,99 \times 10^{-02}$ \\
\hline Skyblue3 & bta05032 & Vício em morfina & 10 & $1,50 \times 10^{-06}$ \\
\hline Skyblue3 & bta04020 & Via de sinalização de cálcio & 10 & $1,28 \times 10^{-04}$ \\
\hline Skyblue3 & bta04970 & Secreção salivar & 7 & $1,82 \times 10^{-04}$ \\
\hline Skyblue3 & bta04971 & Secreção de ácido gástrico & 6 & $1,41 \times 10^{-03}$ \\
\hline Skyblue3 & bta04080 & Interação ligante-receptor neuroativo & 9 & $1,75 \times 10^{-03}$ \\
\hline Skyblue3 & bta04540 & Gap junction & 6 & $4,54 \times 10^{-03}$ \\
\hline Skyblue3 & bta04740 & Transdução olfativa & 4 & $1,03 \times 10^{-02}$ \\
\hline Skyblue3 & bta00230 & Metabolismo das purinas & 7 & $2,21 \times 10^{-02}$ \\
\hline Skyblue3 & bta04727 & Sinapse gabaérgica & 5 & $2,50 \times 10^{-02}$ \\
\hline Skyblue3 & bta04728 & Sinapse dopaminérgica & 6 & $2,50 \times 10^{-02}$ \\
\hline Skyblue3 & bta04713 & Ritmo Circadiano & 5 & $2,50 \times 10^{-02}$ \\
\hline Skyblue3 & bta04015 & Via de sinalização Rap1 & 7 & $3,05 \times 10^{-02}$ \\
\hline Skyblue3 & bta04270 & Contração do músculo liso vascular & 5 & $3,24 \times 10^{-02}$ \\
\hline Skyblue3 & bta04723 & Sinalização endocanabinóide retrógrada & 5 & $3,24 \times 10^{-02}$ \\
\hline Skyblue3 & bta04921 & Via de sinalização da ocitocina & 6 & $3,24 \times 10^{-02}$ \\
\hline Skyblue3 & bta04924 & Secreção de renina & 4 & $3,36 \times 10^{-02}$ \\
\hline Maroon & bta04921 & Via de sinalização da ocitocina & 12 & $8,28 \times 10^{-06}$ \\
\hline Maroon & bta04010 & Via de sinalização MAPK & 10 & $2,36 \times 10^{-02}$ \\
\hline
\end{tabular}


Tabela 5 - Enriquecimento funcional de vias metabólicas (KEEG-STRING) dos genes nos três módulos associados à eficiência alimentar.

\begin{tabular}{|c|c|c|c|c|}
\hline Módulo & KEEG ID & Nome & Genes & FDR \\
\hline Grey60 & bta3008 & Biogênese do ribossomo em eucariotos & 14 & $2,08 \mathrm{E}-04$ \\
\hline Grey60 & bta4120 & Proteólise mediada pela ubiquitina & 19 & 2,08E-04 \\
\hline Grey60 & bta3013 & Transporte de RNA & 18 & $2,21 \mathrm{E}-03$ \\
\hline Grey60 & bta 3050 & Proteassoma & 9 & 2,98E-03 \\
\hline Grey60 & bta3015 & Via de vigilância de mRNA & 12 & 4,74E-03 \\
\hline Grey60 & bta3040 & Spliceosome & 15 & 4,74E-03 \\
\hline Grey60 & bta5211 & Carcinoma de células renais & 9 & $3,69 \mathrm{E}-02$ \\
\hline Skyblue3 & bta5032 & Vício em morfina & 10 & 3,04E-07 \\
\hline Skyblue3 & bta 4020 & Via de sinalização de cálcio & 10 & $8,53 \mathrm{E}-05$ \\
\hline Skyblue3 & bta4970 & Secreção salivar & 7 & $1,83 \mathrm{E}-04$ \\
\hline Skyblue3 & bta4971 & Secreção de ácido gástrico & 6 & $8,01 \mathrm{E}-04$ \\
\hline Skyblue3 & bta 4540 & Interação ligante-receptor neuroativo & 6 & $1,83 \mathrm{E}-03$ \\
\hline Skyblue3 & bta4080 & Gap junction & 9 & $5,51 \mathrm{E}-03$ \\
\hline Skyblue3 & bta4725 & Transdução olfativa & 6 & $5,51 \mathrm{E}-03$ \\
\hline Skyblue3 & bta 230 & Metabolismo das purinas & 7 & $7,48 \mathrm{E}-03$ \\
\hline Skyblue3 & bta4728 & Sinapse gabaérgica & 6 & 7,73E-03 \\
\hline Skyblue3 & bta4727 & Sinapse dopaminérgica & 5 & $9,49 \mathrm{E}-03$ \\
\hline Skyblue3 & bta4713 & Ritmo Circadiano & 5 & $1,32 \mathrm{E}-02$ \\
\hline Skyblue3 & bta4015 & Via de sinalização Rap1 & 7 & $1,52 \mathrm{E}-02$ \\
\hline Skyblue3 & bta4723 & Contração do músculo liso vascular & 5 & $1,52 \mathrm{E}-02$ \\
\hline Skyblue3 & bta4921 & Sinalização endocanabinóide retrógrada & 6 & $1,52 \mathrm{E}-02$ \\
\hline Skyblue3 & bta5034 & Via de sinalização da ocitocina & 6 & $1,91 \mathrm{E}-02$ \\
\hline Skyblue3 & bta 4270 & Secreção de renina & 5 & $2,61 \mathrm{E}-02$ \\
\hline Maroon & bta4921 & Via de sinalização da ocitocina & 12 & $1,05 \mathrm{E}-05$ \\
\hline Maroon & bta4010 & Via de sinalização MAPK & 10 & 2,92E-02 \\
\hline Maroon & bta4720 & Vício em morfina & 5 & $3,19 \mathrm{E}-02$ \\
\hline Maroon & bta4261 & Via de sinalização de cálcio & 7 & $3,87 \mathrm{E}-02$ \\
\hline
\end{tabular}

Genes centrais nos módulos associados à EA foram selecionados com base nas medidas de significância do gene (SG) e de filiação ao módulo (FM). No total, 117 genes nos módulos Grey60 e Skyblue3, e 32 genes no módulo Maroon foram significativos para SG (para CA ou CAR) e apresentaram valores de FM > 0,8 indicando uma forte filiação aos módulos (Figuras 18, 19 e 20). 
Figura 17 - Representação das vias do KEEG (azul escuro) e principais termos do gene ontology (vermelho) enriquecidos (Paj<0,05) nos módulos associados à eficiência alimentar.

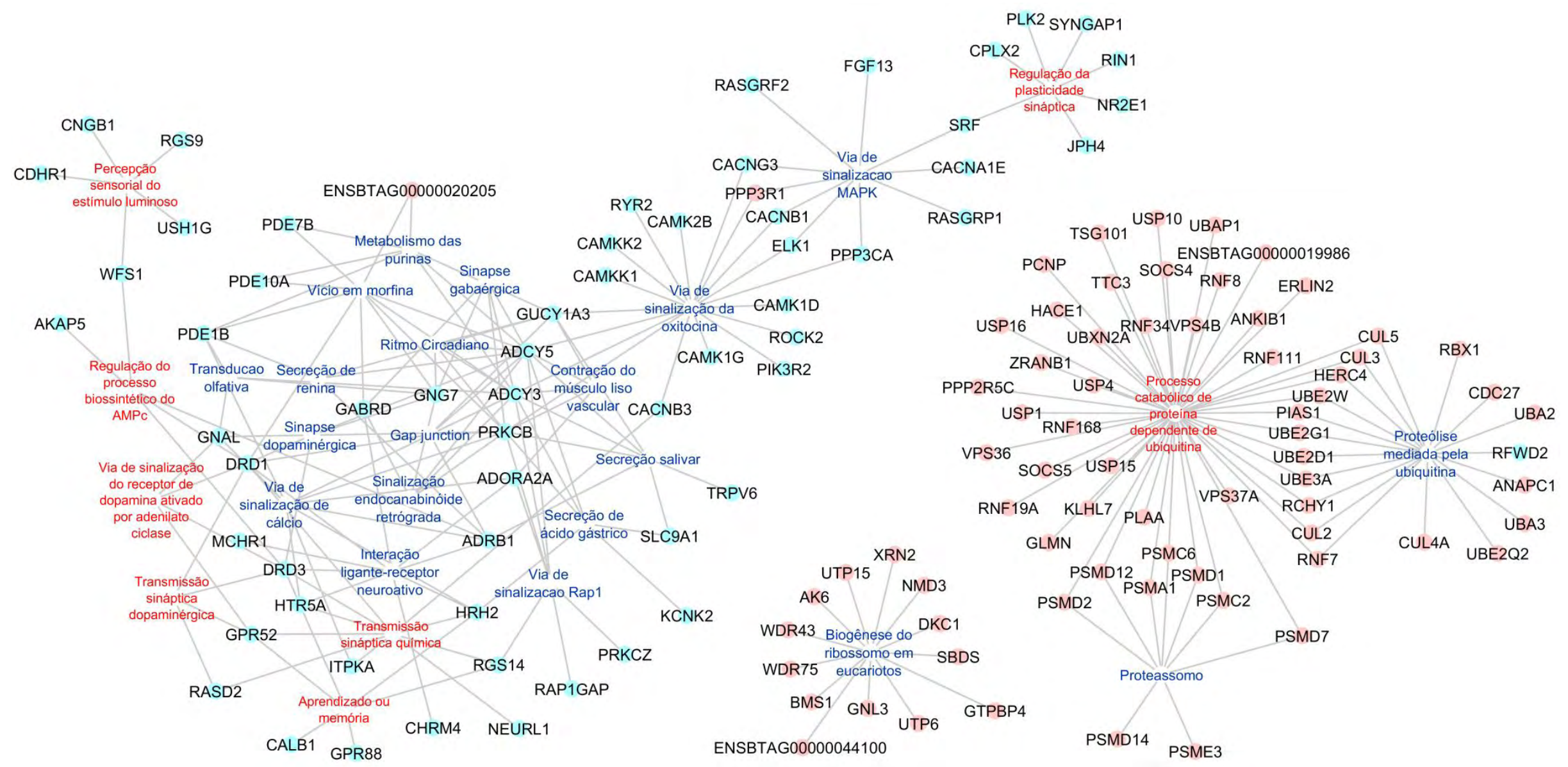

Nódulos azul claro e rosa claro representam genes expressos no hipotálamo e pituitária, respectivamente. Fonte: própria autoria. 
Figura 18 - Genes centrais do módulo Grey60 determinados através de correlação significativa $(\mathrm{P}<0,05)$ com consumo e ganho residual e alta filiação ao módulo $(\mathrm{FM}>0,8)$.

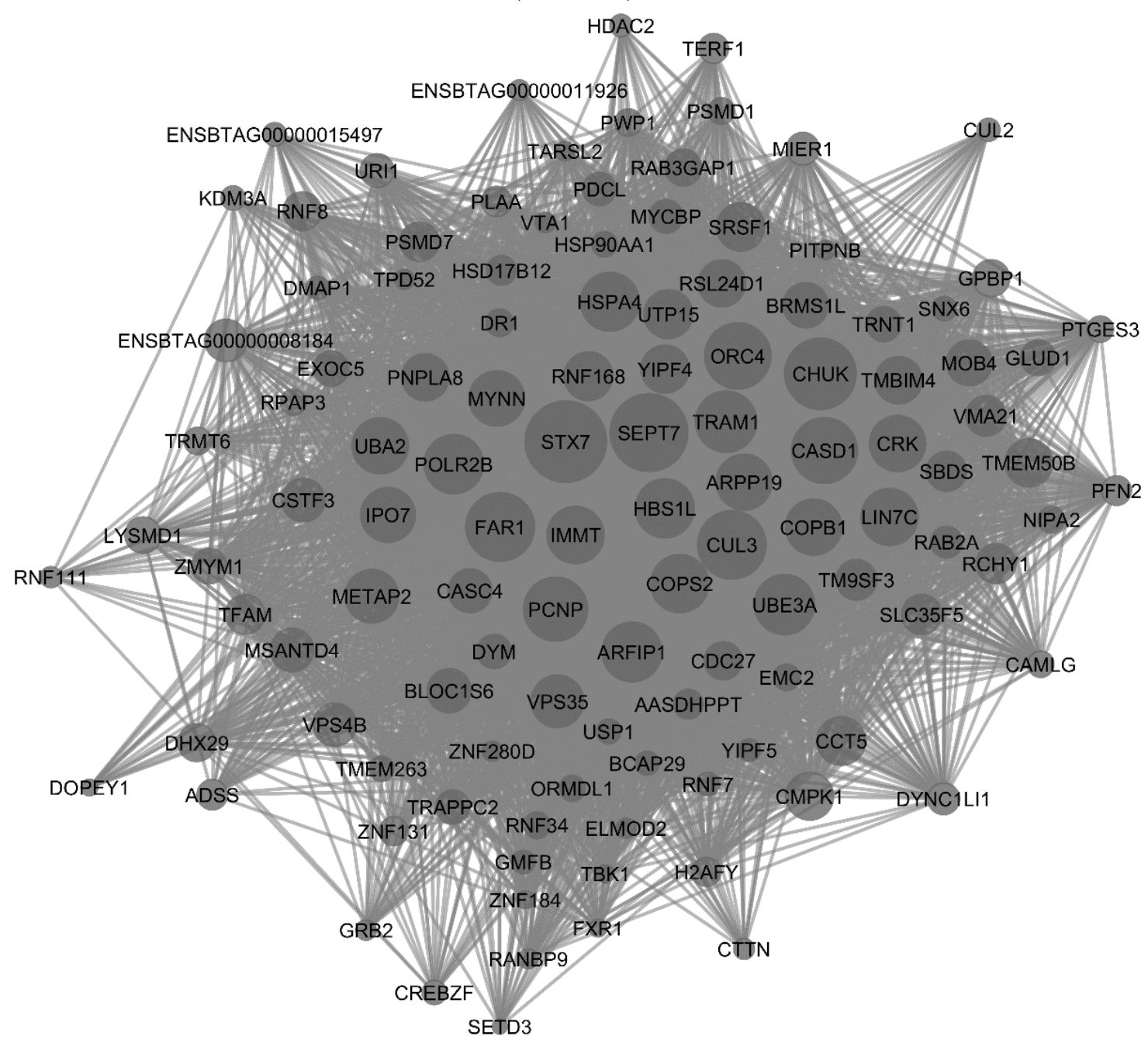

Círculos representam genes expressos na pituitária e seus tamanhos são relativos à conectividade intramodular. Fonte: própria autoria. 
Figura 19 - Genes centrais do módulo Skyblue3 determinados através de correlação significativa $(\mathrm{P}<0,05)$ com conversão alimentar e alta filiação ao módulo $(\mathrm{FM}>0,8)$.

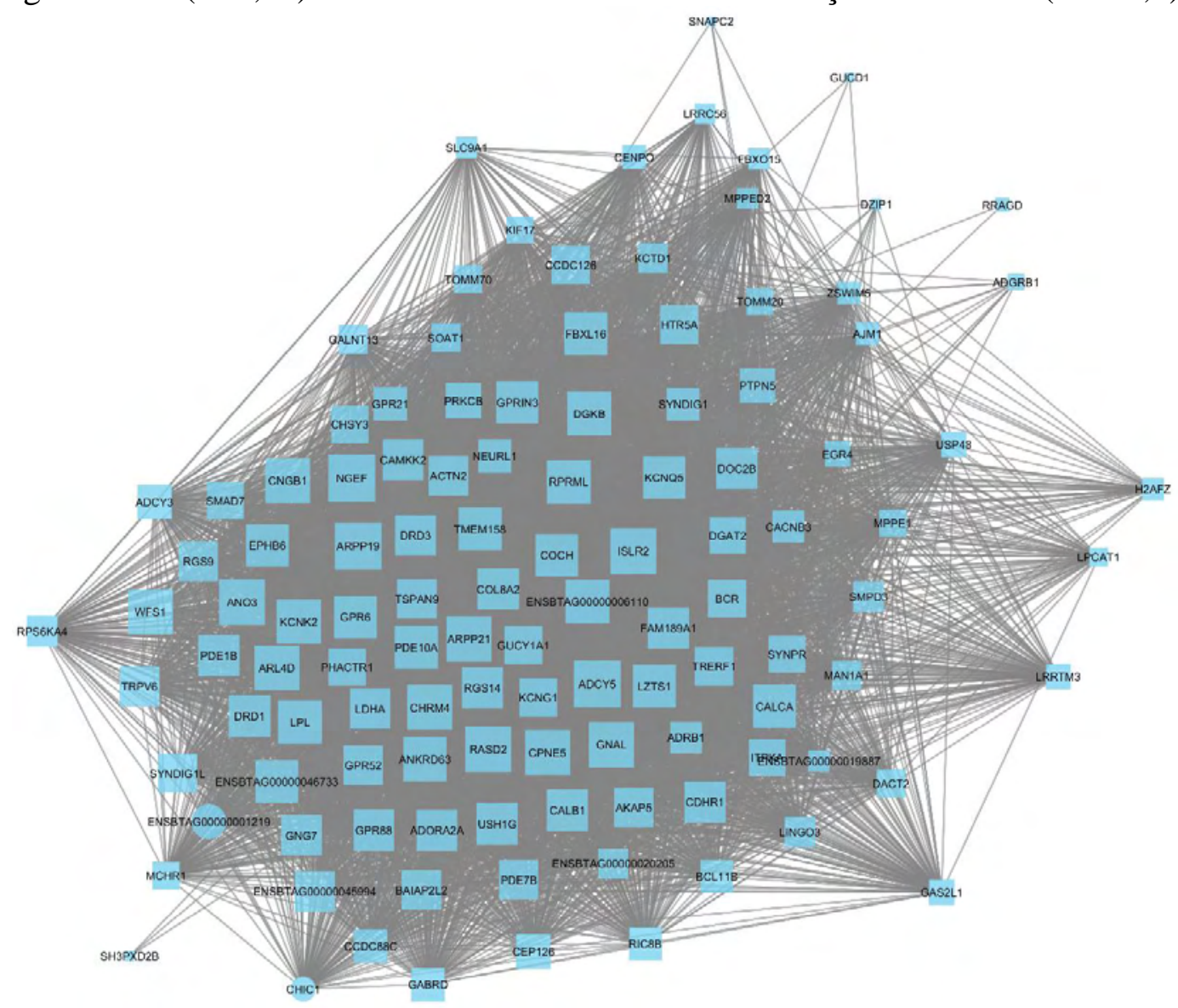

Retângulos e círculos representam genes expressos no hipotálamo e na pituitária, respectivamente, e seus tamanhos são relativos à conectividade intramodular. Fonte: própria autoria.

Figura 20 - Genes centrais do módulo Maroon determinados através de correlação significativa $(\mathrm{P}<0,05)$ com conversão alimentar e alta filiação ao módulo (FM>0,8).

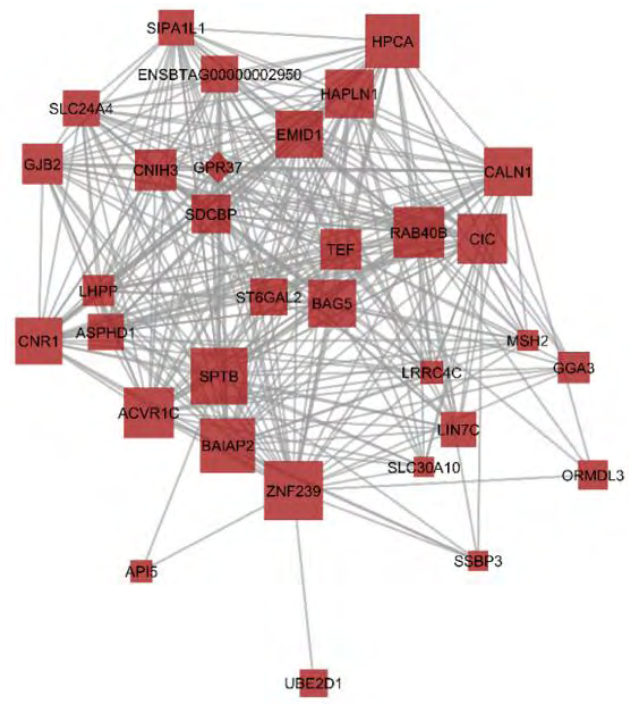

Retângulos e losangos representam genes expressos no hipotálamo e na adrenal, respectivamente, e seus tamanhos são relativos à conectividade intramodular. Fonte: própria autoria. 


\subsubsection{CO-EXPRESSÃO DE GENES NOS ORGÃOS DE FORMA INDIVIDUALIZADA}

Em uma segunda análise, avaliamos os órgãos de forma individualizada para posteriormente analisar a interação entre eles. Assim, para a análise de co-expressão no hipotálamo foram utilizados 13,174 genes que passaram pelo controle de qualidade. Foram identificados inicialmente 39 módulos de genes co-expressos que em seguida foram combinados baseado em correlação superior a 0,9 entre os eigengenes, resultando em 31 módulos de genes co-expressos (Figura 21).

Figura 21 - Clusterização dos módulos do hipotálamo baseado em modulo eigengene

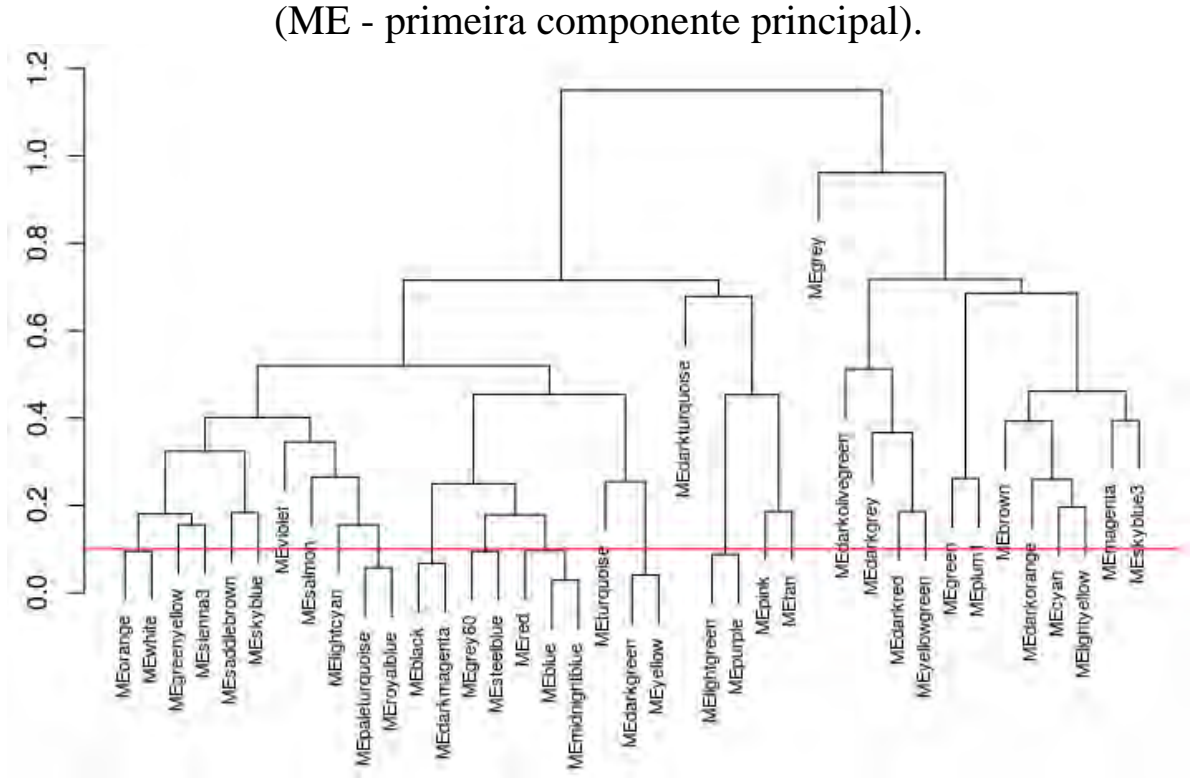

A linha contínua horizontal indica correlação de 0,9 . Fonte: própria autoria.

Dos 31 módulos, dois apresentaram correlação positiva com a conversão alimentar, estando associados à baixa EA ( $r>0,4$ e $\mathrm{P}<0,1$, Figura 22). O módulo Tan apresentou 253 genes e a proporção da variância de seus genes explicada pelo eigengene foi de 71\% (Tabela Suplementar 8). Já o módulo Pink apresentou 367 genes e a proporção da variância de seus genes explicada pelo eigengene foi de 61\% (Tabela Suplementar 9). 
Figura 22 - Correlações entre módulo eigengene (ME) e medidas de conversão alimentar (CA) e consumo alimentar residual (CAR) - hipotálamo.

\begin{tabular}{|c|c|c|c|}
\hline & & & \\
\hline $\begin{array}{r}\text { MEdarkgreen } \\
\text { MEred }\end{array}$ & $\begin{array}{l}0.11(0.7) \\
0.16(0.5)\end{array}$ & $\begin{array}{c}0.0063(1) \\
-0.058(0.8)\end{array}$ & \\
\hline MEturquoise & $-0.029(0.9)$ & $-0.17(0.5)$ & $T 1$ \\
\hline MEviolet & $0.12(0.6)$ & $0.19(0.4)$ & \\
\hline MEpaleturquoise & $0.21(0.4)$ & $0.11(0.7)$ & \\
\hline MEsalmon & $0.081(0.7)$ & $0.14(0.6)$ & \\
\hline MEorange & $0.1(0.7)$ & $0.18(0.5)$ & \\
\hline MEgreenyellow & $0.19(0.5)$ & $0.087(0.7)$ & \\
\hline MEsienna3 & $0.024(0.9)$ & $-0.0046(1)$ & 0.5 \\
\hline MEsaddlebrown & $0.24(0.3)$ & $0.2(0.4)$ & \\
\hline MEskyblue & $0.18(0.5)$ & $0.13(0.6)$ & \\
\hline MEdarkturquoise & $0.056(0.8)$ & $-0.02(0.9)$ & \\
\hline MElightgreen & $0.22(0.4)$ & $-0.1(0.7)$ & \\
\hline MEpink & $0.44(0.07) *$ & $0.089(0.7)$ & \\
\hline MEtan & $0.55(0.02) *$ & $0.3(0.2)$ & \\
\hline MEblack & $0.31(0.2)$ & $-0.025(0.9)$ & -0 \\
\hline MEgrey60 & $0.29(0.2)$ & $-0.063(0.8)$ & \\
\hline MElightcyan & $0.36(0.1)$ & $0.14(0.6)$ & \\
\hline MEdarkolivegreen & $0.085(0.7)$ & $0.28(0.3)$ & \\
\hline MEdarkgrey & $0.12(0.6)$ & $0.24(0.3)$ & \\
\hline MEdarkred & $0.28(0.3)$ & $0.22(0.4)$ & \\
\hline MEyellowgreen & $0.38(0.1)$ & $0.4(0.1)$ & \\
\hline MEgreen & $0.055(0.8)$ & $0.23(0.4)$ & -0.5 \\
\hline MEplum1 & $-0.066(0.8)$ & $0.28(0.3)$ & \\
\hline MEbrown & $-0.16(0.5)$ & $-0.013(1)$ & \\
\hline MEdarkorange & $-0.0077(1)$ & $0.22(0.4)$ & \\
\hline MEcyan & $-0.2(0.4)^{\prime}$ & $0.039(0.9)$ & \\
\hline MElightyellow & $-0.15(0.5)$ & -0.00049 (1) & \\
\hline MEmagenta & $-0.19(0.5)$ & $0.26(0.3)$ & \\
\hline MEskyblue3 & $-0.34(0.2)$ & $0.063(0.8)$ & -1 \\
\hline MEgrey & $0.047(0.9)$ & $-0.1(0.7)$ & \\
\hline
\end{tabular}

$* \mathrm{P}<0,1$. Fonte: própria autoria.

O módulo Tan é semelhante ao módulo Skyblue3, identificado na análise conjunta dos três tecidos, quanto aos genes presentes (66\% dos genes em comum) e o resultado do enriquecimento funcional (Tabela 6). Os poucos termos que não aparecem enriquecidos quando a análise é feita com todos os genes, como via de sinalização de ocitocina e de endocanabinóide retrógrada, aparecem quando selecionamos para a análise de enriquecimento apenas os genes biologicamente mais relevantes, isto é, genes com correlação significativa $(\mathrm{P}<0,05)$ com a $\mathrm{CA}$ e com correlação com o módulo eigengene maior que 0,8 indicando uma forte filiação ao módulo ( $h u b$ genes - Tabela 7). Além disso, na análise de redes de proteínas feitas pelo STRING, o número de interações foi significativo $\left(\mathrm{P}=2,11 \times 10^{-13}\right)$, apresentando 212 interações quando apenas 123 eram esperadas ao acaso. A análise de enriquecimento baseada nessa rede de proteínas apresentou resultados semelhantes aos encontrados pelo WebGestalt para vias metabólicas, mas destacam-se também termos do Gene Ontology como os relacionados a resposta de estresse e de medo (Tabela 8). A Figura 23 demostra as relações encontradas pelo STRING entre as proteínas codificadas pelos $h u b$ genes do módulo Tan. 
Tabela 6 - Enriquecimento funcional de vias metabólicas (KEEG-WebGestalt) dos módulos associados à conversão alimentar no hipotálamo usando todos os genes.

\begin{tabular}{|c|c|c|c|c|}
\hline Módulo & ID & Nome & Genes & FDR \\
\hline Tan & bta05032 & Vício em morfina & 10 & $7,75 \times 10^{-05}$ \\
\hline Tan & bta05030 & Vício em cocaína & 6 & $3,18 \times 10^{-03}$ \\
\hline Tan & bta04020 & Via de sinalização de cálcio & 11 & $5,58 \times 10^{-04}$ \\
\hline Tan & bta04970 & Secreção salivar & 7 & $2,04 \times 10^{-03}$ \\
\hline Tan & bta04971 & Secreção de ácido gástrico & 5 & $4,98 \times 10^{-02}$ \\
\hline Tan & bta04080 & Interação ligante-receptor neuroativo & 13 & $5,57 \times 10^{-05}$ \\
\hline Tan & bta04540 & Gap junction & 8 & $1,79 \times 10^{-03}$ \\
\hline Tan & bta04740 & Transdução olfativa & 4 & $4,05 \times 10^{-02}$ \\
\hline Tan & bta04728 & Sinapse dopaminérgica & 9 & $3,91 \times 10^{-03}$ \\
\hline Tan & bta05034 & Alcoolismo & 7 & $3,44 \times 10^{-02}$ \\
\hline Tan & bta04713 & Ritmo Circadiano & 6 & $4,05 \times 10^{-02}$ \\
\hline Tan & bta04015 & Via de sinalização Rap1 & 9 & $3,61 \times 10^{-02}$ \\
\hline Tan & bta04270 & Contração do músculo liso vascular & 6 & $4,98 \times 10^{-02}$ \\
\hline Pink & bta04921 & Via de sinalização da ocitocina & 10 & $3,56 \times 10^{-02}$ \\
\hline
\end{tabular}

Tabela 7 - Enriquecimento funcional de vias metabólicas (KEEG-WebGestalt) dos genes centrais nos módulos associados à conversão alimentar no hipotálamo.

\begin{tabular}{lllcc}
\hline Módulo & ID & Nome & Genes & FDR \\
\hline Tan & bta05032 & Vício em morfina & 10 & $8,26 \times 10^{-07}$ \\
Tan & bta04020 & Via de sinalização de cálcio & 10 & $3,16 \times 10^{-05}$ \\
Tan & bta04970 & Secreção salivar & 6 & $7,73 \times 10^{-04}$ \\
Tan & bta04971 & Secreção de ácido gástrico & 4 & $3,00 \times 10^{-02}$ \\
Tan & bta04080 & Interação ligante-receptor neuroativo & 10 & $3,16 \times 10^{-06}$ \\
Tan & bta04540 & Gap junction & 8 & $3,16 \times 10^{-05}$ \\
Tan & bta04740 & Transdução olfativa & 4 & $5,96 \times 10^{-03}$ \\
Tan & bta00230 & Metabolismo das purinas & 7 & $9,57 \times 10^{-03}$ \\
Tan & bta04727 & Sinapse gabaérgica & 5 & $1,51 \times 10^{-02}$ \\
Tan & bta04728 & Sinapse dopaminérgica & 8 & $6,58 \times 10^{-04}$ \\
Tan & bta04713 & Ritmo Circadiano & 6 & $2,80 \times 10^{-03}$ \\
Tan & bta04725 & Sinapse colinérgica & 5 & $3,38 \times 10^{-02}$ \\
Tan & bta04270 & Contração do músculo liso vascular & 5 & $2,24 \times 10^{-02}$ \\
Tan & bta04723 & Sinalização endocanabinóide retrógrada & 5 & $2,25 \times 10^{-02}$ \\
Tan & bta04921 & Via de sinalização da ocitocina & 6 & $2,25 \times 10^{-02}$ \\
Tan & bta04924 & Secreção de renina & 4 & $2,25 \times 10^{-02}$ \\
Tan & bta05034 & Alcoolismo & 7 & $1,40 \times 10^{-03}$ \\
Tan & bta05030 & Vício em cocaína & 5 & $2,00 \times 10^{-03}$ \\
Tan & bta04024 & Via de sinalização de AMPc & 7 & $1,12 \times 10^{-02}$ \\
Tan & bta04726 & Sinapse serotonérgica & 5 & $2,24 \times 10^{-02}$ \\
Tan & bta05031 & Vício em anfetamina & 4 & $2,30 \times 10^{-02}$ \\
Tan & bta05414 & Cardiomiopatia dilatada & 4 & $3,32 \times 10^{-02}$ \\
\hline
\end{tabular}


Figura 23 - Rede de interação de proteínas considerando hub genes no módulo Tan do hipotálamo.

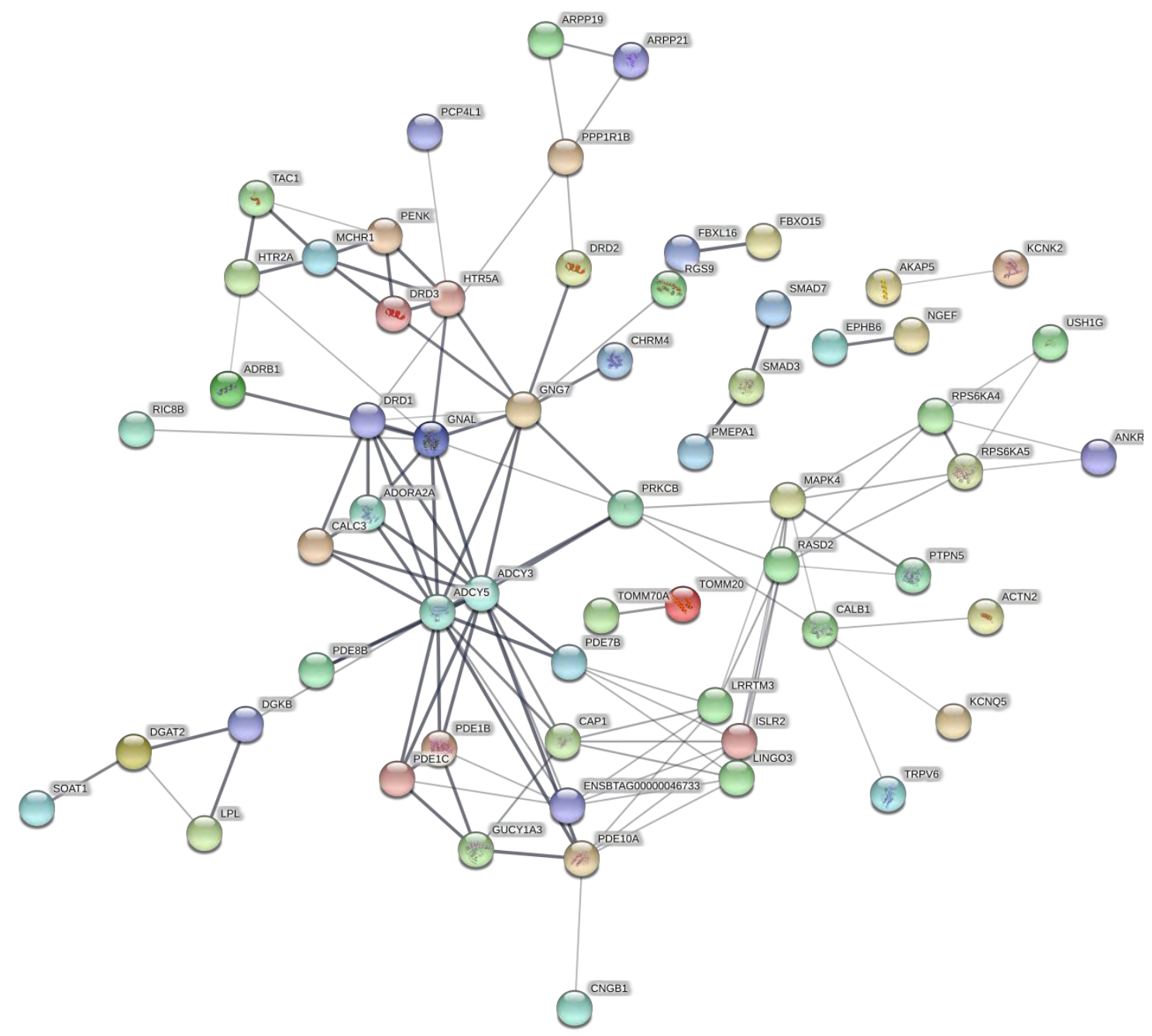

Proteínas que não apresentaram interações não foram representadas na figura. Fonte: própria autoria.

O módulo Pink é semelhante ao módulo Maroon identificado na análise conjunta dos três tecidos quanto aos genes presentes (58\% dos genes em comum) e o resultado do enriquecimento funcional relacionado à via de sinalização de ocitocina (Tabela 6). Os $h u b$ genes desse módulo não apresentaram enriquecimento funcional no WebGestalt e não foi possível gerar uma rede de interação de proteínas no STRING apenas para eles. Por outro lado, considerando todos os genes desse módulo, o número de interações encontradas para a rede foi significativo $\left(\mathrm{P}=1,00 \times 10^{-16}\right)$, apresentando 392 interações quando apenas 238 eram esperadas ao acaso. A análise de enriquecimento baseada nessa rede de proteínas apresentou via de sinalização de ocitocina bastante enriquecida, bem como secreção de ácido gástrico e outros termos relacionados a transdução de sinal (Tabela 8). 
Tabela 8 - Enriquecimento funcional (STRING) dos módulos associados à conversão alimentar no hipotálamo usando todos os genes.

\begin{tabular}{|c|c|c|c|c|}
\hline Módulo & ID & Nome & Genes & FDR \\
\hline Tan & GO:0033555 & Resposta ao estresse de organismo multicelular & 5 & $2,26 \times 10^{-02}$ \\
\hline Tan & GO:0042596 & Resposta de medo & 4 & $2,26 \times 10^{-02}$ \\
\hline Tan & GO:0051705 & Comportamento de multi-organismo & 4 & $2,35 \times 10^{-02}$ \\
\hline Tan & GO:0001975 & Resposta à anfetamina & 3 & $3,13 \times 10^{-02}$ \\
\hline Tan & GO:0007626 & Comportamento locomotor & 6 & $3,13 \times 10^{-02}$ \\
\hline Tan & GO:0033057 & Comportamento reprodutivo de organismo multicelular & 3 & $4,28 \times 10^{-02}$ \\
\hline Tan & GO:0050877 & Processo de sistema neurológico & 10 & $4,28 \times 10^{-02}$ \\
\hline Tan & GO:0050896 & Resposta a estímulo & 36 & $4,28 \times 10^{-02}$ \\
\hline Tan & GO:0065009 & Regulação de função molecular & 20 & $4,46 \times 10^{-02}$ \\
\hline Tan & bta05032 & Vício em morfina & 11 & $5.44 \times 10^{-06}$ \\
\hline Tan & bta 04020 & Via de sinalização de cálcio & 13 & $5.18 \times 10^{-05}$ \\
\hline Tan & bta 04540 & Gap junction & 8 & $1,00 \times 10^{-03}$ \\
\hline Tan & bta 04728 & Sinapse dopaminérgica & 9 & $1,59 \times 10^{-03}$ \\
\hline Tan & bta 04080 & Interação ligante-receptor neuroativo & 13 & $1,60 \times 10^{-03}$ \\
\hline Tan & bta 05030 & Vício em cocaína & 6 & $1,60 \times 10^{-03}$ \\
\hline Tan & bta 04970 & Secreção salivar & 7 & $2,89 \times 10^{-03}$ \\
\hline Tan & bta 04713 & Ritmo circadiano & 7 & $5,30 \times 10^{-03}$ \\
\hline Tan & bta 00230 & Metabolismo de purinas & 8 & $3,58 \times 10^{-02}$ \\
\hline Tan & bta 04015 & Via de sinalização Rap1 & 9 & $3,58 \times 10^{-02}$ \\
\hline Tan & bta 04971 & Secreção de ácido gástrico & 5 & $4,82 \times 10^{-02}$ \\
\hline Tan & PF00001 & 7 transmembrane receptor (rhodopsin family) & 15 & $1,60 \times 10^{-03}$ \\
\hline Tan & PF00233 & 35 -cyclic nucleotide phosphodiesterase & 5 & $8,83 \times 10^{-03}$ \\
\hline Tan & IPR002073 & 35 -cyclic nucleotide phosphodiesterase, catalytic domain & 5 & $1,28 \times 10^{-02}$ \\
\hline Tan & IPR003607 & HD/PDEase domain & 5 & $1,28 \times 10^{-02}$ \\
\hline Tan & IPR023088 & 35 -cyclic nucleotide phosphodiesterase & 5 & $1,28 \times 10^{-02}$ \\
\hline Tan & IPR023174 & 35 -cyclic nucleotide phosphodiesterase, conserved site & 5 & $1,28 \times 10^{-02}$ \\
\hline Tan & IPR000929 & Família de receptores de dopamina & 3 & $1,53 \times 10^{-02}$ \\
\hline Pink & 04921 & Via de sinalização de ocitocina & 14 & $1,11 \times 10^{-02}$ \\
\hline Pink & 04720 & Potenciação de longo termo & 8 & $1,33 \times 10^{-03}$ \\
\hline Pink & 04010 & Via de sinalização de MAPK & 14 & $1,18 \times 10^{-02}$ \\
\hline Pink & 04971 & Secreção de ácido gástrico & 7 & $1,74 \times 10^{-02}$ \\
\hline Pink & 04020 & Via de sinalização de cálcio & 11 & $1,86 \times 10^{-02}$ \\
\hline Pink & IPR001849 & Pleckstrin homology domain & 18 & $2,72 \times 10^{-03}$ \\
\hline Pink & IPR011993 & $\begin{array}{l}\text { Pleckstrin-homology domain (PH domain)/ } \\
\text { Phosphotyrosine-binding domain }(P T B)\end{array}$ & 21 & $3,60 \times 10^{-03}$ \\
\hline
\end{tabular}

Para a análise de co-expressão na pituitária foram utilizados 12,166 genes que passaram pelo controle de qualidade. Foram identificados inicialmente 78 módulos de genes co-expressos que em seguida foram combinados baseado em correlação superior a 0,9 entre os eigengenes, resultando em 70 módulos de genes co-expressos (Figura 24). 
Figura 24 - Clusterização dos módulos da pituitária baseada em module eigengene (ME - primeira componente principal).

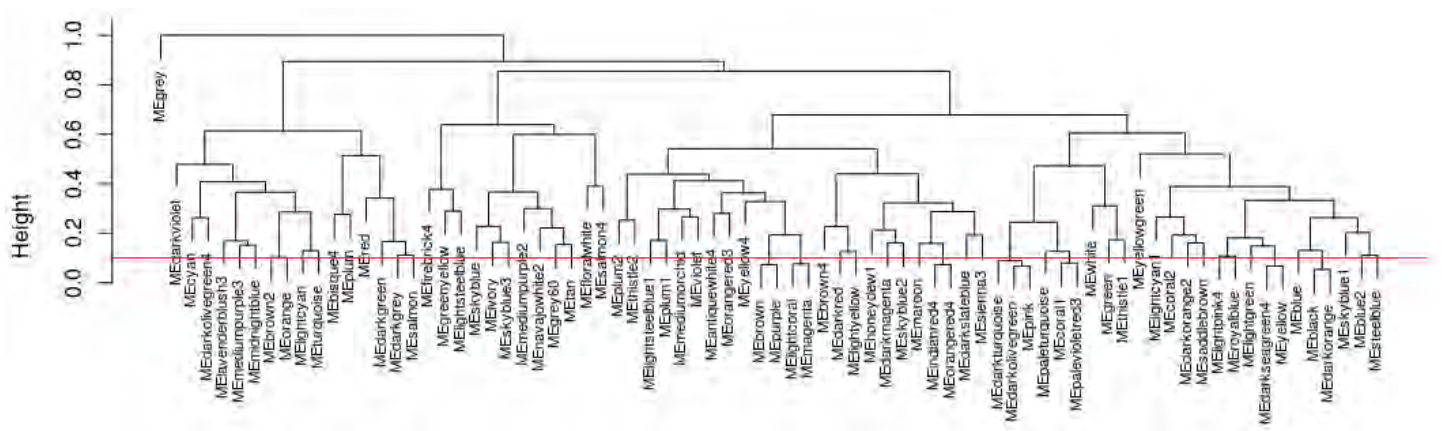

A linha contínua horizontal indica correlação de 0,9. Fonte: própria autoria.

Dos 70 módulos, três apresentaram correlação positiva com o CAR, estando associados à baixa EA ( $r>0,4$ e $\mathrm{P}<0,1$, Figura 25). O módulo Darkturquoise apresentou 659 genes e a proporção da variância de seus genes explicada pelo eigengene foi de $53 \%$ (Tabela Suplementar 10). Já o módulo Lightsteelblue1 apresentou 93 genes e a proporção da variância de seus genes explicada pelo eigengene foi de 54\% (Tabela Suplementar 11). Por fim, o módulo Plum1 apresentou 103 genes e a proporção da variância de seus genes explicada pelo eigengene foi de 58\% (Tabela Suplementar 12). 
Figura 25 - Correlações entre módulo eigengene (ME) e medidas de conversão alimentar (CA) e consumo alimentar residual (CAR) - pituitária.

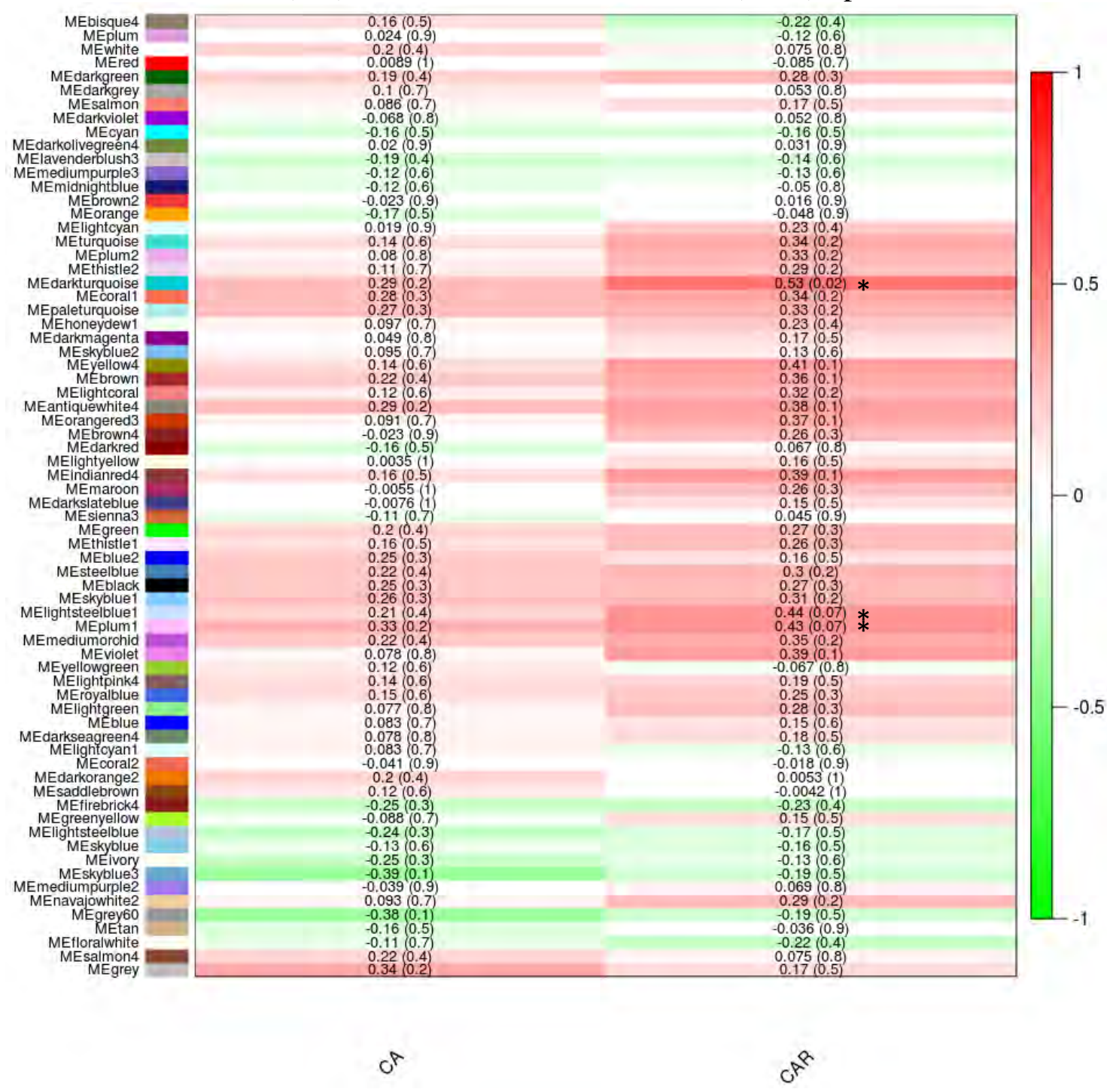

$* \mathrm{P}<0,1$. Fonte: própria autoria.

Nenhum dos módulos associados com o CAR apresentaram enriquecimento significativo usando o WebGestalt. Porém, os módulos Darkturquoise e Lightsteelblue1 apresentaram termos significativamente enriquecidos usando o STRING que parecem estar associados à transcrição de genes e processamento de proteínas (Tabela 9). Além disso, o número de interações foi significativo para os três módulos: o módulo Darkturquoise apresentou 1235 interações quando apenas 801 eram esperadas ao acaso $\left(\mathrm{P}=1,00 \times 10^{-16}\right)$, o módulo Lightsteelblue1 apresentou 123 interações sendo que 39 eram esperadas ao acaso $\left(\mathrm{P}=1,00 \times 10^{-16}\right)$, e o módulo Plum1 apresentou 101 interações quando 21 eram esperadas $\left(7,52 \times 10^{-10}\right)$. A Figura 26 demostra as relações encontradas 
pelo STRING entre as proteínas codificadas pelos hub genes do módulo Darkturquoise e elas sozinhas não apresentaram enriquecimento funcinal.

Tabela 9 - Enriquecimento funcional (STRING) dos módulos associados ao consumo e ganho residual na pituitária usando todos os genes*.

\begin{tabular}{|c|c|c|c|c|}
\hline Módulo & ID & Nome & Genes & FDR \\
\hline Darkturquoise & GO:0008104 & localização de proteínas & 45 & $9,81 \times 10^{-08}$ \\
\hline Darkturquoise & GO:0019941 & $\begin{array}{l}\text { processo catabólico de proteína dependente de } \\
\text { modificação }\end{array}$ & 16 & $5,21 \times 10^{-04}$ \\
\hline Darkturquoise & GO:0042493 & resposta ao medicamento & 8 & $1,02 \times 10^{-02}$ \\
\hline Darkturquoise & GO:0010256 & organização do sistema endomembrana & 13 & $2,59 \times 10^{-03}$ \\
\hline Darkturquoise & GO:0043412 & modificação de macromoléculas & 43 & $3,86 \times 10^{-04}$ \\
\hline Darkturquoise & GO:0030497 & alongamento de ácidos graxos & 3 & $3,88 \times 10^{-02}$ \\
\hline Darkturquoise & GO:0016070 & processo metabólico de RNA & 46 & $4,36 \times 10^{-03}$ \\
\hline Darkturquoise & GO:0006796 & processo metabólico de composto contendo fosfato & 31 & $1,72 \times 10^{-02}$ \\
\hline Darkturquoise & GO:1901360 & processo metabólico de composto cíclico orgânico & 70 & $2,04 \times 10^{-04}$ \\
\hline Darkturquoise & GO:0050821 & estabilização de proteínas & 6 & $4,05 \times 10^{-02}$ \\
\hline Darkturquoise & GO:0006725 & processo metabólico de composto aromático celular & 68 & $1,27 \times 10^{-04}$ \\
\hline Darkturquoise & GO:0046483 & processo metabólico heterocíclico & 68 & $1,05 \times 10^{-04}$ \\
\hline Darkturquoise & GO:0016192 & transporte mediado por vesículas & 22 & $1,61 \times 10^{-02}$ \\
\hline Darkturquoise & GO:0006997 & organização do núcleo & 5 & $1,61 \times 10^{-02}$ \\
\hline Darkturquoise & GO:0044087 & regulação da biogênese do componente celular & 14 & $2,86 \times 10^{-02}$ \\
\hline Darkturquoise & GO:0071702 & transporte de substâncias orgânicas & 42 & $2,01 \times 10^{-05}$ \\
\hline Darkturquoise & GO:0006464 & processo de modificação de proteína celular & 36 & $1,08 \times 10^{-02}$ \\
\hline Darkturquoise & GO:0090304 & processo metabólico de ácido nucleico & 59 & $4,40 \times 10^{-05}$ \\
\hline Darkturquoise & bta03022 & Fatores basais de transcrição & 9 & $2,12 \times 10^{-03}$ \\
\hline Darkturquoise & bta03420 & Reparo de excisão de nucleotídeos & 8 & $1,00 \times 10^{-02}$ \\
\hline Lightsteelblue 1 & GO:0005488 & ligação & 28 & $2,40 \times 10^{-02}$ \\
\hline Lightsteelblue 1 & GO:0097159 & ligação ao composto cíclico orgânico & 19 & $4,24 \times 10^{-02}$ \\
\hline Lightsteelblue1 & GO:1901363 & ligação do composto heterocíclico & 19 & $4,24 \times 10^{-02}$ \\
\hline Lightsteelblue 1 & GO:0005730 & nucléolo & 10 & $3,64 \times 10^{-04}$ \\
\hline Lightsteelblue 1 & GO:0044428 & parte nuclear & 15 & $5,13 \times 10^{-03}$ \\
\hline Lightsteelblue1 & GO:0044452 & parte nucleolar & 3 & $1,08 \times 10^{-02}$ \\
\hline
\end{tabular}

\footnotetext{
*Apenas os termos mais relevantes enriquecidos no módulo Darkturquoise estão presentes nessa tabela, a
} lista completa pode ser encontrada na Tabela Suplementar 13. 
Figura 26 - Rede de interação de proteínas considerando hub genes no módulo Darkturquoise da pituitária.

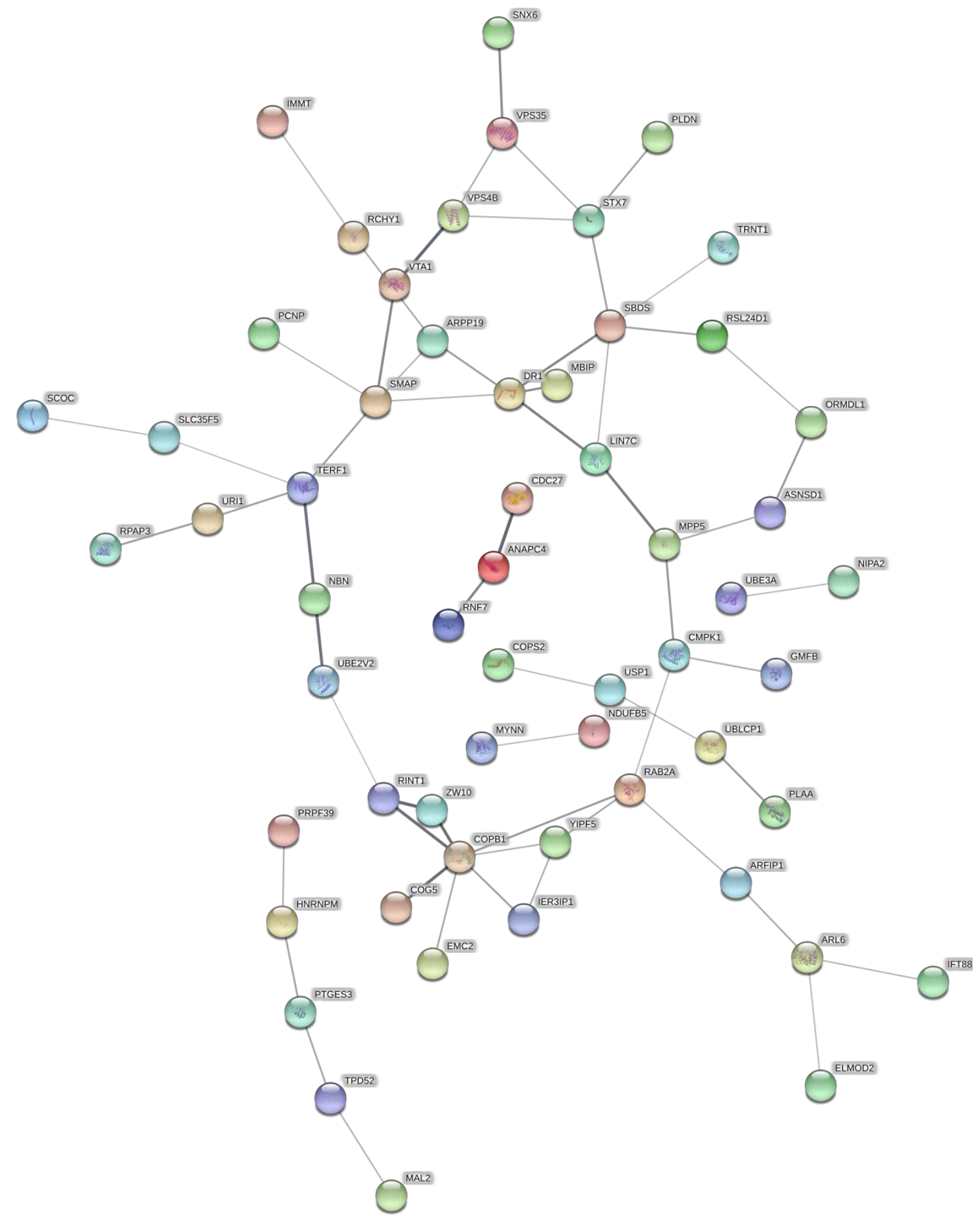

Proteínas que não apresentaram interações não foram representadas na figura. Fonte: própria autoria. 
Para a análise de co-expressão na adrenal foram utilizados 12,540 genes que passaram pelo controle de qualidade. Foram identificados inicialmente 38 módulos de genes co-expressos que em seguida foram combinados baseado em correlação superior a 0,9 entre os eigengenes, resultando em 32 módulos de genes co-expressos (Figura 27).

Figura 27 - Clusterização dos módulos da adrenal baseada em module eigengene (ME primeira componente principal).

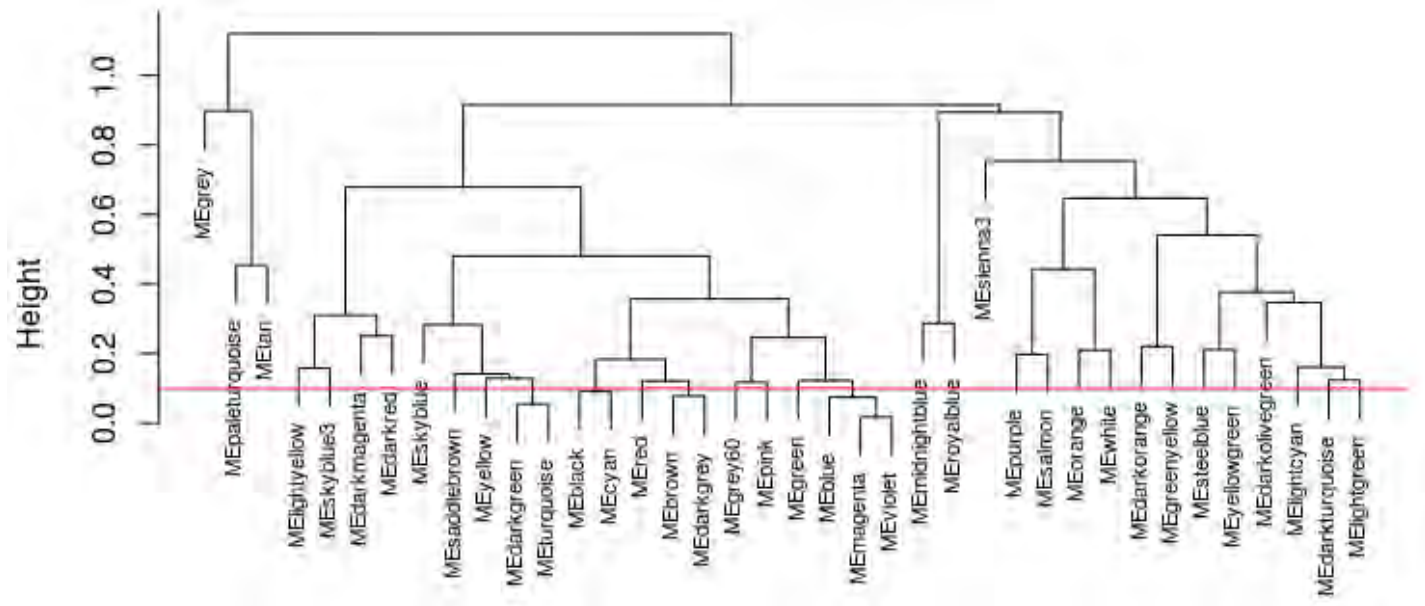

A linha contínua horizontal indica correlação de 0,9 . Fonte: própria autoria.

Dos 32 módulos, um apresentou correlação positiva com a CA, estando associados à baixa EA (r>0,4 e P<0,1, Figura 28). O módulo Grey apresentou 33 genes e a proporção da variância de seus genes explicada pelo eigengene foi de $22 \%$. Espera-se que o eigengene explique uma parte importante da variação dos genes, para que posso ser utilizado como um valor que representa o módulo na análise de correlação com as características fenotípicas. O valor encontrado, de apenas $22 \%$, indica que o valor de eigengene não representa bem o módulo (Tabela Suplementar 14). Além disso, não foram encontrados termos enriquecidos tanto no WebGestalt quando no STRING e também não houve número de interações significativas entre proteínas codificadas por esses genes. 
Figura 28 - Correlações entre módulo eigengene (ME) e medidas de conversão alimentar (CA) e consumo alimentar residual (CAR) - adrenal.

\begin{tabular}{|c|c|c|c|}
\hline MEpurple & $0.0046(1)$ & $-0.044(0.9)$ & \multirow{10}{*}{-0.5} \\
\hline MEsalmon & $-0.097(0.7)$ & $0.081(0.8)$ & \\
\hline MEorange & $-0.0022(1)$ & $0.094(0.7)$ & \\
\hline MEwhite & $-0.16(0.6)$ & $-0.026(0.9)$ & \\
\hline MEpaleturquoise & $-0.27(0.3)$ & $-0.094(0.7)$ & \\
\hline MEtan & $.0 .044(0.9)$ & $-0.13(0.6)$ & \\
\hline MEmidnightblue & $0.084(0.8)$ & $0.23(0.4)$ & \\
\hline MEroyalblue & $-0.078(0.8)$ & $-0.054(0.8)$ & \\
\hline MElightyellow & $0.035(0.9)$ & $0.11(0.7)$ & \\
\hline MEskyblue3 & $-0.17(0.5)$ & $0.094(0.7)$ & \\
\hline MEdarkmagenta & $-0.13(0.7)$ & $0.23(0.4)$ & \\
\hline MEdarkred & $0.095(0.7)$ & $0.047(0.9)$ & \\
\hline MEskyblue & $0.24(0.4)$ & $0.13(0.6)$ & \\
\hline MEsienna3 & $0.1(0.7)$ & $0.3(0.3)$ & \\
\hline MEsteelblue & $-0.019(0.9)$ & $0.24(0.4)$ & \\
\hline MEyellowgreen & $0.09(0.7)$ & $0.19(0.5)$ & -0 \\
\hline MEdarkolivegreen & $0.12(0.7)$ & $0.28(0.3)$ & -0 \\
\hline MElightcyan & $0.11(0.7)$ & $0.27(0.3)$ & 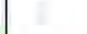 \\
\hline MEdarkturquoise & $0.081(0.8)$ & $0.24(0.4)$ & \\
\hline MElightgreen & $0.17(0.6)$ & $0.36(0.2)$ & \\
\hline MEbrown & $0.15(0.6)$ & $0.3(0.3)$ & \\
\hline MEyellow & $0.18(0.5)$ & D. $33(0.2)$ & \\
\hline MEdarkgreen & $0.21(0.5)$ & $0.33(0.2)$ & \\
\hline MEsaddlebrown & $0.24(0.4)$ & $0.39(0.2)$ & 0.5 \\
\hline MEblue & $0.12(0.7)$ & $0.36(0.2)$ & \\
\hline MEgreen & $0.096(0.7)$ & $0.28(0.3)$ & \\
\hline MEgrey60 & $0.14(0.6)$ & $0.36(0.2)$ & \\
\hline MEpink & $0.16(0.6)$ & $0.43(0.1)$ & \\
\hline MEdarkorange & -0.0038 & $-0.056(0.8)$ & \\
\hline MEblack & $0.18(0.5)$ & $0.2(0.5)$ & \\
\hline MEgreenyellow & $0.11(0.7)$ & $0.15(0.6)$ & \\
\hline MEgrey & Q.66 10.008$) *$ & $0.3(0.3)$ & \\
\hline
\end{tabular}

$* \mathrm{P}<0,1$. Fonte: própria autoria. 


\subsection{Abordagem 3 - Identificação de RNAs longos não codificadores em múltiplos tecidos de bovinos Nelore e sua associação com a eficiência alimentar}

\subsubsection{IDENTIFICAÇÃO DOS lncRNAs EM 5 TECIDOS DE BOVINOS NELORE}

Utilizando dados de expressão gênica de 86 amostras divididas entre hipotálamo, pituitária, fígado, músculo esquelético e glândula adrenal de bovinos Nelore, foi possível identificar 174.793 transcritos novos (Tabela 10) classificados como i (transcritos de introns), j (nova isoforma), o (sobreposição genérica com éxon de gene conhecido), u (transcrito intergênico) e x (sobreposição com gene conhecido na fita oposta). Destes, $174.431(99,8 \%)$ apresentaram comprimento maior que $200 \mathrm{pb}$, critério utilizado para distinguir ncRNA pequenos de longos. O filtro que mais excluiu transcritos foi de ORFs maior que 300nt, mantendo apenas $8,7 \%$ (15,266) dos transcritos identificados inicialmente. Em seguida, 5,931 transcritos foram excluídos por apresentarem alta similaridade com proteínas conhecidas da base de dados no UniProt (e-valor > 10-6) e 12 foram excluídos por apresentarem potencial de codificação segundo análise do CPC2 (KANG et al., 2017). Por fim, 9,323 novos transcritos passaram por todos os filtros e foram considerados potenciais lncRNA.

Tabela 10 - Número de transcritos considerados potenciais lncRNA após aplicação de cada critério de exclusão.

\begin{tabular}{lrrrrrr}
\hline \multirow{2}{*}{ Novos transcritos } & \multicolumn{5}{c}{ Classes } & \\
\cline { 2 - 5 } & $\mathrm{i}$ & $\mathrm{j}$ & $\mathrm{o}$ & $\mathrm{u}$ & $\mathrm{x}$ & Total \\
\hline Total identificado & 30 & 146390 & 4563 & 19179 & 4631 & 174793 \\
$>$ 200nt & 30 & 146390 & 4535 & 18863 & 4613 & 174431 \\
Sem ORF > 300nt & 11 & 3517 & 1098 & 9039 & 1601 & 15266 \\
Sem similaridade com proteína & 10 & 242 & 764 & 7418 & 901 & 9335 \\
Sem potencial de codificação $\left(\mathrm{CPC}^{\S}\right)$ & 10 & 238 & 764 & 7411 & 900 & $* 9323$ \\
\hline
\end{tabular}

$\mathrm{i}$ - transcritos de introns; $\mathrm{j}$ - nova isoforma; o - sobreposição genérica com éxon de gene conhecido; u transcrito intergênico; $x$ - sobreposição com gene conhecido na fita oposta. ${ }^{\S} \mathrm{KANG}$ et al. (2017). *Número de lncRNA identificados.

Dentre os 9,323 transcritos identificados como lncRNAs, a classe mais representada foi a u (Figura 29A), de transcritos intergênicos, também chamados de lincRNA (long intergenic non coding RNA). Porém, quando comparamos os lncRNA 
identificados com a anotação do genoma bovino contendo não apenas genes conhecidos, mas também genes preditos por algoritmos de busca de novos genes (Gnomon, NCBI), verificamos que parte desses lincRNAs possivelmente são novas isoformas de genes preditos (classe j) ou são transcritos de introns desses genes preditos (classe i). Alguns poucos deles (3\%), se sobrepõe perfeitamente com esses genes preditos (Figura 29B). Surgem, também em pequena proporção, lncRNAs nas classes c (contido em gene conhecido), e (sobreposição com um único éxon conhecido) e p (possível transcrição nãoespecífica da polimerase). Ainda assim, a classe mais representada ainda é de lincRNA.

Figura 29 - Distribuição dos lncRNA identificados de acordo com sua classificação.
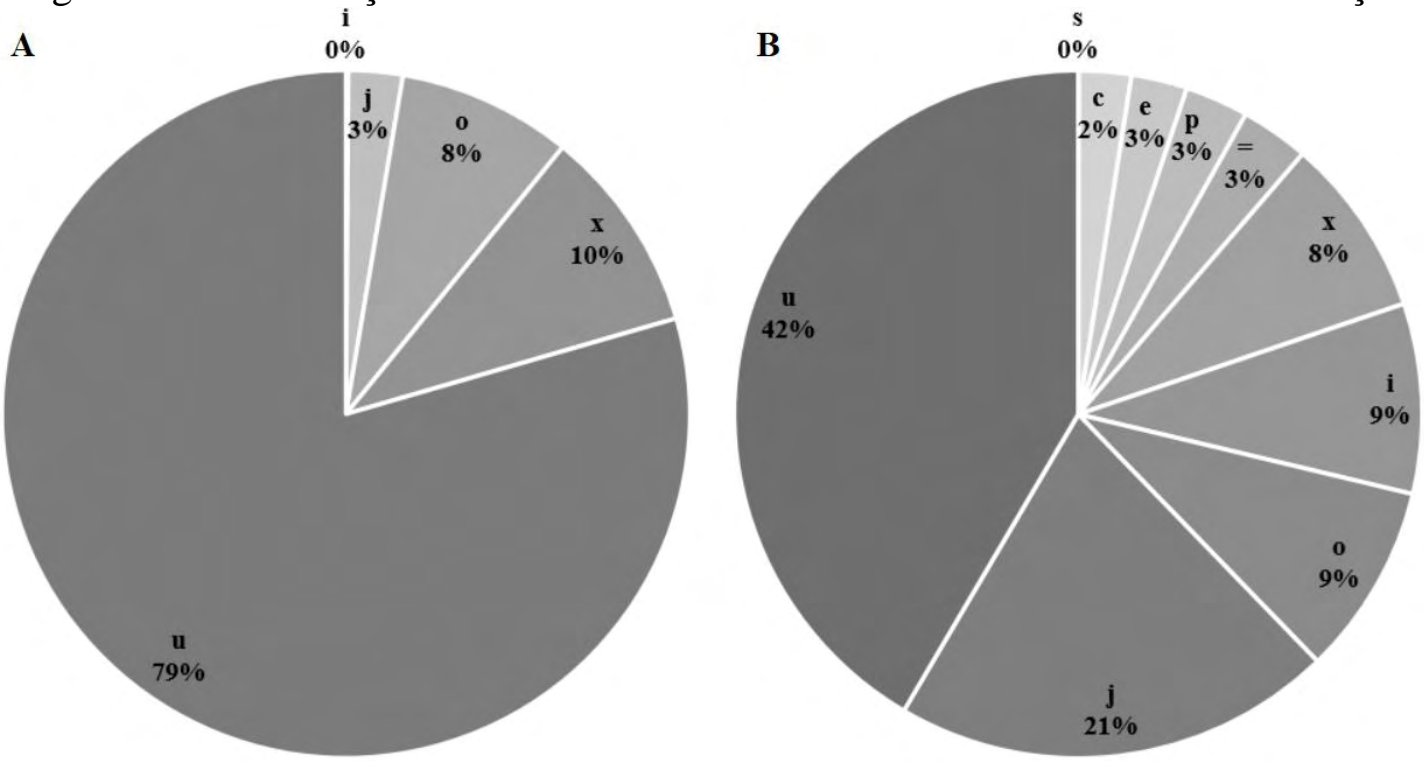

A) apenas a anotação de genes conhecidos e B) a anotação incluindo os genes predicted pelo Gnomon (NCBI). As classes são divididas em: = - sobreposição com gene conhecido; c - contido em gene conhecido; e - possível fragmento de pré-mRNA; i - transcritos de introns; j - nova isoforma; o - sobreposição genérica com éxon de gene conhecido; $\mathrm{p}$ - possível transcrição não-específica da polimerase; s - contém intron que se sobrepõe a intron conhecido na fita oposta; $\mathrm{u}$ - transcrito intergênico; $\mathrm{x}$ - sobreposição com gene conhecido na fita oposta. Fonte: própria autoria.

Apesar de não constarem na anotação de referência, diversos trabalhos já foram realizados no sentido de identificar lncRNA expressos em bovinos e outras espécies. Esses resultados compõem bases de dados como NONCODE (FANG et al., 2018) a qual foi utilizada para verificar se os lncRNAs encontrados já haviam sido descritos anteriormente. Dos 9,323 lncRNA identificados, 5,471 (59\%) apresentaram alta similaridade com a base de lncRNAs bovinos NONCODEv5 (e-valor $<10^{-6}$ e identidade $>70 \%$ ), sugerindo que boa parte destes já foram descritos anteriormente. Do total de lncRNA identificados, 1864 foram expressos na adrenal, 1539 no fígado, 1708 na 
pituitária, 2039 no hipotálamo e 1238 no músculo, sendo que 647 foram expressos em comum entre todos os tecidos (Figura 30). Hipotálamo, pituitária e adrenal apresentaram 253 lncRNA expressos em comum. Esses três tecidos e mais o fígado expressaram 122 lncRNA em comum. O hipotálamo expressou 99 lncRNA em comum com a pituitária e 96 em comum com a adrenal.

Figura 30 - Gráfico de Venn do número de lncRNA expressos por tecido. Os valores entre parênteses indicam o número total de lncRNAs expressos no tecido.

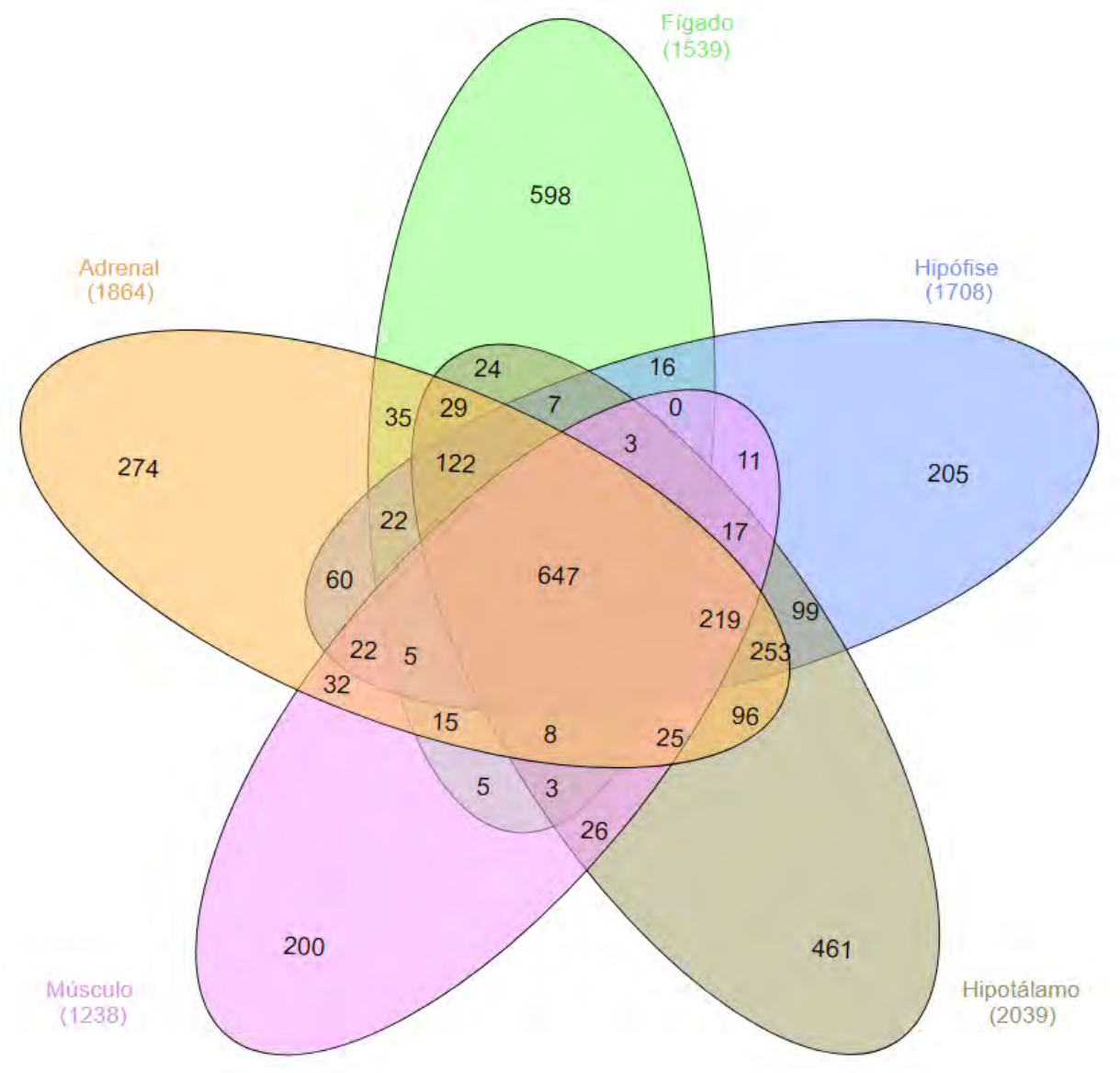

\subsubsection{IncRNA EXPRESSOS DIFERENCIALMENTE ENTRE ALTA E BAIXA EFICIÊNCIA ALIMENTAR}

Os IncRNAs foram avaliados quanto a expressão diferencial em cada tecido, resultando em quatro genes $\mathrm{DE}(\mathrm{Paj}<0,05)$ na adrenal, 21 na pituitária e cinco no músculo (Tabela 11), sendo 20 mais e 10 menos expressos na baixa EA.

Tabela 11 - lncRNA diferencialmente expressos. 


\begin{tabular}{|c|c|c|c|c|c|c|c|}
\hline Tecido & lncRNA & Posição & $\begin{array}{c}\text { Baixa } \\
\text { EA }^{\S}\end{array}$ & $\begin{array}{l}\text { Alta } \\
\text { EA }^{\S}\end{array}$ & $\log 2 \mathrm{FC}^{\S}$ & $\mathrm{P}$ valor & $\begin{array}{r}P \\
\text { ajustado }\end{array}$ \\
\hline Adrenal & TCONS_00005426A & $25: 2518657-2521345$ & 79,7 & 15,2 & $-2,39$ & $5,00 \mathrm{E}-05$ & 0,02 \\
\hline Adrenal & TCONS_00005461A & $25: 36179278-36180697$ & 462 & 857 & 0,89 & $1,00 \mathrm{E}-04$ & 0,03 \\
\hline Adrenal & TCONS_00007036A & $4: 89572822-89573775$ & 157 & 55,4 & $-1,49$ & $5,00 \mathrm{E}-05$ & 0,02 \\
\hline Adrenal & TCONS_00009039A & $X: 23067191-23073768$ & 303 & 180 & $-0,75$ & $1,00 \mathrm{E}-04$ & 0,03 \\
\hline Pituitária & TCONS_00000153P & 1:50558852-50726984 & 650 & 403 & $-0,69$ & $1,00 \mathrm{E}-04$ & 0,01 \\
\hline Pituitária & TCONS_00000165P & $1: 72498271-72728960$ & 1545 & 1045 & $-0,56$ & $1,50 \mathrm{E}-04$ & 0,02 \\
\hline Pituitária & TCONS_00001372P & $12: 25706358-25718182$ & 536 & 319 & $-0,75$ & $5,00 \mathrm{E}-05$ & 0,01 \\
\hline Pituitária & TCONS_00001721P & $13: 67079680-67101375$ & 2130 & 3077 & 0,53 & $5,00 \mathrm{E}-05$ & 0,01 \\
\hline Pituitária & TCONS_00002645P & 16:74930448-74931072 & 158 & 352 & 1,15 & $2,50 \mathrm{E}-04$ & 0,02 \\
\hline Pituitária & TCONS_00003199P & $18: 57324664-57338450$ & 85 & 180 & 1,07 & $5,50 \mathrm{E}-04$ & 0,04 \\
\hline Pituitária & TCONS_00003308P & $18: 53305196-53326536$ & 912 & 510 & $-0,84$ & $4,00 \mathrm{E}-04$ & 0,03 \\
\hline Pituitária & TCONS_00003974P & $2: 103134290-103137287$ & 37,4 & 75,1 & 1,00 & $2,00 \mathrm{E}-04$ & 0,02 \\
\hline Pituitária & TCONS_00004559P & 21:31993883-32000181 & 427 & 176 & $-1,27$ & $4,50 \mathrm{E}-04$ & 0,04 \\
\hline Pituitária & TCONS_00004740P & $22: 41835960-41924456$ & 170 & 55,6 & $-1,61$ & $2,00 \mathrm{E}-04$ & 0,02 \\
\hline Pituitária & TCONS_00004881P & 23:10487141-10491544 & 917 & 654 & $-0,49$ & $2,50 \mathrm{E}-04$ & 0,02 \\
\hline Pituitária & TCONS_00004904P & $23: 28393338-28502836$ & 16016 & 27638 & 0,79 & $2,00 \mathrm{E}-04$ & 0,02 \\
\hline Pituitária & TCONS_00006013P & $28: 41713843-41716586$ & 50,1 & 18,0 & $-1,47$ & $5,00 \mathrm{E}-05$ & 0,01 \\
\hline Pituitária & TCONS_00006530P & $3: 98068517-98105824$ & 102 & 41,6 & $-1,28$ & $5,00 \mathrm{E}-05$ & 0,01 \\
\hline Pituitária & TCONS_00006811P & $4: 94943448-95107230$ & 4903 & 3492 & $-0,49$ & $1,00 \mathrm{E}-04$ & 0,01 \\
\hline Pituitária & TCONS_00006825P & 4:114211685-114212314 & 1538 & 2700 & 0,81 & $1,00 \mathrm{E}-04$ & 0,01 \\
\hline Pituitária & TCONS_00007280P & $5: 44538854-44539600$ & 1529 & 3643 & 1,25 & $5,00 \mathrm{E}-05$ & 0,01 \\
\hline Pituitária & TCONS_00007646P & $6: 115711791-115718205$ & 265 & 445 & 0,75 & $5,00 \mathrm{E}-05$ & 0,01 \\
\hline Pituitária & TCONS_00008651P & 8:99783956-99784496 & 1095 & 592 & $-0,89$ & $5,00 \mathrm{E}-05$ & 0,01 \\
\hline Pituitária & TCONS_00008676P & $9: 26431892-26441900$ & 94,6 & 53,9 & $-0,81$ & $5,00 \mathrm{E}-05$ & 0,01 \\
\hline Pituitária & TCONS_00008933P & $9: 63504758-63507205$ & 108 & 41,0 & $-1,39$ & $5,00 \mathrm{E}-05$ & 0,01 \\
\hline Músculo & TCONS_00002325M & $15: 15522993-15530997$ & 1200 & 653 & $-0,88$ & $5,00 \mathrm{E}-05$ & 0,01 \\
\hline Músculo & TCONS_00004418M & 21:21943817-21953430 & 475 & 235 & $-1,01$ & $5,00 \mathrm{E}-05$ & 0,01 \\
\hline Músculo & TCONS_00006888M & $4: 65830992-66120337$ & 105 & 241 & 1,20 & $5,00 \mathrm{E}-05$ & 0,01 \\
\hline Músculo & TCONS_00008822M & $9: 90250163-90260395$ & 632 & 397 & $-0,67$ & $1,00 \mathrm{E}-04$ & 0,02 \\
\hline Músculo & TCONS_00009033M & $\mathrm{X}: 18289959-18526431$ & 220 & 118 & $-0,89$ & $1,50 \mathrm{E}-04$ & 0,03 \\
\hline
\end{tabular}

${ }^{\S} \mathrm{FPKM}, \mathrm{FC}-$ fold change

Com relação à classe dos lncRNA observamos que nenhum se sobrepôs perfeitamente a um gene predito, porém seis foram considerados isoformas de genes conhecidos ou preditos sem potencial de codificação (Tabela 12). Outros 10 apresentaram sobreposição com éxon de gene conhecido ou predito, mas não foram consideradas novas isoformas. O TCONS_00005461A se sobrepôs com intron de um gene predito como codificador de proteína (LOC787926) e cinco lncRNA foram localizados em regiões intergênicas. Por fim, oito lncRNA apresentaram sobreposição com gene conhecido na fita oposta. 
Tabela 12 - Descrição dos lncRNA diferencialmente expressos e mRNAs com expressão gênica correlacionada à deles.

\begin{tabular}{|c|c|c|c|c|c|c|c|}
\hline Tecido & lncRNA & Gene Associado & Classe & $\begin{array}{l}\mathrm{N}^{\circ} \\
\text { éxons }\end{array}$ & $\begin{array}{c}\text { Tamanho } \\
(\mathrm{pb})\end{array}$ & GC & GC $100 \mathrm{~kb}$ \\
\hline Adrenal & TCONS_00005426A & LOC100141258 & $\mathrm{j}$ & 6 & 1177 & 177 & \\
\hline Adrenal & TCONS_00005461A & LOC787926 & $\mathrm{i}$ & 1 & 1420 & 49 & \\
\hline Adrenal & TCONS_00007036A & - & $\mathrm{u}$ & 1 & 954 & 26 & \\
\hline Adrenal & TCONS_00009039A & MCF2 & $\mathrm{x}$ & 2 & 6287 & 41 & \\
\hline Pituitária & TCONS_00000153P & CBLB & o & 3 & 2324 & 469 & $\operatorname{ALCAM}(0,83)$ \\
\hline Pituitária & TCONS_00000165P & BDH1 & o & 2 & 1837 & 8 & \\
\hline Pituitária & TCONS_00001372P & DCLK1 & $\mathrm{x}$ & 2 & 3436 & 50 & \\
\hline Pituitária & TCONS_00001721P & LOC104973873 & $\mathrm{j}$ & 5 & 684 & 36 & \\
\hline Pituitária & TCONS_00002645P & - & $\mathrm{u}$ & 2 & 597 & 13 & \\
\hline Pituitária & TCONS_00003199P & LOC101906828 & $\mathrm{j}$ & 4 & 1123 & 9 & \\
\hline Pituitária & TCONS_00003308P & EXOC3L2 & o & 2 & 811 & 86 & \\
\hline Pituitária & TCONS_00003974P & VWC2L & $\mathrm{x}$ & 1 & 2998 & 11 & \\
\hline Pituitária & TCONS_00004559P & ETFA & $\mathrm{j}$ & 2 & 388 & 6 & \\
\hline Pituitária & TCONS_00004740P & FHIT & $\mathrm{o}$ & 2 & 668 & 8 & \\
\hline Pituitária & TCONS_00004881P & SRSF3 & o & 2 & 4227 & 235 & SRSF3 $(0,72)$ \\
\hline Pituitária & TCONS_00004904P & LOC104975666 & o & 2 & 208 & 142 & BOLA $(0,90)$ \\
\hline Pituitária & TCONS_00006013P & LDB3 & $\mathrm{x}$ & 2 & 2382 & 12 & \\
\hline Pituitária & TCONS_00006530P & BEND5 & $\mathrm{x}$ & 3 & 1680 & 10 & \\
\hline Pituitária & TCONS_00006811P & MEST & o & 3 & 605 & 24 & \\
\hline Pituitária & TCONS_00006825P & TMEM176A & o & 2 & 276 & 106 & TMEM176A $(0,87)$ \\
\hline Pituitária & TCONS_00007280P & LOC617219 & $\mathrm{x}$ & 1 & 747 & 16 & $\begin{array}{l}\text { ENSBTAG00000042526 } \\
(0,96)\end{array}$ \\
\hline Pituitária & TCONS_00007646P & BST1 & $\mathrm{j}$ & 2 & 1664 & 32 & \\
\hline Pituitária & TCONS_00008651P & - & $\mathrm{u}$ & 1 & 541 & 63 & \\
\hline Pituitária & TCONS_00008676P & - & $\mathrm{u}$ & 2 & 9976 & 9 & \\
\hline Pituitária & TCONS_00008933P & - & $\mathrm{u}$ & 1 & 2448 & 11 & \\
\hline Músculo & TCONS_00002325M & SESN3 & $\mathrm{x}$ & 2 & 7646 & 401 & SESN3 $(0,86)$ \\
\hline Músculo & TCONS_00004418M & LOC101908359 & $\mathrm{j}$ & 3 & 823 & 15 & \\
\hline Músculo & TCONS_00006888M & FAM188B & o & 2 & 1263 & 13 & \\
\hline Músculo & TCONS_00008822M & ESR1 & $\mathrm{x}$ & 2 & 3740 & 86 & \\
\hline Músculo & TCONS_00009033M & LOC100847519 & $\mathrm{o}$ & 2 & 1867 & 44 & \\
\hline
\end{tabular}

Classe: $\mathrm{i}$ - transcritos de introns; $\mathrm{j}$ - nova isoforma; o - sobreposição genérica com éxon de gene conhecido; $\mathrm{u}$ - transcrito intergênico; $\mathrm{x}$ - sobreposição com gene conhecido na fita oposta. GC - mRNAs com expressão gênica com correlação de Spearman acima de |0.7| com os lncRNA. GC 100kb - GC localizados em 100kb ao redor da posição genômica do lncRNA.

Dos 30 lncRNA DE, 20 apresentaram alta homologia com ncRNA presentes na base de dados NONCODE (E valor $<10^{-6}$, identidade $>100 \mathrm{pb}$ ), identificados principalmente em bovinos (16) mas também em suíno (2), gorila (1) e humano (1) (Tabela 13).

Além disso, nove dos lncRNA estão localizados em regiões de QTL para características relacionadas à EA e descritas no AnimalQTLdb (HU et al., 2013). O TCONS_00002325M foi o único em QTL associado à conversão alimentar (QTL:5290). Cinco lncRNA estão em regiões de QTL para espessura de gordura na $12^{\text {a }}$ costela, característica que se mostrou significativamente diferente entre os animais deste experimento (ALEXANDRE et al., 2015): TCONS_00005426A (QTL:11217), TCONS_00005461A (QTL:11217), TCONS_00004740P (QTL:11152), 
TCONS_00004904P (QTL:11172), TCONS_00004418M (QTL:20293, QTL:11118, QTL:20455). Ademais, dois lncRNAs estão em QTLs para gordura intramuscular, o TCONS_00000165P (QTL:4819) e o TCONS_00007280P (QTL:22866). Interessante notar que o TCONS_00004904P, que está em região de QTL para espessura de gordura, também está em uma região de seis QTLs para nível de imunoglobulina G (QTL:66220, QTL:66222, QTL:66217, QTL:66218, QTL:66221, QTL:66216). Também estão em regiões de QTL para nível de imunoglobulina G os lncRNAs TCONS_00004881P (QTL:66220, QTL:66222) e TCONS_00002325M (QTL:66191).

Tabela 13 - Blast dos lncRNA diferencialmente expressos na base de dados NONCODE (FANG et al., 2018).

\begin{tabular}{|c|c|c|c|c|c|c|}
\hline Tecido & $\operatorname{lncRNA}$ & E valor & Identidade & $\%$ Identidade & $\begin{array}{l}\text { NONCODE } \\
\text { Transcript ID }\end{array}$ & Assembly \\
\hline Adrenal & TCONS_00005426A & 0 & $747 / 748$ & 99 & NONBTAT015414.2 & bosTau6 \\
\hline Adrenal & TCONS_00005461A & $5 E-36$ & $127 / 143$ & 88 & NONBTAT030364.1 & bosTau6 \\
\hline Adrenal & TCONS_00007036A & $1 \mathrm{E}-171$ & $306 / 306$ & 100 & NONBTAT030616.1 & bosTau6 \\
\hline Adrenal & TCONS_00009039A & 0 & $594 / 594$ & 100 & NONBTAT026313.2 & bosTau6 \\
\hline Pituitária & TCONS_00000153P & $1 \mathrm{E}-164$ & $514 / 587$ & 87 & NONHSAT194263.1 & hg38 \\
\hline Pituitária & TCONS_00000165P & 0 & $1107 / 1114$ & 99 & NONBTAT000737.2 & bosTau6 \\
\hline Pituitária & TCONS_00001372P & 0 & $390 / 415$ & 93 & NONBTAT004351.2 & bosTau6 \\
\hline Pituitária & TCONS_00001721P & $2 \mathrm{E}-64$ & $126 / 126$ & 100 & NONBTAT028086.1 & bosTau6 \\
\hline Pituitária & TCONS_00002645P & $1 \mathrm{E}-107$ & $212 / 219$ & 96 & NONBTAT028582.1 & bosTau6 \\
\hline Pituitária & TCONS_00003199P & - & - & - & - & - \\
\hline Pituitária & TCONS_00003308P & - & - & - & - & - \\
\hline Pituitária & TCONS_00003974P & 0 & $472 / 480$ & 98 & NONBTAT011640.2 & bosTau6 \\
\hline Pituitária & TCONS_00004559P & $4 \mathrm{E}-40$ & $150 / 168$ & 168 & NONSUST023457.1 & susScr3 \\
\hline Pituitária & TCONS_00004740P & - & - & - & - & - \\
\hline Pituitária & TCONS_00004881P & 0 & $521 / 569$ & 91 & NONSUST023300.1 & susScr3 \\
\hline Pituitária & TCONS_00004904P & $3 \mathrm{E}-51$ & $164 / 183$ & 89 & NONBTAT029582.1 & bosTau6 \\
\hline Pituitária & TCONS_00006013P & 0 & $403 / 415$ & 97 & NONBTAT017241.2 & bosTau6 \\
\hline Pituitária & TCONS_00006530P & - & - & - & - & - \\
\hline Pituitária & TCONS_00006811P & - & - & - & - & - \\
\hline Pituitária & TCONS_00006825P & - & - & - & - & - \\
\hline Pituitária & TCONS_00007280P & - & - & - & - & - \\
\hline Pituitária & TCONS_00007646P & $2,00 \mathrm{E}-72$ & $187 / 202$ & 92 & NONBTAT029500.1 & bosTau6 \\
\hline Pituitária & TCONS_00008651P & & & & - & - \\
\hline Pituitária & TCONS_00008676P & $1,00 \mathrm{E}-135$ & $271 / 283$ & 95 & NONBTAT025200.2 & bosTau6 \\
\hline Pituitária & TCONS_00008933P & 0 & $271 / 283$ & 98 & NONBTAT031630.1 & bosTau6 \\
\hline Músculo & TCONS_00002325M & 0 & $1319 / 1336$ & 98 & NONBTAT006734.2 & bosTau6 \\
\hline Músculo & TCONS_00004418M & - & - & - & - & - \\
\hline Músculo & TCONS_00006888M & - & - & - & - & - \\
\hline Músculo & TCONS_00008822M & 0 & $1375 / 1375$ & 100 & NONBTAT025892.2 & bosTau6 \\
\hline Músculo & TCONS_00009033M & $2,00 \mathrm{E}-60$ & $252 / 294$ & 85 & NONGGOT020718.1 & gorGor3 \\
\hline
\end{tabular}

$\mathrm{Cr}$ - cromossomo 


\subsubsection{FUNÇÃO DOS lncRNA DIFERENCIALMENTE EXPRESSOS COMO "ESPONJAS" DE miRNA}

A busca por regiões homólogas de miRNA nos lncRNA não retornou resultado significativo, não podendo ser determinada nenhuma função dos lncRNA quanto a precursores de miRNA. Porém, foi possível encontrar para todos os lncRNA DE neste trabalho, exceto o TCONS_00004559P, sítios de ligação de miRNA (Tabela suplementar 15), indicando o potencial dessas moléculas como "esponjas", atraindo os miRNAs para si de forma que eles deixam de se ligar aos seus mRNAs alvos. Como pode ser visto na Figura 31, o TCONS_00008676P foi o que apresentou maior número de sítios de ligação diferentes (30), seguido do TCONS_00002325M (24). A análise de enriquecimento dos miRNA com sítio de ligação nos lncRNAs DE por tecido não retornou resultados significativos considerando a correção para múltiplos testes, porém, os termos mais enriquecidos para pituitária, adrenal e músculo respectivamente foram: regulação positiva do processo catabólico de proteínas dependente de ubiquitina $\left(\mathrm{P}=3,1 \times 10^{-5}\right)$, transporte intra golgi mediado por vesículas $(\mathrm{P}=0,01)$ e complexo de homoenzima telomerase $(\mathrm{P}=$ $\left.4,8 \times 10^{-4}\right)$. 
Figura 31 - Relação entre miRNAs e lncRNA diferencialmente expressos (DE) entre alta e baixa eficiência alimentar

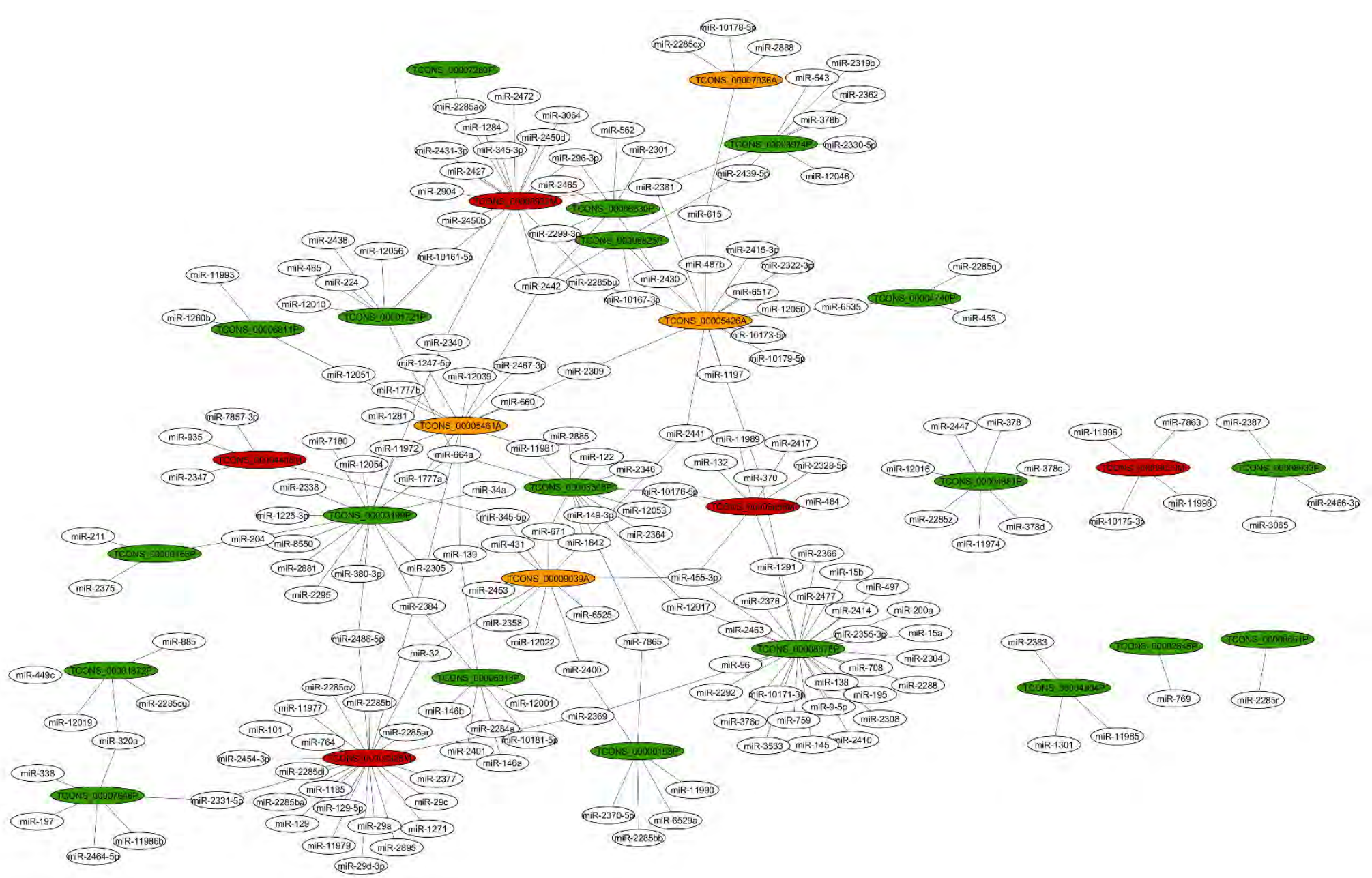

Vértices representam sítio de ligação preditos pelo programa miRanda. Nódulos laranja, verde e vermelho representam lncRNA DE na adrenal, pituitária e músculo, respectivamente. Fonte: própria autoria. 


\subsubsection{FUNÇÃO DOS IncRNA DIFERENCIALMENTE EXPRESSOS COMO REGULADORES DE mRNA}

Com relação a possível função regulatória dos lncRNAs em cis, que diz respeito a genes fisicamente próximos no cromossomo (100kb), foram encontrados alguns mRNAs com expressão altamente correlacionada com a dos lncRNAs (Tabela 12). Dentre eles, o TCONS_00006825P apresentou não só alta correlação $(\rho=0,87)$ de expressão gênica com seu gene associado, o TMEM176A, mas também complementariedade significativa (E-valor $<10^{-6} \mathrm{e}$ identidade $>80 \%$, Figura 32). $\mathrm{O}$ mesmo ocorreu entre o TCONS_00004881P e seu gene associado SRSF3 ( $\rho=0,72$, Evalor $<10^{-6}$ e identidade $>80 \%$ ). O TCONS_00002325M e seu gene associado SESN3 também apresentaram alta correlação de expressão $(\rho=0,86)$, mas não apresentaram complementariedade significativa. Por outro lado, o SESN3 se mostrou diferencialmente expresso entre os grupos na abordagem 1 (Figura 33). Ademais, o TCONS_00000153P apresentou alta correlação de expressão gênica com o gene próximo $\operatorname{ALCAM}(\rho=0,83)$, que também foi diferencialmente expresso entre os grupos na abordagem 1. Também houve alta correlação de expressão gênica com o gene próximo entre TCONS_00007280P e ENSBTAG00000042526 $(\rho=0,96)$, e TCONS_00004904P e BOLA $(\rho=0,90)$, sendo que este último par também apresentou complementariedade significativa (E-valor $<10^{-6} \mathrm{e}$ identidade $>80 \%$, Figura 32 ).

Já com relação a possível função regulatória dos lncRNAs em trans, duas abordagens foram utilizadas: busca por mRNA com alta correlação de expressão gênica com os IncRNA e busca por mRNAs com sequências complementares aos lncRNA. A tabela 12 mostra o número de genes co-expressos com os lncRNAs de cada tecido, sendo que para três deles o conjunto de genes co-expressos apresentou número significativo de conexões entre proteínas e enriquecimento funcional no STRING (Tabela suplementar 16). Os 469 genes co-expressos com o TCONS_00000153P (Figura 34A) apresentaram 508 conexões quando apenas 361 era esperadas ao acaso $\left(\mathrm{P}=1,55 \times 10^{-13}\right)$ e enriquecimento funcional principalmente para termos relacionados à transporte de RNA $\left(\mathrm{P}=7,76 \times 10^{-5}\right)$, spliceossomo $(\mathrm{P}=0,01)$ e ligação de ribonucleosídeos de purina $(\mathrm{P}=0,02)$. Já os 235 genes co-expressos com o TCONS_00004881P (Figura 34C) apresentaram 349 conexões quando 153 eram esperadas ao acaso e enriquecimento funcional para termos como ligação à nucleotídeo $\left(\mathrm{P}=1,11 \times 10^{-6}\right)$, ligação de ribonucleosídeos de purina 
$\left(\mathrm{P}=1,73 \times 10^{-6}\right)$, ligação à RNA $\left(\mathrm{P}=8,76 \times 10^{-5}\right)$, ligação de cauda poliA $\left(\mathrm{P}=2,61 \times 10^{-}\right.$ $\left.{ }^{5}\right)$, atividade de fator de tradução $\left(\mathrm{P}=1,63 \times 10^{-3}\right)$, processo metabólico de proteína celular $(\mathrm{P}=0,01)$, transporte de mRNA $(\mathrm{P}=0,04)$, e exportação de proteínas $(\mathrm{P}=0,04)$. Por fim, os 401 genes co-expressos com o TCONS_00002325M (Figura 34B) apresentaram 860 conexões quando 533 eram esperadas ao acaso e enriquecimento funcional para processo de oxirredução $\left(\mathrm{P}=3,04 \times 10^{-8}\right)$, respiração aeróbica $\left(\mathrm{P}=2,3 \times 10^{-7}\right)$, carregamento de elétrons $(\mathrm{P}=0,04)$, cadeia respiratória $\left(\mathrm{P}=5,83 \times 10^{-10}\right)$, complexo proteico da membrana mitocondrial interna $\left(\mathrm{P}=2,18 \times 10^{-7}\right)$, fosforilação oxidativa $\left(\mathrm{P}=3,88 \times 10^{-11}\right)$ e ciclo do ácido cítrico $\left(1,21 \times 10^{-8}\right)$. Interessante notar que quando repetimos o enriquecimento somente com os genes co-expressos negativamente com o TCONS_00002325M, os mesmos termos enriquecem, porém com valores mais significativos: processo de oxirredução $\left(\mathrm{P}=4,17 \times 10^{-18}\right)$, respiração aeróbica $\left(\mathrm{P}=1,49 \times 10^{-12}\right)$, carregamento de elétrons $\left(\mathrm{P}=9,14 \times 10^{-5}\right)$, cadeia respiratória $\left(\mathrm{P}=3,64 \times 10^{-18}\right)$, complexo proteico da membrana mitocondrial interna $\left(\mathrm{P}=2,77 \times 10^{-13}\right)$, fosforilação oxidativa $\left(\mathrm{P}=1,6 \times 10^{-20}\right)$ e ciclo do ácido cítrico $\left(4,47 \times 10^{-14}\right)$.

Quanto aos mRNAs com sequências complementares aos lncRNA DE, 18 lncRNA foram associados à 211 mRNAs (E-valor $<10^{-6}$ e identidade $>80 \%$ ) sendo alguns deles DE entre os grupos na abordagem 1 ou associados ou reportados na literatura como contendo SNPs associados ao fenótipo. A análise de enriquecimento funcional por tecido não retornou resultado significativo e quando analisados em conjunto, houve enriquecimento para componente integral de membrana $\left(\mathrm{P}=1,45 \times 10^{-3}\right)$. 
Figura 32 - Relação de complementariedade entre lncRNA diferencialmente expressos (DE) entre alta e baixa eficiência alimentar (EA) e mRNAs.

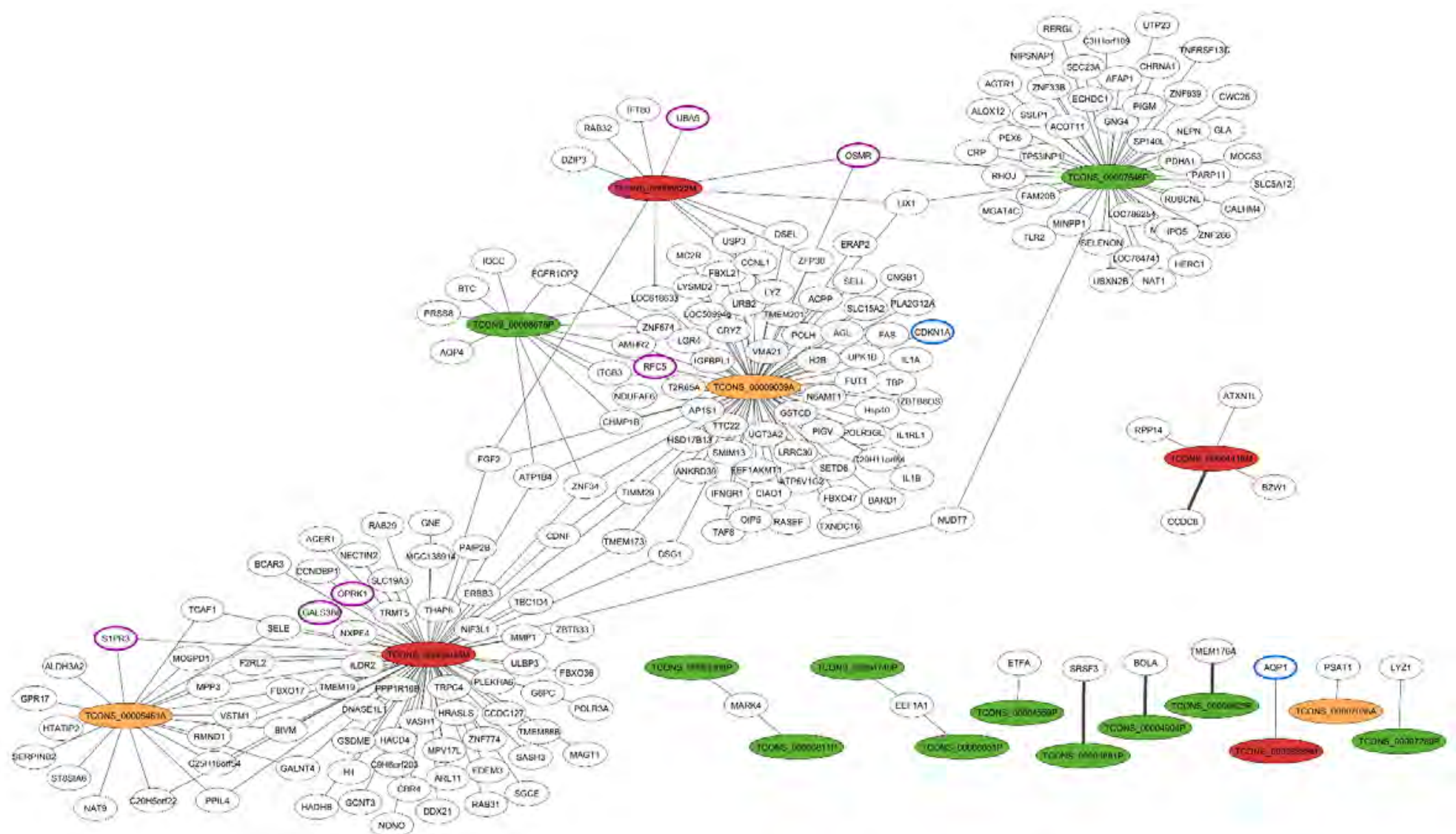

Vértices representam complementariedade entre lncRNA e mRNAs (Blastn, E-valor $<10^{-6}$ e Identidade $>80 \%$ ) e os de maior espessura indicam correlação de Spearman $>|0,7|$ entre os valores de expressão gênica. Nódulos laranja, verde e vermelho representam lncRNA DE na adrenal, pituitária e músculo, respectivamente. Nódulos com contorno azul representam genes DE na abordagem 1 e nódulos com contorno roxo representam genes reportados pela literatura como contendo SNP associado à EA. Fonte: própria autoria. 
Figura 33 - Relação entre lncRNA diferencialmente expressos (DE) entre alta e baixa eficiência alimentar (EA) e mRNA DE entre alta e baixa EA na abordagem 1, por tecido.
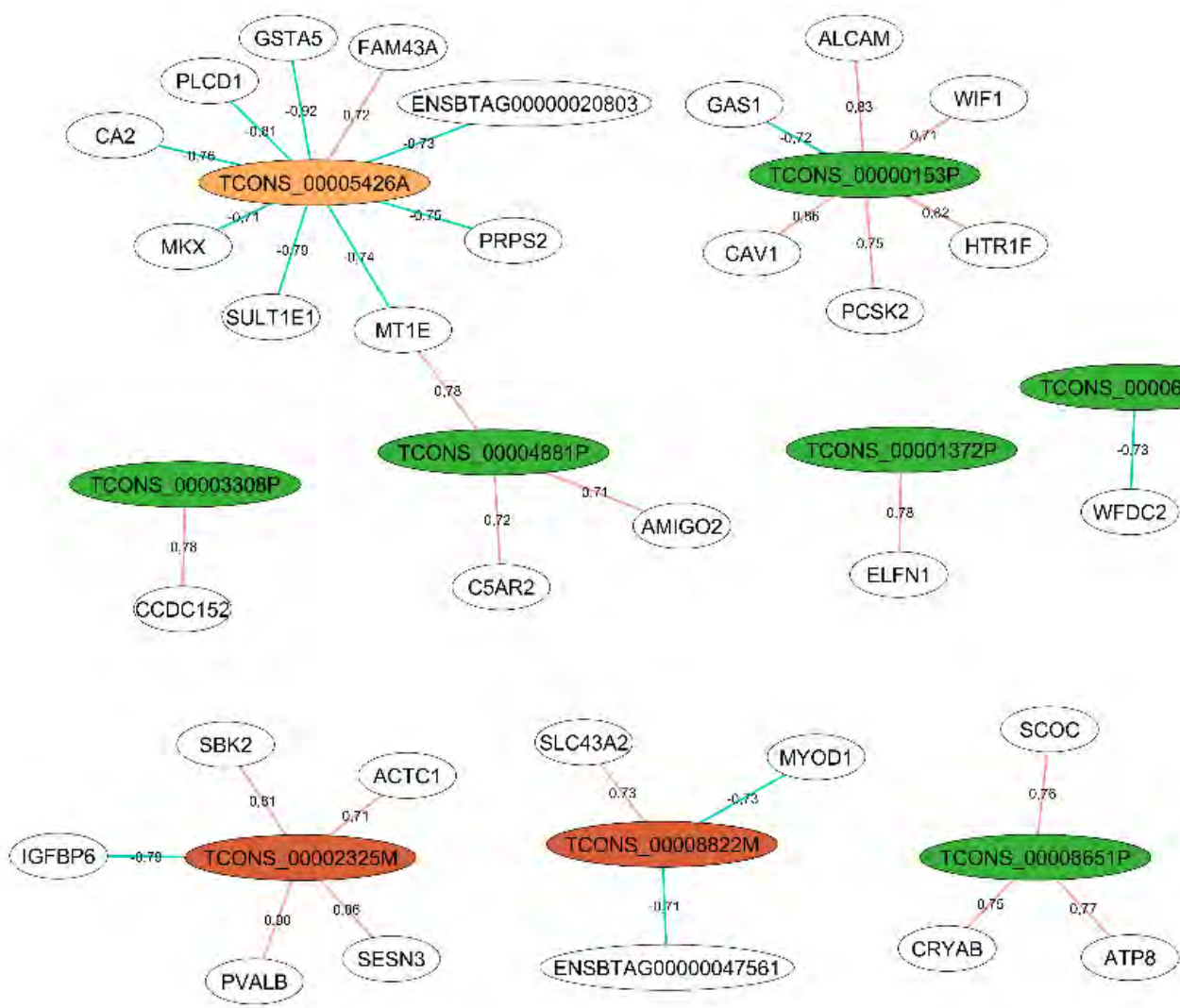

Vértices representam alta correlação de Spearman: > 0,7 (rosa) e < -0,7 (azul). Nódulos laranja, verde e vermelho representam lncRNA DE na adrenal, pituitária e músculo, respectivamente. Fonte: própria autoria. 
Figura 34 - Previsão de estrutura secundária plana dos lncRNAs TCONS_00000153P (A), TCONS_00002325M (B), TCONS_00004881P(C) e TCONS_00005426 (D).

A

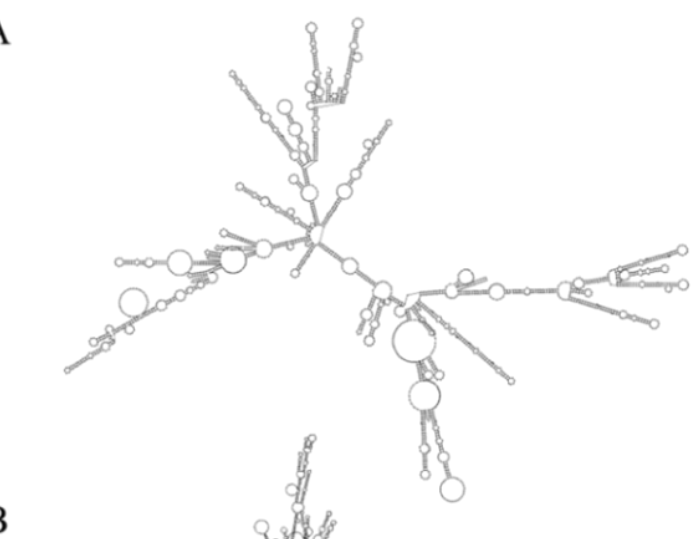

B

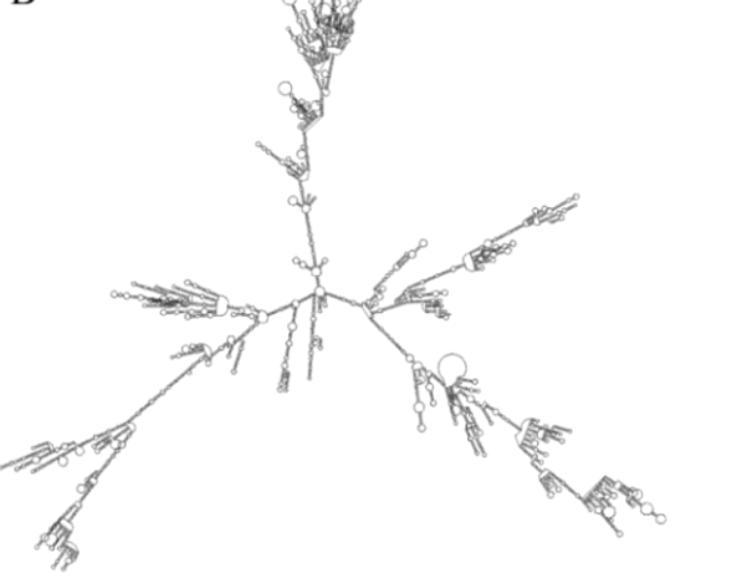

$\mathrm{C}$

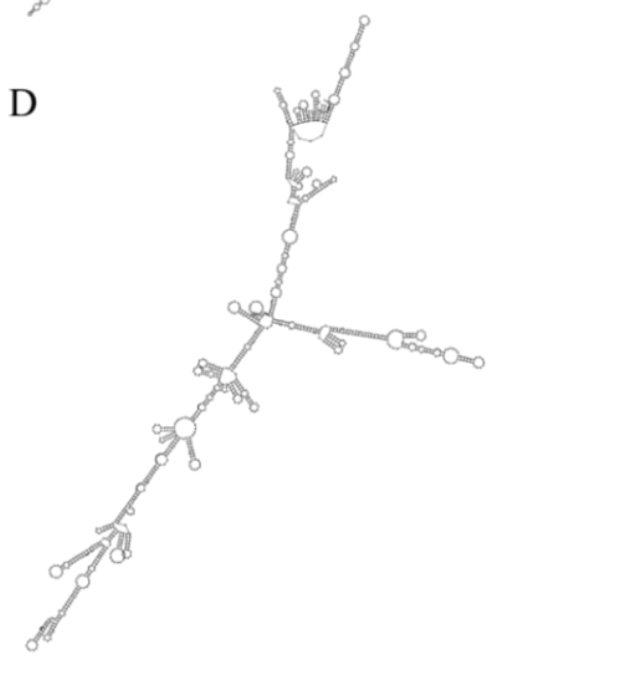




\section{DISCUSSÃO}

\subsection{Abordagem 1 - Expressão gênica multitecidual associada à eficiência alimentar}

A eficiência alimentar é uma característica complexa, regulada por vários processos biológicos. Assim, a indicação de regiões genômicas associadas a esse fenótipo, bem como genes reguladores e biomarcadores para selecionar animais superiores e direcionar decisões de manejo ainda é um grande desafio. Neste trabalho, dados transcriptômicos de múltiplos tecidos de bovinos Nelore de alta e baixa eficiência alimentar foram analisados através de metodologias robustas de redes de co-expressão, a fim de descobrir processos biológicos que governam essas características e apresentar genes candidatos para serem foco de futuras pesquisas. Nesse sentido, a validação de genes alvo dos principais fatores de transcrição (reguladores chave) através da busca por sítios de ligação comprovou a eficácia da metodologia de construção de redes e priorizou alguns fatores de transcrição como reguladores centrais (AERTS et al., 2010; NAVALSAŃCHEZ et al., 2013; POTIER et al., 2014). Além disso, a adição de uma categoria de genes codificadores de proteínas secretadas no plasma na análise de co-expressão destaca genes com potencial para serem explorados como biomarcadores da eficiência alimentar. Fomos capazes de identificar genes relacionados aos principais processos biológicos associado à eficiência alimentar e indicar reguladores chaves, como será discutido a seguir.

Em primeiro lugar, é importante mencionar que os 98 animais utilizados para selecionar os grupos de alta e baixa EA neste estudo foram anteriormente analisados quanto a diversas medidas fenotípicas e moleculares (ALEXANDRE et al., 2015; FONSECA et al., 2018; MOTA et al., 2017; NOVAIS et al., 2018). Observou-se que os grupos de alta e baixa EA apresentaram ganho de peso corporal, rendimento de carcaça e área de olho de lombo semelhantes, porém, animais com baixa EA apresentaram maior ingestão de alimento, maior deposição de gordura, maiores níveis de colesterol sérico e resposta inflamatória hepática, indicada pela análise transcricional de biópsia hepática e comprovada pela análise histopatológica e de GGT sérico (biomarcador de lesão hepática). No presente estudo, a análise simultânea de cinco tecidos distintos revelou uma proeminência do tecido hepático na eficiência alimentar: o fígado apresentou os genes mais conectados na rede, o maior número de genes diferencialmente conectados e maior 
número de genes codificadores de proteínas secretadas no plasma, o que, embora possam ser explicados por sua função biológica, são enriquecidos principalmente para termos relacionados à homeostase lipídica e resposta inflamatória. Além disso, os cinco principais reguladores da rede são co-expressos principalmente com genes mais expressos no fígado e também enriquecidos para resposta inflamatória.

A relação entre EA e genes ou vias relacionadas à resposta imune/inflamação e metabolismo lipídico está se tornando cada vez mais evidente, já que estudos recentes também relataram esses processos em bovinos de corte (KARISA; MOORE; PLASTOW, 2014; MUKIIBI et al., 2018; PARADIS et al., 2015; WEBER et al., 2016; ZAREK et al., 2017) e suínos (RAMAYO-CALDAS et al., 2018; VINCENT et al., 2015). Em nosso trabalho anterior (ALEXANDRE et al., 2015), foi proposto que o aumento de lesões hepáticas associadas a maior resposta inflamatória no fígado de animais de baixa EA poderia ser devido ao aumento da lipogênese e/ou infecção bacteriana mais elevada no fígado. Os resultados deste trabalho corroboraram com a segunda possibilidade já que houve o enriquecimento de termos como indução da aglutinação bacteriana e resposta a lipopolissacarídeo, como também a maior detecção de endotoxina sérica em animais de baixa EA. De fato, suínos com baixa EA foram relatados como tendo maior inflamação intestinal, biomarcadores de infiltração neutrofílica e endotoxina sérica aumentada que poderiam estar relacionados ao aumento da infecção bacteriana ou à diminuição da capacidade de neutralizar endotoxinas (MANI et al., 2013). Os autores sugerem que diferenças na população bacteriana poderiam explicar parcialmente o aumento de endotoxinas na circulação, o que também pode ser verdadeiro para bovinos, dado que diferenças na população bacteriana intestinal e ruminal entre animais de alta e baixa EA já foram relatados (MYER et al., 2015, 2016). Além disso, a literatura relata que lipopolissacarídeos (LPS) podem causar maior expressão do hormônio adrenomedulina (ADM) (SHINDO et al., 1998), um gene que foi significativamente mais expresso nos animais de baixa EA deste trabalho. Também foi demonstrado em ratos que a infusão intravenosa de LPS causou a maior expressão de ADM no intestino (íleo), fígado, pulmão, aorta, músculo esquelético e sangue (SHOJI et al., 1995) ao passo que em nosso estudo, a ADM apresentou expressão diferencial em músculo, mas não no fígado.

Contra a invasão de patógenos, uma resposta imune adaptativa rigidamente regulada deve ser desencadeada a fim de permitir que os linfócitos $\mathrm{T}$ produzam citocinas ou quimiocinas e que as células B se diferenciem e produzam anticorpos (HERMANNKLEITER; BAIER, 2014). Sabe-se que esta regulação é fortemente influenciada pelo 
nível de expressão e atividade transcricional de vários receptores nucleares, incluindo a família NR2F, que consiste em três receptores órfãos: NR2F1, NR2F2 e NR2F6 (HERMANN-KLEITER; BAIER, 2014). Esses receptores apresentam domínio de ligação ao ligante altamente conservados entre si e entre espécies (PEREIRA; TSAI; TSAI, 2000), e os três são expressos em células do sistema imune adaptativo (HERMANN-KLEITER; BAIER, 2014). Em nosso estudo, o NR2F6 apareceu como o segundo gene regulador mais ligado na rede enquanto os outros membros da família, embora presente em nossos dados de expressão, não foram selecionados por qualquer dos critérios de inclusão, indicando, assim, que eles podem não ser tão relevante em nossas condições. De fato, o NR2F6 parece ser um regulador crítico no sistema imune adaptativo, reprimindo diretamente a transcrição de FT de genes produtores de citocinas em células T efetoras (HERMANN-KLEITER et al., 2008; KLEPSCH; HERMANNKLEITER; BAIER, 2016). O papel do NR2F6 como regulador chave da resposta inflamatória em nossa rede foi validado a nível de gene pela identificação de domínios de ligação HNF4-NR2F2 (transfac_pro-M01031) como um dos mais enriquecido em genes alvo do NR2F6, devido à alta semelhança entre os sítios de ligação do NR2F2 e NR2F6. Além disso, utilizando dados de regiões abertas de cromatina disponíveis publicamente, fornecemos evidências experimentais da ligação de FT com sítios de ligação altamente similares aos do NR2F6 em células de hepatócitos humanos e bovinos, assim, indicando que os sítios de ligação preditos são funcionais neste tecido.

Outro regulador indicado por nossa análise é o TGFB1, o sexto gene mais conectado na rede de co-expressão e um potencial condutor de alterações da transcrição entre animais de alta e baixa EA no músculo. Este gene já foi previamente apontado como um regulador central da EA em bovinos de corte, através de análise de rede de interação de genes (baseada em PCIT), selecionados através de estudo de associação ampla (GWAS) entre dados genômicos e características ligadas à EA, incluído dados de metabolômica (WIDMANN et al., 2015). No presente trabalho, a busca por sítios de ligação mostrou que os genes co-expressos com o TGFB1 são principalmente enriquecidos para sítios de ligação de genes reguladores da diferenciação muscular como MEF2 e MYOD. De fato, dados disponíveis publicamente mostram que muitos dos genes alvo do TGFB1 foram associados ao MYOD (MULLEN et al., 2011). Sabe-se que as vias de sinalização são um mecanismo efetivo para que as células respondam a estímulos ambientais por meio da expressão de genes reguladores. A via de sinalização do TGFB1 desencadeia a fosforilação dos fatores de transcrição SMAD2/3 que ligam-se a 
reguladores nucleares, desencadeando mudanças transcricionais específicas desse tipo celular (MULLEN et al., 2011; SCHMIERER; HILL, 2007). Nas células do músculo esquelético, mioblastos e miotubos, o SMAD3 liga-se ao MYOD1 (MULLEN et al., 2011). A sobreposição entre os genes alvo do MYOD1 e do SMAD3 demonstra a associação significativa entre ambos os genes no músculo esquelético, o que está de acordo com a resposta tecido específica da sinalização do TGFB1 (MULLEN et al., 2011). A porcentagem de sobreposição entre os sítios de ligação previstos e os dados de ChIPseq para MYOD1 (18 e 24,5\%) está de acordo com a análise realizada em camundongos em que apenas $20 \%$ dos sítios de ligação preditos em miotubos foram de fato sobrepostos por dados de ChIPseq para MYOD (BLUM et al., 2012). Assim, sugerese que outros FT e/ou modificação de histonas têm um papel fundamental na ligação do MYOD1. Nesse estudo, sítios de ligação em comum entre SMAD3 e MYOD1 para genes alvo conhecidos por seu envolvimento na diferenciação do músculo esquelético foram capturados, tais como as regiões promotoras de ACTA1 e ANKRD1. Também demonstramos que sítios de ligação de MYOD1 são enriquecidas em regiões reguladoras do desenvolvimento muscular em humanos, ratos e bovinos.

De forma geral, mostramos que genes co-expressos com TGFB1 são enriquecidos para sítios de ligação SMAD3/MYOD1, os quais validamos no nível de sítios de ligação, provando não apenas a ligação entre MYOD1 e SMAD3, mas também sua acessibilidade em humanos, camundongos e vacas. Esses resultados corroboram achados em suínos, nos quais acredita-se que o aumento da EA esteja associado à estimulação do crescimento do músculo através de via de sinalização de TGF- $\beta$ (JING et al., 2015). Finalmente, embora não diretamente co-expresso com o TGFB1, a ocitocina (OXT) foi DE no músculo e mais expresso na alta EA. Mesmo com a falta de conhecimento sobre o seu papel neste tecido, trabalhos anteriores em bovinos mostraram um aumento maciço da expressão de OXT no músculo de bovinos cronicamente expostos a esteroides anabolizantes (JAGER et al., 2011). Ainda não se sabe se a ocitocina sozinha tem atividade anabólica, mas em um contexto em que o crescimento muscular parece estar associado a animais com alta EA, este é um hormônio que merece uma investigação mais aprofundada futuramente.

Dos 13 genes reguladores que são DE entre os grupos, seis estão envolvidos na cadeia respiratória e são mais expressos no grupo com alta EA. Os genes ND1, ND4, ND4L, ND5, ND6 e o ND2, que é DE mas não foi considerado como regulador chave em nossa análise, são subunidades do complexo I da cadeia respiratória da membrana mitocondrial que funciona na transferência de elétrons do NADH para a cadeia 
respiratória, enquanto que o ATP8 faz parte do Complexo V e produz ATP a partir do ADP na presença do gradiente de prótons através da membrana. Curiosamente, maior quantidade de proteína mitocondrial CI foi associada com a alta EA por RAMO e KERLEY (2013), enquanto DAVIS, BROOKS e KERLEY (2016) encontraram maiores razões de concentração CI-CII e CI-CIII para o mesmo grupo. Outros estudos demonstraram que animais com alta EA consomem menos oxigênio (CHAVES et al., 2015) e apresentam menores concentrações plasmáticas de $\mathrm{CO} 2$, o que sugere um processo de oxidação diminuído (GONANO et al., 2014). Em geral, a literatura sugere que o ADP mitocondrial tem maior controle da fosforilação oxidativa em indivíduos com alta EA (LANCASTER et al., 2014) e seu aumento na função mitocondrial pode contribuir para a eficiência alimentar (CONNOR et al., 2010). Em suínos, diferenças na função mitocondrial foram relatadas ao analisar transcriptoma muscular (VINCENT et al., 2015), sangue (LIU et al., 2016) e tecido adiposo (LOUVEAU et al., 2016).

Diferenças na taxa metabólica associada a EA têm sido discutidas há algum tempo (HERD; ARTHUR, 2009) e nesse trabalho esse resultado é corroborado pela maior expressão de hormônio estimulante da tireoide beta (TSHB) em animais com alta EA, que tem como função estimular a produção de T3 e T4 na tireoide, aumentando assim o metabolismo. O hormônio tireoestimulante (TSH) é inibido pela somatostatina (SST), um hormônio menos expresso nesse grupo e que também apresentou-se diferencialmente conectado entre alta e baixa EA, mostrando-se promissor como foco de futuras pesquisas. Hormônios relacionados ao metabolismo de nutrientes podem ter papel importante na variação da EA entre animais, principalmente os envolvidos no eixo somatotrópico como o hormônio do crescimento (GH), fatores de crescimento semelhante a insulina (IGFs) e suas proteínas ligadoras (IGFBPs) (CANTALAPIEDRA-HIJAR et al., 2018). Nesse sentido, outro gene que se apresentou DE com maior expressão na alta EA e diferencialmente conectado entre os grupos foi o IGFBP1, que também é TS no fígado e secretado no plasma. Esse gene codifica uma proteína que se liga tanto ao IGF1 quando IGF2 circulante no plasma, prolongando a meia vida dessas moléculas e alterando sua interação com receptores de superfície. De fato, o IGF1 já foi apontando pela literatura como biomarcador da EA em bovinos e suínos (BUNTER et al., 2005, 2010; JING et al., 2015; KELLY et al., 2014; NASCIMENTO et al., 2015) por causa de seu papel na estimulação da síntese proteica e da importância do turnover de proteínas para EA (CANTALAPIEDRA-HIJAR et al., 2018). 
Olhando para os genes DE, outros hormônios podem ser identificados. Os hormônios são proteínas sinalizadoras que são transportadas pelo sistema circulatório para atingir outros órgãos, a fim de regular a fisiologia. A respeito da relação entre EA e outras características produtivas de importância econômica, o FSHB, responsável pela produção de espermatozoides através da ativação das células de Sertoli nos testículos (WALKER; CHENG, 2005), está mais expresso no grupo de baixa EA e é inibido pela folistatina (FST), um gene que foi menos expresso no mesmo grupo. Além disso, em ratos, já foi demonstrado que a secreção de FSH é estimulada pela expressão de somatostatina, que está mais expressa em animais de baixa EA (KITAOKA et al., 1989). Nesse cenário, pode-se argumentar que a seleção para alta EA poderia causar atraso em características reprodutivas, algo que poderia estar relacionado à baixa deposição de gordura nesse grupo, como observado anteriormente (ALEXANDRE et al., 2015; GOMES et al., 2012; SANTANA et al., 2012). De fato, diferenças na composição corporal e no metabolismo podem impactar em características reprodutivas (SHAFFER et al., 2011) e já foi observado que touros eficientes apresentam características de maturidade sexual tardia como diminuição da motilidade do espermatozóide e maior abundância de anormalidades em suas caudas (FONTOURA et al., 2016; MONTANHOLI et al., 2016). Além disso, novilhas de alta EA apresentaram menor deposição de gordura e maturação sexual mais tardia, o que resulta em partos mais tardios quando comparadas a fêmeas de baixa EA (RANDEL; WELSH, 2013; SHAFFER et al., 2011). É importante salientar que animais com baixa EA também apresentam baixa expressão de hormônio anti-mulleriano $(\mathrm{AMH})$ e a queda desse hormônio no soro foi apontada como um excelente marcador do desenvolvimento puberal das células de Sertoli (REY et al., 1993).

Com relação às diferenças no metabolismo lipídico em fenótipos divergentes para EA, o FGF21, um hormônio mais expresso no fígado de animais com alta EA, está associado em humanos à diminuição do peso corporal, triglicerídeos sanguíneos e colesterol LDL, com melhora na sensibilidade à insulina (CHEUNG; DENG, 2014). Esse hormônio é uma hepatocina liberada na corrente sanguínea e um importante regulador do metabolismo de lipídios e de glicose (GIRALT; GAVALDÀ-NAVARRO; VILLARROYA, 2015). Quando selecionamos os primeiros vizinhos desse gene na rede e realizamos uma análise de enriquecimento funcional, de fato encontramos termos relacionados a remodelamento de lipoproteína plasmática, regulação da oxidação de lipoproteínas, efluxo de colesterol, principalmente devido à co-expressão do FGF21 com 
as apolipoproteínas APOA4, APOC3 e APOM. No mesmo contexto, o hormônio concentrador de pro-melanina $(\mathrm{PMCH})$ codifica três neuropeptídios: o neuropeptídio ácido glicina-glutâmico, o neuropeptídio ácido glutâmico-isoleucina e o hormônio concentrador de melanina $(\mathrm{MCH})$ sendo o último mais estudado (HELGESON; SCHMUTZ, 2008). A maior expressão do MCH tem sido relacionada a obesidade e resistência à insulina, bem como ao aumento do apetite e metabolismo reduzido em modelos murinos (ITO et al., 2003; LUDWIG et al., 2001). O gene PMCH é mais expresso em animais de baixa EA e nele estão localizados SNPs associados a níveis mais altos de gordura na carcaça e maior escore de marmoreio (HELGESON; SCHMUTZ, 2008; WALTER et al., 2014).

Com essa abordagem de análise de dados, pudemos identificar vários processos biológicos relacionados à eficiência alimentar que corroboram dados da literatura, o que, juntamente com a validação dos principais fatores de transcrição da rede, demonstram a qualidade dos dados e a robustez das análises, dando-nos a confiança para indicar genes candidatos a reguladores ou biomarcadores de animais superiores para esta característica. Os fatores de transcrição NR2F6 e TGFB1 têm papel central no fígado e músculo, respectivamente, através da regulação de genes relacionados com a resposta inflamatória e desenvolvimento muscular e crescimento, dois principais mecanismos biológicos associados a eficiência alimentar. Da mesma forma, hormônios e outras proteínas secretadas no plasma como ocitocina, adrenomedulina, TSH, somatostatina, folistatina, IGFB e o AMH são moléculas interessantes a serem exploradas como potenciais biomarcadores da eficiência alimentar.

\subsection{Abordagem 2 - O papel do eixo hipotálamo-pituitária-adrenal sobre eficiência alimentar em bovinos de corte}

Diferente da abordagem 1, esta não se baseou na pré-seleção de genes com base em sua função ou associação prévia com o fenótipo, mas sim na identificação de conjuntos de genes altamente co-expressos nos tecidos do eixo HPA (considerando todos os genes) que apresentam correlação significativa com a CA e/ou CAR, medidas de eficiência alimentar. Ao analisarmos os três tecidos ao mesmo tempo observamos que a co-expressão entre genes do mesmo tecido é tão alta que os módulos não são capazes de representar as possíveis interações entre os diferentes transcriptomas teciduais, de forma que as análises foram refeitas para cada tecido separadamente. Desta maneira, foi possível 
identificar vias metabólicas no hipotálamo e pituitária, associadas positivamente à baixa EA, que estão relacionadas principalmente ao sistema de recompensa cerebral.

A medida de EA mais aceita atualmente para seleção de animais, por não ter correlação com ganho de peso e apresentar valores moderados de herdabilidade (ARCHER et al., 1999), é o consumo alimentar residual (CAR), calculado pela diferença entre o consumo alimentar observado e o consumo alimentar predito com base no peso vivo médio metabólico do animal (PVM) e GMD em um determinado período (KOCH et al., 1963). Dessa maneira, o CAR divide o consumo de alimento em porções requeridas para mantença (PVM) e para produção (GMD), restando uma porção residual que estaria relacionada à verdadeira eficiência metabólica (CREWS JR, 2005). Por definição, o CAR é fenotipicamente independente do GMD o que faz com que os animais de alta e baixa EA não apresentem diferença para essa característica. Nesse contexto, surgem as perguntas: (1) se os animais de alta e baixa EA foram criados desde o nascimento e avaliados sob as mesmas condições ambientais, e apresentam o mesmo ganho de peso, o que faz com que os grupos necessitem comer quantidades diferentes de alimentos para ganhar esse mesmo peso? (2) Os animais de baixa EA são menos eficientes porque apresentam maior ingestão ou ingerem mais porque são menos eficientes? Ambas as perguntas são relacionadas à ingestão de alimentos de forma intrínseca aos animais e desta forma, é fundamental compreender o papel do eixo HPA na ingestão de alimentos entre os grupos. Assim, foi testada a associação dos genes expressos nesses tecidos tanto com CAR quanto com a conversão alimentar (CA). Isso porque apesar da CA não ser uma medida ideal para seleção de animais por apresentar alto potencial genético para peso adulto levando a um maior gasto com energia de mantença (CREWS JR, 2005), ela é uma medida direta do consumo em relação ao ganho de peso, diferente do CAR que é o resíduo da regressão linear de duas outras medidas. Dessa forma, trabalhar com um fenótipo mais "puro" torna mais eficaz a análise dos resultados com relação as perguntas que queremos responder (ARTEGOITIA et al., 2017).

O eixo HPA é parte importante do sistema neuroendócrino tendo um papel central na regulação de muitos sistemas homeostáticos do organismo, incluindo os sistemas cardiovascular, imune, reprodutivo e nervoso central. Seu papel na regulação do comportamento alimentar e metabolismo é de particular interesse para entendermos porque os animais de baixa EA ingerem mais alimentos e acumulam mais gordura visceral enquanto que mantém o mesmo ganho de peso que os animais de alta EA. Tanto no hipotálamo quanto na pituitária, os módulos identificados como associados à eficiência 
alimentar parecem estar relacionados à baixa EA, tendo correlação positiva com o CAR e a CA. Uma possível interpretação destes resultados é que os animais de baixa EA seriam os "alterados" e os de alta EA os "normais" de um ponto de vista fisiológico. Dentre os termos enriquecidos nesses módulos, independente da análise ter sido realizada com todos os tecidos juntos ou cada um separadamente, chama atenção os relacionados à vícios como alcoolismo, sinapse colinérgica, anfetamina, cocaína e morfina, bem como secreção de ácido gástrico e salivar. Esses termos estão de acordo com o esperado para baixa EA (grupo com maior ingestão), já que drogas viciantes e comida palatável estimulam regiões e vias muito semelhantes no cérebro (NIEUWENHUIZEN; RUTTERS, 2008).

No conceito de regulação não homeostática da ingestão alimentar, o sistema de recompensa tem um papel fundamental na atitude dos indivíduos em relação ao alimento, pois, assim como drogas viciantes, a comida palatável age como "reforçador", influenciando sua própria ingestão (NIEUWENHUIZEN; RUTTERS, 2008). A busca por alimentos e a busca por drogas viciantes requerem a coordenação dos mesmos movimentos e, portanto, seus mecanismos compartilham os mesmos caminhos: ambos estão associados a desejos subjetivos e ambos estão sujeitos à saciedade momentânea, envolvendo circuitos que contribuem de forma importante para a motivação, o reforço e o estabelecimento de hábitos compulsivos (WISE, 2013). Dois processos físiológicos diferentes, chamados "gostar" (liking) e "querer" (wanting), determinam o reforço de ingestão gerado pelo alimento, cada um regulado por redes neurais e neurotransmissores diferentes. O processo de "querer" está relacionado a via de sinalização dopaminérgica, também enriquecida nos módulos do hipotálamo e nos genes diferencialmente expressos nesse tecido, e evidências sobre o efeito dessa via na formação de hábitos sugere um mecanismo em comum entre obesidade e vícios (WISE, 2013). Aparentemente, a via de sinalização dopaminérgica está mais relacionada a motivação, levando ao impulso de obter recompensa, do que ao prazer de obtê-la de fato, tornando-a parte de um mecanismo importante de regulação da ingestão (LOVE, 2014). É interessante mencionar que o efeito orexigênico do receptor de dopamina DRD1, presente nos módulos associados à baixa EA no hipotálamo, torna-se consideravelmente predominante na obesidade, levando ao aumento da ingestão calórica (NIEUWENHUIZEN; RUTTERS, 2008). Esse fato é importante já que ao considerar os animais de baixa EA como "alterados" fisiologicamente, por vezes os comparamos à humanos obesos. Já no processo de "gostar", o sistema de opióides endógenos no núcleo accumbens em interação com o sistema de endocanabióides, parece ter um papel importante, já que ambos estão 
relacionados ao comportamento ingestivo e sensação de recompensa (NIEUWENHUIZEN; RUTTERS, 2008). Nesse sentido, a via de sinalização endocanabinóide retrógrada também foi enriquecida nos módulos associados à baixa EA.

Outro importante papel do eixo HPA é coordenar a resposta do organismo a qualquer agente estressor que comprometa o equilíbrio homeostático do organismo, seja ele físico ou emocional (PAPADIMITRIOU; PRIFTIS, 2009). A literatura reporta variações na resposta ao estresse entre animais divergentes para EA (medida pelo CAR) podendo contribuir, juntamente com metabolismo tecidual e turnover de proteínas, com $37 \%$ da variação na EA, o que torna o estudo desse eixo primordial para a compreensão desse fenótipo (HERD; ARTHUR, 2009). Estudos mais recentes em bovinos mostram associação entre baixa EA, maior nível de cortisol no sangue e temperamento reativo, bem como maior nível de cortisol em resposta a ACTH exógeno, com os animais menos eficientes tendo uma resposta de cortisol mais prolongada (FOOTE et al., 2016a; FRANCISCO et al., 2015; KELLY et al., 2017). Os mesmos resultados foram observados em ovelhas nas quais também foi observado maior nível de ACTH em animais de baixa EA (KNOTT et al., 2008, 2010; ZHANG et al., 2017). Revisões anteriores sobre o assunto descrevem resultados semelhantes para frangos, suínos e camundongos (HERD; ARTHUR, 2009; HERD; ODDY; RICHARDSON, 2004). Nesse contexto, é importante ressaltar que no momento da coleta dos tecidos para esse estudo, os animais estavam em jejum de 24 horas e haviam sido transportados em caminhão para um novo piquete que dá acesso ao abatedouro, todos fatores estressantes para os animais, mesmo que igualmente entre os grupos.

Quando um organismo encontra um evento estressante, que ameaça sua homeostase, uma série de eventos psicológicos, neurológicos e comportamentais acontecem para ajudá-lo a lidar com a situação (HARRIS, 2015). O iniciador das respostas endócrinas do eixo HPA é o hormônio liberador de corticotrofina $(\mathrm{CRH})$ que é liberado do PVN do hipotálamo (HARRIS, 2015). Um estímulo olfativo, por exemplo, processado pelo sistema olfatório principal e o acessório, pode induzir o PVN a iniciar a secreção de hormônios relacionados ao estresse (STOWERS; CAMERON; KELLER, 2013; TAKAHASHI, 2014). O CRH estimula a liberação de hormônio adrenocorticotrófico (ACTH) na pituitária, que por sua vez estimula a cascata de eventos que levam a liberação de glicocorticoides, como o cortisol, na adrenal. A liberação de CRH após estresse inibe o apetite, inclusive em camundongos em jejum (CICCOCIOPPO et al., 2003). Em algumas situações onde as demandas metabólicas do organismo 
geralmente estimulariam a ingestão, a alimentação deve ser suprimida em favor de outros comportamentos. Por isso processos como estresse e reprodução são regulados por neuropeptídios que também regulam o apetite e, portanto, a ingestão alimentar (PARKER; BLOOM, 2012). Acredita-se que a ativação dessas vias também desencadeia respostas relacionadas a memória, motivação, planejamento, aprendizagem, ação e geração de padrões motores necessários para alimentação (PARKER; BLOOM, 2012).

O ACTH é um peptídeo sintetizado na pituitária a partir de uma molécula precursora maior, chamada pró-opiomelanocortina (POMC). O estímulo para liberação de ACTH é mediado principalmente pela estimulação de adenilato ciclase (AMPc) intracelular e inibido pela ação do SOCS3 (PAPADIMITRIOU; PRIFTIS, 2009), um gene menos expresso na adrenal de animais de baixa EA. O AMPc estimula a liberação de renina e tem como componente importante as purinas, o que pode explicar o enriquecimento de metabolismo de purinas e secreção de renina nos módulos do hipotálamo correlacionado à baixa EA. Outro fator importante para o aumento da resposta celular ao ACTH é a comunicação célula-célula através de gap junctions, que foi uma via também enriquecida no hipotálamo, juntamente com a via de sinalização Rap1, igualmente relacionada a junção celular. Apesar de puramente especulativo nesse momento, o enriquecimento das vias de proteólise mediada pela ubiquitina e proteassomo em um módulo majoritariamente de pituitária, considerando a análise conjunta dos três tecidos, pode indicar um maior turnover de ACTH nos animais de baixa EA. Isso porque recentemente Sesta et al. (2018) forneceram evidências de que de que o sistema ubiquitina-proteassoma está envolvido na degradação da POMC em ACTH, sendo a POMC alvo de ubiquitinação, de forma que esse sistema parece representar um meio para controlar a secreção de ACTH. O aumento da produção de ACTH estimula a produção de cortisol na medula da adrenal que junto com catecolaminas, coordenam a resposta de luta ou fuga, que é o primeiro estágio da "síndrome de adaptação geral" ao estresse (PAPADIMITRIOU; PRIFTIS, 2009).

A regulação do eixo HPA é um processo bastante complicado que envolve feedbacks positivos e negativos (PAPADIMITRIOU; PRIFTIS, 2009). A muito se sabe que agentes estressores ativam não somente sistemas neuroendócrinos clássicos, como o que causa elevação do nível de cortisol no plasma, mas também a secreção de ocitocina dos terminais da neuro-hipófise (pituitária) para a corrente sanguínea (NEUMANN, 2002). A ocitocina é um peptídeo circular formado por apenas nove aminoácidos que impacta significativamente uma série de comportamentos sociais e reprodutivos, mas 
também é liberada em resposta a estressores físicos e psicológicos (LOVE, 2014). De acordo com a literatura, o aumento na concentração de glicocorticoides na corrente sanguínea como resultado da ativação do eixo HPA atua de volta no hipotálamo ativando neurônios produtores de ocitocina no PVN, levando a inibição do ACTH (NEUMANN, 2002). Respostas a estímulos externos e internos são vitais para a sobrevivência de um organismo, porém, a reatividade a esses estímulos deve ser intrinsecamente regulada de maneira e evitar reações tanto excessivas quanto insuficientes. A via de sinalização de ocitocina, enriquecida tanto no módulo Skyblue3 quanto no Maroon e relacionada à baixa EA tem papel importante no enfrentamento do estresse regulando o eixo HPA através de feedback negativo e influenciando outros mecanismos também envolvidos no enfrentamento do estresse como a via de sinalização de dopamina, endocanabinóide retrógrada e GABA (ácido $\gamma$-amino-butirico), todos enriquecidos nos módulos do hipotálamo associados a baixa EA.

Importante mencionar que a literatura demostra que o jejum por si só não influencia a produção de ocitocina (MATSUZAKI et al., 2015; ROJKITTIKHUN; UVNÄS-MOBERG; EINARSSON, 1993) e que a indução da saciedade causada por esse neurotransmissor não requer ingestão de alimentos (HO; BLEVINS, 2013). Isso porque os receptores de ocitocina (OTR) são encontrados nos circuitos mesocorticolímbicos e a ativação desses receptores pode influenciar o sistema de recompensa relacionado a motivação de comportamentos como interação social e vício a drogas, e também o incentivo para alimentação (HO; BLEVINS, 2013; LOVE, 2014). Assim, a presença de OTRs em regiões do hipotálamo relacionadas à recompensa sugere que a ocitocina é capaz de inibir a alimentação pela alteração do apetite (HO; BLEVINS, 2013). Além disso, acredita-se que o efeito da ocitocina na comunicação entre vias relacionadas ao estresse e ao sistema de recompensa é mediada pela sinalização de neurônios dopaminérgicos encontrados nos circuitos mesocorticolimbicos (LOVE, 2014).

Sobre os efeitos da modulação da ocitocina na sinalização dopaminérgica, como discutido anteriormente, esta via está relacionada ao processo de “querer". Assim, neurônios dopaminérgicos também estão envolvidos na resposta a estímulos adversos e estressantes, que bloqueiam a motivação em buscar alimentos (LOVE, 2014). Interessante ressaltar que na abordagem 1 diversos genes relacionados à sinapse dopaminérgica foram mais expressos na baixa EA, como FOS, DRD2, SLC18A2, GNG12 e MAOB. Além disso, relacionado ao possível efeito do estresse no outro processo fisiológico que determina o reforço de ingestão, o processo de "gostar", estudos 
demostram que os endocanabioides estão envolvidos no rápido feedback gerado pelo aumento de glicocorticóides no eixo HPA, a nível do PVN (PAPADIMITRIOU; PRIFTIS, 2009).

Para evitar efeitos catabólicos e imunosupressores desnecessários causados pelo aumento na secreção de glucocorticóides que levam a diminuição do comportamento ingestivo e reprodutivo, mecanismos de feedback precisam ser ativados para regular o eixo HPA e restaurar o funcionamento homeostático hormonal após evento estressante (RIEBE; WOTJAK, 2011). A sinalização de endocanabióides tem papel fundamental nesse processo regulando domínios relacionados a percepção de medo, anciedade e enfrentamento do estresse (LUTZ et al., 2015; RIEBE; WOTJAK, 2011). Ela age em regiões distintas do cérebro modulando diversos tipos celulares que em contrapartida executam alterações nas transmissões sinápticas de acordo com o contexto. Isso resulta um ajuste fino dos padrões de atividade neuronais, de forma que acredita-se que essa via de sinalização seja a efetora das alterações sinápticas causadas por corticosteroides e estradiol (LUTZ et al., 2015). A constante exposição a estressores pode levar a alterações fisiológicas e comportamentais de longa duração, ajudando a habituar a atividade do eixo HPA e proteger contra os efeitos deletérios da ativação repetida desse eixo. Evidências indicam que o sistema endocanabióide desempenha um papel fundamental no desenvolvimento da habituação fisiológica gerando efeitos psicoemocionais e cognitivos no comportamento dos animais em termos de processos de medo condicionado, ansiedade e memória (RIEBE; WOTJAK, 2011).

Como pode ser observado, dentre os vários núcleos hipotalâmicos envolvidos na regulação do eixo HPA e resposta ao estresse, o PVN se destaca como núcleo integrador desses sinais. O PVN é altamente enervado por inputs GABAérgicos que vem de regiões próximas que são alvo de regiões límbicas do cérebro, permitindo a tradução de sinais inibitórios na modulação do eixo HPA (ULRICH-LAI; HERMAN, 2009). Dessa forma, é sugerido que a elaboração da resposta ao estresse envolve a modulação GABAérgica no PVN, principalmente no caso de estresse agudo (HERMAN; CULLINAN, 1997; HERMAN; MUELLER; FIGUEIREDO, 2004; PURDY et al., 1991; SKILBECK; JOHNSTON; HINTON, 2010). Além disso, evidências crescentes indicam que o aumento do CRH leva a ação de neurônios serotoninérgicos que atuam através de receptores de serotonina, GABA e glutamato modulando o enfrentamento do estresse (CHAOULOFF; BERTON; MORMÈDE, 1999; PUGLISI-ALLEGRA; ANDOLINA, 2015). Todos os estímulos gerados no hipotálamo atuam diretamente na pituitária que 
reage produzindo hormônios que são liberados na corrente sanguínea. Nossos resultados indicam maior atividade celular e produção proteica na pituitária dos animais da baixa EA, estando os módulos significativos relacionados tanto à transcrição de RNA e tradução, processamento e transporte de proteínas, quanto à degradação proteossomal mediada por ubiquitina.

É surpreendente que módulos de genes associados a animais de baixa EA, que são o grupo que consome mais alimento, apresentem enriquecimento para algumas vias com efeito anoréxico. Porém, é necessário ressaltar o caráter tempo-específico da expressão gênica, principalmente em se tratando do sistema endócrino, que está diretamente relacionado a respostas adaptativas do indivíduo em relação ao ambiente. Diante disso, apesar de ambos os grupos estarem submetidos ao mesmo estresse no momento do abate, a reação mais acentuada do grupo de baixa EA, evidenciada pelo enriquecimento de termos como "resposta ao estresse" e "resposta de medo", está de acordo com os relatos da literatura e os mecanismos previstos como responsáveis por influenciar esse fenótipo. Apesar da resposta ao estresse agudo ativar mecanismos de bloqueio do apetite, o envolvimento da via de sinalização de endocanabinóide retrógrada sugere a habituação à atividade do eixo HPA. A liberação de glicocorticoides do córtex da adrenal tem um papel importante na coordenação do ritmo circadiano e, mediadores do eixo HPA influenciam direta e indiretamente tanto o sistema de ritmo circadiano quando as regiões do cérebro responsáveis pelo controle da ingestão de alimentos (BLASIAK et al., 2017). Em situações em que outros mecanismos não se sobressaem ao efeito dos glicocorticoides, essas moléculas são, na verdade, orexigênicas, levando ao aumento da ingestão de alimentos palatáveis (BAZHAN; ZELENA, 2013). A elevação prolongada dos níveis de glicocorticoides leva ao aumento do consumo através da inibição do CRH e estimulação da expressão de NPY (BLASIAK et al., 2017). De fato, sabe-se que ingerir alimentos altamente palatáveis ou com altas calorias reduz os efeitos do estresse através do estímulo do sistema de recompensa e leva à obesidade em humanos (BAZHAN; ZELENA, 2013).

Com essa abordagem, podemos indicar o sistema de recompensa do hipotálamo como responsável por mediar a maior ingestão observada nos animais de baixa eficiência, o que sugere que os animais são menos eficientes porque tem maior incentivo para a ingestão de alimentos. O sistema de recompensa hipofisário deve ser foco de novas pesquisas no intuito de validar seu papel regulatório na eficiência alimentar e determinar se ele está ou não relacionado à resposta ao estresse em bovinos. 


\subsection{Abordagem 3 - Identificação de RNAs longos não codificadores em múltiplos tecidos de bovinos Nelore e sua associação com a eficiência alimentar}

O número crescente de dados de sequenciamento de nova geração e desenvolvimento da biologia computacional têm tornado evidente o papel regulatório dos lncRNAs nos processos biológicos, podendo ser essenciais para compreensão mais profunda da variação fenotípica de características complexas em animais de produção (WEIKARD; DEMASIUS; KUEHN, 2016). Nesse experimento, utilizamos dados de transcriptômica de cinco tecidos (hipotálamo, pituitária, adrenal, músculo e fígado) de 18 bovinos Nelore extremos para EA para identificar e caracterizar lncRNAs diferencialmente expressos entre os grupos. A caracterização funcional dos lncRNA é difícil, uma vez que existe baixa conservação entre espécies e sua função por vezes é determinada pela sua estrutura tridimensional (SIGNAL; GLOSS; DINGER, 2016). Dessa forma, utilizamos estratégias diferentes para atribuir função aos 30 lncRNA DE encontrados na pituitária, adrenal e músculo e entender melhor o papel dessas moléculas com relação à EA.

Ao nosso conhecimento, não existem trabalhos na literatura associando lncRNAs à eficiência alimentar de bovinos porém, trabalhos recentes identificaram novos lncRNA a partir de dados de RNAseq relacionados à lactação (ZHENG et al., 2018), mastite (TONG et al., 2017), diferenciação de adipócitos (LI et al., 2016) e desenvolvimento de músculo esquelético (SUN et al., 2016). Além disso, dois trabalhos investigaram a presença de lncRNA em múltiplos tecidos de bovinos (KERN et al., 2018; KOUFARIOTIS et al., 2015). Esses dois trabalhos encontraram 7235 e 16336 novos lncRNA utilizando oito e 18 tecidos, respectivamente, enquanto que nosso trabalho identificou 9323 novos lncRNA utilizando apenas cinco tecidos. Podemos especular que o maior número relativo de novos lncRNA encontrados em nosso trabalho se deve ao fato de termos representado uma maior variabilidade genética, utilizados 18 animais diferentes, enquanto os outros trabalhos usaram 1 ou 2 indivíduos. Apesar disso, quando observamos o número de lncRNA expressos por tecido, que ficou ao redor de 1200 a 2000 transcritos, percebemos que os valores são comparáveis aos encontrados em trabalhos que avaliaram os tecidos/células individualmente, como glândula mamária ou cultivo de adipócitos (LI et al., 2016; ZHENG et al., 2018). 
O filtro que mais excluiu transcritos foi o que avalia a presença de ORFs. Apesar da presença de START e STOP códon não garantir a tradução de uma proteína funcional, é de extrema importância que essa possibilidade seja descartada com relação aos lncRNAs. O filtro que menos descartou transcritos foi o CPC que usa metodologias de machine learning para buscar novamente por ORFs e sequencias homólogas a proteínas conhecidas e foi utilizado para garantir que os outros filtros haviam sido eficientes e excluir qualquer transcrito que ainda tivesse potencial de codificação. No total, 59\% dos transcritos identificados como lncRNAs apresentaram homologia com a base de lncRNAs de bovinos, o que por um lado indica eficiência na identificação de lncRNAs, mas por outro reflete um déficit na anotação dessas moléculas, principalmente considerando diferenças entre as sub-espécies taurus e indicus, já que a maior parte dos experimentos para caracterização de lncRNA foi realizada em raças taurinas (KERN et al., 2018; KOUFARIOTIS et al., 2015). Dado o papel regulatório dessa classe de RNAs e sua aparente falta de conservação entre espécies (WEIKARD; DEMASIUS; KUEHN, 2016), é esperado que diferenças importantes existam entre bovinos zebuínos e taurinos, principalmente com relação a respostas adaptativas.

Quanto à classificação dos lncRNAs identificados por categoria, a mais representada é de lincRNA (intergênicos), representando quase 80\% dos lncRNAs, seguida dos com sobreposição à gene conhecido na fita oposta (10\%). Porém, quando comparamos a posição dos lncRNAs com a anotação contendo genes preditos, além da porcentagem de lincRNA cair para quase metade (42\%), os lncRNAs classificados como novas isoformas passam de $3 \%$ para $21 \%$. Além disso, os transcritos de íntrons de genes conhecidos, que quase não estavam representados, aparecem em 9\% dos lncRNAs, e 3\% se sobrepõe exatamente com os genes preditos. Isso demostra que, de fato, diversos genes preditos no genoma bovino apresentam expressão gênica, e que uma parte importante do genoma ainda precisa ser adequadamente anotada. Por outro lado, a presença da maior parte dos lncRNA em regiões intergênicas era esperada e está de acordo com o observado em diversos tecidos de bovinos e outras espécies de produção (KERN et al., 2018; KOUFARIOTIS et al., 2015).

Do total de lncRNAs identificados, 3542 apresentaram expressão suficiente entre os tecidos para serem testados para expressão diferencial e destes, apenas $18 \%$ foram comuns aos cinco tecidos, o que está de acordo com o caráter tecido-especifico esperado para esses RNAs (DENIZ; ERMAN, 2017; WEIKARD; DEMASIUS; KUEHN, 2016). Além disso, nossos resultados estão de acordo com KERN et al. (2018) que observou 
maior número de lncRNA tecido-específicos no fígado. KOUFARIOTIS et al. (2015) também verificou quantidade decrescente de novos transcritos no fígado, adrenal e músculo, nessa ordem, ao avaliar 18 tecidos bovinos. Dentre os tecidos que apresentaram maior número de lncRNA em comum estão os do eixo HPA que apresentaram 253 transcritos expressos nos três tecidos. Esse fato pode estar relacionado a regulação da função endócrina exercida em comum por esse eixo.

Foram identificados 30 lncRNAs DE entre alta e baixa EA e é interessante notar que apesar de seis deles serem considerados isoformas de genes conhecidos, nenhum apresentou expressão gênica correlacionada com seu gene associado (quantificado considerando todas as isoformas). $\mathrm{O}$ único lncRNA expresso de íntron, o TCONS_00005461A, também não apresentou correlação com seu gene associado, assim como os cinco lincRNAs (intergênicos), como esperado. Por outro lado, alguns genes em outras classes apresentaram correlação com seus genes associados ou genes próximos. A relação dos lncRNAs com outros genes pode ser útil como filtro inicial para procurar por atividades regulatórias e, nesse sentindo, a posição genômica pode ser usada como guia para abordagens baseadas em guilty-by-association (SIGNAL; GLOSS; DINGER, 2016). Assim, correlações positivas, como é o caso das encontradas nesse experimento para genes próximos (cis), podem indicar relações regulatórias positivas ou simplesmente que ambos os genes estão sob a mesma regulação epigenética (SIGNAL; GLOSS; DINGER, 2016). Neste ponto, não somos capazes de distinguir entre as duas possibilidades e contamos com diferentes abordagens para indicar lncRNAs de interesse para futuros estudos.

Dos 10 lncRNAs DE com sobreposição com éxon de gene conhecido, dois apresentaram expressão correlacionada com seu gene associado, o TCONS_00006825P e o TCONS_00004881P. O TCONS_00006825P, mais expresso na alta EA, não apresentou similaridade com lncRNA presente na base de dados NONCODE e apresentou tanto correlação quanto complementariedade com o gene TMEM176A que tem função pouco descrita e parece estar associado à supressão tumoral (GAO et al., 2017; WANG et al., 2017). Já o TCONS_00004881P, mais expresso na baixa EA, apresentou similaridade com o lncRNA NONSUST023300.1 descrito em suínos e tanto correlação quanto complementariedade com o gene SRSF3. O SRSF3 é um fator de splicing de prémRNA e parte constituinte do spliceossomo, apresentando um domínio de reconhecimento de RNA e um domínio para ligação com outras proteínas (STELZER et al., 2016). Parece também ser importante para a exportação do mRNA do núcleo e sua 
tradução. Somado a isso, os outros 235 genes co-expressos com o TCONS_00004881P apresentaram enriquecimento para termos relacionados a ligação à RNA e transporte de mRNA, além de metabolismo, transporte e exportação de proteínas. Esse resultado está de acordo com o encontrado para pituitária na abordagem 2, onde módulos com funções semelhantes (transcrição e tradução) foram associados à baixa EA.

Outros dois lncRNA DE, com sobreposição com éxon de gene conhecido, apresentaram correlação com gene próximo: o TCONS_00004904P e o TCONS_00000153P. O TCONS_00004904P, mais expresso na alta EA, apresentou similaridade com o NONBTAT029582.1 descrito em bovino e tanto correlação quanto complementariedade com o gene BOLA. O BOLA codifica o MHC de classe I que está envolvido na resposta imune contra antígenos, através da ligação com peptídeos gerados a partir de degradação citoplasmática de proteínas pelo proteassomo. Esses genes, além de estarem em região de QTL para espessura de gordura subcutânea (característica que apresentou diferença entre alta e baixa EA -ALEXANDRE et al., 2015), também estão em região de seis QTLs para IgG. Apesar de estar além das pretensões desse experimento discutir diferenças de resposta imune nos animais de alta e baixa EA, de fato os genes DE na pituitária apresentaram enriquecimento para processamento e apresentação de antígenos (abordagem 2) e já foi indicado pela literatura a possibilidade dos animais diferirem nesse sentido (PARADIS et al., 2015; SALLEH et al., 2017). Já o TCONS_00000153P, mais expresso na baixa EA, apresentou similaridade com um lncRNA descrito em humanos, o NONHSAT194263.1 e apresentou correlação com o gene próximo ALCAM que foi diferencialmente expresso entre a alta e a baixa EA na abordagem 1. Além disso, apresentou correlação positiva com quatro genes DE identificados na abordagem 1 (WIF1, HTR1F, PCSK2 e CAV1) e negativa com um (GAS1). O ALCAM é também chamado de molécula de adesão de leucócito ativado (CD166) e é um receptor de imunoglobulina relacionado a ativação de célula $\mathrm{T}$, assim como o CAV1 (STELZER et al., 2016). Além disso, promove orientação e crescimento de axônios que crescem preferencialmente em superfícies que contém a proteína codificada por esse gene. Interessante notar que o GAS1, único gene negativamente correlacionado, está associado com supressão de crescimento. O HTR1F é um receptor de serotonina, assim como o HTR5A que foi encontrado na abordagem 2 em um módulo do hipotálamo associado à baixa EA. A serotonina é um neurotransmissor importante no sistema nervoso central principalmente associado a inibição do apetite, regulação da temperatura corporal e função cognitiva. Também intervém em outros 
neurotransmissores como dopamina e noradrenalina relacionados com angústia, ansiedade, medo e agressividade (CHAOULOFF; BERTON; MORMÈDE, 1999). Por fim, o PCSK2 é uma convertase relacionada à ativação proteolítica de hormônios polipeptídios e precursores de neuropeptídios (STELZER et al., 2016). Considerando todos os genes correlacionados ao TCONS_00000153P, houve enriquecimento funcional para transporte de RNA e spliceossomo, em concordância com os módulos identificados nesse tecido na abordagem 2 e associados à baixa EA.

Oito lncRNA DE apresentaram sobreposição com gene conhecido na fita oposta sendo que um deles, o TCONS_00007280P, apresentou correlação com gene próximo, e o TCONS_00002325M apresentou correlação com seu gene associado. O TCONS_00007280P, mais expresso na alta EA, apresentou alta correlação positiva $(0,96)$ com o gene ENSBTAG00000042526, também identificado como SNORD28, um small nucleolar RNA aparentemente responsável por guiar a metilação sítio específica da ribose de RNA ribossomal (TYCOWSKI et al., 1996). Já o TCONS_00002325M, mais expresso na baixa EA, apresentou correlação com seu gene associado SESN3 que também foi identificado como diferencialmente expresso entre alta e baixa EA na abordagem 1. Além disso, apresentou correlação positiva ABK2, ACTC1 e PVALB e negativa com IGFBP6, todos DE na abordagem 1 no tecido muscular. Este foi o único lncRNA encontrado em região de QTL para EA medida pela conversão alimentar e considerando todos os genes correlacionados, foi identificado enriquecimento para diversos termos relacionados à respiração celular. O SESN3 codifica para uma proteína induzida por estresse relacionada a redução de espécies reativas de oxigênio intracelular e também requerida para regulação na glicose sanguínea, resistência à insulina e armazenamento de lipídeos na obesidade (STELZER et al., 2016). Concordantemente, a alfa actina (ACTC1) de fato já foi associada à diferença de EA relacionada à produção de energia mitocondrial e estresse oxidativo (KEEL et al., 2018). Essa provável maior atividade celular no músculo de animais de baixa EA pode estar associada ao maior turnover de proteínas esperado nesse grupo, que leva ao maior gasto com energia de mantença (CASTRO BULLE et al., 2007; HERD; ARTHUR, 2009). Reforçando esses achados, na abordagem 1 indicamos o TGFB1 como um importante regulador das diferenças entre alta e baixa EA no músculo, sendo co-expresso com genes relacionados ao desenvolvimento muscular. Por fim, o TCONS_00002325M, que presentou alta homologia com o lncRNA NONBTAT006734.2 identificado em bovinos, apresentou sítio de ligação para vários miRNA, dentre eles o miR-101, miR-29C e miR1271. Interessante notar que esses 
miRNA se apresentaram diferencialmente expressos em suínos avaliados para EA, sendo os dois primeiros menos expressos na baixa EA, em concordância com a função de “esponjas” de miRNA exercida pelos lncRNA (JING et al., 2015). Em desacordo, porém, o miR-1271 apresentou maior expressão na baixa EA.

Considerando todos os miRNA com sítio de ligação em lncRNA DE na pituitária, é interessante notar que o termo mais enriquecido, "processo catabólico de proteínas dependente de ubiquitina”, está de acordo com o módulo de pituitária enriquecido para "proteólise mediada por ubiquitina" na abordagem 2, quando avaliamos todos os tecidos do eixo HPA em conjunto. Já com relação à adrenal, o lncRNA DE TCONS_00005426A chama atenção por apresentar correlação negativa com oito genes DE na abordagem $1 \mathrm{e}$ correlação positiva com um gene DE. Este lncRNA foi mais expresso na baixa EA, é isoforma de um gene predito e apresentou alta homologia com o NONBTAT015414.2, descrito em bovinos.

De forma geral, esse estudo encontrou 30 lncRNA DE entre alta e baixa EA e destacou alguns deles, principalmente o TCONS_00000153P, TCONS_00004881P, TCONS_00002325M e TCONS_00005426A, que parecem estar relacionados a funções anteriormente descritas como associadas a este fenótipo, sendo genes candidatos como reguladores da eficiência alimentar. 


\subsection{Discussão final}

Neste trabalho, partimos de resultados e hipóteses geradas anteriormente, que se iniciaram com a avaliação de 98 bovinos Nelore de onde foram selecionados indivíduos extremos para eficiência alimentar medida através do CAR. Foi observado que os animais de baixa EA apresentaram maior consumo de alimento, maior deposição de gordura, maiores níveis de colesterol sérico e resposta inflamatória hepática, indicada pela análise transcricional de biópsia hepática e comprovada por análise histopatológica e de GGT sérico (biomarcador de lesão hepática). Por outro lado, não foram verificadas diferenças quanto a ganho de peso, rendimento de carcaça, peso dos principais cortes, além de também não ter sido observada diferença de idade entre os animais avaliados. Foi então proposto naquele momento que lesões hepáticas em animais de baixa EA ocorreriam em decorrência do estresse gerado por sobrecarga no metabolismo lipídico e/ou devido a maior infecção bacteriana causada pela maior ingestão de alimentos nesse grupo. Considerando os resultados obtidos com a análise de biópsia hepática e sabendo que a EA é uma característica determinada por diferentes processos biológicos, propusemos neste trabalho analisar o transcriptoma de cinco tecidos (hipotálamo, pituitária, adrenal, fígado e músculo) desses animais extremos para EA, com o objetivo de gerar uma compreensão sistêmica da eficiência alimentar. Para tanto, primeiramente avaliamos conjuntamente os cinco tecidos utilizando de critérios de inclusão para construção de uma rede de co-expressão. Em seguida, analisamos somente os tecidos do eixo HPA sem préseleção de genes com base em conhecimento disponível na literatura. Por fim, utilizamos os dados de RNAseq para identificar lncRNAs e testar sua associação e possível papel na regulação da EA. A figura 35 resume os principais achados e questões levantadas em ambos os trabalhos.

Dentre os tecidos analisados o fígado parece ter uma importância central, tendo sido destacado na análise de co-xpressão envolvendo os cinco tecidos. Além disso, foi confirmada a associação de metabolismo lipídico e resposta inflamatória com a baixa EA, descrita em nosso experimento prévio com biopsia hepática. A detecção de maior nível de endotoxina sérica em animais de baixa EA reforça a hipótese de que a maior ingestão de alimentos desse grupo leva a lesões na parede do rumem e migração de bactérias pela corrente sanguínea. Porém, não podemos descartar que a diferença na população bacteriana intestinal já descrita na literatura para animais divergentes para EA também podem contribuir para essa infecção bacteriana, já que aumento de endotoxinas em 
animais de baixa EA também foi observado em suínos. Outra possibilidade é que os animais de baixa EA tenham maior suscetibilidade à infecção bacteriana e/ou menor capacidade de neutralizar endotoxinas. Nesse contexto, o receptor nuclear NR2F6 foi apontado como regulador central das diferenças hepáticas entre animais de alta e baixa EA.

Diferenças na função mitocondrial já haviam sido associadas à EA pela literatura e foram confirmadas pela expressão diferencial de genes ligados à cadeia respiratória com maior expressão na alta EA. Esses genes também foram indicados como reguladores da rede de co-expressão gênica, tendo função central na regulação de vários outros genes. Em concordância, genes relacionados ao metabolismo de nutrientes como o TSH e IGFBP1 também foram mais expressos na alta EA indicando metabolismo energético mais elevado nesse grupo. Por outro lado, o maior turnover de proteínas no músculo de animais de baixa EA vem sendo discutido na literatura como causa do maior “desperdício" energético nesse grupo e, nesse sentido, o lncRNA TCONS_00002325M, mais expresso no músculo de animais de baixa EA e com alta homologia com o NONBTAT006734.2, parece estar relacionado à respiração celular e metabolismo mitocondrial, o que pode indicar um papel regulatório no turnover proteico no músculo. Ele foi o único lncRNA encontrado em região de QTL para EA medida pela conversão alimentar. Além disso, nesse estudo indicamos a via de sinalização do TGF- $\beta$ como mediadora das diferenças no músculo de animais divergentes para EA.

Apesar de nosso estudo não trazer grandes esclarecimentos nesse sentido, não podemos deixar de mencionar a preocupação com a relação EA - deposição de gordura precocidade sexual. Aqui, indicamos que de fato animais menos eficientes depositam mais gordura e apresentam expressão mais elevada de hormônios relacionados ao desenvolvimento puberal como FSH e o AMH, indicativos de maior precocidade sexual. Também indicamos o FGF21 como um gene central na regulação do peso corporal, estando associado à alta EA e, portanto, à menor deposição de gordura. No mesmo contexto, a maior expressão do $\mathrm{MCH}$ nos animais de baixa EA parece estar relacionada a maior deposição de gordura observada nesse grupo.

Com relação ao papel do eixo HPA na regulação da EA o hipotálamo se destaca por apresentar diversas vias relacionadas à vícios e associadas à baixa EA. A atitude dos indivíduos com relação a vícios e a comida palatável é muito semelhante e o enriquecimento dessas vias parece indicar porque os animais menos eficientes consomem mais alimentos: maior ativação do centro de recompensa no cérebro. O que não está claro 
é se existe outro mecanismo por trás da regulação do centro de recompensa. Nesse sentido, algumas das vias enriquecidas no hipotálamo, como a de sinalização de oxitocina e de endocanabinóides, parecem apontar para resposta de adaptação ao estresse mais proeminente nos animais de baixa EA, o que poderia estar associada à recorrência da ativação dessas vias.

Já na pituitária, a baixa EA parece estar relacionada à maior transcrição e tradução, bem como à maior degradação proteica mediada por ubiquitina. Esse foi o tecido com maior número de lncRNA DE e alguns podem ser destacados. TCONS_00004881P é mais expresso na pituitária de animais de baixa EA, apresentou similaridade com o lncRNA NONSUST023300.1 e parece estra relacionado aos processos de transcrição e tradução, em concordância com os resultados da análise de mRNA desse tecido. Da mesma maneira o TCONS_00000153P, mais expresso na baixa EA e similar ao NONHSAT194263.1, parece estar relacionado a transporte de RNA e spliceossomo, ativação proteolítica de hormônios polipeptídios e precursores de neuropeptídios, via de sinalização de serotonina, além de poder estar relacionado à ativação de célula T. Já o TCONS_00004904P, mais expresso na pituitária de animais de alta EA, apresentou similaridade com o NONBTAT029582.1 e parece estar envolvido na resposta imune contra antígenos estando em região de seis QTLs para IgG. De fato, os genes DE na pituitária apresentaram enriquecimento para processamento e apresentação de antígenos e diferenças na suscetibilidade a patógenos já foi indicada na literatura como um dos processos biológicos que podem estar envolvidos nas diferenças de EA. Por fim, considerando todos os miRNA com sítio de ligação em lncRNA DE na pituitária, encontramos processo catabólico de proteínas dependente de ubiquitina como função enriquecida, em concordância com os resultados analisando mRNA.

Por fim, cabe uma observação sobre os resultados da análise de lncRNA. Foi possível perceber, tanto pela sobreposição dos lncRNAs com genes "preditos" (mas que ainda não foram validados) quanto pela porcentagem de similaridade (59\%) com a base de dados de ncRNAs, que grandes esforços ainda são necessários no sentido de identificar, anotar e caracterizar essas moléculas. Apesar disso, existe um grande potencial de exploração desses transcritos como reguladores de características produtivas, já que fomos capazes de identificar 30 lncRNA DE na hipófise, pituitária e músculo de animais divergentes para a EA. 
Figura 35 - Resumo das características associadas à baixa eficiência alimentar em nosso estudo anterior (Alexandre et al., 2015) e no atual.

\section{Baixa Eficiência Alimentar}

NÃO HÁ DIFERENÇA:

Peso

AOL

Ganho de peso

Rendimento de carcaça

Metabolismo de xenobióticos

Resposta imune
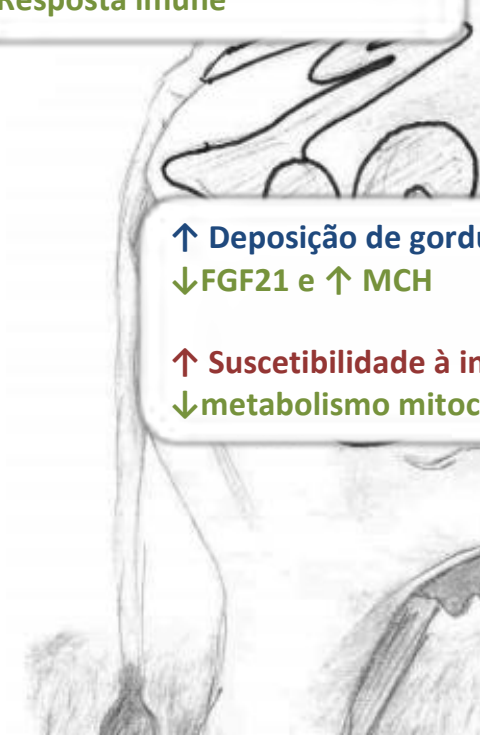

个 Deposição de gordura: レGF21 e $\uparrow \mathrm{MCH}$

Suscetibilidade à infecção? metabolismo mitocondrial

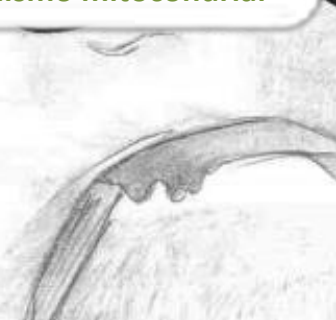

Resposta inflamatória

Metabolismo de lipídeos

个 antioxidante $\uparrow$ ROS?

NR2F6

Características em azul foram observadas no experimento anterior

e em laranja são novas perguntas geradas. Fonte: própria autoria.

\section{HIPOTÁLAMO:}

个 Ativação do centro de recompensa

个esposta ao estresse?

\section{PITUITÁRIA:}

个 Turnover de proteína: Turnover de ACTH ou

resposta imune?

TCONS_00004881P

TCONS_00000153P

TCONS 00004904P 


\section{CONCLUSÃO}

Animais de baixa EA parecem ter várias vias associadas ao centro de recompensa no hipotálamo mais ativas, que podem ou não ter relação com a maior resposta ao estresse observada na literatura para esse grupo, levando à maior ingestão de alimentos. Assim como maior nível de estresse pode causar diminuição na resposta imune do organismo tornando-o mais susceptível à patógenos, maior ingestão de alimentos concentrados pode causar acidose que leva a lesões na parede do rúmen e possibilitam a migração de bactérias pelo sangue, indicada pela maior presença de endotoxinas no soro desse grupo de animais. Não está claro qual desses motivos pode estar associado com a maior resposta inflamatória observada no fígado de animais de baixa EA, que parece ter como regulador central o NR2F6. Além disso, a aparente maior atividade nas células musculares dos animais de baixa EA pode estar ligada a um maior gasto energético, ou seja, menor eficiência, e é possível que esse processo seja mediado pelo TGFB1. A análise transcriptômica é eficiente para apontar processos e genes regulatórios de características importantes como a EA, principalmente com a ajuda de abordagem baseada em coexpressão, que aponta resultados que não seriam identificados apenas por expressão diferencial. Porém, nossos dados não possibilitaram um claro entendimento da interação entre diferentes tecidos na determinação da EA. Estudos delineados para testar as hipóteses levantadas nessa tese são necessários, como forma de validação, principalmente com relação ao papel regulatório de alguns fatores de transcrição e lncRNAs destacados nesse trabalho. 


\section{REFERÊNCIAS}

AERTS, S. et al. Robust target gene discovery through transcriptome perturbations and genome-wide enhancer predictions in drosophila uncovers a regulatory basis for sensory specification. PLoS Biology, San Francisco, v. 8, n. 7, p. e-1000435, 2010.

AL-HUSSEINI, W. et al. Expression of candidate genes for residual feed intake in Angus cattle. Animal Genetics, Chichester, v. 45, n. 1, p. 12-9, Feb. 2014.

ALBERTS, B. et al. Molecular biology of cell. 5th. ed. New York: Garland Science, 2008.

ALEXANDRE, P. A. Caracterização do perfil de expressão gênica hepática global associada à eficiência alimentar em bovinos Nelore. Dissertação (Mestrado em Zootecnia). Faculdade de Zootecnia e Engenharia de Alimentos, Universidade de São Paulo. Pirassununga, p.143, 2015.

ALEXANDRE, P. A. et al. Liver transcriptomic networks reveal main biological processes associated with feed efficiency in beef cattle. BMC Genomics, London, v. 16, n. 1, art. 1073, 2015.

ANDERS, S.; PYL, P. T.; HUBER, W. HTSeq - a python framework to work with high-throughput sequencing data. Bioinformatics, Oxford, v. 31, n. 2, p. 166-9, Sept. 2015 .

ARCHER, J. A. et al. Optimum postweaning test for measurement of growth rate, feed intake, and feed efficiency in British breed cattle. Journal of Animal Science, Cary, v. 75, n. 8, p. 2024-32, Aug. 1997.

ARCHER, J. A. et al. Potential for selection to improve efficiency of feed use in beef cattle: a review. Australian Journal of Agricultural Research, Clayton, v. 50, n. 2, p. 147-61, 1999.

BACKES, C. et al. MiEAA: MicroRNA enrichment analysis and annotation. Nucleic Acids Research, Oxford, v. 44, n. W1, p. W110-W116, 2016.

BALDASSINI, W. A. et al. Proteomic investigation of liver from beef cattle (Bos indicus) divergently ranked on residual feed intake. Molecular Biology Reports, Dordrecht, Sept. 2018. [Epub ahead of print].

BAR-YAM, Y. Concepts: power law. Disponível em:

<http://www.necsi.edu/guide/concepts/powerlaw.html>. Acesso em: 10 set. 2018.

BASARAB, J. A. et al. Residual feed intake and body composition in young growing cattle. Canadian Journal of Animal Science, Ottawa, v. 83, n. 2, p. 189-204, June. 2003.

BATISTA, P. J.; CHANG, H. Y. Long noncoding RNAs: cellular address codes in development and disease. Cell, Cambridge, v. 152, n. 6, p. 1298-307, 2013.

BAZHAN, N.; ZELENA, D. Food-intake regulation during stress by the hypothalamopituitary-adrenal axis. Brain Research Bulletin, Philadelphia, v. 95, p. 46-53, 2013. 
BLASIAK, A. et al. Interactions of circadian rhythmicity, stress and orexigenic neuropeptide systems: Implications for food intake control. Frontiers in Neuroscience, Lausanne, v. 2017, n. 11, art. 127, 2017.

BLUM, R. et al. Genome-wide identification of enhancers in skeletal muscle: the role of MyoD1. Genes \& Development, Woodbury, v. 26, n. 24, p. 2763-2779, 2012.

BOLORMAA, S. et al. Genome-wide association studies for feedlot and growth traits in cattle. Journal of Animal Science, Cary, v. 89, n. 6, p. 1684-97, June. 2011.

BREITLING, R. What is systems biology? Frontiers in Physiology, Lausanne, v. 1, art, 9, May. 2010.

BUNTER, K. L. et al. Insulin-like growth factor-I measured in juvenile pigs is genetically correlated with economically important performance traits. Australian Journal of Experimental Agriculture, Clayton, v. 45, n. 8, p. 783, Sept. 2005.

BUNTER, K. L. et al. Selection to reduce residual feed intake in pigs produces a correlated response in juvenile insulin-like growth factor-I concentration1. Journal of Animal Science, Cary, v. 88, n. 6, p. 1973-1981, June. 2010.

CAMACHO, C. et al. BLAST+: architecture and applications. BMC Bioinformatics, London, v. 10, n. 1, art. 421, Jan. 2009.

CANTALAPIEDRA-HIJAR, G. et al. Review: biological determinants of betweenanimal variation in feed efficiency of growing beef cattle. Animal, Cambridge, p. 1-15, Aug. 2018. [Epub ahead of print].

CAO, P. et al. Statin-induced muscle damage and atrogin-1 induction is the result of a geranylgeranylation defect. FASEB journal: official publication of the Federation of American Societies for Experimental Biology, Bethesda, v. 23, n. 9, p. 2844-2854, 2009.

CASTRO BULLE, F. C. P. et al. Growth, carcass quality, and protein and energy metabolism in beef cattle with different growth potentials and residual feed intakes.

Journal of Animal Science, Cary, v. 85, n. 4, p. 928-36, Apr. 2007.

CHAOULOFF, F.; BERTON, O.; MORMÈDE, P. Serotonin and stress.

Neuropsychopharmacology, London, v. 21, p. 28S-32S, Aug. 1999. 2 Supplement.

CHAVES, A. S. et al. Relationship of efficiency indices with performance, heart rate, oxygen consumption, blood parameters, and estimated heat production in Nellore steers. Journal of Animal Science, Cary, v. 93, n. 10, p. 5036-46, Oct. 2015.

CHEN, Y. et al. Global gene expression profiling reveals genes expressed differentially in cattle with high and low residual feed intake. Animal Genetics, Chichester, v. 42, n. 5, p. 475-90, Oct. 2011.

CHEUNG, B. M.; DENG, H. B. Fibroblast growth factor 21: a promising therapeutic target in obesity-related diseases. Expert Review of Cardiovascular Therapy, London, v. 12, n. 6, p. 659-666, 2014.

CHO, D. Y.; KIM, Y. A.; PRZYTYCKA, T. M. Chapter 5: Network biology approach to complex diseases. PLoS Computational Biology, San Francisco, v. 8, n. 12, p. 
e1002820, Jan. 2012.

CICCOCIOPPO, R. et al. The bed nucleus is a neuroanatomical substrate for the anorectic effect of corticotropin-releasing factor and for its reversal by nociceptin/orphanin FQ. The Journal of Neuroscience: the official journal of the Society for Neuroscience, Washington, v. 23, n. 28, p. 9445-51, Oct. 2003.

CONNOR, E. E. et al. Enhanced mitochondrial complex gene function and reduced liver size may mediate improved feed efficiency of beef cattle during compensatory growth. Functional \& Integrative Genomics, Heidelberg, v. 10, n. 1, p. 39-51, Mar. 2010 .

CREWS JR, D. H. Genetics of efficient feed utilization and national cattle evaluation : a review. Genetics and Molecular Research: GMR, Ribeirão Preto, v. 4, n. 2, p. 152$165,2005$.

DAVIS, M. P.; BROOKS, M. A.; KERLEY, M. S. Relationship between residual feed intake and lymphocyte mitochondrial complex protein concentration and ratio in crossbred steers. Journal of Animal Science, Cary, v. 94, n. 4, p. 1587-1591, 2016.

DE LA FUENTE, A. From 'differential expression' to 'differential networking' identification of dysfunctional regulatory networks in diseases. Trends in Genetics: TIG, Amsterdam, v. 26, n. 7, p. 326-33, July. 2010.

DE OLIVEIRA, P. S. N. et al. Identification of genomic regions associated with feed efficiency in Nelore cattle. BMC Genetics, London, v. 15, n. 1, art. 100, Jan. 2014.

DEBLON, N. et al. Mechanisms of the anti-obesity effects of oxytocin in diet-induced obese rats. PLoS One, San Francisco, v. 6, n. 9, p. e25565, 2011.

DENIZ, E.; ERMAN, B. Long noncoding RNA (lincRNA), a new paradigm in gene expression control. Functional \& Integrative Genomics, Heidelberg, v. 17, n. 2-3, p. 135-143, 2017.

DERRIEN, T. et al. The GENCODE v7 catalog of human long noncoding RNAs: Analysis of their gene structure, evolution, and expression. Genome Research, Cold Spring Harbor, v. 22, n. 9, p. 1775-1789, 2012.

DOBIN, A. et al. STAR: ultrafast universal RNA-seq aligner. Bioinformatics, Oxford, v. 29, n. 1, p. 15-21, Jan. 2013.

ENRIGHT, A. J. et al. MicroRNA targets in Drosophila. Genome Biology, London, v. 5, n. 1, p. R1, 2003.

FANG, S. et al. NONCODEV5: A comprehensive annotation database for long noncoding RNAs. Nucleic Acids Research, Oxford, v. 46, n. D1, p. D308-D314, 2018.

FERREIRA JÚNIOR, R. J. et al. Evidence of negative relationship between female fertility and feed efficiency in Nellore cattle1,2. Journal of Animal Science, Cary, v. 96, n. 10, p. 4035-4044, 2018.

FONSECA, L. D. et al. Livel proteomics unreveal methabolic pathways related to feed efficiency in Beef Cattle. Pirassununga: [s.n.], 2018. 
FONTOURA, A. B. P. et al. Associations between feed efficiency, sexual maturity and fertility-related measures in young beef bulls. Animal: the international journal of animal bioscience, Cambridge, v. 10, n. 1, p. 96-105, Jan. 2016.

FOOD AND AGRICULTURE ORGANIZATION OF THE UNITED NATIONS FAO. 2050: a third more mouths to feed. Rome: FAO, 2009.

FOOTE, A. P. et al. Relationship of glucocorticoids and hematological measures with feed intake, growth, and efficiency of finishing beef cattle. Journal of Animal Science, Cary, v. 94, n. 1, p. 275-283, 2016 a.

FOOTE, A. P. et al. Leptin concentrations in finishing beef steers and heifers and their association with dry matter intake, average daily gain, feed efficiency, and body composition. Domestic Animal Endocrinology, Philadelphia, v. 55, p. 136-141, Jan. 2016b.

FRANCISCO, C. L. et al. Impacts of temperament on Nellore cattle: physiological responses, feedlot performance, and carcass characteristics. Journal of Animal Science, Cary, v. 93, n. 11, p. 5419, Nov. 2015.

FULLER, T. F. et al. Weighted gene coexpression network analysis strategies applied to mouse weight. Mammalian genome: official journal of the International Mammalian Genome Society, New York, v. 18, n. 6-7, p. 463-72, July. 2007.

GAO, D. et al. Methylation of TMEM176A is an independent prognostic marker and is involved in human colorectal cancer development. Epigenetics, New York, v. 12, n. 7, p. 575-583, 2017.

GHOSH, S.; CHAN, C. K. K. Analysis of RNA-Seq data using tophat and cufflinks. Methods in Molecular Biology, Clifton, v. 1374, p. 339-61, 2016.

GIMPL, G. et al. Expression of the human oxytocin receptor in baculovirus-infected insect cells: high-affinity binding is induced by a cholesterol-cyclodextrin complex. Biochemistry, Washington, v. 34, n. 42, p. 13794-13801, 1995.

GIMPL, G.; FAHRENHOLZ, F. The oxytocin receptor system: structure, function, and regulation. Physiological Reviews, Rockville, v. 81, n. 2, p. 629-83, 2001.

GIRALT, M.; GAVALDÀ-NAVARRO, A.; VILLARROYA, F. Fibroblast growth factor-21, energy balance and obesity. Molecular and Cellular Endocrinology, Clifton, v. 418, p. 66-73, 2015.

GOMES, R. C. et al. Feedlot performance, feed efficiency reranking, carcass traits, body composition, energy requirements, meat quality and calpain system activity in Nellore steers with low and high residual feed intake. Livestock Science, Amsterdam, v. 150, n. 1-3, p. 265-273, Dec. 2012.

GONANO, C. et al. The relationship between feed efficiency and the circadian profile of blood plasma analytes measured in beef heifers at different physiological stages. Animal: an international journal of animal bioscience, Cambridge, v. 8, n. 10, p. 16841698, 2014.

GUAN, L. L. et al. Linkage of microbial ecology to phenotype: correlation of rumen microbial ecology to cattle's feed efficiency. FEMS microbiology letters, Oxford, v. 
288, n. 1, p. 85-91, 1 nov. 2008.

HANNUN, Y. A.; OBEID, L. M. The Ceramide-centric universe of lipid-mediated cell regulation: stress encounters of the lipid kind. The Journal of Biological Chemistry, Bethesda, v. 277, n. 29, p. 25847-50, July. 2002.

HARRIS, R. B. S. Chronic and acute effects of stress on energy balance: are there appropriate animal models? American Journal of Physiology. Regulatory, Integrative and Comparative Physiology, Bethesda, v. 308, n. 4, p. R250-R265, 2015.

HAYES, B. J.; LEWIN, H. A; GODDARD, M. E. The future of livestock breeding: genomic selection for efficiency, reduced emissions intensity, and adaptation. Trends in Genetics: TIG, Amsterdam, v. 29, n. 4, p. 206-14, Apr. 2013.

HELGESON, S. C.; SCHMUTZ, S. M. Genetic variation in the pro-melaninconcentrating hormone gene affects carcass traits in Bos taurus cattle. Animal Genetics, Chichester, v. 39, n. 3, p. 310-315, 2008.

HERD, R. M.; ARTHUR, P. F. Physiological basis for residual feed intake. Journal of Animal Science, Cary, v. 87, p. E64-71, 2009. 14 Supplement.

HERD, R. M.; ODDY, V. H.; RICHARDSON, E. C. Biological basis for variation in residual feed intake in beef cattle. 1. Review of potential mechanisms. Australian Journal of Experimental Agriculture, Clayton, v. 44, n. 5, p. 423, 2004.

HERMAN, J. P.; CULLINAN, W. E. Neurocircuitry of stress: central control of the hypothalamo-pituitary-adrenocortical axis. Trends in Neurosciences, Kidlington, $v$. 20, n. 2, p. 78-84, fev. 1997.

HERMAN, J. P.; MUELLER, N. K.; FIGUEIREDO, H. Role of GABA and glutamate circuitry in hypothalamo-pituitary-adrenocortical stress integration. Annals of the New York Academy of Sciences, Malden, v. 1018, n. 1, p. 35-45, June. 2004.

HERRMANN, C. et al. i-cisTarget: An integrative genomics method for the prediction of regulatory features and cis-regulatory modules. Nucleic Acids Research, Oxford, v. 40, n. 15, p. e114, 2012.

HERMANN-KLEITER, N.; BAIER, G. Orphan nuclear receptor NR2F6 acts as an essential gatekeeper of Th17 CD4+ T cell effector functions. Cell Communication and Signaling, London, v. 12, n. 1, p. 1-12, 2014.

HERMANN-KLEITER, N. et al. The Nuclear Orphan receptor NR2F6 suppresses lymphocyte activation and T Helper 17-dependent autoimmunity. Immunity, Cambridge, v. 29, n. 2, p. 205-216, 2008.

HO, J. M.; BLEVINS, J. E. Coming full circle: contributions of central and peripheral oxytocin actions to energy balance. Endocrinology, Cary, v. 154, n. 2, p. 589-596, 2013.

HOFACKER, I. L. et al. Fast folding and comparison of RNA secondary structures. Monatshefte für Chemie, Wien, v. 125, n. 2, p. 167-188, 1989.

HOQUE, M. A.; KATOH, K.; SUZUKI, K. Genetic associations of residual feed intake with serum insulin-like growth factor-I and leptin concentrations, meat quality, and 
carcass cross sectional fat area ratios in Duroc pigs. Journal of Animal Science, Cary, v. 87, n. 10, p. 3069-75, Oct. 2009.

HU, Z. L. et al. Animal QTLdb: an improved database tool for livestock animal QTL/association data dissemination in the post-genome era. Nucleic Acids Research, Oxford, v. 41, n. Database issue, p. D871-9, Jan. 2013.

HUDSON, N. J.; DALRYMPLE, B. P.; REVERTER, A. Beyond differential expression: the quest for causal mutations and effector molecules. BMC Genomics, London, v. 13, art. 356, 2012a.

HUDSON, N. J.; DALRYMPLE, B. P.; REVERTER, A. Beyond differential expression: the quest for causal mutations and effector molecules. BMC Genomics, London, v. 13, art. 356, Jan. 2012b.

HUDSON, N. J.; REVERTER, A.; DALRYMPLE, B. P. A differential wiring analysis of expression data correctly identifies the gene containing the causal mutation. PLoS Computational Biology, San Francisco, v. 5, n. 5, p. e1000382, May. 2009.

HUNTINGTON, G. B. et al. Net absorption and oxygen consumption by Holstein steers fed alfalfa or orchardgrass silage at two equalized intakes. Journal of Animal Science, Cary, v. 66, n. 5, p. 1292-302, May. 1988.

IDEKER, T.; KROGAN, N. J. Differential network biology. Molecular Systems Biology, Chichester, v. 8, n. 565, p. 1-9, 2012.

INSTITUTE FOR SYSTEMS BIOLOGY - ISB. What is systems biology. Seattle, 2018.

ITO, M. et al. Characterization of MCH-mediated obesity in mice. American Journal of Physiology: Endocrinology and Metabolism, Rockville, v. 284, n. 5, p. E940-E945, 2003.

JAGER, N. de et al. Chronic exposure to anabolic steroids induces the muscle expression of oxytocin and a more than fiftyfold increase in circulating oxytocin in cattle. Physiological Genomics, Bethesda, v. 43, n. 9, p. 467-478, 2011.

JANKY, R. et al. iRegulon: from a gene list to a gene regulatory network using large motif and track collections. PLoS Computational Biology, San Francisco, v. 10, n. 7, p. e1003731, 2014.

JÉGOU, M. et al. Whole Blood Transcriptomics Is Relevant to Identify Molecular Changes in Response to Genetic Selection for Feed Efficiency and Nutritional Status in the Pig. PloS one, San Francisco, v. 11, n. 1, p. e0146550, 1 jan. 2016.

JING, L. et al. Transcriptome analysis of mRNA and miRNA in skeletal muscle indicates an important network for differential Residual Feed Intake in pigs. Scientific Reports, London, v. 5, p. 11953, jan. 2015.

KANG, Y. J. et al. CPC2: A fast and accurate coding potential calculator based on sequence intrinsic features. Nucleic Acids Research, Oxford, v. 45, n. W1, p. W12W16, 2017.

KARISA, B.; MOORE, S.; PLASTOW, G. Analysis of biological networks and 
biological pathways associated with residual feed intake in beef cattle. Animal Science Journal, Cary, v. 85, n. 4, p. 374-87, Apr. 2014.

KEEL, B. N. et al. RNA-Seq Meta-analysis identifies genes in skeletal muscle associated with gain and intake across a multi-season study of crossbred beef steers. BMC Genomics, London, v. 19, n. 1, art. 430, 2018.

KELLY, A. K. et al. Stress and immunological response of heifers divergently ranked for residual feed intake following an adrenocorticotropic hormone challenge. Journal of Animal Science and Biotechnology, London, v. 8, art. 65, 2017.

KELLY, A. K. et al. Expression of key genes of the somatotropic axis in longissimus dorsi muscle of beef heifers phenotypically divergent for residual feed intake. Journal of Animal Science, Cary, v. 91, n. 1, p. 159-167, 2014.

KELLY, A. K. et al. Effect of divergence in residual feed intake on feeding behavior, blood metabolic variables, and body composition traits in growing beef heifers. Journal of Animal Science, v. 88, n. 1, p. 109-23, Jan. 2010a.

KELLY, A. K. et al. Repeatability of feed efficiency, carcass ultrasound, feeding behavior, and blood metabolic variables in finishing heifers divergently selected for residual feed intake. Journal of Animal Science, Cary, v. 88, n. 10, p. 3214-25, Oct. $2010 b$.

KENNY, D. A. et al. Invited review: Improving feed efficiency of beef cattle - the current state of the art and future challenges. Animal, Cambridge, v. 12, n. 9, p. 18151826, Sept. 2018.

KERN, C. et al. Genome-wide identification of tissue-specific long non-coding RNA in three farm animal species. BMC Genomics, London, v. 19, n. 1, art. 684, Dec. 2018.

KERN, R. J. et al. Ruminal expression of the NQO1, RGS5, and ACAT1 genes may be indicators of feed efficiency in beef steers. Animal Genetics, Chichester, v. 48, n. 1, p. 90-92, 2017.

KITAOKA, M. et al. A stimulatory effect of somatostatin: enhancement of activin Amediated FSH secretion in rat pituitary cells. Biochemical and Biophysical Research Communications, Philadelphia, v. 162, n. 3, p. 958-962, 1989.

KLEIN, U.; FAHRENHOLZ, F. Reconstitution of the myometrial oxytocin receptor into proteoliposomes: dependence of oxytocin binding on cholesterol. European Journal of Biochemistry, Chichester, v. 220, n. 2, p. 559-567, 1994.

KLEPSCH, V.; HERMANN-KLEITER, N.; BAIER, G. Beyond CTLA-4 and PD-1: Orphan nuclear receptor NR2F6 as T cell signaling switch and emerging target in cancer immunotherapy. Immunology Letters, Amsterdam, v. 178, p. 31-36, 2016.

KNOCKAERT, L.; FROMENTY, B.; ROBIN, M. A. Mechanisms of mitochondrial targeting of cytochrome P450 2E1: physiopathological role in liver injury and obesity. The FEBS Journal, Oxford, v. 278, n. 22, p. 4252-60, Nov. 2011.

KNOTT, S. A. et al. Feed efficiency and body composition are related to cortisol response to adrenocorticotropin hormone and insulin-induced hypoglycemia in rams.

Domestic Animal Endocrinology, Philadelphia, v. 39, n. 2, p. 137-146, 2010. 
KNOTT, S. A. et al. Rams with poor feed efficiency are highly responsive to an exogenous adrenocorticotropin hormone (ACTH) challenge. Domestic Animal Endocrinology, Philadelphia, v. 34, n. 3, p. 261-268, 2008.

KOCH, R. M. et al. Efficiency of Feed Use in Beef Cattle. Journal of Animal Science, Cary, v. 22, p. 486-494, 1963.

KOUFARIOTIS, L. T. et al. A catalogue of novel bovine long noncoding RNA across 18 tissues. PLoS One, San Francisco, v. 10, n. 10, p. 1-24, 2015.

ŁABAJ, P. P. et al. Characterization and improvement of RNA-Seq precision in quantitative transcript expression profiling. Bioinformatics, Oxford, v. 27, n. 13, p. i383-91, July. 2011.

LAM, S. et al. Associations of rumen parameters with feed efficiency and sampling routine in beef cattle. Animal, Cambridge, v. 12, n. 7, p. 1442-1450, July. 2018.

LANCASTER, P. A. et al. Relationships between residual feed intake and hepatic mitochondrial function in growing beef cattle. Journal of Animal Science, Cary, v. 92, n. 7, p. 3134-41, July. 2014.

LANGFELDER, P.; HORVATH, S. WGCNA: an R package for weighted correlation network analysis. BMC Bioinformatics, London, v. 9, p. 559, Jan. 2008.

LECHTENBERG, K. F. et al. Bacteriologic and histologic studies of hepatic abscesses in cattle. American Journal of Veterinary Research, Schaumburg, v. 49, n. 1, p. 5862, Jan. 1988.

LI, F.; GUAN, L. L. Metatranscriptomic profiling reveals linkages between the active rumen microbiome and feed efficiency in beef cattle. Applied and Environmental Microbiology, v. 83, n. 9, p. e00061-17, 2017.

LI, H. et al. The sequence alignment/map format and SAMtools. Bioinformatics, Oxford, v. 25, n. 16, p. 2078-9, Aug. 2009.

LI, M. et al. Long non-coding RNA ADNCR suppresses adipogenic differentiation by targeting miR-204. Biochimica et Biophysica Acta, Amsterdam, v. 1859, n. 7, p. 871882, July. 2016.

LIU, D.; BLACK, B. L.; DERYNCK, R. TGF-beta inhibits muscle differentiation through functional repression of myogenic transcription factors by Smad3. Genes and Development, Woodbury, v. 15, n. 22, p. 2950-2966, 2001.

LIU, H. et al. Post-weaning blood transcriptomic differences between Yorkshire pigs divergently selected for residual feed intake. BMC Genomics, London, v. 17, n. 1, art. 73, Jan. 2016.

LOUVEAU, I. et al. Increased expressions of genes and proteins involved in mitochondrial oxidation and antioxidant pathway in adipose tissue of pigs selected for a low residual feed intake. Journal of Animal Science, Cary, v. 94, n. 12, p. 5042-5054, 2016.

LOVE, T. M. Oxytocin, motivation and the role of dopamine. Pharmacology

Biochemistry and Behavior, Philadelphia, v. 119, p. 49-60, 2014. 
LU, D. et al. Genome-wide association analyses for growth and feed efficiency traits in beef cattle. Journal of Animal Science, Cary, v. 91, n. 8, p. 3612-33, Aug. 2013.

LUDWIG, D. S. et al. Melanin-concentrating hormone overexpression in transgenic mice leads to obesity and insulin resistance. The Journal of Clinical Investigation, Ann Arbor, v. 107, n. 3, p. 379-386, 2001.

LUTZ, B. et al. The endocannabinoid system in guarding against fear, anxiety and stress. Nature Reviews Neuroscience, London, v. 16, n. 12, p. 705-718, 2015.

MADER, C. J. et al. Relationships among measures of growth performance and efficiency with carcass traits, visceral organ mass, and pancreatic digestive enzymes in feedlot cattle. Journal of Animal Science, Cary, v. 87, n. 4, p. 1548-57, Apr. 2009.

MAERE, S.; HEYMANS, K.; KUIPER, M. BiNGO: a cytoscape plugin to assess overrepresentation of gene ontology categories in biological networks. Bioinformatics, Oxford, v. 21, n. 16, p. 3448-3449, 2005.

MANI, V. et al. Intestinal integrity, endotoxin transport and detoxification in pigs divergently selected for residual feed intake. Journal of Animal Science, Cary, v. 91, n. 5, p. 2141-50, May. 2013.

MARTELLO, L. S. et al. Infrared thermography as a tool to evaluate body surface temperature and its relationship with feed efficiency in Bos indicus cattle in tropical conditions. International Journal of Biometeorology, Heidelberg, v. 60, n. 1, p. 17381, Jan. 2016.

MATSUZAKI, T. et al. Developmental changes in hypothalamic oxytocin and oxytocin receptor mRNA expression and their sensitivity to fasting in male and female rats.

International Journal of Developmental Neuroscience, Kidlington, v. 41, p. 105-109, 2015 .

MCGEE, M. et al. Relationships of feeding behaviors with average daily gain, dry matter intake, and residual feed intake in Red Angus-sired cattle. Journal of Animal Science, Cary, v. 92, n. 11, p. 5214-21, Nov. 2014.

MCGOVERN, E. et al. 16S rRNA Sequencing reveals relationship between potent cellulolytic genera and feed efficiency in the rumen of bulls. Frontiers in Microbiology, Lausanne, v. 9, p. 1842, 2018.

MYER, P. R. et al. Rumen microbiome from steers differing in feed efficiency. PloS one, San Francisco, v. 10, n. 6, p. e0129174, jan. 2015.

MEYER, A. M. et al. Small intestinal growth measures are correlated with feed efficiency in market weight cattle, despite minimal effects of maternal nutrition during early to midgestation. Journal of Animal Science, Cary, v. 92, n. 9, p. 3855-67, Sept. 2014.

MILLIGAN, M. J.; LIPOVICH, L. Pseudogene-derived lncRNAs: emerging regulators of gene expression. Frontiers in Genetics, Lausanne, v. 5, p. 476, 2015.

MONTANHOLI, Y. R. et al. Erratum to: Liver morphometrics and metabolic blood profile across divergent phenotypes for feed efficiency in the bovine. Acta Veterinaria Scandinavica, Vanloese, v. 59, p. 24, 2017. 
MONTANHOLI, Y. R. et al. Seminal plasma protein concentrations vary with feed efficiency and fertility-related measures in young beef bulls. Reproductive Biology, Warsaw, v. 16, n. 2, p. 147-156, 2016.

MONTANHOLI, Y. et al. Small intestine histomorphometry of beef cattle with divergent feed efficiency. Acta Veterinaria Scandinavica, Vanloese, v. 55, p. 9, Jan. 2013.

MONTANHOLI, Y. R. et al. Assessing feed efficiency in beef steers through feeding behavior, infrared thermography and glucocorticoids. Animal: an international journal of animal bioscience, Cambridge, v. 4, n. 5, p. 692-701, May. 2010.

MOTA, L. F. M. et al. Circulating leptin and its muscle gene expression in Nellore cattle with divergent feed efficiency. Journal of Animal Science and Biotechnology, London, v. 8, art. 71, 2017.

MUKIIBI, R. et al. Transcriptome analyses reveal reduced hepatic lipid synthesis and accumulation in more feed efficient beef cattle. Scientific Reports, London, v. 8, art. 7303, 2018.

MULLEN, A. C. et al. Master transcription factors determine cell-type-specific responses to TGF- $\beta$ signaling. Cell, Cambridge, v. 147, n. 3, p. 565-576, 2011.

MYER, P. R. et al. Rumen microbiome from steers differing in feed efficiency. PloS One, San Francisco, v. 10, n. 6, p. e0129174, jan. 2015.

MYER, P. R. et al. Microbial community profiles of the jejunum from steers differing in feed efficiency. Journal of Animal Science, Cary, v. 94, n. 1, p. 327-338, Jan. 2016.

MYER, P. R. et al. Analysis of the gut bacterial communities in beef cattle and their association with feed intake, growth, and efficiency. Journal of Animal Science, Cary, v. 95, n. 7, p. 3215-3224, 2017.

MYERS, M. G. et al. Obesity and leptin resistance: distinguishing cause from effect.

Trends in Endocrinology and Metabolism, Kidlington, v. 21, n. 11, p. 643-651, 2010.

NAGARAJA, T. G.; LECHTENBERG, K. F. Liver abscesses in feedlot cattle. The Veterinary Clinics of North America. Food Animal Practice, Philadelphia, v. 23, n. 2, p. 351-69, July. 2007.

NASCIMENTO, C. F. et al. Residual feed intake and blood variables in young Nellore cattle. Journal of Animal Science, Cary, v. 93, n. 3, p. 1318, Mar. 2015.

NAVAL-SAŃCHEZ, M. et al. Comparative motif discovery combined with comparative transcriptomics yields accurate targetome and enhancer predictions.

Genome Research, Cold Spring Harbor, v. 23, n. 1, p. 74-88, 2013.

NEUMANN, I. D. Involvement of the brain oxytocin system in stress coping: Interactions with the hypothalamo-pituitary-adrenal axis. Progress in Brain Research, Amsterdam, v. 139, p. 147-162, 2002.

NIAZI, F.; VALADKHAN, S. Computational analysis of functional long noncoding RNAs reveals lack of peptide-coding capacity and parallels with 3' UTRs. RNA, New York, v. 18, n. 4, p. 825-843, 2012. 
NIEUWENHUIZEN, A. G.; RUTTERS, F. The hypothalamic-pituitary-adrenal-axis in the regulation of energy balance. Physiology and Behavior, Philadelphia, v. 94, n. 2, p. 169-177, 2008.

NKRUMAH, J. D. et al. Genetic and phenotypic relationships of serum leptin concentration with performance, efficiency of gain, and carcass merit of feedlot cattle. Journal of Animal Science, Cary, v. 85, n. 9, p. 2147-55, Sept. 2007.

NKRUMAH, J. D. et al. Relationships of feedlot feed efficiency, performance, and feeding behavior with metabolic rate, methane production, and energy partitioning in beef cattle. Journal of Animal Science, Cary, v. 84, n. 1, p. 145-53, Jan. 2006.

NOVAIS, F. J. et al. Serum metabolomics predicts biological processes associated to feed efficiency in beef cattle [under review]. Scientific Reports, London, 2018.

NOBLE, D. Systems biology and the heart. BioSystems, v.83, p. 75-80, 2006.

OKONECHNIKOV, K.; CONESA, A.; GARCÍA-ALCALDE, F. Qualimap 2: advanced multi-sample quality control for high-throughput sequencing data.

Bioinformatics, Oxford, v. 32, n. 2, p. btv566, Oct. 2015.

OLSON, M. V. The human genome project. Proceedings of the National Academy of Sciences of the United States of America, v. 90, n. 10, p. 4338-44, 15 maio 1993.

OWENS, F. N. et al. Acidosis in cattle: a review. Journal of Animal Science, Cary, v. 76, n. 1, p. 275-86, Jan. 1998.

PAPADIMITRIOU, A.; PRIFTIS, K. N. Regulation of the hypothalamic-pituitaryadrenal axis. Neuroimmunomodulation, Basel, v. 16, n. 5, p. 265-271, 2009.

PARADIS, F. et al. Transcriptomic analysis by RNA sequencing reveals that hepatic interferon-induced genes may be associated with feed efficiency in beef heifers.

Journal of Animal Science, Cary, v. 93, n. 7, p. 3331, July. 2015.

PARKER, J. A.; BLOOM, S. R. Hypothalamic neuropeptides and the regulation of appetite. Neuropharmacology, Kidlington, v. 63, n. 1, p. 18-30, 2012.

PAZ, H. A. et al. Rumen bacterial community structure impacts feed efficiency in beef cattle. Journal of Animal Science, Cary, v. 96, n. 3, p. 1045-1058, Apr. 2018.

PEREIRA, F. A.; TSAI, M. J.; TSAI, S. Y. COUP-TF orphan nuclear receptors in development and differentiation. Cellular and Molecular Life Sciences: CMLS, Basel, v. 57, n. 10, p. 1388-1398, 2000.

PERKINS, S. D. et al. Residual feed intake studies in Angus-sired cattle reveal a potential role for hypothalamic gene expression in regulating feed efficiency. Journal of Animal Science, Cary, v. 92, n. 2, p. 549-60, Feb. 2014a.

PERKINS, S. D. et al. Effect of residual feed intake on hypothalamic gene expression and meat quality in Angus-sired cattle grown during the hot season. Journal of Animal Science, Cary, v. 92, n. 4, p. 1451-61, Apr. 2014b.

POLIZEL, G. H. G. et al. Genetic correlations and heritability estimates for dry matter intake, weight gain and feed efficiency of Nellore cattle in feedlot. Livestock Science, 
v. 214 , p. $209-210,2018$

POTIER, D. et al. Mapping gene regulatory networks in drosophila eye development by large-scale transcriptome perturbations and motif inference. Cell Reports, New York, v. 9, n. 6, p. 2290-2303, 2014.

PUGLISI-ALLEGRA, S.; ANDOLINA, D. Serotonin and stress coping. Behavioural Brain Research, Amsterdam, v. 277, p. 58-67, Jan. 2015.

PURDY, R. H. et al. Stress-induced elevations of gamma-aminobutyric acid type A receptor-active steroids in the rat brain. Proceedings of the National Academy of Sciences of the United States of America, Washington, v. 88, n. 10, p. 4553-7, May. 1991.

QUINN, J. J.; CHANG, H. Y. Unique features of long non-coding RNA biogenesis and function. Nature Reviews. Genetics, London, v. 17, p. 47-62, 2016.

RAMAYO-CALDAS, Y. et al. Integrative approach using liver and duodenum RNASeq data identifies candidate genes and pathways associated with feed efficiency in pigs. Scientific Reports, London, v. 8, art. 558, 2018.

RAMOS, M. H.; KERLEY, M. S. Mitochondrial complex I protein differs among residual feed intake phenotype in beef cattle. Journal of Animal Science, Cary, v. 91, n. 7, p. 3299-304, July. 2013.

RANDEL, R. D.; WELSH, T. H. Joint alpharma-beef species symposium: interactions of feed efficiency with beef heifer reproductive development. Journal of Animal Science, Cary, v. 91, n. 3, p. 1323-8, Mar. 2013.

REVERTER, A. et al. Regulatory impact factors: unraveling the transcriptional regulation of complex traits from expression data. Bioinformatics, Oxford, v. 26, n. 7, p. 896-904, 2010.

REVERTER, A. et al. Validation of alternative methods of data normalization in gene co-expression studies. Bioinformatics, Oxford, v. 21, n. 7, p. 1112-1120, 2005.

REY, R. et al. Anti-müllerian hormone and testosterone serum levels are inversely during normal and precocious pubertal development. Journal of Clinical

Endocrinology and Metabolism, Cary, v. 77, n. 5, p. 1220-1226, 1993.

RICE, P.; LONGDEN, L.; BLEASBY, A. EMBOSS: the european molecular biology open software suite. Trends in Genetics: TIG, Amsterdam, v. 16, n. 6, p. 276-277, 2000 .

RICHARDSON, E. C. et al. Metabolic differences in Angus steers divergently selected for residual feed intake. Australian Journal of Experimental Agriculture, Clayton, v. 44, n. 5, p. 441, 2004.

RIEBE, C. J.; WOTJAK, C. T. Endocannabinoids and stress. Stress, Abingdon, v. 14, n. 4, p. 384-397, 2011.

ROJKITTIKHUN, T.; UVNÄS-MOBERG, K.; EINARSSON, S. Plasma oxytocin, prolactin, insulin and LH after $24 \mathrm{~h}$ of fasting and after refeeding in lactating sows.

Acta Physiologica Scandinavica, Chichester, v. 148, n. 4, p. 413-419, 1993. 
ROLF, M. M. et al. Genome-wide association analysis for feed efficiency in Angus cattle. Animal Genetics, Chichester, v. 43, n. 4, p. 367-374, Oct. 2011.

ROTH, R. A. et al. Is exposure to bacterial endotoxin a determinant of susceptibility to intoxication from xenobiotic agents? Toxicology and Applied Pharmacology, v. 147, n. 2, p. 300-311, 1997.

SALLEH, M. S. et al. RNA-Seq transcriptomics and pathway analyses reveal potential regulatory genes and molecular mechanisms in high- and low-residual feed intake in Nordic dairy cattle. BMC Genomics, London, v. 18, n. 1, art. 258, Dec. 2017.

SALVIANO-SILVA, A. et al. Besides pathology: long non-coding RNA in cell and tissue homeostasis. Non-Coding RNA, Basel, v. 4, n. 1, p. E3, 2018.

SANTANA, M. H. et al. Single nucleotide polymorphisms in genes linked to ion transport and regulation of appetite and their associations with weight gain, feed efficiency and intake of Nellore cattle. Livestock Science, Amsterdam, v. 165, n. 1, p. 33-36, 2014a.

SANTANA, M. H. et al. Genome-wide association analysis of feed intake and residual feed intake in Nellore cattle. BMC Genomics, London, v. 15, n. 1, art. 21, Jan. 2014b.

SANTANA, M. H. A. et al. Genome-wide association analysis of feed intake and residual feed intake in Nellore cattle. BMC Genetics, London, v. 15, art. 21, 2014c.

SANTANA, M. H. A. et al. Feed efficiency and its correlations with carcass traits measured by ultrasound in Nellore bulls. Livestock Science, Amsterdam, v. 145, n. 1-3, p. 252-257, May. 2012.

SARTIN, J. L.; WHITLOCK, B. K.; DANIEL, J. A. Triennial growth symposium: neural regulation of feed intake: modification by hormones, fasting, and disease. Journal of Animal Science, Cary, v. 89, n. 7, p. 1991-2003, July. 2011.

SAVIC, D. et al. CETCh-seq: CRISPR epitope tagging ChIP-seq of DNA-binding proteins. Genome Research, v. 25, n. 10, p. 1581-1589, 2015.

SCHMIERER, B.; HILL, C. S. TGF $\beta$-SMAD signal transduction: molecular specificity and functional flexibility. Nature Reviews. Molecular Cell Biology, London, v. 8, n. 12, p. 970-82, 2007.

SEAL, C. J.; REYNOLDS, C. K. Nutritional implications of gastrointestinal and liver metabolism in ruminants. Nutrition Research Reviews, Cambridge, v. 6, n. 1, p. 185 208, Jan. 1993.

SESTA, A. et al. Role of the ubiquitin/proteasome system on ACTH turnover in rat corticotropes. Endocrine, p. 1-7, 2018.

SHAFFER, K. S. et al. Residual feed intake, body composition, and fertility in yearling beef heifers. Journal of Animal Science, Cary, v. 89, n. 4, p. 1028-34, Apr. 2011.

SHANNON, P. et al. Cytoscape: a software environment for integrated models of biomolecular interaction networks. Genome Research, Cold Spring Harbor, v. 13, n. 11, p. 2498-504, Nov. 2003. 
SHERMAN, E. L. et al. Identification of polymorphisms influencing feed intake and efficiency in beef cattle. Animal Genetics, Chichester, v. 39, n. 3, p. 225-31, June. 2008.

SHERMAN, E. L.; NKRUMAH, J. D.; MOORE, S. S. Whole genome single nucleotide polymorphism associations with feed intake and feed efficiency in beef cattle. Journal of Animal Science, Cary, v. 88, n. 1, p. 16-22, Jan. 2010.

SHIN, J. H. et al. Genome-wide ChIP-seq mapping and analysis reveal butyrate-induced acetylation of $\mathrm{H} 3 \mathrm{~K} 9$ and $\mathrm{H} 3 \mathrm{~K} 27$ correlated with transcription activity in bovine cells. Functional and Integrative Genomics, Heidelberg, v. 12, n. 1, p. 119-130, 2012.

SHINDO, T. et al. Upregulation of endothelin-1 and adrenomedullin gene expression in the mouse endotoxin shock model. Journal of Cardiovascular Pharmacology, New York, v. 31, p. S541-4, 1998. Supplement 1.

SHOJAIE, A. Pathway \& network analysis of omics data. Washington: University of Seattle, 2018.

SHOJI, H. et al. Endotoxin markedly elevates plasma concentration and gene transcription of adrenomedullin in rat. Biochemical and Biophysical Research Communications, Philadelphia, v. 215, n. 2, p. 531-537, 1995.

SIGNAL, B.; GLOSS, B. S.; DINGER, M. E. Computational approaches for functional prediction and characterisation of long noncoding RNAs. Trends in Genetics, Amsterdam, v. 32, n. 10, p. 620-637, 2016.

SKILBECK, K. J.; JOHNSTON, G. A. R.; HINTON, T. Stress and GABA A receptors. Journal of Neurochemistry, Chichester, v. 112, n. 5, p. 1115-1130, Mar. 2010.

SNELLING, W. M. et al. Breeding and genetics symposium: networks and pathways to guide genomic selection. Journal of Animal Science, Cary, v. 91, p. 537-552, 2013.

SOMINSKY, L.; SPENCER, S. J. Eating behavior and stress: a pathway to obesity. Frontiers in Psychology, Lausanne, v. 5, art. 434, 2014.

STELZER, G. et al. The GeneCards suite: from gene data mining to disease genome sequence analyses. Current Protocols in Bioinformatics, Hoboken, v. 54, p. 1.30.11.30.33, 2016.

STOWERS, L.; CAMERON, P.; KELLER, J. A. Ominous odors: olfactory control of instinctive fear and aggression in mice. Current Opinion in Neurobiology, Kidlington, v. 23, n. 3, p. 339-45, June. 2013.

SUN, X. et al. The developmental transcriptome sequencing of bovine skeletal muscle reveals a long noncoding RNA, IncMD, promotes muscle differentiation by sponging miR-125b. Biochimica et Biophysica Acta, Amsterdam, v. 1863, n. 11, p. 2835-2845, Nov. 2016.

SWAMI, M. Networking complex traits. Nature Reviews. Genetics, London, v. 10, art. 2566, 2009.

SZKLARCZYK, D. et al. STRING v10: Protein-protein interaction networks, integrated over the tree of life. Nucleic Acids Research, Oxford, v. 43, n. D1, p. D447-D452, 
2015.

TAKAHASHI, L. K. Olfactory systems and neural circuits that modulate predator odor fear. Frontiers in Behavioral Neuroscience, Lausanne, v. 8, art. 72, 2014.

TIZIOTO, P. C. et al. Global liver gene expression differences in Nelore steers with divergent residual feed intake phenotypes. BMC Genomics, London, v. 16, art. 242, 2015.

TONG, C. et al. Identification and characterization of long intergenic noncoding RNAs in bovine mammary glands. BMC Genomics, London, v. 18, n. 1, art. 468, Dec. 2017.

TRAPNELL, C. et al. Differential analysis of gene regulation at transcript resolution with RNA-seq. Nature Biotechnology, New York, v. 31, n. 1, p. 46-53, Jan. 2013.

TRONCHE, F.; YANIV, M. HNF1, a homeoprotein member of the hepatic transcription regulatory network. BioEssays, Cambridge, v. 14, n. 9, p. 579-87, 1992.

TYCOWSKI, K. T. et al. A small nucleolar RNA requirement for site-specific ribose methylation of rRNA in Xenopus. Proceedings of the National Academy of Sciences of the United States of America, Washington, v. 93, p. 14480-14485, Dec. 1996.

ULRICH-LAI, Y. M.; HERMAN, J. P. Neural regulation of endocrine and autonomic stress responses. Nature Reviews. Neuroscience, London, v. 10, n. 6, p. 397-409, 2009.

UNITED NATIONS, Department of Economic and Social Affairs, Population Division. World population prospects: The 2010 revision, Highlights and Advance TablesPopulation (English Edition). New York: ST/ESA/SER, 2011.

VILLAR, D. et al. Enhancer evolution across 20 mammalian species. Cell, Cambridge, v. 160, n. 3, p. 554-566, 2015.

VINCENT, A. et al. Divergent selection for residual feed intake affects the transcriptomic and proteomic profiles of pig skeletal muscle. Journal of Animal Science, Cary, v. 93, n. 6, p. 2745-58, June. 2015.

VOY, B. H. Systems genetics: a powerful approach for gene-environment interactions. The Journal of Nutrition, New York, v. 141, n. 3, p. 515-519, 2011.

WALKER, W. H.; CHENG, J. FSH and testosterone signaling in Sertoli cells. Reproduction, Cambridge, v. 130, n. 1, p. 15-28, 2005.

WALTER, L. J. et al. Association of pro-melanin concentrating hormone genotype with beef carcass quality and yield. Journal of Animal Science, Cary, v. 92, n. 1, p. 325$331,2014$.

WANG, Y. et al. Epigenetic silencing of TMEM176A promotes esophageal squamous cell cancer development. Oncotarget, v. 8, n. 41, p. 70035-70048, 2017.

WATSON-HAIGH, N. S.; KADARMIDEEN, H. N.; REVERTER, A. PCIT: an R package for weighted gene co-expression networks based on partial correlation and information theory approaches. Bioinformatics, Oxford, v. 26, n. 3, p. 411-3, Feb. 2010 . 
WEBER, K. L. et al. Identification of gene networks for residual feed intake in Angus cattle using genomic prediction and RNA-seq. PLoS One, San Francisco, v. 11, n. 3, e.0152274, 2016.

WEIKARD, R.; DEMASIUS, W.; KUEHN, C. Mining long noncoding RNA in livestock. Animal Genetics, Chichester, v. 48, n. 1, p. 3-18, 2017.

WIDMANN, P. et al. Systems biology analysis merging phenotype, metabolomic and genomic data identifies Non-SMC Condensin I Complex, Subunit G (NCAPG) and cellular maintenance processes as major contributors to genetic variability in Bovine feed efficiency. PLoS One, San Francisco, v. 10, n. 4, p. 1-22, 2015.

WISE, R. A. Dual roles of dopamine in food and drug seeking. Biological Psychiatry, Philadelphia, v. 73, n. 9, p. 819-826, 2013.

XI, Y. M. et al. Gene expression profiling of hormonal regulation related to the residual feed intake of Holstein cattle. Biochemical and Biophysical Research

Communications, Philadelphia, v. 465, n. 1, p. 19-25, Sept. 2015.

ZAREK, C. M. et al. Differential expression of genes related to gain and intake in the liver of beef cattle. BMC Research Notes, London, v. 10, art. 1, 2017.

ZHANG, B.; HORVATH, S. A general framework for weighted gene co-expression network analysis. Statistical Applications in Genetics and Molecular Biology, Berkeley, v. 4, art.17, 2005.

ZHANG, B.; KIROV, S.; SNODDY, J. WebGestalt: an integrated system for exploring gene sets in various biological contexts. Nucleic Acids Research, London, v. 33, p. W741-8, 2005.

ZHANG, X. et al. Association of residual feed intake with growth and slaughtering performance, blood metabolism, and body composition in growing lambs. Scientific Reports, London, v. 7, art. 12681, 2017.

ZHAO, M.; LI, X.; QU, H. EDdb: a web resource for eating disorder and its application to identify an extended adipocytokine signaling pathway related to eating disorder.

Science China. Life Sciences, Beijing, v. 56, n. 12, p. 1086-96, Dec. 2013.

ZHENG, X. et al. Integrated analysis of long noncoding RNA and mRNA expression profiles reveals the potential role of long noncoding RNA in different bovine lactation stages. Journal of Dairy Science, New York, p. S0022-0302, Sept. 2018. 
APÊNDICE A - Figuras Suplementares

Figura Suplementar 1 - Principais termos enriquecidos no módulo Grey60.

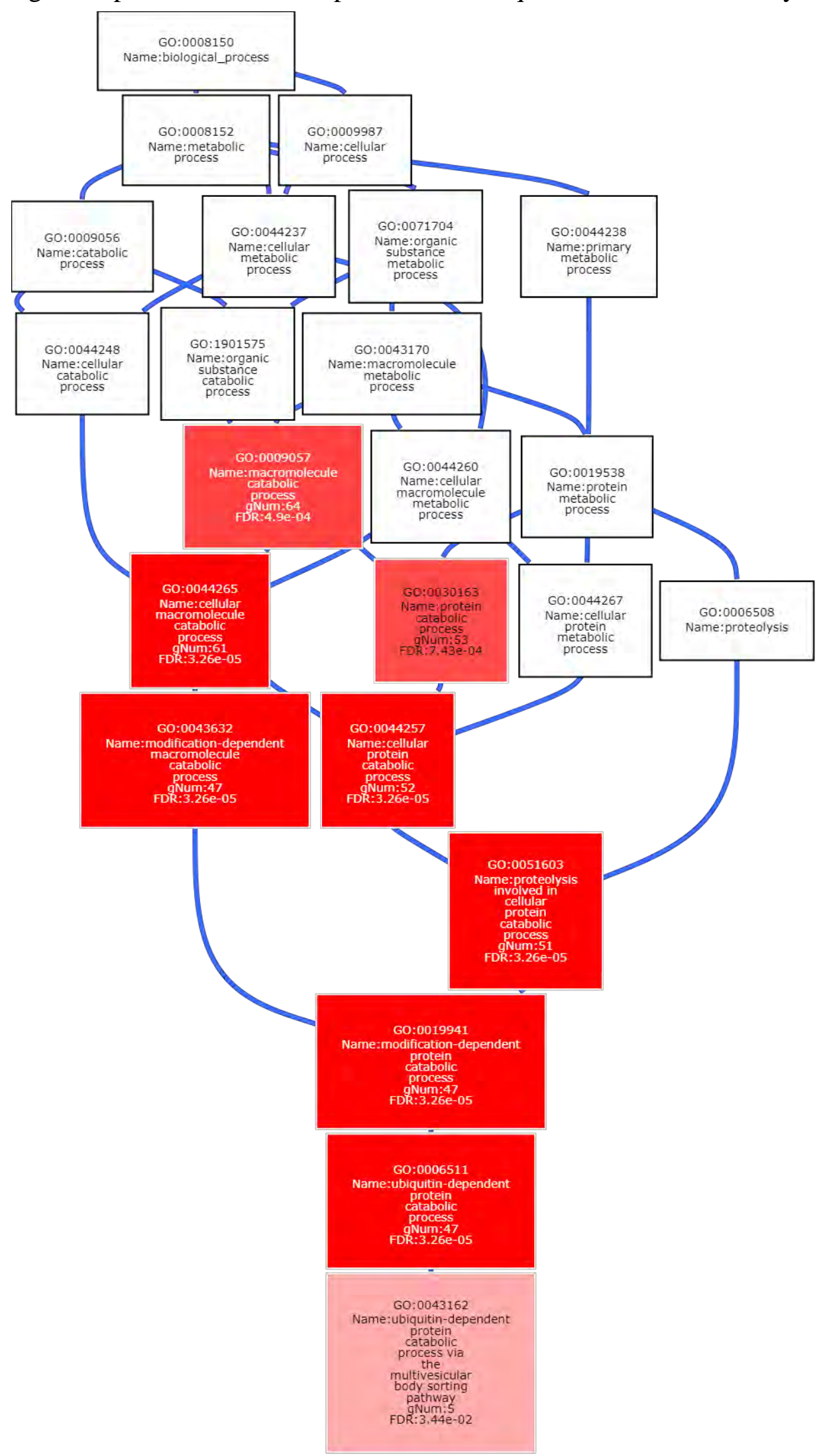


Figura Suplementar 2 - Principais termos enriquecidos no módulo Skyblue3.
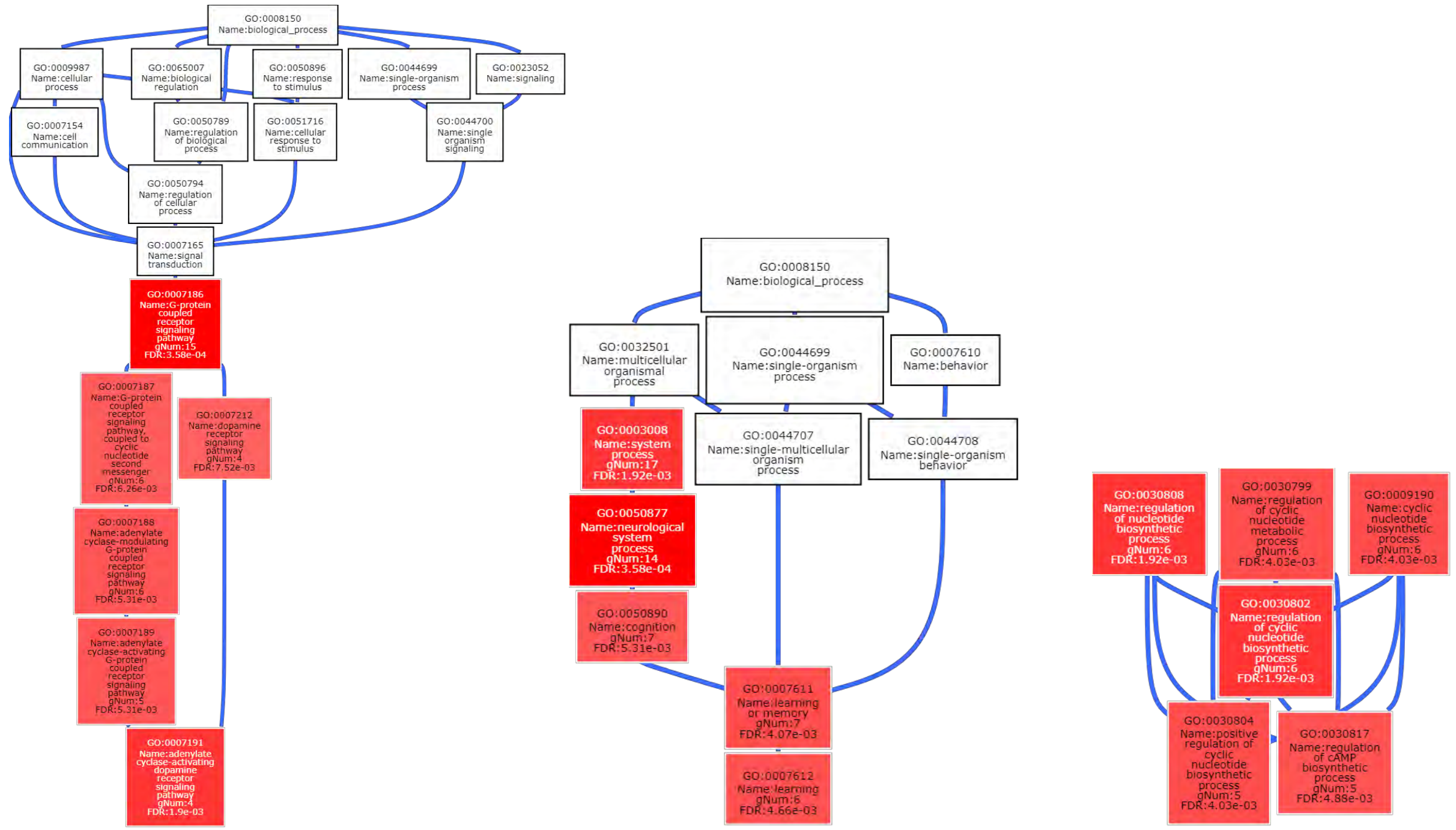
Figura Suplementar 3 - Termos enriquecidos no módulo Maroon.

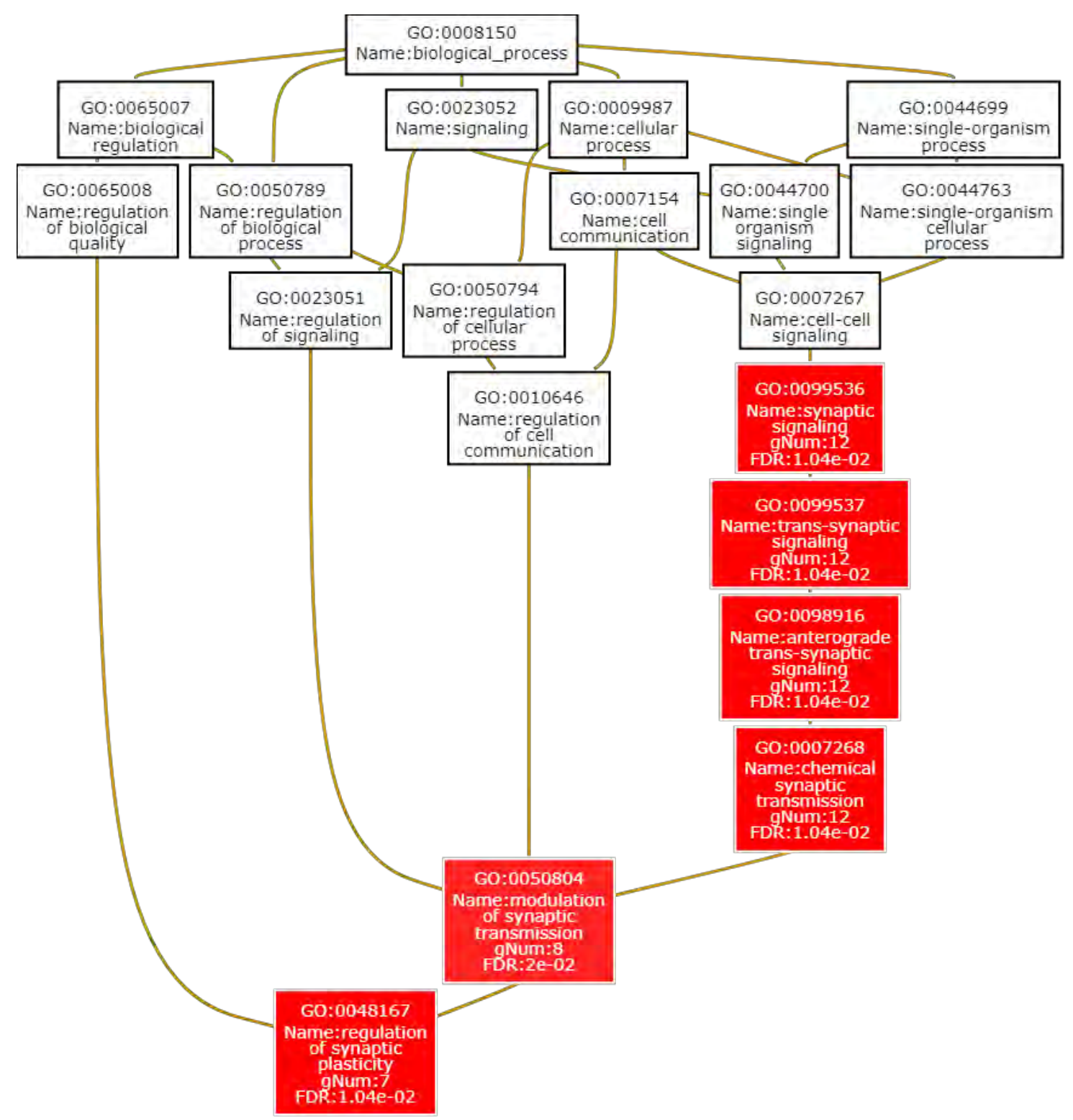


APÊNDICE B - Tabelas Suplementares

Tabela suplementar 1 - Genes diferencialmente expressos entre alta e baixa eficiência alimentar.

\begin{tabular}{|c|c|c|c|c|}
\hline Gene & Tecido & baixa EA* & alta EA* & baixa-alta EA* \\
\hline ADAMTS4 & Adrenal & 3,01 & 3,76 & $-0,75$ \\
\hline ADH6 & Adrenal & 6,30 & 4,60 & 1,71 \\
\hline $\mathrm{AMH}$ & Adrenal & 2,48 & 3,58 & $-1,10$ \\
\hline APOA1 & Adrenal & 2,92 & 2,07 & 0,85 \\
\hline ATP1A2 & Adrenal & 3,52 & 4,28 & $-0,75$ \\
\hline ATP8 & Adrenal & 13,88 & 14,42 & $-0,54$ \\
\hline AVPR1A & Adrenal & 4,14 & 4,63 & $-0,49$ \\
\hline BCL3 & Adrenal & 3,41 & 3,88 & $-0,47$ \\
\hline BLA-DQB & Adrenal & 6,81 & 6,14 & 0,67 \\
\hline BMP3 & Adrenal & 3,70 & 3,02 & 0,67 \\
\hline BOLA-DQA5 & Adrenal & 3,19 & 3,95 & $-0,76$ \\
\hline bta-mir-29c & Adrenal & 2,05 & 2,66 & $-0,62$ \\
\hline bta-mir-4657 & Adrenal & 3,25 & 3,80 & $-0,55$ \\
\hline C11H9orf116 & Adrenal & 3,34 & 3,98 & $-0,63$ \\
\hline C9orf84 & Adrenal & 2,61 & 3,35 & $-0,74$ \\
\hline CA2 & Adrenal & 5,76 & 6,66 & $-0,90$ \\
\hline CCBE1 & Adrenal & 2,21 & 2,97 & $-0,76$ \\
\hline CCL21 & Adrenal & 3,91 & 4,87 & $-0,97$ \\
\hline $\mathrm{CDO} 1$ & Adrenal & 4,60 & 5,31 & $-0,71$ \\
\hline CLDN11 & Adrenal & 2,39 & 3,17 & $-0,78$ \\
\hline CMBL & Adrenal & 6,75 & 7,24 & $-0,49$ \\
\hline CYP17A1 & Adrenal & 11,01 & 11,48 & $-0,47$ \\
\hline CYP4F2 & Adrenal & 5,37 & 5,94 & $-0,58$ \\
\hline cytb & Adrenal & 13,09 & 13,66 & $-0,56$ \\
\hline DAPL1 & Adrenal & 4,07 & 4,60 & $-0,52$ \\
\hline DPT & Adrenal & 4,61 & 5,16 & $-0,56$ \\
\hline EGR4 & Adrenal & 1,58 & 2,72 & $-1,14$ \\
\hline ENSBTAG00000000560 & Adrenal & 1,86 & 2,87 & $-1,01$ \\
\hline ENSBTAG00000009656 & Adrenal & 4.93 & 5,43 & -0.50 \\
\hline ENSBTAG00000010155 & Adrenal & 4,87 & 4,22 & 0,66 \\
\hline ENSBTAG00000020803 & Adrenal & 4,87 & 6,82 & $-1,95$ \\
\hline ENSBTAG00000023372 & Adrenal & 4,37 & 3,70 & 0,67 \\
\hline ENSBTAG00000024608 & Adrenal & 4,60 & 2,85 & 1,74 \\
\hline ENSBTAG00000027075 & Adrenal & 4,52 & 5,73 & $-1,22$ \\
\hline ENSBTAG00000027962 & Adrenal & 3,16 & 3,81 & $-0,65$ \\
\hline ENSBTAG00000031082 & Adrenal & 3,76 & 4,58 & $-0,82$ \\
\hline ENSBTAG00000031160 & Adrenal & 4,08 & 3,07 & 1,01 \\
\hline ENSBTAG00000032057 & Adrenal & 3,58 & 5,11 & $-1,53$ \\
\hline ENSBTAG00000034189 & Adrenal & 4,35 & 4,87 & $-0,51$ \\
\hline ENSBTAG00000037605 & Adrenal & 6,38 & 4,99 & 1,39 \\
\hline ENSBTAG00000045585 & Adrenal & 2,39 & 3,03 & $-0,64$ \\
\hline ENSBTAG00000046711 & Adrenal & 2,09 & 3,43 & $-1,34$ \\
\hline ENSBTAG00000047529 & Adrenal & 3,60 & 2,54 & 1,05 \\
\hline ENSBTAG00000048049 & Adrenal & 2,87 & 1,82 & 1,04 \\
\hline ENSBTAG00000048058 & Adrenal & 3,65 & 4,44 & $-0,79$ \\
\hline ENSBTAG00000048135 & Adrenal & 4,77 & 4,08 & 0,69 \\
\hline FAM43A & Adrenal & 3,84 & 3,19 & 0,65 \\
\hline FATE1 & Adrenal & 5,41 & 6,02 & $-0,62$ \\
\hline FEV & Adrenal & 1,82 & 2,88 & $-1,07$ \\
\hline FZD1 & Adrenal & 3,61 & 4,08 & $-0,47$ \\
\hline GAS2L1 & Adrenal & 5,25 & 6,01 & $-0,75$ \\
\hline GRASP & Adrenal & 3,49 & 3,96 & $-0,46$ \\
\hline GRB14 & Adrenal & 5,67 & 6,18 & $-0,51$ \\
\hline GSTA2 & Adrenal & 6,27 & 6,78 & $-0,51$ \\
\hline GSTA3 & Adrenal & 2,87 & 3,94 & $-1,07$ \\
\hline GSTA5 & Adrenal & 11,11 & 12,11 & $-1,00$ \\
\hline GSTM1 & Adrenal & 7,84 & 8,49 & $-0,65$ \\
\hline HOMER 1 & Adrenal & 2,61 & 3,25 & $-0,64$ \\
\hline
\end{tabular}


Tabela suplementar 1 - Genes diferencialmente expressos entre alta e baixa eficiência alimentar (continuação).

\begin{tabular}{|c|c|c|c|c|}
\hline Gene & Tecido & Baixa EA* & Alta EA* & Baixa-Alta EA* \\
\hline HOPX & Adrenal & 3,61 & 4,49 & $-0,88$ \\
\hline IER3 & Adrenal & 3,33 & 3,80 & $-0,47$ \\
\hline ITGA9 & Adrenal & 3,83 & 4,32 & $-0,50$ \\
\hline KBTBD6 & Adrenal & 3,84 & 4,35 & $-0,51$ \\
\hline KRT19 & Adrenal & 2,60 & 3,27 & $-0,66$ \\
\hline LBH & Adrenal & 4,99 & 5,58 & $-0,59$ \\
\hline LSR & Adrenal & 4,61 & 5,10 & $-0,49$ \\
\hline MEIS2 & Adrenal & 4,90 & 5,37 & $-0,47$ \\
\hline MKX & Adrenal & 2.29 & 3.60 & $-1,31$ \\
\hline MT1E & Adrenal & 3,69 & 4,46 & $-0,77$ \\
\hline MT1E & Adrenal & 6,78 & 7,39 & $-0,61$ \\
\hline MT-ND4L & Adrenal & 11,41 & 12,20 & $-0,79$ \\
\hline ND1 & Adrenal & 13,35 & 13,96 & $-0,61$ \\
\hline ND2 & Adrenal & 12,35 & 13,00 & $-0,65$ \\
\hline ND4 & Adrenal & 12,71 & 13,41 & $-0,70$ \\
\hline ND5 & Adrenal & 10,57 & 11,30 & $-0,73$ \\
\hline ND6 & Adrenal & 10,92 & 11,55 & $-0,62$ \\
\hline NGB & Adrenal & 3,37 & 3,89 & $-0,52$ \\
\hline NOV & Adrenal & 3,13 & 3,77 & $-0,64$ \\
\hline NPPA & Adrenal & 4,48 & 5,19 & $-0,72$ \\
\hline NPTX1 & Adrenal & 4,19 & 3,39 & 0,80 \\
\hline NPY & Adrenal & 6,93 & 8,28 & $-1,35$ \\
\hline NR4A2 & Adrenal & 4,58 & 5,13 & $-0,54$ \\
\hline NRSN1 & Adrenal & 4,72 & 3,90 & 0,82 \\
\hline OTOS & Adrenal & 5,81 & 6,46 & $-0,65$ \\
\hline PFKFB4 & Adrenal & 3,97 & 4,61 & $-0,64$ \\
\hline PLCD1 & Adrenal & 4,72 & 5,27 & $-0,55$ \\
\hline PRPS2 & Adrenal & 5,34 & 7,29 & $-1,95$ \\
\hline PTX3 & Adrenal & 2,39 & 3,00 & $-0,61$ \\
\hline RAB 17 & Adrenal & 3,01 & 3,78 & $-0,76$ \\
\hline RASL11A & Adrenal & 5,11 & 6,37 & $-1,25$ \\
\hline RBP1 & Adrenal & 6,59 & 7,25 & $-0,66$ \\
\hline RGS1 & Adrenal & 4,26 & 3,51 & 0,75 \\
\hline RHBG & Adrenal & 3,90 & 4,40 & $-0,50$ \\
\hline RHOD & Adrenal & 2,77 & 3,36 & $-0,59$ \\
\hline Saa3 & Adrenal & 6,64 & 5,61 & 1,02 \\
\hline SHH & Adrenal & 2,33 & 3,14 & $-0,81$ \\
\hline SLC7A1 & Adrenal & 3,86 & 3,21 & 0,65 \\
\hline SLIT2 & Adrenal & 3,09 & 3,60 & $-0,51$ \\
\hline SMAGP & Adrenal & 3,34 & 3,90 & $-0,56$ \\
\hline snosnR61 & Adrenal & 2,81 & 3,68 & $-0,87$ \\
\hline SOCS3 & Adrenal & 3,24 & 3,82 & $-0,58$ \\
\hline STBD1 & Adrenal & 3,70 & 4,25 & $-0,55$ \\
\hline SULT1E1 & Adrenal & 7,82 & 9,06 & $-1,24$ \\
\hline SYT1 & Adrenal & 4,21 & 3,53 & 0,68 \\
\hline TAF7L & Adrenal & 2,43 & 3,29 & $-0,86$ \\
\hline TMEM158 & Adrenal & 3,99 & 4,51 & $-0,52$ \\
\hline TMEM229B & Adrenal & 3,73 & 4,20 & $-0,47$ \\
\hline TMEM59L & Adrenal & 3,60 & 4,15 & $-0,54$ \\
\hline TNNI3 & Adrenal & 5,14 & 5,62 & $-0,47$ \\
\hline TRAF1 & Adrenal & 4,79 & 5,39 & $-0,60$ \\
\hline TSKU & Adrenal & 3,04 & 3,61 & $-0,58$ \\
\hline VWA7 & Adrenal & 3,00 & 3,56 & $-0,56$ \\
\hline ACHE & Hipotálamo & 5,95 & 4,94 & 1,01 \\
\hline ADAM11 & Hipotálamo & 2,06 & 2,78 & $-0,72$ \\
\hline ADCYAP1 & Hipotálamo & 2,97 & 1,38 & 1,60 \\
\hline ALCAM & Hipotálamo & 5,24 & 4,69 & 0,55 \\
\hline ALDH1A1 & Hipotálamo & 4,97 & 4,21 & 0,76 \\
\hline ANXA1 & Hipotálamo & 3,78 & 3,01 & 0,77 \\
\hline ASS1 & Hipotálamo & 5,27 & 4,53 & 0,74 \\
\hline BAIAP3 & Hipotálamo & 5,68 & 3,41 & 2,27 \\
\hline BLA-DQB & Hipotálamo & 6,04 & 5,26 & 0,78 \\
\hline
\end{tabular}


Tabela suplementar 1 - Genes diferencialmente expressos entre alta e baixa eficiência alimentar (continuação).

\begin{tabular}{|c|c|c|c|c|}
\hline Gene & Tecido & Baixa EA* & Alta EA* & Baixa-Alta EA* \\
\hline BTG2 & Hipotálamo & 4,15 & 3,42 & 0,73 \\
\hline C5AR1 & Hipotálamo & 3,76 & 3,06 & 0,70 \\
\hline C5H12orf75 & Hipotálamo & 3,59 & 4,34 & $-0,75$ \\
\hline CALB2 & Hipotálamo & 7,18 & 6,28 & 0,89 \\
\hline CALCR & Hipotálamo & 5,15 & 4,50 & 0,65 \\
\hline CAMK2D & Hipotálamo & 5,16 & 5,65 & $-0,49$ \\
\hline CAPS & Hipotálamo & 3,44 & 2,44 & 1,00 \\
\hline CARTPT & Hipotálamo & 3,35 & 1,83 & 1,52 \\
\hline CCDC136 & Hipotálamo & 3,80 & 4.37 & $-0,56$ \\
\hline CHGB & Hipotálamo & 6,84 & 6,04 & 0,80 \\
\hline CHRNA2 & Hipotálamo & 2,09 & 2,95 & $-0,86$ \\
\hline $\mathrm{COCH}$ & Hipotálamo & 3,88 & 2,79 & 1,09 \\
\hline COL1A2 & Hipotálamo & 3,55 & 2,73 & 0,82 \\
\hline CPNE7 & Hipotálamo & 3,11 & 4,13 & $-1,02$ \\
\hline CPXM2 & Hipotálamo & 4,23 & 3,23 & 1,00 \\
\hline CRABP1 & Hipotálamo & 5,46 & 4,77 & 0,69 \\
\hline CRTAC1 & Hipotálamo & 3,03 & 2,16 & 0,87 \\
\hline CTNNBIP1 & Hipotálamo & 4,60 & 5,08 & $-0,49$ \\
\hline CTXN1 & Hipotálamo & 5,78 & 4,82 & 0,96 \\
\hline CYB561 & Hipotálamo & 3,98 & 3,21 & 0,78 \\
\hline CYBA & Hipotálamo & 6,06 & 5,51 & 0,55 \\
\hline DIRAS2 & Hipotálamo & 3,60 & 4,27 & $-0,67$ \\
\hline DIRAS3 & Hipotálamo & 8,21 & 7,68 & 0,53 \\
\hline DLK1 & Hipotálamo & 3,64 & 1,70 & 1,93 \\
\hline DRD2 & Hipotálamo & 4,02 & 3,20 & 0,82 \\
\hline DZIP1 & Hipotálamo & 6,17 & 5,65 & 0,51 \\
\hline EDNRB & Hipotálamo & 4,13 & 3,41 & 0,71 \\
\hline EFEMP1 & Hipotálamo & 3,86 & 3,28 & 0,59 \\
\hline EGR1 & Hipotálamo & 4,74 & 3,75 & 0,99 \\
\hline ENC1 & Hipotálamo & 4,37 & 5,08 & $-0,71$ \\
\hline ENSBTAG00000004836 & Hipotálamo & 3,86 & 3,27 & 0,60 \\
\hline ENSBTAG00000010448 & Hipotálamo & 2,56 & 3,25 & $-0,69$ \\
\hline ENSBTAG00000023338 & Hipotálamo & 4,74 & 4,05 & 0,69 \\
\hline ENSBTAG00000025126 & Hipotálamo & 6,41 & 5,43 & 0,98 \\
\hline ENSBTAG00000027075 & Hipotálamo & 3,87 & 5,00 & $-1,13$ \\
\hline ENSBTAG00000027962 & Hipotálamo & 2,35 & 3,07 & $-0,72$ \\
\hline ENSBTAG00000032057 & Hipotálamo & 3,08 & 4,05 & $-0,97$ \\
\hline ENSBTAG00000035654 & Hipotálamo & 3,13 & 3,84 & $-0,71$ \\
\hline ENSBTAG00000037605 & Hipotálamo & 6,16 & 4,91 & 1,25 \\
\hline ENSBTAG00000038326 & Hipotálamo & 6,04 & 4,70 & 1,34 \\
\hline ENSBTAG00000046640 & Hipotálamo & 3,23 & 2,23 & 0,99 \\
\hline ENSBTAG00000046833 & Hipotálamo & 2,97 & 1,14 & 1,83 \\
\hline ENSBTAG00000046933 & Hipotálamo & 4,99 & 5,50 & $-0,52$ \\
\hline ENSBTAG00000047029 & Hipotálamo & 5,89 & 5,38 & 0,51 \\
\hline ENSBTAG00000047595 & Hipotálamo & 3,16 & 1,30 & 1,87 \\
\hline FKBP11 & Hipotálamo & 4,11 & 3,47 & 0,63 \\
\hline FKBP5 & Hipotálamo & 4,93 & 3,99 & 0,94 \\
\hline FOS & Hipotálamo & 5,37 & 4,74 & 0,63 \\
\hline GABBR2 & Hipotálamo & 4,38 & 5,04 & $-0,66$ \\
\hline GABRA5 & Hipotálamo & 2,33 & 3,16 & $-0,83$ \\
\hline GALNT9 & Hipotálamo & 2,22 & 2,95 & $-0,73$ \\
\hline GNG12 & Hipotálamo & 3,73 & 3,13 & 0,59 \\
\hline GPR153 & Hipotálamo & 2,12 & 2,85 & $-0,74$ \\
\hline GPX3 & Hipotálamo & 6,07 & 5,49 & 0,58 \\
\hline GSG1L & Hipotálamo & 3,62 & 3,02 & 0,60 \\
\hline HDC & Hipotálamo & 3,13 & 0,63 & 2,51 \\
\hline IGFBP6 & Hipotálamo & 4,54 & 3,92 & 0,62 \\
\hline IGSF21 & Hipotálamo & 4,00 & 4,63 & $-0,63$ \\
\hline JUNB & Hipotálamo & 5,11 & 4,39 & 0,71 \\
\hline KLHDC8A & Hipotálamo & 3,73 & 3,09 & 0,64 \\
\hline MAOB & Hipotálamo & 5,78 & 5,19 & 0,59 \\
\hline MGC157368 & Hipotálamo & 6,35 & 5,70 & 0,65 \\
\hline
\end{tabular}


Tabela suplementar 1 - Genes diferencialmente expressos entre alta e baixa eficiência alimentar (continuação).

\begin{tabular}{|c|c|c|c|c|}
\hline Gene & Tecido & Baixa EA* & Alta EA* & Baixa-Alta EA* \\
\hline MT1A & Hipotálamo & 6,79 & 6,11 & 0,68 \\
\hline MT1E & Hipotálamo & 4,05 & 3,04 & 1,02 \\
\hline MT2 & Hipotálamo & 8,56 & 8,01 & 0,55 \\
\hline NEURL1 & Hipotálamo & 4,14 & 3,34 & 0,80 \\
\hline NFAM1 & Hipotálamo & 4,30 & 3,61 & 0,69 \\
\hline NNAT & Hipotálamo & 7,32 & 5,99 & 1,32 \\
\hline NR4A1 & Hipotálamo & 4,73 & 3,74 & 0,99 \\
\hline NRN1 & Hipotálamo & 4,52 & 5,06 & $-0,54$ \\
\hline NRSN2 & Hipotálamo & 5,37 & 4.80 & 0,57 \\
\hline NSMF & Hipotálamo & 6,36 & 6,89 & $-0,53$ \\
\hline PAK1 & Hipotálamo & 5,54 & 6,04 & $-0,50$ \\
\hline PCP4L1 & Hipotálamo & 5,62 & 5,05 & 0,57 \\
\hline PDLIM7 & Hipotálamo & 3,79 & 2,97 & 0,82 \\
\hline PEG10 & Hipotálamo & 5,57 & 4,62 & 0,96 \\
\hline PENK & Hipotálamo & 4,87 & 2,91 & 1,96 \\
\hline PLCH2 & Hipotálamo & 2,52 & 3,20 & $-0,68$ \\
\hline $\mathrm{PMCH}$ & Hipotálamo & 3,65 & 1,06 & 2,59 \\
\hline PRKCG & Hipotálamo & 4,06 & 4,58 & $-0,52$ \\
\hline PTK2B & Hipotálamo & 3,33 & 3,88 & $-0,55$ \\
\hline PTPN5 & Hipotálamo & 4,20 & 3,35 & 0,85 \\
\hline PVALB & Hipotálamo & 4,53 & 5,24 & $-0,70$ \\
\hline QPCT & Hipotálamo & 3,79 & 2,56 & 1,23 \\
\hline RAB3B & Hipotálamo & 4,04 & 3,16 & 0,88 \\
\hline RARRES2 & Hipotálamo & 5,72 & 5,07 & 0,66 \\
\hline RGS1 & Hipotálamo & 4,15 & 3,44 & 0,71 \\
\hline RGS16 & Hipotálamo & 2,84 & 3,49 & $-0,65$ \\
\hline RGS4 & Hipotálamo & 4,49 & 3,80 & 0,69 \\
\hline RLBP1 & Hipotálamo & 2,48 & 3,12 & $-0,64$ \\
\hline RNASET2 & Hipotálamo & 4,56 & 3,89 & 0,67 \\
\hline SCG2 & Hipotálamo & 7,73 & 6,45 & 1,28 \\
\hline SCN1B & Hipotálamo & 5,54 & 6,01 & $-0,47$ \\
\hline SEMA7A & Hipotálamo & 4,85 & 5,52 & $-0,67$ \\
\hline SLC18A2 & Hipotálamo & 3,71 & 1,93 & 1,78 \\
\hline SLC24A2 & Hipotálamo & 4,29 & 4,82 & $-0,53$ \\
\hline SLC24A3 & Hipotálamo & 5,09 & 5,63 & $-0,54$ \\
\hline SNCG & Hipotálamo & 6,56 & 4,76 & 1,80 \\
\hline SNORD14 & Hipotálamo & 2,87 & 1,97 & 0,90 \\
\hline snoU2 & Hipotálamo & 19,00 & 2,30 & 3,26 \\
\hline SST & Hipotálamo & 5,40 & 4,35 & 1,05 \\
\hline STUM & Hipotálamo & 2,50 & 3,32 & $-0,82$ \\
\hline SYNDIG1L & Hipotálamo & 4,25 & 3,39 & 0,85 \\
\hline SYT2 & Hipotálamo & 3,23 & 4,13 & $-0,90$ \\
\hline SYT5 & Hipotálamo & 5,05 & 4,50 & 0,55 \\
\hline TAC1 & Hipotálamo & 4,01 & 2,60 & 1,41 \\
\hline TAC3 & Hipotálamo & 3,53 & 1,21 & 2,31 \\
\hline TM4SF1 & Hipotálamo & 3,68 & 3,09 & 0,59 \\
\hline TMEM255A & Hipotálamo & 3,58 & 2,65 & 0,93 \\
\hline TTC12 & Hipotálamo & 2,90 & 2,08 & 0,82 \\
\hline VGF & Hipotálamo & 5,11 & 4,43 & 0,67 \\
\hline VWA5A & Hipotálamo & 5,81 & 4,98 & 0,83 \\
\hline VWC2 & Hipotálamo & 3,06 & 3,69 & $-0,62$ \\
\hline ZDHHC22 & Hipotálamo & 4,08 & 4,83 & $-0,75$ \\
\hline ZFP36 & Hipotálamo & 5,41 & 4,86 & 0,55 \\
\hline ZMAT4 & Hipotálamo & 2,23 & 3,02 & $-0,78$ \\
\hline 5S rRNA & Fígado & 1,18 & 2,50 & $-1,32$ \\
\hline ABCC5 & Fígado & 2,55 & 1,63 & 0,92 \\
\hline ACSM5 & Fígado & 2,64 & 1,38 & 1,26 \\
\hline ADHFE1 & Fígado & 4,46 & 3,72 & 0,74 \\
\hline AKR1C4 & Fígado & 3,88 & 2,93 & 0,94 \\
\hline ANXA13 & Fígado & 4,16 & 5,24 & $-1,08$ \\
\hline ARG2 & Fígado & 1,16 & 2,14 & $-0,98$ \\
\hline BHMT & Fígado & 7,23 & 8,22 & $-0,98$ \\
\hline
\end{tabular}


Tabela suplementar 1 - Genes diferencialmente expressos entre alta e baixa eficiência alimentar (continuação).

\begin{tabular}{|c|c|c|c|c|}
\hline Gene & Tecido & Baixa EA* & Alta EA* & Baixa-Alta EA* \\
\hline BOLA-DQA5 & Fígado & 1,63 & 2,87 & $-1,24$ \\
\hline bta-mir-122 & Fígado & 3,31 & 4,66 & $-1,35$ \\
\hline C1RL & Fígado & 2,68 & 1,73 & 0,95 \\
\hline CCL4 & Fígado & 2,84 & 4,01 & $-1,16$ \\
\hline CD247 & Fígado & 2,08 & 3,06 & $-0,99$ \\
\hline CDHR5 & Fígado & 2,08 & 3,16 & $-1,07$ \\
\hline CNN1 & Fígado & 2,00 & 3,16 & $-1,16$ \\
\hline CXCL17 & Fígado & 3,44 & 4,62 & $-1,18$ \\
\hline CXCL3 & Fígado & 6,34 & 5,69 & 0,65 \\
\hline CYP2E1 & Fígado & 7,01 & 3,20 & 3,81 \\
\hline DENND2A & Fígado & 2,58 & 3,75 & $-1,18$ \\
\hline DLK1 & Fígado & 0,85 & 1,94 & $-1,09$ \\
\hline ENSBTAG00000001219 & Fígado & 4,51 & 5,95 & $-1,44$ \\
\hline ENSBTAG00000001851 & Fígado & 3,44 & 5,53 & $-2,09$ \\
\hline ENSBTAG00000010907 & Fígado & 3,80 & 5,17 & $-1,37$ \\
\hline ENSBTAG00000021368 & Fígado & 3,07 & 2,09 & 0,97 \\
\hline ENSBTAG00000025260 & Fígado & 1,85 & 0,79 & 1,06 \\
\hline ENSBTAG00000031160 & Fígado & 6,12 & 7,38 & $-1,26$ \\
\hline ENSBTAG00000032057 & Fígado & 3,02 & 4,54 & $-1,52$ \\
\hline ENSBTAG00000034323 & Fígado & 2,72 & 1,77 & 0,94 \\
\hline ENSBTAG00000039237 & Fígado & 2,46 & 4,89 & $-2,43$ \\
\hline ENSBTAG00000039321 & Fígado & 3,54 & 2,62 & 0,92 \\
\hline ENSBTAG00000039928 & Fígado & 4,39 & 3,13 & 1,26 \\
\hline ENSBTAG00000040409 & Fígado & 7,17 & 6,01 & 1,16 \\
\hline ENSBTAG00000043729 & Fígado & 1,60 & 2,64 & $-1,03$ \\
\hline ENSBTAG00000046076 & Fígado & 1,89 & 3,05 & $-1,16$ \\
\hline ENSBTAG00000047121 & Fígado & 3,67 & 5,30 & $-1,63$ \\
\hline ENSBTAG00000047529 & Fígado & 3,90 & 5,39 & $-1,49$ \\
\hline ENSBTAG00000047700 & Fígado & 2,62 & 3,81 & $-1,19$ \\
\hline ENSBTAG00000047816 & Fígado & 1,35 & 2,46 & $-1,11$ \\
\hline ENSBTAG00000048013 & Fígado & 5,01 & 4,21 & 0,80 \\
\hline ENSBTAG00000048049 & Fígado & 4,85 & 6,15 & $-1,30$ \\
\hline ENSBTAG00000048135 & Fígado & 6,03 & 7,44 & $-1,42$ \\
\hline ENSBTAG00000048210 & Fígado & 1,22 & 2,51 & $-1,29$ \\
\hline FABP6 & Fígado & 0,03 & 1,80 & $-1,77$ \\
\hline FADS2 & Fígado & 3,31 & 2,48 & 0,82 \\
\hline FBXO44 & Fígado & 2,42 & 1,10 & 1,32 \\
\hline FETUB & Fígado & 7,56 & 6,85 & 0,71 \\
\hline FGF21 & Fígado & 2,92 & 4,39 & $-1,47$ \\
\hline FST & Fígado & 1,51 & 2,54 & $-1,03$ \\
\hline FXYD2 & Fígado & 0,92 & 2,06 & $-1,14$ \\
\hline GPC3 & Fígado & 1,92 & 0,75 & 1,17 \\
\hline GPR143 & Fígado & 2,06 & 3,18 & $-1,12$ \\
\hline HAL & Fígado & 3,34 & 4,32 & $-0,98$ \\
\hline HSD17B12 & Fígado & 3,42 & 2,57 & 0,85 \\
\hline IGFBP1 & Fígado & 4,43 & 6,37 & $-1,93$ \\
\hline IL1R2 & Fígado & 2,24 & 0,88 & 1,36 \\
\hline JCHAIN & Fígado & 3,76 & 4,74 & $-0,98$ \\
\hline KAT6A & Fígado & 0,94 & 1,84 & $-0,90$ \\
\hline KEL & Fígado & 0,61 & 1,70 & $-1,09$ \\
\hline KIAA0753 & Fígado & 2,95 & 1,92 & 1,02 \\
\hline MGC137099 & Fígado & 9,57 & 8,92 & 0,65 \\
\hline MGP & Fígado & 4,23 & 5,45 & $-1,22$ \\
\hline M-SAA3.2 & Fígado & 2,78 & 4,07 & $-1,29$ \\
\hline MUSTN1 & Fígado & 2,17 & 3,32 & $-1,14$ \\
\hline NR0B2 & Fígado & 2,40 & 3,58 & $-1,19$ \\
\hline PBLD & Fígado & 4,27 & 3,57 & 0,70 \\
\hline PON1 & Fígado & 5,04 & 2,32 & 2,72 \\
\hline PPP1R3B & Fígado & 4,64 & 3,99 & 0,65 \\
\hline PRL & Fígado & 0,12 & 1,86 & $-1,74$ \\
\hline PTGDS & Fígado & 2,89 & 4,31 & $-1,42$ \\
\hline REC8 & Fígado & 2,15 & 0,44 & 1,71 \\
\hline
\end{tabular}


Tabela suplementar 1 - Genes diferencialmente expressos entre alta e baixa eficiência alimentar (continuação).

\begin{tabular}{|c|c|c|c|c|}
\hline Gene & Tecido & Baixa EA* & Alta EA* & Baixa-Alta EA* \\
\hline RND1 & Fígado & 1,82 & 3,26 & $-1,44$ \\
\hline RNF125 & Fígado & 2,07 & 1,12 & 0,95 \\
\hline SDS & Fígado & 4,32 & 5,37 & $-1,05$ \\
\hline SERPINI2 & Fígado & 2,40 & 4,00 & $-1,60$ \\
\hline SLC16A11 & Fígado & 3,67 & 4,69 & $-1,02$ \\
\hline SLC17A4 & Fígado & 2,17 & 1,36 & 0,82 \\
\hline SLC $30 A 3$ & Fígado & 1,16 & 2,18 & $-1,02$ \\
\hline SMIM6 & Fígado & 0,89 & 1,87 & $-0,98$ \\
\hline SNORA17 & Fígado & 1.22 & 2.25 & $-1,03$ \\
\hline SNORA3 & Fígado & 0,51 & 1,91 & $-1,40$ \\
\hline SNORA63 & Fígado & 0,53 & 1,76 & $-1,23$ \\
\hline SNORA73 & Fígado & 0,89 & 2,56 & $-1,67$ \\
\hline SNORD39 & Fígado & 0,69 & 1,78 & $-1,09$ \\
\hline SNORD47 & Fígado & 1,89 & 0,30 & 1,59 \\
\hline SNORD96 & Fígado & 2,23 & 1,30 & 0,92 \\
\hline SOD3 & Fígado & 3,75 & 1,80 & 1,95 \\
\hline SPNS3 & Fígado & 0,87 & 1,79 & $-0,92$ \\
\hline TMED6 & Fígado & 2,82 & 1,79 & 1,03 \\
\hline TMEM45A & Fígado & 2,07 & 4,14 & $-2,07$ \\
\hline $\mathrm{U} 4$ & Fígado & 0,89 & 2,90 & $-2,01$ \\
\hline $\mathrm{U} 4$ & Fígado & 2,07 & 4,05 & $-1,98$ \\
\hline ACTA2 & Músculo & 3,27 & 4,35 & $-1,08$ \\
\hline ACTC1 & Músculo & 4,64 & 3,93 & 0,71 \\
\hline ADM & Músculo & 2,15 & 1,47 & 0,69 \\
\hline AIF1L & Músculo & 2,59 & 1,62 & 0,97 \\
\hline ANGPTL4 & Músculo & 3,37 & 4,21 & $-0,85$ \\
\hline ANKRD1 & Músculo & 8,36 & 7,52 & 0,84 \\
\hline AQP1 & Músculo & 2,10 & 3,04 & $-0,93$ \\
\hline ASS 1 & Músculo & 3,97 & 3,42 & 0,54 \\
\hline ATP2B2 & Músculo & 2,32 & 1,36 & 0,96 \\
\hline BARX2 & Músculo & 3,59 & 2,16 & 1,44 \\
\hline BGN & Músculo & 1,32 & 2,21 & $-0,88$ \\
\hline bta-mir-1281 & Músculo & 1,85 & 0,71 & 1,14 \\
\hline bta-mir-29c & Músculo & 2,36 & 0,98 & 1,39 \\
\hline BTG2 & Músculo & 5,77 & 5,19 & 0,58 \\
\hline C15orf61 & Músculo & 4,06 & 3,51 & 0,55 \\
\hline CCNG2 & Músculo & 2,47 & 1,65 & 0,82 \\
\hline CDKN1A & Músculo & 3,88 & 3,12 & 0,76 \\
\hline $\mathrm{CISH}$ & Músculo & 2,44 & 3,66 & $-1,22$ \\
\hline CSRP3 & Músculo & 10,55 & 11,15 & $-0,60$ \\
\hline CSTB & Músculo & 3,70 & 2,82 & 0,88 \\
\hline DAPK2 & Músculo & 4,11 & 3,54 & 0,56 \\
\hline DNAJB1 & Músculo & 3,46 & 4,01 & $-0,55$ \\
\hline DOC2G & Músculo & 2,22 & 1,13 & 1,09 \\
\hline ENHO & Músculo & 3,18 & 2,20 & 0,98 \\
\hline ENSBTAG00000000560 & Músculo & 0,94 & 1,77 & $-0,83$ \\
\hline ENSBTAG00000001851 & Músculo & 2,25 & 1,31 & 0,94 \\
\hline ENSBTAG00000001858 & Músculo & 4,88 & 5,41 & $-0,53$ \\
\hline ENSBTAG00000003152 & Músculo & 2,03 & 1,10 & 0,93 \\
\hline ENSBTAG00000006383 & Músculo & 5,75 & 6,30 & $-0,55$ \\
\hline ENSBTAG00000015297 & Músculo & 2,61 & 1,53 & 1,08 \\
\hline ENSBTAG00000025383 & Músculo & 1,65 & 2,64 & $-0,99$ \\
\hline ENSBTAG00000027075 & Músculo & 3,08 & 4,19 & $-1,11$ \\
\hline ENSBTAG00000027962 & Músculo & 4,01 & 5,39 & $-1,38$ \\
\hline ENSBTAG00000031082 & Músculo & 1,70 & 2,52 & $-0,81$ \\
\hline ENSBTAG00000031913 & Músculo & 3,64 & 4,16 & $-0,52$ \\
\hline ENSBTAG00000032057 & Músculo & 3,77 & 4,43 & $-0,65$ \\
\hline ENSBTAG00000034662 & Músculo & 4,74 & 5,29 & $-0,56$ \\
\hline ENSBTAG00000035654 & Músculo & 1,35 & 2,01 & $-0,66$ \\
\hline ENSBTAG00000037605 & Músculo & 2,72 & 1,65 & 1,08 \\
\hline ENSBTAG00000037794 & Músculo & 4,25 & 3,71 & 0,54 \\
\hline ENSBTAG00000039486 & Músculo & 1,49 & 2,45 & $-0,96$ \\
\hline
\end{tabular}


Tabela suplementar 1 - Genes diferencialmente expressos entre alta e baixa eficiência alimentar (continuação).

\begin{tabular}{|c|c|c|c|c|}
\hline Gene & Tecido & Baixa EA* & Alta EA* & Baixa-Alta EA* \\
\hline ENSBTAG00000039620 & Músculo & 1,70 & 2,39 & $-0,69$ \\
\hline ENSBTAG00000044871 & Músculo & 2,36 & 1,66 & 0,70 \\
\hline ENSBTAG00000046177 & Músculo & 5,01 & 6,83 & $-1,81$ \\
\hline ENSBTAG00000047029 & Músculo & 5,48 & 4,90 & 0,58 \\
\hline ENSBTAG00000047561 & Músculo & 3,45 & 3,97 & $-0,53$ \\
\hline FLNA & Músculo & 2,35 & 3,19 & $-0,84$ \\
\hline FMOD & Músculo & 0,91 & 1,96 & $-1,05$ \\
\hline FOSL2 & Músculo & 2.69 & 1.78 & 0,91 \\
\hline FZD4 & Músculo & 1.42 & 2.11 & -0.69 \\
\hline GAS7 & Músculo & 2,29 & 1,00 & 1,30 \\
\hline GDAP1 & Músculo & 3,13 & 2,44 & 0,69 \\
\hline GREB1 & Músculo & 1,25 & 2,06 & $-0,80$ \\
\hline HIST1H1C & Músculo & 2,45 & 1,67 & 0,78 \\
\hline HOXA4 & Músculo & 0,82 & 1,73 & $-0,92$ \\
\hline HOXC6 & Músculo & 1,98 & 3,32 & $-1,34$ \\
\hline $\mathrm{HOXC} 8$ & Músculo & 1,98 & 3,43 & $-1,44$ \\
\hline HOXC9 & Músculo & 1,03 & 1,76 & $-0,72$ \\
\hline $\mathrm{HR}$ & Músculo & 2,80 & 1,98 & 0,83 \\
\hline HTRA1 & Músculo & 4,75 & 3,93 & 0,81 \\
\hline IGFBP6 & Músculo & 4,32 & 4,81 & $-0,50$ \\
\hline INHA & Músculo & 3,40 & 2,14 & 1,26 \\
\hline KCNIP2 & Músculo & 2,81 & 2,13 & 0,68 \\
\hline KIAA0408 & Músculo & 1,98 & 2,64 & $-0,65$ \\
\hline LRRN1 & Músculo & 2,41 & 1,67 & 0,75 \\
\hline MYBPH & Músculo & 4,08 & 3,51 & 0,56 \\
\hline MYH1 & Músculo & 10,60 & 8,93 & 1,67 \\
\hline MYH2 & Músculo & 11,73 & 12,27 & $-0,54$ \\
\hline MYLK4 & Músculo & 3,42 & 2,14 & 1,28 \\
\hline MYOD1 & Músculo & 1,75 & 3,01 & $-1,26$ \\
\hline NPNT & Músculo & 2,06 & 1,05 & 1,01 \\
\hline NUPR1 & Músculo & 3,03 & 2,34 & 0,69 \\
\hline OTUD1 & Músculo & 6,43 & 5,81 & 0,61 \\
\hline OXT & Músculo & 1,22 & 2,89 & $-1,67$ \\
\hline PCBD1 & Músculo & 2,01 & 0,50 & 1,51 \\
\hline PEBP4 & Músculo & 5,30 & 4,75 & 0,56 \\
\hline PFKFB3 & Músculo & 6,87 & 5,98 & 0,90 \\
\hline PI16 & Músculo & 0,97 & 1,77 & $-0,80$ \\
\hline PIM1 & Músculo & 1,99 & 1,23 & 0,76 \\
\hline PITX1 & Músculo & 2,03 & 1,13 & 0,90 \\
\hline PM20D2 & Músculo & 2,15 & 1,39 & 0,76 \\
\hline PPP1R3C & Músculo & 6,88 & 6,21 & 0,67 \\
\hline PVALB & Músculo & 2,71 & 0,07 & 2,64 \\
\hline RASD1 & Músculo & 3,31 & 1,94 & 1,37 \\
\hline RBM3 & Músculo & 5,92 & 5,20 & 0,72 \\
\hline RNASE13 & Músculo & 2,01 & 0,96 & 1,06 \\
\hline SBK2 & Músculo & 4,12 & 2,90 & 1,22 \\
\hline SERPINE1 & Músculo & 2,89 & 2,10 & 0,79 \\
\hline SESN3 & Músculo & 4,61 & 3,90 & 0,71 \\
\hline SFRS5 & Músculo & 3,87 & 3,24 & 0,63 \\
\hline SLC43A2 & Músculo & 4,28 & 3,73 & 0,54 \\
\hline snoU82P & Músculo & 2,62 & 1,54 & 1,09 \\
\hline TAGLN & Músculo & 4,79 & 5,28 & $-0,49$ \\
\hline TIPARP & Músculo & 4,52 & 3,96 & 0,56 \\
\hline TMBIM1 & Músculo & 5,12 & 4,53 & 0,59 \\
\hline TMEM120A & Músculo & 4,07 & 4,66 & $-0,59$ \\
\hline TNFAIP2 & Músculo & 1,93 & 0,97 & 0,96 \\
\hline TPPP2 & Músculo & 2,21 & 1,51 & 0,69 \\
\hline TRIM45 & Músculo & 2,88 & 3,52 & $-0,64$ \\
\hline TRIM63 & Músculo & 7,29 & 6,71 & 0,58 \\
\hline $\mathrm{UCP} 2$ & Músculo & 3,20 & 2,42 & 0,78 \\
\hline VGLL2 & Músculo & 3,81 & 4,36 & $-0,56$ \\
\hline ZIC1 & Músculo & 1,47 & 2,42 & $-0,95$ \\
\hline
\end{tabular}


Tabela suplementar 1 - Genes diferencialmente expressos entre alta e baixa eficiência alimentar (continuação).

\begin{tabular}{|c|c|c|c|c|}
\hline Gene & Tecido & Baixa EA* & Alta EA* & Baixa-Alta EA* \\
\hline ZNF385C & Músculo & 0,96 & 1,87 & $-0,90$ \\
\hline ACTA2 & Pituitária & 5,43 & 4,49 & 0,95 \\
\hline ACTG2 & Pituitária & 2,91 & 1,99 & 0,92 \\
\hline ADH6 & Pituitária & 3,07 & 3,53 & $-0,46$ \\
\hline ALCAM & Pituitária & 4,28 & 3,70 & 0,58 \\
\hline AMIGO2 & Pituitária & 5,06 & 4,26 & 0,80 \\
\hline APOA1 & Pituitária & 3,15 & 2,14 & 1,01 \\
\hline AQP1 & Pituitária & 2,53 & 3,34 & $-0,81$ \\
\hline ATF3 & Pituitária & 4,10 & 4,51 & $-0,41$ \\
\hline ATP8 & Pituitária & 9,45 & 8,44 & 1,01 \\
\hline BOLA-DQA5 & Pituitária & 2,53 & 3,65 & $-1,11$ \\
\hline BST1 & Pituitária & 3,51 & 4,08 & $-0,57$ \\
\hline BTG2 & Pituitária & 6,64 & 7,22 & $-0,57$ \\
\hline C5AR2 & Pituitária & 2,97 & 1,99 & 0,98 \\
\hline CA3 & Pituitária & 0,81 & 3,27 & $-2,46$ \\
\hline CAV1 & Pituitária & 4,78 & 4,04 & 0,74 \\
\hline CCDC152 & Pituitária & 4,33 & 3,73 & 0,60 \\
\hline CNN1 & Pituitária & 3,78 & 2,45 & 1,33 \\
\hline $\mathrm{COX} 7 \mathrm{C}$ & Pituitária & 5,13 & 4,60 & 0,53 \\
\hline CRYAB & Pituitária & 6,08 & 5,55 & 0,53 \\
\hline CRYM & Pituitária & 4,94 & 4,30 & 0,64 \\
\hline CTGF & Pituitária & 5,01 & 4,27 & 0,73 \\
\hline CYR61 & Pituitária & 3,89 & 3,26 & 0,63 \\
\hline DAPL1 & Pituitária & 3,80 & 4,60 & $-0,80$ \\
\hline DCXR & Pituitária & 6,47 & 7,08 & $-0,61$ \\
\hline DES & Pituitária & 4,40 & 3,03 & 1,37 \\
\hline DLK1 & Pituitária & 6,34 & 7,01 & $-0,67$ \\
\hline DOT1L & Pituitária & 3,47 & 2,88 & 0,59 \\
\hline DSC 3 & Pituitária & 2,68 & 1,90 & 0,78 \\
\hline ELFN1 & Pituitária & 2,61 & 1,80 & 0,80 \\
\hline ENSBTAG00000000560 & Pituitária & 1,71 & 2,87 & $-1,16$ \\
\hline ENSBTAG00000003352 & Pituitária & 4,69 & 5,22 & $-0,53$ \\
\hline ENSBTAG00000005146 & Pituitária & 6,44 & 6,84 & $-0,40$ \\
\hline ENSBTAG00000006383 & Pituitária & 7,69 & 8,19 & $-0,50$ \\
\hline ENSBTAG00000009656 & Pituitária & 4,07 & 5,03 & $-0,96$ \\
\hline ENSBTAG00000020564 & Pituitária & 2,33 & 3,28 & $-0,95$ \\
\hline ENSBTAG00000027075 & Pituitária & 4,50 & 5,68 & $-1,18$ \\
\hline ENSBTAG00000031082 & Pituitária & 3,91 & 4,82 & $-0,91$ \\
\hline ENSBTAG00000031785 & Pituitária & 5,73 & 6,14 & $-0,41$ \\
\hline ENSBTAG00000031834 & Pituitária & 4,27 & 4,67 & $-0,40$ \\
\hline ENSBTAG00000032057 & Pituitária & 3,17 & 4,00 & $-0,84$ \\
\hline ENSBTAG00000035654 & Pituitária & 2,30 & 2,97 & $-0,67$ \\
\hline ENSBTAG00000037605 & Pituitária & 6,15 & 5,38 & 0,78 \\
\hline ENSBTAG00000039236 & Pituitária & 7,68 & 6,79 & 0,89 \\
\hline ENSBTAG00000043706 & Pituitária & 4,76 & 3,87 & 0,89 \\
\hline EPYC & Pituitária & 3,29 & 4,55 & $-1,26$ \\
\hline FKBP7 & Pituitária & 4,54 & 5,36 & $-0,83$ \\
\hline FN1 & Pituitária & 2,87 & 1,89 & 0,98 \\
\hline FSHB & Pituitária & 8,99 & 7,82 & 1,17 \\
\hline GADD45B & Pituitária & 4,83 & 5,56 & $-0,74$ \\
\hline GAS1 & Pituitária & 3,49 & 3,95 & $-0,46$ \\
\hline HIST1H1C & Pituitária & 3,73 & 4,30 & $-0,58$ \\
\hline HTR1F & Pituitária & 2,69 & 1,88 & 0,81 \\
\hline IFI30 & Pituitária & 3,09 & 3,55 & $-0,46$ \\
\hline IGFBP3 & Pituitária & 4,78 & 5,27 & $-0,49$ \\
\hline IGFBP6 & Pituitária & 6,15 & 5,54 & 0,62 \\
\hline JAK3 & Pituitária & 3,52 & 4,18 & $-0,66$ \\
\hline KLK7 & Pituitária & 2,30 & 3,08 & $-0,78$ \\
\hline LUZP2 & Pituitária & 2,83 & 1,78 & 1,05 \\
\hline MIR3618 & Pituitária & 3,46 & 2,86 & 0,60 \\
\hline MT1A & Pituitária & 3,79 & 2,70 & 1,09 \\
\hline MT1E & Pituitária & 4,46 & 3,86 & 0,59 \\
\hline
\end{tabular}


Tabela suplementar 1 - Genes diferencialmente expressos entre alta e baixa eficiência alimentar (continuação).

\begin{tabular}{|c|c|c|c|c|}
\hline Gene & Tecido & Baixa EA* & Alta EA* & Baixa-Alta EA* \\
\hline MUSTN1 & Pituitária & 3,57 & 2,28 & 1,28 \\
\hline MYH11 & Pituitária & 3,17 & 1,95 & 1,22 \\
\hline NEUROD4 & Pituitária & 4,48 & 4,92 & $-0,44$ \\
\hline NOV & Pituitária & 4,17 & 3,40 & 0,77 \\
\hline NR4A2 & Pituitária & 5,88 & 6,31 & $-0,42$ \\
\hline NREP & Pituitária & 3,29 & 3,69 & $-0,41$ \\
\hline PALMD & Pituitária & 2,30 & 2,89 & $-0,58$ \\
\hline PCOLCE & Pituitária & 3,74 & 4,18 & $-0,44$ \\
\hline PCSK2 & Pituitária & 3,78 & 2,86 & 0,93 \\
\hline PGAP2 & Pituitária & 3,61 & 4,06 & $-0,44$ \\
\hline PGF & Pituitária & 2,56 & 3,36 & $-0,80$ \\
\hline PMF1 & Pituitária & 1,65 & 2,59 & $-0,93$ \\
\hline PRR15 & Pituitária & 3,36 & 3,77 & $-0,41$ \\
\hline PTGR1 & Pituitária & 3,43 & 2,69 & 0,74 \\
\hline RD3 & Pituitária & 2,92 & 3,33 & $-0,41$ \\
\hline RGS4 & Pituitária & 1,78 & 2,50 & $-0,73$ \\
\hline S100A4 & Pituitária & 3,66 & 2,76 & 0,90 \\
\hline SCGB1D & Pituitária & 3,58 & 5,33 & $-1,75$ \\
\hline SCOC & Pituitária & 5,19 & 4,66 & 0,53 \\
\hline SFRP2 & Pituitária & 2,65 & 1,06 & 1,59 \\
\hline SGPP2 & Pituitária & 1,97 & 2,60 & $-0,63$ \\
\hline SLC2A4 & Pituitária & 3,10 & 2,15 & 0,94 \\
\hline SNORD107 & Pituitária & 3,18 & 1,97 & 1,21 \\
\hline SPINK7 & Pituitária & 2,32 & 3,27 & $-0,95$ \\
\hline SPP1 & Pituitária & 9,01 & 8,35 & 0,66 \\
\hline SULF2 & Pituitária & 4,34 & 4,87 & $-0,52$ \\
\hline TAGLN & Pituitária & 5,84 & 5,08 & 0,77 \\
\hline TBX19 & Pituitária & 4,97 & 4,44 & 0,53 \\
\hline TMEM213 & Pituitária & 5,05 & 5,77 & $-0,72$ \\
\hline TNFRSF12A & Pituitária & 5,30 & 4,62 & 0,67 \\
\hline TNFRSF18 & Pituitária & 4,16 & 3,48 & 0,68 \\
\hline TPM2 & Pituitária & 3,78 & 3,19 & 0,59 \\
\hline TSHB & Pituitária & 9,85 & 10,96 & $-1,11$ \\
\hline U3 & Pituitária & 2,49 & 3,21 & $-0,72$ \\
\hline VIP & Pituitária & 0,80 & 2,56 & $-1,76$ \\
\hline WFDC2 & Pituitária & 3,17 & 4,26 & $-1,09$ \\
\hline WIF1 & Pituitária & 3,72 & 2,93 & 0,79 \\
\hline
\end{tabular}

*Log2 FPKM 
Tabela suplementar 2 - Genes selecionados para construção da rede de co-expressão.

\begin{tabular}{|c|c|c|c|c|c|}
\hline Gene & Categoria & Tecido de máxima expressão & Tecido DE & Tecido SEC & Tecido REG \\
\hline 5S_rRNA & DE & $\mathrm{F}$ & $\mathrm{F}$ & & \\
\hline $\mathrm{A} 1 \mathrm{BG}$ & TS & F & & & \\
\hline $\mathrm{A} 2 \mathrm{M}$ & SEC & A & & AFM & \\
\hline ABAT & SNP & $\mathrm{H}$ & & & \\
\hline ABCC5 & DE & A & $\mathrm{F}$ & & \\
\hline ABCC6 & TS & $\mathrm{F}$ & & & \\
\hline $\mathrm{ABCC} 9$ & SNP & M & & & \\
\hline ABRA & TS & M & & & \\
\hline ACAD11 & SNP & $\mathrm{F}$ & & & \\
\hline ACHE & DE & $\mathrm{H}$ & $\mathrm{H}$ & & \\
\hline ACSM2A & TS & $\mathrm{F}$ & & & \\
\hline ACSM3 & TS & $\mathrm{F}$ & & & \\
\hline ACSM5 & DE & M & $\mathrm{F}$ & & \\
\hline ACTA1 & TS & M & & & \\
\hline ACTA2 & $\mathrm{DE}$ & $\mathrm{F}$ & MP & & \\
\hline ACTC1 & $\mathrm{DE}$ & M & M & & \\
\hline ACTG2 & DE & A & $\mathrm{P}$ & & \\
\hline ACTN2 & TS & M & & & \\
\hline ACTN3 & TS & M & & & \\
\hline ADAM11 & DE & $\mathrm{H}$ & $\mathrm{H}$ & & \\
\hline ADAM33 & SNP & $\mathrm{P}$ & & & \\
\hline ADAMTS4 & DE & $\mathrm{H}$ & A & & \\
\hline ADAMTS7 & SEC & $\mathrm{F}$ & & A & \\
\hline ADAP1 & TS & $\mathrm{H}$ & & & \\
\hline ADCYAP1 & DE & $\mathrm{H}$ & $\mathrm{H}$ & & \\
\hline $\mathrm{ADH} 4$ & $\mathrm{TS}$ & $\mathrm{F}$ & & & \\
\hline ADH6 & $\mathrm{DE}$ & $\mathrm{F}$ & $P$ & & \\
\hline ADHFE1 & DE & $\mathrm{F}$ & F & & \\
\hline ADIPOQ & SEC & M & & A & \\
\hline $\mathrm{ADM}$ & $\mathrm{DE}$ & A & M & & \\
\hline ADPRHL1 & TSSNP & M & & & \\
\hline ADTRP & $\mathrm{TS}$ & $\mathrm{F}$ & & & \\
\hline AEBP1 & REG & A & & & A \\
\hline AFM & TSSEC & $\mathrm{F}$ & & $\mathrm{F}$ & \\
\hline AFMID & SNP & $\mathrm{F}$ & & & \\
\hline AGMAT & TS & $\mathrm{F}$ & & & \\
\hline AGRP & SEC & $\mathrm{F}$ & & A & \\
\hline AGT & SEC & $\mathrm{H}$ & & AFM & \\
\hline AGXT & TS & $\mathrm{F}$ & & & \\
\hline AGXT2 & $\mathrm{TS}$ & $\mathrm{F}$ & & & \\
\hline AHSG & SEC & $\mathrm{F}$ & & $\mathrm{F}$ & \\
\hline AIF1L & DE & $\mathrm{H}$ & M & & \\
\hline AKR1C3 & TS & $\mathrm{F}$ & & & \\
\hline AKR1C4 & DE & $\mathrm{F}$ & $\mathrm{F}$ & & \\
\hline ALB & TS & $\mathrm{F}$ & & & \\
\hline ALCAM & DE & $\mathrm{H}$ & $\mathrm{HP}$ & & \\
\hline ALDH1A1 & $\mathrm{DE}$ & A & $\mathrm{H}$ & & \\
\hline ALDH6A1 & SNP & $\mathrm{F}$ & & & \\
\hline ALDH8A1 & TS & $\mathrm{F}$ & & & \\
\hline ALDH9A1 & SEC & $\mathrm{F}$ & & AFM & \\
\hline ALG13 & SNP & $\mathrm{H}$ & & & \\
\hline ALKBH1 & SEC & $\mathrm{P}$ & & AFM & \\
\hline AMBP & $\mathrm{TS}$ & $\mathrm{F}$ & & & \\
\hline AMH & DE & $\mathrm{A}$ & A & & \\
\hline AMIGO2 & DE & $\mathrm{P}$ & $\mathrm{P}$ & & \\
\hline AMMECR1 & SNP & $\mathrm{P}$ & & & \\
\hline AMOT & SNP & M & & & \\
\hline AMPD1 & TS & M & & & \\
\hline AMY2B & SEC & $\mathrm{F}$ & & AFM & \\
\hline ANG & SEC & $\mathrm{F}$ & & $\mathrm{AF}$ & \\
\hline ANGPT2 & SEC & $\mathrm{P}$ & & $\mathrm{F}$ & \\
\hline ANGPTL3 & TSSEC & $\mathrm{F}$ & & $\mathrm{F}$ & \\
\hline ANGPTL4 & $\mathrm{DE}$ & F & M & & \\
\hline
\end{tabular}


Tabela suplementar 2 - Genes selecionados para construção da rede de co-expressão

\begin{tabular}{|c|c|c|c|c|c|}
\hline Gene & Categoria & Tecido de máxima expressão & Tecido DE & Tecido SEC & Tecido REG \\
\hline ANGPTL6 & SEC & $\mathrm{F}$ & & $\mathrm{F}$ & \\
\hline ANGPTL8 & TS & $\mathrm{F}$ & & & \\
\hline ANK3 & SNP & $\mathrm{H}$ & & & \\
\hline ANKRD1 & DETS & M & M & & \\
\hline ANKRD2 & TS & M & & & \\
\hline ANKRD23 & TS & M & & & \\
\hline ANXA1 & $\mathrm{DE}$ & $\mathrm{P}$ & $\mathrm{H}$ & & \\
\hline ANXA13 & $\mathrm{DE}$ & $\mathrm{F}$ & $\mathrm{F}$ & & \\
\hline $\mathrm{AOC} 1$ & TS & $\mathrm{F}$ & & & \\
\hline AOX1 & SNP & $\mathrm{F}$ & & & \\
\hline APBB 1 & REG & $\mathrm{H}$ & & & $\mathrm{P}$ \\
\hline APCS & TSSEC & $\mathrm{F}$ & & $\mathrm{F}$ & \\
\hline APIP & SNP & $\mathrm{M}$ & & & \\
\hline APOA1 & $\mathrm{DE}$ & $\mathrm{F}$ & AP & & \\
\hline APOA2 & TS & $\mathrm{F}$ & & & \\
\hline APOA4 & TSSEC & $\mathrm{F}$ & & $\mathrm{F}$ & \\
\hline APOA5 & TSSEC & $\mathrm{F}$ & & $\mathrm{F}$ & \\
\hline APOB & SEC & $\mathrm{F}$ & & $\mathrm{F}$ & \\
\hline APOBEC2 & TS & M & & & \\
\hline APOC2 & SEC & $\mathrm{F}$ & & $\mathrm{AF}$ & \\
\hline APOC3 & TSSEC & $\mathrm{F}$ & & $\mathrm{F}$ & \\
\hline APOC4 & TSSEC & $\mathrm{F}$ & & $\mathrm{F}$ & \\
\hline APOD & SEC & $\mathrm{H}$ & & $\mathrm{AM}$ & \\
\hline APOE & SEC & $\mathrm{F}$ & & AFM & \\
\hline APOF & TSSEC & $\mathrm{F}$ & & $\mathrm{F}$ & \\
\hline $\mathrm{APOH}$ & TS & $\mathrm{F}$ & & & \\
\hline APOM & TS & $\mathrm{F}$ & & & \\
\hline AQP1 & $\mathrm{DE}$ & A & MP & & \\
\hline $\mathrm{AQP7}$ & TS & M & & & \\
\hline AQP8 & TS & $\mathrm{F}$ & & & \\
\hline AQP9 & TS & $\mathrm{F}$ & & & \\
\hline ARG1 & TS & $\mathrm{F}$ & & & \\
\hline ARG2 & $\mathrm{DE}$ & $\mathrm{P}$ & $\mathrm{F}$ & & \\
\hline ARHGAP35 & SNP & M & & & \\
\hline ARPC1B & SNP & $\mathrm{F}$ & & & \\
\hline ARSB & SEC & $\mathrm{H}$ & & $\mathrm{AF}$ & \\
\hline ARSK & SEC & A & & $\mathrm{AF}$ & \\
\hline ASB12 & TS & M & & & \\
\hline ASB2 & TS & M & & & \\
\hline ASB5 & TS & M & & & \\
\hline ASGR1 & TS & $\mathrm{F}$ & & & \\
\hline ASGR2 & TS & $\mathrm{F}$ & & & \\
\hline ASNSD1 & SNP & M & & & \\
\hline ASPDH & TS & $\mathrm{F}$ & & & \\
\hline ASPG & TS & $\mathrm{F}$ & & & \\
\hline ASPH & SNP & M & & & \\
\hline ASPN & SEC & $\mathrm{F}$ & & AFM & \\
\hline ASS1 & $\mathrm{DE}$ & $\mathrm{F}$ & HM & & \\
\hline ATF3 & $\mathrm{DE}$ & M & $\mathrm{P}$ & & \\
\hline ATG4A & SNP & M & & & \\
\hline ATG7 & SNP & $\mathrm{H}$ & & & \\
\hline ATP1A2 & $\mathrm{DE}$ & $\mathrm{H}$ & A & & \\
\hline ATP1B4 & TS & M & & & \\
\hline ATP2A1 & TS & M & & & \\
\hline ATP2B2 & $\mathrm{DE}$ & $\mathrm{H}$ & M & & \\
\hline ATP6V0E1 & SNP & A & & & \\
\hline ATP6V1G2 & TS & $\mathrm{H}$ & & & \\
\hline ATP6V1H & SNP & $\mathrm{H}$ & & & \\
\hline ATP8 & DEREG & M & $\mathrm{AP}$ & & $\mathrm{H}$ \\
\hline ATP8B3 & TS & $\mathrm{F}$ & & & \\
\hline ATRN & SNP & $P$ & & & \\
\hline AUH & SEC & A & & AFM & \\
\hline
\end{tabular}


Tabela suplementar 2 - Genes selecionados para construção da rede de co-expressão

(continuação).

\begin{tabular}{|c|c|c|c|c|c|}
\hline Gene & Categoria & Tecido de máxima expressão & Tecido DE & Tecido SEC & Tecido REG \\
\hline AVPR1A & $\mathrm{DE}$ & A & A & & \\
\hline AZGP1 & TS & $\mathrm{F}$ & & & \\
\hline ApoN & TS & $\mathrm{F}$ & & & \\
\hline $\mathrm{B} 2 \mathrm{M}$ & SEC & $\mathrm{F}$ & & AFM & \\
\hline B4GAT1 & SEC & $\mathrm{H}$ & & AFM & \\
\hline BAIAP3 & $\mathrm{DE}$ & $\mathrm{P}$ & $\mathrm{H}$ & & \\
\hline BARX2 & $\mathrm{DE}$ & M & M & & \\
\hline BCAN & TSSEC & $\mathrm{H}$ & & A & \\
\hline BCAS1 & TS & $\mathrm{H}$ & & & \\
\hline BCL3 & $\mathrm{DE}$ & $\mathrm{F}$ & A & & \\
\hline BCL6 & REG & M & & & A \\
\hline BCOR & SNP & M & & & \\
\hline BGN & $\mathrm{DE}$ & $\mathrm{F}$ & M & & \\
\hline BHLHE40 & REG & M & & & A \\
\hline BHMT & DETS & $\mathrm{F}$ & $\mathrm{F}$ & & \\
\hline BIN1 & SNP & M & & & \\
\hline BIRC5 & SNP & $\mathrm{F}$ & & & \\
\hline BLA-DQB & $\mathrm{DE}$ & $\mathrm{F}$ & $\mathrm{AH}$ & & \\
\hline BMP1 & SEC & A & & $\mathrm{AF}$ & \\
\hline BMP3 & $\mathrm{DE}$ & A & A & & \\
\hline BMPER & SEC & $\mathrm{F}$ & & $\mathrm{F}$ & \\
\hline BNIP1 & SNP & $\mathrm{P}$ & & & \\
\hline BOLA-DQA5 & $\mathrm{DE}$ & A & AFP & & \\
\hline BST1 & $\mathrm{DE}$ & $\mathrm{P}$ & $\mathrm{P}$ & & \\
\hline BTF3 & REG & M & & & $\mathrm{P}$ \\
\hline BTG2 & $\mathrm{DE}$ & $\mathrm{P}$ & HMP & & \\
\hline C10orf71 & $\mathrm{TS}$ & M & & & \\
\hline C11H9orf116 & DE & $\mathrm{F}$ & $\mathrm{A}$ & & \\
\hline C15orf61 & DE & M & M & & \\
\hline C16orf72 & SNP & M & & & \\
\hline C1QA & SEC & $\mathrm{F}$ & & AFM & \\
\hline C1QB & SEC & $\mathrm{F}$ & & $\mathrm{AFM}$ & \\
\hline C1QBP & REG & M & & & $\mathrm{P}$ \\
\hline C1QC & SEC & $\mathrm{F}$ & & AFM & \\
\hline C1QTNF12 & $\mathrm{TS}$ & $\mathrm{F}$ & & & \\
\hline C1QTNF7 & SEC & $\mathrm{F}$ & & A & \\
\hline C1RL & $\mathrm{DE}$ & $\mathrm{F}$ & $\mathrm{F}$ & & \\
\hline $\mathrm{C} 2$ & $\mathrm{TS}$ & $\mathrm{F}$ & & & \\
\hline C29H11orf86 & $\mathrm{TS}$ & $\mathrm{F}$ & & & \\
\hline C4BPA & TSSEC & $\mathrm{F}$ & & $\mathrm{F}$ & \\
\hline C4BPB & TSSEC & $\mathrm{F}$ & & $\mathrm{F}$ & \\
\hline C5 & TSSEC & $\mathrm{F}$ & & $\mathrm{AF}$ & \\
\hline C5AR1 & DE & $\mathrm{H}$ & $\mathrm{H}$ & & \\
\hline C5AR2 & DE & $\mathrm{A}$ & $\mathrm{P}$ & & \\
\hline C5H12orf75 & DE & A & $\mathrm{H}$ & & \\
\hline C6 & TSSEC & $\mathrm{F}$ & & $\mathrm{AF}$ & \\
\hline $\mathrm{C} 7$ & SEC & A & & $\mathrm{AF}$ & \\
\hline $\mathrm{C} 8 \mathrm{~A}$ & TSSEC & $\mathrm{F}$ & & $\mathrm{F}$ & \\
\hline $\mathrm{C} 8 \mathrm{~B}$ & TS & $\mathrm{F}$ & & & \\
\hline $\mathrm{C} 8 \mathrm{G}$ & SEC & $\mathrm{F}$ & & AFM & \\
\hline C9 & TSSEC & $\mathrm{F}$ & & $\mathrm{F}$ & \\
\hline C9orf84 & $\mathrm{DE}$ & A & A & & \\
\hline $\mathrm{CA} 2$ & $\mathrm{DE}$ & $\mathrm{H}$ & A & & \\
\hline CA3 & $\mathrm{DE}$ & M & $\mathrm{P}$ & & \\
\hline CA8 & SNP & A & & & \\
\hline CACNA1G & SNP & $\mathrm{H}$ & & & \\
\hline CACNA1S & TS & M & & & \\
\hline CACNB4 & SNP & $\mathrm{H}$ & & & \\
\hline CACNG1 & TS & M & & & \\
\hline CACNG6 & TS & M & & & \\
\hline CALB2 & DETS & $\mathrm{H}$ & $\mathrm{H}$ & & \\
\hline CALCR & $\mathrm{DE}$ & $\mathrm{H}$ & $\mathrm{H}$ & & \\
\hline
\end{tabular}


Tabela suplementar 2 - Genes selecionados para construção da rede de co-expressão

\begin{tabular}{|c|c|c|c|c|}
\hline Gene & Categoria & Tecido de máxima expressão & Tecido DE & Tecido SEC \\
\hline CAMK2D & $\mathrm{DE}$ & $\mathrm{M}$ & $\mathrm{H}$ & \\
\hline CANT1 & SNP & A & & \\
\hline CAPN3 & TS & M & & \\
\hline CAPN6 & SNP & $\mathrm{P}$ & & \\
\hline CAPS & $\mathrm{DE}$ & $\mathrm{P}$ & $\mathrm{H}$ & \\
\hline CARHSP1 & SNP & $\mathrm{F}$ & & \\
\hline CARTPT & $\mathrm{DE}$ & $\mathrm{P}$ & $\mathrm{H}$ & \\
\hline CASK & SNP & $\mathrm{H}$ & & \\
\hline CASQ2 & TS & M & & \\
\hline CAST & SNP & M & & \\
\hline CAV1 & $\mathrm{DE}$ & M & $\mathrm{P}$ & \\
\hline CAV3 & TS & M & & \\
\hline CAVIN1 & REG & M & & \\
\hline CAVIN4 & TS & M & & \\
\hline CBLN4 & SEC & M & & $\mathrm{AH}$ \\
\hline CCBE1 & $\mathrm{DE}$ & A & A & \\
\hline CCDC136 & $\mathrm{DE}$ & $\mathrm{H}$ & $\mathrm{H}$ & \\
\hline CCDC151 & SNP & $\mathrm{F}$ & & \\
\hline CCDC152 & $\mathrm{DE}$ & $\mathrm{F}$ & $\mathrm{P}$ & \\
\hline CCK & SEC & $\mathrm{H}$ & & $\mathrm{H}$ \\
\hline CCKBR & SNP & $\mathrm{F}$ & & \\
\hline CCL14 & SEC & $\mathrm{F}$ & & AFM \\
\hline CCL16 & SEC & $\mathrm{F}$ & & $\mathrm{F}$ \\
\hline CCL2 & SEC & A & & AFM \\
\hline CCL21 & DESEC & A & A & AFM \\
\hline CCL4 & $\mathrm{DE}$ & $\mathrm{F}$ & $\mathrm{F}$ & \\
\hline CCNG2 & $\mathrm{DE}$ & $\mathrm{P}$ & M & \\
\hline CD14 & SEC & $\mathrm{F}$ & & AFM \\
\hline CD247 & $\mathrm{DE}$ & $\mathrm{H}$ & $\mathrm{F}$ & \\
\hline CD5L & TSSEC & $\mathrm{F}$ & & $\mathrm{F}$ \\
\hline CDC16 & SNP & M & & \\
\hline CDH13 & SNP & $\mathrm{P}$ & & \\
\hline CDHR5 & $\mathrm{DE}$ & $\mathrm{F}$ & $\mathrm{F}$ & \\
\hline CDKN1A & $\mathrm{DE}$ & $\mathrm{P}$ & M & \\
\hline CDO1 & $\mathrm{DE}$ & $\mathrm{F}$ & A & \\
\hline CEND1 & TS & $\mathrm{H}$ & & \\
\hline CES1 & TS & $\mathrm{F}$ & & \\
\hline CES3 & TS & $\mathrm{F}$ & & \\
\hline CFD & SEC & $\mathrm{F}$ & & $\mathrm{AM}$ \\
\hline CFI & SEC & $\mathrm{F}$ & & AFM \\
\hline CFP & SNP & $\mathrm{F}$ & & \\
\hline CGA & SEC & $\mathrm{P}$ & & $\mathrm{P}$ \\
\hline CGN1 & TS & $\mathrm{F}$ & & \\
\hline CHCHD7 & SNP & $\mathrm{F}$ & & \\
\hline CHD7 & SNP & $\mathrm{P}$ & & \\
\hline CHGA & SEC & A & & A \\
\hline CHGB & $\mathrm{DE}$ & A & $\mathrm{H}$ & \\
\hline CHIA & TS & $\mathrm{F}$ & & \\
\hline CHRD & TSSEC & $\mathrm{F}$ & & AFM \\
\hline CHRDL1 & SNP & $P$ & & \\
\hline CHRNA1 & TS & M & & \\
\hline CHRNA2 & $\mathrm{DE}$ & $\mathrm{H}$ & $\mathrm{H}$ & \\
\hline CHST13 & TS & $\mathrm{F}$ & & \\
\hline CIDEB & TS & $\mathrm{F}$ & & \\
\hline CISH & $\mathrm{DE}$ & $\mathrm{F}$ & M & \\
\hline CITED1 & REG & $\mathrm{P}$ & & \\
\hline CKM & TS & M & & \\
\hline CLDN11 & $\mathrm{DE}$ & $\mathrm{H}$ & A & \\
\hline CLDN2 & SNP & $\mathrm{F}$ & & \\
\hline CLEC11A & SEC & $\mathrm{F}$ & & AFM \\
\hline CLEC16A & SNP & $\mathrm{P}$ & & \\
\hline CLP1 & SNP & A & & \\
\hline
\end{tabular}


Tabela suplementar 2 - Genes selecionados para construção da rede de co-expressão

(continuação).

\begin{tabular}{|c|c|c|c|c|c|}
\hline Gene & Categoria & Tecido de máxima expressão & Tecido DE & Tecido SEC & Tecido REG \\
\hline CMBL & $\mathrm{DE}$ & $\mathrm{F}$ & $\mathrm{A}$ & & \\
\hline CMPK1 & SEC & $\mathrm{F}$ & & AFM & \\
\hline CMTM5 & TS & $\mathrm{H}$ & & & \\
\hline CMYA5 & TS & M & & & \\
\hline CNN1 & $\mathrm{DE}$ & A & FP & & \\
\hline CNTFR & SNP & A & & & \\
\hline CNTN1 & SEC & $\mathrm{H}$ & & A & \\
\hline CNTN3 & SEC & $\mathrm{F}$ & & $\mathrm{AF}$ & \\
\hline COBL & TS & M & & & \\
\hline $\mathrm{COCH}$ & $\mathrm{DE}$ & $\mathrm{H}$ & $\mathrm{H}$ & & \\
\hline COL15A1 & SEC & $\mathrm{M}$ & & $\mathrm{AM}$ & \\
\hline COL1A2 & DESEC & $\mathrm{M}$ & $\mathrm{H}$ & AFM & \\
\hline COL22A1 & SNP & M & & & \\
\hline COL4A4 & SEC & A & & $\mathrm{AM}$ & \\
\hline COL4A5 & SNP & $\mathrm{P}$ & & & \\
\hline COL6A1 & SEC & A & & AFM & \\
\hline COL8A1 & SEC & $\mathrm{P}$ & & A & \\
\hline COLEC10 & SEC & $\mathrm{F}$ & & $\mathrm{F}$ & \\
\hline COQ6 & SNP & A & & & \\
\hline COX6A2 & TS & $\mathrm{M}$ & & & \\
\hline $\operatorname{COX} 7 \mathrm{C}$ & $\mathrm{DE}$ & $\mathrm{M}$ & $\mathrm{P}$ & & \\
\hline CPB1 & SEC & A & & A & \\
\hline СРB2 & TSSEC & $\mathrm{F}$ & & $\mathrm{F}$ & \\
\hline CPN2 & SEC & $\mathrm{F}$ & & $\mathrm{AF}$ & \\
\hline CPNE7 & $\mathrm{DE}$ & $\mathrm{H}$ & $\mathrm{H}$ & & \\
\hline CPS1 & TS & $\mathrm{F}$ & & & \\
\hline СРХМ2 & $\mathrm{DE}$ & $\mathrm{P}$ & $\mathrm{H}$ & & \\
\hline CRABP1 & $\mathrm{DE}$ & A & $\mathrm{H}$ & & \\
\hline CREB3L3 & TS & $\mathrm{F}$ & & & \\
\hline CREBRF & SNP & $\mathrm{P}$ & & & \\
\hline CREG1 & REG & $\mathrm{F}$ & & & $P$ \\
\hline CRH & SEC & $\mathrm{F}$ & & HP & \\
\hline CRHBP & SEC & $\mathrm{H}$ & & AFP & \\
\hline CRP & TS & $\mathrm{F}$ & & & \\
\hline CRTAC1 & $\mathrm{DE}$ & $\mathrm{H}$ & $\mathrm{H}$ & & \\
\hline CRYAB & $\mathrm{DE}$ & M & $\mathrm{P}$ & & \\
\hline CRYM & DEREG & $\mathrm{P}$ & $\mathrm{P}$ & & $\mathrm{H}$ \\
\hline CSF1 & SNP & $\mathrm{H}$ & & & \\
\hline CSRP3 & DETS & M & $\mathrm{M}$ & & \\
\hline CST3 & SEC & $\mathrm{H}$ & & AFM & \\
\hline CST7 & SEC & $\mathrm{F}$ & & $\mathrm{AF}$ & \\
\hline CSTB & $\mathrm{DE}$ & $\mathrm{F}$ & $\mathrm{M}$ & & \\
\hline СТВP1 & REG & M & & & A \\
\hline CTGF & DESEC & A & $\mathrm{P}$ & AFM & \\
\hline CTNNBIP1 & DE & $\mathrm{H}$ & $\mathrm{H}$ & & \\
\hline CTNND1 & SNP & $\mathrm{P}$ & & & \\
\hline CTSB & SEC & A & & AFM & \\
\hline CTSS & SEC & $\mathrm{F}$ & & AFM & \\
\hline CTSW & SEC & $\mathrm{F}$ & & $\mathrm{AF}$ & \\
\hline CTSZ & SEC & $\mathrm{F}$ & & AFM & \\
\hline CTXN1 & $\mathrm{DE}$ & $\mathrm{H}$ & $\mathrm{H}$ & & \\
\hline CUX2 & SNP & $\mathrm{F}$ & & & \\
\hline CXCL10 & SEC & $P$ & & $\mathrm{AF}$ & \\
\hline CXCL17 & $\mathrm{DE}$ & $\mathrm{F}$ & $\mathrm{F}$ & & \\
\hline CXCL2 & SEC & $\mathrm{F}$ & & $\mathrm{AF}$ & \\
\hline CXCL3 & DETSSEC & $\mathrm{F}$ & $\mathrm{F}$ & $\mathrm{F}$ & \\
\hline CXCL8 & SEC & $\mathrm{F}$ & & $\mathrm{AF}$ & \\
\hline CXCL9 & SEC & $\mathrm{F}$ & & $\mathrm{AF}$ & \\
\hline CXXC1 & REG & $\mathrm{F}$ & & & A \\
\hline CYB561 & $\mathrm{DE}$ & A & $\mathrm{H}$ & & \\
\hline CYBA & $\mathrm{DE}$ & $\mathrm{F}$ & $\mathrm{H}$ & & \\
\hline CYP17A1 & DETSSEC & A & A & A & \\
\hline
\end{tabular}


Tabela suplementar 2 - Genes selecionados para construção da rede de co-expressão (continuação).

\begin{tabular}{|c|c|c|c|c|c|}
\hline Gene & Categoria & Tecido de máxima expressão & Tecido DE & Tecido SEC & Tecido REG \\
\hline CYP1A2 & TS & $\mathrm{F}$ & & & \\
\hline CYP2B6 & SNP & $\mathrm{F}$ & & & \\
\hline CYP2C18 & SEC & $\mathrm{F}$ & & $\mathrm{F}$ & \\
\hline CYP2C19 & TSSEC & $\mathrm{F}$ & & $\mathrm{F}$ & \\
\hline CYP2E1 & DETS & $\mathrm{F}$ & $\mathrm{F}$ & & \\
\hline CYP3A5 & $\mathrm{TS}$ & $\mathrm{F}$ & & & \\
\hline CYP4A11 & TS & $\mathrm{F}$ & & & \\
\hline CYP4F2 & $\mathrm{DE}$ & $\mathrm{F}$ & A & & \\
\hline CYP7A1 & SNP & $\mathrm{F}$ & & & \\
\hline CYP8B1 & $\mathrm{TS}$ & $\mathrm{F}$ & & & \\
\hline CYR61 & $\mathrm{DE}$ & M & $\mathrm{P}$ & & \\
\hline CYTH1 & SNP & M & & & \\
\hline CYTL1 & SEC & $\mathrm{F}$ & & A & \\
\hline DAPK2 & $\mathrm{DE}$ & M & M & & \\
\hline DAPL1 & $\mathrm{DE}$ & $\mathrm{P}$ & AP & & \\
\hline $\mathrm{DBH}$ & TS & A & & & \\
\hline DCUN1D4 & SNP & $\mathrm{P}$ & & & \\
\hline DCX & SNP & A & & & \\
\hline DCXR & DETS & $P$ & $\mathrm{P}$ & & \\
\hline DDB1 & SNP & $\mathrm{P}$ & & & \\
\hline DDX17 & SEC & $\mathrm{P}$ & & AFM & \\
\hline DDX20 & SEC & A & & AFM & \\
\hline DENND2A & $\mathrm{DE}$ & F & F & & \\
\hline DES & DE & M & $\mathrm{P}$ & & \\
\hline DGKQ & SNP & $\mathrm{H}$ & & & \\
\hline DHRS7C & TS & M & & & \\
\hline DIRAS2 & DE & $\mathrm{H}$ & $\mathrm{H}$ & & \\
\hline DIRAS3 & DE & A & $\mathrm{H}$ & & \\
\hline DKK3 & SEC & $\mathrm{H}$ & & AFM & \\
\hline DLG1 & SNP & $\mathrm{H}$ & & & \\
\hline DLG3 & SNP & $\mathrm{F}$ & & & \\
\hline DLK1 & $\mathrm{DE}$ & $\mathrm{P}$ & HFP & & \\
\hline DNAJB1 & DE & A & M & & \\
\hline DNAL1 & SNP & $\mathrm{H}$ & & & \\
\hline DNM1 & TS & $\mathrm{H}$ & & & \\
\hline DOC2G & $\mathrm{DE}$ & M & M & & \\
\hline DOCK7 & SNP & A & & & \\
\hline DOK1 & SNP & $\mathrm{F}$ & & & \\
\hline DOT1L & $\mathrm{DE}$ & M & $\mathrm{P}$ & & \\
\hline DPT & DE & A & A & & \\
\hline DPYS & TS & $\mathrm{F}$ & & & \\
\hline DRD2 & $\mathrm{DE}$ & $\mathrm{P}$ & $\mathrm{H}$ & & \\
\hline DSC3 & DE & $\mathrm{P}$ & $\mathrm{P}$ & & \\
\hline DUPD1 & $\mathrm{TS}$ & M & & & \\
\hline DUSP1 & SNP & M & & & \\
\hline DUSP13 & $\mathrm{TS}$ & M & & & \\
\hline DUSP27 & $\mathrm{TS}$ & M & & & \\
\hline DZIP1 & DE & $\mathrm{H}$ & $\mathrm{H}$ & & \\
\hline E2F6 & SNP & M & & & \\
\hline ECM1 & SEC & $\mathrm{F}$ & & AFM & \\
\hline ECM2 & SEC & A & & AFM & \\
\hline EDN1 & SEC & $\mathrm{H}$ & & $\mathrm{AF}$ & \\
\hline EDNRB & $\mathrm{DE}$ & $\mathrm{H}$ & $\mathrm{H}$ & & \\
\hline EFCAB6 & SNP & $\mathrm{P}$ & & & \\
\hline EFEMP1 & $\mathrm{DE}$ & $\mathrm{P}$ & $\mathrm{H}$ & & \\
\hline EFNB1 & SNP & A & & & \\
\hline EGR1 & $\mathrm{DE}$ & $\mathrm{P}$ & $\mathrm{H}$ & & \\
\hline EGR4 & DE & A & A & & \\
\hline ELFN1 & $\mathrm{DE}$ & $\mathrm{P}$ & $\mathrm{P}$ & & \\
\hline ELMSAN1 & SNP & M & & & \\
\hline ELN & SEC & M & & AFM & \\
\hline ELP3 & SNP & A & & & \\
\hline
\end{tabular}


Tabela suplementar 2 - Genes selecionados para construção da rede de co-expressão (continuação).

\begin{tabular}{|c|c|c|c|c|c|}
\hline Gene & Categoria & Tecido de máxima expressão & Tecido DE & Tecido SEC & Tecido REG \\
\hline EMILIN2 & SEC & $\mathrm{A}$ & & $\mathrm{A}$ & \\
\hline ENC1 & $\mathrm{DE}$ & $\mathrm{H}$ & $\mathrm{H}$ & & \\
\hline ENDOG & SEC & $\mathrm{F}$ & & AFM & \\
\hline ENHO & $\mathrm{DE}$ & $\mathrm{H}$ & M & & \\
\hline ENSBTAG00000000258 & $\mathrm{TS}$ & $\mathrm{F}$ & & & \\
\hline ENSBTAG00000000560 & $\mathrm{DE}$ & $\mathrm{P}$ & AMP & & \\
\hline ENSBTAG00000001219 & $\mathrm{DE}$ & $\mathrm{F}$ & $\mathrm{F}$ & & \\
\hline ENSBTAG00000001443 & $\mathrm{TS}$ & A & & & \\
\hline ENSBTAG00000001608 & TS & A & & & \\
\hline ENSBTAG00000001851 & $\mathrm{DE}$ & $\mathrm{F}$ & FM & & \\
\hline ENSBTAG00000001858 & $\mathrm{DE}$ & M & $\mathrm{M}$ & & \\
\hline ENSBTAG00000003152 & $\mathrm{DE}$ & $\mathrm{F}$ & M & & \\
\hline ENSBTAG00000003289 & TS & $\mathrm{F}$ & & & \\
\hline ENSBTAG00000003352 & $\mathrm{DE}$ & A & $\mathrm{P}$ & & \\
\hline ENSBTAG00000004586 & SNP & M & & & \\
\hline ENSBTAG00000004596 & TS & A & & & \\
\hline ENSBTAG00000004836 & $\mathrm{DE}$ & $\mathrm{H}$ & $\mathrm{H}$ & & \\
\hline ENSBTAG00000005146 & $\mathrm{DE}$ & A & $\mathrm{P}$ & & \\
\hline ENSBTAG00000006383 & $\mathrm{DE}$ & $P$ & MP & & \\
\hline ENSBTAG00000006568 & SNP & $\mathrm{P}$ & & & \\
\hline ENSBTAG00000007043 & TS & $\mathrm{F}$ & & & \\
\hline ENSBTAG00000008564 & $\mathrm{TS}$ & $\mathrm{F}$ & & & \\
\hline ENSBTAG00000009656 & $\mathrm{DE}$ & A & AP & & \\
\hline ENSBTAG00000009703 & $\mathrm{TS}$ & M & & & \\
\hline ENSBTAG00000010155 & $\mathrm{DE}$ & $\mathrm{F}$ & A & & \\
\hline ENSBTAG00000010448 & $\mathrm{DE}$ & $\mathrm{H}$ & $\mathrm{H}$ & & \\
\hline ENSBTAG00000010907 & $\mathrm{DE}$ & M & $\mathrm{F}$ & & \\
\hline ENSBTAG00000012201 & $\mathrm{TS}$ & $\mathrm{F}$ & & & \\
\hline ENSBTAG00000014220 & TS & $\mathrm{F}$ & & & \\
\hline ENSBTAG00000015047 & TS & $\mathrm{F}$ & & & \\
\hline ENSBTAG00000015297 & $\mathrm{DE}$ & $\mathrm{M}$ & M & & \\
\hline ENSBTAG00000015557 & $\mathrm{TS}$ & $\mathrm{F}$ & & & \\
\hline ENSBTAG00000017335 & TS & $\mathrm{F}$ & & & \\
\hline ENSBTAG00000020375 & TS & $\mathrm{F}$ & & & \\
\hline ENSBTAG00000020564 & $\mathrm{DE}$ & $\mathrm{P}$ & $\mathrm{P}$ & & \\
\hline ENSBTAG00000020803 & $\mathrm{DE}$ & A & A & & \\
\hline ENSBTAG00000021368 & $\mathrm{DE}$ & $\mathrm{F}$ & $\mathrm{F}$ & & \\
\hline ENSBTAG00000022395 & TS & $\mathrm{F}$ & & & \\
\hline ENSBTAG00000022715 & $\mathrm{TS}$ & $\mathrm{F}$ & & & \\
\hline ENSBTAG00000023338 & $\mathrm{DE}$ & $\mathrm{P}$ & $\mathrm{H}$ & & \\
\hline ENSBTAG00000023372 & $\mathrm{DE}$ & A & A & & \\
\hline ENSBTAG00000023939 & TS & $\mathrm{F}$ & & & \\
\hline ENSBTAG00000024608 & $\mathrm{DE}$ & $\mathrm{F}$ & A & & \\
\hline ENSBTAG00000024647 & $\mathrm{TS}$ & $\mathrm{F}$ & & & \\
\hline ENSBTAG00000024700 & $\mathrm{TS}$ & $\mathrm{F}$ & & & \\
\hline ENSBTAG00000025126 & $\mathrm{DE}$ & $\mathrm{P}$ & $\mathrm{H}$ & & \\
\hline ENSBTAG00000025260 & $\mathrm{DE}$ & $\mathrm{F}$ & $\mathrm{F}$ & & \\
\hline ENSBTAG00000025383 & $\mathrm{DE}$ & M & $\mathrm{M}$ & & \\
\hline ENSBTAG00000026502 & $\mathrm{TS}$ & $\mathrm{F}$ & & & \\
\hline ENSBTAG00000027075 & $\mathrm{DE}$ & $\mathrm{F}$ & AHMP & & \\
\hline ENSBTAG00000027930 & SNP & $\mathrm{F}$ & & & \\
\hline ENSBTAG00000027962 & $\mathrm{DE}$ & M & AHM & & \\
\hline ENSBTAG00000030683 & $\mathrm{TS}$ & $\mathrm{F}$ & & & \\
\hline ENSBTAG00000030882 & TS & $\mathrm{F}$ & & & \\
\hline ENSBTAG00000031082 & $\mathrm{DE}$ & $\mathrm{F}$ & AMP & & \\
\hline ENSBTAG00000031160 & $\mathrm{DE}$ & $\mathrm{F}$ & $\mathrm{AF}$ & & \\
\hline ENSBTAG00000031687 & REG & M & & & M \\
\hline ENSBTAG00000031785 & $\mathrm{DE}$ & A & $\mathrm{P}$ & & \\
\hline ENSBTAG00000031834 & $\mathrm{DE}$ & $\mathrm{F}$ & $\mathrm{P}$ & & \\
\hline ENSBTAG00000031913 & $\mathrm{DE}$ & M & M & & \\
\hline ENSBTAG00000032057 & $\mathrm{DE}$ & M & AHFMP & & \\
\hline ENSBTAG00000032350 & $\mathrm{TS}$ & $\mathrm{F}$ & & & \\
\hline
\end{tabular}


Tabela suplementar 2 - Genes selecionados para construção da rede de co-expressão (continuação).

\begin{tabular}{|c|c|c|c|c|c|}
\hline Gene & Categoria & Tecido de máxima expressão & Tecido DE & Tecido SEC & Tecido REG \\
\hline ENSBTAG00000034189 & $\mathrm{DE}$ & $\mathrm{F}$ & $\mathrm{A}$ & & \\
\hline ENSBTAG00000034323 & $\mathrm{DE}$ & $\mathrm{H}$ & $\mathrm{F}$ & & \\
\hline ENSBTAG00000034662 & $\mathrm{DE}$ & M & M & & \\
\hline ENSBTAG00000035654 & $\mathrm{DE}$ & $\mathrm{F}$ & HMP & & \\
\hline ENSBTAG00000037605 & $\mathrm{DE}$ & $\mathrm{P}$ & AHMP & & \\
\hline ENSBTAG00000037613 & TS & $\mathrm{F}$ & & & \\
\hline ENSBTAG00000037794 & $\mathrm{DE}$ & $\mathrm{M}$ & M & & \\
\hline ENSBTAG00000037824 & TS & $\mathrm{A}$ & & & \\
\hline ENSBTAG00000038058 & TS & $\mathrm{F}$ & & & \\
\hline ENSBTAG00000038326 & $\mathrm{DE}$ & $\mathrm{P}$ & $\mathrm{H}$ & & \\
\hline ENSBTAG00000038461 & $\mathrm{TS}$ & $\mathrm{F}$ & & & \\
\hline ENSBTAG00000038549 & TS & $\mathrm{F}$ & & & \\
\hline ENSBTAG00000038849 & TS & M & & & \\
\hline ENSBTAG00000039196 & TS & $\mathrm{F}$ & & & \\
\hline ENSBTAG00000039236 & DETS & $\mathrm{P}$ & $\mathrm{P}$ & & \\
\hline ENSBTAG00000039237 & $\mathrm{DE}$ & $\mathrm{F}$ & $\mathrm{F}$ & & \\
\hline ENSBTAG00000039321 & $\mathrm{DE}$ & $\mathrm{F}$ & $\mathrm{F}$ & & \\
\hline ENSBTAG00000039362 & $\mathrm{TS}$ & $\mathrm{F}$ & & & \\
\hline ENSBTAG00000039486 & $\mathrm{DE}$ & M & M & & \\
\hline ENSBTAG00000039620 & $\mathrm{DE}$ & A & M & & \\
\hline ENSBTAG00000039643 & TS & $\mathrm{F}$ & & & \\
\hline ENSBTAG00000039928 & $\mathrm{DE}$ & $\mathrm{F}$ & $\mathrm{F}$ & & \\
\hline ENSBTAG00000040053 & $\mathrm{TS}$ & M & & & \\
\hline ENSBTAG00000040337 & TS & $\mathrm{F}$ & & & \\
\hline ENSBTAG00000040409 & DETS & $\mathrm{F}$ & $\mathrm{F}$ & & \\
\hline ENSBTAG00000043706 & $\mathrm{DE}$ & $\mathrm{M}$ & $\mathrm{P}$ & & \\
\hline ENSBTAG00000043729 & $\mathrm{DE}$ & $\mathrm{F}$ & $\mathrm{F}$ & & \\
\hline ENSBTAG00000043803 & TS & $\mathrm{H}$ & & & \\
\hline ENSBTAG00000043978 & SNP & $\mathrm{H}$ & & & \\
\hline ENSBTAG00000044871 & $\mathrm{DE}$ & M & M & & \\
\hline ENSBTAG00000045585 & $\mathrm{DE}$ & $\mathrm{H}$ & A & & \\
\hline ENSBTAG00000045889 & $\mathrm{TS}$ & M & & & \\
\hline ENSBTAG00000046076 & $\mathrm{DE}$ & $\mathrm{F}$ & $\mathrm{F}$ & & \\
\hline ENSBTAG00000046177 & DETS & $\mathrm{M}$ & $\mathrm{M}$ & & \\
\hline ENSBTAG00000046333 & TS & M & & & \\
\hline ENSBTAG00000046640 & $\mathrm{DE}$ & $\mathrm{H}$ & $\mathrm{H}$ & & \\
\hline ENSBTAG00000046711 & DEREG & A & A & & $\mathrm{H}$ \\
\hline ENSBTAG00000046833 & $\mathrm{DE}$ & $\mathrm{P}$ & $\mathrm{H}$ & & \\
\hline ENSBTAG00000046933 & $\mathrm{DE}$ & $\mathrm{H}$ & $\mathrm{H}$ & & \\
\hline ENSBTAG00000046975 & $\mathrm{TS}$ & $\mathrm{F}$ & & & \\
\hline ENSBTAG00000047029 & $\mathrm{DE}$ & $\mathrm{P}$ & HM & & \\
\hline ENSBTAG00000047039 & TS & A & & & \\
\hline ENSBTAG00000047121 & $\mathrm{DE}$ & $\mathrm{F}$ & $\mathrm{F}$ & & \\
\hline ENSBTAG00000047174 & TS & M & & & \\
\hline ENSBTAG00000047317 & $\mathrm{TS}$ & $\mathrm{F}$ & & & \\
\hline ENSBTAG00000047529 & $\mathrm{DE}$ & $\mathrm{F}$ & $\mathrm{AF}$ & & \\
\hline ENSBTAG00000047561 & $\mathrm{DE}$ & A & M & & \\
\hline ENSBTAG00000047595 & $\mathrm{DE}$ & $\mathrm{P}$ & $\mathrm{H}$ & & \\
\hline ENSBTAG00000047621 & $\mathrm{TS}$ & $\mathrm{F}$ & & & \\
\hline ENSBTAG00000047700 & $\mathrm{DE}$ & $\mathrm{F}$ & $\mathrm{F}$ & & \\
\hline ENSBTAG00000047815 & TS & $\mathrm{F}$ & & & \\
\hline ENSBTAG00000047816 & $\mathrm{DE}$ & $\mathrm{F}$ & $\mathrm{F}$ & & \\
\hline ENSBTAG00000047901 & $\mathrm{TS}$ & A & & & \\
\hline ENSBTAG00000048013 & $\mathrm{DE}$ & $\mathrm{F}$ & $\mathrm{F}$ & & \\
\hline ENSBTAG00000048049 & $\mathrm{DE}$ & $\mathrm{F}$ & $\mathrm{AF}$ & & \\
\hline ENSBTAG00000048058 & $\mathrm{DE}$ & $\mathrm{F}$ & A & & \\
\hline ENSBTAG00000048094 & $\mathrm{TS}$ & $\mathrm{F}$ & & & \\
\hline ENSBTAG00000048135 & DEREG & $\mathrm{F}$ & $\mathrm{AF}$ & & $\mathrm{H}$ \\
\hline ENSBTAG00000048210 & $\mathrm{DE}$ & $\mathrm{P}$ & $\mathrm{F}$ & & \\
\hline ENTPD5 & SNP & $\mathrm{F}$ & & & \\
\hline ENTPD8 & TS & $\mathrm{F}$ & & & \\
\hline EPC1 & REG & M & & & M \\
\hline
\end{tabular}


Tabela suplementar 2 - Genes selecionados para construção da rede de co-expressão

\begin{tabular}{|c|c|c|c|c|c|}
\hline Gene & Categoria & Tecido de máxima expressão & Tecido DE & Tecido SEC & Tecido REG \\
\hline EPCAM & TS & $\mathrm{P}$ & & & \\
\hline EPS15 & SEC & $\mathrm{H}$ & & AFM & \\
\hline EPYC & $\mathrm{DE}$ & $\mathrm{P}$ & $\mathrm{P}$ & & \\
\hline ERCC3 & REG & M & & & $\mathrm{P}$ \\
\hline ERGIC1 & SNP & A & & & \\
\hline ERMN & TS & $\mathrm{H}$ & & & \\
\hline ERP27 & TS & A & & & \\
\hline ERP44 & SEC & $\mathrm{F}$ & & $\mathrm{AFM}$ & \\
\hline ETV6 & REG & A & & & A \\
\hline EVI2A & TS & $\mathrm{H}$ & & & \\
\hline EXT1 & SNP & A & & & \\
\hline F10 & TSSEC & $\mathrm{F}$ & & AFM & \\
\hline F11 & TS & $\mathrm{F}$ & & & \\
\hline F12 & TSSEC & $\mathrm{F}$ & & $\mathrm{F}$ & \\
\hline F13B & TSSEC & $\mathrm{F}$ & & $\mathrm{F}$ & \\
\hline F2 & TS & $\mathrm{F}$ & & & \\
\hline F5 & SEC & $\mathrm{F}$ & & $\mathrm{F}$ & \\
\hline F7 & TSSEC & $\mathrm{F}$ & & $\mathrm{F}$ & \\
\hline F9 & TSSEC & $\mathrm{F}$ & & $\mathrm{F}$ & \\
\hline FABP1 & TS & $\mathrm{F}$ & & & \\
\hline FABP6 & $\mathrm{DE}$ & A & $\mathrm{F}$ & & \\
\hline FABP7 & TS & $\mathrm{H}$ & & & \\
\hline FADS2 & $\mathrm{DE}$ & A & $\mathrm{F}$ & & \\
\hline FAM110B & SNP & A & & & \\
\hline FAM161B & SNP & $\mathrm{H}$ & & & \\
\hline FAM20C & SEC & $\mathrm{F}$ & & AFM & \\
\hline FAM43A & $\mathrm{DE}$ & $\mathrm{P}$ & A & & \\
\hline FATE1 & $\mathrm{DE}$ & A & A & & \\
\hline FBLN5 & SEC & A & & $\mathrm{AFM}$ & \\
\hline FBN1 & SEC & M & & AFM & \\
\hline FBP2 & TS & M & & & \\
\hline FBXO40 & TS & M & & & \\
\hline FBXO44 & $\mathrm{DE}$ & $\mathrm{H}$ & $\mathrm{F}$ & & \\
\hline FETUB & DETS & $\mathrm{F}$ & $\mathrm{F}$ & & \\
\hline FEV & $\mathrm{DE}$ & A & A & & \\
\hline FGA & TSSEC & $\mathrm{F}$ & & $\mathrm{F}$ & \\
\hline FGB & TS & $\mathrm{F}$ & & & \\
\hline FGF13 & SNP & A & & & \\
\hline FGF21 & $\mathrm{DE}$ & $\mathrm{F}$ & $\mathrm{F}$ & & \\
\hline FGG & TS & $\mathrm{F}$ & & & \\
\hline FGGY & SNP & $\mathrm{F}$ & & & \\
\hline FGL1 & SEC & $\mathrm{F}$ & & $\mathrm{F}$ & \\
\hline FGL2 & SEC & $\mathrm{H}$ & & AFM & \\
\hline FKBP11 & $\mathrm{DE}$ & $\mathrm{F}$ & $\mathrm{H}$ & & \\
\hline FKBP5 & $\mathrm{DE}$ & A & $\mathrm{H}$ & & \\
\hline FKBP7 & $\mathrm{DE}$ & A & $\mathrm{P}$ & & \\
\hline FLNA & $\mathrm{DE}$ & A & M & & \\
\hline FMO1 & TS & $\mathrm{F}$ & & & \\
\hline FMO3 & TS & $\mathrm{F}$ & & & \\
\hline FMOD & $\mathrm{DE}$ & $\mathrm{P}$ & $\mathrm{M}$ & & \\
\hline FN1 & $\mathrm{DE}$ & $\mathrm{F}$ & $\mathrm{P}$ & & \\
\hline FNDC3B & SNP & $\mathrm{P}$ & & & \\
\hline FOS & $\mathrm{DE}$ & M & $\mathrm{H}$ & & \\
\hline FOSB & REG & $\mathrm{P}$ & & & $\mathrm{H}$ \\
\hline FOSL2 & $\mathrm{DE}$ & A & M & & \\
\hline FRMD4B & SNP & $\mathrm{P}$ & & & \\
\hline FSHB & DETS & $\mathrm{P}$ & $\mathrm{P}$ & & \\
\hline FST & $\mathrm{DE}$ & $\mathrm{F}$ & $\mathrm{F}$ & & \\
\hline FTCD & TS & $\mathrm{F}$ & & & \\
\hline FTO & SNP & $\mathrm{H}$ & & & \\
\hline FUCA1 & SEC & A & & AFM & \\
\hline FXYD2 & $\mathrm{DE}$ & $\mathrm{F}$ & $\mathrm{F}$ & & \\
\hline
\end{tabular}


Tabela suplementar 2 - Genes selecionados para construção da rede de co-expressão

$$
\text { (continuação). }
$$

\begin{tabular}{|c|c|c|c|c|c|}
\hline Gene & Categoria & Tecido de máxima expressão & Tecido DE & Tecido SEC & Tecido REG \\
\hline FZD1 & $\mathrm{DE}$ & A & A & & \\
\hline FZD4 & $\mathrm{DE}$ & A & M & & \\
\hline G6PC & TS & $\mathrm{F}$ & & & \\
\hline GABBR2 & $\mathrm{DE}$ & $\mathrm{H}$ & $\mathrm{H}$ & & \\
\hline GABRA5 & $\mathrm{DE}$ & $\mathrm{H}$ & $\mathrm{H}$ & & \\
\hline GADD45B & $\mathrm{DE}$ & A & $\mathrm{P}$ & & \\
\hline GAL & SEC & A & & HP & \\
\hline GALNT2 & SEC & $\mathrm{P}$ & & $\mathrm{AFM}$ & \\
\hline GALNT9 & $\mathrm{DE}$ & $\mathrm{H}$ & $\mathrm{H}$ & & \\
\hline GAP43 & TS & $\mathrm{H}$ & & & \\
\hline GARS & SEC & A & & AFM & \\
\hline GAS1 & $\mathrm{DE}$ & $\mathrm{P}$ & $\mathrm{P}$ & & \\
\hline GAS2L1 & $\mathrm{DE}$ & A & A & & \\
\hline GAS7 & $\mathrm{DE}$ & $\mathrm{H}$ & M & & \\
\hline GAT & TS & $\mathrm{F}$ & & & \\
\hline $\mathrm{GC}$ & TSSEC & $\mathrm{F}$ & & $\mathrm{F}$ & \\
\hline GCGR & TS & $\mathrm{F}$ & & & \\
\hline GDAP1 & $\mathrm{DE}$ & $\mathrm{H}$ & $\mathrm{M}$ & & \\
\hline GDF10 & SEC & $\mathrm{H}$ & & A & \\
\hline GDF2 & SEC & $\mathrm{F}$ & & $\mathrm{F}$ & \\
\hline GFAP & TS & $\mathrm{H}$ & & & \\
\hline GGH & SEC & $\mathrm{F}$ & & $\mathrm{AF}$ & \\
\hline GHDC & SEC & $\mathrm{H}$ & & AFM & \\
\hline GHR & SNP & M & & & \\
\hline GLUD1 & SEC & $\mathrm{H}$ & & AFM & \\
\hline GLYAT & TS & $\mathrm{F}$ & & & \\
\hline GMNN & REG & $\mathrm{P}$ & & & $\mathrm{P}$ \\
\hline GNG12 & $\mathrm{DE}$ & $\mathrm{P}$ & $\mathrm{H}$ & & \\
\hline GNPTG & SEC & $\mathrm{F}$ & & AFM & \\
\hline GOLM1 & SEC & $\mathrm{P}$ & & AFM & \\
\hline GOLT1A & $\mathrm{TS}$ & $\mathrm{F}$ & & & \\
\hline GOT2 & SEC & M & & AFM & \\
\hline GPC3 & $\mathrm{DE}$ & A & $\mathrm{F}$ & & \\
\hline GPC5 & SNP & $\mathrm{H}$ & & & \\
\hline GPLD1 & SEC & $\mathrm{F}$ & & $\mathrm{AF}$ & \\
\hline GPR137 & SNP & $\mathrm{H}$ & & & \\
\hline GPR143 & $\mathrm{DE}$ & $\mathrm{F}$ & $\mathrm{F}$ & & \\
\hline GPR153 & $\mathrm{DE}$ & $\mathrm{P}$ & $\mathrm{H}$ & & \\
\hline GPR37L1 & TS & $\mathrm{H}$ & & & \\
\hline GPX3 & DE & $\mathrm{P}$ & $\mathrm{H}$ & & \\
\hline GRASP & $\mathrm{DE}$ & A & A & & \\
\hline GRB14 & $\mathrm{DE}$ & A & A & & \\
\hline GREB1 & DE & M & M & & \\
\hline GSDMB & TS & $\mathrm{F}$ & & & \\
\hline GSG1L & $\mathrm{DE}$ & $\mathrm{H}$ & $\mathrm{H}$ & & \\
\hline GSTA2 & $\mathrm{DE}$ & $\mathrm{F}$ & A & & \\
\hline GSTA3 & $\mathrm{DE}$ & A & A & & \\
\hline GSTA5 & DETS & A & A & & \\
\hline GSTM1 & $\mathrm{DE}$ & A & A & & \\
\hline GSTP1 & SNP & A & & & \\
\hline GSTT3 & TS & $\mathrm{F}$ & & & \\
\hline GTPBP4 & SNP & M & & & \\
\hline GUCA2B & SEC & M & & $\mathrm{F}$ & \\
\hline GULO & TS & $\mathrm{F}$ & & & \\
\hline GUSB & SEC & $\mathrm{F}$ & & AFM & \\
\hline GYS2 & TS & $\mathrm{F}$ & & & \\
\hline H6PD & SEC & $\mathrm{P}$ & & AFM & \\
\hline HAAO & TS & $\mathrm{F}$ & & & \\
\hline HABP2 & TS & $\mathrm{F}$ & & & \\
\hline HAL & DE & $\mathrm{F}$ & $\mathrm{F}$ & & \\
\hline HAMP & TS & $\mathrm{F}$ & & & \\
\hline $\mathrm{HAO} 2$ & TS & $\mathrm{F}$ & & & \\
\hline
\end{tabular}


Tabela suplementar 2 - Genes selecionados para construção da rede de co-expressão

(continuação).

\begin{tabular}{|c|c|c|c|c|c|}
\hline Gene & Categoria & Tecido de máxima expressão & Tecido DE & Tecido SEC & Tecido REG \\
\hline HAPLN2 & TS & $\mathrm{H}$ & & & \\
\hline HAPLN3 & SNP & $\mathrm{H}$ & & & \\
\hline $\mathrm{HCN} 1$ & SNP & $\mathrm{F}$ & & & \\
\hline HDAC11 & REG & $\mathrm{H}$ & & & $\mathrm{P}$ \\
\hline HDAC6 & SNP & $\mathrm{F}$ & & & \\
\hline HDAC8 & SNP & A & & & \\
\hline HDC & DE & $\mathrm{H}$ & $\mathrm{H}$ & & \\
\hline HEPH & SNP & $\mathrm{P}$ & & & \\
\hline HEXA & SEC & $\mathrm{F}$ & & AFM & \\
\hline HGD & $\mathrm{TS}$ & $\mathrm{F}$ & & & \\
\hline HHATL & TS & M & & & \\
\hline HINT2 & SEC & $\mathrm{F}$ & & AFM & \\
\hline HIST1H1C & $\mathrm{DE}$ & $\mathrm{P}$ & MP & & \\
\hline HMGCS2 & TS & $\mathrm{F}$ & & & \\
\hline HOMER1 & DE & M & $\mathrm{A}$ & & \\
\hline HOPX & DEREG & $\mathrm{H}$ & A & & $\mathrm{P}$ \\
\hline HOXA4 & DE & M & M & & \\
\hline HOXA5 & TS & A & & & \\
\hline HOXC6 & DE & A & M & & \\
\hline HOXC8 & DE & A & M & & \\
\hline HOXC9 & DE & M & M & & \\
\hline HPD & TS & $\mathrm{F}$ & & & \\
\hline HPX & TSSEC & F & & F & \\
\hline HR & DE & $\mathrm{P}$ & M & & \\
\hline HRC & $\mathrm{TS}$ & M & & & \\
\hline HRG & TSSEC & $\mathrm{F}$ & & F & \\
\hline HSD11B2 & TS & A & & & \\
\hline HSD17B12 & DE & A & F & & \\
\hline HSD17B13 & TS & F & & & \\
\hline HSD17B6 & TS & F & & & \\
\hline HSD3B & TS & A & & & \\
\hline HSPB7 & TS & M & & & \\
\hline HSPB8 & SNP & M & & & \\
\hline HTR1F & $\mathrm{DE}$ & A & $\mathrm{P}$ & & \\
\hline HTRA1 & DE & $\mathrm{H}$ & M & & \\
\hline HYOU1 & SEC & $\mathrm{P}$ & & AFM & \\
\hline ID1 & SEC & $\mathrm{F}$ & & AFM & \\
\hline ID2 & REG & A & & & $\mathrm{P}$ \\
\hline ID3 & REG & $\mathrm{P}$ & & & $\mathrm{P}$ \\
\hline IER3 & $\mathrm{DE}$ & $\mathrm{F}$ & $\mathrm{A}$ & & \\
\hline IFI30 & DE & F & $\mathrm{P}$ & & \\
\hline IGF1 & TSSEC & $\mathrm{F}$ & & AFM & \\
\hline IGFALS & TS & F & & & \\
\hline IGFBP1 & DETSSEC & F & F & F & \\
\hline IGFBP3 & DE & F & $\mathrm{P}$ & & \\
\hline IGFBP4 & SEC & F & & AFM & \\
\hline IGFBP5 & SEC & $\mathrm{P}$ & & $\mathrm{AFM}$ & \\
\hline IGFBP6 & DESEC & $\mathrm{P}$ & HMP & $\mathrm{AM}$ & \\
\hline IGFBP7 & SEC & A & & AFM & \\
\hline IGSF21 & DE & $\mathrm{H}$ & $\mathrm{H}$ & & \\
\hline IL1R2 & DE & F & F & & \\
\hline IL7 & SEC & F & & $\mathrm{AF}$ & \\
\hline INHA & $\mathrm{DE}$ & A & M & & \\
\hline INHBA & SEC & $\mathrm{F}$ & & AFP & \\
\hline INHBC & SEC & F & & $\mathrm{F}$ & \\
\hline INMT & TS & F & & & \\
\hline INS & SEC & A & & A & \\
\hline INSIG1 & SNP & F & & & \\
\hline INSR & SNP & A & & & \\
\hline IRF3 & REG & F & & & F \\
\hline IRS4 & SNP & $\mathrm{P}$ & & & \\
\hline IRX3 & SNP & $\mathrm{F}$ & & & \\
\hline
\end{tabular}


Tabela suplementar 2 - Genes selecionados para construção da rede de co-expressão

\begin{tabular}{|c|c|c|c|c|c|}
\hline Gene & Categoria & Tecido de máxima expressão & Tecido DE & Tecido SEC & Tecido REG \\
\hline ITGA9 & $\mathrm{DE}$ & A & A & & \\
\hline ITGB1BP2 & TS & $\mathrm{M}$ & & & \\
\hline ITGB3BP & REG & A & & & $\mathrm{P}$ \\
\hline ITIH1 & TS & $\mathrm{F}$ & & & \\
\hline ITIH2 & TSSEC & $\mathrm{F}$ & & $\mathrm{F}$ & \\
\hline ITIH3 & TSSEC & $\mathrm{F}$ & & $\mathrm{F}$ & \\
\hline JAK3 & $\mathrm{DE}$ & $\mathrm{P}$ & $\mathrm{P}$ & & \\
\hline JCHAIN & DESEC & $\mathrm{F}$ & $\mathrm{F}$ & AFM & \\
\hline JDP2 & REG & A & & & $\mathrm{H}$ \\
\hline JPH2 & TS & $\mathrm{M}$ & & & \\
\hline JUNB & $\mathrm{DE}$ & A & $\mathrm{H}$ & & \\
\hline KAT6A & $\mathrm{DE}$ & $\mathrm{P}$ & $\mathrm{F}$ & & \\
\hline KBTBD12 & TS & $\mathrm{M}$ & & & \\
\hline KBTBD6 & $\mathrm{DE}$ & A & A & & \\
\hline KCNA5 & SNP & $\mathrm{P}$ & & & \\
\hline KCNIP2 & $\mathrm{DE}$ & $\mathrm{H}$ & $\mathrm{M}$ & & \\
\hline KCNJ10 & TS & $\mathrm{H}$ & & & \\
\hline KEL & $\mathrm{DE}$ & $\mathrm{F}$ & $\mathrm{F}$ & & \\
\hline KIAA0408 & $\mathrm{DE}$ & $\mathrm{H}$ & M & & \\
\hline KIAA0753 & $\mathrm{DE}$ & $\mathrm{F}$ & $\mathrm{F}$ & & \\
\hline KIAA1324 & TS & $\mathrm{P}$ & & & \\
\hline KLHDC8A & $\mathrm{DE}$ & $\mathrm{P}$ & $\mathrm{H}$ & & \\
\hline KLHL31 & TS & $\mathrm{M}$ & & & \\
\hline KLHL33 & TS & $\mathrm{M}$ & & & \\
\hline KLHL40 & TS & $\mathrm{M}$ & & & \\
\hline KLK7 & $\mathrm{DE}$ & $\mathrm{P}$ & $\mathrm{P}$ & & \\
\hline KLKB1 & TS & $\mathrm{F}$ & & & \\
\hline KNG1 & TSSEC & $\mathrm{F}$ & & $\mathrm{F}$ & \\
\hline KRT19 & $\mathrm{DE}$ & $P$ & A & & \\
\hline LAMA2 & SEC & M & & AFM & \\
\hline LARGE1 & SNP & M & & & \\
\hline LBH & $\mathrm{DE}$ & A & A & & \\
\hline LBP & TSSEC & $\mathrm{F}$ & & $\mathrm{F}$ & \\
\hline LCN2 & SEC & $\mathrm{F}$ & & $\mathrm{F}$ & \\
\hline LDB1 & REG & $\mathrm{P}$ & & & $\mathrm{F}$ \\
\hline LDB3 & TS & M & & & \\
\hline LEAP2 & TSSEC & $\mathrm{F}$ & & AFM & \\
\hline LECT2 & TS & $\mathrm{F}$ & & & \\
\hline LEMD3 & SNP & $P$ & & & \\
\hline LGALS3BP & SNPSEC & $\mathrm{F}$ & & AFM & \\
\hline LGI2 & SEC & $\mathrm{H}$ & & A & \\
\hline LHX3 & TS & $\mathrm{P}$ & & & \\
\hline LIFR & SNP & A & & & \\
\hline LIN52 & SNP & A & & & \\
\hline LIPC & TS & $\mathrm{F}$ & & & \\
\hline LMOD2 & TS & M & & & \\
\hline LMOD3 & TS & M & & & \\
\hline LOX & SEC & $\mathrm{F}$ & & A & \\
\hline LOXL1 & SEC & $\mathrm{F}$ & & A & \\
\hline LRG1 & SEC & $\mathrm{F}$ & & $\mathrm{AF}$ & \\
\hline LRP5 & SNP & $\mathrm{F}$ & & & \\
\hline LRRC2 & TS & M & & & \\
\hline LRRC39 & TS & M & & & \\
\hline LRRN1 & $\mathrm{DE}$ & $\mathrm{H}$ & $\mathrm{M}$ & & \\
\hline LSR & $\mathrm{DE}$ & A & A & & \\
\hline LUM & SEC & A & & AFM & \\
\hline LUZP2 & DESNP & $\mathrm{H}$ & $\mathrm{P}$ & & \\
\hline LYN & SNP & A & & & \\
\hline LYZ & SEC & $\mathrm{F}$ & & AFM & \\
\hline LZTR1 & SNP & $\mathrm{H}$ & & & \\
\hline M-SAA3,2 & $\mathrm{DE}$ & $\mathrm{F}$ & & & \\
\hline MAG & TS & $\mathrm{H}$ & & & \\
\hline
\end{tabular}


Tabela suplementar 2 - Genes selecionados para construção da rede de co-expressão (continuação).

\begin{tabular}{|c|c|c|c|c|c|}
\hline Gene & Categoria & Tecido de máxima expressão & Tecido DE & Tecido SEC & Tecido REG \\
\hline MAN2B1 & SEC & $\mathrm{F}$ & & AFM & \\
\hline MANBA & SEC & A & & AFM & \\
\hline MAOA & SNP & $\mathrm{H}$ & & & \\
\hline MAOB & DESNP & $\mathrm{F}$ & $\mathrm{H}$ & & \\
\hline MAP2K5 & SNP & M & & & \\
\hline MARCKS & SNP & $\mathrm{H}$ & & & \\
\hline MARCO & TS & $\mathrm{F}$ & & & \\
\hline MASP2 & TSSEC & $\mathrm{F}$ & & AFM & \\
\hline MAT1A & TS & $\mathrm{F}$ & & & \\
\hline $\mathrm{MB}$ & TS & M & & & \\
\hline MBL2 & TSSEC & $\mathrm{F}$ & & $\mathrm{F}$ & \\
\hline $\mathrm{MC} 2 \mathrm{R}$ & TS & A & & & \\
\hline MECP2 & REG & M & & & A \\
\hline MED19 & SNP & A & & & \\
\hline MED21 & REG & M & & & $\mathrm{P}$ \\
\hline MED27 & REG & A & & & $\mathrm{P}$ \\
\hline MEIS2 & $\mathrm{DE}$ & A & A & & \\
\hline MELTF & SEC & $\mathrm{P}$ & & A & \\
\hline METTL21E & $\mathrm{TS}$ & M & & & \\
\hline METTL22 & SNP & M & & & \\
\hline METTL7B & TS & $\mathrm{F}$ & & & \\
\hline MFAP4 & SEC & A & & AFM & \\
\hline MGARP & TS & A & & & \\
\hline MGAT5 & SNP & $\mathrm{H}$ & & & \\
\hline MGC137014 & $\mathrm{TS}$ & $\mathrm{F}$ & & & \\
\hline MGC137099 & DETS & $\mathrm{F}$ & $\mathrm{F}$ & & \\
\hline MGC137211 & TS & $\mathrm{F}$ & & & \\
\hline MGC152010 & $\mathrm{TS}$ & $\mathrm{F}$ & & & \\
\hline MGC152281 & TS & $\mathrm{F}$ & & & \\
\hline MGC157237 & TS & $\mathrm{A}$ & & & \\
\hline MGC157368 & DE & $\mathrm{H}$ & $\mathrm{H}$ & & \\
\hline MGC160092 & SNP & $\mathrm{F}$ & & & \\
\hline MGP & $\mathrm{DE}$ & $\mathrm{A}$ & $\mathrm{F}$ & & \\
\hline MID2 & SNP & A & & & \\
\hline MIR3618 & $\mathrm{DE}$ & M & $\mathrm{P}$ & & \\
\hline MKX & $\mathrm{DE}$ & $\mathrm{P}$ & A & & \\
\hline MLC1 & $\mathrm{TS}$ & $\mathrm{H}$ & & & \\
\hline MLX & REG & $\mathrm{F}$ & & & $\mathrm{A}$ \\
\hline MMP7 & SEC & $\mathrm{F}$ & & $\mathrm{F}$ & \\
\hline MMP9 & SEC & $\mathrm{F}$ & & $\mathrm{F}$ & \\
\hline MOBP & $\mathrm{TS}$ & $\mathrm{H}$ & & & \\
\hline MOG & $\mathrm{TS}$ & $\mathrm{H}$ & & & \\
\hline MPV17L & TS & $\mathrm{F}$ & & & \\
\hline MRPL16 & SNP & $\mathrm{F}$ & & & \\
\hline MSH3 & SEC & $\mathrm{H}$ & & AFM & \\
\hline MSN & SNP & A & & & \\
\hline MSRB3 & SNP & M & & & \\
\hline MSS51 & TS & M & & & \\
\hline MST1 & TS & $\mathrm{F}$ & & & \\
\hline MSTN & SNP & M & & & \\
\hline MT-ND4L & DEREG & $\mathrm{H}$ & A & & $\mathrm{H}$ \\
\hline MT1A & DE & $\mathrm{F}$ & $\mathrm{HP}$ & & \\
\hline MT1E & DE & $\mathrm{F}$ & AHP & & \\
\hline MT2 & DE & $\mathrm{F}$ & $\mathrm{H}$ & & \\
\hline MUSTN1 & DE & M & FP & & \\
\hline MYBPC1 & $\mathrm{TS}$ & M & & & \\
\hline MYBPC2 & TS & M & & & \\
\hline MYBPH & $\mathrm{DE}$ & M & M & & \\
\hline MYF6 & $\mathrm{TS}$ & M & & & \\
\hline MYH1 & DETS & M & M & & \\
\hline MYH11 & $\mathrm{DE}$ & $\mathrm{H}$ & $\mathrm{P}$ & & \\
\hline MYH2 & DETS & M & M & & \\
\hline
\end{tabular}


Tabela suplementar 2 - Genes selecionados para construção da rede de co-expressão

(continuação).

\begin{tabular}{|c|c|c|c|c|c|}
\hline Gene & Categoria & Tecido de máxima expressão & Tecido DE & Tecido SEC & Tecido REG \\
\hline MYL1 & TS & $\mathrm{M}$ & & & \\
\hline MYL2 & TS & $\mathrm{M}$ & & & \\
\hline MYL3 & TS & $\mathrm{M}$ & & & \\
\hline MYLK2 & TS & $\mathrm{M}$ & & & \\
\hline MYLK4 & $\mathrm{DE}$ & M & $\mathrm{M}$ & & \\
\hline MYLPF & TS & $\mathrm{M}$ & & & \\
\hline MYO10 & SNP & $\mathrm{H}$ & & & \\
\hline MYO18B & TS & M & & & \\
\hline MYOC & SEC & $\mathrm{M}$ & & $\mathrm{AM}$ & \\
\hline MYOD1 & $\mathrm{DE}$ & M & $\mathrm{M}$ & & \\
\hline MYOM2 & TS & $\mathrm{M}$ & & & \\
\hline MYOM3 & TS & $\mathrm{M}$ & & & \\
\hline MYOT & TS & $\mathrm{M}$ & & & \\
\hline MYOZ2 & TS & $\mathrm{M}$ & & & \\
\hline MYOZ3 & TS & $\mathrm{M}$ & & & \\
\hline MYPN & TS & $\mathrm{M}$ & & & \\
\hline NACA & REG & $\mathrm{F}$ & & & $\mathrm{P}$ \\
\hline NAGA & SEC & A & & AFM & \\
\hline NAPSA & SEC & $\mathrm{F}$ & & A & \\
\hline ND1 & DEREG & $\mathrm{F}$ & A & & $\mathrm{H}$ \\
\hline ND2 & $\mathrm{DE}$ & $\mathrm{H}$ & A & & \\
\hline ND4 & DEREG & $\mathrm{F}$ & A & & $\mathrm{H}$ \\
\hline ND5 & DEREG & $\mathrm{H}$ & A & & $\mathrm{H}$ \\
\hline ND6 & DEREG & M & A & & $\mathrm{H}$ \\
\hline NDP & SNP & $\mathrm{H}$ & & & \\
\hline NDUFS1 & SNP & M & & & \\
\hline NEB & TS & M & & & \\
\hline NECAP2 & SNP & A & & & \\
\hline NEDD8 & REG & $\mathrm{M}$ & & & MP \\
\hline NENF & SEC & A & & AFM & \\
\hline NEURL1 & $\mathrm{DE}$ & $\mathrm{M}$ & $\mathrm{H}$ & & \\
\hline NEURL1B & SNP & A & & & \\
\hline NEUROD4 & $\mathrm{DE}$ & $\mathrm{P}$ & $P$ & & \\
\hline NFAM1 & $\mathrm{DE}$ & $\mathrm{H}$ & $\mathrm{H}$ & & \\
\hline NFKBIA & REG & $\mathrm{F}$ & & & A \\
\hline NGB & $\mathrm{DE}$ & $\mathrm{H}$ & A & & \\
\hline NGF & SEC & $\mathrm{F}$ & & A & \\
\hline NID1 & SEC & M & & AFM & \\
\hline NMRK2 & TS & M & & & \\
\hline NNAT & $\mathrm{DE}$ & $\mathrm{P}$ & $\mathrm{H}$ & & \\
\hline NOSTRIN & SNP & A & & & \\
\hline NOV & DESEC & $\mathrm{P}$ & $\mathrm{AP}$ & $\mathrm{AM}$ & \\
\hline NPM1 & REG & A & & & $\mathrm{P}$ \\
\hline NPNT & $\mathrm{DE}$ & $P$ & M & & \\
\hline NPPA & DE & A & A & & \\
\hline NPTX1 & $\mathrm{DE}$ & A & A & & \\
\hline NPTXR & SEC & $\mathrm{H}$ & & A & \\
\hline NPY & DETSSEC & A & A & $\mathrm{AH}$ & \\
\hline NR0B2 & $\mathrm{DE}$ & $\mathrm{F}$ & $\mathrm{F}$ & & \\
\hline NR1I2 & TS & $\mathrm{F}$ & & & \\
\hline NR113 & TSSNP & $\mathrm{F}$ & & & \\
\hline NR2F6 & REG & $\mathrm{F}$ & & & $\mathrm{F}$ \\
\hline NR4A1 & $\mathrm{DE}$ & $P$ & $\mathrm{H}$ & & \\
\hline NR4A2 & $\mathrm{DE}$ & $P$ & $\mathrm{AP}$ & & \\
\hline NR4A3 & REG & $P$ & & & $\mathrm{H}$ \\
\hline NRAP & TS & M & & & \\
\hline NREP & $\mathrm{DE}$ & M & $\mathrm{P}$ & & \\
\hline NRIP1 & REG & M & & & M \\
\hline NRN1 & $\mathrm{DE}$ & $\mathrm{H}$ & $\mathrm{H}$ & & \\
\hline NRSN1 & $\mathrm{DE}$ & $\mathrm{P}$ & A & & \\
\hline NRSN2 & $\mathrm{DE}$ & $\mathrm{H}$ & $\mathrm{H}$ & & \\
\hline NSG2 & TS & $\mathrm{H}$ & & & \\
\hline
\end{tabular}


Tabela suplementar 2 - Genes selecionados para construção da rede de co-expressão

\begin{tabular}{|c|c|c|c|c|c|}
\hline Gene & Categoria & Tecido de máxima expressão & Tecido DE & Tecido SEC & Tecido REG \\
\hline NSMF & $\mathrm{DE}$ & $\mathrm{H}$ & $\mathrm{H}$ & & \\
\hline NTN5 & TS & $\mathrm{F}$ & & & \\
\hline NUCB1 & SEC & A & & AFM & \\
\hline NUMB & SNP & $\mathrm{P}$ & & & \\
\hline NUPR1 & $\mathrm{DE}$ & $\mathrm{F}$ & $\mathrm{M}$ & & \\
\hline NXT2 & SNP & $\mathrm{H}$ & & & \\
\hline OCLN & SNP & $\mathrm{H}$ & & & \\
\hline OIT3 & SEC & $\mathrm{F}$ & & $\mathrm{F}$ & \\
\hline OLIG1 & TS & $\mathrm{H}$ & & & \\
\hline OMG & TS & $\mathrm{H}$ & & & \\
\hline OPALIN & TS & $\mathrm{H}$ & & & \\
\hline OPRK1 & SNP & $\mathrm{F}$ & & & \\
\hline OSMR & SNP & A & & & \\
\hline OTC & TS & $\mathrm{F}$ & & & \\
\hline OTOS & $\mathrm{DE}$ & A & A & & \\
\hline OTUD1 & DETS & $\mathrm{M}$ & $\mathrm{M}$ & & \\
\hline OVGP1 & SEC & $\mathrm{F}$ & & $\mathrm{F}$ & \\
\hline OXT & DESEC & $\mathrm{M}$ & $\mathrm{M}$ & HFP & \\
\hline P4HA1 & SEC & $\mathrm{P}$ & & $\mathrm{AFM}$ & \\
\hline PAK1 & $\mathrm{DE}$ & $\mathrm{H}$ & $\mathrm{H}$ & & \\
\hline PAK3 & SNP & $\mathrm{P}$ & & & \\
\hline PALMD & $\mathrm{DE}$ & M & $\mathrm{P}$ & & \\
\hline PAPLN & SNP & $\mathrm{P}$ & & & \\
\hline PAQR6 & TS & $\mathrm{H}$ & & & \\
\hline PARP14 & SNP & A & & & \\
\hline PBLD & $\mathrm{DE}$ & $\mathrm{F}$ & $\mathrm{F}$ & & \\
\hline PCBD1 & $\mathrm{DE}$ & $\mathrm{F}$ & $\mathrm{M}$ & & \\
\hline PCCA & SNP & $\mathrm{F}$ & & & \\
\hline PCK1 & TS & $\mathrm{F}$ & & & \\
\hline PCMTD1 & SNP & M & & & \\
\hline PCOLCE & DESEC & $\mathrm{F}$ & $\mathrm{P}$ & $\mathrm{AFM}$ & \\
\hline PCP4L1 & DE & $\mathrm{H}$ & $\mathrm{H}$ & & \\
\hline PCSK2 & $\mathrm{DE}$ & $P$ & $\mathrm{P}$ & & \\
\hline PCSK6 & SNP & $\mathrm{H}$ & & & \\
\hline PDIA3 & SEC & $\mathrm{P}$ & & $\mathrm{AFM}$ & \\
\hline PDIA4 & SEC & $\mathrm{F}$ & & $\mathrm{AFM}$ & \\
\hline PDLIM7 & $\mathrm{DE}$ & M & $\mathrm{H}$ & & \\
\hline PDYN & SNP & $\mathrm{H}$ & & & \\
\hline PEBP4 & $\mathrm{DE}$ & M & M & & \\
\hline PEG10 & $\mathrm{DE}$ & A & $\mathrm{H}$ & & \\
\hline PENK & DESNPSEC & A & $\mathrm{H}$ & $\mathrm{AM}$ & \\
\hline PERM1 & TS & M & & & \\
\hline PFKFB3 & $\mathrm{DE}$ & M & $\mathrm{M}$ & & \\
\hline PFKFB4 & $\mathrm{DE}$ & M & A & & \\
\hline PGAM2 & TS & M & & & \\
\hline PGAP2 & DE & A & $\mathrm{P}$ & & \\
\hline PGF & DESEC & A & $\mathrm{P}$ & $\mathrm{AFM}$ & \\
\hline PGM5 & SNP & M & & & \\
\hline PGS1 & SNP & A & & & \\
\hline PHF12 & REG & $\mathrm{P}$ & & & M \\
\hline PHF5A & REG & M & & & $\mathrm{M}$ \\
\hline PHOX2A & TS & A & & & \\
\hline PI16 & $\mathrm{DE}$ & A & $\mathrm{M}$ & & \\
\hline PI3 & SEC & M & & $\mathrm{F}$ & \\
\hline PIH1D3 & SNP & $\mathrm{F}$ & & & \\
\hline PIM1 & $\mathrm{DE}$ & $\mathrm{F}$ & $\mathrm{M}$ & & \\
\hline PIR & REG & A & & & $\mathrm{P}$ \\
\hline PITX1 & DEREG & $\mathrm{P}$ & M & & $\mathrm{P}$ \\
\hline PKIA & SNP & M & & & \\
\hline PLA2G12B & TSSEC & $\mathrm{F}$ & & $\mathrm{F}$ & \\
\hline PLA2G7 & SEC & $\mathrm{F}$ & & $\mathrm{AF}$ & \\
\hline PLAT & SEC & $\mathrm{H}$ & & AFM & \\
\hline
\end{tabular}


Tabela suplementar 2 - Genes selecionados para construção da rede de co-expressão

\begin{tabular}{|c|c|c|c|c|c|}
\hline Gene & Categoria & Tecido de máxima expressão & Tecido DE & Tecido SEC & Tecido REG \\
\hline PLCD1 & DEREG & A & A & & $\mathrm{H}$ \\
\hline PLCH2 & DE & $\mathrm{H}$ & $\mathrm{H}$ & & \\
\hline PLEKHA7 & SNP & $\mathrm{P}$ & & & \\
\hline PLEKHM3 & SNP & $\mathrm{H}$ & & & \\
\hline PLG & TSSEC & $\mathrm{F}$ & & $\mathrm{F}$ & \\
\hline PLN & $\mathrm{TS}$ & M & & & \\
\hline PLOD1 & SEC & A & & AFM & \\
\hline PLP1 & TS & $\mathrm{H}$ & & & \\
\hline PLPPR1 & SNP & $\mathrm{H}$ & & & \\
\hline PLS3 & SNP & $\mathrm{H}$ & & & \\
\hline PM20D2 & $\mathrm{DE}$ & M & M & & \\
\hline $\mathrm{PMCH}$ & $\mathrm{DE}$ & $\mathrm{H}$ & $\mathrm{H}$ & & \\
\hline PMF1 & $\mathrm{DE}$ & $\mathrm{F}$ & $\mathrm{P}$ & & \\
\hline PMM2 & SNP & $\mathrm{F}$ & & & \\
\hline PNMA1 & SNP & $\mathrm{P}$ & & & \\
\hline PNMT & TS & A & & & \\
\hline PON1 & DESEC & $\mathrm{F}$ & $\mathrm{F}$ & $\mathrm{AF}$ & \\
\hline PON3 & SEC & $\mathrm{F}$ & & $\mathrm{AF}$ & \\
\hline POSTN & SEC & $\mathrm{P}$ & & $\mathrm{AF}$ & \\
\hline POU1F1 & $\mathrm{TS}$ & $\mathrm{P}$ & & & \\
\hline PPIB & SEC & $\mathrm{F}$ & & AFM & \\
\hline PPM1H & SNP & $\mathrm{H}$ & & & \\
\hline PPP1R27 & $\mathrm{TS}$ & M & & & \\
\hline PPP1R3A & $\mathrm{TS}$ & M & & & \\
\hline PPP1R3B & DE & $\mathrm{F}$ & $\mathrm{F}$ & & \\
\hline PPP1R3C & $\mathrm{DE}$ & M & M & & \\
\hline PPP1R3F & SNP & $\mathrm{H}$ & & & \\
\hline PRDM6 & REG & A & & & A \\
\hline PRELP & SEC & $\mathrm{H}$ & & AFM & \\
\hline PRG4 & SEC & $\mathrm{F}$ & & $\mathrm{AF}$ & \\
\hline PRKCG & $\mathrm{DE}$ & $\mathrm{H}$ & $\mathrm{H}$ & & \\
\hline PRKCSH & SEC & $\mathrm{F}$ & & AFM & \\
\hline PRKG1 & SNP & M & & & \\
\hline PRL & DESEC & $\mathrm{P}$ & $\mathrm{F}$ & $\mathrm{P}$ & \\
\hline PROC & TS & F & & & \\
\hline PRODH2 & $\mathrm{TS}$ & $\mathrm{F}$ & & & \\
\hline PROZ & TSSEC & $\mathrm{F}$ & & $\mathrm{F}$ & \\
\hline PRPS2 & $\mathrm{DE}$ & A & A & & \\
\hline PRR15 & $\mathrm{DE}$ & $\mathrm{P}$ & $\mathrm{P}$ & & \\
\hline PSEN1 & SNP & $\mathrm{H}$ & & & \\
\hline PSMD10 & SNP & $\mathrm{H}$ & & & \\
\hline PSMD7 & SNP & M & & & \\
\hline PSME4 & SNP & M & & & \\
\hline РTBP3 & SNP & A & & & \\
\hline PTGDS & $\mathrm{DE}$ & $\mathrm{H}$ & $\mathrm{F}$ & & \\
\hline PTGR1 & $\mathrm{DE}$ & $\mathrm{F}$ & $\mathrm{P}$ & & \\
\hline PTGS1 & SNP & $\mathrm{F}$ & & & \\
\hline PTK2B & $\mathrm{DE}$ & $\mathrm{P}$ & $\mathrm{H}$ & & \\
\hline PTPN5 & $\mathrm{DE}$ & $\mathrm{H}$ & $\mathrm{H}$ & & \\
\hline PTX3 & DESEC & A & A & A & \\
\hline PUF60 & REG & $\mathrm{H}$ & & & M \\
\hline PVALB & $\mathrm{DE}$ & $\mathrm{H}$ & HM & & \\
\hline PYM1 & SNP & A & & & \\
\hline QPCT & $\mathrm{DE}$ & $\mathrm{P}$ & $\mathrm{H}$ & & \\
\hline QPRT & SEC & $\mathrm{F}$ & & AFM & \\
\hline RAB17 & $\mathrm{DE}$ & $\mathrm{F}$ & A & & \\
\hline RAB28 & SNP & $\mathrm{P}$ & & & \\
\hline RAB3B & $\mathrm{DE}$ & $\mathrm{P}$ & $\mathrm{H}$ & & \\
\hline RARRES2 & DESNPSEC & $\mathrm{F}$ & $\mathrm{H}$ & AFM & \\
\hline RASD1 & $\mathrm{DE}$ & $\mathrm{P}$ & M & & \\
\hline RASGRF2 & SNP & $\mathrm{H}$ & & & \\
\hline RASL11A & $\mathrm{DE}$ & A & A & & \\
\hline
\end{tabular}


Tabela suplementar 2 - Genes selecionados para construção da rede de co-expressão (continuação).

\begin{tabular}{|c|c|c|c|c|c|}
\hline Gene & Categoria & Tecido de máxima expressão & Tecido DE & Tecido SEC & Tecido REG \\
\hline RBM3 & $\mathrm{DE}$ & $\mathrm{A}$ & $\mathrm{M}$ & & \\
\hline RBM39 & REG & A & & & A \\
\hline RBP1 & $\mathrm{DE}$ & $\mathrm{F}$ & A & & \\
\hline RBP5 & TS & $\mathrm{F}$ & & & \\
\hline RCAN3 & SNP & $\mathrm{P}$ & & & \\
\hline RD3 & $\mathrm{DE}$ & $\mathrm{P}$ & $\mathrm{P}$ & & \\
\hline RDH12 & SEC & $\mathrm{H}$ & & $\mathrm{AF}$ & \\
\hline RDH16 & TS & $\mathrm{F}$ & & & \\
\hline REC8 & DE & $\mathrm{F}$ & $\mathrm{F}$ & & \\
\hline REEP3 & SNP & $\mathrm{H}$ & & & \\
\hline RFC5 & SNP & M & & & \\
\hline RGS1 & $\mathrm{DE}$ & $\mathrm{P}$ & $\mathrm{AH}$ & & \\
\hline RGS16 & DE & $\mathrm{F}$ & $\mathrm{H}$ & & \\
\hline RGS4 & $\mathrm{DE}$ & $\mathrm{H}$ & $\mathrm{HP}$ & & \\
\hline RHBG & DE & $\mathrm{F}$ & $\mathrm{A}$ & & \\
\hline RHOD & DE & A & A & & \\
\hline RILPL1 & SNP & M & & & \\
\hline RING1 & REG & A & & & $\mathrm{A}$ \\
\hline RIOX1 & SNP & A & & & \\
\hline RIPPLY1 & SNP & F & & & \\
\hline RLBP1 & $\mathrm{DE}$ & $\mathrm{H}$ & $\mathrm{H}$ & & \\
\hline RLIM & SNP & $\mathrm{P}$ & & & \\
\hline RNASE13 & $\mathrm{DE}$ & M & M & & \\
\hline RNASE4 & SEC & $\mathrm{F}$ & & AFM & \\
\hline RNASET2 & $\mathrm{DE}$ & A & $\mathrm{H}$ & & \\
\hline RND1 & DE & $\mathrm{H}$ & $\mathrm{F}$ & & \\
\hline RNF125 & $\mathrm{DE}$ & F & $\mathrm{F}$ & & \\
\hline RNF138 & REG & $\mathrm{P}$ & & & $\mathrm{P}$ \\
\hline RORB & SNP & $\mathrm{P}$ & & & \\
\hline RPGRIP1L & SNP & $\mathrm{P}$ & & & \\
\hline RPL26L1 & SNP & A & & & \\
\hline RPL3L & $\mathrm{TS}$ & M & & & \\
\hline RPS20 & SNP & $\mathrm{F}$ & & & \\
\hline RPS6KA6 & SNP & $\mathrm{P}$ & & & \\
\hline RTL1 & $\mathrm{TS}$ & A & & & \\
\hline RTL9 & SNP & F & & & \\
\hline RTN4RL2 & SNPSEC & F & & $\mathrm{F}$ & \\
\hline RUFY3 & SNP & $\mathrm{H}$ & & & \\
\hline RWDD3 & SNP & $\mathrm{H}$ & & & \\
\hline RXRB & REG & F & & & $\mathrm{P}$ \\
\hline RYR1 & $\mathrm{TS}$ & M & & & \\
\hline S100A4 & DE & $\mathrm{F}$ & $\mathrm{P}$ & & \\
\hline S1PR3 & SNP & F & & & \\
\hline SAA1 & TS & F & & & \\
\hline SAA4 & TSSEC & F & & F & \\
\hline SAFB2 & REG & F & & & F \\
\hline SAO & $\mathrm{TS}$ & $\mathrm{F}$ & & & \\
\hline SBK2 & DE & M & M & & \\
\hline SCG2 & DESEC & $\mathrm{P}$ & $\mathrm{H}$ & AHP & \\
\hline SCGB1D & $\mathrm{DE}$ & F & $\mathrm{P}$ & & \\
\hline SCN1B & DE & M & $\mathrm{H}$ & & \\
\hline SCOC & DE & $\mathrm{H}$ & $\mathrm{P}$ & & \\
\hline SDCBP & SNP & A & & & \\
\hline SDR16C5 & SNP & $\mathrm{F}$ & & & \\
\hline SDS & $\mathrm{DE}$ & $\mathrm{F}$ & $\mathrm{F}$ & & \\
\hline SDSL & $\mathrm{TS}$ & $\mathrm{H}$ & & & \\
\hline SEMA7A & $\mathrm{DE}$ & $\mathrm{H}$ & $\mathrm{H}$ & & \\
\hline SERPINA1 & $\mathrm{TS}$ & $\mathrm{F}$ & & & \\
\hline SERPINA10 & $\mathrm{TS}$ & F & & & \\
\hline SERPINA11 & TSSEC & $\mathrm{F}$ & & $\mathrm{F}$ & \\
\hline SERPINA3-1 & TS & $\mathrm{F}$ & & & \\
\hline SERPINA3-3 & TS & $\mathrm{F}$ & & & \\
\hline
\end{tabular}


Tabela suplementar 2 - Genes selecionados para construção da rede de co-expressão (continuação).

\begin{tabular}{|c|c|c|c|c|c|}
\hline Gene & Categoria & Tecido de máxima expressão & Tecido DE & Tecido SEC & Tecido REG \\
\hline SERPINA3-7 & TS & $\mathrm{F}$ & & & \\
\hline SERPINA3-8 & TS & $\mathrm{F}$ & & & \\
\hline SERPINA5 & SEC & $\mathrm{F}$ & & AFM & \\
\hline SERPINA6 & TSSEC & $\mathrm{F}$ & & $\mathrm{F}$ & \\
\hline SERPINA7 & TSSEC & $\mathrm{F}$ & & $\mathrm{F}$ & \\
\hline SERPINC1 & TSSEC & $\mathrm{F}$ & & $\mathrm{F}$ & \\
\hline SERPIND1 & TSSEC & $\mathrm{F}$ & & $\mathrm{F}$ & \\
\hline SERPINE1 & DESEC & M & M & $\mathrm{AF}$ & \\
\hline SERPINE2 & SEC & $\mathrm{H}$ & & AFM & \\
\hline SERPINF2 & TSSEC & $\mathrm{F}$ & & $\mathrm{F}$ & \\
\hline SERPING1 & SNP & $\mathrm{F}$ & & & \\
\hline SERPINI2 & $\mathrm{DE}$ & $\mathrm{F}$ & $\mathrm{F}$ & & \\
\hline SESN3 & DE & M & M & & \\
\hline SFRP2 & $\mathrm{DE}$ & $\mathrm{H}$ & $\mathrm{P}$ & & \\
\hline SFRS5 & DESNP & $\mathrm{F}$ & M & & \\
\hline SFTPA1 & TS & $\mathrm{F}$ & & & \\
\hline SGCG & TS & M & & & \\
\hline SGPP2 & DE & $\mathrm{P}$ & $\mathrm{P}$ & & \\
\hline SH3PXD2B & SNP & $\mathrm{P}$ & & & \\
\hline SHC3 & SNP & $\mathrm{H}$ & & & \\
\hline $\mathrm{SHH}$ & $\mathrm{DE}$ & A & A & & \\
\hline SHROOM4 & SNP & A & & & \\
\hline SIGLEC1 & SNP & $\mathrm{F}$ & & & \\
\hline SIX6 & $\mathrm{TS}$ & $\mathrm{P}$ & & & \\
\hline SLC10A1 & TS & $\mathrm{F}$ & & & \\
\hline SLC16A11 & $\mathrm{DE}$ & $\mathrm{F}$ & $\mathrm{F}$ & & \\
\hline SLC16A2 & SNP & $\mathrm{H}$ & & & \\
\hline SLC16A7 & SNP & $\mathrm{F}$ & & & \\
\hline SLC17A2 & $\mathrm{TS}$ & $\mathrm{F}$ & & & \\
\hline SLC17A4 & DE & $\mathrm{F}$ & $\mathrm{F}$ & & \\
\hline SLC18A2 & $\mathrm{DE}$ & A & $\mathrm{H}$ & & \\
\hline SLC1A3 & $\mathrm{TS}$ & $\mathrm{H}$ & & & \\
\hline SLC22A1 & TS & $\mathrm{F}$ & & & \\
\hline SLC22A18 & TS & $\mathrm{F}$ & & & \\
\hline SLC22A7 & TS & $\mathrm{F}$ & & & \\
\hline SLC24A2 & DESNP & $\mathrm{H}$ & $\mathrm{H}$ & & \\
\hline SLC24A3 & DE & $\mathrm{H}$ & $\mathrm{H}$ & & \\
\hline SLC25A47 & $\mathrm{TS}$ & $\mathrm{F}$ & & & \\
\hline SLC27A5 & TS & $\mathrm{F}$ & & & \\
\hline SLC2A4 & $\mathrm{DE}$ & M & $\mathrm{P}$ & & \\
\hline SLC30A3 & DE & $\mathrm{F}$ & $\mathrm{F}$ & & \\
\hline SLC38A11 & SNP & A & & & \\
\hline SLC39A5 & $\mathrm{TS}$ & $\mathrm{F}$ & & & \\
\hline SLC43A2 & DE & M & M & & \\
\hline SLC45A2 & SNP & $\mathrm{F}$ & & & \\
\hline SLC51B & TS & $\mathrm{F}$ & & & \\
\hline SLC7A1 & $\mathrm{DE}$ & $\mathrm{H}$ & A & & \\
\hline SLCO1B3 & $\mathrm{TS}$ & $\mathrm{F}$ & & & \\
\hline SLIT2 & $\mathrm{DE}$ & $\mathrm{P}$ & A & & \\
\hline SLX4IP & SNP & $\mathrm{H}$ & & & \\
\hline SMAGP & $\mathrm{DE}$ & A & A & & \\
\hline SMARCAL1 & SNP & $\mathrm{P}$ & & & \\
\hline SMCO1 & $\mathrm{TS}$ & M & & & \\
\hline SMIM24 & SNP & M & & & \\
\hline SMIM6 & DE & $\mathrm{F}$ & $\mathrm{F}$ & & \\
\hline SMPX & TS & M & & & \\
\hline SMTNL1 & TSSNP & M & & & \\
\hline SMYD1 & TS & M & & & \\
\hline SNCG & $\mathrm{DE}$ & $\mathrm{H}$ & $\mathrm{H}$ & & \\
\hline SNORA17 & DE & M & $\mathrm{F}$ & & \\
\hline SNORA3 & DE & A & $\mathrm{F}$ & & \\
\hline SNORA63 & $\mathrm{DE}$ & F & $\mathrm{F}$ & & \\
\hline
\end{tabular}


Tabela suplementar 2 - Genes selecionados para construção da rede de co-expressão

$$
\text { (continuação). }
$$

\begin{tabular}{|c|c|c|c|c|c|}
\hline Gene & Categoria & Tecido de máxima expressão & Tecido DE & Tecido SEC & Tecido REG \\
\hline SNORA73 & $\mathrm{DE}$ & $\mathrm{F}$ & $\mathrm{F}$ & & \\
\hline SNORD107 & $\mathrm{DE}$ & $\mathrm{H}$ & $\mathrm{P}$ & & \\
\hline SNORD14 & $\mathrm{DE}$ & $\mathrm{P}$ & $\mathrm{H}$ & & \\
\hline SNORD39 & $\mathrm{DE}$ & $\mathrm{H}$ & $\mathrm{F}$ & & \\
\hline SNORD47 & $\mathrm{DE}$ & A & $\mathrm{F}$ & & \\
\hline SNORD96 & $\mathrm{DE}$ & $\mathrm{P}$ & $\mathrm{F}$ & & \\
\hline SNTB1 1 & SEC & M & & AFM & \\
\hline SNTG1 & SNP & $\mathrm{H}$ & & & \\
\hline SOCS3 & DESNP & $\mathrm{F}$ & A & & \\
\hline SOD3 & DESEC & $\mathrm{F}$ & $\mathrm{F}$ & AFM & \\
\hline SORL1 & SNP & $\mathrm{H}$ & & & \\
\hline SORT1 & SNP & $\mathrm{H}$ & & & \\
\hline SPECC1L & SNP & $\mathrm{P}$ & & & \\
\hline SPIN2B & SNP & $\mathrm{H}$ & & & \\
\hline SPINK1 & SEC & M & & $\mathrm{F}$ & \\
\hline SPINK7 & $\mathrm{DE}$ & $\mathrm{P}$ & $\mathrm{P}$ & & \\
\hline SPNS3 & $\mathrm{DE}$ & $\mathrm{F}$ & $\mathrm{F}$ & & \\
\hline SPON1 & SEC & $\mathrm{P}$ & & $\mathrm{AF}$ & \\
\hline SPP1 & DESEC & $\mathrm{P}$ & $\mathrm{P}$ & AFM & \\
\hline SPP2 & TS & $\mathrm{F}$ & & & \\
\hline SPTSSB & SNP & $\mathrm{H}$ & & & \\
\hline SRGN & SEC & $\mathrm{F}$ & & $\mathrm{AFM}$ & \\
\hline SRL & TS & $\mathrm{M}$ & & & \\
\hline SRPX & SEC & A & & $\mathrm{AF}$ & \\
\hline SRSF2 & REG & A & & & M \\
\hline SST & DESEC & $\mathrm{H}$ & $\mathrm{H}$ & AHP & \\
\hline ST18 & SNP & $\mathrm{H}$ & & & \\
\hline STAC3 & TS & M & & & \\
\hline STAR & TS & A & & & \\
\hline STAT3 & REG & A & & & $\mathrm{M}$ \\
\hline STBD1 & $\mathrm{DE}$ & M & A & & \\
\hline STMN4 & TS & $\mathrm{H}$ & & & \\
\hline STUM & $\mathrm{DE}$ & $\mathrm{H}$ & $\mathrm{H}$ & & \\
\hline STX3 & SNP & $\mathrm{P}$ & & & \\
\hline SUCLG1 & SEC & M & & AFM & \\
\hline SULF2 & $\mathrm{DE}$ & $\mathrm{P}$ & $\mathrm{P}$ & & \\
\hline SULT1E1 & $\mathrm{DE}$ & A & A & & \\
\hline SULT2A1 & TS & $\mathrm{F}$ & & & \\
\hline SUMO2 & REG & A & & & $\mathrm{AP}$ \\
\hline SUPT3H & REG & $\mathrm{H}$ & & & $\mathrm{P}$ \\
\hline SUV39H1 & SNP & $\mathrm{F}$ & & & \\
\hline SYNDIG1L & DE & $\mathrm{H}$ & $\mathrm{H}$ & & \\
\hline SYNGR2 & SNP & M & & & \\
\hline SYNPO2L & TS & M & & & \\
\hline SYPL2 & TS & M & & & \\
\hline SYT1 & $\mathrm{DE}$ & $\mathrm{H}$ & A & & \\
\hline SYT2 & $\mathrm{DE}$ & $\mathrm{H}$ & $\mathrm{H}$ & & \\
\hline SYT5 & $\mathrm{DE}$ & $\mathrm{P}$ & $\mathrm{H}$ & & \\
\hline SYTL2 & SNP & $\mathrm{H}$ & & & \\
\hline Saa3 & $\mathrm{DE}$ & $\mathrm{F}$ & A & & \\
\hline TAC1 & $\mathrm{DE}$ & $\mathrm{H}$ & $\mathrm{H}$ & & \\
\hline TAC3 & $\mathrm{DE}$ & $\mathrm{H}$ & $\mathrm{H}$ & & \\
\hline TACC2 & TS & M & & & \\
\hline TADA2A & REG & $\mathrm{H}$ & & & $\mathrm{P}$ \\
\hline TAF10 & REG & $\mathrm{F}$ & & & $\mathrm{H}$ \\
\hline TAF7L & $\mathrm{DE}$ & A & A & & \\
\hline TAGLN & $\mathrm{DE}$ & A & MP & & \\
\hline TAT & TS & $\mathrm{F}$ & & & \\
\hline TBATA & TS & $\mathrm{F}$ & & & \\
\hline TBX15 & TS & M & & & \\
\hline TBX19 & DE & $\mathrm{P}$ & $\mathrm{P}$ & & \\
\hline TCEA2 & REG & $\mathrm{H}$ & & & $\mathrm{P}$ \\
\hline
\end{tabular}


Tabela suplementar 2 - Genes selecionados para construção da rede de co-expressão

\begin{tabular}{|c|c|c|c|c|c|}
\hline Gene & Categoria & Tecido de máxima expressão & Tecido DE & Tecido SEC & Tecido REG \\
\hline TCN1 & SNP & $\mathrm{F}$ & & & \\
\hline TDH & TS & $\mathrm{F}$ & & & \\
\hline TDO2 & TS & $\mathrm{F}$ & & & \\
\hline TEAD2 & REG & $\mathrm{F}$ & & & $\mathrm{M}$ \\
\hline TEX11 & SNP & A & & & \\
\hline TFR2 & TS & $\mathrm{F}$ & & & \\
\hline TGFB1 & REG & $\mathrm{P}$ & & & A \\
\hline TGS1 & SNP & $\mathrm{P}$ & & & \\
\hline TH & TS & A & & & \\
\hline THBS1 & SEC & $\mathrm{P}$ & & AFM & \\
\hline THBS2 & SEC & A & & $\mathrm{AF}$ & \\
\hline THSD7B & SNP & $\mathrm{F}$ & & & \\
\hline TIMP2 & SNP & A & & & \\
\hline TIMP4 & SEC & M & & AM & \\
\hline TIPARP & $\mathrm{DE}$ & M & M & & \\
\hline TK1 & SNP & M & & & \\
\hline TM4SF1 & $\mathrm{DE}$ & A & $\mathrm{H}$ & & \\
\hline TM4SF5 & TS & $\mathrm{F}$ & & & \\
\hline TMBIM1 & $\mathrm{DE}$ & $\mathrm{F}$ & M & & \\
\hline TMC6 & SNP & A & & & \\
\hline TMC8 & SNP & A & & & \\
\hline TMED6 & $\mathrm{DE}$ & $\mathrm{F}$ & $\mathrm{F}$ & & \\
\hline TMEM114 & SNP & $\mathrm{F}$ & & & \\
\hline TMEM120A & $\mathrm{DE}$ & $\mathrm{F}$ & $\mathrm{M}$ & & \\
\hline TMEM135 & SNP & A & & & \\
\hline TMEM158 & $\mathrm{DE}$ & $\mathrm{P}$ & A & & \\
\hline TMEM164 & SNP & $\mathrm{M}$ & & & \\
\hline TMEM182 & TS & M & & & \\
\hline TMEM186 & SNP & A & & & \\
\hline TMEM213 & $\mathrm{DE}$ & $\mathrm{P}$ & $\mathrm{P}$ & & \\
\hline TMEM229B & $\mathrm{DE}$ & A & A & & \\
\hline TMEM255A & $\mathrm{DE}$ & $\mathrm{P}$ & $\mathrm{H}$ & & \\
\hline TMEM39B & SNP & $\mathrm{P}$ & & & \\
\hline TMEM40 & SNP & M & & & \\
\hline TMEM45A & $\mathrm{DE}$ & $\mathrm{P}$ & $\mathrm{F}$ & & \\
\hline TMEM59L & $\mathrm{DE}$ & $\mathrm{H}$ & A & & \\
\hline TMEM68 & SNP & $\mathrm{H}$ & & & \\
\hline TMEM86B & TS & $\mathrm{F}$ & & & \\
\hline TMOD4 & TS & M & & & \\
\hline TMPRSS6 & TS & $\mathrm{F}$ & & & \\
\hline TMX2 & SNP & $\mathrm{H}$ & & & \\
\hline TNFAIP2 & $\mathrm{DE}$ & $\mathrm{P}$ & $\mathrm{M}$ & & \\
\hline TNFRSF11B & SEC & $\mathrm{H}$ & & $\mathrm{AF}$ & \\
\hline TNFRSF12A & $\mathrm{DE}$ & A & $\mathrm{P}$ & & \\
\hline TNFRSF18 & $\mathrm{DE}$ & $\mathrm{P}$ & $\mathrm{P}$ & & \\
\hline TNFSF8 & SNP & $\mathrm{F}$ & & & \\
\hline TNNC1 & TS & M & & & \\
\hline TNNC2 & TS & M & & & \\
\hline TNNI1 & TS & M & & & \\
\hline TNNI2 & TS & M & & & \\
\hline TNNI3 & $\mathrm{DE}$ & A & A & & \\
\hline TNNT3 & TS & M & & & \\
\hline TNRC6C & SNP & $\mathrm{P}$ & & & \\
\hline TOX & SNP & $\mathrm{P}$ & & & \\
\hline TPM2 & $\mathrm{DE}$ & M & $\mathrm{P}$ & & \\
\hline TPPP2 & $\mathrm{DE}$ & M & M & & \\
\hline TRAF1 & $\mathrm{DE}$ & A & A & & \\
\hline TRIM24 & SEC & M & & AFM & \\
\hline TRIM45 & $\mathrm{DE}$ & M & M & & \\
\hline TRIM54 & TS & M & & & \\
\hline TRIM63 & DETS & M & M & & \\
\hline TRIM72 & TS & M & & & \\
\hline
\end{tabular}


Tabela suplementar 2 - Genes selecionados para construção da rede de co-expressão (continuação).

\begin{tabular}{|c|c|c|c|c|c|}
\hline Gene & Categoria & Tecido de máxima expressão & Tecido DE & Tecido SEC & Tecido REG \\
\hline TRPC5 & SNP & $\mathrm{F}$ & & & \\
\hline TSHB & DETS & $\mathrm{P}$ & $\mathrm{P}$ & & \\
\hline TSKU & DE & $\mathrm{F}$ & A & & \\
\hline TTC12 & DE & $\mathrm{P}$ & $\mathrm{H}$ & & \\
\hline TTC28 & SNP & A & & & \\
\hline TTN & TS & M & & & \\
\hline TTR & SEC & $\mathrm{F}$ & & $\mathrm{F}$ & \\
\hline TUBB3 & SNP & $\mathrm{H}$ & & & \\
\hline TXLNB & TS & M & & & \\
\hline TXNDC12 & SEC & A & & AFM & \\
\hline $\mathrm{U} 3$ & $\mathrm{DE}$ & $\mathrm{F}$ & $P$ & & \\
\hline U4 & $\mathrm{DE}$ & $\mathrm{F}$ & $\mathrm{F}$ & & \\
\hline UBA5 & SNP & $\mathrm{H}$ & & & \\
\hline UBE2I & REG & A & & & $\mathrm{AP}$ \\
\hline UBE2J1 & SNP & $\mathrm{P}$ & & & \\
\hline UBE2L6 & SNP & $\mathrm{F}$ & & & \\
\hline $\mathrm{UCP} 2$ & $\mathrm{DE}$ & $\mathrm{P}$ & M & & \\
\hline UCP3 & $\mathrm{TS}$ & M & & & \\
\hline UFL1 & SNP & $\mathrm{P}$ & & & \\
\hline UGT1A6 & TSSNP & $\mathrm{F}$ & & & \\
\hline UGT8 & TS & $\mathrm{H}$ & & & \\
\hline UMPS & SNP & A & & & \\
\hline UNC45B & $\mathrm{TS}$ & M & & & \\
\hline UNC80 & SNP & $\mathrm{P}$ & & & \\
\hline UPB1 & TS & F & & & \\
\hline UQCC2 & SNP & M & & & \\
\hline URAD & $\mathrm{TS}$ & $\mathrm{F}$ & & & \\
\hline USP27X & SNP & $\mathrm{P}$ & & & \\
\hline USP36 & SNP & A & & & \\
\hline USP7 & SNP & M & & & \\
\hline UVRAG & SNP & A & & & \\
\hline VEGFC & SNP & A & & & \\
\hline VGF & DESEC & $\mathrm{P}$ & $\mathrm{H}$ & AHP & \\
\hline VGLL2 & $\mathrm{DE}$ & M & M & & \\
\hline VIP & $\mathrm{DE}$ & $\mathrm{P}$ & $\mathrm{P}$ & & \\
\hline VNN1 & SEC & M & & $\mathrm{AF}$ & \\
\hline VOPP1 & SNP & $\mathrm{P}$ & & & \\
\hline VPS25 & REG & $\mathrm{F}$ & & & $\mathrm{P}$ \\
\hline VPS72 & REG & A & & & A \\
\hline VSIG4 & SNP & $\mathrm{F}$ & & & \\
\hline VSTM2A & SEC & $\mathrm{H}$ & & A & \\
\hline VTN & TSSEC & $\mathrm{F}$ & & $\mathrm{AF}$ & \\
\hline VWA5A & DE & A & $\mathrm{H}$ & & \\
\hline VWA7 & $\mathrm{DE}$ & M & A & & \\
\hline VWC2 & $\mathrm{DE}$ & $\mathrm{H}$ & $\mathrm{H}$ & & \\
\hline VWF & SEC & A & & AFM & \\
\hline WDR13 & SNP & $\mathrm{H}$ & & & \\
\hline WFDC2 & DE & $\mathrm{P}$ & $\mathrm{P}$ & & \\
\hline WIF1 & DESNP & $\mathrm{P}$ & $\mathrm{P}$ & & \\
\hline WISP2 & SEC & F & & $\mathrm{AM}$ & \\
\hline WNT5A & SEC & $\mathrm{P}$ & & $\mathrm{AF}$ & \\
\hline WNT9A & SEC & M & & $\mathrm{AM}$ & \\
\hline WWP2 & SNP & A & & & \\
\hline XIRP1 & $\mathrm{TS}$ & M & & & \\
\hline XIRP2 & TSSNP & M & & & \\
\hline XKR4 & SNP & $\mathrm{P}$ & & & \\
\hline YIPF6 & SNP & $\mathrm{P}$ & & & \\
\hline YIPF7 & TS & M & & & \\
\hline YWHAB & REG & A & & & $\mathrm{P}$ \\
\hline $\mathrm{ZCCHC} 17$ & SNP & $\mathrm{H}$ & & & \\
\hline ZDHHC15 & SNP & $\mathrm{F}$ & & & \\
\hline ZDHHC22 & $\mathrm{DE}$ & $\mathrm{H}$ & $\mathrm{H}$ & & \\
\hline
\end{tabular}


Tabela suplementar 2 - Genes selecionados para construção da rede de co-expressão

(continuação).

\begin{tabular}{|c|c|c|c|c|c|}
\hline Gene & Categoria & Tecido de máxima expressão & Tecido DE & Tecido SEC & Tecido REG \\
\hline ZDHHC5 & SNP & A & & & \\
\hline ZFHX4 & SNP & $\mathrm{P}$ & & & \\
\hline ZFP36 & $\mathrm{DE}$ & M & $\mathrm{H}$ & & \\
\hline ZFP57 & TS & $\mathrm{H}$ & & & \\
\hline $\mathrm{ZHX} 3$ & REG & $\mathrm{H}$ & & & $\mathrm{H}$ \\
\hline $\mathrm{ZIC} 1$ & $\mathrm{DE}$ & $\mathrm{H}$ & M & & \\
\hline ZMAT4 & $\mathrm{DE}$ & $\mathrm{A}$ & $\mathrm{H}$ & & \\
\hline ZNF205 & REG & $\mathrm{F}$ & & & A \\
\hline ZNF276 & REG & $\mathrm{F}$ & & & A \\
\hline ZNF32 & REG & $\mathrm{M}$ & & & $\mathrm{F}$ \\
\hline ZNF335 & REG & $\mathrm{H}$ & & & A \\
\hline ZNF385C & $\mathrm{DE}$ & A & M & & \\
\hline ZNF410 & SNP & $\mathrm{P}$ & & & \\
\hline ZNF423 & SNP & M & & & \\
\hline ZNF653 & SNP & $\mathrm{P}$ & & & \\
\hline ZNF711 & SNP & A & & & \\
\hline ZNF76 & REG & $\mathrm{M}$ & & & $\mathrm{F}$ \\
\hline ZNF768 & REG & $\mathrm{M}$ & & & $\mathrm{P}$ \\
\hline ZSWIM6 & SNP & $\mathrm{H}$ & & & \\
\hline agp & TS & $\mathrm{F}$ & & & \\
\hline bta-mir-1-2 & TS & $\mathrm{M}$ & & & \\
\hline bta-mir-122 & $\mathrm{DE}$ & $\mathrm{F}$ & $\mathrm{F}$ & & \\
\hline bta-mir-1281 & $\mathrm{DE}$ & $\mathrm{P}$ & $\mathrm{M}$ & & \\
\hline bta-mir-133a-2 & TS & M & & & \\
\hline bta-mir-29c & $\mathrm{DE}$ & M & $\mathrm{AM}$ & & \\
\hline bta-mir-374b & SNP & $\mathrm{H}$ & & & \\
\hline bta-mir-421 & SNP & $\mathrm{H}$ & & & \\
\hline bta-mir-4657 & $\mathrm{DE}$ & $\mathrm{H}$ & A & & \\
\hline cytb & DEREG & $\mathrm{F}$ & A & & $\mathrm{H}$ \\
\hline snoU2 19 & DE & $\mathrm{H}$ & $\mathrm{H}$ & & \\
\hline snoU82P & $\mathrm{DE}$ & A & M & & \\
\hline snosnR61 & $\mathrm{DE}$ & $\mathrm{P}$ & $\mathrm{F}$ & & \\
\hline
\end{tabular}

* Genes diferencialmente expressos entre alta e baixa eficiência alimentar (DE), genes tecido-específicos (TS), genes portadores de SNPs relatados pela literatura como associados à eficiência alimentar em bovinos de corte (SNP) e genes codificadores de proteínas secretadas no plasma (SEC). A- adrenal; F - fígado; H - hipotálamo; M - músculo; P pituitária (pituitária). 
Tabela suplementar 3 - Genes diferencialmente conectados entre alta e baixa eficiência alimentar.

\begin{tabular}{|c|c|c|c|c|}
\hline \multirow[b]{2}{*}{ Nome do gene } & \multicolumn{2}{|c|}{ Número de conexões } & \multirow[b]{2}{*}{ Categoria* } & \multirow[b]{2}{*}{$\begin{array}{l}\text { Tecido de maxima } \\
\text { expressão }\end{array}$} \\
\hline & $\begin{array}{c}\text { Baixa } \\
\text { eficiência alimentar }\end{array}$ & $\begin{array}{c}\text { Alta } \\
\text { eficiência alimentar }\end{array}$ & & \\
\hline A1BG & 83 & 0 & TS & Fígado \\
\hline ACSM3 & 45 & 95 & TS & Fígado \\
\hline ACTC1 & 54 & 0 & DE & Músculo \\
\hline ADTRP & 80 & 0 & TS & Fígado \\
\hline AGMAT & 87 & 0 & TS & Fígado \\
\hline AGP & 90 & 0 & $\mathrm{TS}$ & Fígado \\
\hline AGXT & 0 & 93 & $\mathrm{TS}$ & Fígado \\
\hline AKR1C3 & 0 & 78 & $\mathrm{TS}$ & Fígado \\
\hline AMBP & 97 & 49 & $\mathrm{TS}$ & Fígado \\
\hline ANGPTL8 & 120 & 59 & $\mathrm{TS}$ & Fígado \\
\hline ANXA13 & 115 & 63 & DE & Fígado \\
\hline $\mathrm{AOC} 1$ & 89 & 0 & $\mathrm{TS}$ & Fígado \\
\hline APOA2 & 116 & 62 & TS & Fígado \\
\hline AQP9 & 0 & 72 & TS & Fígado \\
\hline ARHGAP35 & 59 & 99 & SNP & Músculo \\
\hline ASPH & 85 & 118 & SNP & Músculo \\
\hline $\mathrm{C} 5$ & 64 & 0 & TSSEC & Fígado \\
\hline CACNA1S & 69 & 0 & TS & Músculo \\
\hline CAV1 & 98 & 50 & $\mathrm{DE}$ & Músculo \\
\hline CES1 & 89 & 39 & TS & Fígado \\
\hline CHRNA1 & 0 & 52 & TS & Músculo \\
\hline COLEC10 & 97 & 51 & SEC & Fígado \\
\hline CPS1 & 0 & 46 & $\mathrm{TS}$ & Fígado \\
\hline CXCL2 & 50 & 0 & SEC & Fígado \\
\hline CYP8B1 & 56 & 0 & $\mathrm{TS}$ & Fígado \\
\hline ENSBTAG00000003289 & 97 & 0 & TS & Fígado \\
\hline ENSBTAG00000021368 & 95 & 0 & $\mathrm{DE}$ & Fígado \\
\hline ENSBTAG00000022395 & 0 & 77 & $\mathrm{TS}$ & Fígado \\
\hline ENSBTAG00000038461 & 92 & 0 & TS & Fígado \\
\hline ENSBTAG00000039928 & 50 & 89 & $\mathrm{DE}$ & Fígado \\
\hline ENSBTAG00000043978 & 0 & 39 & SNP & Hipotálamo \\
\hline ENSBTAG00000047121 & 62 & 111 & $\mathrm{DE}$ & Fígado \\
\hline ENSBTAG00000047700 & 56 & 111 & $\mathrm{DE}$ & Fígado \\
\hline ENSBTAG00000047816 & 53 & 96 & DE & Fígado \\
\hline ENTPD8 & 93 & 0 & TS & Fígado \\
\hline F10 & 130 & 71 & TSSEC & Fígado \\
\hline $\mathrm{F} 2$ & 0 & 48 & TS & Fígado \\
\hline F5 & 86 & 0 & SEC & Fígado \\
\hline FGA & 95 & 1 & TSSEC & Fígado \\
\hline FGB & 95 & 0 & TS & Fígado \\
\hline FMO1 & 0 & 83 & TS & Fígado \\
\hline FN1 & 119 & 69 & $\mathrm{DE}$ & Fígado \\
\hline FST & 113 & 56 & $\mathrm{DE}$ & Fígado \\
\hline FTCD & 58 & 0 & $\mathrm{TS}$ & Fígado \\
\hline GUCA2B & 0 & 50 & SEC & Músculo \\
\hline HABP2 & 93 & 0 & $\mathrm{TS}$ & Fígado \\
\hline $\mathrm{HAO} 2$ & 0 & 77 & TS & Fígado \\
\hline HMGCS2 & 95 & 0 & $\mathrm{TS}$ & Fígado \\
\hline HPX & 100 & 42 & TSSEC & Fígado \\
\hline HR & 119 & 50 & $\mathrm{DE}$ & Pituitary \\
\hline HRG & 0 & 57 & TSSEC & Fígado \\
\hline IGFBP1 & 55 & 0 & DETSSEC & Fígado \\
\hline ITGB1BP2 & 0 & 56 & TS & Músculo \\
\hline ITIH3 & 106 & 55 & TSSEC & Fígado \\
\hline JCHAIN & 52 & 113 & DESEC & Fígado \\
\hline KBTBD12 & 59 & 0 & TS & Músculo \\
\hline KNG1 & 85 & 0 & TSSEC & Fígado \\
\hline LEAP2 & 109 & 61 & TSSEC & Fígado \\
\hline METTL7B & 78 & 113 & $\mathrm{TS}$ & Fígado \\
\hline MGC152281 & 101 & 49 & $\mathrm{TS}$ & Fígado \\
\hline
\end{tabular}


Tabela suplementar 3 - Genes diferencialmente conectados entre alta e baixa eficiência alimentar (continuação).

\begin{tabular}{|c|c|c|c|c|}
\hline \multirow[b]{2}{*}{ Nome do gene } & \multicolumn{2}{|c|}{ Número de conexões } & \multirow[b]{2}{*}{ Categoria* } & \multirow{2}{*}{$\begin{array}{c}\text { Tecido de maxima } \\
\text { expressão }\end{array}$} \\
\hline & $\begin{array}{c}\text { Baixa } \\
\text { eficiência alimentar }\end{array}$ & $\begin{array}{c}\text { Alta } \\
\text { eficiência alimentar }\end{array}$ & & \\
\hline MSS51 & 0 & 53 & TS & Músculo \\
\hline MYF6 & 0 & 62 & $\mathrm{TS}$ & Músculo \\
\hline MYH1 & 0 & 47 & DETS & Músculo \\
\hline MYO18B & 0 & 51 & TS & Músculo \\
\hline OIT3 & 0 & 56 & SEC & Fígado \\
\hline PBLD & 115 & 55 & $\mathrm{DE}$ & Fígado \\
\hline PPP1R27 & 0 & 51 & $\mathrm{TS}$ & Músculo \\
\hline PROC & 83 & 0 & $\mathrm{TS}$ & Fígado \\
\hline PROZ & 74 & 0 & TSSEC & Fígado \\
\hline RIPPLY1 & 99 & 0 & SNP & Fígado \\
\hline SBK2 & 0 & 70 & $\mathrm{DE}$ & Músculo \\
\hline SERPINA3-7 & 0 & 54 & TS & Fígado \\
\hline SERPINF2 & 0 & 82 & TSSEC & Fígado \\
\hline SFRP2 & 41 & 91 & $\mathrm{DE}$ & Hipotálamo \\
\hline SGCG & 64 & 0 & $\mathrm{TS}$ & Músculo \\
\hline SIGLEC1 & 126 & 0 & SNP & Fígado \\
\hline SLC25A47 & 55 & 0 & TS & Fígado \\
\hline SNORA73 & 41 & 108 & DE & Fígado \\
\hline SPINK1 & 88 & 30 & SEC & Músculo \\
\hline SST & 0 & 45 & DESEC & Hipotálamo \\
\hline SYPL2 & 0 & 44 & TS & Músculo \\
\hline TAGLN & 83 & 31 & DE & Adrenal \\
\hline TCN1 & 93 & 0 & SNP & Fígado \\
\hline TFR2 & 0 & 48 & TS & Fígado \\
\hline TMEM182 & 49 & 0 & $\mathrm{TS}$ & Músculo \\
\hline TMPRSS6 & 111 & 0 & $\mathrm{TS}$ & Fígado \\
\hline UPB1 & 91 & 0 & $\mathrm{TS}$ & Fígado \\
\hline
\end{tabular}


Tabela suplementar 4 - Enriquecimento funcional usando a plataforma STRING dos genes diferencialmente expressos na abordagem 1 no hipotálamo, pituitária e adrenal de animais de alta e baixa eficiência alimentar.

\begin{tabular}{|c|c|c|c|c|}
\hline Tecido & ID & Descrição & Genes & FDR \\
\hline Hipotálamo & GO:0050896 & response to stimulus & 31 & $1,27 \mathrm{E}-06$ \\
\hline Hipotálamo & GO:0003008 & system process & 11 & $9,47 \mathrm{E}-04$ \\
\hline Hipotálamo & GO:0007165 & signal transduction & 18 & $9,47 \mathrm{E}-04$ \\
\hline Hipotálamo & GO:0044700 & single organism signaling & 18 & $9,47 \mathrm{E}-04$ \\
\hline Hipotálamo & GO:0044707 & single-multicellular organism process & 22 & $9,47 \mathrm{E}-04$ \\
\hline Hipotálamo & GO:0048731 & system development & 17 & $9,47 \mathrm{E}-04$ \\
\hline Hipotálamo & GO:0051716 & cellular response to stimulus & 22 & $9,47 \mathrm{E}-04$ \\
\hline Hipotálamo & GO:0007186 & G-protein coupled receptor signaling pathway & 9 & $1,13 \mathrm{E}-03$ \\
\hline Hipotálamo & GO:0007154 & cell communication & 18 & $1,52 \mathrm{E}-03$ \\
\hline Hipotálamo & GO:0007268 & synaptic transmission & 6 & 2,99E-03 \\
\hline Hipotálamo & GO:0033555 & multicellular organismal response to stress & 4 & 2,99E-03 \\
\hline Hipotálamo & GO:0051952 & regulation of amine transport & 3 & 2,99E-03 \\
\hline Hipotálamo & GO:0007267 & cell-cell signaling & 7 & $3,01 \mathrm{E}-03$ \\
\hline Hipotálamo & GO:0007218 & neuropeptide signaling pathway & 5 & $3,25 \mathrm{E}-03$ \\
\hline Hipotálamo & GO:0007275 & multicellular organismal development & 17 & $3,92 \mathrm{E}-03$ \\
\hline Hipotálamo & GO:0008015 & blood circulation & 6 & $4,71 \mathrm{E}-03$ \\
\hline Hipotálamo & GO:0010038 & response to metal ion & 5 & $6,11 \mathrm{E}-03$ \\
\hline Hipotálamo & GO:0007399 & nervous system development & 10 & $7,14 \mathrm{E}-03$ \\
\hline Hipotálamo & GO:0065007 & biological regulation & 29 & $7,14 \mathrm{E}-03$ \\
\hline Hipotálamo & GO:0048518 & positive regulation of biological process & 18 & $1,18 \mathrm{E}-02$ \\
\hline Hipotálamo & GO:0050794 & regulation of cellular process & 26 & $1,18 \mathrm{E}-02$ \\
\hline Hipotálamo & GO:0051954 & positive regulation of amine transport & 2 & $1,18 \mathrm{E}-02$ \\
\hline Hipotálamo & GO:0060384 & innervation & 2 & $1,18 \mathrm{E}-02$ \\
\hline Hipotálamo & GO:0071248 & cellular response to metal ion & 4 & $1,18 \mathrm{E}-02$ \\
\hline Hipotálamo & GO:0050789 & regulation of biological process & 27 & $1,35 \mathrm{E}-02$ \\
\hline Hipotálamo & GO:0048856 & anatomical structure development & 16 & $1,45 \mathrm{E}-02$ \\
\hline Hipotálamo & GO:0008150 & biological_process & 41 & $1,56 \mathrm{E}-02$ \\
\hline Hipotálamo & GO:0048519 & negative regulation of biological process & 16 & $1,66 \mathrm{E}-02$ \\
\hline Hipotálamo & GO:0006950 & response to stress & 14 & $1,82 \mathrm{E}-02$ \\
\hline Hipotálamo & GO:0009605 & response to external stimulus & 10 & $1,94 \mathrm{E}-02$ \\
\hline Hipotálamo & GO:0044708 & single-organism behavior & 5 & $2,54 \mathrm{E}-02$ \\
\hline Hipotálamo & GO:0071294 & cellular response to zinc ion & 2 & $2,54 \mathrm{E}-02$ \\
\hline Hipotálamo & GO:0010646 & regulation of cell communication & 12 & $2,80 \mathrm{E}-02$ \\
\hline Hipotálamo & GO:0044699 & single-organism process & 33 & $3,34 \mathrm{E}-02$ \\
\hline Hipotálamo & GO:0051240 & positive regulation of multicellular organismal process & 8 & 4,04E-02 \\
\hline Hipotálamo & GO:0005488 & binding & 34 & $1,03 \mathrm{E}-02$ \\
\hline Hipotálamo & GO:0019871 & sodium channel inhibitor activity & 2 & $4,48 \mathrm{E}-02$ \\
\hline Hipotálamo & GO:0005576 & extracellular region & 22 & $1,74 \mathrm{E}-03$ \\
\hline Hipotálamo & GO:0030424 & axon & 6 & $1,74 \mathrm{E}-03$ \\
\hline Hipotálamo & GO:0043005 & neuron projection & 8 & $1,74 \mathrm{E}-03$ \\
\hline Hipotálamo & GO:0036477 & somatodendritic compartment & 6 & $3,48 \mathrm{E}-03$ \\
\hline Hipotálamo & GO:0044459 & plasma membrane part & 11 & $3,60 \mathrm{E}-03$ \\
\hline Hipotálamo & GO:0045202 & synapse & 7 & $5,64 \mathrm{E}-03$ \\
\hline Hipotálamo & GO:0097458 & neuron part & 8 & $7,55 \mathrm{E}-03$ \\
\hline Hipotálamo & GO:0030141 & secretory granule & 5 & $1,19 \mathrm{E}-02$ \\
\hline Hipotálamo & GO:0005575 & cellular component & 43 & $1,75 \mathrm{E}-02$ \\
\hline Hipotálamo & GO:0005886 & plasma membrane & 15 & $2,83 \mathrm{E}-02$ \\
\hline Hipotálamo & GO:0071944 & cell periphery & 15 & $3,67 \mathrm{E}-02$ \\
\hline Hipotálamo & GO:0005623 & cell & 38 & $4,75 \mathrm{E}-02$ \\
\hline Hipotálamo & GO:0030315 & T-tubule & 2 & $4,75 \mathrm{E}-02$ \\
\hline Hipotálamo & GO:0031988 & membrane-bounded vesicle & 15 & $4,75 \mathrm{E}-02$ \\
\hline Hipotálamo & GO:0044297 & cell body & 4 & $4,75 \mathrm{E}-02$ \\
\hline Hipotálamo & GO:0044464 & cell part & 38 & $4,75 \mathrm{E}-02$ \\
\hline Hipotálamo & 4728 & Dopaminergic synapse & 7 & $2,27 \mathrm{E}-03$ \\
\hline Hipotálamo & 5031 & Amphetamine addiction & 5 & $4,10 \mathrm{E}-03$ \\
\hline Hipotálamo & 4725 & Cholinergic synapse & 5 & $4,44 \mathrm{E}-02$ \\
\hline Hipotálamo & PF00131 & Metallothionein & 3 & $1,80 \mathrm{E}-02$ \\
\hline Hipotálamo & PR000006 & Metallothionein, vertebrate & 3 & $8,04 \mathrm{E}-03$ \\
\hline Hipotálamo & IPR003019 & Metallothionein & 3 & $8,04 \mathrm{E}-03$ \\
\hline Hipotálamo & IPR017854 & Metallothionein domain & 3 & $8,04 \mathrm{E}-03$ \\
\hline Hipotálamo & IPR018064 & Metallothionein, vertebrate, metal binding site & 3 & $8,04 \mathrm{E}-03$ \\
\hline
\end{tabular}


Tabela suplementar 4 - Enriquecimento funcional usando a plataforma STRING dos genes diferencialmente expressos na abordagem 1 no hipotálamo, pituitária e adrenal de animais de alta e baixa eficiência alimentar (continuação).

\begin{tabular}{|c|c|c|c|c|}
\hline Tecido & ID & Descrição & Genes & FDR \\
\hline Hipotálamo & IPR023587 & Metallothionein domain, vertebrate & 3 & $8,04 \mathrm{E}-03$ \\
\hline Pituitária & GO:0005576 & extracellular region & 19 & 7,04E-03 \\
\hline Pituitária & GO:0042383 & sarcolemma & 4 & $7,12 \mathrm{E}-03$ \\
\hline Pituitária & 5320 & Autoimmune thyroid disease & 5 & $9,01 \mathrm{E}-04$ \\
\hline Pituitária & 4612 & Antigen processing and presentation & 5 & $1,18 \mathrm{E}-03$ \\
\hline Pituitária & 5310 & Asthma & 4 & $1,18 \mathrm{E}-03$ \\
\hline Pituitária & 5416 & Viral myocarditis & 5 & $1,18 \mathrm{E}-03$ \\
\hline Pituitária & 5332 & Graft-versus-host disease & 4 & $1,42 \mathrm{E}-03$ \\
\hline Pituitária & 5330 & Allograft rejection & 4 & $2,00 \mathrm{E}-03$ \\
\hline Pituitária & 4940 & Type I diabetes mellitus & 4 & $2,72 \mathrm{E}-03$ \\
\hline Pituitária & 4672 & Intestinal immune network for IgA production & 4 & $3,31 \mathrm{E}-03$ \\
\hline Pituitária & 5150 & Staphylococcus aureus infection & 4 & $3,70 \mathrm{E}-03$ \\
\hline Pituitária & 5321 & Inflammatory bowel disease (IBD) & 4 & $8,28 \mathrm{E}-03$ \\
\hline Pituitária & 5140 & Leishmaniasis & 4 & $8,43 \mathrm{E}-03$ \\
\hline Pituitária & 4514 & Cell adhesion molecules (CAMs) & 5 & $1,43 \mathrm{E}-02$ \\
\hline Pituitária & 5323 & Rheumatoid arthritis & 4 & 2,04E-02 \\
\hline Pituitária & 5166 & HTLV-I infection & 6 & $2,72 \mathrm{E}-02$ \\
\hline Pituitária & 5145 & Toxoplasmosis & 4 & $3,68 \mathrm{E}-02$ \\
\hline Pituitária & 5322 & Systemic lupus erythematosus & 4 & 4,44E-02 \\
\hline Pituitária & 3010 & Ribosome & 4 & 4,99E-02 \\
\hline Pituitária & PF00007 & Cystine-knot domain & 5 & $1,20 \mathrm{E}-06$ \\
\hline Pituitária & PF00219 & Insulin-like growth factor binding protein & 4 & $5,10 \mathrm{E}-04$ \\
\hline Pituitária & PF00993 & Class II histocompatibility antigen, alpha domain & 3 & $5,30 \mathrm{E}-03$ \\
\hline Pituitária & PF07654 & Immunoglobulin $\mathrm{C} 1$-set domain & 5 & $1,59 \mathrm{E}-02$ \\
\hline Pituitária & IPR006208 & Glycoprotein hormone subunit beta, cystine knot & 5 & $2,68 \mathrm{E}-06$ \\
\hline Pituitária & IPR000867 & Insulin-like growth factor-binding protein, IGFBP & 4 & $1,37 \mathrm{E}-03$ \\
\hline Pituitária & IPR018245 & Gonadotropin, beta subunit, conserved site & 3 & $1,37 \mathrm{E}-03$ \\
\hline Pituitária & IPR001545 & Gonadotropin, beta subunit & 3 & $2,55 \mathrm{E}-03$ \\
\hline Pituitária & IPR003006 & Immunoglobulin/major histocompatibility complex, conserved site & 5 & $3,60 \mathrm{E}-03$ \\
\hline Pituitária & IPR001003 & MHC class II, alpha chain, $\mathrm{N}$-terminal & 3 & $5,92 \mathrm{E}-03$ \\
\hline Pituitária & IPR003597 & Immunoglobulin $\mathrm{C} 1$-set & 5 & $2,03 \mathrm{E}-02$ \\
\hline Pituitária & IPR014745 & MHC class II, alpha/beta chain, N-terminal & 3 & $4,51 \mathrm{E}-02$ \\
\hline Adrenal & GO:0006119 & oxidative phosphorylation & 5 & $6,18 \mathrm{E}-04$ \\
\hline Adrenal & GO:0006163 & purine nucleotide metabolic process & 8 & $6,18 \mathrm{E}-04$ \\
\hline Adrenal & GO:0019693 & ribose phosphate metabolic process & 8 & $6,18 \mathrm{E}-04$ \\
\hline Adrenal & GO:0042773 & ATP synthesis coupled electron transport & 5 & $6,18 \mathrm{E}-04$ \\
\hline Adrenal & GO:0009161 & ribonucleoside monophosphate metabolic process & 7 & $9,20 \mathrm{E}-04$ \\
\hline Adrenal & GO:0009150 & purine ribonucleotide metabolic process & 7 & $2,00 \mathrm{E}-03$ \\
\hline Adrenal & GO:0046034 & ATP metabolic process & 6 & $2,00 \mathrm{E}-03$ \\
\hline Adrenal & GO:0045333 & cellular respiration & 5 & $7,68 \mathrm{E}-03$ \\
\hline Adrenal & GO:0044281 & small molecule metabolic process & 12 & $8,29 \mathrm{E}-03$ \\
\hline Adrenal & GO:0030534 & adult behavior & 4 & $1,45 \mathrm{E}-02$ \\
\hline Adrenal & GO:0055114 & oxidation-reduction process & 10 & $2,09 \mathrm{E}-02$ \\
\hline Adrenal & GO:0008217 & regulation of blood pressure & 4 & $2,11 \mathrm{E}-02$ \\
\hline Adrenal & GO:0048513 & organ development & 11 & $2,40 \mathrm{E}-02$ \\
\hline Adrenal & GO:0042775 & mitochondrial ATP synthesis coupled electron transport & 3 & $3,46 \mathrm{E}-02$ \\
\hline Adrenal & GO:0043576 & regulation of respiratory gaseous exchange & 2 & $4,23 \mathrm{E}-02$ \\
\hline Adrenal & GO:0044057 & regulation of system process & 5 & $4,34 \mathrm{E}-02$ \\
\hline Adrenal & GO:0008137 & NADH dehydrogenase (ubiquinone) activity & 6 & $5,18 \mathrm{E}-06$ \\
\hline Adrenal & GO:0016491 & oxidoreductase activity & 9 & $2,86 \mathrm{E}-02$ \\
\hline Adrenal & GO:0070469 & respiratory chain & 7 & $1,86 \mathrm{E}-04$ \\
\hline Adrenal & GO:0043034 & costamere & 2 & 4,97E-02 \\
\hline Adrenal & 190 & Oxidative phosphorylation & 9 & $9,20 \mathrm{E}-06$ \\
\hline Adrenal & 980 & Metabolism of xenobiotics by cytochrome P450 & 6 & $3,04 \mathrm{E}-05$ \\
\hline Adrenal & 982 & Drug metabolism - cytochrome P450 & 6 & $3,04 \mathrm{E}-05$ \\
\hline Adrenal & 5012 & Parkinson s disease & 8 & 4,79E-05 \\
\hline Adrenal & 5204 & Chemical carcinogenesis & 6 & $4,79 \mathrm{E}-05$ \\
\hline Adrenal & 5310 & Asthma & 4 & $1,13 \mathrm{E}-03$ \\
\hline Adrenal & 5332 & Graft-versus-host disease & 4 & $1,57 \mathrm{E}-03$ \\
\hline Adrenal & 5330 & Allograft rejection & 4 & $2,31 \mathrm{E}-03$ \\
\hline Adrenal & 480 & Glutathione metabolism & 4 & $2,89 \mathrm{E}-03$ \\
\hline
\end{tabular}


Tabela suplementar 4 - Enriquecimento funcional usando a plataforma STRING dos genes diferencialmente expressos na abordagem 1 no hipotálamo, pituitária e adrenal de animais de alta e baixa eficiência alimentar (continuação).

\begin{tabular}{lrlrr}
\hline Tecido & ID & Descrição & Genes & FDR \\
\hline Adrenal & 1100 & Metabolic pathways & 17 & $2,89 \mathrm{E}-03$ \\
Adrenal & 4514 & Cell adhesion molecules (CAMs) & 6 & $2,89 \mathrm{E}-03$ \\
Adrenal & 4672 & Intestinal immune network for IgA production & 4 & $2,89 \mathrm{E}-03$ \\
Adrenal & 4940 & Type I diabetes mellitus & 4 & $2,89 \mathrm{E}-03$ \\
Adrenal & 5320 & Autoimmune thyroid disease & 4 & $2,89 \mathrm{E}-03$ \\
Adrenal & 5150 & Staphylococcus aureus infection & 4 & $3,39 \mathrm{E}-03$ \\
Adrenal & 5168 & Herpes simplex infection & 6 & $5,20 \mathrm{E}-03$ \\
Adrenal & 5416 & Viral myocarditis & 4 & $5,20 \mathrm{E}-03$ \\
Adrenal & 4612 & Antigen processing and presentation & 4 & $6,61 \mathrm{E}-03$ \\
Adrenal & 5321 & Inflammatory bowel disease (IBD) & 4 & $6,61 \mathrm{E}-03$ \\
Adrenal & 5140 & Leishmaniasis & 4 & $7,03 \mathrm{E}-03$ \\
Adrenal & 5164 & Influenza A & 5 & $1,88 \mathrm{E}-02$ \\
Adrenal & 5323 & Rheumatoid arthritis & 4 & $1,88 \mathrm{E}-02$ \\
Adrenal & 5145 & Toxoplasmosis & 4 & $3,57 \mathrm{E}-02$ \\
Adrenal & 5322 & Systemic lupus erythematosus & 4 & $4,40 \mathrm{E}-02$ \\
Adrenal & PF07654 & Immunoglobulin C1-set domain & 7 & $2,31 \mathrm{E}-04$ \\
Adrenal & PF00361 & NADH-Ubiquinone/plastoquinone (complex I), various chains & 3 & $3,21 \mathrm{E}-04$ \\
Adrenal & PF00993 & Class II histocompatibility antigen, alpha domain & 3 & $7,38 \mathrm{E}-03$ \\
Adrenal & PF02798 & Glutathione S-transferase, N-terminal domain & 3 & $2,73 \mathrm{E}-02$ \\
Adrenal & PF05995 & Cysteine dioxygenase type I & 2 & $2,73 \mathrm{E}-02$ \\
Adrenal & PF00043 & Glutathione S-transferase, C-terminal domain & 3 & $2,94 \mathrm{E}-02$ \\
Adrenal & IPR003006 & Immunoglobulin/major histocompatibility complex, conserved site & 7 & $2,63 \mathrm{E}-05$ \\
Adrenal & IPR003597 & Immunoglobulin C1-set & 7 & $2,58 \mathrm{E}-04$ \\
Adrenal & IPR001750 & NADH:quinone oxidoreductase/Mrp antiporter, membrane subunit & 3 & $4,78 \mathrm{E}-04$ \\
Adrenal & IPR014745 & MHC class II, alpha/beta chain, N-terminal & 4 & $1,77 \mathrm{E}-03$ \\
Adrenal & IPR001003 & MHC class II, alpha chain, N-terminal & 3 & $9,88 \mathrm{E}-03$ \\
Adrenal & IPR010300 & Cysteine dioxygenase type I & 2 & $4,59 \mathrm{E}-02$ \\
\hline & & &
\end{tabular}


Tabela suplementar 5 - Genes contidos no módulo Grey60.

\begin{tabular}{|c|c|c|c|c|c|c|}
\hline Tecido & Gene & SG CAR & Valor de P SG CAR & FM & Valor de P FM & $\mathbf{K}$ \\
\hline Pituitária & AASDHPPT & 0,50 & 0,03 & 0,83 & $1,82 \mathrm{E}-05$ & 64,17 \\
\hline Pituitária & $\mathrm{ABCE} 1$ & 0,37 & 0,14 & 0,88 & $1,74 \mathrm{E}-06$ & 83,24 \\
\hline Pituitária & $\mathrm{ABCF} 2$ & 0,31 & 0,21 & 0,72 & $8,34 \mathrm{E}-04$ & 27,81 \\
\hline Pituitária & ABLIM1 & 0,25 & 0,32 & 0,76 & $2,52 \mathrm{E}-04$ & 33,71 \\
\hline Pituitária & ABRAXAS1 & 0,43 & 0,07 & 0,86 & $5,35 \mathrm{E}-06$ & 62,45 \\
\hline Pituitária & ACBD3 & 0,45 & 0,06 & 0,87 & $3,45 \mathrm{E}-06$ & 75,08 \\
\hline Pituitária & ACO1 & 0,63 & 0,00 & 0,78 & $1,35 \mathrm{E}-04$ & 36,56 \\
\hline Pituitária & ACTR2 & 0,35 & 0,15 & 0,87 & $2,47 \mathrm{E}-06$ & 74,21 \\
\hline Pituitária & ADAM9 & $-0,01$ & 0,97 & 0,72 & $8,45 \mathrm{E}-04$ & 26,25 \\
\hline Pituitária & ADPGK & 0,03 & 0,91 & 0,75 & $3,63 \mathrm{E}-04$ & 31,04 \\
\hline Pituitária & ADPRM & 0,28 & 0,26 & 0,85 & $8,33 \mathrm{E}-06$ & 58,49 \\
\hline Pituitária & ADSL & 0,15 & 0,55 & 0,77 & $1,60 \mathrm{E}-04$ & 38,37 \\
\hline Pituitária & ADSS & 0,51 & 0,03 & 0,85 & $7,76 \mathrm{E}-06$ & 65,50 \\
\hline Pituitária & AFTPH & 0,44 & 0,07 & 0,90 & $2,59 \mathrm{E}-07$ & 94,18 \\
\hline Pituitária & AGFG1 & 0,36 & 0,14 & 0,92 & $4,27 \mathrm{E}-08$ & 106,82 \\
\hline Pituitária & AGTPBP1 & 0,41 & 0,10 & 0,70 & $1,33 \mathrm{E}-03$ & 18,46 \\
\hline Pituitária & AK6 & 0,49 & 0,04 & 0,75 & $3,23 \mathrm{E}-04$ & 30,71 \\
\hline Pituitária & ALG11 & 0,26 & 0,30 & 0,78 & $1,31 \mathrm{E}-04$ & 37,49 \\
\hline Pituitária & ALKBH1 & 0,36 & 0,15 & 0,81 & $3,81 \mathrm{E}-05$ & 48,43 \\
\hline Pituitária & ANAPC1 & 0,13 & 0,60 & 0,75 & $3,55 \mathrm{E}-04$ & 31,25 \\
\hline Pituitária & ANGEL2 & 0,39 & 0,11 & 0,85 & $1,01 \mathrm{E}-05$ & 58,53 \\
\hline Pituitária & ANKIB1 & 0,40 & 0,10 & 0,94 & $5,23 \mathrm{E}-09$ & 120,27 \\
\hline Pituitária & ANKRD46 & 0,40 & 0,10 & 0,91 & $1,20 \mathrm{E}-07$ & 99,46 \\
\hline Pituitária & ANP32E & 0,44 & 0,07 & 0,77 & $1,62 \mathrm{E}-04$ & 39,40 \\
\hline Pituitária & AP1AR & 0,41 & 0,09 & 0,78 & $1,36 \mathrm{E}-04$ & 43,25 \\
\hline Pituitária & AP3M1 & 0,37 & 0,13 & 0,87 & $2,60 \mathrm{E}-06$ & 74,79 \\
\hline Pituitária & API5 & 0,34 & 0,16 & 0,89 & $6,73 \mathrm{E}-07$ & 87,23 \\
\hline Pituitária & APPBP2 & 0,27 & 0,28 & 0,78 & $1,44 \mathrm{E}-04$ & 40,22 \\
\hline Pituitária & ARAP2 & 0,38 & 0,12 & 0,86 & 5,99E-06 & 63,56 \\
\hline Pituitária & ARF4 & 0,30 & 0,23 & 0,78 & $1,21 \mathrm{E}-04$ & 35,79 \\
\hline Pituitária & ARFIP1 & 0,53 & 0,02 & 0,92 & $5,19 \mathrm{E}-08$ & 109,52 \\
\hline Pituitária & ARL6IP1 & 0,10 & 0,69 & 0,86 & $5,93 \mathrm{E}-06$ & 65,55 \\
\hline Pituitária & ARMC1 & 0,45 & 0,06 & 0,85 & $9,25 \mathrm{E}-06$ & 59,97 \\
\hline Pituitária & ARMC10 & 0,13 & 0,61 & 0,79 & $8,78 \mathrm{E}-05$ & 42,48 \\
\hline Pituitária & ARPP19 & 0,49 & 0,04 & 0,91 & $2,34 \mathrm{E}-07$ & 103,72 \\
\hline Pituitária & ASAP2 & 0,29 & 0,24 & 0,83 & $1,71 \mathrm{E}-05$ & 61,04 \\
\hline Pituitária & ASNSD1 & 0,61 & 0,01 & 0,73 & $6,02 \mathrm{E}-04$ & 28,40 \\
\hline Pituitária & ATAD1 & 0,32 & 0,20 & 0,88 & $1,74 \mathrm{E}-06$ & 74,57 \\
\hline Pituitária & ATF1 & 0,40 & 0,10 & 0,86 & $4,85 \mathrm{E}-06$ & 74,66 \\
\hline Pituitária & ATG5 & 0,49 & 0,04 & 0,76 & $2,71 \mathrm{E}-04$ & 31,18 \\
\hline Pituitária & ATL2 & 0,30 & 0,23 & 0,86 & $5,82 \mathrm{E}-06$ & 63,66 \\
\hline Pituitária & ATP1B3 & 0,43 & 0,07 & 0,76 & $2,27 \mathrm{E}-04$ & 35,97 \\
\hline Pituitária & ATP5F1B & 0,17 & 0,50 & 0,74 & $4,73 \mathrm{E}-04$ & 29,32 \\
\hline Pituitária & ATP6AP1 & 0,21 & 0,41 & 0,79 & $1,08 \mathrm{E}-04$ & 38,81 \\
\hline Pituitária & ATP6V1A & 0,38 & 0,12 & 0,87 & $2,92 \mathrm{E}-06$ & 78,87 \\
\hline Pituitária & ATP6V1D & 0,31 & 0,20 & 0,76 & $2,30 \mathrm{E}-04$ & 39,67 \\
\hline Pituitária & AZI2 & 0,37 & 0,14 & 0,87 & $2,07 \mathrm{E}-06$ & 77,72 \\
\hline Pituitária & B3GALNT1 & 0,33 & 0,18 & 0,75 & $2,95 \mathrm{E}-04$ & 29,50 \\
\hline Pituitária & B3GALNT2 & 0,21 & 0,41 & 0,67 & $2,16 \mathrm{E}-03$ & 23,05 \\
\hline Pituitária & B4GALT4 & 0,20 & 0,43 & 0,78 & $1,26 \mathrm{E}-04$ & 40,67 \\
\hline Pituitária & BCAP29 & 0,51 & 0,03 & 0,83 & $2,46 \mathrm{E}-05$ & 55,78 \\
\hline Pituitária & BCLAF3 & 0,20 & 0,42 & 0,75 & $2,93 \mathrm{E}-04$ & 36,57 \\
\hline Pituitária & BLOC1S6 & 0,52 & 0,03 & 0,88 & $1,32 \mathrm{E}-06$ & 86,09 \\
\hline Pituitária & BMS1 & 0,43 & 0,07 & 0,81 & $5,10 \mathrm{E}-05$ & 46,11 \\
\hline Pituitária & BRD7 & 0,36 & 0,14 & 0,89 & $8,82 \mathrm{E}-07$ & 79,77 \\
\hline Pituitária & BRK1 & 0,39 & 0,11 & 0,82 & $2,86 \mathrm{E}-05$ & 59,70 \\
\hline Pituitária & BRMS1L & 0,59 & 0,01 & 0,89 & $7,28 \mathrm{E}-07$ & 87,78 \\
\hline Pituitária & BTBD1 & 0,42 & 0,08 & 0,96 & $7,30 \mathrm{E}-10$ & 126,29 \\
\hline Pituitária & BUB3 & 0,31 & 0,21 & 0,81 & $4,80 \mathrm{E}-05$ & 42,64 \\
\hline Pituitária & C11H9orf78 & 0,24 & 0,33 & 0,83 & $2,08 \mathrm{E}-05$ & 54,24 \\
\hline Pituitária & $\mathrm{C} 15 \mathrm{H} 11$ orf58 & 0,64 & 0,00 & 0,79 & $1,03 \mathrm{E}-04$ & 46,06 \\
\hline Pituitária & CAAP1 & 0,33 & 0,19 & 0,82 & $3,08 \mathrm{E}-05$ & 56,79 \\
\hline Pituitária & CAB39 & 0,42 & 0,08 & 0,94 & $9,37 \mathrm{E}-09$ & 117,23 \\
\hline
\end{tabular}


Tabela suplementar 5 - Genes contidos no módulo Grey60 (continuação).

\begin{tabular}{|c|c|c|c|c|c|c|}
\hline Tecido & Gene & SG CAR & Valor de P SG CAR & FM & Valor de P FM & $\mathbf{K}$ \\
\hline Pituitária & CABLES2 & 0,24 & 0,34 & 0,66 & $2,78 \mathrm{E}-03$ & 18,28 \\
\hline Pituitária & CACYBP & 0,46 & 0,05 & 0,79 & $1,00 \mathrm{E}-04$ & 44,28 \\
\hline Pituitária & CALCOCO2 & 0,39 & 0,10 & 0,88 & $1,07 \mathrm{E}-06$ & 80,97 \\
\hline Pituitária & CALM2 & 0,42 & 0,08 & 0,83 & $2,00 \mathrm{E}-05$ & 58,07 \\
\hline Pituitária & CAMLG & 0,49 & 0,04 & 0,83 & $1,73 \mathrm{E}-05$ & 59,26 \\
\hline Pituitária & CAND1 & 0,45 & 0,06 & 0,96 & $6,86 \mathrm{E}-10$ & 134,08 \\
\hline Pituitária & CANX & 0,39 & 0,11 & 0,83 & $2,29 \mathrm{E}-05$ & 61,41 \\
\hline Pituitária & CAPN2 & 0,45 & 0,06 & 0,83 & $1,98 \mathrm{E}-05$ & 56,74 \\
\hline Pituitária & CAPZA2 & 0,56 & 0,01 & 0,80 & $7,78 \mathrm{E}-05$ & 45,55 \\
\hline Pituitária & CARNMT1 & 0,39 & 0,11 & 0,73 & $5,57 \mathrm{E}-04$ & 24,81 \\
\hline Pituitária & CASC4 & 0,54 & 0,02 & 0,88 & $1,07 \mathrm{E}-06$ & 85,70 \\
\hline Pituitária & CASD1 & 0,55 & 0,02 & 0,93 & $1,88 \mathrm{E}-08$ & 118,59 \\
\hline Pituitária & CAV1 & 0,49 & 0,04 & 0,73 & $6,08 \mathrm{E}-04$ & 29,11 \\
\hline Pituitária & CBLL1 & 0,25 & 0,31 & 0,80 & $6,66 \mathrm{E}-05$ & 42,93 \\
\hline Pituitária & CCAR1 & 0,32 & 0,19 & 0,84 & $1,49 \mathrm{E}-05$ & 63,23 \\
\hline Pituitária & $\mathrm{CCDC} 47$ & 0,24 & 0,34 & 0,85 & $1,01 \mathrm{E}-05$ & 61,41 \\
\hline Pituitária & CCDC50 & 0,44 & 0,07 & 0,80 & $7,33 \mathrm{E}-05$ & 48,99 \\
\hline Pituitária & CCDC91 & 0,28 & 0,26 & 0,77 & $1,99 \mathrm{E}-04$ & 36,29 \\
\hline Pituitária & $\mathrm{CCNI}$ & 0,45 & 0,06 & 0,82 & $3,01 \mathrm{E}-05$ & 58,48 \\
\hline Pituitária & СCT3 & 0,18 & 0,48 & 0,79 & $1,08 \mathrm{E}-04$ & 38,10 \\
\hline Pituitária & CCT4 & 0,34 & 0,17 & 0,84 & $1,06 \mathrm{E}-05$ & 72,42 \\
\hline Pituitária & CCT5 & 0,49 & 0,04 & 0,90 & $3,53 \mathrm{E}-07$ & 92,90 \\
\hline Pituitária & ССТ8 & 0,43 & 0,07 & 0,85 & $9,85 \mathrm{E}-06$ & 74,99 \\
\hline Pituitária & CD302 & 0,54 & 0,02 & 0,78 & $1,51 \mathrm{E}-04$ & 39,16 \\
\hline Pituitária & CD46 & 0,22 & 0,37 & 0,75 & $3,58 \mathrm{E}-04$ & 37,40 \\
\hline Pituitária & CD47 & 0,28 & 0,26 & 0,87 & $3,52 \mathrm{E}-06$ & 72,11 \\
\hline Pituitária & $\mathrm{CDC} 27$ & 0,53 & 0,02 & 0,86 & $5,21 \mathrm{E}-06$ & 76,83 \\
\hline Pituitária & CDC37L1 & 0,46 & 0,06 & 0,88 & $1,65 \mathrm{E}-06$ & 80,77 \\
\hline Pituitária & CDC42SE2 & 0,31 & 0,21 & 0,74 & $3,92 \mathrm{E}-04$ & 29,48 \\
\hline Hipotálamo & CDV3 & 0,17 & 0,49 & 0,75 & $3,06 \mathrm{E}-04$ & 30,39 \\
\hline Pituitária & CENPC & 0,42 & 0,09 & 0,92 & 4,84E-08 & 105,01 \\
\hline Pituitária & CEP290 & 0,38 & 0,12 & 0,84 & $1,44 \mathrm{E}-05$ & 60,25 \\
\hline Pituitária & CEP295 & 0,14 & 0,58 & 0,74 & $4,04 \mathrm{E}-04$ & 33,03 \\
\hline Pituitária & CEPT1 & 0,39 & 0,11 & 0,84 & $1,10 \mathrm{E}-05$ & 62,38 \\
\hline Pituitária & CFL2 & 0,38 & 0,12 & 0,87 & $3,08 \mathrm{E}-06$ & 80,75 \\
\hline Pituitária & CHD1 & 0,35 & 0,15 & 0,72 & $8,50 \mathrm{E}-04$ & 26,13 \\
\hline Pituitária & CHORDC1 & 0,37 & 0,13 & 0,84 & $1,19 \mathrm{E}-05$ & 70,80 \\
\hline Pituitária & CHTF8 & 0,38 & 0,12 & 0,82 & $3,69 \mathrm{E}-05$ & 51,80 \\
\hline Pituitária & CHUK & 0,50 & 0,03 & 0,95 & $2,01 \mathrm{E}-09$ & 127,13 \\
\hline Pituitária & CHURC1 & 0,20 & 0,42 & 0,80 & $6,32 \mathrm{E}-05$ & 49,23 \\
\hline Pituitária & CISD2 & 0,47 & 0,05 & 0,79 & $8,17 \mathrm{E}-05$ & 49,81 \\
\hline Pituitária & CLINT1 & 0,25 & 0,31 & 0,91 & $1,71 \mathrm{E}-07$ & 98,85 \\
\hline Pituitária & CMPK1 & 0,56 & 0,02 & 0,89 & $5,46 \mathrm{E}-07$ & 91,66 \\
\hline Pituitária & CMTM6 & 0,36 & 0,14 & 0,86 & $4,23 \mathrm{E}-06$ & 66,04 \\
\hline Pituitária & CNIH1 & 0,46 & 0,05 & 0,84 & $1,60 \mathrm{E}-05$ & 65,26 \\
\hline Pituitária & CNOT2 & 0,51 & 0,03 & 0,76 & $2,43 \mathrm{E}-04$ & 34,81 \\
\hline Pituitária & CNOT4 & 0,17 & 0,51 & 0,79 & $1,11 \mathrm{E}-04$ & 37,17 \\
\hline Pituitária & CNOT7 & 0,39 & 0,11 & 0,91 & $1,07 \mathrm{E}-07$ & 106,87 \\
\hline Pituitária & COG6 & 0,48 & 0,04 & 0,79 & $9,44 \mathrm{E}-05$ & 45,21 \\
\hline Pituitária & COP1 & 0,23 & 0,36 & 0,81 & $5,27 \mathrm{E}-05$ & 44,67 \\
\hline Pituitária & COPB1 & 0,50 & 0,04 & 0,93 & $3,21 \mathrm{E}-08$ & 103,92 \\
\hline Pituitária & COPS2 & 0,52 & 0,03 & 0,91 & $1,12 \mathrm{E}-07$ & 107,06 \\
\hline Pituitária & COPS4 & 0,32 & 0,20 & 0,84 & $1,20 \mathrm{E}-05$ & 63,51 \\
\hline Pituitária & CORO1C & 0,24 & 0,34 & 0,72 & $7,43 \mathrm{E}-04$ & 22,83 \\
\hline Pituitária & CREBZF & 0,50 & 0,03 & 0,84 & $1,57 \mathrm{E}-05$ & 56,31 \\
\hline Pituitária & CRK & 0,47 & 0,05 & 0,92 & $6,83 \mathrm{E}-08$ & 104,01 \\
\hline Hipotálamo & CRKL & 0,47 & 0,05 & 0,70 & $1,20 \mathrm{E}-03$ & 17,03 \\
\hline Pituitária & CRNKL1 & 0,41 & 0,09 & 0,78 & $1,35 \mathrm{E}-04$ & 34,39 \\
\hline Pituitária & CRY1 & 0,27 & 0,27 & 0,69 & $1,64 \mathrm{E}-03$ & 20,25 \\
\hline Pituitária & CRYZ & 0,43 & 0,08 & 0,74 & $4,52 \mathrm{E}-04$ & 30,68 \\
\hline Pituitária & CSDE1 & 0,34 & 0,16 & 0,91 & $1,16 \mathrm{E}-07$ & 97,75 \\
\hline Pituitária & CSNK1D & 0,22 & 0,37 & 0,83 & $1,88 \mathrm{E}-05$ & 58,15 \\
\hline Pituitária & CSRNP2 & 0,25 & 0,32 & 0,72 & $7,38 \mathrm{E}-04$ & 22,96 \\
\hline
\end{tabular}


Tabela suplementar 5 - Genes contidos no módulo Grey60 (continuação).

\begin{tabular}{|c|c|c|c|c|c|c|}
\hline Tecido & Gene & SG CAR & Valor de P SG CAR & FM & Valor de P FM & $\mathbf{K}$ \\
\hline Pituitária & CSTF1 & 0,39 & 0,11 & 0,73 & $5,53 \mathrm{E}-04$ & 26,95 \\
\hline Pituitária & CSTF2 & 0,34 & 0,17 & 0,92 & $5,28 \mathrm{E}-08$ & 106,62 \\
\hline Pituitária & CSTF3 & 0,49 & 0,04 & 0,90 & $4,00 \mathrm{E}-07$ & 85,09 \\
\hline Pituitária & CTNNA1 & 0,41 & 0,09 & 0,85 & $9,07 \mathrm{E}-06$ & 67,66 \\
\hline Pituitária & CTTN & 0,49 & 0,04 & 0,82 & $2,73 \mathrm{E}-05$ & 51,03 \\
\hline Pituitária & CUL2 & 0,53 & 0,02 & 0,83 & $2,22 \mathrm{E}-05$ & 54,16 \\
\hline Pituitária & CUL3 & 0,53 & 0,02 & 0,95 & 2,82E-09 & 122,55 \\
\hline Pituitária & CUL4A & 0,48 & 0,04 & 0,74 & $4,14 \mathrm{E}-04$ & 34,27 \\
\hline Pituitária & CUL5 & 0,37 & 0,13 & 0,86 & 4,44E-06 & 69,29 \\
\hline Pituitária & CWC15 & 0,37 & 0,13 & 0,80 & $7,69 \mathrm{E}-05$ & 47,80 \\
\hline Pituitária & CWF19L2 & 0,22 & 0,39 & 0,83 & $1,83 \mathrm{E}-05$ & 54,72 \\
\hline Pituitária & CYB5R4 & 0,37 & 0,13 & 0,77 & $2,06 \mathrm{E}-04$ & 34,12 \\
\hline Pituitária & DARS & 0,35 & 0,15 & 0,84 & $1,25 \mathrm{E}-05$ & 61,83 \\
\hline Pituitária & DCK & 0,43 & 0,08 & 0,78 & $1,22 \mathrm{E}-04$ & 41,59 \\
\hline Pituitária & DCLRE1C & 0,26 & 0,29 & 0,71 & $9,29 \mathrm{E}-04$ & 23,92 \\
\hline Pituitária & DCUN1D1 & 0,47 & 0,05 & 0,86 & $4,76 \mathrm{E}-06$ & 69,15 \\
\hline Pituitária & DDX20 & 0,43 & 0,07 & 0,71 & $9,29 \mathrm{E}-04$ & 26,16 \\
\hline Pituitária & DDX 24 & 0,28 & 0,26 & 0,86 & $5,84 \mathrm{E}-06$ & 69,17 \\
\hline Pituitária & DDX27 & 0,40 & 0,10 & 0,74 & $4,78 \mathrm{E}-04$ & 29,77 \\
\hline Pituitária & DDX50 & 0,43 & 0,08 & 0,83 & $1,75 \mathrm{E}-05$ & 58,05 \\
\hline Pituitária & DDX52 & 0,42 & 0,08 & 0,82 & $3,07 \mathrm{E}-05$ & 59,11 \\
\hline Pituitária & DEK & 0,47 & 0,05 & 0,86 & $4,12 \mathrm{E}-06$ & 71,95 \\
\hline Pituitária & DHX29 & 0,50 & 0,03 & 0,87 & $2,06 \mathrm{E}-06$ & 76,38 \\
\hline Pituitária & DHX36 & 0,38 & 0,12 & 0,88 & $1,22 \mathrm{E}-06$ & 79,89 \\
\hline Pituitária & DHX57 & 0,37 & 0,13 & 0,71 & $9,66 \mathrm{E}-04$ & 21,98 \\
\hline Pituitária & DHX9 & 0,44 & 0,07 & 0,85 & $7,84 \mathrm{E}-06$ & 67,10 \\
\hline Pituitária & DKC1 & 0,30 & 0,23 & 0,78 & $1,18 \mathrm{E}-04$ & 41,48 \\
\hline Pituitária & DMAP1 & 0,53 & 0,02 & 0,80 & $5,93 \mathrm{E}-05$ & 54,67 \\
\hline Pituitária & DNAJA2 & 0,35 & 0,16 & 0,90 & 4,99E-07 & 92,80 \\
\hline Pituitária & DNAJA3 & 0,42 & 0,08 & 0,76 & $2,32 \mathrm{E}-04$ & 36,90 \\
\hline Pituitária & DNAJA4 & 0,27 & 0,28 & 0,82 & $3,69 \mathrm{E}-05$ & 55,73 \\
\hline Pituitária & DNAJC10 & 0,35 & 0,16 & 0,87 & $3,29 \mathrm{E}-06$ & 76,01 \\
\hline Pituitária & DNAJC2 & 0,42 & 0,09 & 0,74 & $4,67 \mathrm{E}-04$ & 28,84 \\
\hline Pituitária & DNAJC6 & 0,44 & 0,07 & 0,81 & $5,13 \mathrm{E}-05$ & 46,60 \\
\hline Pituitária & DNM1L & 0,41 & 0,09 & 0,95 & $1,43 \mathrm{E}-09$ & 129,40 \\
\hline Pituitária & DOCK9 & 0,42 & 0,09 & 0,69 & $1,56 \mathrm{E}-03$ & 19,77 \\
\hline Pituitária & DOLK & 0,47 & 0,05 & 0,76 & $2,66 \mathrm{E}-04$ & 31,80 \\
\hline Pituitária & DOPEY1 & 0,53 & 0,02 & 0,81 & $5,10 \mathrm{E}-05$ & 44,78 \\
\hline Pituitária & DPP3 & 0,38 & 0,12 & 0,71 & $9,54 \mathrm{E}-04$ & 22,70 \\
\hline Pituitária & DPY19L4 & 0,37 & 0,13 & 0,86 & $3,85 \mathrm{E}-06$ & 73,69 \\
\hline Pituitária & DR1 & 0,54 & 0,02 & 0,83 & $1,78 \mathrm{E}-05$ & 61,32 \\
\hline Pituitária & DRG1 & 0,25 & 0,32 & 0,76 & $2,57 \mathrm{E}-04$ & 35,95 \\
\hline Pituitária & DYM & 0,66 & 0,00 & 0,86 & $5,43 \mathrm{E}-06$ & 71,35 \\
\hline Pituitária & DYNC1LI1 & 0,58 & 0,01 & 0,86 & $5,10 \mathrm{E}-06$ & 67,52 \\
\hline Pituitária & DYNLT3 & 0,34 & 0,17 & 0,81 & $4,40 \mathrm{E}-05$ & 60,45 \\
\hline Pituitária & E2F5 & 0,30 & 0,22 & 0,66 & $2,67 \mathrm{E}-03$ & 13,75 \\
\hline Pituitária & EBNA1BP2 & 0,20 & 0,43 & 0,74 & $4,28 \mathrm{E}-04$ & 26,61 \\
\hline Pituitária & ECHDC1 & 0,14 & 0,58 & 0,75 & $3,44 \mathrm{E}-04$ & 32,26 \\
\hline Pituitária & EGLN1 & 0,40 & 0,10 & 0,73 & $6,25 \mathrm{E}-04$ & 26,49 \\
\hline Pituitária & EIF2S2 & 0,31 & 0,20 & 0,82 & $3,27 \mathrm{E}-05$ & 55,10 \\
\hline Pituitária & EIF3B & 0,33 & 0,17 & 0,72 & $8,12 \mathrm{E}-04$ & 25,77 \\
\hline Pituitária & EIF5 & 0,43 & 0,07 & 0,83 & $1,98 \mathrm{E}-05$ & 59,23 \\
\hline Pituitária & ELMOD2 & 0,50 & 0,04 & 0,81 & $4,99 \mathrm{E}-05$ & 49,84 \\
\hline Pituitária & ELMOD3 & 0,14 & 0,58 & 0,73 & $5,81 \mathrm{E}-04$ & 24,45 \\
\hline Pituitária & ELOVL5 & 0,24 & 0,35 & 0,76 & $2,37 \mathrm{E}-04$ & 38,84 \\
\hline Pituitária & ELOVL6 & 0,33 & 0,19 & 0,77 & $2,13 \mathrm{E}-04$ & 33,45 \\
\hline Pituitária & EMC2 & 0,54 & 0,02 & 0,83 & $1,64 \mathrm{E}-05$ & 59,62 \\
\hline Pituitária & EML4 & 0,13 & 0,62 & 0,74 & $4,52 \mathrm{E}-04$ & 26,71 \\
\hline Pituitária & ENPP4 & 0,11 & 0,67 & 0,80 & $7,43 \mathrm{E}-05$ & 43,22 \\
\hline Pituitária & ENSBTAG00000000586 & 0,30 & 0,23 & 0,81 & $4,52 \mathrm{E}-05$ & 47,19 \\
\hline Pituitária & ENSBTAG00000004925 & 0,38 & 0,12 & 0,81 & $3,92 \mathrm{E}-05$ & 50,34 \\
\hline Pituitária & ENSBTAG00000006252 & 0,13 & 0,62 & 0,80 & $7,64 \mathrm{E}-05$ & 39,85 \\
\hline Pituitária & ENSBTAG00000006819 & 0,25 & 0,31 & 0,90 & $3,94 \mathrm{E}-07$ & 88,50 \\
\hline
\end{tabular}


Tabela suplementar 5 - Genes contidos no módulo Grey60 (continuação).

\begin{tabular}{|c|c|c|c|c|c|c|}
\hline Tecido & Gene & SG CAR & Valor de P SG CAR & FM & Valor de P FM & $\mathbf{K}$ \\
\hline Pituitária & ENSBTAG00000007696 & 0,35 & 0,15 & 0,92 & $5,65 \mathrm{E}-08$ & 101,34 \\
\hline Pituitária & ENSBTAG00000008184 & 0,49 & 0,04 & 0,87 & 2,35E-06 & 83,20 \\
\hline Pituitária & ENSBTAG00000008346 & 0,20 & 0,43 & 0,77 & $1,93 \mathrm{E}-04$ & 39,09 \\
\hline Pituitária & ENSBTAG00000010500 & 0,34 & 0,17 & 0,78 & $1,38 \mathrm{E}-04$ & 42,39 \\
\hline Pituitária & ENSBTAG00000011052 & 0,23 & 0,35 & 0,82 & $3,13 \mathrm{E}-05$ & 47,85 \\
\hline Pituitária & ENSBTAG00000011926 & 0,51 & 0,03 & 0,82 & $3,17 \mathrm{E}-05$ & 50,24 \\
\hline Pituitária & ENSBTAG00000013311 & 0,41 & 0,09 & 0,85 & $6,38 \mathrm{E}-06$ & 64,98 \\
\hline Pituitária & ENSBTAG00000014515 & 0,49 & 0,04 & 0,74 & $4,84 \mathrm{E}-04$ & 26,12 \\
\hline Pituitária & ENSBTAG00000015077 & 0,27 & 0,27 & 0,79 & $8,12 \mathrm{E}-05$ & 42,68 \\
\hline Pituitária & ENSBTAG00000015497 & 0,49 & 0,04 & 0,82 & $3,12 \mathrm{E}-05$ & 54,81 \\
\hline Pituitária & ENSBTAG00000015899 & 0,12 & 0,63 & 0,68 & $1,77 \mathrm{E}-03$ & 19,14 \\
\hline Pituitária & ENSBTAG00000016721 & 0,25 & 0,33 & 0,72 & $7,02 \mathrm{E}-04$ & 26,52 \\
\hline Pituitária & ENSBTAG00000017734 & 0,26 & 0,30 & 0,75 & 2,95E-04 & 34,06 \\
\hline Pituitária & ENSBTAG00000019285 & 0,39 & 0,11 & 0,82 & $2,57 \mathrm{E}-05$ & 54,67 \\
\hline Pituitária & ENSBTAG00000030384 & 0,30 & 0,23 & 0,72 & $8,38 \mathrm{E}-04$ & 28,98 \\
\hline Pituitária & ENSBTAG00000031572 & 0,34 & 0,17 & 0,80 & $6,30 \mathrm{E}-05$ & 44,06 \\
\hline Pituitária & ENSBTAG00000039453 & 0,63 & 0,00 & 0,76 & $2,55 \mathrm{E}-04$ & 32,32 \\
\hline Pituitária & ENSBTAG00000040568 & 0,27 & 0,28 & 0,73 & $6,58 \mathrm{E}-04$ & 23,25 \\
\hline Pituitária & ENSBTAG00000044125 & 0,03 & 0,90 & 0,73 & $6,42 \mathrm{E}-04$ & 24,88 \\
\hline Pituitária & ENSBTAG00000046808 & 0,17 & 0,51 & 0,88 & $1,35 \mathrm{E}-06$ & 77,70 \\
\hline Pituitária & ENSBTAG00000047008 & 0,35 & 0,15 & 0,82 & $3,58 \mathrm{E}-05$ & 51,64 \\
\hline Pituitária & ENSBTAG00000047699 & 0,46 & 0,06 & 0,89 & $6,86 \mathrm{E}-07$ & 84,39 \\
\hline Pituitária & ENSBTAG00000047868 & 0,21 & 0,40 & 0,72 & $7,84 \mathrm{E}-04$ & 19,72 \\
\hline Pituitária & EPB41L5 & 0,28 & 0,26 & 0,77 & $1,70 \mathrm{E}-04$ & 36,81 \\
\hline Pituitária & ERGIC2 & 0,30 & 0,22 & 0,83 & $2,06 \mathrm{E}-05$ & 62,60 \\
\hline Pituitária & ERI1 & 0,47 & 0,05 & 0,74 & $4,18 \mathrm{E}-04$ & 25,43 \\
\hline Pituitária & ERLIN2 & 0,20 & 0,42 & 0,82 & $3,61 \mathrm{E}-05$ & 49,07 \\
\hline Pituitária & ERP44 & 0,23 & 0,35 & 0,81 & $4,45 \mathrm{E}-05$ & 49,90 \\
\hline Pituitária & ESCO1 & 0,37 & 0,13 & 0,86 & $3,87 \mathrm{E}-06$ & 67,27 \\
\hline Pituitária & ESF1 & 0,35 & 0,16 & 0,87 & $3,56 \mathrm{E}-06$ & 75,42 \\
\hline Pituitária & EXOC5 & 0,47 & 0,05 & 0,86 & $4,45 \mathrm{E}-06$ & 72,84 \\
\hline Pituitária & EXOC6 & 0,61 & 0,01 & 0,75 & $3,81 \mathrm{E}-04$ & 31,48 \\
\hline Pituitária & FAM111B & 0,39 & 0,11 & 0,80 & $7,64 \mathrm{E}-05$ & 43,07 \\
\hline Pituitária & FAM13B & 0,24 & 0,34 & 0,91 & $1,40 \mathrm{E}-07$ & 98,30 \\
\hline Pituitária & FAM168B & 0,39 & 0,11 & 0,94 & $9,02 \mathrm{E}-09$ & 116,91 \\
\hline Pituitária & FAM177A1 & 0,46 & 0,06 & 0,88 & $1,11 \mathrm{E}-06$ & 80,16 \\
\hline Pituitária & FAM206A & 0,46 & 0,06 & 0,77 & $1,81 \mathrm{E}-04$ & 38,76 \\
\hline Pituitária & FAM208A & 0,43 & 0,08 & 0,83 & $2,02 \mathrm{E}-05$ & 59,17 \\
\hline Pituitária & FAM210A & 0,49 & 0,04 & 0,78 & $1,31 \mathrm{E}-04$ & 36,43 \\
\hline Pituitária & FAM21A & 0,24 & 0,35 & 0,66 & $3,05 \mathrm{E}-03$ & 15,12 \\
\hline Pituitária & FAR1 & 0,50 & 0,03 & 0,94 & $1,02 \mathrm{E}-08$ & 122,91 \\
\hline Pituitária & FASTKD1 & 0,29 & 0,24 & 0,83 & $1,72 \mathrm{E}-05$ & 55,09 \\
\hline Hipotálamo & FBXL21 & 0,24 & 0,34 & 0,68 & $1,77 \mathrm{E}-03$ & 17,81 \\
\hline Pituitária & FEM1C & 0,45 & 0,06 & 0,79 & $9,14 \mathrm{E}-05$ & 44,60 \\
\hline Pituitária & FERMT2 & 0,14 & 0,59 & 0,64 & $4,04 \mathrm{E}-03$ & 17,49 \\
\hline Pituitária & FKRP & 0,02 & 0,93 & 0,66 & $2,85 \mathrm{E}-03$ & 15,39 \\
\hline Pituitária & FNTA & 0,39 & 0,11 & 0,76 & $2,45 \mathrm{E}-04$ & 37,74 \\
\hline Pituitária & FTSJ1 & 0,33 & 0,18 & 0,78 & $1,25 \mathrm{E}-04$ & 38,44 \\
\hline Pituitária & FTSJ3 & 0,50 & 0,04 & 0,72 & $6,74 \mathrm{E}-04$ & 25,00 \\
\hline Pituitária & FUBP1 & 0,19 & 0,46 & 0,85 & $8,87 \mathrm{E}-06$ & 65,77 \\
\hline Pituitária & FXR1 & 0,47 & 0,05 & 0,81 & $4,97 \mathrm{E}-05$ & 46,41 \\
\hline Pituitária & G3BP1 & 0,15 & 0,55 & 0,91 & $1,88 \mathrm{E}-07$ & 92,68 \\
\hline Pituitária & G3BP2 & 0,41 & 0,09 & 0,93 & $2,41 \mathrm{E}-08$ & 111,05 \\
\hline Pituitária & GALNT1 & 0,34 & 0,17 & 0,82 & $2,82 \mathrm{E}-05$ & 50,52 \\
\hline Hipotálamo & GALNT11 & 0,33 & 0,18 & 0,71 & $9,48 \mathrm{E}-04$ & 19,90 \\
\hline Pituitária & GALNT2 & 0,54 & 0,02 & 0,77 & $1,93 \mathrm{E}-04$ & 36,62 \\
\hline Pituitária & GATAD1 & 0,43 & 0,07 & 0,76 & 2,32E-04 & 28,13 \\
\hline Pituitária & GCFC2 & 0,28 & 0,26 & 0,69 & $1,50 \mathrm{E}-03$ & 21,00 \\
\hline Pituitária & GGPS1 & 0,39 & 0,11 & 0,84 & $1,17 \mathrm{E}-05$ & 66,43 \\
\hline Pituitária & GHITM & 0,55 & 0,02 & 0,80 & $7,28 \mathrm{E}-05$ & 46,78 \\
\hline Pituitária & GIPC2 & 0,19 & 0,45 & 0,76 & $2,26 \mathrm{E}-04$ & 37,70 \\
\hline Pituitária & GLMN & 0,38 & 0,12 & 0,77 & $1,91 \mathrm{E}-04$ & 43,12 \\
\hline Pituitária & GLUD1 & 0,58 & 0,01 & 0,87 & $2,62 \mathrm{E}-06$ & 73,06 \\
\hline
\end{tabular}


Tabela suplementar 5 - Genes contidos no módulo Grey60 (continuação).

\begin{tabular}{|c|c|c|c|c|c|c|}
\hline Tecido & Gene & SG CAR & Valor de P SG CAR & FM & Valor de P FM & $\mathbf{K}$ \\
\hline Pituitária & GLYR1 & 0,36 & 0,14 & 0,82 & $3,58 \mathrm{E}-05$ & 58,49 \\
\hline Pituitária & GMCL1 & 0,28 & 0,25 & 0,88 & $1,57 \mathrm{E}-06$ & 82,09 \\
\hline Pituitária & GMEB1 & 0,47 & 0,05 & 0,68 & $1,77 \mathrm{E}-03$ & 19,27 \\
\hline Pituitária & GMFB & 0,49 & 0,04 & 0,82 & $3,04 \mathrm{E}-05$ & 54,77 \\
\hline Pituitária & GMPS & 0,51 & 0,03 & 0,79 & $8,25 \mathrm{E}-05$ & 39,20 \\
\hline Pituitária & GNB1 & 0,24 & 0,34 & 0,71 & $1,07 \mathrm{E}-03$ & 21,77 \\
\hline Pituitária & GNB5 & 0,37 & 0,13 & 0,84 & $1,33 \mathrm{E}-05$ & 60,69 \\
\hline Pituitária & GNL3 & 0,33 & 0,19 & 0,69 & $1,57 \mathrm{E}-03$ & 27,09 \\
\hline Pituitária & GNPNAT1 & 0,18 & 0,48 & 0,80 & $6,53 \mathrm{E}-05$ & 45,00 \\
\hline Pituitária & GNPTAB & 0,11 & 0,65 & 0,72 & $7,45 \mathrm{E}-04$ & 22,45 \\
\hline Pituitária & GOLM1 & 0,15 & 0,56 & 0,74 & $4,63 \mathrm{E}-04$ & 29,60 \\
\hline Pituitária & GORASP2 & 0,40 & 0,10 & 0,85 & $8,51 \mathrm{E}-06$ & 59,96 \\
\hline Pituitária & GPATCH2 & 0,19 & 0,45 & 0,84 & $1,51 \mathrm{E}-05$ & 54,73 \\
\hline Pituitária & GPBP1 & 0,50 & 0,04 & 0,85 & $7,98 \mathrm{E}-06$ & 75,26 \\
\hline Pituitária & GPCPD1 & 0,26 & 0,30 & 0,86 & $6,01 \mathrm{E}-06$ & 72,32 \\
\hline Pituitária & GPN1 & 0,43 & 0,07 & 0,81 & $5,16 \mathrm{E}-05$ & 51,23 \\
\hline Pituitária & GPN2 & 0,35 & 0,15 & 0,81 & $3,88 \mathrm{E}-05$ & 47,15 \\
\hline Pituitária & GPR155 & 0,40 & 0,10 & 0,77 & $1,93 \mathrm{E}-04$ & 37,15 \\
\hline Pituitária & GPR89A & 0,39 & 0,11 & 0,82 & $3,54 \mathrm{E}-05$ & 46,21 \\
\hline Pituitária & GRB2 & 0,47 & 0,05 & 0,83 & $2,06 \mathrm{E}-05$ & 50,24 \\
\hline Pituitária & GRSF1 & 0,41 & 0,09 & 0,81 & $4,03 \mathrm{E}-05$ & 48,26 \\
\hline Pituitária & GTF2E1 & 0,26 & 0,29 & 0,74 & $5,07 \mathrm{E}-04$ & 26,49 \\
\hline Pituitária & GTPBP10 & 0,35 & 0,15 & 0,73 & $6,15 \mathrm{E}-04$ & 29,97 \\
\hline Pituitária & GTPBP4 & 0,39 & 0,11 & 0,72 & $6,85 \mathrm{E}-04$ & 32,56 \\
\hline Pituitária & GUF1 & 0,12 & 0,65 & 0,68 & $1,72 \mathrm{E}-03$ & 22,19 \\
\hline Pituitária & H2AFY & 0,52 & 0,03 & 0,85 & $9,20 \mathrm{E}-06$ & 63,19 \\
\hline Pituitária & HACD3 & 0,44 & 0,07 & 0,89 & $5,45 \mathrm{E}-07$ & 92,45 \\
\hline Pituitária & HACE1 & 0,47 & 0,05 & 0,81 & $5,31 \mathrm{E}-05$ & 47,62 \\
\hline Pituitária & HBS1L & 0,53 & 0,02 & 0,92 & $6,03 \mathrm{E}-08$ & 108,29 \\
\hline Pituitária & $\mathrm{HDAC} 2$ & 0,55 & 0,02 & 0,82 & $2,87 \mathrm{E}-05$ & 53,40 \\
\hline Pituitária & HEATR1 & 0,34 & 0,17 & 0,78 & $1,54 \mathrm{E}-04$ & 32,88 \\
\hline Pituitária & HEATR3 & 0,43 & 0,08 & 0,79 & $8,34 \mathrm{E}-05$ & 44,72 \\
\hline Pituitária & HERC4 & 0,25 & 0,32 & 0,82 & $2,56 \mathrm{E}-05$ & 51,89 \\
\hline Pituitária & HIF1A & 0,25 & 0,33 & 0,92 & $8,38 \mathrm{E}-08$ & 97,98 \\
\hline Pituitária & HIST1H2BB & 0,36 & 0,14 & 0,85 & $7,26 \mathrm{E}-06$ & 63,92 \\
\hline Pituitária & HMGCL & 0,38 & 0,12 & 0,78 & $1,15 \mathrm{E}-04$ & 40,89 \\
\hline Pituitária & HMGN1 & 0,35 & 0,16 & 0,71 & $1,06 \mathrm{E}-03$ & 30,30 \\
\hline Pituitária & HMGN4 & 0,38 & 0,12 & 0,79 & $1,08 \mathrm{E}-04$ & 45,20 \\
\hline Pituitária & HNRNPA3 & 0,28 & 0,26 & 0,87 & $3,30 \mathrm{E}-06$ & 72,71 \\
\hline Pituitária & HNRNPC & 0,30 & 0,23 & 0,88 & $1,68 \mathrm{E}-06$ & 78,70 \\
\hline Pituitária & HNRNPR & 0,38 & 0,12 & 0,83 & $1,69 \mathrm{E}-05$ & 55,58 \\
\hline Pituitária & HOMEZ & 0,51 & 0,03 & 0,74 & $4,41 \mathrm{E}-04$ & 28,68 \\
\hline Pituitária & HSD17B12 & 0,57 & 0,01 & 0,85 & $9,17 \mathrm{E}-06$ & 64,42 \\
\hline Pituitária & HSP90AA1 & 0,48 & 0,04 & 0,82 & $3,02 \mathrm{E}-05$ & 57,84 \\
\hline Pituitária & HSP90AB1 & 0,36 & 0,14 & 0,81 & $5,03 \mathrm{E}-05$ & 46,54 \\
\hline Pituitária & HSPA14 & 0,47 & 0,05 & 0,89 & $9,39 \mathrm{E}-07$ & 85,90 \\
\hline Pituitária & HSPA4 & 0,51 & 0,03 & 0,91 & $1,34 \mathrm{E}-07$ & 108,19 \\
\hline Pituitária & HSPD1 & 0,41 & 0,09 & 0,89 & $8,59 \mathrm{E}-07$ & 90,34 \\
\hline Pituitária & IBTK & 0,43 & 0,08 & 0,78 & $1,24 \mathrm{E}-04$ & 38,33 \\
\hline Pituitária & ICE2 & 0,45 & 0,06 & 0,81 & $4,55 \mathrm{E}-05$ & 48,51 \\
\hline Pituitária & IDH3A & 0,43 & 0,07 & 0,88 & $1,10 \mathrm{E}-06$ & 84,39 \\
\hline Pituitária & IFIT5 & 0,36 & 0,15 & 0,79 & $1,09 \mathrm{E}-04$ & 43,88 \\
\hline Pituitária & IFNAR1 & 0,28 & 0,26 & 0,63 & $5,10 \mathrm{E}-03$ & 15,17 \\
\hline Pituitária & IMMT & 0,49 & 0,04 & 0,93 & $3,85 \mathrm{E}-08$ & 105,60 \\
\hline Pituitária & IPO7 & 0,49 & 0,04 & 0,91 & $1,32 \mathrm{E}-07$ & 101,86 \\
\hline Pituitária & ISCA1 & 0,21 & 0,39 & 0,86 & $5,37 \mathrm{E}-06$ & 67,84 \\
\hline Pituitária & IST1 & 0,23 & 0,36 & 0,87 & $3,32 \mathrm{E}-06$ & 66,53 \\
\hline Pituitária & ITFG1 & 0,40 & 0,10 & 0,86 & $5,28 \mathrm{E}-06$ & 73,64 \\
\hline Pituitária & ITGB 1 & 0,30 & 0,23 & 0,84 & $1,46 \mathrm{E}-05$ & 58,54 \\
\hline Pituitária & ITGB1BP1 & 0,42 & 0,09 & 0,80 & $7,33 \mathrm{E}-05$ & 42,77 \\
\hline Pituitária & JAK1 & 0,29 & 0,25 & 0,88 & $1,36 \mathrm{E}-06$ & 80,81 \\
\hline Pituitária & JAK2 & 0,28 & 0,25 & 0,89 & $7,28 \mathrm{E}-07$ & 83,31 \\
\hline Pituitária & KANSL2 & 0,34 & 0,17 & 0,76 & $2,45 \mathrm{E}-04$ & 38,21 \\
\hline
\end{tabular}


Tabela suplementar 5 - Genes contidos no módulo Grey60 (continuação).

\begin{tabular}{|c|c|c|c|c|c|c|}
\hline Tecido & Gene & SG CAR & Valor de P SG CAR & FM & Valor de P FM & $\mathbf{K}$ \\
\hline Pituitária & KAT2B & 0,19 & 0,44 & 0,75 & $3,42 \mathrm{E}-04$ & 29,06 \\
\hline Pituitária & KATNA1 & 0,43 & 0,07 & 0,89 & $1,01 \mathrm{E}-06$ & 78,65 \\
\hline Pituitária & KATNBL1 & 0,40 & 0,10 & 0,76 & $2,66 \mathrm{E}-04$ & 32,93 \\
\hline Pituitária & KCMF1 & 0,14 & 0,57 & 0,70 & $1,10 \mathrm{E}-03$ & 20,67 \\
\hline Pituitária & KDELR2 & 0,26 & 0,30 & 0,76 & $2,20 \mathrm{E}-04$ & 38,72 \\
\hline Pituitária & KDM1A & 0,46 & 0,06 & 0,81 & $5,34 \mathrm{E}-05$ & 43,88 \\
\hline Pituitária & KDM3A & 0,48 & 0,04 & 0,84 & $1,33 \mathrm{E}-05$ & 56,24 \\
\hline Pituitária & KHDRBS1 & 0,41 & 0,09 & 0,83 & $1,90 \mathrm{E}-05$ & 56,57 \\
\hline Pituitária & KIAA0753 & 0,26 & 0,29 & 0,78 & $1,38 \mathrm{E}-04$ & 38,57 \\
\hline Pituitária & KIAA1191 & 0,30 & 0,23 & 0,80 & $7,21 \mathrm{E}-05$ & 49,28 \\
\hline Pituitária & KIAA1468 & 0,06 & 0,80 & 0,68 & $1,77 \mathrm{E}-03$ & 21,60 \\
\hline Pituitária & KIF1BP & 0,43 & 0,07 & 0,84 & $1,33 \mathrm{E}-05$ & 59,09 \\
\hline Pituitária & KIF27 & 0,34 & 0,17 & 0,73 & $6,36 \mathrm{E}-04$ & 25,75 \\
\hline Pituitária & KLHL7 & 0,28 & 0,26 & 0,88 & $1,15 \mathrm{E}-06$ & 81,24 \\
\hline Pituitária & KRR1 & 0,43 & 0,07 & 0,83 & $1,85 \mathrm{E}-05$ & 57,49 \\
\hline Pituitária & LACTB2 & 0,30 & 0,23 & 0,73 & $6,48 \mathrm{E}-04$ & 27,02 \\
\hline Pituitária & LASP1 & 0,52 & 0,03 & 0,75 & $3,21 \mathrm{E}-04$ & 28,77 \\
\hline Pituitária & LEO1 & 0,35 & 0,16 & 0,70 & $1,17 \mathrm{E}-03$ & 19,59 \\
\hline Pituitária & LIN52 & 0,31 & 0,22 & 0,69 & $1,58 \mathrm{E}-03$ & 24,70 \\
\hline Pituitária & LIN7C & 0,47 & 0,05 & 0,91 & $2,16 \mathrm{E}-07$ & 105,51 \\
\hline Pituitária & LMBR1 & 0,23 & 0,35 & 0,81 & $3,85 \mathrm{E}-05$ & 49,30 \\
\hline Pituitária & LNPK & 0,31 & 0,22 & 0,88 & $1,18 \mathrm{E}-06$ & 90,91 \\
\hline Pituitária & LRRC40 & 0,39 & 0,11 & 0,83 & $1,80 \mathrm{E}-05$ & 53,43 \\
\hline Pituitária & LRRC42 & 0,42 & 0,08 & 0,75 & $3,87 \mathrm{E}-04$ & 26,30 \\
\hline Pituitária & LRRCC1 & 0,51 & 0,03 & 0,79 & $1,06 \mathrm{E}-04$ & 43,78 \\
\hline Pituitária & LRRFIP2 & 0,19 & 0,44 & 0,73 & $5,67 \mathrm{E}-04$ & 27,22 \\
\hline Pituitária & LTV1 & 0,33 & 0,17 & 0,77 & $1,62 \mathrm{E}-04$ & 46,59 \\
\hline Pituitária & LYPLA1 & 0,38 & 0,12 & 0,77 & $1,78 \mathrm{E}-04$ & 41,52 \\
\hline Pituitária & LYSMD1 & 0,51 & 0,03 & 0,86 & $4,35 \mathrm{E}-06$ & 74,36 \\
\hline Pituitária & M6PR & 0,20 & 0,42 & 0,78 & $1,20 \mathrm{E}-04$ & 39,29 \\
\hline Pituitária & MAK16 & 0,29 & 0,24 & 0,81 & $4,01 \mathrm{E}-05$ & 50,13 \\
\hline Pituitária & MAP4K5 & 0,30 & 0,23 & 0,86 & $5,17 \mathrm{E}-06$ & 70,32 \\
\hline Pituitária & MARCH5 & 0,15 & 0,55 & 0,86 & $5,80 \mathrm{E}-06$ & 63,31 \\
\hline Pituitária & MARK1 & 0,34 & 0,17 & 0,85 & $6,33 \mathrm{E}-06$ & 62,44 \\
\hline Pituitária & MAT2A & 0,32 & 0,20 & 0,87 & $3,22 \mathrm{E}-06$ & 77,75 \\
\hline Pituitária & MATR3 & 0,37 & 0,13 & 0,95 & $2,83 \mathrm{E}-09$ & 125,10 \\
\hline Pituitária & MAX & 0,14 & 0,57 & 0,77 & $1,63 \mathrm{E}-04$ & 37,43 \\
\hline Pituitária & MBIP & 0,51 & 0,03 & 0,79 & $1,08 \mathrm{E}-04$ & 41,58 \\
\hline Pituitária & MCM6 & 0,15 & 0,56 & 0,74 & $4,46 \mathrm{E}-04$ & 26,76 \\
\hline Pituitária & MCUR1 & 0,26 & 0,29 & 0,72 & $7,31 \mathrm{E}-04$ & 25,02 \\
\hline Pituitária & ME2 & 0,37 & 0,13 & 0,86 & $5,02 \mathrm{E}-06$ & 66,43 \\
\hline Pituitária & MED28 & 0,33 & 0,19 & 0,87 & $3,42 \mathrm{E}-06$ & 73,54 \\
\hline Pituitária & MED30 & 0,41 & 0,09 & 0,73 & $5,69 \mathrm{E}-04$ & 27,81 \\
\hline Pituitária & METAP1 & 0,42 & 0,09 & 0,76 & $2,37 \mathrm{E}-04$ & 37,30 \\
\hline Pituitária & METAP2 & 0,50 & 0,03 & 0,91 & $1,83 \mathrm{E}-07$ & 100,17 \\
\hline Pituitária & MFSD14A & 0,28 & 0,27 & 0,82 & $2,81 \mathrm{E}-05$ & 55,18 \\
\hline Pituitária & MFSD14B & 0,41 & 0,09 & 0,84 & $1,04 \mathrm{E}-05$ & 56,87 \\
\hline Pituitária & MIA3 & 0,34 & 0,16 & 0,91 & $2,14 \mathrm{E}-07$ & 96,02 \\
\hline Pituitária & MICU3 & 0,38 & 0,12 & 0,85 & $8,11 \mathrm{E}-06$ & 65,27 \\
\hline Pituitária & MIER1 & 0,50 & 0,04 & 0,84 & $1,36 \mathrm{E}-05$ & 68,79 \\
\hline Pituitária & MINPP1 & 0,44 & 0,07 & 0,76 & $2,34 \mathrm{E}-04$ & 34,82 \\
\hline Pituitária & MKRN1 & 0,24 & 0,35 & 0,86 & $5,15 \mathrm{E}-06$ & 63,96 \\
\hline Pituitária & MLH1 & 0,42 & 0,09 & 0,84 & $1,35 \mathrm{E}-05$ & 55,84 \\
\hline Pituitária & MMP16 & 0,46 & 0,06 & 0,75 & $3,36 \mathrm{E}-04$ & 34,18 \\
\hline Pituitária & MOB1A & 0,35 & 0,15 & 0,84 & $1,30 \mathrm{E}-05$ & 63,22 \\
\hline Pituitária & MOB4 & 0,53 & 0,02 & 0,89 & $5,98 \mathrm{E}-07$ & 88,34 \\
\hline Pituitária & MORF4L1 & 0,34 & 0,17 & 0,90 & $2,73 \mathrm{E}-07$ & 95,33 \\
\hline Pituitária & MORF4L2 & 0,42 & 0,09 & 0,83 & $1,71 \mathrm{E}-05$ & 65,78 \\
\hline Pituitária & MPHOSPH8 & 0,31 & 0,22 & 0,86 & $4,05 \mathrm{E}-06$ & 66,71 \\
\hline Pituitária & MPP5 & 0,55 & 0,02 & 0,79 & $1,13 \mathrm{E}-04$ & 39,91 \\
\hline Pituitária & MRFAP1L1 & 0,29 & 0,25 & 0,76 & $2,18 \mathrm{E}-04$ & 36,18 \\
\hline Pituitária & MRPS10 & 0,33 & 0,18 & 0,73 & $5,63 \mathrm{E}-04$ & 26,38 \\
\hline Pituitária & MRPS30 & 0,35 & 0,16 & 0,73 & $5,27 \mathrm{E}-04$ & 29,38 \\
\hline
\end{tabular}


Tabela suplementar 5 - Genes contidos no módulo Grey60 (continuação).

\begin{tabular}{|c|c|c|c|c|c|c|}
\hline Tecido & Gene & SG CAR & Valor de P SG CAR & FM & Valor de P FM & $\mathbf{K}$ \\
\hline Pituitária & MRPS31 & 0,42 & 0,08 & 0,67 & $2,42 \mathrm{E}-03$ & 16,61 \\
\hline Pituitária & MRTO4 & 0,19 & 0,45 & 0,71 & $8,91 \mathrm{E}-04$ & 28,86 \\
\hline Pituitária & MSANTD4 & 0,50 & 0,04 & 0,89 & $7,24 \mathrm{E}-07$ & 84,94 \\
\hline Pituitária & MTDH & 0,39 & 0,11 & 0,88 & $1,23 \mathrm{E}-06$ & 84,22 \\
\hline Pituitária & MTF2 & 0,25 & 0,32 & 0,74 & $3,89 \mathrm{E}-04$ & 25,98 \\
\hline Pituitária & MTFR1 & 0,33 & 0,19 & 0,87 & $3,12 \mathrm{E}-06$ & 68,52 \\
\hline Pituitária & MTMR1 & 0,35 & 0,16 & 0,85 & $6,89 \mathrm{E}-06$ & 59,50 \\
\hline Pituitária & MTMR6 & 0,43 & 0,08 & 0,83 & $1,98 \mathrm{E}-05$ & 56,11 \\
\hline Pituitária & MTPAP & 0,26 & 0,29 & 0,72 & $7,65 \mathrm{E}-04$ & 25,82 \\
\hline Pituitária & MYCBP & 0,61 & 0,01 & 0,86 & $4,74 \mathrm{E}-06$ & 70,28 \\
\hline Pituitária & MYNN & 0,48 & 0,05 & 0,92 & $6,85 \mathrm{E}-08$ & 103,18 \\
\hline Pituitária & N4BP2L2 & 0,27 & 0,27 & 0,92 & $4,80 \mathrm{E}-08$ & 104,98 \\
\hline Pituitária & NAA15 & 0,40 & 0,10 & 0,95 & $1,59 \mathrm{E}-09$ & 130,96 \\
\hline Pituitária & NAA35 & 0,39 & 0,11 & 0,89 & $5,65 \mathrm{E}-07$ & 83,11 \\
\hline Pituitária & NAA50 & 0,46 & 0,05 & 0,85 & $6,55 \mathrm{E}-06$ & 77,99 \\
\hline Pituitária & NADK & 0,53 & 0,03 & 0,72 & $7,25 \mathrm{E}-04$ & 23,68 \\
\hline Pituitária & NAP1L1 & 0,43 & 0,07 & 0,74 & $4,58 \mathrm{E}-04$ & 31,11 \\
\hline Pituitária & NAPB & 0,48 & 0,04 & 0,72 & $8,10 \mathrm{E}-04$ & 24,61 \\
\hline Pituitária & NARS2 & 0,43 & 0,08 & 0,86 & $5,87 \mathrm{E}-06$ & 73,91 \\
\hline Pituitária & NCBP1 & 0,37 & 0,13 & 0,90 & $4,61 \mathrm{E}-07$ & 96,57 \\
\hline Pituitária & NCEH1 & 0,14 & 0,58 & 0,72 & $7,36 \mathrm{E}-04$ & 27,02 \\
\hline Pituitária & NCK1 & 0,43 & 0,08 & 0,80 & $5,80 \mathrm{E}-05$ & 48,88 \\
\hline Pituitária & NCOA4 & 0,34 & 0,17 & 0,91 & $2,36 \mathrm{E}-07$ & 92,27 \\
\hline Pituitária & NDUFAF1 & 0,33 & 0,18 & 0,86 & $4,07 \mathrm{E}-06$ & 73,06 \\
\hline Pituitária & NDUFAF6 & 0,39 & 0,11 & 0,75 & $3,57 \mathrm{E}-04$ & 28,98 \\
\hline Pituitária & NEK10 & 0,46 & 0,06 & 0,80 & $6,28 \mathrm{E}-05$ & 42,97 \\
\hline Pituitária & NIP7 & 0,36 & 0,14 & 0,84 & $1,22 \mathrm{E}-05$ & 65,57 \\
\hline Pituitária & NIPA2 & 0,51 & 0,03 & 0,83 & $2,22 \mathrm{E}-05$ & 59,75 \\
\hline Pituitária & NLK & 0,35 & 0,15 & 0,81 & $5,12 \mathrm{E}-05$ & 42,66 \\
\hline Pituitária & NMD3 & 0,62 & 0,01 & 0,76 & $2,80 \mathrm{E}-04$ & 35,59 \\
\hline Pituitária & NOC3L & 0,44 & 0,07 & 0,92 & 4,70E-08 & 102,80 \\
\hline Pituitária & NOL11 & 0,29 & 0,24 & 0,94 & $6,16 \mathrm{E}-09$ & 117,62 \\
\hline Pituitária & NOL4 & 0,45 & 0,06 & 0,77 & $2,01 \mathrm{E}-04$ & 30,97 \\
\hline Pituitária & NPEPPS & 0,43 & 0,08 & 0,84 & $1,46 \mathrm{E}-05$ & 56,24 \\
\hline Pituitária & NR2C2AP & 0,01 & 0,98 & 0,75 & $3,38 \mathrm{E}-04$ & 31,30 \\
\hline Pituitária & NRBP1 & 0,31 & 0,21 & 0,73 & $6,61 \mathrm{E}-04$ & 29,60 \\
\hline Pituitária & NSRP1 & 0,41 & 0,09 & 0,70 & $1,13 \mathrm{E}-03$ & 20,64 \\
\hline Pituitária & NT5C 2 & 0,25 & 0,31 & 0,75 & $2,98 \mathrm{E}-04$ & 29,59 \\
\hline Pituitária & NUDCD1 & 0,33 & 0,18 & 0,75 & $3,81 \mathrm{E}-04$ & 29,92 \\
\hline Hipotálamo & NUFIP2 & 0,37 & 0,13 & 0,74 & $4,39 \mathrm{E}-04$ & 25,48 \\
\hline Pituitária & NUP133 & 0,23 & 0,35 & 0,77 & $1,76 \mathrm{E}-04$ & 31,51 \\
\hline Pituitária & NUP58 & 0,01 & 0,97 & 0,63 & $4,79 \mathrm{E}-03$ & 12,23 \\
\hline Pituitária & NUP88 & 0,33 & 0,18 & 0,83 & $1,66 \mathrm{E}-05$ & 57,92 \\
\hline Pituitária & OCIAD1 & 0,45 & 0,06 & 0,80 & $7,44 \mathrm{E}-05$ & 51,03 \\
\hline Pituitária & ODR4 & 0,49 & 0,04 & 0,78 & $1,37 \mathrm{E}-04$ & 41,59 \\
\hline Pituitária & ORC4 & 0,54 & 0,02 & 0,93 & $1,54 \mathrm{E}-08$ & 119,47 \\
\hline Pituitária & ORMDL1 & 0,50 & 0,03 & 0,83 & $1,93 \mathrm{E}-05$ & 58,95 \\
\hline Pituitária & OSBPL6 & 0,39 & 0,11 & 0,85 & $8,12 \mathrm{E}-06$ & 63,80 \\
\hline Pituitária & OSGIN2 & 0,22 & 0,38 & 0,72 & $7,57 \mathrm{E}-04$ & 25,91 \\
\hline Pituitária & OSTM1 & 0,21 & 0,39 & 0,79 & $1,12 \mathrm{E}-04$ & 44,75 \\
\hline Pituitária & OTULINL & 0,60 & 0,01 & 0,77 & $1,61 \mathrm{E}-04$ & 39,58 \\
\hline Pituitária & PA2G4 & 0,10 & 0,69 & 0,82 & $2,89 \mathrm{E}-05$ & 50,87 \\
\hline Pituitária & PACSIN2 & 0,21 & 0,40 & 0,78 & $1,50 \mathrm{E}-04$ & 39,02 \\
\hline Pituitária & PAFAH1B2 & 0,41 & 0,09 & 0,85 & $8,36 \mathrm{E}-06$ & 61,78 \\
\hline Pituitária & PAIP1 & 0,39 & 0,11 & 0,83 & $2,17 \mathrm{E}-05$ & 60,09 \\
\hline Pituitária & PANK2 & 0,39 & 0,11 & 0,72 & $7,14 \mathrm{E}-04$ & 28,47 \\
\hline Pituitária & PAPOLA & 0,37 & 0,13 & 0,85 & $6,27 \mathrm{E}-06$ & 77,78 \\
\hline Pituitária & PBDC1 & 0,27 & 0,29 & 0,77 & $1,67 \mathrm{E}-04$ & 38,33 \\
\hline Pituitária & PCNP & 0,50 & 0,03 & 0,92 & $4,33 \mathrm{E}-08$ & 115,97 \\
\hline Pituitária & PDCL & 0,48 & 0,05 & 0,86 & $3,86 \mathrm{E}-06$ & 69,73 \\
\hline Pituitária & PDHA1 & 0,32 & 0,19 & 0,91 & $1,52 \mathrm{E}-07$ & 97,09 \\
\hline Pituitária & PEX7 & 0,45 & 0,06 & 0,74 & $4,75 \mathrm{E}-04$ & 27,69 \\
\hline Pituitária & PFN2 & 0,64 & 0,00 & 0,83 & $1,83 \mathrm{E}-05$ & 64,22 \\
\hline
\end{tabular}


Tabela suplementar 5 - Genes contidos no módulo Grey60 (continuação).

\begin{tabular}{|c|c|c|c|c|c|c|}
\hline Tecido & Gene & SG CAR & Valor de P SG CAR & FM & Valor de P FM & $\mathbf{K}$ \\
\hline Pituitária & PGK1 & 0,34 & 0,17 & 0,88 & 1,19E-06 & 84,43 \\
\hline Pituitária & PGM1 & 0,54 & 0,02 & 0,70 & $1,21 \mathrm{E}-03$ & 27,05 \\
\hline Pituitária & PHAX & 0,44 & 0,07 & 0,89 & $1,01 \mathrm{E}-06$ & 79,50 \\
\hline Pituitária & PHF10 & 0,21 & 0,40 & 0,84 & $1,17 \mathrm{E}-05$ & 63,40 \\
\hline Pituitária & PHKA2 & 0,30 & 0,22 & 0,74 & $4,23 \mathrm{E}-04$ & 26,42 \\
\hline Pituitária & PHKB & 0,24 & 0,35 & 0,85 & $9,71 \mathrm{E}-06$ & 61,59 \\
\hline Pituitária & PIAS1 & 0,15 & 0,54 & 0,76 & $2,77 \mathrm{E}-04$ & 29,36 \\
\hline Pituitária & PIGC & 0,41 & 0,09 & 0,81 & $5,48 \mathrm{E}-05$ & 48,41 \\
\hline Pituitária & PIK3R4 & 0,41 & 0,09 & 0,84 & $1,41 \mathrm{E}-05$ & 56,61 \\
\hline Pituitária & PITPNB & 0,65 & 0,00 & 0,81 & $5,02 \mathrm{E}-05$ & 48,61 \\
\hline Pituitária & PKP4 & 0,33 & 0,19 & 0,79 & $9,35 \mathrm{E}-05$ & 41,08 \\
\hline Pituitária & PLAA & 0,64 & 0,00 & 0,86 & $5,74 \mathrm{E}-06$ & 65,23 \\
\hline Pituitária & PLEKHA3 & 0,30 & 0,22 & 0,88 & $1,33 \mathrm{E}-06$ & 77,82 \\
\hline Pituitária & PLEKHA4 & 0,28 & 0,26 & 0,72 & $6,96 \mathrm{E}-04$ & 22,45 \\
\hline Pituitária & PLEKHA5 & 0,24 & 0,33 & 0,61 & $6,77 \mathrm{E}-03$ & 12,57 \\
\hline Pituitária & PNN & 0,24 & 0,34 & 0,72 & $7,12 \mathrm{E}-04$ & 25,83 \\
\hline Pituitária & PNPLA8 & 0,50 & 0,04 & 0,90 & $4,36 \mathrm{E}-07$ & 90,68 \\
\hline Pituitária & PNRC2 & 0,36 & 0,14 & 0,71 & $9,34 \mathrm{E}-04$ & 28,56 \\
\hline Pituitária & POGK & 0,31 & 0,22 & 0,70 & $1,20 \mathrm{E}-03$ & 21,06 \\
\hline Pituitária & POLR1B & 0,42 & 0,08 & 0,68 & 2,09E-03 & 19,82 \\
\hline Hipotálamo & POLR1D & 0,19 & 0,44 & 0,72 & 7,34E-04 & 21,37 \\
\hline Pituitária & POLR2B & 0,58 & 0,01 & 0,93 & $3,48 \mathrm{E}-08$ & 109,08 \\
\hline Pituitária & POLR2M & 0,25 & 0,31 & 0,82 & $2,60 \mathrm{E}-05$ & 54,81 \\
\hline Pituitária & PPIL4 & 0,44 & 0,07 & 0,86 & $3,77 \mathrm{E}-06$ & 78,49 \\
\hline Pituitária & PPM1A & 0,13 & 0,62 & 0,70 & $1,16 \mathrm{E}-03$ & 19,20 \\
\hline Pituitária & PPP1CB & 0,42 & 0,08 & 0,90 & $2,54 \mathrm{E}-07$ & 106,69 \\
\hline Pituitária & PPP1CC & 0,26 & 0,29 & 0,85 & $6,54 \mathrm{E}-06$ & 71,96 \\
\hline Pituitária & PPP2R5C & 0,33 & 0,18 & 0,80 & $7,24 \mathrm{E}-05$ & 41,10 \\
\hline Pituitária & PPP3R1 & 0,36 & 0,14 & 0,86 & 4,41E-06 & 69,38 \\
\hline Pituitária & PPP4R3A & 0,39 & 0,11 & 0,95 & $1,27 \mathrm{E}-09$ & 125,96 \\
\hline Pituitária & PPP6C & 0,29 & 0,25 & 0,82 & $3,22 \mathrm{E}-05$ & 51,92 \\
\hline Pituitária & PPWD1 & 0,40 & 0,10 & 0,78 & $1,40 \mathrm{E}-04$ & 35,65 \\
\hline Pituitária & PREP & 0,24 & 0,34 & 0,72 & $6,81 \mathrm{E}-04$ & 23,97 \\
\hline Pituitária & PRMT3 & 0,32 & 0,20 & 0,84 & $1,15 \mathrm{E}-05$ & 64,37 \\
\hline Pituitária & PRMT5 & 0,27 & 0,28 & 0,72 & $8,32 \mathrm{E}-04$ & 21,87 \\
\hline Pituitária & PRNP & 0,49 & 0,04 & 0,78 & $1,48 \mathrm{E}-04$ & 44,44 \\
\hline Pituitária & PRPF18 & 0,39 & 0,11 & 0,78 & $1,37 \mathrm{E}-04$ & 37,88 \\
\hline Pituitária & PRPF38B & 0,28 & 0,27 & 0,77 & $1,87 \mathrm{E}-04$ & 40,28 \\
\hline Pituitária & PRPF39 & 0,48 & 0,04 & 0,80 & $7,42 \mathrm{E}-05$ & 41,53 \\
\hline Pituitária & PRPF40A & 0,41 & 0,09 & 0,91 & $1,28 \mathrm{E}-07$ & 99,44 \\
\hline Pituitária & PRPS1 & 0,10 & 0,70 & 0,70 & $1,35 \mathrm{E}-03$ & 22,28 \\
\hline Pituitária & PSMA1 & 0,21 & 0,41 & 0,85 & $9,71 \mathrm{E}-06$ & 63,83 \\
\hline Pituitária & PSMC2 & 0,34 & 0,16 & 0,93 & $1,88 \mathrm{E}-08$ & 108,82 \\
\hline Pituitária & PSMC6 & 0,25 & 0,31 & 0,87 & $2,54 \mathrm{E}-06$ & 77,03 \\
\hline Pituitária & PSMD1 & 0,52 & 0,03 & 0,84 & $1,21 \mathrm{E}-05$ & 59,44 \\
\hline Pituitária & PSMD12 & 0,43 & 0,07 & 0,89 & $5,43 \mathrm{E}-07$ & 96,68 \\
\hline Pituitária & PSMD14 & 0,41 & 0,09 & 0,90 & 4,49E-07 & 91,54 \\
\hline Pituitária & PSMD2 & 0,25 & 0,32 & 0,83 & $1,64 \mathrm{E}-05$ & 52,83 \\
\hline Pituitária & PSMD5 & 0,41 & 0,09 & 0,85 & $9,22 \mathrm{E}-06$ & 68,13 \\
\hline Pituitária & PSMD7 & 0,55 & 0,02 & 0,87 & $2,92 \mathrm{E}-06$ & 78,49 \\
\hline Pituitária & PSME3 & 0,16 & 0,52 & 0,86 & $4,27 \mathrm{E}-06$ & 67,28 \\
\hline Pituitária & PTCD3 & 0,33 & 0,19 & 0,70 & $1,12 \mathrm{E}-03$ & 22,78 \\
\hline Pituitária & PTGES3 & 0,52 & 0,03 & 0,80 & $5,61 \mathrm{E}-05$ & 59,12 \\
\hline Pituitária & PTGR2 & 0,41 & 0,09 & 0,81 & $3,96 \mathrm{E}-05$ & 48,28 \\
\hline Pituitária & РТP4A2 & 0,41 & 0,09 & 0,81 & $5,32 \mathrm{E}-05$ & 55,08 \\
\hline Pituitária & PTPN12 & 0,09 & 0,72 & 0,73 & $6,55 \mathrm{E}-04$ & 28,34 \\
\hline Pituitária & PTPRZ1 & 0,44 & 0,07 & 0,71 & $9,69 \mathrm{E}-04$ & 20,63 \\
\hline Pituitária & PUF60 & 0,30 & 0,23 & 0,75 & $3,48 \mathrm{E}-04$ & 30,72 \\
\hline Pituitária & PUS3 & 0,26 & 0,30 & 0,83 & $2,12 \mathrm{E}-05$ & 54,89 \\
\hline Pituitária & PWP1 & 0,62 & 0,01 & 0,82 & $2,87 \mathrm{E}-05$ & 60,73 \\
\hline Pituitária & RAB 10 & 0,42 & 0,08 & 0,96 & $4,40 \mathrm{E}-10$ & 139,32 \\
\hline Pituitária & RAB 18 & 0,43 & 0,08 & 0,84 & $1,11 \mathrm{E}-05$ & 62,24 \\
\hline Pituitária & RAB1A & 0,35 & 0,16 & 0,87 & $3,20 \mathrm{E}-06$ & 81,83 \\
\hline
\end{tabular}


Tabela suplementar 5 - Genes contidos no módulo Grey60 (continuação).

\begin{tabular}{|c|c|c|c|c|c|c|}
\hline Tecido & Gene & SG CAR & Valor de P SG CAR & FM & Valor de P FM & $\mathbf{K}$ \\
\hline Pituitária & RAB21 & 0,18 & 0,47 & 0,77 & $2,13 \mathrm{E}-04$ & 36,42 \\
\hline Pituitária & RAB23 & 0,34 & 0,17 & 0,71 & $9,26 \mathrm{E}-04$ & 21,29 \\
\hline Pituitária & RAB2A & 0,53 & 0,02 & 0,84 & $1,22 \mathrm{E}-05$ & 67,40 \\
\hline Pituitária & RAB33B & 0,40 & 0,10 & 0,82 & $3,01 \mathrm{E}-05$ & 53,22 \\
\hline Pituitária & RAB3GAP1 & 0,53 & 0,02 & 0,88 & $1,60 \mathrm{E}-06$ & 75,05 \\
\hline Pituitária & RAB3GAP2 & 0,18 & 0,47 & 0,78 & $1,20 \mathrm{E}-04$ & 38,74 \\
\hline Pituitária & RAB4A & 0,09 & 0,74 & 0,72 & $7,29 \mathrm{E}-04$ & 23,04 \\
\hline Pituitária & RAB5C & 0,33 & 0,17 & 0,75 & $3,86 \mathrm{E}-04$ & 31,30 \\
\hline Pituitária & RAB8B & 0,46 & 0,06 & 0,84 & $1,25 \mathrm{E}-05$ & 70,65 \\
\hline Pituitária & RALBP1 & 0,17 & 0,50 & 0,80 & $5,97 \mathrm{E}-05$ & 42,15 \\
\hline Pituitária & RANBP9 & 0,49 & 0,04 & 0,82 & $3,25 \mathrm{E}-05$ & 49,60 \\
\hline Pituitária & RAP1A & 0,22 & 0,39 & 0,84 & $1,60 \mathrm{E}-05$ & 55,77 \\
\hline Pituitária & RAP1B & 0,28 & 0,25 & 0,92 & $7,76 \mathrm{E}-08$ & 106,14 \\
\hline Pituitária & RARS & 0,09 & 0,73 & 0,75 & 2,99E-04 & 27,88 \\
\hline Pituitária & RASA1 & 0,55 & 0,02 & 0,78 & $1,27 \mathrm{E}-04$ & 35,49 \\
\hline Pituitária & RBBP4 & 0,34 & 0,16 & 0,92 & $5,02 \mathrm{E}-08$ & 109,55 \\
\hline Pituitária & RBBP6 & 0,12 & 0,63 & 0,60 & $8,47 \mathrm{E}-03$ & 14,14 \\
\hline Pituitária & RBBP8 & 0,20 & 0,43 & 0,82 & $3,24 \mathrm{E}-05$ & 50,57 \\
\hline Pituitária & RBM10 & 0,40 & 0,10 & 0,86 & $4,68 \mathrm{E}-06$ & 67,34 \\
\hline Pituitária & RBM12B & 0,39 & 0,11 & 0,79 & $8,17 \mathrm{E}-05$ & 41,45 \\
\hline Pituitária & RBM39 & 0,21 & 0,41 & 0,70 & $1,09 \mathrm{E}-03$ & 24,31 \\
\hline Pituitária & RBM5 & 0,26 & 0,31 & 0,67 & $2,41 \mathrm{E}-03$ & 17,58 \\
\hline Pituitária & RBM6 & 0,34 & 0,17 & 0,77 & $1,82 \mathrm{E}-04$ & 36,70 \\
\hline Pituitária & $\mathrm{RBX} 1$ & 0,15 & 0,56 & 0,64 & $3,92 \mathrm{E}-03$ & 17,38 \\
\hline Pituitária & RCHY1 & 0,56 & 0,02 & 0,87 & $2,45 \mathrm{E}-06$ & 79,54 \\
\hline Pituitária & $\mathrm{RCN} 2$ & 0,31 & 0,20 & 0,84 & $1,48 \mathrm{E}-05$ & 67,42 \\
\hline Pituitária & REEP3 & 0,26 & 0,30 & 0,86 & 4,79E-06 & 71,10 \\
\hline Pituitária & REEP5 & 0,38 & 0,12 & 0,81 & $4,95 \mathrm{E}-05$ & 56,43 \\
\hline Pituitária & RHOT1 & 0,32 & 0,20 & 0,91 & $2,27 \mathrm{E}-07$ & 91,08 \\
\hline Pituitária & RINT1 & 0,52 & 0,03 & 0,75 & $3,70 \mathrm{E}-04$ & 34,87 \\
\hline Pituitária & RLF & 0,21 & 0,40 & 0,83 & $1,94 \mathrm{E}-05$ & 54,03 \\
\hline Pituitária & RMDN3 & 0,14 & 0,58 & 0,70 & $1,13 \mathrm{E}-03$ & 21,05 \\
\hline Pituitária & RNF11 & 0,30 & 0,23 & 0,85 & $9,42 \mathrm{E}-06$ & 68,53 \\
\hline Pituitária & RNF111 & 0,51 & 0,03 & 0,82 & $3,64 \mathrm{E}-05$ & 51,42 \\
\hline Pituitária & RNF115 & 0,07 & 0,78 & 0,74 & $3,89 \mathrm{E}-04$ & 31,07 \\
\hline Pituitária & RNF121 & 0,18 & 0,49 & 0,68 & $1,98 \mathrm{E}-03$ & 19,86 \\
\hline Pituitária & RNF168 & 0,59 & 0,01 & 0,90 & $3,83 \mathrm{E}-07$ & 92,93 \\
\hline Pituitária & RNF19A & 0,36 & 0,14 & 0,66 & $2,65 \mathrm{E}-03$ & 22,80 \\
\hline Pituitária & RNF2 & 0,25 & 0,32 & 0,76 & $2,53 \mathrm{E}-04$ & 34,00 \\
\hline Pituitária & RNF34 & 0,67 & 0,00 & 0,85 & $8,18 \mathrm{E}-06$ & 59,80 \\
\hline Pituitária & RNF7 & 0,76 & 0,00 & 0,83 & $2,27 \mathrm{E}-05$ & 54,96 \\
\hline Pituitária & RNF8 & 0,49 & 0,04 & 0,88 & $1,56 \mathrm{E}-06$ & 77,61 \\
\hline Pituitária & RNFT1 & 0,47 & 0,05 & 0,88 & $1,23 \mathrm{E}-06$ & 85,34 \\
\hline Pituitária & RPAP2 & 0,47 & 0,05 & 0,74 & $4,46 \mathrm{E}-04$ & 28,85 \\
\hline Pituitária & RPAP3 & 0,58 & 0,01 & 0,83 & $1,88 \mathrm{E}-05$ & 58,69 \\
\hline Pituitária & RPF2 & 0,21 & 0,41 & 0,85 & $1,01 \mathrm{E}-05$ & 62,97 \\
\hline Pituitária & RPS6KA6 & 0,44 & 0,07 & 0,72 & $6,91 \mathrm{E}-04$ & 24,01 \\
\hline Pituitária & RRAGC & 0,33 & 0,17 & 0,82 & $2,60 \mathrm{E}-05$ & 57,13 \\
\hline Pituitária & RRAS2 & 0,23 & 0,35 & 0,67 & $2,15 \mathrm{E}-03$ & 19,31 \\
\hline Pituitária & RRP15 & 0,30 & 0,23 & 0,77 & $1,94 \mathrm{E}-04$ & 37,57 \\
\hline Pituitária & RSL24D1 & 0,57 & 0,01 & 0,89 & $7,63 \mathrm{E}-07$ & 90,57 \\
\hline Pituitária & RTCA & 0,40 & 0,10 & 0,82 & $2,79 \mathrm{E}-05$ & 52,44 \\
\hline Pituitária & RTCB & 0,34 & 0,16 & 0,87 & $3,16 \mathrm{E}-06$ & 73,90 \\
\hline Pituitária & RTF1 & 0,39 & 0,11 & 0,87 & $2,20 \mathrm{E}-06$ & 70,86 \\
\hline Pituitária & RUVBL1 & 0,53 & 0,02 & 0,76 & $2,20 \mathrm{E}-04$ & 32,06 \\
\hline Pituitária & SAMD8 & 0,18 & 0,47 & 0,79 & $1,12 \mathrm{E}-04$ & 42,52 \\
\hline Pituitária & SAP30BP & 0,35 & 0,15 & 0,68 & $1,88 \mathrm{E}-03$ & 19,37 \\
\hline Pituitária & SASS6 & 0,30 & 0,22 & 0,82 & $3,65 \mathrm{E}-05$ & 49,68 \\
\hline Hipotálamo & SAV1 & 0,21 & 0,40 & 0,76 & $2,18 \mathrm{E}-04$ & 33,67 \\
\hline Pituitária & SBDS & 0,50 & 0,04 & 0,86 & $4,87 \mathrm{E}-06$ & 80,03 \\
\hline Pituitária & SC5D & 0,41 & 0,09 & 0,85 & $8,93 \mathrm{E}-06$ & 57,44 \\
\hline Pituitária & SCLT1 & 0,49 & 0,04 & 0,73 & $5,74 \mathrm{E}-04$ & 32,44 \\
\hline Pituitária & SENP3 & 0,32 & 0,20 & 0,84 & $1,03 \mathrm{E}-05$ & 58,38 \\
\hline
\end{tabular}


Tabela suplementar 5 - Genes contidos no módulo Grey60 (continuação).

\begin{tabular}{|c|c|c|c|c|c|c|}
\hline Tecido & Gene & SG CAR & Valor de P SG CAR & FM & Valor de P FM & $\mathbf{K}$ \\
\hline Pituitária & SEPT2 & 0,39 & 0,11 & 0,87 & $2,17 \mathrm{E}-06$ & 79,51 \\
\hline Pituitária & SEPT7 & 0,56 & 0,02 & 0,95 & $1,07 \mathrm{E}-09$ & 136,43 \\
\hline Pituitária & SERINC1 & 0,37 & 0,13 & 0,96 & $2,94 \mathrm{E}-10$ & 138,15 \\
\hline Pituitária & SERINC3 & 0,20 & 0,42 & 0,71 & $1,04 \mathrm{E}-03$ & 27,64 \\
\hline Pituitária & SERTM1 & 0,12 & 0,64 & 0,74 & $4,79 \mathrm{E}-04$ & 25,65 \\
\hline Pituitária & SET & 0,36 & 0,14 & 0,87 & $2,63 \mathrm{E}-06$ & 78,53 \\
\hline Pituitária & SETD3 & 0,48 & 0,04 & 0,80 & $6,14 \mathrm{E}-05$ & 42,33 \\
\hline Pituitária & SF3B3 & 0,35 & 0,15 & 0,86 & $5,08 \mathrm{E}-06$ & 70,41 \\
\hline Pituitária & SFT2D2 & 0,36 & 0,14 & 0,75 & $3,77 \mathrm{E}-04$ & 31,25 \\
\hline Pituitária & SHOC2 & 0,45 & 0,06 & 0,94 & $7,72 \mathrm{E}-09$ & 123,79 \\
\hline Pituitária & SLAIN2 & 0,18 & 0,48 & 0,78 & $1,32 \mathrm{E}-04$ & 37,87 \\
\hline Pituitária & SLC17A5 & 0,34 & 0,16 & 0,75 & $3,04 \mathrm{E}-04$ & 29,84 \\
\hline Pituitária & SLC25A15 & 0,40 & 0,10 & 0,86 & $4,87 \mathrm{E}-06$ & 71,14 \\
\hline Pituitária & SLC25A32 & 0,49 & 0,04 & 0,76 & $2,29 \mathrm{E}-04$ & 32,94 \\
\hline Pituitária & SLC25A4 & 0,43 & 0,07 & 0,74 & $4,21 \mathrm{E}-04$ & 35,05 \\
\hline Pituitária & SLC25A44 & 0,41 & 0,09 & 0,85 & $6,70 \mathrm{E}-06$ & 61,79 \\
\hline Pituitária & SLC25A51 & 0,22 & 0,37 & 0,74 & $4,72 \mathrm{E}-04$ & 25,72 \\
\hline Pituitária & SLC30A4 & 0,29 & 0,24 & 0,77 & $1,68 \mathrm{E}-04$ & 33,55 \\
\hline Pituitária & SLC30A5 & 0,40 & 0,10 & 0,84 & $1,06 \mathrm{E}-05$ & 66,59 \\
\hline Pituitária & SLC35A5 & 0,17 & 0,50 & 0,72 & $8,06 \mathrm{E}-04$ & 23,31 \\
\hline Pituitária & SLC35F5 & 0,52 & 0,03 & 0,87 & $3,04 \mathrm{E}-06$ & 80,05 \\
\hline Pituitária & SLC37A4 & 0,27 & 0,27 & 0,72 & $7,66 \mathrm{E}-04$ & 26,78 \\
\hline Pituitária & SLC3A1 & 0,38 & 0,12 & 0,88 & $1,28 \mathrm{E}-06$ & 83,05 \\
\hline Pituitária & SLC5A6 & 0,08 & 0,75 & 0,70 & $1,13 \mathrm{E}-03$ & 26,05 \\
\hline Pituitária & SLC9A6 & 0,35 & 0,15 & 0,89 & $6,36 \mathrm{E}-07$ & 88,81 \\
\hline Pituitária & SLTM & 0,30 & 0,23 & 0,83 & $2,47 \mathrm{E}-05$ & 55,24 \\
\hline Hipotálamo & SMAD2 & 0,29 & 0,25 & 0,71 & $8,65 \mathrm{E}-04$ & 19,80 \\
\hline Pituitária & SMAD2 & 0,14 & 0,59 & 0,82 & $3,65 \mathrm{E}-05$ & 52,94 \\
\hline Pituitária & SMAD5 & 0,38 & 0,12 & 0,82 & $3,60 \mathrm{E}-05$ & 54,94 \\
\hline Pituitária & SMARCA1 & 0,30 & 0,23 & 0,77 & $1,60 \mathrm{E}-04$ & 39,28 \\
\hline Pituitária & SMARCA4 & 0,29 & 0,25 & 0,71 & $1,05 \mathrm{E}-03$ & 20,36 \\
\hline Pituitária & SMARCE1 & 0,43 & 0,08 & 0,83 & $1,75 \mathrm{E}-05$ & 54,82 \\
\hline Pituitária & SMC6 & 0,33 & 0,18 & 0,88 & $1,79 \mathrm{E}-06$ & 68,32 \\
\hline Pituitária & SMG5 & 0,13 & 0,60 & 0,67 & $2,39 \mathrm{E}-03$ & 17,35 \\
\hline Pituitária & SMU1 & 0,29 & 0,24 & 0,94 & $1,01 \mathrm{E}-08$ & 111,75 \\
\hline Pituitária & SNAP23 & 0,14 & 0,58 & 0,77 & $2,11 \mathrm{E}-04$ & 32,34 \\
\hline Pituitária & SNAP25 & 0,44 & 0,07 & 0,81 & $3,91 \mathrm{E}-05$ & 55,25 \\
\hline Pituitária & SNRNP27 & 0,18 & 0,48 & 0,68 & $1,93 \mathrm{E}-03$ & 22,20 \\
\hline Pituitária & SNW1 & 0,38 & 0,11 & 0,86 & $4,85 \mathrm{E}-06$ & 71,35 \\
\hline Pituitária & SNX10 & 0,34 & 0,17 & 0,88 & $1,97 \mathrm{E}-06$ & 77,01 \\
\hline Pituitária & SNX14 & 0,29 & 0,24 & 0,70 & $1,12 \mathrm{E}-03$ & 22,15 \\
\hline Pituitária & SNX16 & 0,28 & 0,27 & 0,83 & $1,95 \mathrm{E}-05$ & 56,73 \\
\hline Pituitária & SNX2 & 0,42 & 0,09 & 0,91 & $1,23 \mathrm{E}-07$ & 95,70 \\
\hline Pituitária & SNX4 & 0,33 & 0,18 & 0,79 & $9,29 \mathrm{E}-05$ & 46,90 \\
\hline Pituitária & SNX6 & 0,47 & 0,05 & 0,82 & $3,57 \mathrm{E}-05$ & 56,18 \\
\hline Pituitária & SOCS4 & 0,15 & 0,56 & 0,74 & $4,35 \mathrm{E}-04$ & 27,30 \\
\hline Pituitária & SOCS5 & 0,34 & 0,17 & 0,72 & $7,26 \mathrm{E}-04$ & 22,07 \\
\hline Pituitária & SPCS2 & 0,26 & 0,29 & 0,78 & $1,36 \mathrm{E}-04$ & 40,62 \\
\hline Pituitária & SPIN1 & 0,40 & 0,10 & 0,82 & $3,46 \mathrm{E}-05$ & 54,29 \\
\hline Pituitária & SPRED1 & 0,17 & 0,49 & 0,80 & $7,20 \mathrm{E}-05$ & 49,60 \\
\hline Pituitária & SPRTN & 0,05 & 0,84 & 0,72 & $7,78 \mathrm{E}-04$ & 22,02 \\
\hline Pituitária & SRP54 & 0,18 & 0,48 & 0,85 & $8,23 \mathrm{E}-06$ & 64,13 \\
\hline Pituitária & SRPK1 & 0,15 & 0,56 & 0,89 & $9,66 \mathrm{E}-07$ & 78,72 \\
\hline Pituitária & SRPRB & 0,42 & 0,08 & 0,81 & $4,22 \mathrm{E}-05$ & 54,06 \\
\hline Pituitária & SRRD & 0,32 & 0,20 & 0,80 & $7,64 \mathrm{E}-05$ & 47,66 \\
\hline Pituitária & SRSF1 & 0,48 & 0,04 & 0,90 & $3,76 \mathrm{E}-07$ & 92,04 \\
\hline Pituitária & SRSF10 & 0,29 & 0,24 & 0,89 & $6,05 \mathrm{E}-07$ & 87,68 \\
\hline Pituitária & SRSF11 & 0,09 & 0,72 & 0,78 & $1,18 \mathrm{E}-04$ & 37,65 \\
\hline Pituitária & SS18 & 0,47 & 0,05 & 0,95 & $2,88 \mathrm{E}-09$ & 123,73 \\
\hline Pituitária & SSFA2 & 0,15 & 0,54 & 0,72 & $7,56 \mathrm{E}-04$ & 32,26 \\
\hline Pituitária & ST13 & 0,18 & 0,48 & 0,71 & $9,28 \mathrm{E}-04$ & 30,77 \\
\hline Pituitária & STAG2 & 0,41 & 0,09 & 0,90 & $2,82 \mathrm{E}-07$ & 95,91 \\
\hline Pituitária & STAMBP & 0,44 & 0,07 & 0,85 & $7,97 \mathrm{E}-06$ & 65,45 \\
\hline
\end{tabular}


Tabela suplementar 5 - Genes contidos no módulo Grey60 (continuação).

\begin{tabular}{|c|c|c|c|c|c|c|}
\hline Tecido & Gene & SG CAR & Valor de P SG CAR & FM & Valor de P FM & $\mathbf{K}$ \\
\hline Pituitária & STAU1 & 0,10 & 0,69 & 0,81 & $3,99 \mathrm{E}-05$ & 49,51 \\
\hline Pituitária & STIP1 & 0,32 & 0,19 & 0,75 & $2,95 \mathrm{E}-04$ & 35,15 \\
\hline Pituitária & STK26 & 0,19 & 0,46 & 0,74 & 4,49E-04 & 28,18 \\
\hline Pituitária & STRBP & 0,07 & 0,78 & 0,74 & $4,78 \mathrm{E}-04$ & 26,51 \\
\hline Pituitária & STRIP1 & 0,24 & 0,33 & 0,83 & $2,21 \mathrm{E}-05$ & 50,64 \\
\hline Pituitária & STRN3 & 0,37 & 0,13 & 0,85 & $7,86 \mathrm{E}-06$ & 65,15 \\
\hline Pituitária & STX17 & 0,31 & 0,22 & 0,80 & $5,71 \mathrm{E}-05$ & 45,93 \\
\hline Pituitária & STX7 & 0,55 & 0,02 & 0,96 & $2,43 \mathrm{E}-10$ & 142,09 \\
\hline Pituitária & SUCLA2 & 0,34 & 0,17 & 0,90 & $4,12 \mathrm{E}-07$ & 92,40 \\
\hline Pituitária & SUCO & 0,21 & 0,41 & 0,92 & $9,93 \mathrm{E}-08$ & 100,80 \\
\hline Pituitária & SUGT1 & 0,40 & 0,10 & 0,81 & $4,30 \mathrm{E}-05$ & 56,89 \\
\hline Pituitária & SUPT16H & 0,46 & 0,06 & 0,92 & $7,35 \mathrm{E}-08$ & 100,47 \\
\hline Pituitária & SUPT20H & 0,36 & 0,14 & 0,76 & $2,48 \mathrm{E}-04$ & 32,28 \\
\hline Pituitária & SUZ12 & 0,15 & 0,56 & 0,88 & $1,22 \mathrm{E}-06$ & 78,85 \\
\hline Pituitária & SYNPR & 0,35 & 0,15 & 0,69 & $1,40 \mathrm{E}-03$ & 27,58 \\
\hline Pituitária & TAF13 & 0,46 & 0,05 & 0,78 & $1,40 \mathrm{E}-04$ & 44,71 \\
\hline Pituitária & TAF2 & 0,45 & 0,06 & 0,76 & $2,69 \mathrm{E}-04$ & 37,93 \\
\hline Pituitária & TAF9 & 0,37 & 0,13 & 0,83 & $1,72 \mathrm{E}-05$ & 57,86 \\
\hline Pituitária & TARS & 0,40 & 0,10 & 0,87 & $3,36 \mathrm{E}-06$ & 79,70 \\
\hline Pituitária & TARSL2 & 0,62 & 0,01 & 0,82 & $3,64 \mathrm{E}-05$ & 48,63 \\
\hline Pituitária & TAX1BP1 & 0,44 & 0,07 & 0,87 & $2,60 \mathrm{E}-06$ & 71,61 \\
\hline Pituitária & TBK1 & 0,58 & 0,01 & 0,81 & $4,75 \mathrm{E}-05$ & 47,03 \\
\hline Pituitária & TCEA1 & 0,35 & 0,15 & 0,90 & $2,71 \mathrm{E}-07$ & 89,24 \\
\hline Pituitária & TCERG1 & 0,43 & 0,07 & 0,76 & $2,44 \mathrm{E}-04$ & 32,34 \\
\hline Pituitária & TCF12 & 0,24 & 0,34 & 0,79 & $8,41 \mathrm{E}-05$ & 45,49 \\
\hline Pituitária & TCP1 & 0,49 & 0,04 & 0,74 & $4,04 \mathrm{E}-04$ & 32,72 \\
\hline Hipotálamo & TCTN3 & 0,40 & 0,10 & 0,74 & $4,97 \mathrm{E}-04$ & 28,01 \\
\hline Pituitária & TEFM & 0,33 & 0,18 & 0,79 & $1,07 \mathrm{E}-04$ & 48,47 \\
\hline Pituitária & TERF1 & 0,52 & 0,03 & 0,85 & $8,55 \mathrm{E}-06$ & 64,48 \\
\hline Pituitária & TERF2 & 0,19 & 0,45 & 0,76 & $2,53 \mathrm{E}-04$ & 32,49 \\
\hline Pituitária & TFAM & 0,48 & 0,04 & 0,88 & $1,56 \mathrm{E}-06$ & 79,12 \\
\hline Pituitária & TFB2M & 0,43 & 0,07 & 0,84 & $1,07 \mathrm{E}-05$ & 67,33 \\
\hline Pituitária & TFG & 0,40 & 0,10 & 0,78 & $1,30 \mathrm{E}-04$ & 44,94 \\
\hline Pituitária & THOC1 & 0,44 & 0,06 & 0,82 & $3,69 \mathrm{E}-05$ & 48,25 \\
\hline Pituitária & TIA1 & 0,11 & 0,68 & 0,69 & $1,54 \mathrm{E}-03$ & 20,48 \\
\hline Pituitária & TIMM8A & 0,34 & 0,17 & 0,83 & $2,00 \mathrm{E}-05$ & 55,92 \\
\hline Pituitária & TIPIN & 0,44 & 0,07 & 0,82 & $3,17 \mathrm{E}-05$ & 54,71 \\
\hline Pituitária & TLE1 & 0,20 & 0,43 & 0,74 & $4,26 \mathrm{E}-04$ & 32,21 \\
\hline Pituitária & TM2D1 & 0,45 & 0,06 & 0,77 & $1,70 \mathrm{E}-04$ & 34,22 \\
\hline Pituitária & TM9SF2 & 0,40 & 0,10 & 0,87 & $3,29 \mathrm{E}-06$ & 75,37 \\
\hline Pituitária & TM9SF3 & 0,53 & 0,03 & 0,87 & $3,50 \mathrm{E}-06$ & 80,59 \\
\hline Pituitária & TMBIM4 & 0,48 & 0,04 & 0,89 & $8,03 \mathrm{E}-07$ & 90,93 \\
\hline Pituitária & TMED5 & 0,15 & 0,56 & 0,90 & $3,65 \mathrm{E}-07$ & 87,61 \\
\hline Pituitária & TMED7 & 0,33 & 0,18 & 0,91 & $2,11 \mathrm{E}-07$ & 96,04 \\
\hline Pituitária & TMEM183A & 0,33 & 0,18 & 0,81 & $4,63 \mathrm{E}-05$ & 50,12 \\
\hline Pituitária & TMEM184C & 0,38 & 0,12 & 0,85 & $6,99 \mathrm{E}-06$ & 73,79 \\
\hline Pituitária & TMEM259 & 0,37 & 0,13 & 0,76 & $2,37 \mathrm{E}-04$ & 31,26 \\
\hline Pituitária & TMEM263 & 0,54 & 0,02 & 0,82 & $3,23 \mathrm{E}-05$ & 57,42 \\
\hline Pituitária & TMEM30B & 0,38 & 0,12 & 0,88 & $1,63 \mathrm{E}-06$ & 78,34 \\
\hline Pituitária & TMEM33 & 0,30 & 0,22 & 0,80 & $5,87 \mathrm{E}-05$ & 50,83 \\
\hline Pituitária & TMEM43 & 0,29 & 0,24 & 0,76 & $2,48 \mathrm{E}-04$ & 29,80 \\
\hline Pituitária & TMEM50B & 0,49 & 0,04 & 0,89 & $8,14 \mathrm{E}-07$ & 91,69 \\
\hline Pituitária & TMEM87A & 0,40 & 0,10 & 0,68 & $1,83 \mathrm{E}-03$ & 21,22 \\
\hline Pituitária & TMX1 & 0,41 & 0,09 & 0,79 & $9,53 \mathrm{E}-05$ & 44,79 \\
\hline Pituitária & TNK2 & 0,21 & 0,40 & 0,68 & $2,01 \mathrm{E}-03$ & 20,95 \\
\hline Pituitária & TOMM70 & 0,46 & 0,05 & 0,89 & $7,34 \mathrm{E}-07$ & 89,42 \\
\hline Pituitária & TOP2B & 0,44 & 0,07 & 0,91 & $1,31 \mathrm{E}-07$ & 102,60 \\
\hline Pituitária & TOPBP1 & 0,28 & 0,26 & 0,77 & $1,70 \mathrm{E}-04$ & 37,09 \\
\hline Pituitária & TOPORS & 0,16 & 0,52 & 0,65 & $3,46 \mathrm{E}-03$ & 18,62 \\
\hline Pituitária & TPD52 & 0,64 & 0,00 & 0,81 & $4,41 \mathrm{E}-05$ & 49,74 \\
\hline Pituitária & TPR & 0,41 & 0,09 & 0,85 & $8,60 \mathrm{E}-06$ & 60,55 \\
\hline Pituitária & TRAM1 & 0,49 & 0,04 & 0,91 & $1,08 \mathrm{E}-07$ & 111,77 \\
\hline Pituitária & TRAPPC2 & 0,49 & 0,04 & 0,87 & $2,41 \mathrm{E}-06$ & 70,72 \\
\hline
\end{tabular}


Tabela suplementar 5 - Genes contidos no módulo Grey60 (continuação).

\begin{tabular}{|c|c|c|c|c|c|c|}
\hline Tecido & Gene & SG CAR & Valor de P SG CAR & FM & Valor de P FM & $\mathbf{K}$ \\
\hline Pituitária & TRIM2 & 0,22 & 0,38 & 0,69 & $1,71 \mathrm{E}-03$ & 22,31 \\
\hline Pituitária & TRIM52 & 0,38 & 0,12 & 0,81 & $4,47 \mathrm{E}-05$ & 52,44 \\
\hline Pituitária & TRIP4 & 0,29 & 0,25 & 0,78 & $1,24 \mathrm{E}-04$ & 38,14 \\
\hline Pituitária & TRMT1L & 0,22 & 0,39 & 0,72 & $7,47 \mathrm{E}-04$ & 28,60 \\
\hline Pituitária & TRMT5 & 0,40 & 0,10 & 0,90 & $3,19 \mathrm{E}-07$ & 95,04 \\
\hline Pituitária & TRMT6 & 0,48 & 0,04 & 0,81 & $4,11 \mathrm{E}-05$ & 60,80 \\
\hline Pituitária & TRNT1 & 0,56 & 0,02 & 0,85 & $6,36 \mathrm{E}-06$ & 72,42 \\
\hline Pituitária & TSG101 & 0,14 & 0,59 & 0,74 & $4,65 \mathrm{E}-04$ & 29,15 \\
\hline Pituitária & TSNAX & 0,38 & 0,12 & 0,78 & $1,51 \mathrm{E}-04$ & 40,37 \\
\hline Pituitária & TSPAN13 & 0,51 & 0,03 & 0,79 & $9,11 \mathrm{E}-05$ & 53,03 \\
\hline Pituitária & TSPAN3 & 0,09 & 0,73 & 0,76 & $2,73 \mathrm{E}-04$ & 33,63 \\
\hline Pituitária & TTC3 & 0,36 & 0,15 & 0,80 & $7,71 \mathrm{E}-05$ & 42,90 \\
\hline Pituitária & ТTC9C & 0,47 & 0,05 & 0,78 & 1,49E-04 & 39,32 \\
\hline Pituitária & TWF1 & 0,38 & 0,12 & 0,82 & $3,66 \mathrm{E}-05$ & 55,07 \\
\hline Pituitária & TWSG1 & 0,30 & 0,23 & 0,85 & $9,58 \mathrm{E}-06$ & 64,79 \\
\hline Pituitária & UBA2 & 0,48 & 0,04 & 0,91 & $1,09 \mathrm{E}-07$ & 104,39 \\
\hline Pituitária & UBA3 & 0,34 & 0,16 & 0,76 & $2,82 \mathrm{E}-04$ & 34,10 \\
\hline Pituitária & UBA5 & 0,39 & 0,11 & 0,89 & $8,75 \mathrm{E}-07$ & 88,31 \\
\hline Pituitária & UBAP1 & 0,40 & 0,10 & 0,75 & $3,22 \mathrm{E}-04$ & 28,97 \\
\hline Pituitária & UBAP2 & 0,16 & 0,52 & 0,72 & $7,62 \mathrm{E}-04$ & 27,01 \\
\hline Pituitária & UBE2D1 & 0,49 & 0,04 & 0,79 & $9,24 \mathrm{E}-05$ & 48,91 \\
\hline Pituitária & UBE2G1 & 0,35 & 0,16 & 0,86 & $4,77 \mathrm{E}-06$ & 71,32 \\
\hline Pituitária & UBE2Q2 & 0,17 & 0,51 & 0,78 & $1,56 \mathrm{E}-04$ & 38,81 \\
\hline Pituitária & UBE2W & 0,37 & 0,13 & 0,92 & $8,97 \mathrm{E}-08$ & 111,54 \\
\hline Pituitária & UBE3A & 0,50 & 0,04 & 0,92 & $5,16 \mathrm{E}-08$ & 110,26 \\
\hline Pituitária & UBL3 & 0,31 & 0,21 & 0,83 & $1,93 \mathrm{E}-05$ & 59,53 \\
\hline Pituitária & UBP1 & 0,08 & 0,75 & 0,75 & $3,24 \mathrm{E}-04$ & 29,37 \\
\hline Pituitária & UBXN2A & 0,33 & 0,18 & 0,74 & $4,77 \mathrm{E}-04$ & 25,69 \\
\hline Pituitária & UHRF1BP1L & 0,40 & 0,10 & 0,86 & $3,85 \mathrm{E}-06$ & 77,01 \\
\hline Pituitária & URI1 & 0,52 & 0,03 & 0,87 & $2,72 \mathrm{E}-06$ & 70,40 \\
\hline Pituitária & URM1 & 0,23 & 0,35 & 0,69 & $1,39 \mathrm{E}-03$ & 23,43 \\
\hline Pituitária & USP1 & 0,55 & 0,02 & 0,82 & $3,12 \mathrm{E}-05$ & 56,68 \\
\hline Pituitária & USP10 & 0,45 & 0,06 & 0,91 & $1,08 \mathrm{E}-07$ & 100,79 \\
\hline Pituitária & USP15 & 0,40 & 0,10 & 0,95 & $2,65 \mathrm{E}-09$ & 124,77 \\
\hline Pituitária & USP16 & 0,35 & 0,15 & 0,81 & $4,23 \mathrm{E}-05$ & 54,56 \\
\hline Pituitária & USP25 & 0,42 & 0,08 & 0,82 & $2,91 \mathrm{E}-05$ & 51,80 \\
\hline Pituitária & USP4 & 0,48 & 0,04 & 0,69 & $1,62 \mathrm{E}-03$ & 21,26 \\
\hline Pituitária & UTP15 & 0,69 & 0,00 & 0,90 & $3,37 \mathrm{E}-07$ & 93,27 \\
\hline Pituitária & UTP25 & 0,34 & 0,16 & 0,83 & $1,93 \mathrm{E}-05$ & 56,81 \\
\hline Pituitária & UTP3 & 0,62 & 0,01 & 0,80 & $7,93 \mathrm{E}-05$ & 48,10 \\
\hline Pituitária & UTP6 & 0,34 & 0,17 & 0,80 & $7,07 \mathrm{E}-05$ & 41,60 \\
\hline Pituitária & VMA21 & 0,57 & 0,01 & 0,86 & $3,96 \mathrm{E}-06$ & 80,45 \\
\hline Pituitária & VPS26B & 0,43 & 0,08 & 0,75 & $3,67 \mathrm{E}-04$ & 31,34 \\
\hline Pituitária & VPS35 & 0,54 & 0,02 & 0,91 & $1,22 \mathrm{E}-07$ & 98,75 \\
\hline Pituitária & VPS36 & 0,39 & 0,11 & 0,71 & $9,83 \mathrm{E}-04$ & 22,27 \\
\hline Pituitária & VPS37A & 0,39 & 0,11 & 0,83 & $2,28 \mathrm{E}-05$ & 52,11 \\
\hline Pituitária & VPS4B & 0,51 & 0,03 & 0,89 & $8,32 \mathrm{E}-07$ & 84,91 \\
\hline Pituitária & VPS54 & 0,34 & 0,16 & 0,81 & $4,40 \mathrm{E}-05$ & 50,21 \\
\hline Pituitária & VTA1 & 0,47 & 0,05 & 0,81 & $3,98 \mathrm{E}-05$ & 50,21 \\
\hline Pituitária & WASL & 0,32 & 0,19 & 0,92 & $8,34 \mathrm{E}-08$ & 103,76 \\
\hline Pituitária & WBP11 & 0,25 & 0,31 & 0,76 & $2,35 \mathrm{E}-04$ & 32,15 \\
\hline Pituitária & WDR43 & 0,38 & 0,12 & 0,91 & $2,00 \mathrm{E}-07$ & 99,64 \\
\hline Pituitária & WDR61 & 0,12 & 0,65 & 0,71 & $9,57 \mathrm{E}-04$ & 24,92 \\
\hline Pituitária & WDR75 & 0,36 & 0,14 & 0,84 & 1,08E-05 & 59,98 \\
\hline Pituitária & WDR82 & 0,51 & 0,03 & 0,78 & $1,46 \mathrm{E}-04$ & 36,33 \\
\hline Hipotálamo & WTAP & 0,14 & 0,59 & 0,74 & $4,13 \mathrm{E}-04$ & 27,79 \\
\hline Pituitária & XPOT & 0,27 & 0,28 & 0,80 & $6,91 \mathrm{E}-05$ & 45,32 \\
\hline Pituitária & XRN2 & 0,44 & 0,06 & 0,84 & $1,48 \mathrm{E}-05$ & 57,27 \\
\hline Pituitária & YIPF4 & 0,59 & 0,01 & 0,90 & $4,76 \mathrm{E}-07$ & 91,90 \\
\hline Pituitária & YIPF5 & 0,51 & 0,03 & 0,81 & $4,37 \mathrm{E}-05$ & 53,31 \\
\hline Pituitária & YIPF6 & 0,47 & 0,05 & 0,78 & $1,26 \mathrm{E}-04$ & 40,37 \\
\hline Pituitária & YME1L1 & 0,43 & 0,07 & 0,81 & $4,35 \mathrm{E}-05$ & 54,71 \\
\hline Pituitária & YTHDF1 & 0,43 & 0,07 & 0,68 & $1,84 \mathrm{E}-03$ & 18,84 \\
\hline
\end{tabular}


Tabela suplementar 5 - Genes contidos no módulo Grey60 (continuação).

\begin{tabular}{llccccc}
\hline Tecido & Gene & SG CAR & Valor de P SG CAR & FM & Valor de P FM & K \\
\hline Pituitária & YTHDF3 & 0,40 & 0,10 & 0,86 & $5,33 \mathrm{E}-06$ & 71,45 \\
Pituitária & YWHAB & 0,45 & 0,06 & 0,79 & $1,09 \mathrm{E}-04$ & 45,79 \\
Pituitária & YY1 & 0,44 & 0,07 & 0,80 & $5,79 \mathrm{E}-05$ & 46,34 \\
Pituitária & ZC3H14 & 0,49 & 0,04 & 0,77 & $2,04 \mathrm{E}-04$ & 38,02 \\
Pituitária & ZDHHC23 & 0,24 & 0,33 & 0,67 & $2,31 \mathrm{E}-03$ & 17,07 \\
Pituitária & ZFC3H1 & 0,14 & 0,57 & 0,64 & $4,31 \mathrm{E}-03$ & 14,69 \\
Pituitária & ZMYM1 & 0,50 & 0,04 & 0,86 & $4,31 \mathrm{E}-06$ & 72,86 \\
Pituitária & ZMYM2 & 0,45 & 0,06 & 0,80 & $7,69 \mathrm{E}-05$ & 43,75 \\
Pituitária & ZMYM5 & 0,46 & 0,06 & 0,82 & $3,42 \mathrm{E}-05$ & 55,53 \\
Pituitária & ZMYND11 & 0,35 & 0,15 & 0,91 & $2,35 \mathrm{E}-07$ & 94,62 \\
Pituitária & ZNF112 & 0,22 & 0,37 & 0,85 & $8,03 \mathrm{E}-06$ & 60,81 \\
Pituitária & ZNF131 & 0,50 & 0,04 & 0,86 & $5,59 \mathrm{E}-06$ & 63,19 \\
Pituitária & ZNF184 & 0,51 & 0,03 & 0,82 & $3,19 \mathrm{E}-05$ & 46,58 \\
Pituitária & ZNF207 & 0,17 & 0,49 & 0,75 & $3,66 \mathrm{E}-04$ & 32,00 \\
Pituitária & ZNF280D & 0,55 & 0,02 & 0,80 & $6,34 \mathrm{E}-05$ & 49,87 \\
Pituitária & ZNF292 & 0,24 & 0,34 & 0,74 & $4,24 \mathrm{E}-04$ & 27,34 \\
Pituitária & ZNF329 & 0,31 & 0,20 & 0,80 & $6,43 \mathrm{E}-05$ & 45,49 \\
Pituitária & ZNF354B & 0,34 & 0,16 & 0,84 & $1,46 \mathrm{E}-05$ & 60,67 \\
Pituitária & ZNF45 & 0,29 & 0,71 & $1,03 \mathrm{E}-03$ & 24,31 \\
Pituitária & ZNF583 & 0,26 & 0,02 & 0,79 & $9,94 \mathrm{E}-05$ & 42,45 \\
Pituitária & ZNF638 & 0,53 & 0,39 & $1,71 \mathrm{E}-08$ & 113,38 \\
Pituitária & ZNF644 & 0,39 & 0,11 & 0,93 & $4,24 \mathrm{E}-08$ & 108,27 \\
Pituitária & ZNF711 & 0,40 & 0,10 & 0,92 & 25,63 \\
Pituitária & ZNF770 & 0,43 & 0,08 & 0,73 & $5,94 \mathrm{E}-04$ & 21,83 \\
Pituitária & ZNF800 & 0,31 & 0,21 & 0,70 & $1,31 \mathrm{E}-03$ & 16,98 \\
Pituitária & ZNHIT6 & 0,15 & 0,54 & 0,66 & $2,91 \mathrm{E}-03$ & 22,35 \\
Pituitária & ZRANB1 & 0,37 & 0,13 & 0,70 & $1,34 \mathrm{E}-03$ & 43,01 \\
Pituitária & ZSCAN25 & 0,36 & 0,15 & 0,81 & $4,75 \mathrm{E}-05$ & 22,04 \\
\hline SG - signis & 0,45 & 0,06 & 0,71 & $8,77 \mathrm{E}-04$ &
\end{tabular}

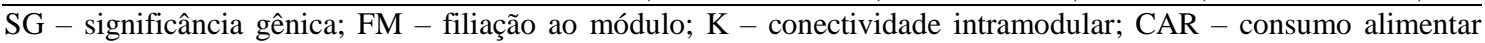
residual 
Tabela suplementar 6 - Genes contidos no módulo Skyblue3.

\begin{tabular}{|c|c|c|c|c|c|c|}
\hline Tecido & Gene & SG CA & Valor de P SG CA & FM & Valor de P FM & $\mathbf{K}$ \\
\hline Hipotálamo & ABL2 & 0,46 & 0,0524 & 0,97 & $3,49 \mathrm{E}-11$ & 72,42 \\
\hline Hipotálamo & ACTN2 & 0,58 & 0,0118 & 0,97 & $5,25 \mathrm{E}-11$ & 73,46 \\
\hline Hipotálamo & ADCY3 & 0,47 & 0,0493 & 0,95 & $1,51 \mathrm{E}-09$ & 63,79 \\
\hline Hipotálamo & ADCY5 & 0,52 & 0,0274 & 0,99 & $3,99 \mathrm{E}-14$ & 86,40 \\
\hline Hipotálamo & ADGRB1 & 0,49 & 0,0402 & 0,86 & $3,89 \mathrm{E}-06$ & 31,92 \\
\hline Hipotálamo & ADORA2A & 0,52 & 0,0262 & 0,96 & $3,92 \mathrm{E}-10$ & 74,55 \\
\hline Hipotálamo & ADRB1 & 0,56 & 0,0165 & 0,93 & $1,84 \mathrm{E}-08$ & 58,29 \\
\hline Hipotálamo & AJM1 & 0,49 & 0,0401 & 0,90 & $4,27 \mathrm{E}-07$ & 43,35 \\
\hline Hipotálamo & AKAP5 & 0,54 & 0,0207 & 0,96 & $1,33 \mathrm{E}-10$ & 72,56 \\
\hline Hipotálamo & ANKRD63 & 0,52 & 0,0267 & 0,97 & $2,42 \mathrm{E}-11$ & 79,92 \\
\hline Hipotálamo & ANO3 & 0,53 & 0,0243 & 0,98 & $7,39 \mathrm{E}-13$ & 84,13 \\
\hline Hipotálamo & AP1S1 & 0,44 & 0,0665 & 0,88 & $1,95 \mathrm{E}-06$ & 37,62 \\
\hline Hipotálamo & ARL4D & 0,53 & 0,0224 & 0,98 & $2,18 \mathrm{E}-12$ & 82,66 \\
\hline Hipotálamo & ARPP19 & 0,51 & 0,0308 & 0,99 & $2,46 \mathrm{E}-14$ & 85,88 \\
\hline Hipotálamo & ARPP21 & 0,53 & 0,0225 & 0,98 & $2,47 \mathrm{E}-12$ & 82,63 \\
\hline Hipotálamo & ASPHD2 & 0,47 & 0,0509 & 0,91 & $1,61 \mathrm{E}-07$ & 48,58 \\
\hline Hipotálamo & AZIN2 & 0,46 & 0,0569 & 0,84 & $1,36 \mathrm{E}-05$ & 26,83 \\
\hline Hipotálamo & BAIAP2L2 & 0,50 & 0,0339 & 0,96 & $3,96 \mathrm{E}-10$ & 73,19 \\
\hline Hipotálamo & BCL11B & 0,51 & 0,0325 & 0,94 & $7,29 \mathrm{E}-09$ & 60,32 \\
\hline Hipotálamo & $\mathrm{BCR}$ & 0,52 & 0,0258 & 0,96 & $1,18 \mathrm{E}-10$ & 70,05 \\
\hline Hipotálamo & CACNB3 & 0,50 & 0,0331 & 0,94 & $5,62 \mathrm{E}-09$ & 59,15 \\
\hline Hipotálamo & CALB1 & 0,51 & 0,0316 & 0,96 & $2,19 \mathrm{E}-10$ & 75,62 \\
\hline Hipotálamo & CALCA & 0,56 & 0,0147 & 0,97 & $2,20 \mathrm{E}-11$ & 78,73 \\
\hline Hipotálamo & CAMKK2 & 0,48 & 0,0452 & 0,97 & $7,23 \mathrm{E}-12$ & 75,48 \\
\hline Hipotálamo & CCDC126 & 0,59 & 0,0106 & 0,97 & $6,60 \mathrm{E}-11$ & 70,94 \\
\hline Hipotálamo & CCDC88C & 0,48 & 0,0415 & 0,93 & $1,62 \mathrm{E}-08$ & 62,22 \\
\hline Hipotálamo & CDHR1 & 0,53 & 0,0252 & 0,96 & $1,82 \mathrm{E}-10$ & 76,19 \\
\hline Hipotálamo & CDKL1 & 0,37 & 0,1270 & 0,88 & $1,44 \mathrm{E}-06$ & 36,47 \\
\hline Hipotálamo & CENPO & 0,57 & 0,0145 & 0,90 & $2,51 \mathrm{E}-07$ & 44,94 \\
\hline Hipotálamo & CEP126 & 0,56 & 0,0156 & 0,95 & $9,63 \mathrm{E}-10$ & 63,91 \\
\hline Pituitária & CHIC1 & 0,48 & 0,0430 & 0,91 & $1,53 \mathrm{E}-07$ & 47,09 \\
\hline Hipotálamo & CHRM4 & 0,53 & 0,0248 & 0,98 & $1,27 \mathrm{E}-12$ & 82,69 \\
\hline Hipotálamo & CHSY3 & 0,55 & 0,0173 & 0,96 & $2,92 \mathrm{E}-10$ & 69,00 \\
\hline Hipotálamo & CNGB1 & 0,51 & 0,0304 & 0,98 & $1,50 \mathrm{E}-12$ & 82,56 \\
\hline Hipotálamo & $\mathrm{COCH}$ & 0,58 & 0,0111 & 0,97 & $7,39 \mathrm{E}-12$ & 77,98 \\
\hline Hipotálamo & COL8A2 & 0,53 & 0,0228 & 0,96 & $1,59 \mathrm{E}-10$ & 76,38 \\
\hline Hipotálamo & CPNE5 & 0,53 & 0,0249 & 0,98 & $3,79 \mathrm{E}-12$ & 82,40 \\
\hline Hipotálamo & DACT2 & 0,52 & 0,0256 & 0,92 & $5,76 \mathrm{E}-08$ & 53,23 \\
\hline Hipotálamo & DGAT2 & 0,49 & 0,0395 & 0,96 & $7,27 \mathrm{E}-10$ & 66,42 \\
\hline Hipotálamo & DGKB & 0,58 & 0,0112 & 0,98 & $2,35 \mathrm{E}-13$ & 80,58 \\
\hline Hipotálamo & DLX6 & 0,46 & 0,0543 & 0,96 & $1,26 \mathrm{E}-10$ & 72,32 \\
\hline Hipotálamo & DOC2B & 0,55 & 0,0192 & 0,98 & $6,39 \mathrm{E}-12$ & 75,97 \\
\hline Hipotálamo & DRD1 & 0,51 & 0,0324 & 0,97 & $3,07 \mathrm{E}-11$ & 77,25 \\
\hline Hipotálamo & DRD3 & 0,51 & 0,0309 & 0,96 & $1,90 \mathrm{E}-10$ & 74,75 \\
\hline Hipotálamo & DZIP1 & 0,55 & 0,0189 & 0,80 & $5,96 \mathrm{E}-05$ & 21,04 \\
\hline Hipotálamo & EGR4 & 0,48 & 0,0450 & 0,91 & $1,35 \mathrm{E}-07$ & 47,17 \\
\hline Pituitária & ENSBTAG00000001219 & 0,51 & 0,0304 & 0,94 & $3,63 \mathrm{E}-09$ & 64,51 \\
\hline Hipotálamo & ENSBTAG00000006110 & 0,54 & 0,0194 & 0,98 & $1,86 \mathrm{E}-12$ & 80,35 \\
\hline Hipotálamo & ENSBTAG00000019887 & 0,53 & 0,0251 & 0,90 & $5,10 \mathrm{E}-07$ & 40,13 \\
\hline Hipotálamo & ENSBTAG00000020205 & 0,51 & 0,0305 & 0,93 & $2,49 \mathrm{E}-08$ & 55,41 \\
\hline Hipotálamo & ENSBTAG00000021729 & 0,43 & 0,0713 & 0,95 & 3,33E-09 & 60,05 \\
\hline Hipotálamo & ENSBTAG00000038985 & 0,43 & 0,0722 & 0,91 & $1,69 \mathrm{E}-07$ & 47,79 \\
\hline Hipotálamo & ENSBTAG00000045994 & 0,49 & 0,0384 & 0,96 & $4,01 \mathrm{E}-10$ & 74,27 \\
\hline Hipotálamo & ENSBTAG00000046733 & 0,50 & 0,0329 & 0,97 & $5,07 \mathrm{E}-11$ & 78,33 \\
\hline Hipotálamo & ЕРНB6 & 0,50 & 0,0327 & 0,98 & $6,90 \mathrm{E}-12$ & 78,08 \\
\hline Hipotálamo & FAM189A1 & 0,50 & 0,0336 & 0,98 & $6,52 \mathrm{E}-12$ & 75,23 \\
\hline Hipotálamo & FBXL16 & 0,50 & 0,0353 & 0,98 & $3,65 \mathrm{E}-13$ & 79,30 \\
\hline Hipotálamo & FBXO15 & 0,53 & 0,0247 & 0,90 & $3,96 \mathrm{E}-07$ & 40,79 \\
\hline Hipotálamo & GABRD & 0,50 & 0,0349 & 0,95 & $1,66 \mathrm{E}-09$ & 62,33 \\
\hline Hipotálamo & GALNT13 & 0,51 & 0,0288 & 0,93 & $2,32 \mathrm{E}-08$ & 54,04 \\
\hline Hipotálamo & GAS2L1 & 0,48 & 0,0443 & 0,92 & $7,92 \mathrm{E}-08$ & 47,67 \\
\hline Hipotálamo & GNAL & 0,53 & 0,0233 & 0,98 & $2,41 \mathrm{E}-12$ & 83,22 \\
\hline Hipotálamo & GNG7 & 0,51 & 0,0305 & 0,96 & $2,98 \mathrm{E}-10$ & 74,69 \\
\hline
\end{tabular}


Tabela suplementar 6 - Genes contidos no módulo Skyblue3 (continuação).

\begin{tabular}{|c|c|c|c|c|c|c|}
\hline Tecido & Gene & SG CA & Valor de P SG CA & FM & Valor de P FM & $\mathbf{K}$ \\
\hline Hipotálamo & GP1BB & 0,49 & 0,0400 & 0,80 & $6,30 \mathrm{E}-05$ & 18,84 \\
\hline Hipotálamo & GPR21 & 0,47 & 0,0491 & 0,95 & $2,09 \mathrm{E}-09$ & 61,95 \\
\hline Hipotálamo & GPR52 & 0,56 & 0,0166 & 0,96 & $4,33 \mathrm{E}-10$ & 72,16 \\
\hline Hipotálamo & GPR6 & 0,50 & 0,0327 & 0,97 & $3,13 \mathrm{E}-11$ & 78,78 \\
\hline Hipotálamo & GPR63 & 0,40 & 0,1022 & 0,89 & $6,07 \mathrm{E}-07$ & 42,42 \\
\hline Hipotálamo & GPR88 & 0,52 & 0,0259 & 0,96 & $3,33 \mathrm{E}-10$ & 74,88 \\
\hline Hipotálamo & GPRIN3 & 0,49 & 0,0382 & 0,97 & $1,72 \mathrm{E}-11$ & 76,98 \\
\hline Hipotálamo & GUCD1 & 0,53 & 0,0240 & 0,81 & $4,29 \mathrm{E}-05$ & 18,82 \\
\hline Hipotálamo & GUCY1A1 & 0,58 & 0,0119 & 0,96 & $4,40 \mathrm{E}-10$ & 70,32 \\
\hline Hipotálamo & $\mathrm{H} 2 \mathrm{AFZ}$ & 0,52 & 0,0276 & 0,89 & $8,39 \mathrm{E}-07$ & 41,34 \\
\hline Adrenal & HDDC2 & 0,40 & 0,0961 & 0,69 & $1,48 \mathrm{E}-03$ & 64,15 \\
\hline Hipotálamo & HEY1 & 0,41 & 0,0925 & 0,93 & $2,20 \mathrm{E}-08$ & 51,69 \\
\hline Hipotálamo & HIRA & 0,44 & 0,0685 & 0,86 & $5,63 \mathrm{E}-06$ & 28,65 \\
\hline Hipotálamo & HRH2 & 0,47 & 0,0517 & 0,94 & $6,71 \mathrm{E}-09$ & 57,24 \\
\hline Hipotálamo & HTR5A & 0,60 & 0,0085 & 0,96 & $1,04 \mathrm{E}-10$ & 70,54 \\
\hline Hipotálamo & ISLR2 & 0,54 & 0,0215 & 0,99 & $3,48 \mathrm{E}-14$ & 84,36 \\
\hline Hipotálamo & ITPKA & 0,49 & 0,0412 & 0,96 & $3,26 \mathrm{E}-10$ & 68,04 \\
\hline Hipotálamo & KCNAB 1 & 0,46 & 0,0530 & 0,96 & $7,09 \mathrm{E}-10$ & 64,63 \\
\hline Hipotálamo & KCNG1 & 0,51 & 0,0317 & 0,96 & $7,33 \mathrm{E}-10$ & 70,03 \\
\hline Hipotálamo & KCNK2 & 0,49 & 0,0381 & 0,98 & $2,73 \mathrm{E}-13$ & 81,37 \\
\hline Hipotálamo & KCNQ5 & 0,58 & 0,0109 & 0,98 & $8,84 \mathrm{E}-13$ & 77,82 \\
\hline Hipotálamo & KCNT1 & 0,42 & 0,0832 & 0,92 & $7,74 \mathrm{E}-08$ & 50,82 \\
\hline Hipotálamo & KCTD1 & 0,48 & 0,0414 & 0,93 & $2,30 \mathrm{E}-08$ & 54,74 \\
\hline Hipotálamo & KIF17 & 0,48 & 0,0447 & 0,92 & $5,19 \mathrm{E}-08$ & 50,91 \\
\hline Hipotálamo & KLHL2 & 0,47 & 0,0510 & 0,93 & $1,43 \mathrm{E}-08$ & 55,94 \\
\hline Hipotálamo & LDHA & 0,55 & 0,0173 & 0,97 & $8,10 \mathrm{E}-11$ & 73,64 \\
\hline Hipotálamo & LINGO3 & 0,55 & 0,0191 & 0,93 & $1,97 \mathrm{E}-08$ & 56,83 \\
\hline Hipotálamo & LPCAT1 & 0,48 & 0,0456 & 0,88 & $1,34 \mathrm{E}-06$ & 35,63 \\
\hline Hipotálamo & LPL & 0,48 & 0,0445 & 0,98 & $2,43 \mathrm{E}-12$ & 80,33 \\
\hline Hipotálamo & LRRC56 & 0,50 & 0,0326 & 0,89 & $6,27 \mathrm{E}-07$ & 38,51 \\
\hline Hipotálamo & LRRTM3 & 0,50 & 0,0330 & 0,91 & $1,58 \mathrm{E}-07$ & 46,80 \\
\hline Hipotálamo & LZTS1 & 0,52 & 0,0257 & 0,98 & $6,77 \mathrm{E}-12$ & 78,37 \\
\hline Hipotálamo & MAN1A1 & 0,58 & 0,0125 & 0,93 & $3,82 \mathrm{E}-08$ & 54,30 \\
\hline Hipotálamo & MCHR1 & 0,50 & 0,0359 & 0,92 & $5,19 \mathrm{E}-08$ & 51,23 \\
\hline Pituitária & MDH1B & 0,42 & 0,0799 & 0,77 & $1,76 \mathrm{E}-04$ & 14,43 \\
\hline Pituitária & MFHAS1 & 0,25 & 0,3249 & 0,88 & $1,61 \mathrm{E}-06$ & 34,24 \\
\hline Hipotálamo & MPPE1 & 0,57 & 0,0133 & 0,92 & $4,10 \mathrm{E}-08$ & 50,10 \\
\hline Hipotálamo & MPPED2 & 0,52 & 0,0254 & 0,90 & $5,23 \mathrm{E}-07$ & 39,34 \\
\hline Hipotálamo & MPRIP & 0,40 & 0,0974 & 0,89 & $8,33 \mathrm{E}-07$ & 40,82 \\
\hline Hipotálamo & NEURL1 & 0,55 & 0,0177 & 0,95 & $3,14 \mathrm{E}-09$ & 61,64 \\
\hline Hipotálamo & NGEF & 0,54 & 0,0203 & 0,99 & $3,73 \mathrm{E}-14$ & 86,64 \\
\hline Hipotálamo & PDE10A & 0,52 & 0,0256 & 0,97 & $2,99 \mathrm{E}-11$ & 79,53 \\
\hline Hipotálamo & PDE1B & 0,52 & 0,0282 & 0,97 & $1,82 \mathrm{E}-11$ & 75,88 \\
\hline Hipotálamo & PDE7B & 0,53 & 0,0248 & 0,96 & $1,12 \mathrm{E}-10$ & 72,38 \\
\hline Hipotálamo & PDZD2 & 0,38 & 0,1247 & 0,90 & $3,86 \mathrm{E}-07$ & 44,27 \\
\hline Hipotálamo & PHACTR1 & 0,53 & 0,0223 & 0,95 & $1,17 \mathrm{E}-09$ & 68,51 \\
\hline Hipotálamo & PRKCB & 0,48 & 0,0449 & 0,96 & $6,24 \mathrm{E}-10$ & 65,18 \\
\hline Hipotálamo & PRKCZ & 0,44 & 0,0682 & 0,90 & $3,70 \mathrm{E}-07$ & 43,86 \\
\hline Hipotálamo & PRSS53 & 0,42 & 0,0837 & 0,84 & $1,27 \mathrm{E}-05$ & 32,18 \\
\hline Hipotálamo & PTPN5 & 0,60 & 0,0084 & 0,95 & $8,01 \mathrm{E}-10$ & 64,84 \\
\hline Hipotálamo & PTPRR & 0,39 & 0,1109 & 0,85 & $6,58 \mathrm{E}-06$ & 32,76 \\
\hline Hipotálamo & RAP1GAP & 0,46 & 0,0522 & 0,95 & $1,54 \mathrm{E}-09$ & 63,78 \\
\hline Hipotálamo & RARB & 0,45 & 0,0595 & 0,93 & $1,32 \mathrm{E}-08$ & 57,46 \\
\hline Hipotálamo & RASD2 & 0,52 & 0,0267 & 0,98 & $3,15 \mathrm{E}-13$ & 84,12 \\
\hline Hipotálamo & RGS14 & 0,52 & 0,0259 & 0,97 & $4,82 \mathrm{E}-11$ & 75,51 \\
\hline Hipotálamo & RGS9 & 0,51 & 0,0315 & 0,97 & $4,20 \mathrm{E}-11$ & 72,72 \\
\hline Hipotálamo & RIC8B & 0,52 & 0,0261 & 0,95 & 2,93E-09 & 60,96 \\
\hline Hipotálamo & RPRML & 0,53 & 0,0246 & 0,98 & $5,01 \mathrm{E}-13$ & 80,13 \\
\hline Hipotálamo & RPS6KA4 & 0,57 & 0,0129 & 0,94 & $1,18 \mathrm{E}-08$ & 57,00 \\
\hline Hipotálamo & RRAGD & 0,47 & 0,0486 & 0,83 & $1,91 \mathrm{E}-05$ & 27,03 \\
\hline Hipotálamo & SH3PXD2B & 0,56 & 0,0156 & 0,81 & $4,38 \mathrm{E}-05$ & 19,14 \\
\hline Hipotálamo & SLC9A1 & 0,51 & 0,0288 & 0,89 & $7,56 \mathrm{E}-07$ & 39,65 \\
\hline Hipotálamo & SMAD7 & 0,47 & 0,0492 & 0,96 & $5,58 \mathrm{E}-10$ & 67,73 \\
\hline
\end{tabular}


Tabela suplementar 6 - Genes contidos no módulo Skyblue3 (continuação).

\begin{tabular}{llcccrr}
\hline Tecido & Gene & SG CA & Valor de P SG CA & FM & Valor de P FM & K \\
\hline Hipotálamo & SMPD3 & 0,47 & 0,0477 & 0,94 & $4,40 \mathrm{E}-09$ & 57,60 \\
Hipotálamo & SNAPC2 & 0,63 & 0,0054 & 0,80 & $6,15 \mathrm{E}-05$ & 18,48 \\
Hipotálamo & SOAT1 & 0,52 & 0,0277 & 0,93 & $2,43 \mathrm{E}-08$ & 53,67 \\
Hipotálamo & SYNDIG1 & 0,66 & 0,0032 & 0,95 & $2,16 \mathrm{E}-09$ & 60,93 \\
Hipotálamo & SYNDIG1L & 0,55 & 0,0190 & 0,96 & $2,11 \mathrm{E}-10$ & 71,99 \\
Hipotálamo & SYNPR & 0,49 & 0,0387 & 0,96 & $3,18 \mathrm{E}-10$ & 68,45 \\
Hipotálamo & TCF20 & 0,43 & 0,0773 & 0,88 & $1,64 \mathrm{E}-06$ & 37,96 \\
Hipotálamo & TLNRD1 & 0,26 & 0,2945 & 0,88 & $1,30 \mathrm{E}-06$ & 38,61 \\
Hipotálamo & TMEM158 & 0,50 & 0,0359 & 0,98 & $2,76 \mathrm{E}-13$ & 78,96 \\
Hipotálamo & TOMM20 & 0,51 & 0,0306 & 0,91 & $1,26 \mathrm{E}-07$ & 50,27 \\
Hipotálamo & TOMM70 & 0,49 & 0,0389 & 0,92 & $7,03 \mathrm{E}-08$ & 51,94 \\
Hipotálamo & TRERF1 & 0,50 & 0,0347 & 0,97 & $8,60 \mathrm{E}-11$ & 71,35 \\
Hipotálamo & TRPV6 & 0,47 & 0,0483 & 0,97 & $7,15 \mathrm{E}-11$ & 73,46 \\
Hipotálamo & TSPAN9 & 0,54 & 0,0201 & 0,96 & $2,73 \mathrm{E}-10$ & 72,85 \\
Hipotálamo & USH1G & 0,52 & 0,0268 & 0,96 & $1,76 \mathrm{E}-10$ & 76,38 \\
Hipotálamo & USP48 & 0,50 & 0,0349 & 0,91 & $1,28 \mathrm{E}-07$ & 47,23 \\
Hipotálamo & WFS1 & 0,57 & 0,0133 & 0,98 & $1,25 \mathrm{E}-12$ & 82,52 \\
Hipotálamo & YPEL1 & 0,47 & 0,0505 & 0,93 & $2,22 \mathrm{E}-08$ & 53,52 \\
Hipotálamo & ZSWIM5 & 0,56 & 0,0155 & 0,90 & $3,00 \mathrm{E}-07$ & 43,12 \\
\hline SG significân
\end{tabular}

SG - significância gênica; FM - filiação ao módulo; K - conectividade intramodular; CA - conversão alimentar 
Tabela suplementar 7 - Genes contidos no módulo Maroon.

\begin{tabular}{|c|c|c|c|c|c|c|}
\hline Tecido & Gene & SG CA & Valor de P SG CA & FM & Valor de P FM & $\mathbf{K}$ \\
\hline Hipotálamo & ACTR3 & 0,46 & 0,05 & 0,87 & $3,40 \mathrm{E}-06$ & 39,95 \\
\hline Hipotálamo & ACVR1C & 0,53 & 0,02 & 0,95 & $1,73 \mathrm{E}-09$ & 83,07 \\
\hline Hipotálamo & ADGRB2 & 0,42 & 0,08 & 0,97 & $2,03 \mathrm{E}-11$ & 91,03 \\
\hline Hipotálamo & AGAP2 & 0,42 & 0,08 & 0,98 & $3,62 \mathrm{E}-13$ & 101,54 \\
\hline Hipotálamo & AMPD2 & 0,36 & 0,14 & 0,92 & $6,20 \mathrm{E}-08$ & 61,14 \\
\hline Pituitária & ANGEL1 & 0,27 & 0,28 & 0,75 & $3,01 \mathrm{E}-04$ & 13,47 \\
\hline Hipotálamo & ANKRD11 & 0,34 & 0,17 & 0,91 & $2,22 \mathrm{E}-07$ & 51,98 \\
\hline Hipotálamo & ANKRD33B & 0,42 & 0,08 & 0,97 & $9,09 \mathrm{E}-11$ & 91,15 \\
\hline Hipotálamo & API5 & 0,55 & 0,02 & 0,85 & $7,99 \mathrm{E}-06$ & 31,91 \\
\hline Hipotálamo & ARHGEF3 & 0,36 & 0,14 & 0,91 & $1,22 \mathrm{E}-07$ & 57,50 \\
\hline Hipotálamo & ARPC2 & 0,29 & 0,24 & 0,92 & $7,30 \mathrm{E}-08$ & 62,87 \\
\hline Hipotálamo & ASH1L & 0,40 & 0,10 & 0,89 & $8,16 \mathrm{E}-07$ & 46,50 \\
\hline Hipotálamo & ASPHD1 & 0,64 & 0,00 & 0,91 & $2,14 \mathrm{E}-07$ & 57,43 \\
\hline Hipotálamo & BAG5 & 0,51 & 0,03 & 0,95 & $2,58 \mathrm{E}-09$ & 78,25 \\
\hline Hipotálamo & BAIAP2 & 0,49 & 0,04 & 0,97 & $9,96 \mathrm{E}-11$ & 91,11 \\
\hline Hipotálamo & BCL11A & 0,22 & 0,38 & 0,91 & $2,08 \mathrm{E}-07$ & 59,78 \\
\hline Hipotálamo & C11 orf95 & 0,39 & 0,11 & 0,98 & $1,23 \mathrm{E}-12$ & 98,47 \\
\hline Hipotálamo & CACNA1E & 0,33 & 0,18 & 0,97 & $4,66 \mathrm{E}-11$ & 89,38 \\
\hline Hipotálamo & CACNB1 & 0,46 & 0,05 & 0,91 & $1,40 \mathrm{E}-07$ & 60,31 \\
\hline Hipotálamo & CACNG3 & 0,41 & 0,09 & 0,99 & $4,61 \mathrm{E}-14$ & 104,33 \\
\hline Hipotálamo & CALN1 & 0,52 & 0,03 & 0,95 & $1,90 \mathrm{E}-09$ & 80,42 \\
\hline Hipotálamo & CAMK1D & 0,40 & 0,10 & 0,99 & $1,44 \mathrm{E}-14$ & 105,20 \\
\hline Hipotálamo & CAMK1G & 0,43 & 0,08 & 0,99 & $9,01 \mathrm{E}-16$ & 107,66 \\
\hline Hipotálamo & CAMK2B & 0,39 & 0,11 & 0,93 & $3,03 \mathrm{E}-08$ & 68,83 \\
\hline Hipotálamo & CAMKK1 & 0,19 & 0,44 & 0,89 & $9,68 \mathrm{E}-07$ & 51,71 \\
\hline Hipotálamo & CAMSAP2 & 0,33 & 0,18 & 0,93 & $1,77 \mathrm{E}-08$ & 68,68 \\
\hline Hipotálamo & CAP2 & 0,40 & 0,10 & 0,97 & $1,50 \mathrm{E}-11$ & 94,30 \\
\hline Hipotálamo & CAPN15 & 0,24 & 0,34 & 0,83 & $1,80 \mathrm{E}-05$ & 31,18 \\
\hline Hipotálamo & CARNMT1 & 0,46 & 0,05 & 0,92 & $8,94 \mathrm{E}-08$ & 61,94 \\
\hline Hipotálamo & CCKBR & 0,41 & 0,09 & 0,97 & $9,62 \mathrm{E}-11$ & 91,22 \\
\hline Hipotálamo & $\mathrm{CCNY}$ & 0,21 & 0,40 & 0,76 & 2,29E-04 & 16,79 \\
\hline Hipotálamo & CDH9 & 0,38 & 0,12 & 0,96 & $5,47 \mathrm{E}-10$ & 84,02 \\
\hline Hipotálamo & CDK17 & 0,36 & 0,15 & 0,97 & $4,77 \mathrm{E}-11$ & 88,66 \\
\hline Hipotálamo & CELF1 & 0,29 & 0,25 & 0,92 & $4,57 \mathrm{E}-08$ & 61,26 \\
\hline Hipotálamo & CELF3 & 0,31 & 0,21 & 0,94 & $6,10 \mathrm{E}-09$ & 73,54 \\
\hline Hipotálamo & CELF5 & 0,34 & 0,17 & 0,94 & $1,01 \mathrm{E}-08$ & 72,04 \\
\hline Hipotálamo & CETN4 & 0,35 & 0,15 & 0,85 & $9,63 \mathrm{E}-06$ & 35,50 \\
\hline Hipotálamo & CHRM1 & 0,45 & 0,06 & 0,96 & $5,66 \mathrm{E}-10$ & 83,30 \\
\hline Hipotálamo & CIC & 0,50 & 0,03 & 0,95 & $7,37 \mathrm{E}-10$ & 82,68 \\
\hline Hipotálamo & CNIH3 & 0,51 & 0,03 & 0,93 & $2,24 \mathrm{E}-08$ & 66,53 \\
\hline Hipotálamo & CNKSR2 & 0,37 & 0,13 & 0,98 & $3,84 \mathrm{E}-13$ & 101,07 \\
\hline Hipotálamo & CNR1 & 0,48 & 0,04 & 0,94 & $7,55 \mathrm{E}-09$ & 77,30 \\
\hline Hipotálamo & CORT & 0,22 & 0,37 & 0,89 & $5,48 \mathrm{E}-07$ & 56,39 \\
\hline Hipotálamo & CPLX2 & 0,46 & 0,05 & 0,97 & $1,89 \mathrm{E}-11$ & 95,07 \\
\hline Hipotálamo & CRTC1 & 0,29 & 0,25 & 0,94 & $7,43 \mathrm{E}-09$ & 74,97 \\
\hline Hipotálamo & CTXN1 & 0,46 & 0,05 & 0,95 & $7,59 \mathrm{E}-10$ & 84,41 \\
\hline Hipotálamo & DDN & 0,45 & 0,06 & 0,96 & $6,10 \mathrm{E}-10$ & 86,80 \\
\hline Hipotálamo & DGKZ & 0,31 & 0,21 & 0,95 & $1,29 \mathrm{E}-09$ & 81,68 \\
\hline Hipotálamo & DLK2 & 0,44 & 0,07 & 0,88 & $1,36 \mathrm{E}-06$ & 46,83 \\
\hline Hipotálamo & DMTN & 0,45 & 0,06 & 0,88 & $1,88 \mathrm{E}-06$ & 47,00 \\
\hline Hipotálamo & DOK6 & 0,32 & 0,20 & 0,95 & $1,05 \mathrm{E}-09$ & 80,16 \\
\hline Hipotálamo & $\mathrm{DPH} 2$ & 0,28 & 0,26 & 0,81 & $5,44 \mathrm{E}-05$ & 21,76 \\
\hline Hipotálamo & DPYSL4 & 0,34 & 0,16 & 0,97 & $1,39 \mathrm{E}-11$ & 92,59 \\
\hline Hipotálamo & EGR3 & 0,42 & 0,08 & 0,90 & $4,73 \mathrm{E}-07$ & 54,87 \\
\hline Hipotálamo & ELK1 & 0,43 & 0,07 & 0,99 & $2,51 \mathrm{E}-14$ & 104,10 \\
\hline Hipotálamo & EMID1 & 0,47 & 0,05 & 0,94 & $8,11 \mathrm{E}-09$ & 77,22 \\
\hline Hipotálamo & EMX2 & 0,21 & 0,40 & 0,87 & $3,37 \mathrm{E}-06$ & 44,37 \\
\hline Hipotálamo & ENOX1 & 0,39 & 0,11 & 0,95 & $2,41 \mathrm{E}-09$ & 74,70 \\
\hline Hipotálamo & ENSBTAG00000002950 & 0,51 & 0,03 & 0,91 & $2,09 \mathrm{E}-07$ & 58,54 \\
\hline Hipotálamo & ENSBTAG00000003580 & 0,43 & 0,07 & 0,98 & $1,96 \mathrm{E}-12$ & 99,89 \\
\hline Hipotálamo & ENSBTAG00000011113 & 0,37 & 0,13 & 0,96 & $2,70 \mathrm{E}-10$ & 88,04 \\
\hline Hipotálamo & ENSBTAG00000027868 & 0,38 & 0,12 & 0,94 & $7,96 \mathrm{E}-09$ & 72,39 \\
\hline Hipotálamo & ENSBTAG00000046336 & 0,41 & 0,09 & 0,97 & $9,25 \mathrm{E}-11$ & 87,09 \\
\hline
\end{tabular}


Tabela suplementar 7 - Genes contidos no módulo Maroon (continuação).

\begin{tabular}{|c|c|c|c|c|c|c|}
\hline Tecido & Gene & SG CA & Valor de P SG CA & FM & Valor de P FM & $\mathbf{K}$ \\
\hline Hipotálamo & ENSBTAG00000046752 & 0,43 & 0,08 & 0,97 & $1,32 \mathrm{E}-11$ & 95,13 \\
\hline Hipotálamo & ENSBTAG00000047547 & 0,33 & 0,18 & 0,80 & $6,19 \mathrm{E}-05$ & 22,55 \\
\hline Hipotálamo & EPB41L1 & 0,40 & 0,10 & 0,86 & 4,09E-06 & 38,11 \\
\hline Hipotálamo & EXD2 & 0,29 & 0,24 & 0,96 & $2,44 \mathrm{E}-10$ & 84,06 \\
\hline Hipotálamo & FAM163B & 0,42 & 0,08 & 0,89 & $5,49 \mathrm{E}-07$ & 51,41 \\
\hline Hipotálamo & FAM171A1 & 0,46 & 0,06 & 0,89 & $6,17 \mathrm{E}-07$ & 52,21 \\
\hline Hipotálamo & FAM208B & 0,36 & 0,14 & 0,90 & $3,68 \mathrm{E}-07$ & 51,35 \\
\hline Hipotálamo & FAM212B & 0,30 & 0,23 & 0,90 & $3,78 \mathrm{E}-07$ & 57,69 \\
\hline Hipotálamo & FBXL18 & 0,31 & 0,20 & 0,96 & $3,72 \mathrm{E}-10$ & 84,04 \\
\hline Hipotálamo & FBXO44 & 0,47 & 0,05 & 0,95 & $3,45 \mathrm{E}-09$ & 76,91 \\
\hline Hipotálamo & FEM1A & 0,47 & 0,05 & 0,87 & $2,63 \mathrm{E}-06$ & 39,17 \\
\hline Hipotálamo & FGD1 & 0,32 & 0,20 & 0,94 & $4,45 \mathrm{E}-09$ & 71,21 \\
\hline Hipotálamo & FGF13 & 0,47 & 0,05 & 0,97 & $1,13 \mathrm{E}-11$ & 93,10 \\
\hline Hipotálamo & FHIT & 0,41 & 0,09 & 0,87 & $2,72 \mathrm{E}-06$ & 38,97 \\
\hline Hipotálamo & FILIP1 & 0,36 & 0,14 & 0,95 & $2,91 \mathrm{E}-09$ & 79,49 \\
\hline Hipotálamo & FKBP1A & 0,46 & 0,05 & 0,95 & $1,58 \mathrm{E}-09$ & 82,99 \\
\hline Hipotálamo & FRRS1L & 0,21 & 0,41 & 0,87 & $2,10 \mathrm{E}-06$ & 47,09 \\
\hline Hipotálamo & GABRA2 & 0,33 & 0,19 & 0,91 & $1,08 \mathrm{E}-07$ & 61,32 \\
\hline Hipotálamo & GALNT15 & 0,46 & 0,05 & 0,91 & $1,94 \mathrm{E}-07$ & 61,31 \\
\hline Hipotálamo & GGA3 & 0,50 & 0,03 & 0,90 & $5,06 \mathrm{E}-07$ & 48,68 \\
\hline Hipotálamo & GJB2 & 0,50 & 0,03 & 0,92 & $4,35 \mathrm{E}-08$ & 65,77 \\
\hline Adrenal & GPR37 & 0,49 & 0,04 & 0,75 & $3,81 \mathrm{E}-04$ & 49,81 \\
\hline Hipotálamo & GRIA2 & 0,27 & 0,29 & 0,95 & $2,25 \mathrm{E}-09$ & 77,82 \\
\hline Hipotálamo & HAPLN1 & 0,48 & 0,05 & 0,96 & $7,15 \mathrm{E}-10$ & 80,15 \\
\hline Hipotálamo & HDGFL2 & 0,42 & 0,08 & 0,86 & $4,93 \mathrm{E}-06$ & 36,85 \\
\hline Hipotálamo & HECTD2 & 0,38 & 0,12 & 0,81 & $5,14 \mathrm{E}-05$ & 23,24 \\
\hline Hipotálamo & HPCA & 0,47 & 0,05 & 0,96 & $1,36 \mathrm{E}-10$ & 90,05 \\
\hline Hipotálamo & HPCAL4 & 0,37 & 0,13 & 0,99 & $4,06 \mathrm{E}-14$ & 103,23 \\
\hline Hipotálamo & ICAM5 & 0,33 & 0,18 & 0,95 & $1,03 \mathrm{E}-09$ & 83,58 \\
\hline Hipotálamo & IQSEC2 & 0,27 & 0,28 & 0,92 & $6,59 \mathrm{E}-08$ & 66,08 \\
\hline Hipotálamo & JPH4 & 0,46 & 0,06 & 0,97 & $9,44 \mathrm{E}-11$ & 90,27 \\
\hline Hipotálamo & $\mathrm{KCNH} 3$ & 0,35 & 0,15 & 0,95 & $1,82 \mathrm{E}-09$ & 81,46 \\
\hline Hipotálamo & KCNIP2 & 0,45 & 0,06 & 0,95 & $1,71 \mathrm{E}-09$ & 82,62 \\
\hline Hipotálamo & KIAA1671 & 0,43 & 0,07 & 0,92 & $4,50 \mathrm{E}-08$ & 64,19 \\
\hline Hipotálamo & LARGE1 & 0,33 & 0,18 & 0,95 & $3,11 \mathrm{E}-09$ & 77,17 \\
\hline Hipotálamo & LATS1 & 0,24 & 0,34 & 0,67 & $2,14 \mathrm{E}-03$ & 6,97 \\
\hline Hipotálamo & LHPP & 0,58 & 0,01 & 0,89 & $1,06 \mathrm{E}-06$ & 48,20 \\
\hline Hipotálamo & LIMD2 & 0,34 & 0,17 & 0,88 & $1,17 \mathrm{E}-06$ & 44,60 \\
\hline Hipotálamo & LIN7C & 0,50 & 0,04 & 0,91 & $1,69 \mathrm{E}-07$ & 55,59 \\
\hline Hipotálamo & LMO7 & 0,40 & 0,10 & 0,96 & $1,29 \mathrm{E}-10$ & 87,87 \\
\hline Hipotálamo & LRRC10B & 0,36 & 0,14 & 0,94 & $5,67 \mathrm{E}-09$ & 76,87 \\
\hline Hipotálamo & LRRC4C & 0,52 & 0,03 & 0,83 & $1,85 \mathrm{E}-05$ & 33,23 \\
\hline Hipotálamo & MAST3 & 0,31 & 0,21 & 0,89 & $8,15 \mathrm{E}-07$ & 49,32 \\
\hline Hipotálamo & MINK1 & 0,34 & 0,16 & 0,94 & $8,43 \mathrm{E}-09$ & 73,72 \\
\hline Hipotálamo & MKL2 & 0,34 & 0,16 & 0,98 & $2,84 \mathrm{E}-12$ & 97,12 \\
\hline Hipotálamo & MMD & 0,43 & 0,08 & 0,97 & $7,61 \mathrm{E}-12$ & 94,43 \\
\hline Hipotálamo & MSH2 & 0,47 & 0,05 & 0,84 & $1,47 \mathrm{E}-05$ & 29,18 \\
\hline Hipotálamo & MYH7B & 0,43 & 0,07 & 0,90 & $2,61 \mathrm{E}-07$ & 57,37 \\
\hline Hipotálamo & NCOR1 & 0,19 & 0,46 & 0,84 & $1,28 \mathrm{E}-05$ & 31,44 \\
\hline Hipotálamo & NEDD4L & 0,39 & 0,11 & 0,95 & $2,82 \mathrm{E}-09$ & 77,00 \\
\hline Hipotálamo & NETO1 & 0,43 & 0,07 & 0,98 & $1,18 \mathrm{E}-12$ & 100,30 \\
\hline Hipotálamo & NEURL2 & 0,36 & 0,14 & 0,88 & $1,18 \mathrm{E}-06$ & 44,61 \\
\hline Hipotálamo & NPY & 0,21 & 0,40 & 0,89 & $5,92 \mathrm{E}-07$ & 52,84 \\
\hline Hipotálamo & NPY5R & 0,45 & 0,06 & 0,96 & $1,26 \mathrm{E}-10$ & 87,91 \\
\hline Hipotálamo & NR2E1 & 0,32 & 0,19 & 0,83 & $1,96 \mathrm{E}-05$ & 28,69 \\
\hline Hipotálamo & NRF1 & 0,45 & 0,06 & 0,90 & $4,45 \mathrm{E}-07$ & 51,87 \\
\hline Hipotálamo & NRGN & 0,45 & 0,06 & 0,96 & $1,46 \mathrm{E}-10$ & 91,04 \\
\hline Hipotálamo & NUDT10 & 0,41 & 0,09 & 0,91 & $2,21 \mathrm{E}-07$ & 55,38 \\
\hline Hipotálamo & OAF & 0,40 & 0,10 & 0,95 & $8,64 \mathrm{E}-10$ & 80,75 \\
\hline Hipotálamo & ORMDL3 & 0,54 & 0,02 & 0,88 & $1,54 \mathrm{E}-06$ & 44,98 \\
\hline Hipotálamo & PDE2A & 0,33 & 0,18 & 0,97 & $9,72 \mathrm{E}-11$ & 90,20 \\
\hline Hipotálamo & PDZD4 & 0,47 & 0,05 & 0,94 & $7,64 \mathrm{E}-09$ & 72,74 \\
\hline Hipotálamo & PHLDB3 & 0,29 & 0,25 & 0,87 & 2,31E-06 & 43,10 \\
\hline
\end{tabular}


Tabela suplementar 7 - Genes contidos no módulo Maroon (continuação).

\begin{tabular}{|c|c|c|c|c|c|c|}
\hline Tecido & Gene & SG CA & Valor de P SG CA & FM & Valor de P FM & $\mathbf{K}$ \\
\hline Hipotálamo & PHYHIP & 0,38 & 0,12 & 0,99 & $1,95 \mathrm{E}-15$ & 106,24 \\
\hline Hipotálamo & PIK3R2 & 0,34 & 0,17 & 0,97 & $1,23 \mathrm{E}-11$ & 94,52 \\
\hline Hipotálamo & PISD & 0,28 & 0,26 & 0,90 & $2,50 \mathrm{E}-07$ & 52,48 \\
\hline Hipotálamo & PKIA & 0,41 & 0,09 & 0,94 & 3,97E-09 & 76,86 \\
\hline Hipotálamo & PLK2 & 0,41 & 0,09 & 0,92 & $4,15 \mathrm{E}-08$ & 67,49 \\
\hline Hipotálamo & PLPPR1 & 0,32 & 0,19 & 0,95 & $1,97 \mathrm{E}-09$ & 79,66 \\
\hline Hipotálamo & PLPPR4 & 0,32 & 0,20 & 0,96 & $1,10 \mathrm{E}-10$ & 89,26 \\
\hline Hipotálamo & POU3F1 & 0,41 & 0,09 & 0,96 & $2,89 \mathrm{E}-10$ & 87,76 \\
\hline Hipotálamo & POU6F1 & 0,35 & 0,16 & 0,95 & $8,33 \mathrm{E}-10$ & 79,72 \\
\hline Hipotálamo & PPP1R16A & 0,45 & 0,06 & 0,93 & $3,06 \mathrm{E}-08$ & 65,29 \\
\hline Hipotálamo & PPP1R1A & 0,39 & 0,11 & 0,88 & $1,16 \mathrm{E}-06$ & 47,34 \\
\hline Hipotálamo & PPP1R9A & 0,40 & 0,10 & 0,90 & $3,96 \mathrm{E}-07$ & 54,23 \\
\hline Hipotálamo & PPP3CA & 0,47 & 0,05 & 0,97 & $1,32 \mathrm{E}-11$ & 96,45 \\
\hline Hipotálamo & PPP3R1 & 0,33 & 0,18 & 0,91 & $2,15 \mathrm{E}-07$ & 59,45 \\
\hline Hipotálamo & PRR7 & 0,46 & 0,06 & 0,94 & $1,21 \mathrm{E}-08$ & 72,69 \\
\hline Hipotálamo & PTPRE & 0,42 & 0,08 & 0,95 & $8,15 \mathrm{E}-10$ & 83,73 \\
\hline Hipotálamo & RAB11FIP4 & 0,31 & 0,21 & 0,83 & $1,71 \mathrm{E}-05$ & 31,99 \\
\hline Hipotálamo & RAB15 & 0,46 & 0,05 & 0,99 & $9,89 \mathrm{E}-15$ & 105,30 \\
\hline Hipotálamo & RAB40B & 0,49 & 0,04 & 0,96 & $4,83 \mathrm{E}-10$ & 85,23 \\
\hline Hipotálamo & RAPGEF4 & 0,23 & 0,36 & 0,91 & $1,09 \mathrm{E}-07$ & 60,99 \\
\hline Hipotálamo & RASGEF1A & 0,33 & 0,19 & 0,95 & $3,02 \mathrm{E}-09$ & 77,95 \\
\hline Hipotálamo & RASGRF2 & 0,40 & 0,10 & 0,95 & $1,03 \mathrm{E}-09$ & 81,26 \\
\hline Hipotálamo & RASGRP1 & 0,45 & 0,06 & 0,93 & $2,19 \mathrm{E}-08$ & 71,46 \\
\hline Hipotálamo & REM2 & 0,43 & 0,07 & 0,98 & $3,70 \mathrm{E}-13$ & 100,59 \\
\hline Hipotálamo & RFX3 & 0,27 & 0,29 & 0,85 & $8,14 \mathrm{E}-06$ & 37,01 \\
\hline Hipotálamo & RGS4 & 0,47 & 0,05 & 0,91 & $1,52 \mathrm{E}-07$ & 56,23 \\
\hline Hipotálamo & RIN1 & 0,34 & 0,16 & 0,94 & $1,29 \mathrm{E}-08$ & 69,13 \\
\hline Hipotálamo & ROCK2 & 0,34 & 0,17 & 0,93 & $1,51 \mathrm{E}-08$ & 68,88 \\
\hline Hipotálamo & RPP25 & 0,26 & 0,30 & 0,85 & $9,73 \mathrm{E}-06$ & 32,79 \\
\hline Hipotálamo & RYR2 & 0,46 & 0,06 & 0,98 & $3,90 \mathrm{E}-12$ & 96,93 \\
\hline Hipotálamo & SCGN & 0,46 & 0,05 & 0,84 & $1,39 \mathrm{E}-05$ & 33,22 \\
\hline Hipotálamo & SDCBP & 0,48 & 0,04 & 0,92 & $4,33 \mathrm{E}-08$ & 62,52 \\
\hline Hipotálamo & SGSM2 & 0,39 & 0,11 & 0,84 & $1,32 \mathrm{E}-05$ & 34,72 \\
\hline Hipotálamo & SH3RF1 & 0,38 & 0,12 & 0,91 & $2,38 \mathrm{E}-07$ & 54,62 \\
\hline Hipotálamo & SH3RF3 & 0,30 & 0,23 & 0,89 & $6,99 \mathrm{E}-07$ & 52,72 \\
\hline Hipotálamo & SHISA7 & 0,34 & 0,17 & 0,98 & $3,14 \mathrm{E}-12$ & 95,79 \\
\hline Hipotálamo & SIPA1L1 & 0,54 & 0,02 & 0,90 & $4,56 \mathrm{E}-07$ & 56,28 \\
\hline Hipotálamo & SLC1A2 & 0,43 & 0,07 & 0,91 & $1,09 \mathrm{E}-07$ & 60,11 \\
\hline Hipotálamo & SLC24A4 & 0,50 & 0,03 & 0,91 & $2,46 \mathrm{E}-07$ & 58,30 \\
\hline Hipotálamo & SLC25A23 & 0,33 & 0,19 & 0,95 & $2,82 \mathrm{E}-09$ & 79,31 \\
\hline Hipotálamo & SLC30A10 & 0,49 & 0,04 & 0,83 & $2,22 \mathrm{E}-05$ & 28,27 \\
\hline Hipotálamo & SLC $35 F 3$ & 0,36 & 0,14 & 0,97 & $5,59 \mathrm{E}-11$ & 89,05 \\
\hline Hipotálamo & SLCO1C1 & 0,40 & 0,10 & 0,96 & $5,97 \mathrm{E}-10$ & 85,56 \\
\hline Hipotálamo & SLITRK4 & 0,41 & 0,09 & 0,97 & $2,15 \mathrm{E}-11$ & 90,56 \\
\hline Hipotálamo & SNN & 0,36 & 0,14 & 0,95 & $2,65 \mathrm{E}-09$ & 78,22 \\
\hline Hipotálamo & SOWAHA & 0,45 & 0,06 & 0,96 & $2,42 \mathrm{E}-10$ & 89,51 \\
\hline Hipotálamo & SPEG & 0,28 & 0,25 & 0,89 & $7,96 \mathrm{E}-07$ & 50,67 \\
\hline Hipotálamo & SPTB & 0,47 & 0,05 & 0,98 & $2,46 \mathrm{E}-12$ & 94,97 \\
\hline Hipotálamo & SPTBN2 & 0,43 & 0,07 & 0,98 & $1,01 \mathrm{E}-12$ & 99,39 \\
\hline Hipotálamo & SRF & 0,37 & 0,13 & 0,91 & $1,40 \mathrm{E}-07$ & 58,49 \\
\hline Hipotálamo & SSBP3 & 0,57 & 0,01 & 0,82 & $2,52 \mathrm{E}-05$ & 27,51 \\
\hline Hipotálamo & SSLP1 & 0,30 & 0,23 & 0,90 & $4,91 \mathrm{E}-07$ & 53,55 \\
\hline Hipotálamo & ST6GAL2 & 0,50 & 0,03 & 0,90 & $2,50 \mathrm{E}-07$ & 58,38 \\
\hline Hipotálamo & ST6GALNAC6 & 0,42 & 0,08 & 0,87 & $2,33 \mathrm{E}-06$ & 45,16 \\
\hline Hipotálamo & ST8SIA3 & 0,44 & 0,07 & 0,89 & $6,04 \mathrm{E}-07$ & 52,76 \\
\hline Hipotálamo & STXBP5L & 0,37 & 0,14 & 0,99 & $6,60 \mathrm{E}-14$ & 103,17 \\
\hline Hipotálamo & SYNGAP1 & 0,22 & 0,38 & 0,91 & $1,86 \mathrm{E}-07$ & 60,98 \\
\hline Hipotálamo & SYNPO & 0,42 & 0,08 & 0,94 & $4,72 \mathrm{E}-09$ & 75,64 \\
\hline Hipotálamo & SYT16 & 0,32 & 0,19 & 0,96 & $1,13 \mathrm{E}-10$ & 87,63 \\
\hline Hipotálamo & TBC1D14 & 0,40 & 0,10 & 0,94 & $4,17 \mathrm{E}-09$ & 73,55 \\
\hline Hipotálamo & TEF & 0,49 & 0,04 & 0,92 & $5,30 \mathrm{E}-08$ & 66,60 \\
\hline Hipotálamo & TIGD5 & 0,32 & 0,20 & 0,91 & $2,28 \mathrm{E}-07$ & 54,87 \\
\hline Hipotálamo & TYRP1 & 0,40 & 0,10 & 0,96 & $3,23 \mathrm{E}-10$ & 88,00 \\
\hline
\end{tabular}


Tabela suplementar 7 - Genes contidos no módulo Maroon (continuação).

\begin{tabular}{llccccc}
\hline Tecido & Gene & SG CA & Valor de P SG CA & FM & Valor de P FM & K \\
\hline Hipotálamo & UBALD1 & 0,36 & 0,14 & 0,89 & $7,49 \mathrm{E}-07$ & 47,61 \\
Hipotálamo & UBE2D1 & 0,49 & 0,04 & 0,87 & $2,37 \mathrm{E}-06$ & 41,95 \\
Hipotálamo & UBL7 & 0,37 & 0,13 & 0,83 & $2,32 \mathrm{E}-05$ & 27,85 \\
Hipotálamo & UBXN2B & 0,31 & 0,21 & 0,96 & $6,16 \mathrm{E}-10$ & 83,24 \\
Hipotálamo & USP21 & 0,21 & 0,41 & 0,87 & $3,50 \mathrm{E}-06$ & 41,55 \\
Hipotálamo & VXN & 0,31 & 0,21 & 0,88 & $1,88 \mathrm{E}-06$ & 48,07 \\
Hipotálamo & WASF1 & 0,34 & 0,17 & 0,94 & $5,05 \mathrm{E}-09$ & 75,42 \\
Hipotálamo & WDR44 & 0,29 & 0,24 & 0,84 & $1,21 \mathrm{E}-05$ & 32,09 \\
Hipotálamo & WDR92 & 0,36 & 0,14 & 0,96 & $5,26 \mathrm{E}-10$ & 82,36 \\
Hipotálamo & WSCD2 & 0,39 & 0,11 & 0,95 & $1,83 \mathrm{E}-09$ & 80,62 \\
Hipotálamo & ZDHHC23 & 0,44 & 0,07 & 0,91 & $1,48 \mathrm{E}-07$ & 58,98 \\
Hipotálamo & ZNF239 & 0,48 & 0,04 & 0,98 & $6,32 \mathrm{E}-13$ & 99,20 \\
Hipotálamo & ZNF398 & 0,47 & 0,05 & 0,88 & $1,96 \mathrm{E}-06$ & 41,62 \\
Hipotálamo & ZNF436 & 0,43 & 0,07 & 0,87 & $2,35 \mathrm{E}-06$ & 42,33 \\
Hipotálamo & ZNF628 & 0,31 & 0,21 & 0,82 & $3,04 \mathrm{E}-05$ & 26,91 \\
Hipotálamo & ZNF653 & 0,33 & 0,18 & 0,92 & $6,34 \mathrm{E}-08$ & 62,86 \\
\hline
\end{tabular}


Tabela suplementar 8 - Genes contidos no módulo Tan do hipotálamo.

\begin{tabular}{|c|c|c|c|c|c|}
\hline Gene & SG CA & Valor de P SG CA & FM & Valor de P FM & $\mathbf{K}$ \\
\hline AATF & $-0,33$ & 0,17 & $-0,63$ & $4,99 \mathrm{E}-03$ & 5,87 \\
\hline ABL2 & 0,46 & 0,05 & 0,95 & $1,56 \mathrm{E}-09$ & 85,08 \\
\hline ACTN1 & 0,37 & 0,13 & 0,86 & $3,62 \mathrm{E}-06$ & 44,34 \\
\hline ACTN2 & 0,58 & 0,01 & 0,98 & $2,16 \mathrm{E}-12$ & 97,96 \\
\hline ADCY3 & 0,47 & 0,05 & 0,93 & $3,17 \mathrm{E}-08$ & 74,18 \\
\hline ADCY5 & 0,52 & 0,03 & 0,99 & $3,04 \mathrm{E}-15$ & 106,98 \\
\hline ADORA2A & 0,52 & 0,03 & 0,98 & $2,37 \mathrm{E}-12$ & 98,27 \\
\hline ADRB 1 & 0,56 & 0,02 & 0,95 & $1,41 \mathrm{E}-09$ & 82,58 \\
\hline AKAP5 & 0,54 & 0,02 & 0,97 & $6,90 \mathrm{E}-11$ & 94,39 \\
\hline ANGEL2 & 0,48 & 0,04 & 0,81 & $4,32 \mathrm{E}-05$ & 30,87 \\
\hline ANGPTL6 & 0,51 & 0,03 & 0,77 & $1,83 \mathrm{E}-04$ & 21,11 \\
\hline ANKRD34B & 0,59 & 0,01 & 0,86 & $3,64 \mathrm{E}-06$ & 44,01 \\
\hline ANKRD63 & 0,52 & 0,03 & 0,99 & $6,20 \mathrm{E}-14$ & 103,36 \\
\hline ANO3 & 0,53 & 0,02 & 0,99 & $2,91 \mathrm{E}-15$ & 107,39 \\
\hline APOA2 & 0,21 & 0,41 & 0,72 & $7,40 \mathrm{E}-04$ & 15,64 \\
\hline ARHGAP10 & 0,55 & 0,02 & 0,94 & $7,08 \mathrm{E}-09$ & 75,82 \\
\hline ARHGAP25 & 0,51 & 0,03 & 0,95 & $1,66 \mathrm{E}-09$ & 80,52 \\
\hline ARHGAP6 & 0,39 & 0,11 & 0,80 & $6,86 \mathrm{E}-05$ & 26,93 \\
\hline ARL4D & 0,53 & 0,02 & 0,99 & $1,65 \mathrm{E}-15$ & 106,60 \\
\hline ARPP19 & 0,51 & 0,03 & 0,99 & $5,14 \mathrm{E}-14$ & 104,50 \\
\hline ARPP21 & 0,53 & 0,02 & 0,99 & $3,91 \mathrm{E}-14$ & 104,56 \\
\hline ASPHD2 & 0,47 & 0,05 & 0,87 & $2,89 \mathrm{E}-06$ & 54,34 \\
\hline B3GNT2 & 0,60 & 0,01 & 0,54 & $2,15 \mathrm{E}-02$ & 2,61 \\
\hline BAIAP2L2 & 0,50 & 0,03 & 0,98 & $3,41 \mathrm{E}-12$ & 97,41 \\
\hline BCL11B & 0,51 & 0,03 & 0,94 & $8,32 \mathrm{E}-09$ & 80,36 \\
\hline BCR & 0,52 & 0,03 & 0,95 & $1,87 \mathrm{E}-09$ & 86,99 \\
\hline $\mathrm{C} 16 \mathrm{H} 1$ orf115 & 0,47 & 0,05 & 0,83 & $2,47 \mathrm{E}-05$ & 31,32 \\
\hline C23H6orf 47 & 0,01 & 0,97 & $-0,50$ & $3,43 \mathrm{E}-02$ & 2,02 \\
\hline $\mathrm{C} 2 \mathrm{CD} 3$ & 0,37 & 0,13 & 0,81 & $4,30 \mathrm{E}-05$ & 26,91 \\
\hline $\mathrm{C} 2 \mathrm{H} 2$ orf 76 & 0,51 & 0,03 & 0,49 & $3,87 \mathrm{E}-02$ & 1,92 \\
\hline CACNA1H & 0,53 & 0,02 & 0,80 & $6,56 \mathrm{E}-05$ & 29,67 \\
\hline CACNB3 & 0,50 & 0,03 & 0,92 & $9,10 \mathrm{E}-08$ & 71,51 \\
\hline CALB1 & 0,51 & 0,03 & 0,98 & $5,89 \mathrm{E}-13$ & 99,71 \\
\hline CALCA & 0,56 & 0,01 & 0,99 & $4,98 \mathrm{E}-14$ & 103,22 \\
\hline CAMKK2 & 0,48 & 0,05 & 0,95 & 1,98E-09 & 86,49 \\
\hline CAP1 & 0,48 & 0,04 & 0,85 & $7,20 \mathrm{E}-06$ & 41,06 \\
\hline CARHSP1 & 0,58 & 0,01 & 0,91 & $2,24 \mathrm{E}-07$ & 59,05 \\
\hline CCDC126 & 0,59 & 0,01 & 0,95 & $2,41 \mathrm{E}-09$ & 83,45 \\
\hline CCDC88C & 0,48 & 0,04 & 0,96 & $6,86 \mathrm{E}-10$ & 84,76 \\
\hline CCM2 & 0,41 & 0,09 & 0,86 & $5,00 \mathrm{E}-06$ & 46,05 \\
\hline CCND2 & 0,50 & 0,03 & 0,69 & $1,47 \mathrm{E}-03$ & 11,84 \\
\hline CD163 & 0,57 & 0,01 & 0,96 & $2,95 \mathrm{E}-10$ & 85,61 \\
\hline CD3EAP & 0,30 & 0,23 & 0,61 & $7,81 \mathrm{E}-03$ & 4,59 \\
\hline CDHR1 & 0,53 & 0,03 & 0,98 & $7,53 \mathrm{E}-13$ & 100,02 \\
\hline CENPO & 0,57 & 0,01 & 0,88 & $1,78 \mathrm{E}-06$ & 53,47 \\
\hline CEP126 & 0,56 & 0,02 & 0,92 & $6,07 \mathrm{E}-08$ & 73,21 \\
\hline CHRM4 & 0,53 & 0,02 & 0,99 & $6,37 \mathrm{E}-16$ & 106,99 \\
\hline CHSY3 & 0,55 & 0,02 & 0,95 & $3,10 \mathrm{E}-09$ & 82,75 \\
\hline CNGB1 & 0,51 & 0,03 & 0,99 & $1,43 \mathrm{E}-16$ & 107,34 \\
\hline CNOT11 & $-0,41$ & 0,09 & $-0,53$ & $2,48 \mathrm{E}-02$ & 1,74 \\
\hline $\mathrm{COCH}$ & 0,58 & 0,01 & 0,99 & $8,99 \mathrm{E}-14$ & 101,67 \\
\hline COL15A1 & $-0,09$ & 0,73 & 0,37 & $1,30 \mathrm{E}-01$ & 0,53 \\
\hline COL8A2 & 0,53 & 0,02 & 0,98 & $4,08 \mathrm{E}-13$ & 100,71 \\
\hline CORO7 & 0,24 & 0,34 & 0,54 & $1,98 \mathrm{E}-02$ & 2,54 \\
\hline CPNE5 & 0,53 & 0,02 & 0,99 & $4,19 \mathrm{E}-16$ & 106,84 \\
\hline CST3 & 0,44 & 0,06 & 0,43 & $7,63 \mathrm{E}-02$ & 0,79 \\
\hline CTDSPL & 0,39 & 0,11 & 0,85 & $6,56 \mathrm{E}-06$ & 42,03 \\
\hline CYB561 & 0,52 & 0,03 & 0,92 & $4,46 \mathrm{E}-08$ & 68,19 \\
\hline DACT2 & 0,52 & 0,03 & 0,93 & $3,45 \mathrm{E}-08$ & 73,81 \\
\hline DAP & 0,45 & 0,06 & 0,71 & $1,04 \mathrm{E}-03$ & 15,25 \\
\hline $\mathrm{DBH}$ & 0,25 & 0,32 & 0,77 & $2,12 \mathrm{E}-04$ & 20,26 \\
\hline DDX19B & 0,26 & 0,31 & 0,54 & $2,00 \mathrm{E}-02$ & 2,76 \\
\hline DGAT2 & 0,49 & 0,04 & 0,95 & $8,57 \mathrm{E}-10$ & 85,56 \\
\hline
\end{tabular}


Tabela suplementar 8 - Genes contidos no módulo Tan do hipotálamo (continuação).

\begin{tabular}{|c|c|c|c|c|c|}
\hline Gene & SG CA & Valor de P SG CA & FM & Valor de P FM & $\mathbf{K}$ \\
\hline DGKB & 0,58 & 0,01 & 0,99 & $1,11 \mathrm{E}-13$ & 103,06 \\
\hline DKK2 & 0,08 & 0,76 & 0,66 & $2,66 \mathrm{E}-03$ & 8,89 \\
\hline DLX6 & 0,46 & 0,05 & 0,97 & $4,22 \mathrm{E}-11$ & 91,52 \\
\hline DNAJC17 & $-0,46$ & 0,06 & $-0,47$ & $5,12 \mathrm{E}-02$ & 0,84 \\
\hline DOC2B & 0,55 & 0,02 & 0,97 & $8,11 \mathrm{E}-11$ & 93,19 \\
\hline DRD1 & 0,51 & 0,03 & 0,97 & $1,93 \mathrm{E}-11$ & 95,67 \\
\hline DRD2 & 0,49 & 0,04 & 0,83 & $2,51 \mathrm{E}-05$ & 34,10 \\
\hline DRD3 & 0,51 & 0,03 & 0,97 & $8,24 \mathrm{E}-12$ & 96,45 \\
\hline DUSP14 & 0,60 & 0,01 & 0,60 & $8,41 \mathrm{E}-03$ & 5,87 \\
\hline DZIP1 & 0,55 & 0,02 & 0,80 & $6,55 \mathrm{E}-05$ & 31,06 \\
\hline EGR4 & 0,48 & 0,04 & 0,91 & $1,22 \mathrm{E}-07$ & 65,91 \\
\hline EIF3B & 0,67 & 0,00 & 0,76 & $2,74 \mathrm{E}-04$ & 18,09 \\
\hline ELAC1 & $-0,05$ & 0,85 & $-0,59$ & $9,84 \mathrm{E}-03$ & 5,23 \\
\hline ELL & 0,48 & 0,05 & 0,58 & $1,19 \mathrm{E}-02$ & 5,21 \\
\hline EMID1 & 0,47 & 0,05 & 0,89 & $6,99 \mathrm{E}-07$ & 60,76 \\
\hline ENSBTAG00000006110 & 0,54 & 0,02 & 0,98 & $1,18 \mathrm{E}-12$ & 102,14 \\
\hline ENSBTAG00000019887 & 0,53 & 0,03 & 0,90 & $4,80 \mathrm{E}-07$ & 56,47 \\
\hline ENSBTAG00000020205 & 0,51 & 0,03 & 0,95 & $3,11 \mathrm{E}-09$ & 77,72 \\
\hline ENSBTAG00000021729 & 0,43 & 0,07 & 0,91 & $1,14 \mathrm{E}-07$ & 68,67 \\
\hline ENSBTAG00000023806 & 0,56 & 0,02 & 0,51 & $3,21 \mathrm{E}-02$ & 1,95 \\
\hline ENSBTAG00000027787 & $-0,31$ & 0,22 & $-0,33$ & $1,78 \mathrm{E}-01$ & 0,17 \\
\hline ENSBTAG00000037582 & 0,29 & 0,25 & 0,65 & $3,84 \mathrm{E}-03$ & 7,28 \\
\hline ENSBTAG00000038985 & 0,43 & 0,07 & 0,88 & $1,24 \mathrm{E}-06$ & 56,08 \\
\hline ENSBTAG00000039384 & 0,58 & 0,01 & 0,82 & $2,83 \mathrm{E}-05$ & 33,99 \\
\hline ENSBTAG00000043985 & 0,53 & 0,03 & 0,92 & $8,35 \mathrm{E}-08$ & 62,86 \\
\hline ENSBTAG00000045994 & 0,49 & 0,04 & 0,98 & $3,00 \mathrm{E}-12$ & 97,80 \\
\hline ENSBTAG00000046733 & 0,50 & 0,03 & 0,98 & $4,60 \mathrm{E}-13$ & 100,93 \\
\hline ENSBTAG00000047342 & 0,66 & 0,00 & 0,63 & $4,80 \mathrm{E}-03$ & 6,11 \\
\hline ENSBTAG00000047805 & 0,43 & 0,07 & 0,83 & $2,14 \mathrm{E}-05$ & 33,56 \\
\hline EPHB6 & 0,50 & 0,03 & 0,97 & $8,73 \mathrm{E}-11$ & 93,14 \\
\hline ERCC2 & 0,00 & 1,00 & 0,50 & $3,35 \mathrm{E}-02$ & 2,21 \\
\hline FAM171A1 & 0,46 & 0,06 & 0,85 & $8,83 \mathrm{E}-06$ & 44,52 \\
\hline FAM181A & 0,54 & 0,02 & 0,74 & $4,98 \mathrm{E}-04$ & 16,05 \\
\hline FAM189A1 & 0,50 & 0,03 & 0,96 & $4,02 \mathrm{E}-10$ & 91,30 \\
\hline FAM229A & 0,26 & 0,29 & 0,64 & $4,10 \mathrm{E}-03$ & 8,39 \\
\hline FBXL16 & 0,50 & 0,04 & 0,96 & $6,33 \mathrm{E}-10$ & 90,97 \\
\hline FBXO15 & 0,53 & 0,02 & 0,87 & 2,04E-06 & 51,44 \\
\hline FKBP1A & 0,46 & 0,05 & 0,89 & $5,55 \mathrm{E}-07$ & 62,26 \\
\hline FZD3 & 0,48 & 0,04 & 0,74 & $4,54 \mathrm{E}-04$ & 16,05 \\
\hline GABRD & 0,50 & 0,03 & 0,92 & $9,96 \mathrm{E}-08$ & 70,88 \\
\hline GALNT13 & 0,51 & 0,03 & 0,92 & $9,96 \mathrm{E}-08$ & 67,97 \\
\hline GAS2L1 & 0,48 & 0,04 & 0,87 & $2,90 \mathrm{E}-06$ & 53,90 \\
\hline GAS7 & 0,37 & 0,13 & 0,87 & $2,01 \mathrm{E}-06$ & 47,83 \\
\hline GLRA4 & 0,25 & 0,31 & 0,82 & $2,88 \mathrm{E}-05$ & 32,05 \\
\hline GNAL & 0,53 & 0,02 & 0,99 & $5,98 \mathrm{E}-16$ & 107,45 \\
\hline GNG7 & 0,51 & 0,03 & 0,98 & $4,67 \mathrm{E}-12$ & 98,02 \\
\hline GPR21 & 0,47 & 0,05 & 0,93 & $3,17 \mathrm{E}-08$ & 74,05 \\
\hline GPR52 & 0,56 & 0,02 & 0,98 & $1,96 \mathrm{E}-12$ & 97,28 \\
\hline GPR6 & 0,50 & 0,03 & 0,98 & $3,20 \mathrm{E}-13$ & 101,20 \\
\hline GPR88 & 0,52 & 0,03 & 0,98 & $2,24 \mathrm{E}-12$ & 98,42 \\
\hline GPRIN3 & 0,49 & 0,04 & 0,98 & $3,32 \mathrm{E}-13$ & 99,77 \\
\hline GRM3 & 0,23 & 0,37 & 0,58 & $1,18 \mathrm{E}-02$ & 5,61 \\
\hline GUCY1A1 & 0,58 & 0,01 & 0,97 & $3,46 \mathrm{E}-11$ & 92,08 \\
\hline GULP1 & 0,45 & 0,06 & 0,84 & $1,40 \mathrm{E}-05$ & 36,53 \\
\hline HERC6 & 0,45 & 0,06 & 0,91 & $1,53 \mathrm{E}-07$ & 60,92 \\
\hline HEY1 & 0,41 & 0,09 & 0,91 & $1,15 \mathrm{E}-07$ & 64,87 \\
\hline HPDL & 0,70 & 0,00 & 0,66 & $3,01 \mathrm{E}-03$ & 7,90 \\
\hline HRH 2 & 0,47 & 0,05 & 0,91 & $1,82 \mathrm{E}-07$ & 67,90 \\
\hline HTR2A & 0,58 & 0,01 & 0,97 & $9,38 \mathrm{E}-11$ & 88,28 \\
\hline HTR5A & 0,60 & 0,01 & 0,96 & $1,79 \mathrm{E}-10$ & 89,11 \\
\hline IGFBP4 & 0,33 & 0,18 & 0,81 & $5,39 \mathrm{E}-05$ & 28,10 \\
\hline IGFBP6 & 0,42 & 0,08 & 0,67 & $2,27 \mathrm{E}-03$ & 11,97 \\
\hline IPCEF1 & 0,58 & 0,01 & 0,86 & 4,97E-06 & 41,86 \\
\hline
\end{tabular}


Tabela suplementar 8 - Genes contidos no módulo Tan do hipotálamo (continuação).

\begin{tabular}{|c|c|c|c|c|c|}
\hline Gene & SG CA & Valor de P SG CA & FM & Valor de P FM & $\mathbf{K}$ \\
\hline ISLR2 & 0,54 & 0,02 & 0,99 & $3,82 \mathrm{E}-15$ & 106,70 \\
\hline ITM2B & 0,12 & 0,64 & $-0,49$ & $3,98 \mathrm{E}-02$ & 2,50 \\
\hline ITPKA & 0,49 & 0,04 & 0,95 & 2,29E-09 & 85,74 \\
\hline KCNAB1 & 0,46 & 0,05 & 0,93 & $3,79 \mathrm{E}-08$ & 76,23 \\
\hline KCNG1 & 0,51 & 0,03 & 0,97 & $3,48 \mathrm{E}-11$ & 91,92 \\
\hline KCNK2 & 0,49 & 0,04 & 0,98 & $9,43 \mathrm{E}-13$ & 99,99 \\
\hline KCNQ5 & 0,58 & 0,01 & 0,97 & $9,50 \mathrm{E}-12$ & 96,76 \\
\hline KCTD1 & 0,48 & 0,04 & 0,88 & $1,62 \mathrm{E}-06$ & 58,47 \\
\hline KIF17 & 0,48 & 0,04 & 0,90 & $5,06 \mathrm{E}-07$ & 60,62 \\
\hline KLHL2 & 0,47 & 0,05 & 0,93 & $2,45 \mathrm{E}-08$ & 73,72 \\
\hline LCLAT1 & 0,54 & 0,02 & 0,57 & $1,43 \mathrm{E}-02$ & 3,82 \\
\hline LDHA & 0,55 & 0,02 & 0,97 & $9,48 \mathrm{E}-12$ & 95,50 \\
\hline LINGO3 & 0,55 & 0,02 & 0,93 & $1,43 \mathrm{E}-08$ & 77,51 \\
\hline LIPT1 & $-0,32$ & 0,19 & $-0,49$ & $3,77 \mathrm{E}-02$ & 1,35 \\
\hline LIX1L & 0,20 & 0,42 & $-0,41$ & $9,13 \mathrm{E}-02$ & 0,73 \\
\hline LPL & 0,48 & 0,04 & 0,97 & $1,60 \mathrm{E}-11$ & 97,24 \\
\hline LRRC56 & 0,50 & 0,03 & 0,88 & $1,97 \mathrm{E}-06$ & 50,86 \\
\hline LRRC75A & 0,58 & 0,01 & 0,61 & $6,64 \mathrm{E}-03$ & 7,49 \\
\hline LRRTM3 & 0,50 & 0,03 & 0,89 & $8,86 \mathrm{E}-07$ & 56,16 \\
\hline LZTS1 & 0,52 & 0,03 & 0,98 & $3,10 \mathrm{E}-12$ & 100,22 \\
\hline MAN1A1 & 0,58 & 0,01 & 0,94 & $7,87 \mathrm{E}-09$ & 77,02 \\
\hline MAPK4 & 0,67 & 0,00 & 0,88 & $1,70 \mathrm{E}-06$ & 51,93 \\
\hline MBD2 & 0,37 & 0,13 & 0,73 & $6,19 \mathrm{E}-04$ & 15,33 \\
\hline MBNL2 & 0,30 & 0,22 & 0,56 & $1,47 \mathrm{E}-02$ & 4,45 \\
\hline MCHR1 & 0,50 & 0,04 & 0,89 & $6,81 \mathrm{E}-07$ & 61,21 \\
\hline MEIS2 & 0,46 & 0,06 & 0,91 & $2,07 \mathrm{E}-07$ & 62,38 \\
\hline MFSD8 & 0,04 & 0,87 & $-0,53$ & $2,26 \mathrm{E}-02$ & 2,00 \\
\hline MGME1 & 0,06 & 0,81 & $-0,58$ & $1,10 \mathrm{E}-02$ & 5,27 \\
\hline MN1 & 0,65 & 0,00 & 0,97 & $9,18 \mathrm{E}-12$ & 94,91 \\
\hline MPPE1 & 0,57 & 0,01 & 0,90 & $2,74 \mathrm{E}-07$ & 62,52 \\
\hline MPPED2 & 0,52 & 0,03 & 0,88 & $1,37 \mathrm{E}-06$ & 51,66 \\
\hline MPRIP & 0,40 & 0,10 & 0,90 & $4,20 \mathrm{E}-07$ & 60,05 \\
\hline MSRA & $-0,18$ & 0,48 & $-0,56$ & $1,67 \mathrm{E}-02$ & 3,19 \\
\hline NAA80 & 0,60 & 0,01 & 0,64 & $4,62 \mathrm{E}-03$ & 6,68 \\
\hline NADK & 0,46 & 0,06 & 0,91 & $2,40 \mathrm{E}-07$ & 57,85 \\
\hline NCKAP1L & 0,40 & 0,10 & 0,81 & $4,73 \mathrm{E}-05$ & 28,94 \\
\hline NEURL1 & 0,55 & 0,02 & 0,95 & $1,53 \mathrm{E}-09$ & 81,65 \\
\hline NGEF & 0,54 & 0,02 & 1,00 & $5,59 \mathrm{E}-19$ & 110,42 \\
\hline NGFR & 0,32 & 0,20 & 0,62 & $5,58 \mathrm{E}-03$ & 8,90 \\
\hline NMRK2 & 0,59 & 0,01 & 0,86 & $3,62 \mathrm{E}-06$ & 43,51 \\
\hline NPB & 0,42 & 0,08 & 0,91 & $2,15 \mathrm{E}-07$ & 58,32 \\
\hline OPRK1 & 0,32 & 0,19 & 0,79 & $1,10 \mathrm{E}-04$ & 25,03 \\
\hline PBX3 & 0,51 & 0,03 & 0,88 & $1,28 \mathrm{E}-06$ & 48,90 \\
\hline PCP4L1 & 0,56 & 0,02 & 0,86 & $5,64 \mathrm{E}-06$ & 42,46 \\
\hline PDE10A & 0,52 & 0,03 & 0,98 & $1,35 \mathrm{E}-13$ & 102,71 \\
\hline PDE1B & 0,52 & 0,03 & 0,96 & $6,04 \mathrm{E}-10$ & 89,04 \\
\hline PDE1C & 0,55 & 0,02 & 0,97 & $1,66 \mathrm{E}-11$ & 92,91 \\
\hline PDE7B & 0,53 & 0,02 & 0,98 & $4,56 \mathrm{E}-12$ & 95,77 \\
\hline PEAK1 & 0,42 & 0,09 & 0,75 & $3,12 \mathrm{E}-04$ & 18,11 \\
\hline PENK & 0,48 & 0,04 & 0,95 & $1,80 \mathrm{E}-09$ & 78,79 \\
\hline PHACTR1 & 0,53 & 0,02 & 0,97 & $5,09 \mathrm{E}-11$ & 92,45 \\
\hline PKIG & 0,49 & 0,04 & 0,87 & $2,39 \mathrm{E}-06$ & 48,40 \\
\hline PLAGL1 & 0,14 & 0,57 & 0,70 & $1,21 \mathrm{E}-03$ & 11,31 \\
\hline PLCL2 & 0,58 & 0,01 & 0,88 & $1,20 \mathrm{E}-06$ & 52,44 \\
\hline PLXND1 & 0,55 & 0,02 & 0,94 & $1,16 \mathrm{E}-08$ & 76,80 \\
\hline PMEPA1 & 0,56 & 0,02 & 0,94 & $8,52 \mathrm{E}-09$ & 72,09 \\
\hline PPP1R16B & 0,33 & 0,18 & 0,76 & $2,53 \mathrm{E}-04$ & 23,63 \\
\hline PPP1R1B & 0,55 & 0,02 & 0,97 & $1,91 \mathrm{E}-11$ & 94,39 \\
\hline PPP2R2A & 0,40 & 0,10 & 0,80 & $7,10 \mathrm{E}-05$ & 27,31 \\
\hline PRKCB & 0,48 & 0,04 & 0,92 & $6,90 \mathrm{E}-08$ & 73,40 \\
\hline PRKCQ & 0,49 & 0,04 & 0,76 & $2,80 \mathrm{E}-04$ & 19,07 \\
\hline PRSS53 & 0,42 & 0,08 & 0,87 & $2,26 \mathrm{E}-06$ & 49,48 \\
\hline PTPN5 & 0,60 & 0,01 & 0,96 & $2,78 \mathrm{E}-10$ & 86,61 \\
\hline
\end{tabular}


Tabela suplementar 8 - Genes contidos no módulo Tan do hipotálamo (continuação).

\begin{tabular}{|c|c|c|c|c|c|}
\hline Gene & SG CA & Valor de P SG CA & FM & Valor de P FM & $\mathbf{K}$ \\
\hline PXK & $-0,13$ & 0,61 & $-0,50$ & $3,65 \mathrm{E}-02$ & 2,03 \\
\hline RAP1GAP & 0,46 & 0,05 & 0,92 & 4,39E-08 & 73,16 \\
\hline RARB & 0,45 & 0,06 & 0,91 & $2,31 \mathrm{E}-07$ & 65,53 \\
\hline RASD2 & 0,52 & 0,03 & 0,98 & $4,09 \mathrm{E}-13$ & 102,94 \\
\hline RASGRP2 & 0,45 & 0,06 & 0,60 & $8,50 \mathrm{E}-03$ & 5,33 \\
\hline RASSF1 & 0,07 & 0,77 & 0,50 & $3,48 \mathrm{E}-02$ & 1,91 \\
\hline RF00580 & 0,56 & 0,02 & 0,76 & $2,26 \mathrm{E}-04$ & 19,18 \\
\hline RGS14 & 0,52 & 0,03 & 0,97 & $7,82 \mathrm{E}-12$ & 98,42 \\
\hline RGS9 & 0,51 & 0,03 & 0,96 & $5,14 \mathrm{E}-10$ & 88,14 \\
\hline RHBDD3 & $-0,22$ & 0,39 & $-0,60$ & $8,00 \mathrm{E}-03$ & 5,65 \\
\hline RIC8B & 0,52 & 0,03 & 0,94 & 7,31E-09 & 76,63 \\
\hline RILP & $-0,08$ & 0,74 & $-0,57$ & $1,38 \mathrm{E}-02$ & 3,71 \\
\hline RINL & 0,21 & 0,39 & 0,77 & $2,06 \mathrm{E}-04$ & 22,22 \\
\hline RNF144A & 0,16 & 0,54 & 0,66 & $3,01 \mathrm{E}-03$ & 9,11 \\
\hline RPRML & 0,53 & 0,02 & 0,98 & $2,12 \mathrm{E}-12$ & 99,22 \\
\hline RPS6KA4 & 0,57 & 0,01 & 0,92 & $4,21 \mathrm{E}-08$ & 70,20 \\
\hline RPS6KA5 & 0,54 & 0,02 & 0,92 & $9,04 \mathrm{E}-08$ & 63,93 \\
\hline RXRG & 0,35 & 0,16 & 0,76 & $2,48 \mathrm{E}-04$ & 21,55 \\
\hline SERPINB1 & 0,37 & 0,13 & 0,71 & $1,04 \mathrm{E}-03$ & 15,64 \\
\hline SERTAD4 & 0,38 & 0,12 & 0,71 & $1,03 \mathrm{E}-03$ & 15,31 \\
\hline SHMT2 & $-0,09$ & 0,71 & $-0,43$ & 7,27E-02 & 0,62 \\
\hline SLC22A18 & 0,60 & 0,01 & 0,91 & $1,58 \mathrm{E}-07$ & 61,13 \\
\hline SLC35E4 & 0,34 & 0,16 & 0,76 & $2,91 \mathrm{E}-04$ & 20,83 \\
\hline SMAD3 & 0,54 & 0,02 & 0,91 & $2,27 \mathrm{E}-07$ & 62,10 \\
\hline SMAD7 & 0,47 & 0,05 & 0,97 & $8,25 \mathrm{E}-11$ & 89,18 \\
\hline SMPD3 & 0,47 & 0,05 & 0,91 & $1,81 \mathrm{E}-07$ & 67,73 \\
\hline SMURF2 & 0,44 & 0,07 & 0,72 & $7,78 \mathrm{E}-04$ & 15,10 \\
\hline SNX15 & $-0,30$ & 0,22 & $-0,49$ & $3,70 \mathrm{E}-02$ & 1,93 \\
\hline SOAT1 & 0,52 & 0,03 & 0,92 & $9,88 \mathrm{E}-08$ & 66,65 \\
\hline SORCS1 & 0,38 & 0,12 & 0,86 & $3,71 \mathrm{E}-06$ & 43,78 \\
\hline SPRED1 & 0,44 & 0,06 & 0,75 & $3,58 \mathrm{E}-04$ & 18,17 \\
\hline SYNDIG1 & 0,66 & 0,00 & 0,95 & $2,64 \mathrm{E}-09$ & 80,49 \\
\hline SYNDIG1L & 0,55 & 0,02 & 0,97 & $6,01 \mathrm{E}-11$ & 92,02 \\
\hline SYNPR & 0,49 & 0,04 & 0,95 & $1,35 \mathrm{E}-09$ & 86,25 \\
\hline SYT6 & 0,39 & 0,11 & 0,74 & 4,33E-04 & 18,27 \\
\hline TAC1 & 0,48 & 0,05 & 0,85 & $7,03 \mathrm{E}-06$ & 39,90 \\
\hline TBL1X & 0,46 & 0,05 & 0,76 & $2,44 \mathrm{E}-04$ & 20,45 \\
\hline TIMP4 & $-0,03$ & 0,92 & $-0,59$ & $1,00 \mathrm{E}-02$ & 3,76 \\
\hline TLE4 & 0,47 & 0,05 & 0,87 & $2,32 \mathrm{E}-06$ & 45,49 \\
\hline TLNRD1 & 0,26 & 0,29 & 0,90 & $5,31 \mathrm{E}-07$ & 56,37 \\
\hline TMEM158 & 0,50 & 0,04 & 0,97 & $7,91 \mathrm{E}-11$ & 93,54 \\
\hline TMEM200B & 0,25 & 0,32 & 0,71 & $9,45 \mathrm{E}-04$ & 13,99 \\
\hline TOMM20 & 0,51 & 0,03 & 0,87 & $3,55 \mathrm{E}-06$ & 53,42 \\
\hline TOMM70 & 0,49 & 0,04 & 0,88 & $1,91 \mathrm{E}-06$ & 55,65 \\
\hline TRERF1 & 0,50 & 0,03 & 0,97 & $9,00 \mathrm{E}-11$ & 91,80 \\
\hline TRIM35 & $-0,56$ & 0,02 & $-0,50$ & $3,36 \mathrm{E}-02$ & 1,50 \\
\hline TRIM52 & 0,27 & 0,27 & 0,58 & $1,12 \mathrm{E}-02$ & 4,12 \\
\hline TRPV6 & 0,47 & 0,05 & 0,95 & $8,93 \mathrm{E}-10$ & 87,14 \\
\hline TSPAN9 & 0,54 & 0,02 & 0,97 & $2,04 \mathrm{E}-11$ & 94,48 \\
\hline TSSK3 & 0,52 & 0,03 & 0,78 & $1,32 \mathrm{E}-04$ & 24,58 \\
\hline UFD1 & 0,56 & 0,01 & 0,97 & $4,64 \mathrm{E}-11$ & 88,11 \\
\hline USH1G & 0,52 & 0,03 & 0,98 & $4,64 \mathrm{E}-13$ & 100,52 \\
\hline USP48 & 0,50 & 0,03 & 0,90 & $4,32 \mathrm{E}-07$ & 59,33 \\
\hline UTRN & 0,45 & 0,06 & 0,55 & $1,90 \mathrm{E}-02$ & 3,16 \\
\hline VTI1B & 0,43 & 0,07 & 0,71 & $1,07 \mathrm{E}-03$ & 12,59 \\
\hline WFS 1 & 0,57 & 0,01 & 0,99 & $9,26 \mathrm{E}-16$ & 106,58 \\
\hline YPEL1 & 0,47 & 0,05 & 0,90 & $2,95 \mathrm{E}-07$ & 62,40 \\
\hline ZBTB1 & 0,65 & 0,00 & 0,51 & $3,25 \mathrm{E}-02$ & 2,09 \\
\hline ZBTB14 & 0,17 & 0,50 & 0,61 & $7,51 \mathrm{E}-03$ & 5,01 \\
\hline ZNF467 & 0,55 & 0,02 & 0,91 & $1,41 \mathrm{E}-07$ & 61,59 \\
\hline ZNF526 & 0,53 & 0,02 & 0,89 & $7,01 \mathrm{E}-07$ & 52,60 \\
\hline ZNF710 & 0,39 & 0,11 & 0,56 & $1,53 \mathrm{E}-02$ & 3,20 \\
\hline ZNRF2 & $-0,25$ & 0,32 & $-0,44$ & $6,64 \mathrm{E}-02$ & 0,65 \\
\hline ZSWIM5 & 0,56 & 0,02 & 0,88 & $1,29 \mathrm{E}-06$ & 55,00 \\
\hline
\end{tabular}


Tabela suplementar 9 - Genes contidos no módulo Pink do hipotálamo.

\begin{tabular}{|c|c|c|c|c|c|}
\hline Gene & SG CA & Valor de P SG CA & FM & Valor de P FM & $\mathbf{K}$ \\
\hline ABHD17C & 0,64 & $4,25 \mathrm{E}-03$ & 0,44 & $6,83 \mathrm{E}-02$ & 58,82 \\
\hline ACADVL & 0,08 & 0,75 & 0,63 & $4,66 \mathrm{E}-03$ & 2,59 \\
\hline ACAT2 & $-1,03 \mathrm{E}-04$ & 1,00 & $-0,40$ & $9,72 \mathrm{E}-02$ & 3,44 \\
\hline ACSS1 & 0,61 & 0,01 & 0,79 & $9,54 \mathrm{E}-05$ & 14,58 \\
\hline ACTR3 & 0,46 & 0,05 & 0,99 & $9,11 \mathrm{E}-14$ & 50,47 \\
\hline ACVR1C & 0,53 & 0,02 & 0,84 & $1,29 \mathrm{E}-05$ & 98,16 \\
\hline ADGRB2 & 0,42 & 0,08 & 0,98 & $5,07 \mathrm{E}-12$ & 86,82 \\
\hline ADGRE5 & $-0,32$ & 0,19 & 0,84 & $1,18 \mathrm{E}-05$ & 10,63 \\
\hline AFAP1 & 0,16 & 0,54 & 0,59 & $1,01 \mathrm{E}-02$ & 12,10 \\
\hline AGAP2 & 0,42 & 0,08 & 0,98 & $5,88 \mathrm{E}-12$ & 105,13 \\
\hline AJM1 & 0,49 & 0,04 & 0,92 & $7,39 \mathrm{E}-08$ & 63,87 \\
\hline AKAP1 & 0,50 & 0,04 & 0,96 & $2,60 \mathrm{E}-10$ & 4,60 \\
\hline AMZ1 & 0,39 & 0,11 & 0,82 & $3,28 \mathrm{E}-05$ & 28,21 \\
\hline ANAPC11 & $-0,21$ & 0,41 & 0,77 & $2,15 \mathrm{E}-04$ & 4,17 \\
\hline ANKH & 0,27 & 0,28 & 0,75 & $3,51 \mathrm{E}-04$ & 1,53 \\
\hline ANKRD11 & 0,34 & 0,17 & 0,94 & $5,75 \mathrm{E}-09$ & 61,18 \\
\hline ANKRD33B & 0,42 & 0,08 & 0,80 & $7,41 \mathrm{E}-05$ & 99,66 \\
\hline APH1A & $-0,31$ & 0,20 & $-0,58$ & $1,17 \mathrm{E}-02$ & 18,35 \\
\hline API5 & 0,55 & 0,02 & 0,79 & $9,08 \mathrm{E}-05$ & 38,24 \\
\hline ARHGAP33 & 0,25 & 0,31 & $-0,52$ & $2,63 \mathrm{E}-02$ & 30,46 \\
\hline ARHGEF3 & 0,36 & 0,14 & 0,95 & $2,14 \mathrm{E}-09$ & 61,47 \\
\hline ASPHD1 & 0,64 & $4,34 \mathrm{E}-03$ & 0,89 & $5,68 \mathrm{E}-07$ & 71,76 \\
\hline BACE2 & $-0,44$ & 0,06 & 0,92 & $6,27 \mathrm{E}-08$ & 8,09 \\
\hline BAG5 & 0,51 & 0,03 & 0,94 & $1,16 \mathrm{E}-08$ & 87,61 \\
\hline BAHCC1 & 0,18 & 0,46 & $-0,61$ & $7,26 \mathrm{E}-03$ & 29,36 \\
\hline BAIAP2 & 0,49 & 0,04 & 0,81 & $4,23 \mathrm{E}-05$ & 104,70 \\
\hline BCAR3 & $-0,14$ & 0,59 & 0,59 & $9,56 \mathrm{E}-03$ & 1,47 \\
\hline BMP1 & 0,48 & 0,04 & 0,75 & $3,36 \mathrm{E}-04$ & 6,09 \\
\hline BPTF & 0,24 & 0,34 & 0,53 & $2,35 \mathrm{E}-02$ & 7,71 \\
\hline BRAT1 & $-0,36$ & 0,15 & $-0,54$ & $2,00 \mathrm{E}-02$ & 8,36 \\
\hline BRF1 & 0,20 & 0,42 & $-0,52$ & $2,85 \mathrm{E}-02$ & 3,66 \\
\hline BZW2 & 0,16 & 0,53 & $-0,66$ & $3,01 \mathrm{E}-03$ & 5,66 \\
\hline C10H15orf48 & $-0,11$ & 0,66 & 0,55 & $1,69 \mathrm{E}-02$ & 1,26 \\
\hline C15H11orf42 & 0,14 & 0,59 & $-0,47$ & $4,93 \mathrm{E}-02$ & 27,53 \\
\hline C29H11orf95 & 0,39 & 0,11 & 0,87 & $2,79 \mathrm{E}-06$ & 104,87 \\
\hline C6H4orf19 & 0,55 & 0,02 & 0,56 & $1,48 \mathrm{E}-02$ & 61,52 \\
\hline $\mathrm{C} 8 \mathrm{G}$ & $-0,28$ & 0,26 & 0,89 & $9,67 \mathrm{E}-07$ & 2,63 \\
\hline CA11 & 0,50 & 0,04 & 0,76 & $2,78 \mathrm{E}-04$ & 70,78 \\
\hline CABIN1 & 0,28 & 0,27 & 0,37 & $1,35 \mathrm{E}-01$ & 7,28 \\
\hline CACNA1E & 0,33 & 0,18 & 0,80 & $7,29 \mathrm{E}-05$ & 84,53 \\
\hline CACNB1 & 0,46 & 0,05 & 0,95 & $3,01 \mathrm{E}-09$ & 66,16 \\
\hline CACNG3 & 0,41 & 0,09 & 0,90 & $3,94 \mathrm{E}-07$ & 106,25 \\
\hline CALN1 & 0,52 & 0,03 & 0,78 & $1,54 \mathrm{E}-04$ & 96,79 \\
\hline CAMK1D & 0,40 & 0,10 & 0,94 & $1,15 \mathrm{E}-08$ & 108,13 \\
\hline CAMK1G & 0,43 & 0,08 & 0,98 & $5,99 \mathrm{E}-13$ & 110,28 \\
\hline CAMK2B & 0,39 & 0,11 & 0,97 & $9,79 \mathrm{E}-12$ & 74,59 \\
\hline CAMSAP2 & 0,33 & 0,18 & 0,84 & $1,11 \mathrm{E}-05$ & 68,41 \\
\hline CAP2 & 0,40 & 0,10 & 0,97 & $1,49 \mathrm{E}-11$ & 98,55 \\
\hline CARNMT1 & 0,46 & 0,05 & 0,98 & $1,16 \mathrm{E}-12$ & 78,21 \\
\hline CAVIN4 & 0,14 & 0,57 & $-0,41$ & $8,81 \mathrm{E}-02$ & 16,45 \\
\hline CCDC28B & $-0,26$ & 0,31 & 0,82 & $2,69 \mathrm{E}-05$ & 2,21 \\
\hline CCDC84 & $-0,22$ & 0,39 & 0,75 & $3,88 \mathrm{E}-04$ & 1,93 \\
\hline CCDC97 & 0,28 & 0,25 & $-0,58$ & $1,24 \mathrm{E}-02$ & 23,84 \\
\hline CCKBR & 0,41 & 0,09 & 0,62 & $5,81 \mathrm{E}-03$ & 102,39 \\
\hline CCNA1 & 0,59 & 0,01 & 0,56 & $1,60 \mathrm{E}-02$ & 34,40 \\
\hline CCNY & 0,21 & 0,40 & $-0,54$ & $1,99 \mathrm{E}-02$ & 26,22 \\
\hline CCS & $-0,38$ & 0,11 & 0,89 & $7,53 \mathrm{E}-07$ & 15,58 \\
\hline CCSAP & 0,05 & 0,84 & $-0,51$ & $3,06 \mathrm{E}-02$ & 9,64 \\
\hline $\mathrm{CDC} 40$ & 0,52 & 0,03 & 0,54 & $2,18 \mathrm{E}-02$ & 50,13 \\
\hline CDC42SE2 & 0,35 & 0,16 & $-0,54$ & $2,18 \mathrm{E}-02$ & 27,03 \\
\hline CDH9 & 0,38 & 0,12 & 0,88 & $1,96 \mathrm{E}-06$ & 93,71 \\
\hline CDK17 & 0,36 & 0,15 & $-0,63$ & $4,81 \mathrm{E}-03$ & 89,39 \\
\hline CDK18 & $-0,43$ & 0,08 & 0,98 & $1,86 \mathrm{E}-13$ & 8,91 \\
\hline
\end{tabular}


Tabela suplementar 9 - Genes contidos no módulo Pink do hipotálamo (continuação).

\begin{tabular}{|c|c|c|c|c|c|}
\hline Gene & SG CA & Valor de P SG CA & FM & Valor de P FM & $\mathbf{K}$ \\
\hline CELF1 & 0,29 & 0,25 & 0,61 & $7,14 \mathrm{E}-03$ & 70,50 \\
\hline CELF3 & 0,31 & 0,21 & 0,84 & $1,03 \mathrm{E}-05$ & 70,35 \\
\hline CELF5 & 0,34 & 0,17 & 0,91 & $1,98 \mathrm{E}-07$ & 74,26 \\
\hline CEP85 & 0,25 & 0,32 & 0,68 & $2,03 \mathrm{E}-03$ & 8,42 \\
\hline CEP85L & 0,57 & 0,01 & 0,77 & $1,71 \mathrm{E}-04$ & 6,79 \\
\hline CETN4 & 0,35 & 0,15 & 0,95 & 2,31E-09 & 46,05 \\
\hline CHD2 & 0,13 & 0,60 & 0,80 & $7,18 \mathrm{E}-05$ & 10,89 \\
\hline CHI3L1 & 0,53 & 0,02 & 0,97 & $1,27 \mathrm{E}-11$ & 3,26 \\
\hline CHRM1 & 0,45 & 0,06 & 0,85 & $8,65 \mathrm{E}-06$ & 91,96 \\
\hline CHTF8 & 0,50 & 0,04 & 0,57 & $1,36 \mathrm{E}-02$ & 23,43 \\
\hline CIC & 0,50 & 0,03 & 0,94 & $9,53 \mathrm{E}-09$ & 93,73 \\
\hline CNIH3 & 0,51 & 0,03 & 0,74 & $4,12 \mathrm{E}-04$ & 80,03 \\
\hline CNKSR2 & 0,37 & 0,13 & 0,96 & $1,13 \mathrm{E}-10$ & 98,53 \\
\hline CNOT6 & 0,27 & 0,27 & 0,89 & $9,50 \mathrm{E}-07$ & 5,85 \\
\hline CNR1 & 0,48 & 0,04 & 0,87 & 2,41E-06 & 93,74 \\
\hline COL4A2 & $-0,23$ & 0,37 & $-0,73$ & 5,89E-04 & 1,25 \\
\hline CPLX2 & 0,46 & 0,05 & 0,63 & $5,13 \mathrm{E}-03$ & 103,00 \\
\hline CRISPLD1 & 0,04 & 0,86 & $-0,50$ & 3,37E-02 & 4,07 \\
\hline CRYL1 & 0,42 & 0,08 & 0,93 & $1,40 \mathrm{E}-08$ & 32,74 \\
\hline CSRP2 & $-0,11$ & 0,67 & $-0,45$ & $5,87 \mathrm{E}-02$ & 16,94 \\
\hline CTXN1 & 0,46 & 0,05 & 0,98 & $4,57 \mathrm{E}-13$ & 98,28 \\
\hline CUL9 & 0,13 & 0,61 & $-0,56$ & $1,48 \mathrm{E}-02$ & 2,60 \\
\hline CYGB & 0,52 & 0,03 & 0,88 & 1,39E-06 & 30,54 \\
\hline DBN1 & 0,41 & 0,09 & 0,96 & $1,06 \mathrm{E}-10$ & 10,25 \\
\hline DDN & 0,45 & 0,06 & 0,92 & $6,19 \mathrm{E}-08$ & 99,27 \\
\hline DDR1 & 0,08 & 0,76 & $-0,47$ & $4,88 \mathrm{E}-02$ & 6,89 \\
\hline DENND4B & 0,37 & 0,13 & 0,79 & $9,19 \mathrm{E}-05$ & 9,29 \\
\hline DESI2 & 0,36 & 0,14 & 0,88 & $1,64 \mathrm{E}-06$ & 3,18 \\
\hline DGKA & $-0,05$ & 0,85 & $-0,59$ & $1,07 \mathrm{E}-02$ & 4,26 \\
\hline DGKD & 0,27 & 0,27 & 0,61 & $6,96 \mathrm{E}-03$ & 55,77 \\
\hline DGUOK & $-0,31$ & 0,21 & 0,90 & $3,28 \mathrm{E}-07$ & 5,13 \\
\hline DHCR7 & $-0,08$ & 0,77 & $-0,60$ & $8,66 \mathrm{E}-03$ & 9,76 \\
\hline DHRS12 & $-0,09$ & 0,73 & $-0,41$ & $8,81 \mathrm{E}-02$ & 2,97 \\
\hline DHX34 & 0,22 & 0,39 & 0,47 & $5,10 \mathrm{E}-02$ & 11,13 \\
\hline DLK2 & 0,44 & 0,07 & 0,75 & $3,31 \mathrm{E}-04$ & 60,35 \\
\hline DMTN & 0,45 & 0,06 & 0,99 & $9,33 \mathrm{E}-14$ & 54,80 \\
\hline DOK4 & 0,54 & 0,02 & 0,88 & $1,60 \mathrm{E}-06$ & 38,53 \\
\hline DPH2 & 0,28 & 0,26 & $-0,63$ & $4,83 \mathrm{E}-03$ & 28,07 \\
\hline DPYSL4 & 0,34 & 0,16 & 0,93 & $3,61 \mathrm{E}-08$ & 88,74 \\
\hline DSEL & 0,11 & 0,66 & $-0,78$ & $1,51 \mathrm{E}-04$ & 4,12 \\
\hline DTNB & 0,47 & 0,05 & 0,68 & $1,73 \mathrm{E}-03$ & 48,04 \\
\hline EFHD2 & $-0,54$ & 0,02 & 0,95 & $2,91 \mathrm{E}-09$ & 13,15 \\
\hline EFNB2 & 0,23 & 0,37 & $-0,44$ & $6,99 \mathrm{E}-02$ & 15,18 \\
\hline EGR3 & 0,42 & 0,08 & 0,87 & $2,36 \mathrm{E}-06$ & 71,43 \\
\hline ELK1 & 0,43 & 0,07 & 0,98 & $4,70 \mathrm{E}-13$ & 108,68 \\
\hline EMP2 & 0,03 & 0,90 & $-0,43$ & $7,65 \mathrm{E}-02$ & 6,33 \\
\hline ENOX1 & 0,39 & 0,11 & $-0,57$ & $1,30 \mathrm{E}-02$ & 85,07 \\
\hline ENSBTAG00000002950 & 0,51 & 0,03 & 0,84 & $1,02 \mathrm{E}-05$ & 73,59 \\
\hline ENSBTAG00000003580 & 0,43 & 0,07 & 0,97 & $3,13 \mathrm{E}-11$ & 107,62 \\
\hline ENSBTAG00000011113 & 0,37 & 0,13 & 0,41 & $9,18 \mathrm{E}-02$ & 89,69 \\
\hline ENSBTAG00000011984 & 0,37 & 0,13 & 0,92 & $5,88 \mathrm{E}-08$ & 6,78 \\
\hline ENSBTAG00000017645 & $-0,36$ & 0,15 & 0,82 & $3,52 \mathrm{E}-05$ & 4,08 \\
\hline ENSBTAG00000021011 & 0,55 & 0,02 & 0,74 & $4,71 \mathrm{E}-04$ & 40,76 \\
\hline ENSBTAG00000027868 & 0,38 & 0,12 & 0,97 & $7,10 \mathrm{E}-11$ & 80,92 \\
\hline ENSBTAG00000032450 & 0,04 & 0,87 & 0,43 & $7,22 \mathrm{E}-02$ & 8,61 \\
\hline ENSBTAG00000033749 & $-0,04$ & 0,87 & $-0,64$ & $4,59 \mathrm{E}-03$ & 3,05 \\
\hline ENSBTAG00000045685 & 0,57 & 0,01 & 0,90 & $3,78 \mathrm{E}-07$ & 2,71 \\
\hline ENSBTAG00000045689 & 0,10 & 0,69 & $-0,65$ & $3,63 \mathrm{E}-03$ & 4,57 \\
\hline ENSBTAG00000045881 & 0,18 & 0,48 & $-0,54$ & $2,19 \mathrm{E}-02$ & 12,07 \\
\hline ENSBTAG00000046336 & 0,41 & 0,09 & 0,98 & $1,08 \mathrm{E}-12$ & 85,96 \\
\hline ENSBTAG00000046752 & 0,43 & 0,08 & 0,98 & $2,92 \mathrm{E}-13$ & 104,20 \\
\hline ENSBTAG00000046795 & 0,22 & 0,38 & $-0,44$ & $6,88 \mathrm{E}-02$ & 16,79 \\
\hline ENSBTAG00000047265 & 0,07 & 0,80 & $-0,43$ & 7,64E-02 & 14,32 \\
\hline
\end{tabular}


Tabela suplementar 9 - Genes contidos no módulo Pink do hipotálamo (continuação).

\begin{tabular}{|c|c|c|c|c|c|}
\hline Gene & SG CA & Valor de P SG CA & FM & Valor de P FM & $\mathbf{K}$ \\
\hline ENSBTAG00000047776 & $-0,14$ & 0,59 & $-0,46$ & $5,36 \mathrm{E}-02$ & 2,76 \\
\hline EOGT & 0,34 & 0,17 & 0,92 & 7,84E-08 & 15,30 \\
\hline EPB41L1 & 0,40 & 0,10 & 0,98 & $3,28 \mathrm{E}-13$ & 44,61 \\
\hline EPS8 & 0,13 & 0,60 & 0,46 & $5,21 \mathrm{E}-02$ & 5,98 \\
\hline ERCC6 & 0,25 & 0,31 & 0,80 & $5,87 \mathrm{E}-05$ & 10,58 \\
\hline EVC & 0,42 & 0,08 & 0,93 & $1,40 \mathrm{E}-08$ & 30,92 \\
\hline FAHD2A & $-0,11$ & 0,67 & $-0,55$ & $1,83 \mathrm{E}-02$ & 3,13 \\
\hline FAM117A & 0,49 & 0,04 & 0,86 & $5,49 \mathrm{E}-06$ & 45,46 \\
\hline FAM208B & 0,36 & 0,14 & 0,97 & $6,06 \mathrm{E}-11$ & 56,91 \\
\hline FBXL18 & 0,31 & 0,20 & $-0,74$ & $4,70 \mathrm{E}-04$ & 81,89 \\
\hline FBXO44 & 0,47 & 0,05 & 0,77 & $2,17 \mathrm{E}-04$ & 91,95 \\
\hline FDFT1 & $-0,18$ & 0,48 & 0,79 & $8,15 \mathrm{E}-05$ & 4,36 \\
\hline FEM1A & 0,47 & 0,05 & 0,92 & $5,28 \mathrm{E}-08$ & 44,23 \\
\hline FGD1 & 0,32 & 0,20 & 0,92 & $9,72 \mathrm{E}-08$ & 74,84 \\
\hline FGD3 & 0,09 & 0,73 & $-0,53$ & $2,38 \mathrm{E}-02$ & 3,35 \\
\hline FGF13 & 0,47 & 0,05 & 0,96 & $1,38 \mathrm{E}-10$ & 99,83 \\
\hline FGFR3 & 0,09 & 0,72 & 0,57 & $1,31 \mathrm{E}-02$ & 4,72 \\
\hline FILIP1 & 0,36 & 0,14 & $-0,53$ & $2,26 \mathrm{E}-02$ & 83,51 \\
\hline FOXO1 & 0,55 & 0,02 & 0,85 & $9,03 \mathrm{E}-06$ & 42,61 \\
\hline GALNT15 & 0,46 & 0,05 & 0,86 & $4,48 \mathrm{E}-06$ & 78,59 \\
\hline GIPC1 & $-0,36$ & 0,14 & 0,92 & 5,79E-08 & 4,29 \\
\hline GJB2 & 0,50 & 0,03 & 0,93 & $1,59 \mathrm{E}-08$ & 79,02 \\
\hline GPAM & $-0,06$ & 0,82 & $-0,61$ & $6,68 \mathrm{E}-03$ & 11,72 \\
\hline GRASP & 0,39 & 0,11 & 0,90 & $2,63 \mathrm{E}-07$ & 46,40 \\
\hline GRB10 & $-0,16$ & 0,54 & 0,69 & $1,53 \mathrm{E}-03$ & 2,69 \\
\hline GRIFIN & $-0,06$ & 0,83 & $-0,67$ & $2,19 \mathrm{E}-03$ & 2,76 \\
\hline HACD1 & $-0,05$ & 0,84 & 0,63 & $4,81 \mathrm{E}-03$ & 5,45 \\
\hline HACD2 & 0,34 & 0,17 & 0,71 & $8,76 \mathrm{E}-04$ & 9,72 \\
\hline HACL1 & 0,29 & 0,24 & 0,89 & $9,19 \mathrm{E}-07$ & 7,64 \\
\hline HAPLN1 & 0,48 & 0,05 & 0,90 & $2,64 \mathrm{E}-07$ & 84,17 \\
\hline HDGFL2 & 0,42 & 0,08 & 0,96 & $5,17 \mathrm{E}-10$ & 51,26 \\
\hline HPCA & 0,47 & 0,05 & 0,84 & $1,24 \mathrm{E}-05$ & 101,62 \\
\hline HPCAL4 & 0,37 & 0,13 & 0,93 & $2,65 \mathrm{E}-08$ & 101,06 \\
\hline HSPB8 & $-0,08$ & 0,77 & $-0,68$ & $2,09 \mathrm{E}-03$ & 3,35 \\
\hline ICAM5 & 0,33 & 0,18 & 0,81 & $4,89 \mathrm{E}-05$ & 80,18 \\
\hline INKA2 & 0,30 & 0,23 & 0,67 & $2,54 \mathrm{E}-03$ & 57,32 \\
\hline INO80 & 0,27 & 0,28 & 0,44 & $6,92 \mathrm{E}-02$ & 2,93 \\
\hline INTS2 & 0,16 & 0,52 & $-0,56$ & $1,52 \mathrm{E}-02$ & 5,35 \\
\hline INTS7 & 0,32 & 0,20 & 0,68 & $1,87 \mathrm{E}-03$ & 22,49 \\
\hline IRX1 & 0,02 & 0,95 & $-0,68$ & $1,74 \mathrm{E}-03$ & 14,67 \\
\hline IRX2 & $-0,03$ & 0,91 & $-0,57$ & $1,38 \mathrm{E}-02$ & 14,21 \\
\hline ITPR3 & 0,39 & 0,11 & 0,86 & $5,59 \mathrm{E}-06$ & 32,35 \\
\hline JPH3 & 0,36 & 0,14 & 0,96 & $1,77 \mathrm{E}-10$ & 58,02 \\
\hline JPH4 & 0,46 & 0,06 & 0,95 & $1,08 \mathrm{E}-09$ & 99,07 \\
\hline KCNA5 & $-0,23$ & 0,36 & 0,67 & $2,27 \mathrm{E}-03$ & 17,21 \\
\hline KCNH3 & 0,35 & 0,15 & 0,85 & $9,34 \mathrm{E}-06$ & 82,65 \\
\hline KCNIP2 & 0,45 & 0,06 & 0,93 & $2,47 \mathrm{E}-08$ & 94,95 \\
\hline KCNJ16 & 0,02 & 0,92 & $-0,57$ & $1,38 \mathrm{E}-02$ & 11,91 \\
\hline KCTD12 & 0,03 & 0,89 & 0,46 & $5,24 \mathrm{E}-02$ & 2,03 \\
\hline KIAA1671 & 0,43 & 0,07 & 0,99 & $7,96 \mathrm{E}-14$ & 75,46 \\
\hline KLF16 & 0,48 & 0,04 & 0,97 & $1,38 \mathrm{E}-11$ & 53,62 \\
\hline LAMP5 & 0,41 & 0,09 & 0,98 & $1,80 \mathrm{E}-13$ & 32,13 \\
\hline LATS2 & 0,14 & 0,59 & $-0,57$ & $1,43 \mathrm{E}-02$ & 6,92 \\
\hline LCN9 & $-0,22$ & 0,38 & 0,57 & $1,27 \mathrm{E}-02$ & 1,30 \\
\hline LENG1 & $-0,40$ & 0,10 & 0,96 & $1,10 \mathrm{E}-10$ & 4,97 \\
\hline LHPP & 0,58 & 0,01 & 0,83 & $2,07 \mathrm{E}-05$ & 61,26 \\
\hline LIMD2 & 0,34 & 0,17 & 0,88 & $1,13 \mathrm{E}-06$ & 51,14 \\
\hline LMO3 & 0,53 & 0,02 & 0,82 & $3,27 \mathrm{E}-05$ & 42,40 \\
\hline LMO7 & 0,40 & 0,10 & 0,92 & $5,38 \mathrm{E}-08$ & 90,33 \\
\hline LOXL1 & 0,37 & 0,13 & 0,96 & $6,13 \mathrm{E}-10$ & 4,89 \\
\hline LPCAT1 & 0,48 & 0,05 & 0,94 & $1,21 \mathrm{E}-08$ & 50,29 \\
\hline LRMP & 0,32 & 0,19 & 0,94 & $1,17 \mathrm{E}-08$ & 39,99 \\
\hline LRRC10B & 0,36 & 0,14 & 0,55 & $1,74 \mathrm{E}-02$ & 74,25 \\
\hline
\end{tabular}


Tabela suplementar 9 - Genes contidos no módulo Pink do hipotálamo (continuação).

\begin{tabular}{|c|c|c|c|c|c|}
\hline Gene & SG CA & Valor de P SG CA & FM & Valor de P FM & $\mathbf{K}$ \\
\hline LRRC4C & 0,52 & 0,03 & 0,97 & $9,82 \mathrm{E}-12$ & 45,42 \\
\hline LRRC8B & 0,26 & 0,29 & 0,52 & $2,73 \mathrm{E}-02$ & 33,95 \\
\hline LZTS3 & 0,34 & 0,17 & 0,63 & $4,70 \mathrm{E}-03$ & 67,63 \\
\hline MAF1 & 0,49 & 0,04 & 0,98 & $2,82 \mathrm{E}-12$ & 6,71 \\
\hline MAPK1 & 0,39 & 0,11 & 0,97 & $2,71 \mathrm{E}-11$ & 60,37 \\
\hline MAPK15 & 0,41 & 0,09 & 0,96 & $5,44 \mathrm{E}-10$ & 21,44 \\
\hline MAPKBP1 & $-0,08$ & 0,74 & $-0,58$ & $1,24 \mathrm{E}-02$ & 8,15 \\
\hline MARK2 & 0,23 & 0,35 & 0,76 & $2,77 \mathrm{E}-04$ & 13,53 \\
\hline $\mathrm{MCC}$ & 0,06 & 0,81 & $-0,71$ & $8,93 \mathrm{E}-04$ & 7,35 \\
\hline MCEE & $-1,91 \mathrm{E}-03$ & 0,99 & $-0,48$ & $4,50 \mathrm{E}-02$ & 0,80 \\
\hline MET & 0,05 & 0,86 & $-0,54$ & $2,18 \mathrm{E}-02$ & 2,13 \\
\hline MEX3C & 0,27 & 0,27 & 0,61 & $7,05 \mathrm{E}-03$ & 15,49 \\
\hline MMD & 0,43 & 0,08 & $-0,61$ & $7,27 \mathrm{E}-03$ & 97,10 \\
\hline MMP17 & 0,40 & 0,10 & 0,96 & $1,93 \mathrm{E}-10$ & 80,77 \\
\hline MPP2 & 0,22 & 0,39 & $-0,44$ & $6,97 \mathrm{E}-02$ & 2,34 \\
\hline MRTFB & 0,34 & 0,16 & 0,94 & $5,48 \mathrm{E}-09$ & 91,02 \\
\hline MSH2 & 0,47 & 0,05 & 0,87 & $2,15 \mathrm{E}-06$ & 38,35 \\
\hline MVK & $-0,22$ & 0,38 & 0,70 & $1,24 \mathrm{E}-03$ & 16,11 \\
\hline MYH7B & 0,43 & 0,07 & 0,99 & $2,35 \mathrm{E}-14$ & 69,94 \\
\hline MYO10 & 0,47 & 0,05 & 0,74 & $5,06 \mathrm{E}-04$ & 13,89 \\
\hline NAA60 & 0,27 & 0,27 & 0,72 & $7,90 \mathrm{E}-04$ & 20,28 \\
\hline NACC1 & 0,33 & 0,18 & 0,95 & $3,41 \mathrm{E}-09$ & 33,00 \\
\hline NACC2 & $-0,16$ & 0,52 & 0,55 & $1,77 \mathrm{E}-02$ & 10,15 \\
\hline NADSYN1 & $-0,15$ & 0,55 & $-0,49$ & $3,77 \mathrm{E}-02$ & 1,58 \\
\hline NEDD4L & 0,39 & 0,11 & 0,85 & $7,86 \mathrm{E}-06$ & 91,03 \\
\hline NETO1 & 0,43 & 0,07 & 0,89 & $6,05 \mathrm{E}-07$ & 108,26 \\
\hline NPM3 & 0,42 & 0,09 & 0,65 & $3,33 \mathrm{E}-03$ & 39,35 \\
\hline NPY5R & 0,45 & 0,06 & 0,95 & $3,35 \mathrm{E}-09$ & 99,80 \\
\hline $\mathrm{NR} 1 \mathrm{H} 2$ & $-0,07$ & 0,77 & $-0,53$ & $2,25 \mathrm{E}-02$ & 6,54 \\
\hline NRDE2 & 0,33 & 0,18 & 0,89 & $6,99 \mathrm{E}-07$ & 29,57 \\
\hline NRF1 & 0,45 & 0,06 & 0,86 & $3,86 \mathrm{E}-06$ & 66,17 \\
\hline NRGN & 0,45 & 0,06 & 0,98 & $3,06 \mathrm{E}-13$ & 103,60 \\
\hline NT5C3A & 0,42 & 0,09 & 0,80 & $7,47 \mathrm{E}-05$ & 10,56 \\
\hline NUDT10 & 0,41 & 0,09 & 0,82 & $3,51 \mathrm{E}-05$ & 63,64 \\
\hline NUDT2 & $-0,01$ & 0,97 & $-0,55$ & $1,91 \mathrm{E}-02$ & 6,47 \\
\hline OAF & 0,40 & 0,10 & 0,96 & $4,81 \mathrm{E}-10$ & 75,61 \\
\hline OAS1X & $-0,12$ & 0,64 & 0,49 & $4,08 \mathrm{E}-02$ & 0,84 \\
\hline ORMDL3 & 0,54 & 0,02 & $-0,70$ & $1,23 \mathrm{E}-03$ & 57,77 \\
\hline OTUD1 & 0,24 & 0,33 & 0,74 & $4,37 \mathrm{E}-04$ & 12,33 \\
\hline PAFAH1B3 & $-0,24$ & 0,33 & 0,80 & $5,61 \mathrm{E}-05$ & 3,13 \\
\hline PALMD & 0,55 & 0,02 & 0,86 & $4,88 \mathrm{E}-06$ & 26,42 \\
\hline PDE2A & 0,33 & 0,18 & 0,93 & $3,36 \mathrm{E}-08$ & 85,23 \\
\hline PDE9A & 0,30 & 0,23 & $-0,39$ & $1,12 \mathrm{E}-01$ & 8,73 \\
\hline PDZD4 & 0,47 & 0,05 & 0,91 & $1,27 \mathrm{E}-07$ & 80,67 \\
\hline PER2 & 0,73 & $5,98 \mathrm{E}-04$ & 0,44 & $6,83 \mathrm{E}-02$ & 1,82 \\
\hline PFDN4 & $2,69 \mathrm{E}-03$ & 0,99 & $-0,53$ & $2,39 \mathrm{E}-02$ & 2,28 \\
\hline PHYHIP & 0,38 & 0,12 & 0,94 & $8,15 \mathrm{E}-09$ & 102,37 \\
\hline PID1 & 0,44 & 0,07 & 0,72 & $7,13 \mathrm{E}-04$ & 23,64 \\
\hline PIK3R2 & 0,34 & 0,17 & 0,96 & $6,57 \mathrm{E}-10$ & 89,80 \\
\hline PISD & 0,28 & 0,26 & 0,79 & $8,82 \mathrm{E}-05$ & 57,12 \\
\hline PKIA & 0,41 & 0,09 & 0,94 & $9,49 \mathrm{E}-09$ & 87,40 \\
\hline PLCB3 & 0,01 & 0,96 & $-0,72$ & $7,07 \mathrm{E}-04$ & 3,76 \\
\hline PLCD3 & $-0,08$ & 0,74 & 0,66 & $2,86 \mathrm{E}-03$ & 4,16 \\
\hline PLEC & 0,61 & 0,01 & 0,71 & $9,64 \mathrm{E}-04$ & 4,41 \\
\hline PLEKHM2 & 0,36 & 0,15 & 0,89 & $6,13 \mathrm{E}-07$ & 39,72 \\
\hline PLK2 & 0,41 & 0,09 & 0,94 & $5,16 \mathrm{E}-09$ & 82,25 \\
\hline PLPPR1 & 0,32 & 0,19 & 0,77 & $1,75 \mathrm{E}-04$ & 76,24 \\
\hline PLPPR4 & 0,32 & 0,20 & $-0,45$ & $5,80 \mathrm{E}-02$ & 79,18 \\
\hline POU3F1 & 0,41 & 0,09 & 0,76 & $2,66 \mathrm{E}-04$ & 93,49 \\
\hline POU6F1 & 0,35 & 0,16 & 0,77 & $2,06 \mathrm{E}-04$ & 80,22 \\
\hline PPP1R16A & 0,45 & 0,06 & 0,82 & $3,50 \mathrm{E}-05$ & 74,81 \\
\hline PPP1R1A & 0,39 & 0,11 & 0,78 & $1,49 \mathrm{E}-04$ & 58,43 \\
\hline PPP1R9A & 0,40 & 0,10 & 0,84 & $1,13 \mathrm{E}-05$ & 59,70 \\
\hline
\end{tabular}


Tabela suplementar 9 - Genes contidos no módulo Pink do hipotálamo (continuação).

\begin{tabular}{|c|c|c|c|c|c|}
\hline Gene & SG CA & Valor de P SG CA & FM & Valor de P FM & $\mathbf{K}$ \\
\hline PPP2R5C & 0,24 & 0,34 & 0,69 & $1,43 \mathrm{E}-03$ & 3,14 \\
\hline PPP3CA & 0,47 & 0,05 & 0,87 & 2,95E-06 & 106,97 \\
\hline PPP3R1 & 0,33 & 0,18 & $-0,60$ & $8,00 \mathrm{E}-03$ & 55,83 \\
\hline PRDM2 & 0,32 & 0,20 & 0,90 & $2,53 \mathrm{E}-07$ & 11,77 \\
\hline PRIMPOL & 0,37 & 0,13 & 0,62 & $6,35 \mathrm{E}-03$ & 0,82 \\
\hline PRKCA & 0,09 & 0,73 & $-0,61$ & $7,06 \mathrm{E}-03$ & 10,34 \\
\hline PRR7 & 0,46 & 0,06 & 0,95 & 3,00E-09 & 87,76 \\
\hline PTPRE & 0,42 & 0,08 & $-0,79$ & $1,12 \mathrm{E}-04$ & 97,45 \\
\hline QARS & $-0,35$ & 0,16 & 0,95 & $2,95 \mathrm{E}-09$ & 4,42 \\
\hline R3HDM4 & 0,43 & 0,07 & $-0,41$ & $9,30 \mathrm{E}-02$ & 20,38 \\
\hline RAB11FIP4 & 0,31 & 0,21 & 0,71 & $1,06 \mathrm{E}-03$ & 43,72 \\
\hline RAB 15 & 0,46 & 0,05 & 0,88 & $1,85 \mathrm{E}-06$ & 109,72 \\
\hline RAB40B & 0,49 & 0,04 & 0,91 & $1,18 \mathrm{E}-07$ & 99,46 \\
\hline RAMP1 & $-0,36$ & 0,14 & 0,93 & 3,33E-08 & 3,10 \\
\hline RAPGEF1 & 0,26 & 0,29 & 0,79 & $8,87 \mathrm{E}-05$ & 45,98 \\
\hline RASGRF2 & 0,40 & 0,10 & 0,87 & $2,40 \mathrm{E}-06$ & 91,56 \\
\hline RASGRP1 & 0,45 & 0,06 & 0,97 & $8,33 \mathrm{E}-11$ & 84,44 \\
\hline RBAK & 0,24 & 0,34 & 0,52 & $2,56 \mathrm{E}-02$ & 2,41 \\
\hline RBBP7 & 0,57 & 0,01 & 0,53 & $2,29 \mathrm{E}-02$ & 25,33 \\
\hline RECQL5 & $3,98 \mathrm{E}-03$ & 0,99 & $-0,61$ & $6,75 \mathrm{E}-03$ & 3,09 \\
\hline REG4 & 0,57 & 0,01 & 0,82 & $2,75 \mathrm{E}-05$ & 2,87 \\
\hline RELN & 0,37 & 0,13 & 0,97 & $9,82 \mathrm{E}-11$ & 76,60 \\
\hline REM2 & 0,43 & 0,07 & 0,93 & $1,99 \mathrm{E}-08$ & 104,46 \\
\hline RF00001 & 0,23 & 0,35 & 0,63 & $5,41 \mathrm{E}-03$ & 18,90 \\
\hline RF00026 & $-0,07$ & 0,79 & 0,57 & $1,40 \mathrm{E}-02$ & 0,97 \\
\hline RF00418 & 0,28 & 0,27 & $-0,51$ & $3,04 \mathrm{E}-02$ & 0,41 \\
\hline RGS10 & $-0,31$ & 0,20 & 0,93 & $3,15 \mathrm{E}-08$ & 4,13 \\
\hline RGS4 & 0,47 & 0,05 & 0,96 & $1,28 \mathrm{E}-10$ & 67,70 \\
\hline RIPOR1 & 0,47 & 0,05 & 0,98 & $8,21 \mathrm{E}-13$ & 17,38 \\
\hline RIPOR2 & 0,24 & 0,33 & $-0,61$ & $7,60 \mathrm{E}-03$ & 32,04 \\
\hline RNF166 & 0,46 & 0,05 & 0,97 & $7,14 \mathrm{E}-12$ & 8,87 \\
\hline ROPN1 & 0,56 & 0,01 & 0,63 & $5,40 \mathrm{E}-03$ & 19,05 \\
\hline RPIA & $-0,30$ & 0,22 & $-0,39$ & $1,08 \mathrm{E}-01$ & 0,88 \\
\hline RPP25 & 0,26 & 0,30 & 0,69 & $1,67 \mathrm{E}-03$ & 38,68 \\
\hline RPUSD3 & $-0,31$ & 0,21 & $-0,57$ & $1,44 \mathrm{E}-02$ & 0,86 \\
\hline RTP4 & $-0,42$ & 0,08 & $-0,55$ & $1,69 \mathrm{E}-02$ & 25,00 \\
\hline RYR2 & 0,46 & 0,06 & 0,96 & $1,70 \mathrm{E}-10$ & 104,95 \\
\hline SAPCD1 & $-0,14$ & 0,57 & 0,70 & $1,28 \mathrm{E}-03$ & 3,96 \\
\hline SCGN & 0,46 & 0,05 & 0,88 & $1,42 \mathrm{E}-06$ & 49,18 \\
\hline SCMH1 & 0,48 & 0,04 & 0,97 & $9,87 \mathrm{E}-12$ & 20,55 \\
\hline SCX & $-0,11$ & 0,67 & $-0,73$ & $5,84 \mathrm{E}-04$ & 3,62 \\
\hline SDCBP & 0,48 & 0,04 & 0,86 & $3,85 \mathrm{E}-06$ & 67,65 \\
\hline SDR42E1 & $-0,32$ & 0,20 & 0,77 & $2,00 \mathrm{E}-04$ & 1,34 \\
\hline SERPINB6 & $-0,03$ & 0,90 & $-0,63$ & $4,98 \mathrm{E}-03$ & 5,34 \\
\hline SETD1A & 0,07 & 0,77 & $-0,59$ & $9,80 \mathrm{E}-03$ & 3,88 \\
\hline SGSH & $-0,15$ & 0,54 & $-0,52$ & $2,71 \mathrm{E}-02$ & 3,25 \\
\hline SGSM2 & 0,39 & 0,11 & 0,95 & $1,64 \mathrm{E}-09$ & 46,95 \\
\hline SHISA7 & 0,34 & 0,17 & 0,86 & $3,71 \mathrm{E}-06$ & 92,53 \\
\hline SIPA1L1 & 0,54 & 0,02 & 0,90 & $2,87 \mathrm{E}-07$ & 76,56 \\
\hline SKI & 0,51 & 0,03 & 0,93 & $2,01 \mathrm{E}-08$ & 12,63 \\
\hline SLC13A3 & $-0,29$ & 0,24 & 0,62 & $6,57 \mathrm{E}-03$ & 17,39 \\
\hline SLC24A4 & 0,50 & 0,03 & 0,92 & $7,80 \mathrm{E}-08$ & 72,56 \\
\hline SLC25A42 & 0,24 & 0,33 & $-0,48$ & $4,59 \mathrm{E}-02$ & 16,48 \\
\hline SLC $30 A 10$ & 0,49 & 0,04 & 0,61 & $7,29 \mathrm{E}-03$ & 37,34 \\
\hline SLC $35 F 3$ & 0,36 & 0,14 & 0,85 & $7,69 \mathrm{E}-06$ & 82,92 \\
\hline SLC4A2 & $-0,11$ & 0,65 & $-0,38$ & $1,18 \mathrm{E}-01$ & 21,81 \\
\hline SLC4A5 & $-0,42$ & 0,08 & 0,94 & $7,67 \mathrm{E}-09$ & 3,57 \\
\hline SLC7A10 & 0,16 & 0,52 & $-0,59$ & $9,48 \mathrm{E}-03$ & 5,04 \\
\hline SLC9A5 & 0,29 & 0,25 & $-0,73$ & $6,19 \mathrm{E}-04$ & 5,79 \\
\hline SLCO1C1 & 0,40 & 0,10 & 0,95 & $9,63 \mathrm{E}-10$ & 91,82 \\
\hline SLITRK4 & 0,41 & 0,09 & 0,94 & $8,31 \mathrm{E}-09$ & 87,11 \\
\hline SNAPC2 & 0,63 & 0,01 & 0,91 & $1,50 \mathrm{E}-07$ & 29,13 \\
\hline SOWAHA & 0,45 & 0,06 & 0,88 & $1,52 \mathrm{E}-06$ & 101,63 \\
\hline
\end{tabular}


Tabela suplementar 9 - Genes contidos no módulo Pink do hipotálamo (continuação).

\begin{tabular}{|c|c|c|c|c|c|}
\hline Gene & SG CA & Valor de P SG CA & FM & Valor de P FM & $\mathbf{K}$ \\
\hline SPTB & 0,47 & 0,05 & 0,84 & $1,57 \mathrm{E}-05$ & 96,02 \\
\hline SPTBN2 & 0,43 & 0,07 & 0,75 & $3,61 \mathrm{E}-04$ & 103,59 \\
\hline SRF & 0,37 & 0,13 & 0,54 & $1,94 \mathrm{E}-02$ & 71,31 \\
\hline SRR & 0,32 & 0,19 & 0,93 & $2,76 \mathrm{E}-08$ & 22,59 \\
\hline SSBP3 & 0,57 & 0,01 & 0,84 & $1,29 \mathrm{E}-05$ & 39,15 \\
\hline SSBP4 & 0,48 & 0,04 & 0,72 & $7,06 \mathrm{E}-04$ & 51,70 \\
\hline ST6GAL2 & 0,50 & 0,03 & 0,94 & 4,44E-09 & 71,57 \\
\hline ST8SIA3 & 0,44 & 0,07 & $-0,62$ & $5,68 \mathrm{E}-03$ & 64,26 \\
\hline STMN1 & $-0,21$ & 0,40 & 0,70 & $1,17 \mathrm{E}-03$ & 4,65 \\
\hline STXBP5L & 0,37 & 0,14 & 0,65 & $3,84 \mathrm{E}-03$ & 97,35 \\
\hline SYNPO & 0,42 & 0,08 & 0,97 & $1,20 \mathrm{E}-11$ & 82,50 \\
\hline SYT16 & 0,32 & 0,19 & $-0,67$ & $2,39 \mathrm{E}-03$ & 83,18 \\
\hline TALDO1 & $-0,03$ & 0,92 & $-0,71$ & $9,84 \mathrm{E}-04$ & 5,12 \\
\hline TBC1D14 & 0,40 & 0,10 & 0,92 & $4,17 E-08$ & 78,48 \\
\hline TDRD7 & $-0,17$ & 0,51 & 0,70 & $1,32 \mathrm{E}-03$ & 6,29 \\
\hline TEF & 0,49 & 0,04 & 0,99 & $1,47 \mathrm{E}-14$ & 77,13 \\
\hline TESC & 0,47 & 0,05 & 0,96 & $1,10 \mathrm{E}-10$ & 22,31 \\
\hline THBS2 & 0,20 & 0,44 & 0,57 & $1,28 \mathrm{E}-02$ & 6,36 \\
\hline TIAM2 & 0,13 & 0,60 & 0,67 & $2,38 \mathrm{E}-03$ & 2,39 \\
\hline TIMM8B & $-0,43$ & 0,07 & 0,89 & $1,00 \mathrm{E}-06$ & 1,01 \\
\hline TIRAP & $-0,33$ & 0,18 & 0,94 & $4,32 \mathrm{E}-09$ & 5,99 \\
\hline TLR4 & $-0,28$ & 0,25 & 0,78 & $1,21 \mathrm{E}-04$ & 9,02 \\
\hline TMEM131L & 0,44 & 0,06 & 0,97 & $3,02 \mathrm{E}-11$ & 64,13 \\
\hline TMEM201 & 0,42 & 0,09 & 0,83 & $1,80 \mathrm{E}-05$ & 54,32 \\
\hline TNFSF13 & 0,45 & 0,06 & 0,98 & $3,28 \mathrm{E}-13$ & 32,31 \\
\hline TNRC18 & 0,22 & 0,38 & $-0,73$ & $5,36 \mathrm{E}-04$ & 4,68 \\
\hline TRAPPC6A & $-0,10$ & 0,68 & $-0,52$ & $2,81 \mathrm{E}-02$ & 9,21 \\
\hline TSC22D1 & 0,57 & 0,01 & 0,50 & $3,57 \mathrm{E}-02$ & 42,59 \\
\hline TSPAN4 & $-0,29$ & 0,25 & 0,93 & $2,63 \mathrm{E}-08$ & 4,43 \\
\hline TYRP1 & 0,40 & 0,10 & 0,89 & $5,86 \mathrm{E}-07$ & 97,61 \\
\hline UBE2D1 & 0,49 & 0,04 & 0,89 & $1,06 \mathrm{E}-06$ & 51,33 \\
\hline UBL7 & 0,37 & 0,13 & 0,96 & $3,53 \mathrm{E}-10$ & 32,30 \\
\hline UBXN11 & 0,48 & 0,04 & 0,90 & $2,53 \mathrm{E}-07$ & 20,08 \\
\hline ULK3 & 0,31 & 0,21 & 0,92 & $5,29 \mathrm{E}-08$ & 14,55 \\
\hline UNC119 & $-0,25$ & 0,32 & 0,61 & $6,64 \mathrm{E}-03$ & 7,14 \\
\hline UPF1 & 0,51 & 0,03 & 0,69 & $1,40 \mathrm{E}-03$ & 18,35 \\
\hline UPF3A & 0,21 & 0,39 & 0,68 & $1,87 \mathrm{E}-03$ & 15,30 \\
\hline UTP25 & $-0,04$ & 0,86 & $-0,54$ & $2,00 \mathrm{E}-02$ & 1,44 \\
\hline VAV2 & 0,45 & 0,06 & 0,98 & $2,23 \mathrm{E}-12$ & 52,83 \\
\hline WASF1 & 0,34 & 0,17 & 0,90 & $3,32 \mathrm{E}-07$ & 77,96 \\
\hline WDR25 & 0,55 & 0,02 & 0,83 & $2,19 \mathrm{E}-05$ & 5,35 \\
\hline WDR92 & 0,36 & 0,14 & $-0,53$ & $2,38 \mathrm{E}-02$ & 91,18 \\
\hline WSCD2 & 0,39 & 0,11 & 0,98 & $3,36 \mathrm{E}-13$ & 94,02 \\
\hline ZAP70 & 0,44 & 0,07 & 0,89 & $6,37 \mathrm{E}-07$ & 15,40 \\
\hline ZCCHC14 & 0,38 & 0,12 & $-0,71$ & $1,08 \mathrm{E}-03$ & 46,17 \\
\hline ZCCHC4 & 0,09 & 0,73 & 0,53 & $2,35 \mathrm{E}-02$ & 5,26 \\
\hline ZHX1 & 0,45 & 0,06 & 0,98 & $2,25 \mathrm{E}-12$ & 43,86 \\
\hline ZNF239 & 0,48 & 0,04 & 0,60 & $7,93 \mathrm{E}-03$ & 105,36 \\
\hline ZNF282 & 0,26 & 0,30 & 0,85 & $9,49 \mathrm{E}-06$ & 11,73 \\
\hline ZNF398 & 0,47 & 0,05 & 0,84 & $1,39 \mathrm{E}-05$ & 49,36 \\
\hline ZNF436 & 0,43 & 0,07 & 0,91 & $1,56 \mathrm{E}-07$ & 56,12 \\
\hline ZNF782 & 0,09 & 0,73 & $-0,52$ & $2,64 \mathrm{E}-02$ & 1,16 \\
\hline
\end{tabular}


Tabela suplementar 10 - Genes contidos no módulo Darkturquoise da pituitária.

\begin{tabular}{|c|c|c|c|c|c|}
\hline Gene & SG CAR & Valor de P SG CAR & FM & Valor de P FM & $\mathbf{K}$ \\
\hline AASDHPPT & 0,50 & 0,03 & 0,91 & $1,51 \mathrm{E}-07$ & 44,36 \\
\hline $\mathrm{ABCB} 7$ & 0,19 & 0,46 & 0,75 & $3,32 \mathrm{E}-04$ & 11,77 \\
\hline ABCD3 & 0,34 & 0,17 & 0,87 & $3,26 \mathrm{E}-06$ & 35,27 \\
\hline ABHD12 & 0,35 & 0,16 & 0,31 & $2,11 \mathrm{E}-01$ & 0,31 \\
\hline ABHD17C & 0,37 & 0,13 & 0,56 & $1,65 \mathrm{E}-02$ & 3,13 \\
\hline ABRAXAS1 & 0,43 & 0,07 & 0,85 & $9,53 \mathrm{E}-06$ & 26,70 \\
\hline ACADM & $-0,05$ & 0,83 & 0,59 & $9,41 \mathrm{E}-03$ & 3,78 \\
\hline ACTR2 & 0,35 & 0,15 & 0,89 & $7,86 \mathrm{E}-07$ & 38,88 \\
\hline ACTR6 & 0,60 & 0,01 & 0,78 & $1,55 \mathrm{E}-04$ & 15,45 \\
\hline ACYP2 & 0,34 & 0,16 & 0,64 & $4,50 \mathrm{E}-03$ & 4,90 \\
\hline ADGRB2 & 0,45 & 0,06 & 0,29 & $2,42 \mathrm{E}-01$ & 0,32 \\
\hline AFMID & $-0,49$ & 0,04 & $-0,24$ & $3,35 \mathrm{E}-01$ & 0,24 \\
\hline AGFG1 & 0,36 & 0,14 & 0,85 & 7,51E-06 & 41,33 \\
\hline AIF1L & 0,21 & 0,40 & 0,62 & $5,94 \mathrm{E}-03$ & 4,31 \\
\hline AIFM1 & 0,08 & 0,74 & 0,58 & $1,23 \mathrm{E}-02$ & 3,21 \\
\hline AKTIP & 0,21 & 0,41 & 0,74 & $4,44 \mathrm{E}-04$ & 11,79 \\
\hline ALAS1 & 0,65 & $3,24 \mathrm{E}-03$ & 0,55 & $1,86 \mathrm{E}-02$ & 1,78 \\
\hline ALDH7A1 & 0,47 & 0,05 & 0,38 & $1,20 \mathrm{E}-01$ & 0,78 \\
\hline ALDOB & 0,50 & 0,03 & 0,35 & $1,54 \mathrm{E}-01$ & 0,46 \\
\hline ALG6 & 0,80 & $5,91 \mathrm{E}-05$ & 0,64 & $4,40 \mathrm{E}-03$ & 4,58 \\
\hline ALOX5 & $-0,38$ & 0,12 & $-0,35$ & $1,60 \mathrm{E}-01$ & 0,67 \\
\hline ANAPC4 & 0,60 & 0,01 & 0,80 & $6,28 \mathrm{E}-05$ & 18,44 \\
\hline ANKIB1 & 0,40 & 0,10 & 0,86 & $5,56 \mathrm{E}-06$ & 43,74 \\
\hline ANKRD46 & 0,40 & 0,10 & 0,89 & $9,14 \mathrm{E}-07$ & 44,90 \\
\hline ANKRD54 & 0,38 & 0,12 & 0,49 & $3,77 \mathrm{E}-02$ & 1,69 \\
\hline ARF4 & 0,30 & 0,23 & 0,78 & $1,29 \mathrm{E}-04$ & 16,66 \\
\hline ARFIP1 & 0,53 & 0,02 & 0,97 & $5,65 \mathrm{E}-11$ & 68,72 \\
\hline ARHGAP18 & 0,02 & 0,93 & 0,59 & $1,06 \mathrm{E}-02$ & 3,66 \\
\hline ARL6 & 0,68 & $2,05 \mathrm{E}-03$ & 0,83 & $1,85 \mathrm{E}-05$ & 21,73 \\
\hline ARMC1 & 0,45 & 0,06 & 0,86 & $4,43 \mathrm{E}-06$ & 31,31 \\
\hline ARMCX2 & 0,34 & 0,16 & 0,62 & $5,70 \mathrm{E}-03$ & 4,72 \\
\hline ARPP19 & 0,49 & 0,04 & 0,92 & $6,77 \mathrm{E}-08$ & 58,38 \\
\hline ARSB & 0,50 & 0,04 & 0,33 & $1,75 \mathrm{E}-01$ & 0,35 \\
\hline ASNSD1 & 0,61 & 0,01 & 0,81 & $4,56 \mathrm{E}-05$ & 20,24 \\
\hline ASRGL1 & $-0,14$ & 0,57 & 0,39 & $1,08 \mathrm{E}-01$ & 0,38 \\
\hline ATG5 & 0,49 & 0,04 & 0,76 & $2,19 \mathrm{E}-04$ & 14,17 \\
\hline ATG7 & 0,21 & 0,40 & 0,54 & $2,15 \mathrm{E}-02$ & 1,86 \\
\hline $\mathrm{ATP} 2 \mathrm{C} 1$ & 0,34 & 0,17 & 0,84 & $1,31 \mathrm{E}-05$ & 27,88 \\
\hline ATP6AP2 & 0,31 & 0,21 & 0,81 & $4,38 \mathrm{E}-05$ & 27,04 \\
\hline ATP6V1D & 0,31 & 0,20 & 0,82 & $2,57 \mathrm{E}-05$ & 23,13 \\
\hline BAG1 & 0,18 & 0,46 & 0,69 & $1,61 \mathrm{E}-03$ & 7,73 \\
\hline BAG2 & 0,25 & 0,33 & 0,73 & $5,25 \mathrm{E}-04$ & 11,03 \\
\hline BBS4 & 0,52 & 0,03 & 0,61 & $6,68 \mathrm{E}-03$ & 3,64 \\
\hline BBS5 & 0,56 & 0,02 & 0,69 & $1,51 \mathrm{E}-03$ & 7,89 \\
\hline BCAP29 & 0,51 & 0,03 & 0,83 & $1,80 \mathrm{E}-05$ & 26,45 \\
\hline BCDIN3D & 0,35 & 0,16 & 0,65 & $3,18 \mathrm{E}-03$ & 9,13 \\
\hline BEND6 & 0,36 & 0,14 & 0,86 & $3,84 \mathrm{E}-06$ & 30,06 \\
\hline BET1 & 0,41 & 0,09 & 0,85 & $7,98 \mathrm{E}-06$ & 29,78 \\
\hline BLOC1S4 & 0,43 & 0,08 & 0,51 & $3,19 \mathrm{E}-02$ & 1,36 \\
\hline BLOC1S6 & 0,52 & 0,03 & 0,92 & $7,35 \mathrm{E}-08$ & 50,99 \\
\hline BPIFA2C & $-0,41$ & 0,09 & $-0,40$ & $1,04 \mathrm{E}-01$ & 0,64 \\
\hline BRD7 & 0,36 & 0,14 & 0,83 & $1,76 \mathrm{E}-05$ & 30,37 \\
\hline BRK1 & 0,39 & 0,11 & 0,88 & $1,48 \mathrm{E}-06$ & 38,61 \\
\hline BSPRY & 0,09 & 0,72 & 0,51 & $3,02 \mathrm{E}-02$ & 1,86 \\
\hline bta-mir-1281 & 0,19 & 0,45 & 0,36 & $1,45 \mathrm{E}-01$ & 0,46 \\
\hline bta-mir-568 & 0,16 & 0,52 & 0,37 & $1,34 \mathrm{E}-01$ & 0,66 \\
\hline BTBD1 & 0,42 & 0,08 & 0,90 & $3,66 \mathrm{E}-07$ & 50,83 \\
\hline C15H11orf58 & 0,64 & $4,60 \mathrm{E}-03$ & 0,91 & $2,01 \mathrm{E}-07$ & 39,78 \\
\hline C17H12orf65 & 0,22 & 0,37 & 0,51 & $3,10 \mathrm{E}-02$ & 2,07 \\
\hline C27H4orf47 & 0,44 & 0,07 & 0,68 & $1,75 \mathrm{E}-03$ & 7,38 \\
\hline C5H12orf45 & 0,42 & 0,08 & 0,69 & $1,66 \mathrm{E}-03$ & 6,58 \\
\hline C5H12orf73 & 0,53 & 0,02 & 0,59 & $9,93 \mathrm{E}-03$ & 3,00 \\
\hline C9H6orf 120 & 0,38 & 0,12 & 0,81 & $4,43 \mathrm{E}-05$ & 19,50 \\
\hline
\end{tabular}


Tabela suplementar 10 - Genes contidos no módulo Darkturquoise da pituitária (continuação).

\begin{tabular}{|c|c|c|c|c|c|}
\hline Gene & SG CAR & Valor de P SG CAR & FM & Valor de P FM & $\mathbf{K}$ \\
\hline CA10 & 0,56 & 0,02 & 0,71 & $9,74 \mathrm{E}-04$ & 8,08 \\
\hline CAB39 & 0,42 & 0,08 & 0,89 & $6,79 \mathrm{E}-07$ & 46,33 \\
\hline CALCOCO2 & 0,39 & 0,10 & 0,83 & $1,75 \mathrm{E}-05$ & 33,63 \\
\hline CALM2 & 0,42 & 0,08 & 0,80 & $6,91 \mathrm{E}-05$ & 21,27 \\
\hline CAPZA2 & 0,56 & 0,01 & 0,84 & $1,60 \mathrm{E}-05$ & 24,93 \\
\hline CASC4 & 0,54 & 0,02 & 0,94 & $5,29 \mathrm{E}-09$ & 56,19 \\
\hline CASD1 & 0,55 & 0,02 & 0,93 & 3,32E-08 & 59,33 \\
\hline CAT & 0,48 & 0,04 & 0,60 & $8,28 \mathrm{E}-03$ & 3,20 \\
\hline CCDC112 & 0,42 & 0,09 & 0,73 & $5,73 \mathrm{E}-04$ & 10,03 \\
\hline CCDC22 & 0,48 & 0,04 & 0,57 & $1,40 \mathrm{E}-02$ & 1,83 \\
\hline CCDC43 & 0,02 & 0,93 & 0,69 & $1,48 \mathrm{E}-03$ & 7,43 \\
\hline CCDC50 & 0,44 & 0,07 & 0,79 & $8,91 \mathrm{E}-05$ & 23,26 \\
\hline CCDC90B & 0,26 & 0,30 & 0,64 & $3,89 \mathrm{E}-03$ & 5,79 \\
\hline CCDC91 & 0,28 & 0,26 & 0,81 & $5,20 \mathrm{E}-05$ & 20,57 \\
\hline CCNI & 0,45 & 0,06 & 0,88 & $1,24 \mathrm{E}-06$ & 39,07 \\
\hline CCNK & 0,42 & 0,08 & 0,63 & $5,32 \mathrm{E}-03$ & 4,30 \\
\hline ССТ3 & 0,18 & 0,48 & 0,76 & $2,85 \mathrm{E}-04$ & 14,33 \\
\hline CD37 & $-0,23$ & 0,37 & $-0,56$ & $1,47 \mathrm{E}-02$ & 2,29 \\
\hline CD3G & $-0,55$ & 0,02 & $-0,41$ & $8,87 \mathrm{E}-02$ & 0,61 \\
\hline CD47 & 0,28 & 0,26 & 0,78 & $1,34 \mathrm{E}-04$ & 24,19 \\
\hline $\mathrm{CDC} 27$ & 0,53 & 0,02 & 0,92 & 4,97E-08 & 49,85 \\
\hline CDC37L1 & 0,46 & 0,06 & 0,89 & $9,75 \mathrm{E}-07$ & 43,25 \\
\hline $\mathrm{CDH} 2$ & 0,42 & 0,08 & 0,62 & $6,40 \mathrm{E}-03$ & 4,64 \\
\hline CDK7 & 0,36 & 0,14 & 0,53 & $2,47 \mathrm{E}-02$ & 1,48 \\
\hline CENPL & 0,59 & 0,01 & 0,66 & $2,93 \mathrm{E}-03$ & 5,33 \\
\hline CEP290 & 0,38 & 0,12 & 0,83 & $1,78 \mathrm{E}-05$ & 27,74 \\
\hline CEP70 & 0,35 & 0,15 & 0,66 & $2,78 \mathrm{E}-03$ & 4,98 \\
\hline CEPT1 & 0,39 & 0,11 & 0,84 & $1,09 \mathrm{E}-05$ & 31,58 \\
\hline CGGBP1 & 0,40 & 0,10 & 0,86 & $5,42 \mathrm{E}-06$ & 35,09 \\
\hline CGRRF1 & 0,42 & 0,08 & 0,86 & $5,17 \mathrm{E}-06$ & 27,25 \\
\hline CHAC1 & $-0,46$ & 0,05 & $-0,64$ & $3,85 \mathrm{E}-03$ & 4,15 \\
\hline CHAC2 & 0,23 & 0,35 & 0,72 & $7,51 \mathrm{E}-04$ & 8,95 \\
\hline CHMP2B & 0,40 & 0,10 & 0,81 & $4,40 \mathrm{E}-05$ & 24,84 \\
\hline CHMP3 & 0,25 & 0,33 & 0,71 & $1,05 \mathrm{E}-03$ & 9,18 \\
\hline CHURC1 & 0,20 & 0,42 & 0,86 & $6,06 \mathrm{E}-06$ & 31,34 \\
\hline CIPC & 0,61 & 0,01 & 0,77 & $2,14 \mathrm{E}-04$ & 17,45 \\
\hline CITED2 & 0,44 & 0,07 & 0,53 & 2,31E-02 & 2,55 \\
\hline CLYBL & 0,45 & 0,06 & 0,73 & $5,91 \mathrm{E}-04$ & 10,91 \\
\hline CMPK1 & 0,56 & 0,02 & 0,90 & $4,07 \mathrm{E}-07$ & 43,41 \\
\hline CMTR2 & 0,37 & 0,13 & 0,79 & $8,54 \mathrm{E}-05$ & 22,19 \\
\hline CNIH1 & 0,46 & 0,05 & 0,93 & $2,73 \mathrm{E}-08$ & 49,86 \\
\hline CNOT7 & 0,39 & 0,11 & 0,89 & $9,90 \mathrm{E}-07$ & 47,59 \\
\hline COG5 & 0,59 & 0,01 & 0,83 & $1,93 \mathrm{E}-05$ & 23,55 \\
\hline COG6 & 0,48 & 0,04 & 0,79 & $8,22 \mathrm{E}-05$ & 22,91 \\
\hline COMMD10 & 0,45 & 0,06 & 0,78 & $1,48 \mathrm{E}-04$ & 15,57 \\
\hline COMMD8 & 0,35 & 0,15 & 0,73 & $5,88 \mathrm{E}-04$ & 8,65 \\
\hline COPB1 & 0,50 & 0,04 & 0,88 & $1,16 \mathrm{E}-06$ & 41,12 \\
\hline COPS2 & 0,52 & 0,03 & 0,97 & $9,90 \mathrm{E}-12$ & 70,04 \\
\hline COPS4 & 0,32 & 0,20 & 0,91 & $2,43 \mathrm{E}-07$ & 42,08 \\
\hline COQ2 & 0,37 & 0,13 & 0,68 & $1,95 \mathrm{E}-03$ & 6,48 \\
\hline COX19 & 0,30 & 0,23 & 0,60 & $9,15 \mathrm{E}-03$ & 3,62 \\
\hline CREBL2 & 0,18 & 0,47 & 0,78 & $1,25 \mathrm{E}-04$ & 18,06 \\
\hline CRISPLD1 & 0,47 & 0,05 & 0,61 & $7,36 \mathrm{E}-03$ & 4,08 \\
\hline CSDE1 & 0,34 & 0,16 & 0,89 & 1,01E-06 & 44,10 \\
\hline CSNK1G3 & 0,47 & 0,05 & 0,75 & $3,63 \mathrm{E}-04$ & 11,90 \\
\hline CSTF2 & 0,34 & 0,17 & 0,88 & $1,92 \mathrm{E}-06$ & 43,78 \\
\hline CTGF & 0,48 & 0,04 & 0,61 & $7,66 \mathrm{E}-03$ & 3,87 \\
\hline CTPS2 & 0,15 & 0,55 & 0,73 & $6,22 \mathrm{E}-04$ & 8,90 \\
\hline CUL5 & 0,37 & 0,13 & 0,83 & $1,94 \mathrm{E}-05$ & 30,80 \\
\hline CWF19L2 & 0,22 & 0,39 & 0,80 & $6,45 \mathrm{E}-05$ & 20,54 \\
\hline CYP2F1 & 0,15 & 0,56 & 0,32 & $1,96 \mathrm{E}-01$ & 0,45 \\
\hline DAPL1 & $-0,29$ & 0,25 & $-0,41$ & $8,94 \mathrm{E}-02$ & 0,63 \\
\hline
\end{tabular}


Tabela suplementar 10 - Genes contidos no módulo Darkturquoise da pituitária (continuação).

\begin{tabular}{|c|c|c|c|c|c|}
\hline Gene & SG CAR & Valor de P SG CAR & FM & Valor de P FM & $\mathbf{K}$ \\
\hline DARS & 0,35 & 0,15 & 0,86 & $4,39 \mathrm{E}-06$ & 31,36 \\
\hline DBX2 & 0,38 & 0,12 & 0,58 & $1,23 \mathrm{E}-02$ & 2,66 \\
\hline DCK & 0,43 & 0,08 & 0,83 & $1,96 \mathrm{E}-05$ & 24,03 \\
\hline DCUN1D1 & 0,47 & 0,05 & 0,87 & $3,53 \mathrm{E}-06$ & 32,50 \\
\hline DEK & 0,47 & 0,05 & 0,91 & $2,08 \mathrm{E}-07$ & 43,27 \\
\hline DELE1 & 0,32 & 0,19 & 0,43 & $7,86 \mathrm{E}-02$ & 1,20 \\
\hline DERL2 & 0,31 & 0,21 & 0,64 & $4,19 \mathrm{E}-03$ & 5,46 \\
\hline DHX29 & 0,50 & 0,03 & 0,86 & $3,85 \mathrm{E}-06$ & 33,34 \\
\hline DHX36 & 0,38 & 0,12 & 0,81 & $4,33 \mathrm{E}-05$ & 30,80 \\
\hline DIRC2 & 0,35 & 0,16 & 0,79 & $8,49 \mathrm{E}-05$ & 17,11 \\
\hline DIS3L & 0,46 & 0,06 & 0,64 & $4,12 \mathrm{E}-03$ & 4,57 \\
\hline DLD & 0,61 & 0,01 & 0,86 & $5,62 \mathrm{E}-06$ & 35,96 \\
\hline DLG3 & 0,04 & 0,86 & 0,59 & $1,07 \mathrm{E}-02$ & 2,66 \\
\hline DNAJC10 & 0,35 & 0,16 & 0,91 & $1,39 \mathrm{E}-07$ & 48,30 \\
\hline DNM1L & 0,41 & 0,09 & 0,90 & 2,73E-07 & 54,40 \\
\hline DPF2 & 0,42 & 0,08 & 0,58 & $1,14 \mathrm{E}-02$ & 3,32 \\
\hline DPY19L4 & 0,37 & 0,13 & 0,80 & $5,89 \mathrm{E}-05$ & 29,86 \\
\hline DR1 & 0,54 & 0,02 & 0,91 & $1,07 \mathrm{E}-07$ & 44,33 \\
\hline DRAM2 & 0,55 & 0,02 & 0,80 & $7,46 \mathrm{E}-05$ & 15,86 \\
\hline DTNA & 0,24 & 0,33 & 0,58 & $1,09 \mathrm{E}-02$ & 3,60 \\
\hline DTWD1 & 0,41 & 0,09 & 0,67 & $2,31 \mathrm{E}-03$ & 5,92 \\
\hline DUT & 0,24 & 0,33 & 0,51 & $3,15 \mathrm{E}-02$ & 1,70 \\
\hline DXO & $-0,46$ & 0,06 & $-0,50$ & $3,29 \mathrm{E}-02$ & 1,34 \\
\hline DYM & 0,66 & $2,98 \mathrm{E}-03$ & 0,93 & $2,19 \mathrm{E}-08$ & 49,31 \\
\hline DYNC1LI1 & 0,58 & 0,01 & 0,85 & $6,43 \mathrm{E}-06$ & 28,99 \\
\hline DYNLT3 & 0,34 & 0,17 & 0,90 & $3,84 \mathrm{E}-07$ & 44,66 \\
\hline ECHDC1 & 0,14 & 0,58 & 0,81 & $5,15 \mathrm{E}-05$ & 20,05 \\
\hline ECI1 & 0,39 & 0,11 & 0,53 & $2,35 \mathrm{E}-02$ & 1,87 \\
\hline EID1 & 0,44 & 0,07 & 0,81 & $5,05 \mathrm{E}-05$ & 20,10 \\
\hline EIF2D & 0,44 & 0,07 & 0,65 & $3,21 \mathrm{E}-03$ & 4,93 \\
\hline ELAVL1 & 0,41 & 0,09 & 0,80 & $6,28 \mathrm{E}-05$ & 25,44 \\
\hline ELMOD2 & 0,50 & 0,04 & 0,86 & $3,77 \mathrm{E}-06$ & 31,71 \\
\hline ELP2 & 0,44 & 0,07 & 0,61 & $6,75 \mathrm{E}-03$ & 3,66 \\
\hline ELP4 & 0,37 & 0,13 & 0,64 & $4,33 \mathrm{E}-03$ & 4,42 \\
\hline EMC2 & 0,54 & 0,02 & 0,85 & $8,97 \mathrm{E}-06$ & 28,28 \\
\hline EMC3 & 0,19 & 0,44 & 0,75 & $3,57 \mathrm{E}-04$ & 12,75 \\
\hline EMC8 & 0,63 & $4,66 \mathrm{E}-03$ & 0,54 & $2,04 \mathrm{E}-02$ & 2,29 \\
\hline ENDOD1 & 0,34 & 0,17 & 0,69 & $1,37 \mathrm{E}-03$ & 8,03 \\
\hline ENSBTAG00000008248 & 0,08 & 0,75 & 0,61 & $6,71 \mathrm{E}-03$ & 4,21 \\
\hline ENSBTAG00000009823 & 0,11 & 0,66 & 0,78 & $1,53 \mathrm{E}-04$ & 16,12 \\
\hline ENSBTAG00000010500 & 0,34 & 0,17 & 0,83 & $1,97 \mathrm{E}-05$ & 24,93 \\
\hline ENSBTAG00000011052 & 0,23 & 0,35 & 0,79 & $1,02 \mathrm{E}-04$ & 19,39 \\
\hline ENSBTAG00000011911 & 0,31 & 0,21 & 0,78 & $1,43 \mathrm{E}-04$ & 17,41 \\
\hline ENSBTAG00000011926 & 0,51 & 0,03 & 0,77 & $1,61 \mathrm{E}-04$ & 18,90 \\
\hline ENSBTAG00000013020 & 0,06 & 0,80 & $-0,37$ & $1,28 \mathrm{E}-01$ & 0,39 \\
\hline ENSBTAG00000013311 & 0,41 & 0,09 & 0,84 & $1,62 \mathrm{E}-05$ & 26,79 \\
\hline ENSBTAG00000014448 & 0,42 & 0,09 & 0,70 & $1,21 \mathrm{E}-03$ & 13,34 \\
\hline ENSBTAG00000016999 & 0,34 & 0,17 & 0,80 & $7,37 \mathrm{E}-05$ & 18,45 \\
\hline ENSBTAG00000017330 & 0,11 & 0,67 & 0,51 & $2,90 \mathrm{E}-02$ & 1,65 \\
\hline ENSBTAG00000017759 & 0,42 & 0,08 & 0,55 & $1,74 \mathrm{E}-02$ & 1,86 \\
\hline ENSBTAG00000019285 & 0,39 & 0,11 & 0,86 & $4,22 \mathrm{E}-06$ & 32,14 \\
\hline ENSBTAG00000019464 & 0,24 & 0,34 & 0,63 & $4,75 \mathrm{E}-03$ & 4,11 \\
\hline ENSBTAG00000020803 & 0,33 & 0,18 & 0,49 & $4,09 \mathrm{E}-02$ & 1,22 \\
\hline ENSBTAG00000026848 & 0,33 & 0,18 & 0,39 & $1,07 \mathrm{E}-01$ & 0,61 \\
\hline ENSBTAG00000030305 & 0,29 & 0,24 & 0,56 & $1,50 \mathrm{E}-02$ & 2,16 \\
\hline ENSBTAG00000032806 & 0,46 & 0,05 & 0,25 & $3,23 \mathrm{E}-01$ & 0,31 \\
\hline ENSBTAG00000037375 & 0,54 & 0,02 & 0,59 & $1,01 \mathrm{E}-02$ & 3,11 \\
\hline ENSBTAG00000038430 & 0,26 & 0,30 & 0,34 & $1,71 \mathrm{E}-01$ & 0,55 \\
\hline ENSBTAG00000043706 & 0,57 & 0,01 & 0,73 & $5,71 \mathrm{E}-04$ & 12,57 \\
\hline ENSBTAG00000044190 & 0,38 & 0,12 & 0,76 & $2,60 \mathrm{E}-04$ & 11,58 \\
\hline ENSBTAG00000045867 & 0,39 & 0,11 & 0,70 & $1,14 \mathrm{E}-03$ & 7,15 \\
\hline ENSBTAG00000045971 & 0,33 & 0,19 & 0,87 & $2,03 \mathrm{E}-06$ & 37,00 \\
\hline
\end{tabular}


Tabela suplementar 10 - Genes contidos no módulo Darkturquoise da pituitária (continuação).

\begin{tabular}{|c|c|c|c|c|c|}
\hline Gene & SG CAR & Valor de P SG CAR & FM & Valor de P FM & $\mathbf{K}$ \\
\hline ENSBTAG00000046229 & 0,68 & 1,92E-03 & 0,68 & $1,99 \mathrm{E}-03$ & 7,33 \\
\hline ENSBTAG00000046259 & 0,27 & 0,28 & 0,54 & $2,21 \mathrm{E}-02$ & 1,96 \\
\hline ENSBTAG00000046324 & $-0,11$ & 0,66 & $-0,57$ & 1,31E-02 & 2,04 \\
\hline ENSBTAG00000046690 & 0,13 & 0,60 & 0,41 & $9,28 \mathrm{E}-02$ & 0,58 \\
\hline ENSBTAG00000047051 & 0,64 & $3,93 \mathrm{E}-03$ & 0,51 & $2,88 \mathrm{E}-02$ & 1,47 \\
\hline ENSBTAG00000047084 & 0,16 & 0,52 & 0,26 & $2,93 \mathrm{E}-01$ & 0,50 \\
\hline ENSBTAG00000047582 & 0,12 & 0,63 & 0,46 & $5,71 \mathrm{E}-02$ & 0,80 \\
\hline ERCC8 & 0,24 & 0,33 & 0,65 & $3,44 \mathrm{E}-03$ & 7,47 \\
\hline ERGIC1 & 0,23 & 0,35 & 0,70 & $1,32 \mathrm{E}-03$ & 7,77 \\
\hline ETAA1 & 0,31 & 0,21 & 0,56 & $1,51 \mathrm{E}-02$ & 2,61 \\
\hline ETFRF1 & 0,24 & 0,34 & 0,55 & $1,72 \mathrm{E}-02$ & 2,47 \\
\hline EXOC6 & 0,61 & 0,01 & 0,81 & 4,24E-05 & 20,99 \\
\hline FAM111B & 0,39 & 0,11 & 0,84 & $1,02 \mathrm{E}-05$ & 25,08 \\
\hline FAM117B & 0,51 & 0,03 & 0,49 & 3,94E-02 & 1,54 \\
\hline FAM122A & 0,20 & 0,42 & 0,63 & $4,79 \mathrm{E}-03$ & 4,72 \\
\hline FAM161A & 0,43 & 0,07 & 0,61 & $7,34 \mathrm{E}-03$ & 3,57 \\
\hline FAM168B & 0,39 & 0,11 & 0,86 & $4,24 \mathrm{E}-06$ & 41,70 \\
\hline FAM206A & 0,46 & 0,06 & 0,84 & $1,34 \mathrm{E}-05$ & 26,56 \\
\hline FAM210A & 0,49 & 0,04 & 0,77 & $2,16 \mathrm{E}-04$ & 15,42 \\
\hline FAM3C & 0,19 & 0,44 & 0,84 & $1,09 \mathrm{E}-05$ & 23,16 \\
\hline FAM45A & 0,48 & 0,04 & 0,84 & $1,28 \mathrm{E}-05$ & 22,03 \\
\hline FAM98A & 0,52 & 0,03 & 0,86 & $4,82 \mathrm{E}-06$ & 30,98 \\
\hline FAR1 & 0,50 & 0,03 & 0,89 & $6,05 \mathrm{E}-07$ & 52,66 \\
\hline FASTKD1 & 0,29 & 0,24 & 0,80 & $7,30 \mathrm{E}-05$ & 21,08 \\
\hline FASTKD2 & 0,29 & 0,24 & 0,55 & $1,83 \mathrm{E}-02$ & 2,43 \\
\hline FBXO15 & 0,20 & 0,44 & 0,65 & $3,18 \mathrm{E}-03$ & 5,43 \\
\hline FBXO2 & 0,43 & 0,08 & 0,12 & $6,32 \mathrm{E}-01$ & 0,25 \\
\hline FBXO22 & 0,34 & 0,17 & 0,77 & $1,97 \mathrm{E}-04$ & 14,07 \\
\hline FCGR2B & $-0,23$ & 0,36 & $-0,27$ & $2,81 \mathrm{E}-01$ & 0,28 \\
\hline FGL1 & 0,21 & 0,40 & 0,67 & $2,48 \mathrm{E}-03$ & 6,90 \\
\hline FKBP14 & 0,46 & 0,05 & 0,50 & $3,67 \mathrm{E}-02$ & 1,03 \\
\hline FPGT & 0,34 & 0,16 & 0,81 & $4,03 \mathrm{E}-05$ & 21,01 \\
\hline FRA10AC1 & 0,46 & 0,05 & 0,61 & $6,79 \mathrm{E}-03$ & 3,59 \\
\hline FTL & $-0,43$ & 0,07 & $-0,52$ & $2,77 \mathrm{E}-02$ & 2,26 \\
\hline FUK & $-0,35$ & 0,16 & $-0,33$ & $1,83 \mathrm{E}-01$ & 0,44 \\
\hline FXR1 & 0,47 & 0,05 & 0,82 & $3,11 \mathrm{E}-05$ & 21,82 \\
\hline G3BP1 & 0,15 & 0,55 & 0,81 & $3,95 \mathrm{E}-05$ & 30,38 \\
\hline GFPT2 & 0,40 & 0,10 & 0,73 & $5,50 \mathrm{E}-04$ & 10,03 \\
\hline GGPS1 & 0,39 & 0,11 & 0,86 & $3,62 \mathrm{E}-06$ & 37,67 \\
\hline GGT7 & 0,19 & 0,45 & 0,44 & $7,01 \mathrm{E}-02$ & 0,77 \\
\hline GHITM & 0,55 & 0,02 & 0,82 & $3,70 \mathrm{E}-05$ & 24,13 \\
\hline GKAP1 & 0,50 & 0,03 & 0,84 & $1,41 \mathrm{E}-05$ & 25,98 \\
\hline GMFB & 0,49 & 0,04 & 0,86 & $3,85 \mathrm{E}-06$ & 33,27 \\
\hline GNA12 & 0,32 & 0,20 & 0,62 & $5,69 \mathrm{E}-03$ & 4,63 \\
\hline GNAI3 & 0,38 & 0,12 & 0,92 & $6,15 \mathrm{E}-08$ & 50,38 \\
\hline GNG10 & 0,32 & 0,19 & 0,77 & $1,63 \mathrm{E}-04$ & 16,31 \\
\hline GOLT1B & 0,28 & 0,25 & 0,73 & $5,17 \mathrm{E}-04$ & 10,75 \\
\hline GORAB & 0,38 & 0,12 & 0,74 & $4,22 \mathrm{E}-04$ & 10,62 \\
\hline GORASP2 & 0,40 & 0,10 & 0,82 & $3,30 \mathrm{E}-05$ & 24,35 \\
\hline GPBP1 & 0,50 & 0,04 & 0,89 & $9,43 \mathrm{E}-07$ & 44,40 \\
\hline GPM6B & 0,46 & 0,05 & 0,64 & $4,02 \mathrm{E}-03$ & 4,51 \\
\hline GPR155 & 0,40 & 0,10 & 0,77 & $2,03 \mathrm{E}-04$ & 15,65 \\
\hline GPR158 & 0,33 & 0,18 & 0,54 & $1,98 \mathrm{E}-02$ & 2,49 \\
\hline GPR 160 & 0,40 & 0,10 & 0,72 & $6,68 \mathrm{E}-04$ & 10,79 \\
\hline GPX8 & 0,74 & 4,71E-04 & 0,65 & $3,81 \mathrm{E}-03$ & 5,19 \\
\hline GSG1L & 0,38 & 0,12 & 0,32 & $1,89 \mathrm{E}-01$ & 0,44 \\
\hline GTF2B & 0,23 & 0,36 & 0,72 & $6,79 \mathrm{E}-04$ & 10,37 \\
\hline GTF2H1 & 0,34 & 0,17 & 0,77 & $2,02 \mathrm{E}-04$ & 14,25 \\
\hline GTPBP8 & 0,41 & 0,09 & 0,73 & $5,99 \mathrm{E}-04$ & 10,92 \\
\hline GULP1 & 0,51 & 0,03 & 0,57 & $1,35 \mathrm{E}-02$ & 2,38 \\
\hline HACD2 & 0,54 & 0,02 & 0,87 & $2,24 \mathrm{E}-06$ & 35,31 \\
\hline HACD3 & 0,44 & 0,07 & 0,93 & $2,71 \mathrm{E}-08$ & 53,66 \\
\hline
\end{tabular}


Tabela suplementar 10 - Genes contidos no módulo Darkturquoise da pituitária (continuação).

\begin{tabular}{|c|c|c|c|c|c|}
\hline Gene & SG CAR & Valor de P SG CAR & FM & Valor de P FM & $\mathbf{K}$ \\
\hline HACD4 & 0,34 & 0,16 & 0,68 & $2,05 \mathrm{E}-03$ & 5,87 \\
\hline HAUS6 & 0,36 & 0,14 & 0,77 & $1,85 \mathrm{E}-04$ & 13,79 \\
\hline HBS1L & 0,53 & 0,02 & 0,91 & $2,40 \mathrm{E}-07$ & 49,63 \\
\hline HDAC8 & 0,51 & 0,03 & 0,67 & $2,22 \mathrm{E}-03$ & 7,45 \\
\hline HERC4 & 0,25 & 0,32 & 0,87 & 2,13E-06 & 32,13 \\
\hline HIST1H2BB & 0,36 & 0,14 & 0,90 & 4,76E-07 & 39,31 \\
\hline HMG20A & 0,51 & 0,03 & 0,72 & 6,94E-04 & 10,26 \\
\hline HMGN1 & 0,35 & 0,16 & 0,82 & $3,14 \mathrm{E}-05$ & 25,48 \\
\hline HNRNPLL & 0,52 & 0,03 & 0,87 & 2,93E-06 & 38,16 \\
\hline HNRNPM & 0,56 & 0,02 & 0,82 & $2,60 \mathrm{E}-05$ & 26,54 \\
\hline HP1BP3 & 0,50 & 0,03 & 0,60 & $8,45 \mathrm{E}-03$ & 3,37 \\
\hline HSD17B7 & 0,42 & 0,09 & 0,44 & $6,63 \mathrm{E}-02$ & 1,06 \\
\hline HSF2 & 0,25 & 0,31 & 0,76 & $2,41 \mathrm{E}-04$ & 14,65 \\
\hline ICE2 & 0,45 & 0,06 & 0,79 & $8,40 \mathrm{E}-05$ & 22,61 \\
\hline IDH1 & 0,61 & 0,01 & 0,69 & $1,53 \mathrm{E}-03$ & 7,42 \\
\hline IER3IP1 & 0,56 & 0,02 & 0,81 & $5,28 \mathrm{E}-05$ & 18,27 \\
\hline IFIT5 & 0,36 & 0,15 & 0,82 & $2,74 \mathrm{E}-05$ & 25,18 \\
\hline IFNAR2 & 0,43 & 0,07 & 0,71 & $8,87 \mathrm{E}-04$ & 10,82 \\
\hline IFT80 & 0,34 & 0,17 & 0,80 & $7,03 \mathrm{E}-05$ & 20,87 \\
\hline IFT88 & 0,62 & 0,01 & 0,82 & $3,76 \mathrm{E}-05$ & 18,13 \\
\hline IKBIP & 0,47 & 0,05 & 0,77 & $1,79 \mathrm{E}-04$ & 14,19 \\
\hline IKZF5 & 0,20 & 0,43 & 0,68 & $1,77 \mathrm{E}-03$ & 8,92 \\
\hline IL4R & 0,11 & 0,67 & 0,43 & $7,52 \mathrm{E}-02$ & 0,93 \\
\hline IMMT & 0,49 & 0,04 & 0,87 & $3,55 \mathrm{E}-06$ & 38,75 \\
\hline INSIG2 & 0,35 & 0,16 & 0,70 & $1,22 \mathrm{E}-03$ & 7,60 \\
\hline IPO11 & 0,32 & 0,19 & 0,82 & $3,35 \mathrm{E}-05$ & 20,60 \\
\hline IPO7 & 0,49 & 0,04 & 0,88 & $1,86 \mathrm{E}-06$ & 46,06 \\
\hline IRAK1BP1 & 0,61 & 0,01 & 0,71 & $9,55 \mathrm{E}-04$ & 7,09 \\
\hline IRF3 & $-0,40$ & 0,10 & $-0,59$ & $1,02 \mathrm{E}-02$ & 2,44 \\
\hline ITFG1 & 0,40 & 0,10 & 0,90 & $3,45 \mathrm{E}-07$ & 43,88 \\
\hline JAK2 & 0,28 & 0,25 & 0,87 & 2,61E-06 & 37,33 \\
\hline JMJD1C & 0,35 & 0,15 & 0,67 & $2,49 \mathrm{E}-03$ & 7,33 \\
\hline JMJD7 & $-0,22$ & 0,39 & $-0,36$ & $1,46 \mathrm{E}-01$ & 0,36 \\
\hline KATNA1 & 0,43 & 0,07 & 0,85 & $6,34 \mathrm{E}-06$ & 32,00 \\
\hline KATNBL1 & 0,40 & 0,10 & 0,74 & $4,60 \mathrm{E}-04$ & 13,84 \\
\hline KCTD9 & 0,42 & 0,08 & 0,72 & $7,49 \mathrm{E}-04$ & 11,61 \\
\hline KDM1A & 0,46 & 0,06 & 0,75 & $3,87 \mathrm{E}-04$ & 13,85 \\
\hline KLC3 & 0,42 & 0,09 & 0,35 & $1,55 \mathrm{E}-01$ & 0,36 \\
\hline KLHL7 & 0,28 & 0,26 & 0,91 & $1,58 \mathrm{E}-07$ & 47,70 \\
\hline KNOP1 & 0,15 & 0,55 & 0,49 & $4,08 \mathrm{E}-02$ & 1,59 \\
\hline KRBA1 & $-0,30$ & 0,22 & $-0,50$ & $3,39 \mathrm{E}-02$ & 1,45 \\
\hline LACTB2 & 0,30 & 0,23 & 0,74 & $4,26 \mathrm{E}-04$ & 12,59 \\
\hline LAIR1 & $-0,05$ & 0,83 & $-0,32$ & $2,02 \mathrm{E}-01$ & 0,22 \\
\hline LAMP2 & 0,33 & 0,18 & 0,70 & $1,16 \mathrm{E}-03$ & 9,15 \\
\hline LAMTOR3 & 0,53 & 0,03 & 0,88 & $1,98 \mathrm{E}-06$ & 39,21 \\
\hline LAPTM4A & 0,25 & 0,31 & 0,82 & $3,51 \mathrm{E}-05$ & 25,13 \\
\hline LARP7 & 0,46 & 0,05 & 0,77 & $1,92 \mathrm{E}-04$ & 14,92 \\
\hline LEPR & 0,14 & 0,59 & 0,53 & 2,29E-02 & 1,89 \\
\hline LIN7C & 0,47 & 0,05 & 0,93 & $3,90 \mathrm{E}-08$ & 58,53 \\
\hline LMBR1L & $-0,45$ & 0,06 & $-0,40$ & $1,03 \mathrm{E}-01$ & 0,68 \\
\hline LONP1 & 0,38 & 0,12 & 0,68 & $2,06 \mathrm{E}-03$ & 5,28 \\
\hline LRIF1 & 0,39 & 0,11 & 0,43 & $7,86 \mathrm{E}-02$ & 1,11 \\
\hline LRRC26 & 0,26 & 0,30 & 0,70 & $1,21 \mathrm{E}-03$ & 7,73 \\
\hline LRRC38 & $-0,09$ & 0,73 & 0,33 & $1,81 \mathrm{E}-01$ & 0,29 \\
\hline LRRC49 & 0,13 & 0,60 & 0,61 & $7,20 \mathrm{E}-03$ & 4,83 \\
\hline LRRCC1 & 0,51 & 0,03 & 0,80 & $7,30 \mathrm{E}-05$ & 21,83 \\
\hline LSM14A & 0,43 & 0,07 & 0,77 & 1,97E-04 & 16,40 \\
\hline LY6D & $-0,16$ & 0,53 & $-0,69$ & $1,57 \mathrm{E}-03$ & 6,77 \\
\hline LYPLA1 & 0,38 & 0,12 & 0,81 & $4,35 \mathrm{E}-05$ & 25,43 \\
\hline LYSMD2 & 0,63 & $4,67 \mathrm{E}-03$ & 0,62 & $5,77 \mathrm{E}-03$ & 4,54 \\
\hline MACROD2 & 0,10 & 0,69 & 0,51 & $2,92 \mathrm{E}-02$ & 1,57 \\
\hline MAGOHB & 0,43 & 0,07 & 0,68 & $1,88 \mathrm{E}-03$ & 6,17 \\
\hline
\end{tabular}


Tabela suplementar 10 - Genes contidos no módulo Darkturquoise da pituitária (continuação).

\begin{tabular}{|c|c|c|c|c|c|}
\hline Gene & SG CAR & Valor de P SG CAR & FM & Valor de P FM & $\mathbf{K}$ \\
\hline MAL2 & 0,51 & 0,03 & 0,86 & $4,30 \mathrm{E}-06$ & 30,37 \\
\hline MANBAL & 0,45 & 0,06 & 0,29 & $2,48 \mathrm{E}-01$ & 0,25 \\
\hline MANEA & 0,44 & 0,07 & 0,84 & $1,60 \mathrm{E}-05$ & 29,18 \\
\hline MARCH3 & 0,09 & 0,73 & 0,48 & 4,39E-02 & 1,33 \\
\hline MARK1 & 0,34 & 0,17 & 0,86 & $5,31 \mathrm{E}-06$ & 29,21 \\
\hline MBIP & 0,51 & 0,03 & 0,85 & $7,05 \mathrm{E}-06$ & 27,25 \\
\hline ME1 & 0,69 & $1,37 \mathrm{E}-03$ & 0,57 & $1,44 \mathrm{E}-02$ & 2,63 \\
\hline METTL18 & 0,41 & 0,09 & 0,76 & $2,35 \mathrm{E}-04$ & 15,40 \\
\hline MFAP3 & 0,53 & 0,02 & 0,86 & $4,74 \mathrm{E}-06$ & 26,58 \\
\hline MID1IP1 & 0,42 & 0,09 & 0,33 & $1,77 \mathrm{E}-01$ & 0,47 \\
\hline MILR1 & $-0,54$ & 0,02 & $-0,40$ & $1,04 \mathrm{E}-01$ & 0,94 \\
\hline MKRN1 & 0,24 & 0,35 & 0,79 & $8,25 \mathrm{E}-05$ & 22,32 \\
\hline MNAT1 & 0,48 & 0,05 & 0,68 & $1,72 \mathrm{E}-03$ & 7,45 \\
\hline MOB4 & 0,53 & 0,02 & 0,86 & $3,78 \mathrm{E}-06$ & 39,20 \\
\hline MORF4L2 & 0,42 & 0,09 & 0,82 & $3,39 \mathrm{E}-05$ & 31,01 \\
\hline MPHOSPH6 & 0,58 & 0,01 & 0,49 & $4,07 \mathrm{E}-02$ & 1,92 \\
\hline MPHOSPH8 & 0,31 & 0,22 & 0,76 & $2,20 \mathrm{E}-04$ & 20,67 \\
\hline MPLKIP & 0,42 & 0,08 & 0,55 & $1,71 \mathrm{E}-02$ & 2,04 \\
\hline MPP5 & 0,55 & 0,02 & 0,82 & $3,72 \mathrm{E}-05$ & 21,17 \\
\hline MPZL3 & 0,36 & 0,14 & 0,72 & $8,43 \mathrm{E}-04$ & 9,48 \\
\hline MRFAP1L1 & 0,29 & 0,25 & 0,77 & $1,60 \mathrm{E}-04$ & 15,83 \\
\hline MRPL22 & 0,45 & 0,06 & 0,65 & $3,35 \mathrm{E}-03$ & 5,22 \\
\hline MRPL53 & 0,37 & 0,13 & 0,75 & $3,12 \mathrm{E}-04$ & 12,93 \\
\hline MRPS18C & 0,45 & 0,06 & 0,69 & $1,58 \mathrm{E}-03$ & 7,97 \\
\hline MRPS22 & 0,15 & 0,55 & 0,68 & $2,07 \mathrm{E}-03$ & 6,91 \\
\hline MSANTD4 & 0,50 & 0,04 & 0,89 & $1,03 \mathrm{E}-06$ & 42,23 \\
\hline MSH2 & 0,38 & 0,12 & 0,71 & $9,59 \mathrm{E}-04$ & 8,91 \\
\hline MT3 & 0,33 & 0,19 & 0,55 & $1,91 \mathrm{E}-02$ & 2,81 \\
\hline MT-АТP8 & 0,53 & 0,02 & 0,66 & $3,05 \mathrm{E}-03$ & 7,30 \\
\hline MTDH & 0,39 & 0,11 & 0,94 & $4,36 \mathrm{E}-09$ & 55,76 \\
\hline MTERF2 & 0,51 & 0,03 & 0,71 & $9,96 \mathrm{E}-04$ & 10,82 \\
\hline MTFR1 & 0,33 & 0,19 & 0,82 & $3,67 \mathrm{E}-05$ & 24,62 \\
\hline MTURN & 0,13 & 0,62 & 0,65 & $3,49 \mathrm{E}-03$ & 6,85 \\
\hline MYCBP & 0,61 & 0,01 & 0,87 & $2,37 \mathrm{E}-06$ & 35,46 \\
\hline MYD88 & 0,43 & 0,07 & 0,51 & $3,19 \mathrm{E}-02$ & 1,60 \\
\hline MYNN & 0,48 & 0,05 & 0,87 & $2,30 \mathrm{E}-06$ & 44,12 \\
\hline N4BP2L2 & 0,27 & 0,27 & 0,86 & $5,89 \mathrm{E}-06$ & 41,16 \\
\hline NAA15 & 0,40 & 0,10 & 0,89 & $9,58 \mathrm{E}-07$ & 52,65 \\
\hline NAA16 & 0,44 & 0,07 & 0,75 & $3,28 \mathrm{E}-04$ & 12,47 \\
\hline NAA35 & 0,39 & 0,11 & 0,86 & $5,87 \mathrm{E}-06$ & 32,51 \\
\hline NAA50 & 0,46 & 0,05 & 0,84 & $1,10 \mathrm{E}-05$ & 36,71 \\
\hline NADSYN1 & $-0,45$ & 0,06 & $-0,47$ & $5,16 \mathrm{E}-02$ & 1,37 \\
\hline NAF1 & 0,53 & 0,02 & 0,79 & $1,04 \mathrm{E}-04$ & 17,51 \\
\hline NBN & 0,49 & 0,04 & 0,86 & $4,02 \mathrm{E}-06$ & 29,26 \\
\hline NCBP2 & 0,21 & 0,41 & 0,68 & $1,90 \mathrm{E}-03$ & 8,40 \\
\hline NCK1 & 0,43 & 0,08 & 0,85 & $9,24 \mathrm{E}-06$ & 27,65 \\
\hline NDUFAF4 & 0,71 & $1,03 \mathrm{E}-03$ & 0,66 & $2,93 \mathrm{E}-03$ & 6,37 \\
\hline NDUFB5 & 0,48 & 0,05 & 0,87 & $2,47 \mathrm{E}-06$ & 30,80 \\
\hline NECAP2 & 0,52 & 0,03 & 0,55 & $1,87 \mathrm{E}-02$ & 2,18 \\
\hline NEK10 & 0,46 & 0,06 & 0,79 & $8,73 \mathrm{E}-05$ & 18,82 \\
\hline NEPRO & 0,41 & 0,09 & 0,69 & $1,39 \mathrm{E}-03$ & 8,53 \\
\hline NIPA2 & 0,51 & 0,03 & 0,87 & $2,83 \mathrm{E}-06$ & 35,86 \\
\hline NLK & 0,35 & 0,15 & 0,78 & $1,48 \mathrm{E}-04$ & 16,10 \\
\hline NQO2 & 0,53 & 0,02 & 0,50 & $3,45 \mathrm{E}-02$ & 1,69 \\
\hline NRCAM & 0,20 & 0,42 & 0,64 & $4,03 \mathrm{E}-03$ & 6,20 \\
\hline NSMF & 0,50 & 0,03 & 0,29 & $2,43 \mathrm{E}-01$ & 0,22 \\
\hline NT5C3A & 0,37 & 0,13 & 0,84 & $1,59 \mathrm{E}-05$ & 22,88 \\
\hline NUDT2 & $-0,13$ & 0,60 & $-0,37$ & $1,29 \mathrm{E}-01$ & 0,63 \\
\hline NUDT4 & 0,21 & 0,41 & 0,75 & $3,58 \mathrm{E}-04$ & 16,64 \\
\hline OCIAD1 & 0,45 & 0,06 & 0,86 & $4,29 \mathrm{E}-06$ & 32,92 \\
\hline ODF2L & 0,51 & 0,03 & 0,72 & $6,89 \mathrm{E}-04$ & 12,90 \\
\hline ORC4 & 0,54 & 0,02 & 0,93 & $1,36 \mathrm{E}-08$ & 58,82 \\
\hline
\end{tabular}


Tabela suplementar 10 - Genes contidos no módulo Darkturquoise da pituitária (continuação).

\begin{tabular}{|c|c|c|c|c|c|}
\hline Gene & SG CAR & Valor de P SG CAR & FM & Valor de P FM & $\mathbf{K}$ \\
\hline ORMDL1 & 0,50 & 0,03 & 0,89 & $6,71 \mathrm{E}-07$ & 35,93 \\
\hline OSTC & 0,53 & 0,02 & 0,66 & $2,92 \mathrm{E}-03$ & 5,06 \\
\hline OXCT1 & 0,45 & 0,06 & 0,63 & $4,95 \mathrm{E}-03$ & 4,94 \\
\hline OXR1 & 0,19 & 0,44 & 0,76 & $2,45 \mathrm{E}-04$ & 13,05 \\
\hline PAIP2 & 0,38 & 0,12 & 0,83 & $2,51 \mathrm{E}-05$ & 26,01 \\
\hline PARP14 & 0,40 & 0,10 & 0,65 & $3,23 \mathrm{E}-03$ & 5,70 \\
\hline PCBP2 & 0,34 & 0,16 & 0,72 & $8,52 \mathrm{E}-04$ & 9,13 \\
\hline PCGF3 & 0,19 & 0,45 & 0,59 & $9,86 \mathrm{E}-03$ & 3,18 \\
\hline PCGF6 & 0,44 & 0,07 & 0,67 & $2,16 \mathrm{E}-03$ & 6,39 \\
\hline PCNP & 0,50 & 0,03 & 0,95 & $9,81 \mathrm{E}-10$ & 68,03 \\
\hline PCP4L1 & 0,21 & 0,41 & 0,50 & $3,61 \mathrm{E}-02$ & 1,45 \\
\hline PDHA1 & 0,32 & 0,19 & 0,84 & $1,43 \mathrm{E}-05$ & 37,41 \\
\hline PDK1 & 0,39 & 0,11 & 0,78 & $1,42 \mathrm{E}-04$ & 21,96 \\
\hline PEX11B & 0,25 & 0,32 & 0,68 & $1,95 \mathrm{E}-03$ & 6,23 \\
\hline PFN2 & 0,64 & $4,43 \mathrm{E}-03$ & 0,89 & $1,02 \mathrm{E}-06$ & 40,07 \\
\hline PGGT1B & 0,35 & 0,15 & 0,74 & $4,93 \mathrm{E}-04$ & 15,32 \\
\hline PGRMC2 & 0,27 & 0,27 & 0,50 & $3,32 \mathrm{E}-02$ & 1,34 \\
\hline PHAX & 0,44 & 0,07 & 0,82 & $2,72 \mathrm{E}-05$ & 28,22 \\
\hline PHOSPHO2 & 0,69 & $1,40 \mathrm{E}-03$ & 0,79 & $9,11 \mathrm{E}-05$ & 18,25 \\
\hline PHTF1 & 0,15 & 0,55 & 0,69 & $1,54 \mathrm{E}-03$ & 10,21 \\
\hline PID1 & 0,23 & 0,36 & 0,56 & $1,57 \mathrm{E}-02$ & 2,25 \\
\hline PIGC & 0,41 & 0,09 & 0,88 & $1,48 \mathrm{E}-06$ & 33,22 \\
\hline PIGH & 0,54 & 0,02 & 0,79 & $1,13 \mathrm{E}-04$ & 14,87 \\
\hline PIGW & 0,32 & 0,19 & 0,68 & $1,81 \mathrm{E}-03$ & 6,84 \\
\hline PIK3R4 & 0,41 & 0,09 & 0,81 & $5,18 \mathrm{E}-05$ & 23,19 \\
\hline PITPNB & 0,65 & $3,42 \mathrm{E}-03$ & 0,82 & $2,58 \mathrm{E}-05$ & 23,65 \\
\hline PLA2G6 & $-0,35$ & 0,15 & $-0,37$ & $1,32 \mathrm{E}-01$ & 0,39 \\
\hline PLAA & 0,64 & $4,14 \mathrm{E}-03$ & 0,83 & $1,74 \mathrm{E}-05$ & 28,04 \\
\hline PLD4 & $-0,31$ & 0,21 & $-0,36$ & $1,39 \mathrm{E}-01$ & 0,59 \\
\hline PLEKHA7 & $-0,01$ & 0,98 & 0,48 & $4,23 \mathrm{E}-02$ & 1,15 \\
\hline PLEKHF2 & 0,46 & 0,06 & 0,78 & $1,33 \mathrm{E}-04$ & 19,32 \\
\hline PLPBP & 0,61 & 0,01 & 0,67 & $2,46 \mathrm{E}-03$ & 6,23 \\
\hline PLPPR2 & $-0,03$ & 0,90 & $-0,48$ & $4,37 \mathrm{E}-02$ & 1,12 \\
\hline PLRG1 & 0,32 & 0,19 & 0,84 & $1,04 \mathrm{E}-05$ & 33,61 \\
\hline PLS3 & 0,43 & 0,07 & 0,68 & $2,09 \mathrm{E}-03$ & 7,50 \\
\hline PLSCR2 & 0,56 & 0,02 & 0,59 & $9,20 \mathrm{E}-03$ & 3,43 \\
\hline РMPCB & 0,36 & 0,14 & 0,68 & $1,71 \mathrm{E}-03$ & 8,74 \\
\hline PMS1 & 0,46 & 0,06 & 0,75 & $3,69 \mathrm{E}-04$ & 10,68 \\
\hline PNKP & $-0,27$ & 0,28 & $-0,44$ & $6,91 \mathrm{E}-02$ & 0,68 \\
\hline PNRC2 & 0,36 & 0,14 & 0,82 & $3,43 \mathrm{E}-05$ & 23,21 \\
\hline POLD3 & 0,57 & 0,01 & 0,67 & $2,40 \mathrm{E}-03$ & 6,80 \\
\hline POLR1E & 0,27 & 0,28 & 0,79 & $9,82 \mathrm{E}-05$ & 15,80 \\
\hline PPHLN1 & 0,47 & 0,05 & 0,79 & $1,10 \mathrm{E}-04$ & 17,08 \\
\hline PPIC & 0,10 & 0,69 & 0,48 & $4,19 \mathrm{E}-02$ & 1,24 \\
\hline PPIL3 & 0,40 & 0,10 & 0,65 & $3,65 \mathrm{E}-03$ & 4,57 \\
\hline PPIP5K2 & 0,31 & 0,21 & 0,84 & $1,39 \mathrm{E}-05$ & 30,47 \\
\hline PPP1CB & 0,42 & 0,08 & 0,91 & $1,85 \mathrm{E}-07$ & 54,61 \\
\hline PPP1CC & 0,26 & 0,29 & 0,86 & $5,68 \mathrm{E}-06$ & 35,44 \\
\hline PPP2R3A & 0,02 & 0,93 & 0,66 & $3,01 \mathrm{E}-03$ & 5,19 \\
\hline PPP3CB & 0,61 & 0,01 & 0,90 & $5,09 \mathrm{E}-07$ & 39,61 \\
\hline PPP4R3A & 0,39 & 0,11 & 0,87 & $2,46 \mathrm{E}-06$ & 44,81 \\
\hline PPP6R1 & 0,59 & 0,01 & 0,51 & $2,94 \mathrm{E}-02$ & 1,44 \\
\hline PRKACB & 0,52 & 0,03 & 0,72 & $7,26 \mathrm{E}-04$ & 11,53 \\
\hline PRNP & 0,49 & 0,04 & 0,76 & $2,35 \mathrm{E}-04$ & 18,77 \\
\hline PRPF39 & 0,48 & 0,04 & 0,81 & $5,28 \mathrm{E}-05$ & 18,79 \\
\hline PRPF40A & 0,41 & 0,09 & 0,89 & $9,67 \mathrm{E}-07$ & 46,04 \\
\hline PRXL2A & 0,19 & 0,44 & 0,75 & $3,13 \mathrm{E}-04$ & 13,04 \\
\hline PSMA4 & 0,53 & 0,02 & 0,74 & $5,08 \mathrm{E}-04$ & 12,44 \\
\hline PSMD12 & 0,43 & 0,07 & 0,85 & $7,15 \mathrm{E}-06$ & 39,44 \\
\hline РТBP2 & 0,30 & 0,22 & 0,69 & $1,51 \mathrm{E}-03$ & 9,22 \\
\hline PTGES3 & 0,52 & 0,03 & 0,87 & $2,92 \mathrm{E}-06$ & 38,30 \\
\hline PTGR2 & 0,41 & 0,09 & 0,81 & $5,15 \mathrm{E}-05$ & 21,10 \\
\hline
\end{tabular}


Tabela suplementar 10 - Genes contidos no módulo Darkturquoise da pituitária (continuação).

\begin{tabular}{|c|c|c|c|c|c|}
\hline Gene & SG CAR & Valor de P SG CAR & FM & Valor de P FM & $\mathbf{K}$ \\
\hline РTP4A2 & 0,41 & 0,09 & 0,86 & $5,84 \mathrm{E}-06$ & 31,50 \\
\hline PUS3 & 0,26 & 0,30 & 0,87 & $3,22 \mathrm{E}-06$ & 31,40 \\
\hline PYROXD1 & 0,44 & 0,07 & 0,71 & $9,07 \mathrm{E}-04$ & 8,58 \\
\hline RAB10 & 0,42 & 0,08 & 0,95 & $2,25 \mathrm{E}-09$ & 71,39 \\
\hline RAB18 & 0,43 & 0,08 & 0,89 & $7,48 \mathrm{E}-07$ & 37,18 \\
\hline RAB1A & 0,35 & 0,16 & 0,86 & $3,75 \mathrm{E}-06$ & 41,88 \\
\hline RAB2A & 0,53 & 0,02 & 0,93 & $2,46 \mathrm{E}-08$ & 50,58 \\
\hline RAB3GAP1 & 0,53 & 0,02 & 0,88 & $1,54 \mathrm{E}-06$ & 35,16 \\
\hline RAB5C & 0,33 & 0,17 & 0,76 & $2,22 \mathrm{E}-04$ & 15,53 \\
\hline RAB8B & 0,46 & 0,06 & 0,92 & $6,41 \mathrm{E}-08$ & 51,27 \\
\hline RABEP2 & 0,26 & 0,30 & 0,37 & $1,26 \mathrm{E}-01$ & 0,69 \\
\hline RAC2 & $-0,58$ & 0,01 & $-0,64$ & $4,45 \mathrm{E}-03$ & 4,03 \\
\hline RAD21 & 0,28 & 0,27 & 0,69 & $1,55 \mathrm{E}-03$ & 9,08 \\
\hline RAD23B & 0,43 & 0,07 & 0,89 & $5,82 \mathrm{E}-07$ & 42,06 \\
\hline RADIL & $-0,03$ & 0,91 & $-0,42$ & $8,38 \mathrm{E}-02$ & 0,75 \\
\hline RAP1A & 0,22 & 0,39 & 0,84 & $1,22 \mathrm{E}-05$ & 26,26 \\
\hline RAP2C & 0,34 & 0,16 & 0,73 & $5,64 \mathrm{E}-04$ & 12,49 \\
\hline RBBP4 & 0,34 & 0,16 & 0,92 & $9,03 \mathrm{E}-08$ & 54,03 \\
\hline RBM11 & 0,54 & 0,02 & 0,74 & $4,12 \mathrm{E}-04$ & 10,06 \\
\hline RCC1L & 0,51 & 0,03 & 0,62 & $5,55 \mathrm{E}-03$ & 5,30 \\
\hline RCHY1 & 0,56 & 0,02 & 0,90 & $5,20 \mathrm{E}-07$ & 44,81 \\
\hline RDH14 & 0,46 & 0,06 & 0,63 & $4,82 \mathrm{E}-03$ & 5,00 \\
\hline REEP3 & 0,26 & 0,30 & 0,84 & $1,24 \mathrm{E}-05$ & 34,72 \\
\hline REEP4 & $-0,12$ & 0,64 & $-0,44$ & $6,87 \mathrm{E}-02$ & 0,66 \\
\hline REEP5 & 0,38 & 0,12 & 0,91 & $1,62 \mathrm{E}-07$ & 44,52 \\
\hline REXO2 & 0,57 & 0,01 & 0,47 & $4,78 \mathrm{E}-02$ & 1,89 \\
\hline RF00012 & $-0,47$ & 0,05 & $-0,64$ & $4,54 \mathrm{E}-03$ & 4,27 \\
\hline RF00213 & 0,57 & 0,01 & 0,64 & $4,09 \mathrm{E}-03$ & 4,16 \\
\hline RF00581 & $-0,24$ & 0,33 & $-0,33$ & 1,79E-01 & 0,31 \\
\hline RF01164 & 0,52 & 0,03 & 0,70 & $1,33 \mathrm{E}-03$ & 7,22 \\
\hline RFC3 & 0,44 & 0,07 & 0,57 & $1,36 \mathrm{E}-02$ & 3,60 \\
\hline RFX4 & 0,20 & 0,42 & 0,45 & $6,42 \mathrm{E}-02$ & 1,11 \\
\hline RIIAD1 & $-0,12$ & 0,63 & $-0,30$ & $2,32 \mathrm{E}-01$ & 0,36 \\
\hline RIMKLB & 0,44 & 0,06 & 0,60 & $9,08 \mathrm{E}-03$ & 3,34 \\
\hline RINT1 & 0,52 & 0,03 & 0,80 & $6,69 \mathrm{E}-05$ & 20,18 \\
\hline RNF11 & 0,30 & 0,23 & 0,87 & $3,00 \mathrm{E}-06$ & 37,88 \\
\hline RNF135 & $-0,42$ & 0,09 & $-0,56$ & $1,61 \mathrm{E}-02$ & 2,52 \\
\hline RNF14 & 0,38 & 0,12 & 0,83 & $2,45 \mathrm{E}-05$ & 20,39 \\
\hline RNF146 & 0,43 & 0,07 & 0,75 & $3,25 \mathrm{E}-04$ & 13,28 \\
\hline RNF34 & 0,67 & $2,32 \mathrm{E}-03$ & 0,82 & $3,13 \mathrm{E}-05$ & 21,24 \\
\hline RNF6 & 0,26 & 0,31 & 0,77 & $2,04 \mathrm{E}-04$ & 13,57 \\
\hline RNF7 & 0,76 & $2,80 \mathrm{E}-04$ & 0,87 & $2,41 \mathrm{E}-06$ & 31,25 \\
\hline RNFT1 & 0,47 & 0,05 & 0,89 & $9,94 \mathrm{E}-07$ & 41,48 \\
\hline RPAP3 & 0,58 & 0,01 & 0,87 & $2,56 \mathrm{E}-06$ & 33,52 \\
\hline RPIA & 0,30 & 0,22 & 0,61 & $7,54 \mathrm{E}-03$ & 4,72 \\
\hline RPN2 & 0,13 & 0,62 & 0,56 & $1,60 \mathrm{E}-02$ & 2,15 \\
\hline RPP30 & 0,24 & 0,34 & 0,75 & 2,96E-04 & 12,51 \\
\hline RPRM & 0,14 & 0,58 & 0,60 & $9,13 \mathrm{E}-03$ & 4,02 \\
\hline RPS19BP1 & 0,21 & 0,41 & 0,33 & $1,82 \mathrm{E}-01$ & 0,21 \\
\hline RRAGC & 0,33 & 0,17 & 0,80 & $5,93 \mathrm{E}-05$ & 23,88 \\
\hline RSL24D1 & 0,57 & 0,01 & 0,92 & $7,87 \mathrm{E}-08$ & 50,51 \\
\hline RWDD1 & 0,50 & 0,03 & 0,81 & $4,67 \mathrm{E}-05$ & 20,64 \\
\hline SAMD10 & $-0,06$ & 0,80 & $-0,53$ & $2,34 \mathrm{E}-02$ & 1,27 \\
\hline SASS6 & 0,30 & 0,22 & 0,81 & $5,31 \mathrm{E}-05$ & 21,91 \\
\hline SBDS & 0,50 & 0,04 & 0,92 & $4,21 \mathrm{E}-08$ & 54,93 \\
\hline SCNN1A & 0,38 & 0,12 & 0,36 & $1,48 \mathrm{E}-01$ & 0,58 \\
\hline SCOC & 0,58 & 0,01 & 0,84 & $1,16 \mathrm{E}-05$ & 29,35 \\
\hline SCP2 & 0,30 & 0,23 & 0,81 & $3,91 \mathrm{E}-05$ & 18,39 \\
\hline SCRN3 & 0,49 & 0,04 & 0,60 & $8,62 \mathrm{E}-03$ & 4,01 \\
\hline SEC22A & 0,43 & 0,07 & 0,73 & $5,64 \mathrm{E}-04$ & 9,93 \\
\hline SENP6 & 0,45 & 0,06 & 0,74 & $4,31 \mathrm{E}-04$ & 10,20 \\
\hline SENP7 & 0,44 & 0,07 & 0,72 & $7,30 \mathrm{E}-04$ & 11,26 \\
\hline
\end{tabular}


Tabela suplementar 10 - Genes contidos no módulo Darkturquoise da pituitária (continuação).

\begin{tabular}{|c|c|c|c|c|c|}
\hline Gene & SG CAR & Valor de P SG CAR & FM & Valor de P FM & $\mathbf{K}$ \\
\hline SEPT7 & 0,56 & 0,02 & 0,95 & $1,06 \mathrm{E}-09$ & 70,98 \\
\hline SERBP1 & 0,34 & 0,17 & 0,82 & $3,43 \mathrm{E}-05$ & 28,68 \\
\hline SGCB & 0,34 & 0,17 & 0,80 & $5,82 \mathrm{E}-05$ & 20,17 \\
\hline SH3BGRL & 0,26 & 0,30 & 0,77 & $1,81 \mathrm{E}-04$ & 17,14 \\
\hline SHLD3 & 0,44 & 0,07 & 0,71 & 1,04E-03 & 8,53 \\
\hline SHOC2 & 0,45 & 0,06 & 0,94 & $6,00 \mathrm{E}-09$ & 63,35 \\
\hline SIPA1 & $-0,28$ & 0,25 & $-0,46$ & $5,46 \mathrm{E}-02$ & 1,14 \\
\hline SIRT1 & 0,29 & 0,24 & 0,76 & $2,86 \mathrm{E}-04$ & 13,05 \\
\hline SIRT6 & 0,56 & 0,02 & 0,44 & 6,49E-02 & 0,98 \\
\hline SLC1A3 & 0,51 & 0,03 & 0,59 & $9,88 \mathrm{E}-03$ & 4,37 \\
\hline SLC24A5 & 0,35 & 0,16 & 0,86 & $3,75 \mathrm{E}-06$ & 32,73 \\
\hline SLC25A24 & 0,38 & 0,12 & 0,62 & $5,64 \mathrm{E}-03$ & 5,33 \\
\hline SLC25A32 & 0,49 & 0,04 & 0,79 & $9,54 \mathrm{E}-05$ & 17,70 \\
\hline SLC30A7 & 0,22 & 0,38 & 0,74 & $4,46 \mathrm{E}-04$ & 13,76 \\
\hline SLC35A5 & 0,17 & 0,50 & 0,73 & $5,18 \mathrm{E}-04$ & 11,38 \\
\hline SLC35F5 & 0,52 & 0,03 & 0,90 & $4,52 \mathrm{E}-07$ & 45,62 \\
\hline SLC38A6 & 0,37 & 0,13 & 0,52 & $2,83 \mathrm{E}-02$ & 1,70 \\
\hline SLC4A11 & 0,31 & 0,22 & 0,49 & $3,69 \mathrm{E}-02$ & 1,56 \\
\hline SLC9A5 & 0,22 & 0,38 & 0,50 & $3,41 \mathrm{E}-02$ & 1,23 \\
\hline SLC9A6 & 0,35 & 0,15 & 0,90 & $2,87 \mathrm{E}-07$ & 46,92 \\
\hline SMAD1 & 0,29 & 0,24 & 0,61 & $7,31 \mathrm{E}-03$ & 3,85 \\
\hline SMAD5 & 0,38 & 0,12 & 0,88 & $1,32 \mathrm{E}-06$ & 37,43 \\
\hline SMARCE1 & 0,43 & 0,08 & 0,83 & $2,12 \mathrm{E}-05$ & 25,83 \\
\hline SMC4 & 0,45 & 0,06 & 0,79 & $9,90 \mathrm{E}-05$ & 20,37 \\
\hline SMC6 & 0,33 & 0,18 & 0,82 & $2,57 \mathrm{E}-05$ & 24,49 \\
\hline SNX18 & 0,47 & 0,05 & 0,69 & $1,38 \mathrm{E}-03$ & 6,61 \\
\hline SNX24 & 0,48 & 0,04 & 0,63 & $5,43 \mathrm{E}-03$ & 3,96 \\
\hline SNX6 & 0,47 & 0,05 & 0,89 & $7,38 \mathrm{E}-07$ & 38,92 \\
\hline SOX 21 & 0,32 & 0,20 & 0,60 & $9,09 \mathrm{E}-03$ & 3,62 \\
\hline SPCS2 & 0,26 & 0,29 & 0,82 & $3,40 \mathrm{E}-05$ & 22,30 \\
\hline SPCS3 & 0,27 & 0,28 & 0,78 & $1,31 \mathrm{E}-04$ & 19,05 \\
\hline SPIN1 & 0,40 & 0,10 & 0,91 & $1,22 \mathrm{E}-07$ & 41,89 \\
\hline SPRYD4 & 0,21 & 0,41 & 0,56 & $1,47 \mathrm{E}-02$ & 3,26 \\
\hline SRP14 & 0,43 & 0,07 & 0,79 & $9,65 \mathrm{E}-05$ & 18,06 \\
\hline SRPK1 & 0,15 & 0,56 & 0,80 & $6,59 \mathrm{E}-05$ & 25,31 \\
\hline SSX2IP & 0,20 & 0,42 & 0,76 & $2,53 \mathrm{E}-04$ & 16,92 \\
\hline ST3GAL6 & 0,58 & 0,01 & 0,72 & $8,33 \mathrm{E}-04$ & 11,23 \\
\hline STAG2 & 0,41 & 0,09 & 0,87 & $2,54 \mathrm{E}-06$ & 42,44 \\
\hline STARD7 & 0,60 & 0,01 & 0,75 & $3,21 \mathrm{E}-04$ & 12,05 \\
\hline STK3 & 0,26 & 0,31 & 0,78 & $1,14 \mathrm{E}-04$ & 20,08 \\
\hline STMN2 & 0,13 & 0,62 & 0,48 & $4,44 \mathrm{E}-02$ & 1,42 \\
\hline STRN3 & 0,37 & 0,13 & 0,83 & $2,45 \mathrm{E}-05$ & 27,42 \\
\hline STX12 & 0,52 & 0,03 & 0,70 & $1,19 \mathrm{E}-03$ & 8,65 \\
\hline STX7 & 0,55 & 0,02 & 0,92 & $6,95 \mathrm{E}-08$ & 60,52 \\
\hline STXBP3 & 0,46 & 0,05 & 0,76 & $2,17 \mathrm{E}-04$ & 14,32 \\
\hline SULT2B1 & 0,17 & 0,50 & 0,38 & $1,21 \mathrm{E}-01$ & 0,56 \\
\hline SUMO2 & 0,41 & 0,09 & 0,57 & $1,38 \mathrm{E}-02$ & 2,43 \\
\hline SUPT4H1 & 0,36 & 0,14 & 0,54 & $2,20 \mathrm{E}-02$ & 2,90 \\
\hline SUSD3 & $-0,45$ & 0,06 & $-0,44$ & $6,74 \mathrm{E}-02$ & 1,08 \\
\hline SUV39H2 & 0,40 & 0,10 & 0,71 & $1,07 \mathrm{E}-03$ & 6,73 \\
\hline SYNPR & 0,35 & 0,15 & 0,78 & $1,56 \mathrm{E}-04$ & 17,85 \\
\hline TAF13 & 0,46 & 0,05 & 0,82 & $3,31 \mathrm{E}-05$ & 27,21 \\
\hline TAF15 & 0,60 & 0,01 & 0,72 & $8,31 \mathrm{E}-04$ & 8,45 \\
\hline TAF7 & 0,47 & 0,05 & 0,63 & $5,42 \mathrm{E}-03$ & 3,76 \\
\hline TAF9 & 0,37 & 0,13 & 0,82 & $3,76 \mathrm{E}-05$ & 23,73 \\
\hline TAZ & 0,25 & 0,31 & 0,36 & $1,42 \mathrm{E}-01$ & 0,78 \\
\hline TBC1D19 & 0,34 & 0,17 & 0,72 & $6,96 \mathrm{E}-04$ & 10,61 \\
\hline TBC1D32 & 0,36 & 0,15 & 0,76 & $2,62 \mathrm{E}-04$ & 18,55 \\
\hline TBCC & 0,55 & 0,02 & 0,49 & $4,05 \mathrm{E}-02$ & 1,17 \\
\hline TBPL1 & 0,01 & 0,98 & 0,49 & $4,13 \mathrm{E}-02$ & 1,26 \\
\hline TCEA1 & 0,35 & 0,15 & 0,85 & $7,36 \mathrm{E}-06$ & 32,68 \\
\hline TDP2 & 0,25 & 0,32 & 0,63 & $5,40 \mathrm{E}-03$ & 4,83 \\
\hline
\end{tabular}


Tabela suplementar 10 - Genes contidos no módulo Darkturquoise da pituitária (continuação).

\begin{tabular}{|c|c|c|c|c|c|}
\hline Gene & SG CAR & Valor de P SG CAR & FM & Valor de P FM & $\mathbf{K}$ \\
\hline TERF1 & 0,52 & 0,03 & 0,88 & $1,75 \mathrm{E}-06$ & 33,88 \\
\hline TEX30 & 0,05 & 0,84 & 0,26 & $2,92 \mathrm{E}-01$ & 0,18 \\
\hline TFB2M & 0,43 & 0,07 & 0,90 & $3,31 \mathrm{E}-07$ & 43,59 \\
\hline TGDS & 0,58 & 0,01 & 0,54 & $2,09 \mathrm{E}-02$ & 1,70 \\
\hline TIFA & 0,56 & 0,02 & 0,49 & $3,93 \mathrm{E}-02$ & 0,95 \\
\hline TIGD7 & 0,09 & 0,72 & 0,65 & $3,28 \mathrm{E}-03$ & 5,66 \\
\hline TIMM9 & 0,43 & 0,07 & 0,76 & $2,88 \mathrm{E}-04$ & 14,07 \\
\hline TINAGL1 & 0,39 & 0,11 & 0,48 & $4,55 \mathrm{E}-02$ & 1,17 \\
\hline TM6SF1 & 0,24 & 0,35 & 0,72 & $7,82 \mathrm{E}-04$ & 9,93 \\
\hline TM9SF2 & 0,40 & 0,10 & 0,92 & $5,44 \mathrm{E}-08$ & 47,59 \\
\hline TM9SF3 & 0,53 & 0,03 & 0,96 & $5,09 \mathrm{E}-10$ & 59,32 \\
\hline TMBIM4 & 0,48 & 0,04 & 0,88 & $1,20 \mathrm{E}-06$ & 42,93 \\
\hline TMED5 & 0,15 & 0,56 & 0,88 & $1,73 \mathrm{E}-06$ & 40,69 \\
\hline TMED7 & 0,33 & 0,18 & 0,90 & $3,92 \mathrm{E}-07$ & 48,35 \\
\hline TMEM126B & 0,49 & 0,04 & 0,68 & $1,88 \mathrm{E}-03$ & 7,48 \\
\hline TMEM128 & 0,39 & 0,11 & 0,75 & $3,59 \mathrm{E}-04$ & 12,85 \\
\hline TMEM150C & $-0,02$ & 0,92 & 0,49 & $3,92 \mathrm{E}-02$ & 1,42 \\
\hline TMEM167A & 0,29 & 0,25 & 0,80 & $8,01 \mathrm{E}-05$ & 16,91 \\
\hline TMEM167B & 0,37 & 0,13 & 0,76 & $2,62 \mathrm{E}-04$ & 15,21 \\
\hline TMEM168 & 0,48 & 0,05 & 0,78 & $1,33 \mathrm{E}-04$ & 15,74 \\
\hline TMEM183A & 0,33 & 0,18 & 0,83 & $2,41 \mathrm{E}-05$ & 23,46 \\
\hline TMEM184C & 0,38 & 0,12 & 0,88 & $1,35 \mathrm{E}-06$ & 40,79 \\
\hline TMEM251 & 0,41 & 0,09 & 0,66 & $2,97 \mathrm{E}-03$ & 6,02 \\
\hline TMEM30A & 0,29 & 0,25 & 0,81 & $3,84 \mathrm{E}-05$ & 24,20 \\
\hline TMEM35A & $-0,12$ & 0,63 & 0,46 & $5,62 \mathrm{E}-02$ & 1,04 \\
\hline TMEM43 & 0,29 & 0,24 & 0,70 & $1,24 \mathrm{E}-03$ & 8,84 \\
\hline TMEM50B & 0,49 & 0,04 & 0,89 & $5,52 \mathrm{E}-07$ & 46,54 \\
\hline TMEM60 & 0,30 & 0,22 & 0,62 & $6,26 \mathrm{E}-03$ & 4,47 \\
\hline TMPO & 0,45 & 0,06 & 0,65 & $3,58 \mathrm{E}-03$ & 4,92 \\
\hline TMX1 & 0,41 & 0,09 & 0,82 & $2,80 \mathrm{E}-05$ & 23,52 \\
\hline TOMM70 & 0,46 & 0,05 & 0,89 & $8,33 \mathrm{E}-07$ & 42,45 \\
\hline TPD52 & 0,64 & $4,09 \mathrm{E}-03$ & 0,84 & $1,16 \mathrm{E}-05$ & 26,04 \\
\hline TPMT & 0,38 & 0,12 & 0,75 & $3,12 \mathrm{E}-04$ & 10,60 \\
\hline TRAPPC6B & 0,59 & 0,01 & 0,77 & $1,66 \mathrm{E}-04$ & 13,72 \\
\hline TRDMT1 & 0,60 & 0,01 & 0,76 & $2,60 \mathrm{E}-04$ & 12,55 \\
\hline TRIT1 & 0,35 & 0,16 & 0,60 & $8,44 \mathrm{E}-03$ & 3,47 \\
\hline TRMT1L & 0,22 & 0,39 & 0,73 & $5,20 \mathrm{E}-04$ & 13,01 \\
\hline TRNT1 & 0,56 & 0,02 & 0,91 & $1,08 \mathrm{E}-07$ & 45,71 \\
\hline TSN & 0,40 & 0,10 & 0,75 & $3,22 \mathrm{E}-04$ & 14,93 \\
\hline TSPAN1 & 0,28 & 0,27 & 0,61 & $7,03 \mathrm{E}-03$ & 3,37 \\
\hline TSPAN13 & 0,51 & 0,03 & 0,91 & $2,05 \mathrm{E}-07$ & 43,16 \\
\hline TSR2 & 0,33 & 0,18 & 0,58 & $1,14 \mathrm{E}-02$ & 3,37 \\
\hline TUSC3 & 0,13 & 0,60 & 0,68 & $1,89 \mathrm{E}-03$ & 6,86 \\
\hline TWF1 & 0,38 & 0,12 & 0,86 & $4,72 \mathrm{E}-06$ & 33,40 \\
\hline TXNDC9 & 0,29 & 0,23 & 0,74 & $4,30 \mathrm{E}-04$ & 12,13 \\
\hline TYW5 & 0,12 & 0,63 & 0,53 & $2,29 \mathrm{E}-02$ & 2,54 \\
\hline UBA5 & 0,39 & 0,11 & 0,84 & $1,60 \mathrm{E}-05$ & 36,44 \\
\hline UBE2K & 0,21 & 0,41 & 0,80 & $7,16 \mathrm{E}-05$ & 27,06 \\
\hline UBE2V2 & 0,57 & 0,01 & 0,87 & $3,15 \mathrm{E}-06$ & 27,18 \\
\hline UBE2W & 0,37 & 0,13 & 0,91 & $1,46 \mathrm{E}-07$ & 56,63 \\
\hline UBE3A & 0,50 & 0,04 & 0,95 & $2,03 \mathrm{E}-09$ & 61,98 \\
\hline UBL3 & 0,31 & 0,21 & 0,79 & $1,09 \mathrm{E}-04$ & 23,47 \\
\hline UBLCP1 & 0,68 & $2,02 \mathrm{E}-03$ & 0,84 & $1,15 \mathrm{E}-05$ & 27,82 \\
\hline UEVLD & 0,15 & 0,55 & 0,62 & $6,51 \mathrm{E}-03$ & 5,39 \\
\hline URI1 & 0,52 & 0,03 & 0,89 & $1,06 \mathrm{E}-06$ & 36,03 \\
\hline UROS & $-0,13$ & 0,60 & $-0,41$ & $8,90 \mathrm{E}-02$ & 0,40 \\
\hline USP1 & 0,55 & 0,02 & 0,89 & $6,52 \mathrm{E}-07$ & 38,48 \\
\hline USP10 & 0,45 & 0,06 & 0,85 & $9,38 \mathrm{E}-06$ & 35,22 \\
\hline USP33 & 0,46 & 0,05 & 0,81 & $4,07 \mathrm{E}-05$ & 24,74 \\
\hline VEZT & 0,29 & 0,25 & 0,78 & $1,36 \mathrm{E}-04$ & 16,15 \\
\hline VLDLR & 0,39 & 0,11 & 0,47 & $4,98 \mathrm{E}-02$ & 1,01 \\
\hline VMA21 & 0,57 & 0,01 & 0,87 & $3,55 \mathrm{E}-06$ & 39,69 \\
\hline
\end{tabular}


Tabela suplementar 10 - Genes contidos no módulo Darkturquoise da pituitária (continuação).

\begin{tabular}{|c|c|c|c|c|c|}
\hline Gene & SG CAR & Valor de P SG CAR & FM & Valor de P FM & $\mathbf{K}$ \\
\hline VPS35 & 0,54 & 0,02 & 0,93 & $1,45 \mathrm{E}-08$ & 54,33 \\
\hline VPS4A & 0,24 & 0,33 & 0,62 & $5,60 \mathrm{E}-03$ & 3,97 \\
\hline VPS4B & 0,51 & 0,03 & 0,89 & $5,50 \mathrm{E}-07$ & 42,42 \\
\hline VPS50 & 0,59 & 0,01 & 0,74 & 4,70E-04 & 9,74 \\
\hline VSTM2A & 0,15 & 0,55 & 0,66 & $3,02 \mathrm{E}-03$ & 6,53 \\
\hline VTA1 & 0,47 & 0,05 & 0,87 & $2,43 \mathrm{E}-06$ & 32,39 \\
\hline VTI1B & 0,24 & 0,35 & 0,66 & $2,75 \mathrm{E}-03$ & 6,09 \\
\hline WASHC3 & 0,41 & 0,09 & 0,67 & 2,29E-03 & 6,49 \\
\hline WASL & 0,32 & 0,19 & 0,84 & $1,15 \mathrm{E}-05$ & 36,60 \\
\hline WBP4 & 0,32 & 0,20 & 0,53 & $2,37 \mathrm{E}-02$ & 2,38 \\
\hline WDR89 & 0,50 & 0,04 & 0,76 & $2,28 \mathrm{E}-04$ & 13,42 \\
\hline WRB & 0,48 & 0,04 & 0,83 & $2,33 \mathrm{E}-05$ & 21,94 \\
\hline XPA & 0,12 & 0,63 & 0,59 & $1,05 \mathrm{E}-02$ & 3,52 \\
\hline XRCC5 & 0,57 & 0,01 & 0,59 & $1,06 \mathrm{E}-02$ & 2,94 \\
\hline YEATS4 & 0,11 & 0,68 & 0,53 & 2,37E-02 & 1,72 \\
\hline YIPF4 & 0,59 & 0,01 & 0,93 & $2,54 \mathrm{E}-08$ & 52,56 \\
\hline YIPF5 & 0,51 & 0,03 & 0,91 & $1,07 \mathrm{E}-07$ & 41,06 \\
\hline YME1L1 & 0,43 & 0,07 & 0,82 & $3,53 \mathrm{E}-05$ & 26,36 \\
\hline YWHAB & 0,45 & 0,06 & 0,84 & $1,30 \mathrm{E}-05$ & 28,13 \\
\hline ZBTB17 & 0,15 & 0,55 & 0,54 & $1,95 \mathrm{E}-02$ & 1,84 \\
\hline ZBTB8OS & 0,49 & 0,04 & 0,63 & $4,66 \mathrm{E}-03$ & 3,45 \\
\hline ZC3H14 & 0,49 & 0,04 & 0,73 & $6,55 \mathrm{E}-04$ & 11,32 \\
\hline ZFAND3 & 0,59 & 0,01 & 0,76 & $2,34 \mathrm{E}-04$ & 12,30 \\
\hline ZFYVE9 & 0,45 & 0,06 & 0,84 & $1,25 \mathrm{E}-05$ & 29,83 \\
\hline ZMYM1 & 0,50 & 0,04 & 0,82 & $2,90 \mathrm{E}-05$ & 30,98 \\
\hline ZMYM5 & 0,46 & 0,06 & 0,86 & $5,08 \mathrm{E}-06$ & 32,73 \\
\hline ZMYND11 & 0,35 & 0,15 & 0,89 & $7,41 \mathrm{E}-07$ & 44,64 \\
\hline ZNF133 & 0,39 & 0,11 & 0,52 & 2,69E-02 & 1,79 \\
\hline ZNF280D & 0,55 & 0,02 & 0,91 & $1,85 \mathrm{E}-07$ & 39,89 \\
\hline ZNF354A & 0,36 & 0,14 & 0,65 & $3,43 \mathrm{E}-03$ & 5,77 \\
\hline ZNF527 & 0,62 & 0,01 & 0,76 & $2,21 \mathrm{E}-04$ & 12,04 \\
\hline ZNF569 & 0,61 & 0,01 & 0,76 & $2,22 \mathrm{E}-04$ & 14,10 \\
\hline ZNF644 & 0,40 & 0,10 & 0,90 & $3,49 \mathrm{E}-07$ & 51,84 \\
\hline ZNF667 & 0,40 & 0,10 & 0,63 & $5,31 \mathrm{E}-03$ & 4,33 \\
\hline ZNF746 & 0,64 & $4,00 \mathrm{E}-03$ & 0,43 & $7,27 \mathrm{E}-02$ & 0,79 \\
\hline ZNF770 & 0,31 & 0,21 & 0,74 & $5,05 \mathrm{E}-04$ & 12,43 \\
\hline ZUP1 & 0,63 & $4,88 \mathrm{E}-03$ & 0,70 & $1,17 \mathrm{E}-03$ & 7,31 \\
\hline ZW10 & 0,53 & 0,02 & 0,82 & $3,11 \mathrm{E}-05$ & 24,83 \\
\hline
\end{tabular}


Tabela suplementar 11 - Genes contidos no módulo Lightsteelblue1 da pituitária.

\begin{tabular}{|c|c|c|c|c|c|}
\hline Gene & SG CAR & Valor de P SG CAR & FM & Valor de P FM & $\mathbf{K}$ \\
\hline ADSS & 0,51 & 0,03 & 0,87 & $2,03 \mathrm{E}-06$ & 6,04 \\
\hline AGK & 0,49 & 0,04 & 0,70 & $1,31 \mathrm{E}-03$ & 0,85 \\
\hline AK8 & 0,11 & 0,66 & $-0,34$ & $1,65 \mathrm{E}-01$ & 0,08 \\
\hline ANKRD34C & 0,16 & 0,54 & 0,51 & $2,93 \mathrm{E}-02$ & 0,14 \\
\hline ARFIP2 & 0,09 & 0,72 & 0,43 & $7,60 \mathrm{E}-02$ & 0,12 \\
\hline ARFRP1 & 0,43 & 0,07 & 0,72 & 7,37E-04 & 1,52 \\
\hline ASIC1 & $-0,12$ & 0,65 & $-0,56$ & $1,51 \mathrm{E}-02$ & 0,36 \\
\hline ATRIP & 0,44 & 0,07 & 0,82 & $2,89 \mathrm{E}-05$ & 2,48 \\
\hline CAVIN2 & $-0,29$ & 0,24 & $-0,41$ & $9,13 \mathrm{E}-02$ & 0,10 \\
\hline CAVIN3 & 0,52 & 0,03 & 0,34 & $1,74 \mathrm{E}-01$ & 0,03 \\
\hline CCT5 & 0,49 & 0,04 & 0,90 & $2,95 \mathrm{E}-07$ & 8,11 \\
\hline ССТ6A & 0,49 & 0,04 & 0,93 & $2,22 \mathrm{E}-08$ & 9,12 \\
\hline CEP295 & 0,14 & 0,58 & 0,81 & $4,36 \mathrm{E}-05$ & 4,16 \\
\hline CPNE2 & 0,59 & 0,01 & 0,57 & $1,45 \mathrm{E}-02$ & 0,34 \\
\hline CTNNBL1 & 0,58 & 0,01 & 0,63 & $5,35 \mathrm{E}-03$ & 0,77 \\
\hline CWC15 & 0,37 & 0,13 & 0,85 & $7,83 \mathrm{E}-06$ & 4,88 \\
\hline DNAJA3 & 0,42 & 0,08 & 0,84 & $1,02 \mathrm{E}-05$ & 5,08 \\
\hline EIPR1 & $-0,05$ & 0,85 & 0,68 & $1,99 \mathrm{E}-03$ & 0,84 \\
\hline ENSBTAG00000000801 & 0,53 & 0,02 & 0,84 & $1,32 \mathrm{E}-05$ & 5,22 \\
\hline ENSBTAG00000002051 & $-0,16$ & 0,52 & $-0,79$ & $9,66 \mathrm{E}-05$ & 2,66 \\
\hline ENSBTAG00000003743 & 0,28 & 0,27 & 0,36 & $1,43 \mathrm{E}-01$ & 0,12 \\
\hline ENSBTAG00000030384 & 0,30 & 0,23 & 0,92 & $7,71 \mathrm{E}-08$ & 5,97 \\
\hline ENSBTAG00000032057 & $-0,11$ & 0,66 & $-0,44$ & $6,63 \mathrm{E}-02$ & 0,22 \\
\hline ENSBTAG00000045888 & 0,28 & 0,26 & 0,64 & $4,30 \mathrm{E}-03$ & 0,58 \\
\hline FAM118B & $-0,12$ & 0,63 & 0,54 & $2,13 \mathrm{E}-02$ & 0,31 \\
\hline GAS8 & $-0,28$ & 0,26 & $-0,68$ & $2,06 \mathrm{E}-03$ & 0,64 \\
\hline GFM2 & 0,56 & 0,02 & 0,86 & $4,57 \mathrm{E}-06$ & 5,03 \\
\hline GLUD1 & 0,58 & 0,01 & 0,83 & $2,51 \mathrm{E}-05$ & 5,14 \\
\hline GNL3 & 0,33 & 0,19 & 0,91 & $1,07 \mathrm{E}-07$ & 6,36 \\
\hline GPR162 & $-0,04$ & 0,88 & $-0,61$ & $7,46 \mathrm{E}-03$ & 0,67 \\
\hline GPR176 & $-0,40$ & 0,10 & $-0,54$ & $2,20 \mathrm{E}-02$ & 0,56 \\
\hline HACE1 & 0,47 & 0,05 & 0,83 & $1,68 \mathrm{E}-05$ & 5,53 \\
\hline HIBCH & 0,45 & 0,06 & 0,86 & $3,93 \mathrm{E}-06$ & 4,15 \\
\hline HSPA14 & 0,47 & 0,05 & 0,91 & $1,45 \mathrm{E}-07$ & 8,15 \\
\hline HSPBP1 & 0,19 & 0,46 & 0,71 & $9,28 \mathrm{E}-04$ & 1,41 \\
\hline IMP4 & 0,40 & 0,10 & 0,83 & $1,83 \mathrm{E}-05$ & 2,75 \\
\hline INSIG1 & $-0,03$ & 0,91 & $-0,47$ & $4,79 \mathrm{E}-02$ & 0,31 \\
\hline INTS10 & 0,38 & 0,12 & 0,78 & $1,37 \mathrm{E}-04$ & 1,82 \\
\hline IRF8 & $-0,08$ & 0,74 & $-0,59$ & $1,06 \mathrm{E}-02$ & 0,51 \\
\hline LIN52 & 0,31 & 0,22 & 0,85 & $8,35 \mathrm{E}-06$ & 4,11 \\
\hline LTV1 & 0,33 & 0,17 & 0,89 & $7,70 \mathrm{E}-07$ & 6,17 \\
\hline LYSMD1 & 0,51 & 0,03 & 0,92 & $9,24 \mathrm{E}-08$ & 8,27 \\
\hline METAP2 & 0,50 & 0,03 & 0,89 & $8,30 \mathrm{E}-07$ & 7,34 \\
\hline MPC2 & 0,56 & 0,02 & 0,84 & $1,31 \mathrm{E}-05$ & 4,42 \\
\hline MRM3 & 0,46 & 0,06 & 0,77 & $1,63 \mathrm{E}-04$ & 2,20 \\
\hline MRPL32 & 0,10 & 0,70 & 0,71 & $9,58 \mathrm{E}-04$ & 1,97 \\
\hline MRTO4 & 0,19 & 0,45 & 0,90 & $4,76 \mathrm{E}-07$ & 6,02 \\
\hline MT1E & $-0,12$ & 0,64 & 0,70 & $1,14 \mathrm{E}-03$ & 1,76 \\
\hline NCDN & 0,43 & 0,08 & 0,61 & $7,22 \mathrm{E}-03$ & 0,94 \\
\hline NDUFAF1 & 0,33 & 0,18 & 0,87 & $2,33 \mathrm{E}-06$ & 6,89 \\
\hline NDUFV3 & 0,28 & 0,25 & 0,81 & $5,24 \mathrm{E}-05$ & 3,94 \\
\hline NMD3 & 0,62 & 0,01 & 0,78 & $1,25 \mathrm{E}-04$ & 3,27 \\
\hline NR2C2AP & 0,01 & 0,98 & 0,83 & $1,99 \mathrm{E}-05$ & 4,06 \\
\hline NSUN5 & 0,27 & 0,27 & 0,66 & $2,77 \mathrm{E}-03$ & 0,51 \\
\hline NT5C3B & 0,21 & 0,41 & 0,67 & $2,45 \mathrm{E}-03$ & 0,81 \\
\hline NUP88 & 0,33 & 0,18 & 0,83 & $2,16 \mathrm{E}-05$ & 4,78 \\
\hline PACRGL & 0,29 & 0,24 & 0,60 & $8,07 \mathrm{E}-03$ & 0,48 \\
\hline PDCD2 & 0,42 & 0,08 & 0,70 & $1,18 \mathrm{E}-03$ & 1,18 \\
\hline PGAM5 & 0,33 & 0,17 & 0,74 & 4,47E-04 & 1,61 \\
\hline POLR1B & 0,42 & 0,08 & 0,88 & $1,20 \mathrm{E}-06$ & 4,68 \\
\hline POLR1C & 0,31 & 0,21 & 0,73 & $6,38 \mathrm{E}-04$ & 1,04 \\
\hline PPID & 0,40 & 0,10 & 0,89 & $6,83 \mathrm{E}-07$ & 5,46 \\
\hline PPP4C & 0,18 & 0,47 & 0,71 & $9,22 \mathrm{E}-04$ & 1,32 \\
\hline
\end{tabular}


Tabela suplementar 11 - Genes contidos no módulo Lightsteelblue1 da pituitária

\begin{tabular}{lrrrrr}
\multicolumn{5}{c}{ (continuação) } \\
\hline Gene & SG CAR & Valor de P SG CAR & FM & Valor de P FM & K \\
\hline PUM3 & 0,27 & 0,29 & 0,81 & $5,31 \mathrm{E}-05$ & 3,06 \\
RCN3 & $-0,27$ & 0,28 & $-0,77$ & $2,07 \mathrm{E}-04$ & 2,59 \\
RIPPLY2 & 0,27 & 0,28 & 0,62 & $5,78 \mathrm{E}-03$ & 0,79 \\
RNF8 & 0,49 & 0,04 & 0,81 & $4,45 \mathrm{E}-05$ & 5,53 \\
RPAP2 & 0,05 & 0,79 & $9,82 \mathrm{E}-05$ & 2,57 \\
RPP38 & 0,47 & 0,44 & 0,59 & $9,75 \mathrm{E}-03$ & 0,35 \\
RPUSD3 & 0,19 & 0,95 & 0,63 & $5,10 \mathrm{E}-03$ & 0,70 \\
SCLT1 & 0,02 & 0,04 & $4,06 \mathrm{E}-08$ & 7,45 \\
SESN1 & 0,49 & 0,19 & 0,78 & $1,22 \mathrm{E}-04$ & 2,64 \\
SNRNP40 & 0,33 & 0,03 & $2,18 \mathrm{E}-05$ & 3,62 \\
SNW1 & 0,51 & 0,11 & 0,83 & $9,83 \mathrm{E}-07$ & 7,14 \\
SOBP & 0,57 & $-0,63$ & $5,40 \mathrm{E}-03$ & 0,85 \\
SRPRB & 0,38 & 0,08 & $8,05 \mathrm{E}-06$ & 5,10 \\
STOML3 & 0,11 & $-0,46$ & $5,66 \mathrm{E}-02$ & 0,12 \\
SURF6 & 0,14 & 0,50 & 0,60 & $7,92 \mathrm{E}-03$ & 0,72 \\
SYT17 & 0,42 & 0,28 & $-0,63$ & $4,96 \mathrm{E}-03$ & 0,90 \\
TEFM & $-0,39$ & 0,18 & 0,93 & $1,36 \mathrm{E}-08$ & 7,62 \\
TIPIN & 0,17 & 0,07 & 0,84 & $1,15 \mathrm{E}-05$ & 4,47 \\
TRMU & $-0,27$ & 0,38 & 0,70 & $1,12 \mathrm{E}-03$ & 0,82 \\
UQCRC1 & 0,12 & 0,68 & $1,95 \mathrm{E}-03$ & 1,17 \\
UQCRH & 0,33 & 0,41 & $-0,59$ & $1,05 \mathrm{E}-02$ & 0,35 \\
VWA5B2 & 0,44 & 0,28 & $-0,76$ & $2,28 \mathrm{E}-04$ & 2,14 \\
WDR46 & 0,22 & 0,18 & 0,63 & $5,54 \mathrm{E}-03$ & 1,06 \\
WDR70 & 0,12 & 0,75 & $2,96 \mathrm{E}-04$ & 1,82 \\
WFIKKN1 & 0,38 & 0,66 & $-0,44$ & $6,48 \mathrm{E}-02$ & 0,09 \\
WLS & $-0,21$ & 0,21 & 0,71 & $9,18 \mathrm{E}-04$ & 1,23 \\
YARS & 0,29 & 0,87 & $3,01 \mathrm{E}-06$ & 4,54 \\
ZCCHC7 & 0,52 & 0,65 & $3,26 \mathrm{E}-03$ & 0,52 \\
ZNF132 & 0,27 & 0,76 & $2,56 \mathrm{E}-04$ & 2,46 \\
ZNHIT6 & 0,33 & 0,79 & $9,67 \mathrm{E}-05$ & 2,56 \\
\hline
\end{tabular}


Tabela suplementar 12 - Genes contidos no módulo Plum1 da pituitária.

\begin{tabular}{|c|c|c|c|c|c|}
\hline Gene & SG CAR & Valor de P SG CAR & FM & Valor de P FM & $\mathbf{K}$ \\
\hline AAR2 & 0,34 & 0,17 & 0,79 & $9,61 \mathrm{E}-05$ & 3,11 \\
\hline ALK & 0,32 & 0,20 & 0,71 & $9,94 \mathrm{E}-04$ & 1,85 \\
\hline ANKRD42 & 0,12 & 0,63 & 0,72 & $6,68 \mathrm{E}-04$ & 2,26 \\
\hline ANKRD45 & 0,52 & 0,03 & 0,68 & $2,02 \mathrm{E}-03$ & 1,10 \\
\hline ANXA11 & 0,56 & 0,01 & 0,68 & $1,98 \mathrm{E}-03$ & 1,61 \\
\hline ASH2L & 0,12 & 0,63 & 0,77 & $1,79 \mathrm{E}-04$ & 3,78 \\
\hline ATXN7L2 & 0,05 & 0,86 & 0,79 & $1,06 \mathrm{E}-04$ & 2,46 \\
\hline BATF3 & $-0,07$ & 0,80 & 0,56 & $1,67 \mathrm{E}-02$ & 0,53 \\
\hline BHLHA15 & 0,15 & 0,54 & 0,62 & $6,57 \mathrm{E}-03$ & 0,49 \\
\hline BLCAP & 0,55 & 0,02 & 0,74 & $4,23 \mathrm{E}-04$ & 2,47 \\
\hline BOP1 & 0,32 & 0,19 & 0,80 & $6,74 \mathrm{E}-05$ & 3,79 \\
\hline C18H19orf12 & 0,48 & 0,05 & 0,47 & $5,03 \mathrm{E}-02$ & 0,36 \\
\hline CAV2 & 0,29 & 0,24 & 0,83 & $2,22 \mathrm{E}-05$ & 4,97 \\
\hline $\mathrm{CBX} 7$ & 0,23 & 0,35 & 0,58 & $1,08 \mathrm{E}-02$ & 0,68 \\
\hline CCDC97 & 0,36 & 0,14 & 0,69 & $1,51 \mathrm{E}-03$ & 1,04 \\
\hline CEP41 & 0,02 & 0,94 & 0,53 & $2,24 \mathrm{E}-02$ & 0,82 \\
\hline CGREF1 & $-0,35$ & 0,16 & $-0,58$ & $1,20 \mathrm{E}-02$ & 0,42 \\
\hline CHL1 & 0,39 & 0,11 & 0,78 & $1,33 \mathrm{E}-04$ & 3,43 \\
\hline CLPX & 0,31 & 0,21 & 0,80 & $5,90 \mathrm{E}-05$ & 3,94 \\
\hline CNOT2 & 0,51 & 0,03 & 0,88 & $1,26 \mathrm{E}-06$ & 6,27 \\
\hline DBR1 & 0,53 & 0,02 & 0,79 & $9,99 \mathrm{E}-05$ & 2,95 \\
\hline DDX 20 & 0,43 & 0,07 & 0,88 & $1,54 \mathrm{E}-06$ & 6,24 \\
\hline DDX 28 & 0,48 & 0,04 & 0,85 & $6,79 \mathrm{E}-06$ & 5,37 \\
\hline DDX55 & 0,50 & 0,03 & 0,79 & $1,09 \mathrm{E}-04$ & 2,75 \\
\hline DEPDC7 & 0,34 & 0,16 & 0,87 & $3,56 \mathrm{E}-06$ & 5,50 \\
\hline DNAH7 & 0,26 & 0,30 & 0,86 & $3,77 \mathrm{E}-06$ & 4,92 \\
\hline DOCK10 & 0,27 & 0,29 & 0,87 & $2,34 \mathrm{E}-06$ & 6,17 \\
\hline DOK1 & 0,24 & 0,34 & 0,73 & $5,27 \mathrm{E}-04$ & 1,61 \\
\hline DPH2 & 0,21 & 0,41 & 0,85 & $6,76 \mathrm{E}-06$ & 5,66 \\
\hline EDC3 & 0,19 & 0,44 & 0,83 & $2,01 \mathrm{E}-05$ & 5,43 \\
\hline EI24 & 0,32 & 0,19 & 0,92 & $6,94 \mathrm{E}-08$ & 8,08 \\
\hline EIF3L & 0,09 & 0,73 & 0,77 & $2,11 \mathrm{E}-04$ & 3,08 \\
\hline EIF4A2 & 0,43 & 0,08 & 0,74 & $4,81 \mathrm{E}-04$ & 2,87 \\
\hline ELOVL6 & 0,33 & 0,19 & 0,74 & $4,25 \mathrm{E}-04$ & 2,40 \\
\hline ENSBTAG00000007105 & 0,33 & 0,18 & 0,77 & $2,04 \mathrm{E}-04$ & 3,16 \\
\hline ENSBTAG00000008346 & 0,20 & 0,43 & 0,84 & $1,30 \mathrm{E}-05$ & 5,17 \\
\hline ENSBTAG00000021433 & 0,46 & 0,05 & 0,88 & $1,36 \mathrm{E}-06$ & 5,49 \\
\hline ENSBTAG00000033344 & 0,29 & 0,25 & 0,68 & $1,80 \mathrm{E}-03$ & 1,29 \\
\hline ENTPD6 & 0,43 & 0,08 & 0,81 & $3,89 \mathrm{E}-05$ & 3,98 \\
\hline ESS2 & 0,37 & 0,13 & 0,74 & $4,26 \mathrm{E}-04$ & 2,42 \\
\hline FAM155B & 0,20 & 0,43 & 0,72 & $6,99 \mathrm{E}-04$ & 1,84 \\
\hline FAM19A1 & 0,35 & 0,16 & 0,48 & $4,56 \mathrm{E}-02$ & 0,10 \\
\hline FAM222A & $-0,31$ & 0,22 & $-0,69$ & $1,42 \mathrm{E}-03$ & 1,30 \\
\hline FAM229B & $-0,44$ & 0,07 & $-0,57$ & $1,34 \mathrm{E}-02$ & 0,59 \\
\hline FARSA & 0,34 & 0,17 & 0,86 & $5,57 \mathrm{E}-06$ & 5,56 \\
\hline FXR2 & 0,32 & 0,19 & 0,74 & $4,38 \mathrm{E}-04$ & 2,66 \\
\hline GEMIN4 & 0,44 & 0,07 & 0,81 & $4,01 \mathrm{E}-05$ & 3,00 \\
\hline GPATCH4 & 0,33 & 0,18 & 0,75 & $3,18 \mathrm{E}-04$ & 2,64 \\
\hline GREB1L & 0,21 & 0,41 & 0,81 & $4,48 \mathrm{E}-05$ & 4,82 \\
\hline GTF3C2 & 0,34 & 0,16 & 0,86 & $5,07 \mathrm{E}-06$ & 5,21 \\
\hline HIF1AN & 0,31 & 0,21 & 0,83 & $2,14 \mathrm{E}-05$ & 5,13 \\
\hline HTATSF1 & 0,14 & 0,58 & 0,90 & $3,85 \mathrm{E}-07$ & 6,88 \\
\hline IFI35 & $-0,19$ & 0,45 & $-0,40$ & $1,05 \mathrm{E}-01$ & 0,14 \\
\hline ING5 & 0,34 & 0,17 & 0,78 & $1,29 \mathrm{E}-04$ & 3,89 \\
\hline INTS6L & 0,50 & 0,04 & 0,91 & $1,34 \mathrm{E}-07$ & 7,40 \\
\hline KALRN & 0,46 & 0,05 & 0,84 & $1,48 \mathrm{E}-05$ & 5,02 \\
\hline KANSL2 & 0,34 & 0,17 & 0,85 & $8,32 \mathrm{E}-06$ & 4,96 \\
\hline KRI1 & 0,33 & 0,18 & 0,77 & $1,75 \mathrm{E}-04$ & 2,04 \\
\hline KRR1 & 0,43 & 0,07 & 0,87 & $2,37 \mathrm{E}-06$ & 6,50 \\
\hline LDOC1 & 0,12 & 0,64 & 0,79 & $8,16 \mathrm{E}-05$ & 2,69 \\
\hline LIPT1 & 0,34 & 0,17 & 0,82 & $2,60 \mathrm{E}-05$ & 3,46 \\
\hline LRRC8D & 0,48 & 0,05 & 0,86 & $4,86 \mathrm{E}-06$ & 5,25 \\
\hline LUZP2 & 0,64 & $4,55 \mathrm{E}-03$ & 0,61 & $7,52 \mathrm{E}-03$ & 0,56 \\
\hline
\end{tabular}


Tabela suplementar 12 - Genes contidos no módulo Plum1 da pituitária (continuação).

\begin{tabular}{|c|c|c|c|c|c|}
\hline Gene & SG CAR & Valor de P SG CAR & FM & Valor de P FM & $\mathbf{K}$ \\
\hline MAP6D1 & 0,44 & 0,06 & 0,91 & $1,22 \mathrm{E}-07$ & 8,03 \\
\hline MFSD12 & 0,31 & 0,21 & 0,76 & 2,37E-04 & 2,37 \\
\hline MTHFD1 & 0,46 & 0,06 & 0,86 & $3,66 \mathrm{E}-06$ & 5,20 \\
\hline MTPAP & 0,26 & 0,29 & 0,84 & $1,46 \mathrm{E}-05$ & 5,05 \\
\hline NEDD4 & 0,24 & 0,35 & 0,87 & $2,81 \mathrm{E}-06$ & 5,28 \\
\hline NFX1 & 0,39 & 0,11 & 0,85 & $6,51 \mathrm{E}-06$ & 5,62 \\
\hline NUP54 & 0,33 & 0,19 & 0,76 & $2,55 \mathrm{E}-04$ & 2,95 \\
\hline ORC6 & 0,10 & 0,68 & 0,71 & $9,72 \mathrm{E}-04$ & 1,90 \\
\hline PARP16 & 0,35 & 0,15 & 0,43 & 7,39E-02 & 0,13 \\
\hline PI4K2B & 0,14 & 0,58 & 0,62 & $6,30 \mathrm{E}-03$ & 1,02 \\
\hline PI4KB & 0,22 & 0,37 & 0,75 & $3,29 \mathrm{E}-04$ & 2,16 \\
\hline PIP5K1B & 0,29 & 0,25 & 0,69 & $1,63 \mathrm{E}-03$ & 2,07 \\
\hline PITRM1 & 0,38 & 0,12 & 0,91 & $1,50 \mathrm{E}-07$ & 7,25 \\
\hline PKP4 & 0,33 & 0,19 & 0,78 & $1,32 \mathrm{E}-04$ & 3,47 \\
\hline POLRMT & 0,45 & 0,06 & 0,80 & $7,62 \mathrm{E}-05$ & 3,60 \\
\hline PPM1G & 0,42 & 0,08 & 0,72 & $7,16 \mathrm{E}-04$ & 2,34 \\
\hline PPP1R8 & 0,34 & 0,17 & 0,79 & $1,02 \mathrm{E}-04$ & 3,27 \\
\hline PUF60 & 0,30 & 0,23 & 0,79 & $8,56 \mathrm{E}-05$ & 3,68 \\
\hline PWWP2A & 0,42 & 0,08 & 0,84 & $1,10 \mathrm{E}-05$ & 5,11 \\
\hline PXYLP1 & 0,22 & 0,39 & 0,73 & $6,42 \mathrm{E}-04$ & 1,59 \\
\hline R3HCC1L & 0,44 & 0,07 & 0,85 & $8,85 \mathrm{E}-06$ & 5,00 \\
\hline RAD23A & 0,23 & 0,36 & 0,54 & $2,21 \mathrm{E}-02$ & 1,20 \\
\hline RF00560 & 0,03 & 0,91 & 0,46 & $5,68 \mathrm{E}-02$ & 0,08 \\
\hline RUVBL2 & 0,46 & 0,05 & 0,64 & $4,08 \mathrm{E}-03$ & 2,16 \\
\hline SCRN2 & 0,22 & 0,37 & 0,55 & $1,86 \mathrm{E}-02$ & 0,28 \\
\hline SDAD1 & 0,60 & 0,01 & 0,91 & $1,23 \mathrm{E}-07$ & 7,38 \\
\hline SEPT9 & 0,40 & 0,10 & 0,86 & 4,33E-06 & 4,97 \\
\hline SF3A3 & 0,32 & 0,20 & 0,81 & $4,14 \mathrm{E}-05$ & 3,84 \\
\hline SLC12A8 & 0,06 & 0,80 & $-0,43$ & 7,31E-02 & 0,19 \\
\hline SLC $25 A 13$ & $-0,55$ & 0,02 & $-0,62$ & $6,35 \mathrm{E}-03$ & 0,78 \\
\hline TAP1 & $-0,48$ & 0,04 & $-0,63$ & $4,86 \mathrm{E}-03$ & 0,72 \\
\hline TIGAR & 0,29 & 0,25 & 0,69 & $1,44 \mathrm{E}-03$ & 1,35 \\
\hline TMED6 & 0,45 & 0,06 & 0,80 & $5,71 \mathrm{E}-05$ & 4,09 \\
\hline TMEM237 & 0,30 & 0,22 & 0,88 & $1,22 \mathrm{E}-06$ & 5,96 \\
\hline TRIM39-RPP21 & 0,42 & 0,08 & 0,82 & $3,61 \mathrm{E}-05$ & 4,41 \\
\hline UNC5B & 0,36 & 0,14 & 0,77 & $1,68 \mathrm{E}-04$ & 3,75 \\
\hline WDR91 & 0,52 & 0,03 & 0,88 & $1,21 \mathrm{E}-06$ & 5,75 \\
\hline XKR7 & 0,27 & 0,29 & 0,74 & $3,91 \mathrm{E}-04$ & 2,46 \\
\hline ZNF331 & 0,37 & 0,14 & 0,96 & $1,14 \mathrm{E}-10$ & 11,12 \\
\hline ZNF786 & 0,32 & 0,20 & 0,68 & $1,91 \mathrm{E}-03$ & 1,39 \\
\hline
\end{tabular}


Tabela suplementar 13 - Enriquecimento funcional (STRING) dos genes contidos no módulo Darkturquoise associado ao consumo alimentar residual na pituitária.

\begin{tabular}{|c|c|c|c|}
\hline ID & Nome & Genes & FDR \\
\hline GO:0008104 & protein localization & 45 & $9,81 \mathrm{E}-08$ \\
\hline GO:0033036 & macromolecule localization & 48 & 2,23E-07 \\
\hline GO:0008150 & biological_process & 188 & $4,96 \mathrm{E}-07$ \\
\hline GO:0043170 & macromolecule metabolic process & 107 & 4,96E-07 \\
\hline GO:0008152 & metabolic process & 146 & $6,23 \mathrm{E}-07$ \\
\hline GO:0044260 & cellular macromolecule metabolic process & 97 & $1,70 \mathrm{E}-06$ \\
\hline GO:0044237 & cellular metabolic process & 120 & $4,10 \mathrm{E}-06$ \\
\hline GO:0044238 & primary metabolic process & 122 & $4,92 \mathrm{E}-06$ \\
\hline GO:0071704 & organic substance metabolic process & 125 & $7,11 \mathrm{E}-06$ \\
\hline GO:0009987 & cellular process & 161 & 9,99E-06 \\
\hline GO:0050794 & regulation of cellular process & 105 & 9,99E-06 \\
\hline GO:0045184 & establishment of protein localization & 35 & $1,01 \mathrm{E}-05$ \\
\hline GO:0015031 & protein transport & 34 & $1,03 \mathrm{E}-05$ \\
\hline GO:0065007 & biological regulation & 115 & $1,44 \mathrm{E}-05$ \\
\hline GO:0071702 & organic substance transport & 42 & $2,01 \mathrm{E}-05$ \\
\hline GO:0050789 & regulation of biological process & 109 & $2,05 \mathrm{E}-05$ \\
\hline GO:0034641 & cellular nitrogen compound metabolic process & 80 & $3,18 \mathrm{E}-05$ \\
\hline GO:0006139 & nucleobase-containing compound metabolic process & 67 & $3,85 \mathrm{E}-05$ \\
\hline GO:0090304 & nucleic acid metabolic process & 59 & $4,40 \mathrm{E}-05$ \\
\hline GO:0006807 & nitrogen compound metabolic process & 83 & $1,05 \mathrm{E}-04$ \\
\hline GO:0046483 & heterocycle metabolic process & 68 & $1,05 \mathrm{E}-04$ \\
\hline GO:0006725 & cellular aromatic compound metabolic process & 68 & $1,27 \mathrm{E}-04$ \\
\hline GO: 1901360 & organic cyclic compound metabolic process & 70 & 2,04E-04 \\
\hline GO:0034613 & cellular protein localization & 26 & $3,86 \mathrm{E}-04$ \\
\hline GO:0043412 & macromolecule modification & 43 & $3,86 \mathrm{E}-04$ \\
\hline GO:0060255 & regulation of macromolecule metabolic process & 65 & $4,58 \mathrm{E}-04$ \\
\hline GO:0019941 & modification-dependent protein catabolic process & 16 & $5,21 \mathrm{E}-04$ \\
\hline GO:0051179 & localization & 67 & $5,92 \mathrm{E}-04$ \\
\hline GO:0044763 & single-organism cellular process & 121 & 7,83E-04 \\
\hline GO:0044249 & cellular biosynthetic process & 66 & 9,77E-04 \\
\hline GO:0006511 & ubiquitin-dependent protein catabolic process & 15 & $1,23 \mathrm{E}-03$ \\
\hline GO:0051234 & establishment of localization & 59 & $1,30 \mathrm{E}-03$ \\
\hline GO:0080090 & regulation of primary metabolic process & 63 & $1,30 \mathrm{E}-03$ \\
\hline GO:0006810 & transport & 58 & $1,35 \mathrm{E}-03$ \\
\hline GO:0019222 & regulation of metabolic process & 72 & $1,38 \mathrm{E}-03$ \\
\hline GO: 1901576 & organic substance biosynthetic process & 66 & $1,87 \mathrm{E}-03$ \\
\hline GO:0010256 & endomembrane system organization & 13 & 2,59E-03 \\
\hline GO:0044265 & cellular macromolecule catabolic process & 19 & 2,77E-03 \\
\hline GO:0044257 & cellular protein catabolic process & 16 & $2,89 \mathrm{E}-03$ \\
\hline GO:0031323 & regulation of cellular metabolic process & 63 & $3,13 \mathrm{E}-03$ \\
\hline GO:0061512 & protein localization to cilium & 4 & $3,26 \mathrm{E}-03$ \\
\hline GO:0016070 & RNA metabolic process & 46 & $4,36 \mathrm{E}-03$ \\
\hline GO:0034654 & nucleobase-containing compound biosynthetic process & 39 & $5,27 \mathrm{E}-03$ \\
\hline GO:0051641 & cellular localization & 33 & $5,32 \mathrm{E}-03$ \\
\hline GO:0044699 & single-organism process & 131 & $6,67 \mathrm{E}-03$ \\
\hline GO:0043161 & proteasome-mediated ubiquitin-dependent protein catabolic process & 11 & $8,13 \mathrm{E}-03$ \\
\hline GO:0009059 & macromolecule biosynthetic process & 50 & $8,65 \mathrm{E}-03$ \\
\hline GO:0019438 & aromatic compound biosynthetic process & 40 & $8,91 \mathrm{E}-03$ \\
\hline GO:0042493 & response to drug & 8 & $1,02 \mathrm{E}-02$ \\
\hline GO:0006464 & cellular protein modification process & 36 & $1,08 \mathrm{E}-02$ \\
\hline GO:0010468 & regulation of gene expression & 46 & 1,09E-02 \\
\hline GO:0034645 & cellular macromolecule biosynthetic process & 49 & 1,09E-02 \\
\hline GO:0019538 & protein metabolic process & 57 & $1,18 \mathrm{E}-02$ \\
\hline GO:0051171 & regulation of nitrogen compound metabolic process & 46 & $1,23 \mathrm{E}-02$ \\
\hline GO:0018130 & heterocycle biosynthetic process & 39 & $1,44 \mathrm{E}-02$ \\
\hline GO:0006997 & nucleus organization & 5 & $1,61 \mathrm{E}-02$ \\
\hline GO:0016192 & vesicle-mediated transport & 22 & $1,61 \mathrm{E}-02$ \\
\hline GO:0048518 & positive regulation of biological process & 55 & $1,65 \mathrm{E}-02$ \\
\hline GO:0006796 & phosphate-containing compound metabolic process & 31 & $1,72 \mathrm{E}-02$ \\
\hline GO:0009889 & regulation of biosynthetic process & 45 & $2,02 \mathrm{E}-02$ \\
\hline GO:0019219 & regulation of nucleobase-containing compound metabolic process & 42 & $2,28 \mathrm{E}-02$ \\
\hline GO:0031326 & regulation of cellular biosynthetic process & 44 & 2,38E-02 \\
\hline
\end{tabular}


Tabela suplementar 13 - Enriquecimento funcional (STRING) dos genes contidos no módulo Darkturquoise associado ao consumo alimentar residual na pituitária

(continuação).

\begin{tabular}{|c|c|c|c|}
\hline ID & Nome & Genes & FDR \\
\hline GO:0044271 & cellular nitrogen compound biosynthetic process & 48 & $2,38 \mathrm{E}-02$ \\
\hline GO:0044087 & regulation of cellular component biogenesis & 14 & $2,86 \mathrm{E}-02$ \\
\hline GO:0010556 & regulation of macromolecule biosynthetic process & 42 & $2,89 \mathrm{E}-02$ \\
\hline GO:0044267 & cellular protein metabolic process & 48 & $3,28 \mathrm{E}-02$ \\
\hline GO:0033365 & protein localization to organelle & 12 & $3,32 \mathrm{E}-02$ \\
\hline GO:0016043 & cellular component organization & 55 & $3,62 \mathrm{E}-02$ \\
\hline GO:0030497 & fatty acid elongation & 3 & $3,88 \mathrm{E}-02$ \\
\hline GO:0050821 & protein stabilization & 6 & $4,05 \mathrm{E}-02$ \\
\hline GO:0032774 & RNA biosynthetic process & 31 & $4,20 \mathrm{E}-02$ \\
\hline GO:0006793 & phosphorus metabolic process & 30 & $4,26 \mathrm{E}-02$ \\
\hline GO: 1901362 & organic cyclic compound biosynthetic process & 39 & $4,26 \mathrm{E}-02$ \\
\hline GO:0044248 & cellular catabolic process & 24 & $4,57 \mathrm{E}-02$ \\
\hline GO:2000112 & regulation of cellular macromolecule biosynthetic process & 40 & $4,58 \mathrm{E}-02$ \\
\hline GO:0003674 & molecular_function & 185 & $5,74 \mathrm{E}-09$ \\
\hline GO:0003824 & catalytic activity & 102 & 4,03E-06 \\
\hline GO:0005488 & binding & 130 & $6,18 \mathrm{E}-05$ \\
\hline GO:1901363 & heterocyclic compound binding & 82 & $5,71 \mathrm{E}-04$ \\
\hline GO:0097159 & organic cyclic compound binding & 82 & 7,38E-04 \\
\hline GO:0016787 & hydrolase activity & 47 & $3,72 \mathrm{E}-03$ \\
\hline GO:0018812 & 3-hydroxyacyl-CoA dehydratase activity & 3 & $1,21 \mathrm{E}-02$ \\
\hline GO:0003676 & nucleic acid binding & 50 & $2,39 \mathrm{E}-02$ \\
\hline GO:0043167 & ion binding & 81 & 2,39E-02 \\
\hline & hydrolase activity, acting on acid anhydrides, in phosphorus-containing & & \\
\hline GO:0016818 & anhydrides & 19 & 4,97E-02 \\
\hline GO:0017076 & purine nucleotide binding & 34 & $4,97 \mathrm{E}-02$ \\
\hline GO:0032550 & purine ribonucleoside binding & 33 & 4,97E-02 \\
\hline GO:0035639 & purine ribonucleoside triphosphate binding & 33 & $4,97 \mathrm{E}-02$ \\
\hline GO:0043227 & membrane-bounded organelle & 195 & $2,19 \mathrm{E}-19$ \\
\hline GO:0043231 & intracellular membrane-bounded organelle & 184 & $4,73 \mathrm{E}-19$ \\
\hline GO:0043229 & intracellular organelle & 189 & $3,02 \mathrm{E}-17$ \\
\hline GO:0043226 & organelle & 193 & $2,05 \mathrm{E}-16$ \\
\hline GO:0044424 & intracellular part & 202 & $2,05 \mathrm{E}-16$ \\
\hline GO:0005623 & cell & 216 & $3,18 \mathrm{E}-16$ \\
\hline GO:0044464 & cell part & 215 & $3,42 \mathrm{E}-16$ \\
\hline GO:0005622 & intracellular & 203 & $5,97 E-16$ \\
\hline GO:0005737 & cytoplasm & 181 & $1,98 \mathrm{E}-14$ \\
\hline GO:0005575 & cellular_component & 224 & $6,78 \mathrm{E}-14$ \\
\hline GO:0044444 & cytoplasmic part & 130 & $8,05 \mathrm{E}-11$ \\
\hline GO:0044446 & intracellular organelle part & 126 & $6,43 \mathrm{E}-10$ \\
\hline GO:0044422 & organelle part & 127 & $1,37 \mathrm{E}-09$ \\
\hline GO:0012505 & endomembrane system & 70 & $5,48 E-09$ \\
\hline GO:0098588 & bounding membrane of organelle & 55 & $2,35 \mathrm{E}-08$ \\
\hline GO:0005634 & nucleus & 98 & $3,30 \mathrm{E}-08$ \\
\hline GO:0016020 & membrane & 122 & $3,26 \mathrm{E}-07$ \\
\hline GO:0031090 & organelle membrane & 66 & $3,40 \mathrm{E}-06$ \\
\hline GO:0031224 & intrinsic component of membrane & 78 & $3,06 \mathrm{E}-05$ \\
\hline GO:0016021 & integral component of membrane & 76 & $4,26 \mathrm{E}-05$ \\
\hline GO:0031988 & membrane-bounded vesicle & 59 & $8,76 \mathrm{E}-05$ \\
\hline GO:0043232 & intracellular non-membrane-bounded organelle & 64 & $8,76 \mathrm{E}-05$ \\
\hline GO:0032991 & macromolecular complex & 81 & $1,10 \mathrm{E}-04$ \\
\hline GO:0005769 & early endosome & 11 & $1,16 \mathrm{E}-04$ \\
\hline GO:0044425 & membrane part & 87 & $1,28 \mathrm{E}-04$ \\
\hline GO:0043234 & protein complex & 68 & 2,84E-04 \\
\hline GO:0005768 & endosome & 20 & 2,95E-04 \\
\hline GO:0005794 & Golgi apparatus & 28 & $2,96 \mathrm{E}-04$ \\
\hline GO:0031981 & nuclear lumen & 47 & $4,30 \mathrm{E}-04$ \\
\hline GO:0070062 & extracellular exosome & 46 & $1,44 \mathrm{E}-03$ \\
\hline GO:0070013 & intracellular organelle lumen & 53 & $1,45 \mathrm{E}-03$ \\
\hline GO:0031974 & membrane-enclosed lumen & 54 & $1,59 \mathrm{E}-03$ \\
\hline GO:0044428 & nuclear part & 49 & $2,03 \mathrm{E}-03$ \\
\hline GO:0005654 & nucleoplasm & 36 & $2,06 \mathrm{E}-03$ \\
\hline
\end{tabular}


Tabela suplementar 13 - Enriquecimento funcional (STRING) dos genes contidos no módulo Darkturquoise associado ao consumo alimentar residual na pituitária (continuação).

\begin{tabular}{llrr}
\hline ID & Nome & Genes & FDR \\
\hline GO:0005730 & nucleolus & 21 & $2,48 \mathrm{E}-03$ \\
GO:0098805 & whole membrane & 33 & $2,76 \mathrm{E}-03$ \\
GO:0005789 & endoplasmic reticulum membrane & 22 & $3,76 \mathrm{E}-03$ \\
GO:0042175 & nuclear outer membrane-endoplasmic reticulum membrane network & $4,28 \mathrm{E}-03$ \\
GO:0005783 & endoplasmic reticulum & 22 & $7,22 \mathrm{E}-03$ \\
GO:0044432 & endoplasmic reticulum part & 23 & $7,53 \mathrm{E}-03$ \\
GO:0044440 & endosomal part & 11 & $7,98 \mathrm{E}-03$ \\
GO:0005773 & vacuole & 14 & $2,34 \mathrm{E}-02$ \\
GO:0008250 & oligosaccharyltransferase complex & 3 \\
GO:0008287 & protein serinelthreonine phosphatase complex & $2,34 \mathrm{E}-02$ \\
GO:0010008 & endosome membrane & $4,34 \mathrm{E}-02$ \\
GO:0035097 & histone methyltransferase complex & 10 \\
GO:0070971 & endoplasmic reticulum exit site & $2,34 \mathrm{E}-02$ \\
GO:0071944 & cell periphery & 4 & $2,34 \mathrm{E}-02$ \\
GO:1990391 & DNA repair complex & 2 & $2,34 \mathrm{E}-02$ \\
GO:0042995 & cell projection & 47 & $2,34 \mathrm{E}-02$ \\
GO:0005770 & late endosome & 3 & $2,34 \mathrm{E}-02$ \\
GO:0005669 & transcription factor TFIID complex & 23 & $2,94 \mathrm{E}-02$ \\
GO:0072546 & ER membrane protein complex & 8 & $3,08 \mathrm{E}-02$ \\
GO:0016023 & cytoplasmic membrane-bounded vesicle & 3 & $3,28 \mathrm{E}-02$ \\
GO:0005764 & lysosome & 3 & $3,28 \mathrm{E}-02$ \\
GO:0044427 & chromosomal part & 20 \\
GO:0044451 & nucleoplasm part & $3,29 \mathrm{E}-02$ \\
GO:0005739 & mitochondrion & $4,12 \mathrm{E}-02$ \\
GO:0005886 & plasma membrane & 12 \\
bta3022 & Basal transcription factors & 14 & $4,14 \mathrm{E}-02$ \\
bta3420 & Nucleotide excision repair & $4,14 \mathrm{E}-02$ \\
\hline & & $4,52 \mathrm{E}-02$ \\
& & 38 \\
\hline
\end{tabular}


Tabela suplementar 14 - Genes contidos no módulo Grey da adrenal.

\begin{tabular}{|c|c|c|c|c|c|}
\hline Gene & SG CA & Valor de P SG CA & FM & Valor de P FM & $\mathbf{K}$ \\
\hline C14H8orf76 & $-0,44$ & 0,10 & $-0,24$ & 0,39 & 0,14 \\
\hline C17H22orf39 & 0,20 & 0,47 & 0,36 & 0,19 & 0,12 \\
\hline CSRP1 & 0,76 & $9,93 \mathrm{E}-04$ & 0,58 & 0,02 & 0,21 \\
\hline CYP2D14 & $-0,26$ & 0,36 & 0,19 & 0,50 & 0,08 \\
\hline EGR1 & $-0,28$ & 0,31 & $-0,67$ & 0,01 & 0,25 \\
\hline ENSBTAG00000024407 & 0,12 & 0,68 & $-0,33$ & 0,23 & 0,38 \\
\hline ENSBTAG00000037925 & $-0,40$ & 0,14 & $-0,73$ & $1,88 \mathrm{E}-03$ & 0,31 \\
\hline ENSBTAG00000046595 & 0,59 & 0,02 & 0,68 & 0,01 & 0,35 \\
\hline ENSBTAG00000046974 & $-0,28$ & 0,32 & $-0,34$ & 0,22 & 0,03 \\
\hline FBLIM1 & 0,66 & 0,01 & 0,69 & $4,14 \mathrm{E}-03$ & 0,25 \\
\hline GATD1 & $-0,02$ & 0,95 & 0,39 & 0,15 & 0,06 \\
\hline GDF11 & $-0,34$ & 0,22 & 0,03 & 0,91 & 0,17 \\
\hline GZMB & 0,50 & 0,06 & 0,53 & 0,04 & 0,27 \\
\hline HIP1 & $-0,50$ & 0,06 & $-0,48$ & 0,07 & 0,09 \\
\hline LURAP1L & $-0,22$ & 0,43 & 0,00 & 0,99 & 0,02 \\
\hline MYPOP & 0,53 & 0,04 & 0,63 & 0,01 & 0,08 \\
\hline NDUFS5 & 0,02 & 0,95 & 0,32 & 0,25 & 0,09 \\
\hline NTAN1 & $-0,46$ & 0,08 & $-0,82$ & $1,99 \mathrm{E}-04$ & 0,56 \\
\hline NTS & $-0,27$ & 0,34 & $-0,38$ & 0,16 & 0,16 \\
\hline PPM1H & 0,40 & 0,14 & 0,62 & 0,01 & 0,16 \\
\hline PPP1R12C & 0,09 & 0,74 & 0,13 & 0,66 & 0,18 \\
\hline PPP1R14A & 0,43 & 0,11 & 0,25 & 0,37 & 0,13 \\
\hline PTMS & $-0,17$ & 0,54 & 0,36 & 0,19 & 0,07 \\
\hline PUSL1 & $-0,02$ & 0,95 & $-0,54$ & 0,04 & 0,60 \\
\hline RF00231 & $-0,01$ & 0,97 & $-0,49$ & 0,06 & 0,71 \\
\hline RF00340 & 0,12 & 0,67 & 0,40 & 0,14 & 0,21 \\
\hline RF00403 & $-0,59$ & 0,02 & $-0,73$ & $2,17 \mathrm{E}-03$ & 0,50 \\
\hline RFWD3 & $-0,02$ & 0,95 & $-0,45$ & 0,10 & 0,08 \\
\hline SIRT5 & $-0,24$ & 0,38 & $-0,24$ & 0,38 & 0,04 \\
\hline SNX8 & 0,19 & 0,50 & 0,16 & 0,57 & 0,08 \\
\hline SOD3 & $-0,34$ & 0,21 & $-0,21$ & 0,46 & 0,03 \\
\hline SPP1 & 0,80 & $2,96 \mathrm{E}-04$ & 0,70 & $3,89 \mathrm{E}-03$ & 0,20 \\
\hline TFPT & $-0,05$ & 0,86 & 0,01 & 0,98 & 0,07 \\
\hline
\end{tabular}


Tabela suplementar 15 - Sítios de ligação de miRNA previstos em lncRNA diferencialmente expressos entre alta e baixa eficiência alimentar.

\begin{tabular}{|c|c|c|c|c|}
\hline IncRNA & $\begin{array}{c}\text { Número } \\
\text { de miRNA }\end{array}$ & miRNA & Score de alinhamento & Energia (kcal/mol) \\
\hline \multirow{6}{*}{ TCONS_00000153P } & \multirow[t]{6}{*}{ (1) } & bta-miR-11990 & 162 & $-20,95$ \\
\hline & & bta-miR-2400 & 162 & $-21,16$ \\
\hline & & bta-miR-2285bb & 163 & $-22,16$ \\
\hline & & bta-miR-6529a & 171 & $-31,20$ \\
\hline & & bta-miR-7865 & 163 & $-32,04$ \\
\hline & & bta-miR-2370-5p & 330 & $-36,26$ \\
\hline \multirow{3}{*}{ TCONS_00000165P } & \multirow{3}{*}{3} & bta-miR-204 & 160 & $-20,17$ \\
\hline & & bta-miR-211 & 160 & $-20,17$ \\
\hline & & bta-miR-2375 & 167 & $-21,68$ \\
\hline \multirow{5}{*}{ TCONS_00001372P } & \multirow{5}{*}{5} & bta-miR-449c & 167 & $-22,25$ \\
\hline & & bta-miR-320a & 168 & $-22,29$ \\
\hline & & bta-miR-2285cu & 161 & $-22,81$ \\
\hline & & bta-miR-12019 & 164 & $-24,75$ \\
\hline & & bta-miR-885 & 172 & $-26,21$ \\
\hline \multirow{7}{*}{ TCONS_00001721P } & \multirow{7}{*}{7} & bta-miR-224 & 163 & $-20,12$ \\
\hline & & bta-miR-10161-5p & 164 & $-23,70$ \\
\hline & & bta-miR-485 & 160 & $-23,79$ \\
\hline & & bta-miR-12056 & 160 & $-25,83$ \\
\hline & & bta-miR-2438 & 163 & $-26,17$ \\
\hline & & bta-miR-664a & 161 & $-28,75$ \\
\hline & & bta-miR-12010 & 167 & $-30,31$ \\
\hline \multirow{24}{*}{ TCONS_00002325M } & \multirow{24}{*}{24} & bta-miR-1271 & 163 & $-20,10$ \\
\hline & & bta-miR-2285ba & 171 & $-20,44$ \\
\hline & & bta-miR-2369 & 162 & $-20,66$ \\
\hline & & bta-miR-129 & 161 & $-20,81$ \\
\hline & & bta-miR-129-5p & 161 & $-20,81$ \\
\hline & & bta-miR-2285di & 167 & $-21,43$ \\
\hline & & bta-miR-32 & 167 & $-21,94$ \\
\hline & & bta-miR-29d-3p & 162 & $-22,04$ \\
\hline & & bta-miR-2285ar & 162 & $-22,07$ \\
\hline & & bta-miR-29a & 168 & $-22,26$ \\
\hline & & bta-miR-101 & 167 & $-22,52$ \\
\hline & & bta-miR-2285cv & 176 & $-22,77$ \\
\hline & & bta-miR-2377 & 161 & $-23,30$ \\
\hline & & bta-miR-29c & 163 & $-23,42$ \\
\hline & & bta-miR-1185 & 172 & $-24,55$ \\
\hline & & bta-miR-2285bj & 171 & $-25,36$ \\
\hline & & bta-miR-11979 & 163 & $-26,35$ \\
\hline & & bta-miR-2895 & 167 & $-26,39$ \\
\hline & & bta-miR-2486-5p & 163 & $-26,41$ \\
\hline & & bta-miR-764 & 167 & $-28,82$ \\
\hline & & bta-miR-11977 & 169 & $-28,86$ \\
\hline & & bta-miR-2331-5p & 162 & $-29,72$ \\
\hline & & bta-miR-2454-3p & 173 & $-31,72$ \\
\hline & & bta-miR-2305 & 170 & $-36,66$ \\
\hline \multirow[t]{8}{*}{ TCONS_00002645P } & 1 & bta-miR-769 & 167 & $-30,89$ \\
\hline & & bta-miR-2384 & 166 & $-20,25$ \\
\hline & & bta-miR-380-3p & 162 & $-21,19$ \\
\hline & & bta-miR-34a & 162 & $-22,58$ \\
\hline & & bta-miR-2340 & 160 & $-24,17$ \\
\hline & & bta-miR-8550 & 161 & $-25,98$ \\
\hline & & bta-miR-204 & 166 & $-26,48$ \\
\hline & & bta-miR-1225-3p & 160 & $-26,85$ \\
\hline \multirow{8}{*}{ TCONS_00003199P } & 17 & bta-miR-7180 & 161 & $-26,97$ \\
\hline & & bta-miR-2486-5p & 164 & $-28,76$ \\
\hline & & bta-miR-12054 & 160 & $-29,57$ \\
\hline & & bta-miR-2295 & 163 & $-32,26$ \\
\hline & & bta-miR-2338 & 161 & $-32,35$ \\
\hline & & bta-miR-11972 & 169 & $-38,91$ \\
\hline & & bta-miR-2881 & 162 & $-38,96$ \\
\hline & & bta-miR-2305 & 166 & $-39,19$ \\
\hline
\end{tabular}


Tabela suplementar 15 - Sítios de ligação de miRNA previstos em lncRNA diferencialmente expressos entre alta e baixa eficiência alimentar (continuação).

\begin{tabular}{|c|c|c|c|c|}
\hline IncRNA & $\begin{array}{c}\text { Número } \\
\text { de miRNA }\end{array}$ & miRNA & Score de alinhamento & Energia (kcal/mol) \\
\hline \multirow{16}{*}{ TCONS_00003199P } & \multirow{2}{*}{17} & bta-miR-1777a & 164 & $-41,11$ \\
\hline & & bta-miR-664a & 322 & $-50,43$ \\
\hline & & bta-miR-12017 & 162 & $-20,14$ \\
\hline & & bta-miR-10176-5p & 160 & $-22,07$ \\
\hline & & bta-miR-2364 & 162 & $-22,24$ \\
\hline & & bta-miR-122 & 165 & $-22,61$ \\
\hline & & bta-miR-2346 & 160 & $-24,44$ \\
\hline & & bta-miR-1842 & 162 & $-25,85$ \\
\hline & & bta-miR-34a & 168 & $-28,15$ \\
\hline & & bta-miR-664a & 170 & $-30,64$ \\
\hline & & bta-miR-12053 & 172 & $-31,88$ \\
\hline & & bta-miR-149-3p & 160 & $-32,68$ \\
\hline & & bta-miR-11981 & 165 & $-33,09$ \\
\hline & & bta-miR-671 & 164 & $-34,33$ \\
\hline & & bta-miR-7865 & 168 & $-35,93$ \\
\hline & & bta-miR-2885 & 160 & $-35,97$ \\
\hline \multirow{8}{*}{ TCONS_00003974P } & \multirow{8}{*}{8} & bta-miR-2319b & 160 & $-20,81$ \\
\hline & & bta-miR-378b & 163 & $-23,20$ \\
\hline & & bta-miR-543 & 161 & $-23,28$ \\
\hline & & bta-miR-2381 & 165 & $-26,53$ \\
\hline & & bta-miR-2330-5p & 169 & $-27,46$ \\
\hline & & bta-miR-2439-5p & 163 & $-27,52$ \\
\hline & & bta-miR-12046 & 166 & $-29,10$ \\
\hline & & bta-miR-2362 & 339 & $-50,13$ \\
\hline \multirow{4}{*}{ TCONS_00004418M } & \multirow{4}{*}{4} & bta-miR-345-5p & 161 & $-20,58$ \\
\hline & & bta-miR-2347 & 164 & $-21,53$ \\
\hline & & bta-miR-7857-3p & 168 & $-24,35$ \\
\hline & & bta-miR-935 & 162 & $-27,22$ \\
\hline \multirow{3}{*}{ TCONS_00004740P } & \multirow{3}{*}{3} & bta-miR-2285q & 167 & $-23,30$ \\
\hline & & bta-miR-453 & 162 & $-24,13$ \\
\hline & & bta-miR-6535 & 160 & $-24,89$ \\
\hline \multirow{7}{*}{ TCONS_00004881P } & \multirow{7}{*}{7} & bta-miR-378c & 165 & $-23,14$ \\
\hline & & bta-miR-378 & 165 & $-23,44$ \\
\hline & & bta-miR-2285z & 172 & $-23,77$ \\
\hline & & bta-miR-378d & 160 & $-23,80$ \\
\hline & & bta-miR-11974 & 161 & $-25,93$ \\
\hline & & bta-miR-2447 & 180 & $-30,47$ \\
\hline & & bta-miR-12016 & 329 & $-33,56$ \\
\hline \multirow{3}{*}{ TCONS_00004904P } & \multirow{3}{*}{3} & bta-miR-1301 & 167 & $-26,16$ \\
\hline & & bta-miR-2383 & 161 & $-26,94$ \\
\hline & & bta-miR-11985 & 165 & $-34,78$ \\
\hline \multirow{16}{*}{ TCONS_00005426A } & \multirow{16}{*}{16} & bta-miR-2285bu & 168 & $-22,00$ \\
\hline & & bta-miR-10173-5p & 161 & $-22,25$ \\
\hline & & bta-miR-2322-3p & 161 & $-22,43$ \\
\hline & & bta-miR-2309 & 162 & $-24,03$ \\
\hline & & bta-miR-2415-3p & 163 & $-24,28$ \\
\hline & & bta-miR-1197 & 160 & $-25,36$ \\
\hline & & bta-miR-487b & 173 & $-25,91$ \\
\hline & & bta-miR-2441 & 164 & $-26,49$ \\
\hline & & bta-miR-6535 & 160 & $-27,77$ \\
\hline & & bta-miR-10179-5p & 161 & $-27,98$ \\
\hline & & bta-miR-370 & 164 & $-28,65$ \\
\hline & & bta-miR-12050 & 173 & $-29,25$ \\
\hline & & bta-miR-2381 & 171 & $-30,03$ \\
\hline & & bta-miR-615 & 163 & $-33,49$ \\
\hline & & bta-miR-6517 & 163 & $-33,90$ \\
\hline & & bta-miR-2430 & 169 & $-34,55$ \\
\hline \multirow{4}{*}{ TCONS_00005461A } & \multirow{4}{*}{14} & bta-miR-139 & 169 & $-20,15$ \\
\hline & & bta-miR-660 & 160 & $-23,35$ \\
\hline & & bta-miR-1281 & 160 & $-26,27$ \\
\hline & & bta-miR-2309 & 161 & $-29,90$ \\
\hline
\end{tabular}


Tabela suplementar 15 - Sítios de ligação de miRNA previstos em lncRNA diferencialmente expressos entre alta e baixa eficiência alimentar (continuação).

\begin{tabular}{|c|c|c|c|c|}
\hline IncRNA & $\begin{array}{c}\text { Número } \\
\text { de miRNA }\end{array}$ & miRNA & Score de alinhamento & Energia (kcal/mol) \\
\hline \multirow{10}{*}{ TCONS_00005461A } & \multirow{10}{*}{14} & bta-miR-12051 & 168 & $-30,73$ \\
\hline & & bta-miR-12039 & 170 & $-31,34$ \\
\hline & & bta-miR-2467-3p & 168 & $-32,72$ \\
\hline & & bta-miR-11981 & 166 & $-37,06$ \\
\hline & & bta-miR-1247-5p & 162 & $-38,07$ \\
\hline & & bta-miR-2305 & 174 & $-38,49$ \\
\hline & & bta-miR-11972 & 165 & $-42,02$ \\
\hline & & bta-miR-2442 & 330 & $-61,00$ \\
\hline & & bta-miR-1777b & 325 & $-80,66$ \\
\hline & & bta-miR-1777a & 340 & $-84,38$ \\
\hline \multirow{8}{*}{ TCONS_00006013P } & \multirow{8}{*}{8} & bta-miR-2284a & 170 & $-20,07$ \\
\hline & & bta-miR-2384 & 164 & $-20,28$ \\
\hline & & bta-miR-10181-5p & 162 & $-23,19$ \\
\hline & & bta-miR-146a & 162 & $-25,61$ \\
\hline & & bta-miR-139 & 161 & $-25,83$ \\
\hline & & bta-miR-146b & 162 & $-25,88$ \\
\hline & & bta-miR-2401 & 161 & $-26,75$ \\
\hline & & bta-miR-12001 & 169 & $-32,76$ \\
\hline \multirow{7}{*}{ TCONS_00006530P } & \multirow{7}{*}{7} & bta-miR-562 & 161 & $-21,07$ \\
\hline & & bta-miR-2301 & 160 & $-21,96$ \\
\hline & & bta-miR-296-3p & 161 & $-22,93$ \\
\hline & & bta-miR-2299-3p & 160 & $-27,14$ \\
\hline & & bta-miR-2465 & 168 & $-30,97$ \\
\hline & & bta-miR-2442 & 162 & $-31,23$ \\
\hline & & bta-miR-2430 & 184 & $-37,86$ \\
\hline \multirow{3}{*}{ TCONS_00006811P } & \multirow{3}{*}{3} & bta-miR-11993 & 160 & $-23,89$ \\
\hline & & bta-miR-1260b & 164 & $-24,69$ \\
\hline & & bta-miR-12051 & 167 & $-29,34$ \\
\hline \multirow{4}{*}{ TCONS_00006825P } & \multirow{4}{*}{4} & bta-miR-2430 & 164 & $-29,10$ \\
\hline & & bta-miR-10167-3p & 163 & $-30,64$ \\
\hline & & bta-miR-2442 & 162 & $-31,52$ \\
\hline & & bta-miR-2439-5p & 162 & $-32,81$ \\
\hline \multirow{8}{*}{ TCONS_00006888M } & \multirow{8}{*}{8} & bta-miR-455-3p & 163 & $-22,93$ \\
\hline & & bta-miR-2417 & 167 & $-23,20$ \\
\hline & & bta-miR-11989 & 163 & $-23,80$ \\
\hline & & bta-miR-484 & 172 & $-25,35$ \\
\hline & & bta-miR-132 & 168 & $-25,82$ \\
\hline & & bta-miR-10176-5p & 173 & $-28,09$ \\
\hline & & bta-miR-2328-5p & 162 & $-29,78$ \\
\hline & & bta-miR-1291 & 167 & $-30,77$ \\
\hline \multirow{4}{*}{ TCONS_00007036A } & \multirow{4}{*}{4} & bta-miR-2285cx & 178 & $-23,33$ \\
\hline & & bta-miR-10178-5p & 161 & $-26,85$ \\
\hline & & bta-miR-615 & 161 & $-29,71$ \\
\hline & & bta-miR-2888 & 160 & $-30,06$ \\
\hline TCONS_00007280P & 1 & bta-miR-2285ao & 162 & $-23,24$ \\
\hline \multirow{6}{*}{ TCONS_00007646P } & \multirow{6}{*}{6} & bta-miR-320a & 160 & $-20,28$ \\
\hline & & bta-miR-2464-5p & 162 & $-21,22$ \\
\hline & & bta-miR-197 & 160 & $-25,45$ \\
\hline & & bta-miR-11986b & 184 & $-27,96$ \\
\hline & & bta-miR-2331-5p & 161 & $-28,61$ \\
\hline & & bta-miR-338 & 331 & $-43,67$ \\
\hline TCONS_00008651P & 1 & bta-miR-2285r & 161 & $-23,48$ \\
\hline & & bta-miR-376c & 171 & $-20,01$ \\
\hline & & bta-miR-15a & 160 & $-20,04$ \\
\hline & & bta-miR-145 & 160 & $-20,53$ \\
\hline & & bta-miR-2414 & 162 & $-20,58$ \\
\hline TCONS_00008676P & 30 & bta-miR-3533 & 165 & $-20,60$ \\
\hline & & bta-miR-759 & 164 & $-20,68$ \\
\hline & & bta-miR-2369 & 162 & $-20,70$ \\
\hline & & bta-miR-200a & 167 & $-20,94$ \\
\hline & & bta-miR-9-5p & 167 & $-20,94$ \\
\hline
\end{tabular}


Tabela suplementar 15 - Sítios de ligação de miRNA previstos em lncRNA diferencialmente expressos entre alta e baixa eficiência alimentar (continuação).

\begin{tabular}{|c|c|c|c|c|}
\hline IncRNA & $\begin{array}{c}\text { Número } \\
\text { de miRNA }\end{array}$ & miRNA & Score de alinhamento & Energia (kcal/mol) \\
\hline \multirow{21}{*}{ TCONS_00008676P } & \multirow{21}{*}{30} & bta-miR-2477 & 175 & $-21,03$ \\
\hline & & bta-miR-12017 & 163 & $-21,64$ \\
\hline & & bta-miR-96 & 171 & $-21,70$ \\
\hline & & bta-miR-138 & 163 & $-21,79$ \\
\hline & & bta-miR-2288 & 165 & $-21,85$ \\
\hline & & bta-miR-2463 & 169 & $-21,85$ \\
\hline & & bta-miR-2304 & 162 & $-22,63$ \\
\hline & & bta-miR-2292 & 161 & $-22,82$ \\
\hline & & bta-miR-497 & 160 & $-22,95$ \\
\hline & & bta-miR-195 & 166 & $-23,52$ \\
\hline & & bta-miR-15b & 168 & $-23,64$ \\
\hline & & bta-miR-10171-3p & 163 & $-24,01$ \\
\hline & & bta-miR-708 & 165 & $-24,41$ \\
\hline & & bta-miR-1291 & 162 & $-24,56$ \\
\hline & & bta-miR-2308 & 162 & $-25,03$ \\
\hline & & bta-miR-2366 & 161 & $-25,44$ \\
\hline & & bta-miR-455-3p & 166 & $-25,62$ \\
\hline & & bta-miR-2376 & 165 & $-27,27$ \\
\hline & & bta-miR-370 & 166 & $-28,83$ \\
\hline & & bta-miR-2410 & 164 & $-32,93$ \\
\hline & & bta-miR-2355-3p & 334 & $-40,50$ \\
\hline \multirow{16}{*}{ TCONS_00008822M } & \multirow{16}{*}{16} & bta-miR-2427 & 160 & $-20,34$ \\
\hline & & bta-miR-2285ao & 168 & $-22,44$ \\
\hline & & bta-miR-3064 & 168 & $-22,76$ \\
\hline & & bta-miR-10161-5p & 165 & $-23,07$ \\
\hline & & bta-miR-345-3p & 161 & $-24,83$ \\
\hline & & bta-miR-1284 & 166 & $-25,57$ \\
\hline & & bta-miR-2285bu & 168 & $-26,08$ \\
\hline & & bta-miR-2442 & 160 & $-26,16$ \\
\hline & & bta-miR-2472 & 163 & $-26,48$ \\
\hline & & bta-miR-2904 & 163 & $-27,39$ \\
\hline & & bta-miR-2431-3p & 160 & $-28,37$ \\
\hline & & bta-miR-2450b & 166 & $-28,67$ \\
\hline & & bta-miR-2450d & 161 & $-28,67$ \\
\hline & & bta-miR-2340 & 172 & $-29,45$ \\
\hline & & bta-miR-2381 & 163 & $-31,51$ \\
\hline & & bta-miR-296-3p & 166 & $-33,32$ \\
\hline \multirow{3}{*}{ TCONS_00008933P } & \multirow{3}{*}{3} & bta-miR-3065 & 172 & $-21,26$ \\
\hline & & bta-miR-2387 & 166 & $-22,26$ \\
\hline & & bta-miR-2466-3p & 164 & $-23,58$ \\
\hline \multirow{4}{*}{ TCONS_00009033M } & \multirow{4}{*}{4} & bta-miR-10175-3p & 165 & $-23,46$ \\
\hline & & bta-miR-11996 & 165 & $-24,51$ \\
\hline & & bta-miR-7863 & 161 & $-25,58$ \\
\hline & & bta-miR-11998 & 176 & $-27,69$ \\
\hline \multirow{11}{*}{ TCONS_00009039A } & \multirow{11}{*}{11} & bta-miR-6525 & 162 & $-20,13$ \\
\hline & & bta-miR-2358 & 163 & $-20,56$ \\
\hline & & bta-miR-455-3p & 164 & $-21,91$ \\
\hline & & bta-miR-32 & 174 & $-22,22$ \\
\hline & & bta-miR-431 & 166 & $-22,87$ \\
\hline & & bta-miR-345-5p & 162 & $-26,45$ \\
\hline & & bta-miR-12022 & 170 & $-26,50$ \\
\hline & & bta-miR-2453 & 162 & $-27,51$ \\
\hline & & bta-miR-2441 & 167 & $-28,18$ \\
\hline & & bta-miR-2400 & 177 & $-29,61$ \\
\hline & & bta-miR-671 & 164 & $-32,00$ \\
\hline
\end{tabular}


Tabela suplementar 16 - Enriquecimento funcional (STRING) dos genes com homologia com a fita complementar dos RNAs longos não codificadores diferencialmente expressos entre alta e baixa eficiência alimentar.

\begin{tabular}{|c|c|c|c|c|}
\hline Genes & ID & Nome & Genes & FDR \\
\hline \multirow{9}{*}{$\begin{array}{c}\text { Genes co-expressos } \\
\text { com } \\
\text { TCONS_00000153P }\end{array}$} & GO:0000166 & nucleotide binding & 32 & $1,34 \mathrm{E}-02$ \\
\hline & GO:0017076 & purine nucleotide binding & 26 & $1,92 \mathrm{E}-02$ \\
\hline & GO:0032550 & purine ribonucleoside binding & 25 & $1,92 \mathrm{E}-02$ \\
\hline & GO:0035639 & purine ribonucleoside triphosphate binding & 25 & $1,92 \mathrm{E}-02$ \\
\hline & GO:0032555 & purine ribonucleotide binding & 25 & $2,34 \mathrm{E}-02$ \\
\hline & GO:0043168 & anion binding & 31 & $3,30 \mathrm{E}-02$ \\
\hline & KEEG3013 & $R N A$ transport & 15 & $7,76 \mathrm{E}-05$ \\
\hline & KEEG5169 & Epstein-Barr virus infection & 14 & $2,00 \mathrm{E}-03$ \\
\hline & KEEG3040 & Spliceosome & 10 & $1,59 \mathrm{E}-02$ \\
\hline \multirow{33}{*}{$\begin{array}{l}\text { Genes co-expressos } \\
\text { com }\end{array}$} & GO:0000166 & nucleotide binding & 30 & $1,11 \mathrm{E}-06$ \\
\hline & GO:0032550 & purine ribonucleoside binding & 25 & $1,53 \mathrm{E}-06$ \\
\hline & GO:0035639 & purine ribonucleoside triphosphate binding & 25 & $1,53 \mathrm{E}-06$ \\
\hline & GO:0032555 & purine ribonucleotide binding & 25 & $1,73 \mathrm{E}-06$ \\
\hline & GO:0097159 & organic cyclic compound binding & 44 & $1,73 \mathrm{E}-06$ \\
\hline & GO: 1901363 & heterocyclic compound binding & 44 & $1,73 \mathrm{E}-06$ \\
\hline & GO:0044822 & $\operatorname{poly}(A) R N A$ binding & 17 & $2,61 \mathrm{E}-05$ \\
\hline & GO:0003723 & RNA binding & 20 & $8,76 \mathrm{E}-05$ \\
\hline & GO:0043168 & anion binding & 26 & $1,98 \mathrm{E}-04$ \\
\hline & GO:0005488 & binding & 55 & $5,51 \mathrm{E}-04$ \\
\hline & GO:0005524 & ATP binding & 16 & $1,63 \mathrm{E}-03$ \\
\hline & GO:0008135 & translation factor activity, RNA binding & 6 & $1,63 \mathrm{E}-03$ \\
\hline & GO:0043167 & ion binding & 39 & $1,81 \mathrm{E}-03$ \\
\hline & GO:0017111 & nucleoside-triphosphatase activity & 11 & $4,18 \mathrm{E}-03$ \\
\hline & GO:0005525 & GTP binding & 9 & $9,82 \mathrm{E}-03$ \\
\hline & GO:0003674 & molecular_function & 63 & $1,91 \mathrm{E}-02$ \\
\hline & GO:0003676 & nucleic acid binding & 23 & $1,97 \mathrm{E}-02$ \\
\hline & GO:0003743 & translation initiation factor activity & 4 & $3,36 \mathrm{E}-02$ \\
\hline & GO:0003924 & GTPase activity & 6 & $3,96 \mathrm{E}-02$ \\
\hline & GO:0005622 & intracellular & 65 & $3,99 \mathrm{E}-02$ \\
\hline & GO:0044424 & intracellular part & 64 & $3,99 \mathrm{E}-02$ \\
\hline & GO:0016281 & $\begin{array}{l}\text { eukaryotic translation initiation factor } 4 F \\
\text { complex }\end{array}$ & 2 & 4,42E-02 \\
\hline & GO:0031981 & nuclear lumen & 21 & $4,42 \mathrm{E}-02$ \\
\hline & GO:0044428 & nuclear part & 23 & $4,42 \mathrm{E}-02$ \\
\hline & GO:0044267 & cellular protein metabolic process & 28 & $1,22 \mathrm{E}-02$ \\
\hline & GO:0044237 & cellular metabolic process & 49 & $2,16 \mathrm{E}-02$ \\
\hline & GO:0044260 & cellular macromolecule metabolic process & 39 & $2,62 \mathrm{E}-02$ \\
\hline & GO:0008152 & metabolic process & 56 & $3,19 \mathrm{E}-02$ \\
\hline & GO:0043170 & macromolecule metabolic process & 41 & $3,19 \mathrm{E}-02$ \\
\hline & GO:0009987 & cellular process & 63 & $3,76 \mathrm{E}-02$ \\
\hline & GO:0051028 & $m R N A$ transport & 5 & $3,85 \mathrm{E}-02$ \\
\hline & GO:0071704 & organic substance metabolic process & 49 & $3,85 \mathrm{E}-02$ \\
\hline & KEEG3060 & Protein export & 4 & $3,74 \mathrm{E}-02$ \\
\hline \multirow{10}{*}{$\begin{array}{c}\text { Genes co-expressos } \\
\text { com } \\
\text { TCONS_00002325 } \\
\text { M }\end{array}$} & GO:0008150 & biological_process & 133 & $1,45 \mathrm{E}-08$ \\
\hline & GO:0044699 & single-organism process & 111 & $1,45 \mathrm{E}-08$ \\
\hline & GO:0055114 & oxidation-reduction process & 33 & $3,04 \mathrm{E}-08$ \\
\hline & GO:0044710 & single-organism metabolic process & 61 & $6,73 \mathrm{E}-08$ \\
\hline & GO:0006099 & tricarboxylic acid cycle & 9 & $2,30 \mathrm{E}-07$ \\
\hline & GO:0009060 & aerobic respiration & 10 & $2,30 \mathrm{E}-07$ \\
\hline & GO:0045333 & cellular respiration & 13 & $2,30 \mathrm{E}-07$ \\
\hline & GO:0044763 & single-organism cellular process & 90 & $8,13 \mathrm{E}-06$ \\
\hline & GO:0009987 & cellular process & 108 & $1,94 \mathrm{E}-05$ \\
\hline & GO:0008152 & metabolic process & 92 & $1,25 \mathrm{E}-04$ \\
\hline
\end{tabular}


Tabela suplementar 16 - Enriquecimento funcional (STRING) dos genes com homologia com a fita complementar dos RNAs longos não codificadores diferencialmente expressos entre alta e baixa eficiência alimentar (continuação).

\begin{tabular}{|c|c|c|c|c|}
\hline Genes & ID & Nome & Genes & FDR \\
\hline \multirow{51}{*}{$\begin{array}{c}\text { Genes co-expressos } \\
\text { com } \\
\text { TCONS_00002325 } \\
\text { M }\end{array}$} & GO:0006810 & transport & 41 & $2,85 \mathrm{E}-03$ \\
\hline & GO:0044237 & cellular metabolic process & 73 & $2,98 \mathrm{E}-03$ \\
\hline & GO:0051179 & localization & 45 & 4,97E-03 \\
\hline & GO: 1902578 & single-organism localization & 33 & $1,18 \mathrm{E}-02$ \\
\hline & GO:0044765 & single-organism transport & 31 & 1,76E-02 \\
\hline & GO:0044281 & small molecule metabolic process & 25 & $1,96 \mathrm{E}-02$ \\
\hline & GO:0009167 & $\begin{array}{l}\text { purine ribonucleoside monophosphate metabolic } \\
\text { process }\end{array}$ & 9 & $2,71 \mathrm{E}-02$ \\
\hline & GO:0044267 & cellular protein metabolic process & 35 & $2,72 \mathrm{E}-02$ \\
\hline & GO:0006511 & ubiquitin-dependent protein catabolic process & 10 & $3,11 \mathrm{E}-02$ \\
\hline & GO:0015992 & proton transport & 8 & $3,11 \mathrm{E}-02$ \\
\hline & GO:0051603 & $\begin{array}{l}\text { proteolysis involved in cellular protein catabolic } \\
\text { process }\end{array}$ & 11 & $3,11 \mathrm{E}-02$ \\
\hline & GO:0044257 & cellular protein catabolic process & 11 & $3,51 \mathrm{E}-02$ \\
\hline & GO:0046034 & ATP metabolic process & 8 & $3,51 \mathrm{E}-02$ \\
\hline & GO:0044238 & primary metabolic process & 69 & $3,81 \mathrm{E}-02$ \\
\hline & GO:0006950 & response to stress & 29 & $3,84 \mathrm{E}-02$ \\
\hline & GO:0071704 & organic substance metabolic process & 71 & $3,98 \mathrm{E}-02$ \\
\hline & GO:0006812 & cation transport & 14 & $4,55 \mathrm{E}-02$ \\
\hline & GO:0006793 & phosphorus metabolic process & 22 & $4,62 \mathrm{E}-02$ \\
\hline & GO: 1902600 & hydrogen ion transmembrane transport & 7 & $4,62 \mathrm{E}-02$ \\
\hline & GO:0003674 & molecular_function & 114 & $2,46 \mathrm{E}-05$ \\
\hline & GO:0005488 & binding & 90 & $2,46 \mathrm{E}-05$ \\
\hline & GO:0043167 & ion binding & 66 & $2,46 \mathrm{E}-05$ \\
\hline & GO:0016491 & oxidoreductase activity & 23 & $1,31 \mathrm{E}-04$ \\
\hline & GO:0046872 & metal ion binding & 44 & $1,55 \mathrm{E}-03$ \\
\hline & GO:0003824 & catalytic activity & 62 & $1,90 \mathrm{E}-03$ \\
\hline & GO:0048038 & quinone binding & 4 & $3,14 \mathrm{E}-03$ \\
\hline & GO:0015078 & hydrogen ion transmembrane transporter activity & 7 & 4,44E-02 \\
\hline & GO:0003954 & NADH dehydrogenase activity & 5 & $4,59 \mathrm{E}-02$ \\
\hline & GO:0009055 & electron carrier activity & 6 & $4,59 \mathrm{E}-02$ \\
\hline & GO:0005737 & cytoplasm & 124 & $1,92 \mathrm{E}-12$ \\
\hline & GO:0044444 & cytoplasmic part & 91 & $5,83 \mathrm{E}-10$ \\
\hline & GO:0070469 & respiratory chain & 16 & $5,83 \mathrm{E}-10$ \\
\hline & GO:0005622 & intracellular & 121 & $3,97 \mathrm{E}-08$ \\
\hline & GO:0005623 & cell & 128 & $3,97 \mathrm{E}-08$ \\
\hline & GO:0016020 & membrane & 88 & $3,97 \mathrm{E}-08$ \\
\hline & GO:0043227 & membrane-bounded organelle & 109 & $3,97 \mathrm{E}-08$ \\
\hline & GO:0005575 & cellular_component & 137 & 4,60E-08 \\
\hline & GO:0044464 & cell part & 127 & $4,60 \mathrm{E}-08$ \\
\hline & GO:1990204 & oxidoreductase complex & 12 & $7,29 \mathrm{E}-08$ \\
\hline & GO:0043226 & organelle & 112 & $7,47 \mathrm{E}-08$ \\
\hline & GO:0098803 & respiratory chain complex & 12 & $7,60 \mathrm{E}-08$ \\
\hline & GO:0044424 & intracellular part & 117 & $9,36 \mathrm{E}-08$ \\
\hline & GO:0031982 & vesicle & 50 & $1,01 \mathrm{E}-07$ \\
\hline & GO:0031988 & membrane-bounded vesicle & 49 & $1,01 \mathrm{E}-07$ \\
\hline & GO:0005739 & mitochondrion & 41 & $1,33 \mathrm{E}-07$ \\
\hline & GO:0043231 & intracellular membrane-bounded organelle & 100 & $2,18 \mathrm{E}-07$ \\
\hline & GO:0098800 & inner mitochondrial membrane protein complex & 12 & $2,18 \mathrm{E}-07$ \\
\hline & GO:0043229 & intracellular organelle & 105 & 4,04E-07 \\
\hline & GO:0044422 & organelle part & 81 & $7,46 \mathrm{E}-07$ \\
\hline & GO:0070062 & extracellular exosome & 40 & $1,21 \mathrm{E}-06$ \\
\hline & GO:0044446 & intracellular organelle part & 78 & $2,13 \mathrm{E}-06$ \\
\hline
\end{tabular}


Tabela suplementar 16 - Enriquecimento funcional (STRING) dos genes com homologia com a fita complementar dos RNAs longos não codificadores diferencialmente expressos entre alta e baixa eficiência alimentar (continuação).

\begin{tabular}{|c|c|c|c|c|}
\hline Genes & ID & Nome & Genes & FDR \\
\hline \multirow{45}{*}{$\begin{array}{c}\text { Genes co-expressos } \\
\text { com } \\
\text { TCONS_00002325 } \\
\text { M }\end{array}$} & GO:0044425 & membrane part & 65 & $2,35 \mathrm{E}-06$ \\
\hline & GO:0031090 & organelle membrane & 47 & $2,52 \mathrm{E}-06$ \\
\hline & GO:0005743 & mitochondrial inner membrane & 21 & $8,67 \mathrm{E}-06$ \\
\hline & GO:0043234 & protein complex & 51 & $1,22 \mathrm{E}-05$ \\
\hline & GO:0005746 & mitochondrial respiratory chain & 9 & $1,55 \mathrm{E}-05$ \\
\hline & GO:0031967 & organelle envelope & 26 & $3,11 \mathrm{E}-05$ \\
\hline & GO:0098796 & membrane protein complex & 23 & $3,27 \mathrm{E}-05$ \\
\hline & GO:0005740 & mitochondrial envelope & 23 & $3,57 \mathrm{E}-05$ \\
\hline & GO:1902494 & catalytic complex & 21 & $3,57 \mathrm{E}-05$ \\
\hline & GO:0031966 & mitochondrial membrane & 22 & $7,11 \mathrm{E}-05$ \\
\hline & GO:0032991 & macromolecular complex & 56 & $7,11 \mathrm{E}-05$ \\
\hline & GO:0044429 & mitochondrial part & 25 & $7,11 \mathrm{E}-05$ \\
\hline & GO:0016021 & integral component of membrane & 51 & $1,13 \mathrm{E}-04$ \\
\hline & GO:0044421 & extracellular region part & 43 & $1,25 \mathrm{E}-04$ \\
\hline & GO:0005576 & extracellular region & 48 & 2,37E-04 \\
\hline & GO:0045275 & respiratory chain complex III & 3 & 7,83E-04 \\
\hline & GO:0070069 & cytochrome complex & 5 & 9,05E-04 \\
\hline & GO:0005634 & nucleus & 54 & $1,96 \mathrm{E}-03$ \\
\hline & GO:0031519 & PcG protein complex & 4 & 2,27E-03 \\
\hline & GO:0005912 & adherens junction & 10 & 7,54E-03 \\
\hline & GO:0005747 & mitochondrial respiratory chain complex I & 5 & $1,27 \mathrm{E}-02$ \\
\hline & GO:0033177 & $\begin{array}{l}\text { proton-transporting two-sector ATPase complex, } \\
\text { proton-transporting domain }\end{array}$ & 4 & $1,27 \mathrm{E}-02$ \\
\hline & GO:0005750 & mitochondrial respiratory chain complex III & 2 & $2,37 \mathrm{E}-02$ \\
\hline & GO:0005753 & $\begin{array}{l}\text { mitochondrial proton-transporting ATP synthase } \\
\text { complex }\end{array}$ & 3 & $2,37 \mathrm{E}-02$ \\
\hline & GO:0043034 & costamere & 2 & 2,37E-02 \\
\hline & GO:0071944 & cell periphery & 32 & $2,56 \mathrm{E}-02$ \\
\hline & GO:0005886 & plasma membrane & 31 & $2,89 \mathrm{E}-02$ \\
\hline & GO:0045263 & $\begin{array}{l}\text { proton-transporting ATP synthase complex, } \\
\text { coupling factor } F(o)\end{array}$ & 3 & $2,89 \mathrm{E}-02$ \\
\hline & GO:0005749 & $\begin{array}{l}\text { mitochondrial respiratory chain complex II, } \\
\text { succinate dehydrogenase complex (ubiquinone) }\end{array}$ & 2 & $4,12 \mathrm{E}-02$ \\
\hline & GO:0045273 & respiratory chain complex II & 2 & $4,12 \mathrm{E}-02$ \\
\hline & GO:0005924 & cell-substrate adherens junction & 8 & $4,20 \mathrm{E}-02$ \\
\hline & GO:0016469 & proton-transporting two-sector ATPase complex & 4 & $4,67 \mathrm{E}-02$ \\
\hline & KEEG190 & Oxidative phosphorylation & 21 & $3,88 \mathrm{E}-11$ \\
\hline & KEEG5012 & Parkinson s disease & 20 & $6,84 \mathrm{E}-10$ \\
\hline & KEEG5010 & Alzheimer s disease & 20 & $6,20 \mathrm{E}-09$ \\
\hline & KEEG20 & Citrate cycle (TCA cycle) & 10 & $1,21 \mathrm{E}-08$ \\
\hline & KEEG4932 & Non-alcoholic fatty liver disease (NAFLD) & 18 & $5,37 \mathrm{E}-08$ \\
\hline & KEEG5016 & Huntington s disease & 19 & $7,80 \mathrm{E}-08$ \\
\hline & KEEG1200 & Carbon metabolism & 12 & $2,67 \mathrm{E}-05$ \\
\hline & KEEG1100 & Metabolic pathways & 46 & $2,06 \mathrm{E}-04$ \\
\hline & KEEG4260 & Cardiac muscle contraction & 8 & $2,71 \mathrm{E}-03$ \\
\hline & KEEG1210 & 2-Oxocarboxylic acid metabolism & 4 & $8,27 \mathrm{E}-03$ \\
\hline & KEEG1120 & Microbial metabolism in diverse environments & 10 & $1,74 \mathrm{E}-02$ \\
\hline & KEEG4152 & AMPK signaling pathway & 9 & $1,74 \mathrm{E}-02$ \\
\hline & KEEG4114 & Oocyte meiosis & 8 & 2,64E-02 \\
\hline \multirow{5}{*}{$\begin{array}{c}\text { Genes co-expressos } \\
\text { negativamente com } \\
\text { TCONS_00002325 } \\
\text { M }\end{array}$} & GO:0055114 & oxidation-reduction process & 28 & $4,17 \mathrm{E}-18$ \\
\hline & GO:0008150 & biological_process & 64 & $7,18 \mathrm{E}-14$ \\
\hline & GO:0045333 & cellular respiration & 13 & $8,71 \mathrm{E}-14$ \\
\hline & GO:0044710 & single-organism metabolic process & 37 & $1,09 \mathrm{E}-13$ \\
\hline & GO:0044699 & single-organism process & 54 & $8,57 \mathrm{E}-13$ \\
\hline
\end{tabular}


Tabela suplementar 16 - Enriquecimento funcional (STRING) dos genes com homologia com a fita complementar dos RNAs longos não codificadores diferencialmente expressos entre alta e baixa eficiência alimentar (continuação).

\begin{tabular}{|c|c|c|c|c|}
\hline Genes & ID & Nome & Genes & FDR \\
\hline \multirow{50}{*}{$\begin{array}{c}\text { Genes co-expressos } \\
\text { negativamente com } \\
\text { TCONS_00002325 } \\
\text { M }\end{array}$} & GO:0009060 & aerobic respiration & 10 & $1,49 \mathrm{E}-12$ \\
\hline & GO:0006099 & tricarboxylic acid cycle & 9 & $3,50 \mathrm{E}-12$ \\
\hline & GO:0044763 & single-organism cellular process & 39 & $4,13 \mathrm{E}-06$ \\
\hline & GO:0008152 & metabolic process & 41 & 4,67E-06 \\
\hline & GO:0044281 & small molecule metabolic process & 17 & 7,33E-06 \\
\hline & GO:0046034 & ATP metabolic process & 8 & $8,84 \mathrm{E}-06$ \\
\hline & GO:0009987 & cellular process & 43 & $4,58 \mathrm{E}-05$ \\
\hline & GO:0015992 & proton transport & 7 & $8,44 \mathrm{E}-05$ \\
\hline & GO:0009142 & nucleoside triphosphate biosynthetic process & 5 & $3,58 \mathrm{E}-04$ \\
\hline & GO: 1902600 & hydrogen ion transmembrane transport & 6 & 4,34E-04 \\
\hline & GO:0009168 & $\begin{array}{l}\text { purine ribonucleoside monophosphate } \\
\text { biosynthetic process }\end{array}$ & 5 & $5,05 \mathrm{E}-04$ \\
\hline & GO:0019637 & organophosphate metabolic process & 10 & $7,11 \mathrm{E}-04$ \\
\hline & GO:0019752 & carboxylic acid metabolic process & 10 & $7,43 \mathrm{E}-04$ \\
\hline & GO:0006793 & phosphorus metabolic process & 13 & $9,85 \mathrm{E}-04$ \\
\hline & GO:0046129 & purine ribonucleoside biosynthetic process & 5 & $1,28 \mathrm{E}-03$ \\
\hline & GO:0006754 & ATP biosynthetic process & 4 & $1,47 \mathrm{E}-03$ \\
\hline & GO:0009152 & purine ribonucleotide biosynthetic process & 5 & $2,54 \mathrm{E}-03$ \\
\hline & GO:0044711 & single-organism biosynthetic process & 11 & $2,87 \mathrm{E}-03$ \\
\hline & GO:0090407 & organophosphate biosynthetic process & 7 & $3,23 \mathrm{E}-03$ \\
\hline & GO:0022904 & respiratory electron transport chain & 4 & $4,14 \mathrm{E}-03$ \\
\hline & GO:1901135 & carbohydrate derivative metabolic process & 9 & 4,44E-03 \\
\hline & GO:0040011 & locomotion & 8 & $6,48 \mathrm{E}-03$ \\
\hline & GO:0009117 & nucleotide metabolic process & 7 & $7,21 \mathrm{E}-03$ \\
\hline & GO:0044237 & cellular metabolic process & 28 & $7,80 \mathrm{E}-03$ \\
\hline & GO:0098660 & inorganic ion transmembrane transport & 7 & $8,89 \mathrm{E}-03$ \\
\hline & GO:0042060 & wound healing & 5 & $1,12 \mathrm{E}-02$ \\
\hline & GO:0006796 & $\begin{array}{l}\text { phosphate-containing compound metabolic } \\
\text { process }\end{array}$ & 11 & $1,27 \mathrm{E}-02$ \\
\hline & GO:0006108 & malate metabolic process & 2 & $1,29 \mathrm{E}-02$ \\
\hline & GO:0015986 & ATP synthesis coupled proton transport & 3 & $2,09 \mathrm{E}-02$ \\
\hline & GO:0042775 & $\begin{array}{l}\text { mitochondrial ATP synthesis coupled electron } \\
\text { transport }\end{array}$ & 3 & 2,09E-02 \\
\hline & GO:0071704 & organic substance metabolic process & 28 & $2,15 \mathrm{E}-02$ \\
\hline & GO:1901137 & carbohydrate derivative biosynthetic process & 6 & $2,37 \mathrm{E}-02$ \\
\hline & GO:0044238 & primary metabolic process & 27 & $2,60 \mathrm{E}-02$ \\
\hline & GO:1901564 & organonitrogen compound metabolic process & 12 & $3,08 \mathrm{E}-02$ \\
\hline & GO:0007596 & blood coagulation & 4 & $3,50 \mathrm{E}-02$ \\
\hline & GO:0055085 & transmembrane transport & 8 & $4,19 \mathrm{E}-02$ \\
\hline & GO:0006119 & oxidative phosphorylation & 3 & $4,74 \mathrm{E}-02$ \\
\hline & GO:0016491 & oxidoreductase activity & 18 & $2,46 \mathrm{E}-09$ \\
\hline & GO:0003674 & molecular_function & 51 & $1,32 \mathrm{E}-07$ \\
\hline & GO:0003824 & catalytic activity & 30 & $5,05 \mathrm{E}-05$ \\
\hline & GO:0048038 & quinone binding & 4 & $5,05 \mathrm{E}-05$ \\
\hline & GO:0009055 & electron carrier activity & 6 & $9,14 \mathrm{E}-05$ \\
\hline & GO:0016651 & oxidoreductase activity, acting on $N A D(P) H$ & 6 & $9,14 \mathrm{E}-05$ \\
\hline & GO:0043167 & ion binding & 28 & $9,14 \mathrm{E}-05$ \\
\hline & GO:0003954 & NADH dehydrogenase activity & 5 & $1,85 \mathrm{E}-04$ \\
\hline & GO:0015078 & hydrogen ion transmembrane transporter activity & 6 & $3,68 \mathrm{E}-04$ \\
\hline & GO:0005488 & binding & 34 & $8,35 \mathrm{E}-04$ \\
\hline & GO:0046872 & metal ion binding & 20 & $9,10 \mathrm{E}-04$ \\
\hline & GO:0048037 & cofactor binding & 7 & $1,33 \mathrm{E}-03$ \\
\hline & GO:0051539 & 4 iron, 4 sulfur cluster binding & 4 & $1,70 \mathrm{E}-03$ \\
\hline
\end{tabular}


Tabela suplementar 16 - Enriquecimento funcional (STRING) dos genes com homologia com a fita complementar dos RNAs longos não codificadores diferencialmente expressos entre alta e baixa eficiência alimentar (continuação).

\begin{tabular}{|c|c|c|c|c|}
\hline Genes & ID & Nome & Genes & FDR \\
\hline \multirow{51}{*}{$\begin{array}{c}\text { Genes co-expressos } \\
\text { negativamente com } \\
\text { TCONS_00002325 } \\
\text { M }\end{array}$} & GO:0008137 & NADH dehydrogenase (ubiquinone) activity & 4 & $2,48 \mathrm{E}-03$ \\
\hline & & oxidoreductase activity, acting on the $\mathrm{CH}-\mathrm{OH}$ & & $3.23 \mathrm{E}-03$ \\
\hline & GO:0016616 & group of donors, NAD or NADP as acceptor & 5 & $3,23 \mathrm{E}-03$ \\
\hline & GO:0030060 & L-malate dehydrogenase activity & 2 & 4,40E-03 \\
\hline & GO:0004449 & isocitrate dehydrogenase $(N A D+)$ activity & 2 & $1,01 \mathrm{E}-02$ \\
\hline & GO:0048039 & ubiquinone binding & 2 & $1,01 \mathrm{E}-02$ \\
\hline & GO:0051287 & $N A D$ binding & 3 & $2,96 \mathrm{E}-02$ \\
\hline & GO:0015075 & ion transmembrane transporter activity & 7 & 2,99E-02 \\
\hline & GO:0005739 & mitochondrion & 34 & $1,81 \mathrm{E}-18$ \\
\hline & GO:0070469 & respiratory chain & 16 & $3,64 \mathrm{E}-18$ \\
\hline & GO:0005743 & mitochondrial inner membrane & 21 & $6,72 \mathrm{E}-15$ \\
\hline & GO:1990204 & oxidoreductase complex & 12 & $8,52 \mathrm{E}-14$ \\
\hline & GO:0098803 & respiratory chain complex & 12 & $8,99 \mathrm{E}-14$ \\
\hline & GO:0044429 & mitochondrial part & 23 & $1,69 \mathrm{E}-13$ \\
\hline & GO:0098800 & inner mitochondrial membrane protein complex & 12 & $2,77 \mathrm{E}-13$ \\
\hline & GO:0005740 & mitochondrial envelope & 21 & $3,95 \mathrm{E}-13$ \\
\hline & GO:0031967 & organelle envelope & 22 & $1,36 \mathrm{E}-12$ \\
\hline & GO:0016020 & membrane & 43 & $5,69 \mathrm{E}-11$ \\
\hline & GO:0044425 & membrane part & 36 & $1,53 \mathrm{E}-10$ \\
\hline & GO:0005746 & mitochondrial respiratory chain & 9 & $7,54 \mathrm{E}-10$ \\
\hline & GO:0098796 & membrane protein complex & 16 & $2,77 \mathrm{E}-08$ \\
\hline & GO:0005575 & cellular_component & 53 & 4,39E-07 \\
\hline & GO:0016021 & integral component of membrane & 27 & $6,52 \mathrm{E}-07$ \\
\hline & GO:0044444 & cytoplasmic part & 35 & $8,36 \mathrm{E}-07$ \\
\hline & GO:0005737 & cytoplasm & 43 & $1,22 \mathrm{E}-06$ \\
\hline & GO:0031090 & organelle membrane & 23 & $1,23 \mathrm{E}-06$ \\
\hline & GO:0070069 & cytochrome complex & 5 & $4,54 \mathrm{E}-06$ \\
\hline & GO:0044464 & cell part & 46 & $1,81 \mathrm{E}-05$ \\
\hline & GO:0005623 & cell & 46 & $2,01 \mathrm{E}-05$ \\
\hline & GO:0045275 & respiratory chain complex III & 3 & $3,29 \mathrm{E}-05$ \\
\hline & GO:0005747 & mitochondrial respiratory chain complex I & 5 & $6,91 \mathrm{E}-05$ \\
\hline & GO:0005622 & intracellular & 42 & $9,56 \mathrm{E}-05$ \\
\hline & GO:0005576 & extracellular region & 22 & $1,33 \mathrm{E}-04$ \\
\hline & GO:0044421 & extracellular region part & 19 & $3,45 \mathrm{E}-04$ \\
\hline & GO:0044424 & intracellular part & 40 & $3,45 \mathrm{E}-04$ \\
\hline & GO:0070062 & extracellular exosome & 16 & $3,45 \mathrm{E}-04$ \\
\hline & GO:0043227 & membrane-bounded organelle & 36 & $6,96 \mathrm{E}-04$ \\
\hline & GO:0043229 & intracellular organelle & 36 & $7,72 \mathrm{E}-04$ \\
\hline & GO:0043231 & intracellular membrane-bounded organelle & 34 & $8,57 \mathrm{E}-04$ \\
\hline & GO:0005753 & $\begin{array}{l}\text { mitochondrial proton-transporting ATP synthase } \\
\text { complex }\end{array}$ & 3 & $8,67 \mathrm{E}-04$ \\
\hline & GO:0043226 & organelle & 37 & $8,89 \mathrm{E}-04$ \\
\hline & GO:0044446 & intracellular organelle part & 28 & $8,89 \mathrm{E}-04$ \\
\hline & GO:0045263 & $\begin{array}{l}\text { proton-transporting ATP synthase complex, } \\
\text { coupling factor } F(o)\end{array}$ & 3 & $1,08 \mathrm{E}-03$ \\
\hline & GO:0031988 & membrane-bounded vesicle & 17 & $1,24 \mathrm{E}-03$ \\
\hline & GO:0043234 & protein complex & 19 & $2,10 \mathrm{E}-03$ \\
\hline & GO:0005750 & mitochondrial respiratory chain complex III & 2 & $2,33 \mathrm{E}-03$ \\
\hline & GO:0005912 & adherens junction & 6 & $3,06 \mathrm{E}-03$ \\
\hline & GO:0032991 & macromolecular complex & 21 & $3,38 \mathrm{E}-03$ \\
\hline & GO:0005749 & $\begin{array}{l}\text { mitochondrial respiratory chain complex II, } \\
\text { succinate dehydrogenase complex (ubiquinone) }\end{array}$ & 2 & 4,02E-03 \\
\hline & GO:0045273 & respiratory chain complex II & 2 & $4,02 \mathrm{E}-03$ \\
\hline & GO:0005759 & mitochondrial matrix & 6 & $7,38 \mathrm{E}-03$ \\
\hline
\end{tabular}


Tabela suplementar 16 - Enriquecimento funcional (STRING) dos genes com homologia com a fita complementar dos RNAs longos não codificadores diferencialmente expressos entre alta e baixa eficiência alimentar (continuação).

\begin{tabular}{|c|c|c|c|c|}
\hline Genes & ID & Nome & Genes & FDR \\
\hline \multirow{18}{*}{$\begin{array}{c}\text { Genes co-expressos } \\
\text { negativamente com } \\
\text { TCONS_00002325 } \\
\text { M }\end{array}$} & GO:1902495 & transmembrane transporter complex & 4 & $1,49 \mathrm{E}-02$ \\
\hline & GO:0043209 & myelin sheath & 4 & $2,30 \mathrm{E}-02$ \\
\hline & GO:0005886 & plasma membrane & 13 & $3,72 \mathrm{E}-02$ \\
\hline & GO:0071944 & cell periphery & 13 & $4,90 \mathrm{E}-02$ \\
\hline & KEEG190 & Oxidative phosphorylation & 20 & $1,60 \mathrm{E}-20$ \\
\hline & KEEG5012 & Parkinson s disease & 19 & $1,06 \mathrm{E}-18$ \\
\hline & KEEG5010 & Alzheimer s disease & 18 & $2,86 \mathrm{E}-16$ \\
\hline & KEEG5016 & Huntington s disease & 18 & $7,92 \mathrm{E}-16$ \\
\hline & KEEG1100 & Metabolic pathways & 35 & $2,14 \mathrm{E}-14$ \\
\hline & KEEG20 & Citrate cycle (TCA cycle) & 10 & $4,47 \mathrm{E}-14$ \\
\hline & KEEG4932 & Non-alcoholic fatty liver disease (NAFLD) & 15 & $4,51 \mathrm{E}-13$ \\
\hline & KEEG1200 & Carbon metabolism & 11 & $6,09 \mathrm{E}-10$ \\
\hline & KEEG1120 & Microbial metabolism in diverse environments & 9 & $6,68 \mathrm{E}-06$ \\
\hline & KEEG4260 & Cardiac muscle contraction & 7 & $6,68 \mathrm{E}-06$ \\
\hline & KEEG1210 & 2-Oxocarboxylic acid metabolism & 4 & $6,68 \mathrm{E}-05$ \\
\hline & KEEG620 & Pyruvate metabolism & 4 & $1,91 \mathrm{E}-03$ \\
\hline & KEEG630 & Glyoxylate and dicarboxylate metabolism & 3 & $8,09 \mathrm{E}-03$ \\
\hline & KEEG1230 & Biosynthesis of amino acids & 4 & $1,59 \mathrm{E}-02$ \\
\hline
\end{tabular}

